\title{
Calculating Value: Using and Collecting the Tools of Early Modern Mathematics
}

Tracey, Kevin G.

How to cite:

Tracey, Kevin G. (2019) Calculating Value: Using and Collecting the Tools of Early Modern Mathematics. Doctoral thesis, Swansea University.

http://cronfa.swan.ac.uk/Record/cronfa51299

Use policy:

This item is brought to you by Swansea University. Any person downloading material is agreeing to abide by the terms of the repository licence: copies of full text items may be used or reproduced in any format or medium, without prior permission for personal research or study, educational or non-commercial purposes only. The copyright for any work remains with the original author unless otherwise specified. The full-text must not be sold in any format or medium without the formal permission of the copyright holder. Permission for multiple reproductions should be obtained from the original author.

Authors are personally responsible for adhering to copyright and publisher restrictions when uploading content to the repository.

Please link to the metadata record in the Swansea University repository, Cronfa (link given in the citation reference above.)

http://www.swansea.ac.uk/library/researchsupport/ris-support/ 
Calculating Value: Using and Collecting the Tools of Early Modern Mathematics

\author{
Kevin Gerard Tracey
}

Submitted to Swansea University in fulfilment of the requirements for the Degree of Doctor of Philosophy

Swansea University

2019 
$\underline{\text { Table of Contents }}$

\begin{tabular}{|c|c|}
\hline SECTION & PAGE \\
\hline Thesis Summary & $\mathrm{i}$ \\
\hline Declarations and Statements & ii \\
\hline Acknowledgements & iii \\
\hline List of tables and figures & vi \\
\hline Introduction & 1 \\
\hline $\begin{array}{l}\text { Chapter One: A Return to Rara Arithmetica: The Science Museum } \\
\text { Library's Rare Book Collection }\end{array}$ & 49 \\
\hline $\begin{array}{l}\text { Chapter Two: Reading Mathematics in Sixteenth-Century Germany: } \\
\text { The 'Wittenberg Sammelband' as an Instrument of Knowing }\end{array}$ & 99 \\
\hline $\begin{array}{l}\text { Chapter Three: 'A Key to that Whole Art': Instruments and } \\
\text { Instrumental Knowledge in Print and Practice }\end{array}$ & 179 \\
\hline $\begin{array}{l}\text { Chapter Four: Hydrography, Astronomy, Chronology: Knowing, } \\
\text { Using and Collecting Mathematics in Early Modern England }\end{array}$ & 256 \\
\hline $\begin{array}{l}\text { Chapter Five: The identities and institutional afterlives of early } \\
\text { modern and modern libraries }\end{array}$ & 327 \\
\hline $\begin{array}{l}\text { Conclusion: Rambling among the Mathematical Book Collection, } \\
\text { 1486-1799 }\end{array}$ & 386 \\
\hline Bibliography & 396 \\
\hline APPENDICES & \\
\hline $\begin{array}{l}\text { Appendix 1: The Science Museum's Rare Books Collection: Data on } \\
\text { subject groupings and unseen texts }\end{array}$ & 454 \\
\hline $\begin{array}{l}\text { Appendix 2: A Reconstruction of Nathaniel Torporley's Library, via } \\
\text { his Bequest to Sion College }\end{array}$ & 459 \\
\hline
\end{tabular}


Appendix 3: Titles purchased by the Science Museum, London, from the Hodgson \& Co. auction of Rare Early Scientific Books from the Library of Sion College London, 1938-1939

Appendix 4: Titles purchased by the Science Museum, London, from the Sotheby's Honeyman Sales Auction, 1978-1981 


\section{Thesis Summary}

Through detailed evaluation of the Science Museum Library's Rare Books Collection, this thesis explores the use, ownership and subsequent collection of mathematical books produced between 1550 and 1750. Research has been undertaken as part of a Collaborative Doctoral Award between Swansea University and the Science Museum, London, funded by the UK Arts and Humanities Research Council from 1 January 2016 to 31 December 2018.

Consisting of close to 1,700 titles published between 1486 and 1800 encompassing the pre-modern classification of mathematics, this subset of the Rare Books Collection represents a remarkable accumulation of the practical and the theoretical across a variety of disciplines and languages. My thesis begins by characterising these mathematical holdings in aggregate, analysing the contents and physical features of the texts therein. Findings are supplemented by examination of accompanying provenance, including bindings, bookplates, and signatures.

Discrete case-studies then present key texts as part of their readers' burgeoning mathematical practice, with chapters focussing on the spread of Ramist pedagogies of arithmetic, geometry, and trigonometry in sixteenth-century Germany; the interconnected use of text, instrument and theory in early modern English intellectual and navigational cultures; and the value attached to the related disciplines of mathematical astronomy and chronology at the University of Cambridge in the late 1690s.

The thesis closes with a reconstruction of the library of the clergyman and mathematician, Nathaniel Torporley (1564-1632), tracing the journey of Torporley's materials to the collection of the antiquarian Robert Brodhead Honeyman (18971987) and to the Science Museum thereafter. By placing the Museum's Library and its holdings in their correct historical contexts, this thesis contributes to our understanding of mathematical culture in the early modern period, to the history of collecting in the modern era, and to the Science Museum's understanding of its own holdings and of its role as an institutional collector. 


\section{DECLARATION}

This work has not previously been accepted in substance for any degree and is not being concurrently submitted in candidature for any degree.

Signed:

(candidate)

Date:

\section{STATEMENT 1}

This thesis is the result of my own investigations, except where otherwise stated.

Other sources are acknowledged by footnotes giving explicit references. A bibliography is appended.

Signed: (candidate)

Date:

\section{STATEMENT 2}

I hereby give consent for my thesis, if accepted, to be available for photocopying and for inter-library loans after expiry of a bar on access approved by the Swansea University.

Signed: (candidate)

Date: 


\section{$\underline{\text { Acknowledgements }}$}

Owing to the funding and the unique nature of the Arts and Humanities Research Council's (AHRC) Collaborative Doctoral Award, I have been extremely fortunate to complete this thesis while belonging to two vibrant intellectual communities. I gratefully acknowledge the research funding provided by the AHRC which enabled this project, and which provided my access to communities of learning in the academic and heritage sectors. Additionally, the current thesis has benefited from the award of an AHRC International Placement Scheme Fellowship, undertaken at the Huntington Library, California, where the unique environment of expert research, world-class collections, scholarly exchange, and remarkable surroundings inspired significant developments in my research.

My sincere thanks are due to each of my doctoral supervisors, Dr Adam Mosley at Swansea University, and Nick Wyatt at the Science Museum. I am privileged to have benefited from two such expert and complementary figures, both of whom have consistently worked with my best interests uppermost in their minds. From Nick, I have gained new insights into rare books, their handling, organisation, and history; furthermore, I have gained a unique insight into the life cycle of a library both as a day-to-day place of work and as a historical institution in its own right. His management of the library and archives both in London and in Wroughton are reflected in the inspiring environments of each location. Adam, meanwhile, has unfailingly gone some distance above and beyond what is expected of a doctoral supervisor, offering unstinting academic and personal support whilst guiding my professional development throughout. It would be an understatement to say that the progress I have made as a historian is entirely the product of his tutelage. I am also grateful to my secondary supervisors, Dr David Turner at Swansea University and Dr Tim Boon at the Science Museum, who in their own ways have each provided a reassuring presence at one remove from the sturm und drang of doctoral research.

The current work owes much to friends, colleagues and peers in both academic and heritage environments, whose support, encouragement, and scholarly expertise have been given freely and without hesitation. I am indebted to the scholars who have guided and assisted this research, and I am especially grateful to Jim 
Bennett, whose thoughts on how best to approach both John Seller and Thomas Blundeville reaped significant benefits. Other scholars to whom I owe a debt of thanks include Angela Axworthy, Philip Beeley, Katie Birkwood, Richard Blakemore, Elizabeth Bruton, Rupert Cole, Jane Desborough, Mordechai Feingold, Margaret Gaida, Boris Jardine, Kevin Killeen, Richard L. Kremer, Mordechai LeviEichel, Dan Lewis, Joshua Nall, Renée Raphael, Matt Symonds, Bill Sherman, Helen Smith, Stephen Tabor, Glenn van Brummelen, Victoria van Hyning, Benjamin Wardhaugh, Sophie Waring, and Vanessa Wilkie. Finally, I am grateful to Stephen Clucas and to Stephen Johnston for their helpful corrections and clarifications, each of which has improved the quality, insight, and readability of this thesis innumerably.

Without the constant assistance of the staff, past and present, of the Science Museum Library and Archives in London and in Wroughton, much of this project would have proved impossible. I wish to express my particular gratitude to John Underwood, Prabha Shah, and Doug Stimson, each of whom has dealt with my many requests with good humour, enthusiasm, and expert professional understanding. I am grateful to Jessica Crann, the library and archives conservator, and to Ian Wilkes, for checking, preparing and transporting rare materials to London on countless occasions. At Swansea University, Gabriela Wasiniak and Liz Whitwell have been a constant source of administrative aid, often heading off problems before I knew they were on the horizon. The Research and Public History team at the Science Museum, including Bergit Arends, Adam Boal, and Alison Hess have often been my first port of call for a host of matters related to this project, for which I am thankful.

Scholars would be lost without archivists and librarians, and my thanks are also due to the staff at all of the archives, libraries and other repositories I have visited during the last three years. Special thanks are due to Ken Gibb and to the staff at Lambeth Palace Library for their help in reconstructing the library of Nathaniel Torporley; further afield, I am grateful to Steve Hindle, Catherine Wehrey-Miller, Juan Gomez, and the staff of the Huntington Library, California, whose warmth, hospitality and professional assistance were in evidence daily during my time there. 
Finally, but for the continuing encouragement of my immediate and extended family it is unlikely that I would have sought out this opportunity, or returned to academic research more generally. To have done so would have been to miss out on a remarkable set of experiences and encounters that could not have been replicated otherwise. This research, and any and all achievements that may arise from it, is therefore dedicated entirely to them, and most particularly to Aoife and Aifric. 
$\underline{\text { List of Tables and Figures }}$

\section{CAPTION NUMBER AND TITLE \\ Chapter One: A Return to Rara Arithmetica: The Science Museum Library's Rare Book Collection}

PAGE

Figure 1.1. Sample image of 'Sheet 1, Pre-1800 Books, A-Z', from the 56

'Rare Books - Complete List' spreadsheet.

Figure 1.2. Categories added to pre-existing data to allow for qualitative and quantitative data collection and subsequent analysis.

Table 1.1. Examples of data validation applied to sub-categories to return quantitative data.

Figure 1.3. An example of data validation applied to the [Text Language]

field, taken from the adapted 'Rare Books - Complete List' spreadsheet.

Figure 1.4. Image of the adapted 'Rare Books - Complete List'

spreadsheet displaying additional cross-referencing with Science Museum library catalogue.

Figure 1.5. Sample image of 'Provenance Markers' data from the adapted

'Rare Books - Complete List' spreadsheet.

Figure 1.6. Line graph showing the rise in printed mathematical literature per decade, 1480-1799.

Table 1.2. Table showing the leading frequencies of texts printed between

1486 and 1800 belonging to subject groupings identified as mathematical or mathematically-adjacent.

Figure 1.7. Stacked bar chart showing the top ten subjects across the

entirety of the mathematical subset by decade, 1480 to 1799 .

Table 1.3. Table showing the leading frequencies of texts printed between

1486 and 1599 belonging to subject groupings identified as mathematical or mathematically-adjacent.

Table 1.4. Table showing the leading frequencies by location of texts printed between 1486 and 1799 belonging to subject groupings identified as mathematical or mathematically-adjacent.

Figure 1.8. Stacked bar chart showing the top ten publishing locations across the entirety of the mathematical subset by decade, 1480 to 1799 .

Figure 1.9. Bar chart showing the five most popular print locations by

frequency of texts published, 1480-1599. 
Figure 1.10. Line graph contrasting growth and decline of publishing
locations identified in the collection by count of texts published, 1600-
1699.

Table 1.5. Printed texts grouped by most prominent subjects, 1600-1699.

Figure 1.11. Line graph displaying frequencies of textual language occurrence identified in the collection by decade between 1480 and 1799 .

Figure 1.12. Stacked bar chart displaying identified provenance markers, 1486-1799.

Figure 1.13. Image of [Marginalia Type] data validation from the adapted 'Rare Books - Complete List' spreadsheet.

Figure 1.14. Combined line / bar diagram displaying total number and percentage of marginalia found in titles printed, 1486-1799.

Figure 1.15. Stacked bar chart displaying total distribution of texts with marginalia discovered, 1486-1799.

Table 1.6. Frequency of texts annotated by sub-discipline per decade, 1510-1799.

Figure 1.16. Stacked bar chart showing the incidence of annotation by most popular sub-discipline across the entirety of the mathematical subset by decade, 1480 to 1799 .

79

79

\section{Chapter Two: Reading Mathematics in Sixteenth-Century Germany: The 'Wittenberg Sammelband' as an Instrument of Knowing}

Figure 2.1. Composite image of the outer binding of the Wittenberg Sammelband, Science Museum Library Shelfmark O.B. RAM RAMUS 30209019362784.

Figure 2.2. Ownership inscription of Nicholas Hommer, Wittenberg Sammelband, Science Museum Library Shelfmark O. B. RAM RAMUS 30209019362784.

Figure 2.3. Possible album amicorum inscription from Johannes Coppius to Nicholas Hommer, Wittenberg Sammelband, Science Museum Library Shelfmark O. B. RAM RAMUS 30209019362784.

Figure 2.4. Composite image of possible amicorum inscriptions from David Johannis Klynaeus and Johannes Lobhartzberger, Wittenberg, 1593. Wittenberg Sammelband, Science Museum Library Shelfmark O. B. RAM RAMUS 30209019362784. 
Figure 2.5. Excerpt from a diagram explicating the Ramist organisation, chapter by chapter, of Thomas Fincke's Geometriae rotundi (1583).

Figure 2.6. An example of Thomas Fincke excerpting material directly from Petrus Ramus's Geometriae septem et viginti, in this case detailing isoperimetric figures.

Figure 2.7. The text of the seventeenth proposition of Geometriae rotundi's Book VII.

Figure 2.8. The remaining text of the seventeenth proposition of

Geometriae rotundi's Book VII and its accompanying diagram.

Figure 2.9. Greek inscription as found in the front leaves of Peckham's text in the Wittenberg Sammelband. Science Museum Library Shelfmark O. B. RAM RAMUS 30209019362791.

Figure 2.10. The annotating style most commonly found in the Wittenberg Sammelband. Science Museum Library Shelfmark O. B. RAM RAMUS 30209019362784.

Figure 2.11. Composite image showing 'nota bene' ('NB') with text lined through, and, on the same page, a range of mathematical authors underlined. Wittenberg Sammelband, Science Museum Library Shelfmark O.B. RAM RAMUS 30209019362777.

Figure 2.12. Excerpt of marginalia covering a third of a page of Petrus Ramus's Arithmeticae Libri Duo, Septem et Viginti. Wittenberg Sammelband, Science Museum Library Shelfmark O.B. RAM RAMUS 30209019362784.

Figure 2.13. Expanded section of marginalia shown previously in Figure 2.11 .

Figure 2.14. Annotations on equilateral triangles from Petrus Ramus's

Geometriae septem et viginti, Wittenberg Sammelband, Science Museum Library Shelfmark O.B. RAM RAMUS 30209019362784.

Figure 2.15. The annotator's use of the Tironian symbol for 'est', circled in red, followed by a brief note adding a Euclidean reference to Thomas Fincke's Geometriae rotundi. Wittenberg Sammelband, Science Museum Library Shelfmark O. B. RAM RAMUS 30209019362777.

Figure 2.16. Image of annotations to Thomas Fincke's Geometriae Rotundi found in the Wittenberg Sammelband, Science Museum Library Shelfmark O.B. RAM RAMUS 30209019362777.

Figure 2.17. An annotator's example of branching, Ramist dichotomies drawn within the Wittenberg Sammelband, Museum Library Shelfmark O.B. RAM RAMUS 30209019362784. 
Figure 2.18. Further examples of the printed text of the Wittenberg Sammelband being dichotomised according to both Ramist method and the content of the text itself. Wittenberg Sammelband, Science Museum Library Shelfmark O.B. RAM RAMUS 30209019362784.

Figure 2.19. Image of the system of dichotomy, division and definition continued throughout the Wittenberg Sammelband, Science Museum Library Shelfmark O.B. RAM RAMUS 30209019362777.

Figure 2.20. The text of Petrus Ramus' Arithmeticae libri duo, showing the styles of marginalia common to the Wittenberg Sammelband, Science Museum Library Shelfmark O.B. RAM RAMUS 30209019362784.

Figure 2.21. Image of redaction found in the Wittenberg Sammelband, Science Museum Library Shelfmark O.B. RAM RAMUS 30209019362784 .

Figure 2.22. Image of additional information, provided in contrast to that of the printed text. Wittenberg Sammelband, Science Museum Library Shelfmark O.B. RAM RAMUS 30209019362784.

Figure 2.23. A summary of the method of prosthaphaeresis in Petrus Ramus's Arithmeticae libri duo. Wittenberg Sammelband, Science Museum Library Shelfmark O.B. RAM RAMUS 30209019362784.

\section{Chapter Three: 'A Key to that Whole Art': Instruments and Instrumental Knowledge in Print and Practice}

Figure 3.1. Composite image of Thomas Blundeville's trigonometric work, encapsulating (1) its basis in theoretical geometry and (2) the canons of sines made widely available by Christoph Clavius.

Figure 3.2. Robert Hartwell's advertisement as appended to the final leaves of the seventh edition of Thomas Blundeville's M Blundevile his Exercises contayning Eight Treatises (London: Richard Bishop, 1636).

Figure 3.3. Bookplate of Sir George Schuckburgh-Evelyn, 6th Baronet, to the front pastedown of his copy of Sacrobosco's Sphere. Science Museum Library Shelfmark O. B. SAC SACRO 461008-2001.

Figure 3.4. Indexical, marginal commonplacing of topics in a 1505 copy of Sacrobosco's Sphere. Science Museum Library Shelfmark O. B. SAC SACRO 461008-2001.

Figure 3.5. The indexical annotations in Schuckburgh's copy of the Sphere continued with a marking of the parts of the zodiac and the position of the sun in either hemisphere. Science Museum Library Shelfmark O. B. SAC SACRO 461008-2001. 
Figure 3.6. Blundeville's reprint of Sacrobosco's figure of the world, as featured in each edition of the Exercises.

Figure 3.7. One example of Peter Apian's horary quadrants from his Folium Populi (1533), created for use between 50 and 52 degrees of latitude.

Figure 3.8. Annotation on the composite geometrical parts of Johannes

Stöffler's astrolabe and their relation to the position of the earth within the celestial sphere. Science Museum Library Shelfmark Q. O. B. STO STOEFFLER 461834-2001.

Figure 3.9. Annotation to a printed diagram marking the hour lines of Johannes Stöffler's astrolabe. Science Museum Library Shelfmark Q. O. B. STO STOEFFLER 461834-2001.

Figure 3.10. An example of a volvelle used to demonstrate the theoric of the Moon, in Thomas Blundeville's Theoriques of the Seven Planets (1602). British Library, Shelfmark C.184.d.2.

Figure 3.11. Side-by-side comparison of the armillary sphere printed to the title page of John Blagrave's The Mathematical Jewel with that the armillary sphere featured in Thomas Blundeville's Exercises.

Figure 3.12. Composite image of Thomas Blundeville's diagrams of the equinoctial and the zodiacal circles of the celestial sphere.

Figure 3.13. Expanded image of the gloss amending the sun's declination from 3 degrees to 23 degrees 30 minutes found in the Science Museum's copy of Thomas Blundeville's Exercises. Science Museum Library Shelfmark O. B. BLU BLUNDEVILLE 459578-2001.

Figure 3.14. Thomas Blundeville's printed instrument to find the constellation and degree of the Sun daily, taken from the author's Exercises, 7th edn, 1636. Science Museum Library Shelfmark O. B. BLU BLUNDEVILLE 459578-2001.

Figure 3.15. An example of the instrument in use, a substituted thread intersecting the inner dial at May 4th and returning a value of the Sun's position as $23^{\circ}$ in Taurus.

Figure 3.16. A user's addition of Johannes Stadius's ephemerides to the first edition of Thomas Blundeville's Exercises (1594), British Library Shelfmark C.145.C.16.

Figure 3.17. Composite image showing Science Museum Object 19801913, a celestial globe fashioned between 1603 and 1610 by Willem Janszoon Blaeu (1571-1638) and dedicated to Tycho Brahe. Copyright The Board of Trustees of the Science Museum, London. 
Figure 3.18. A modern-day star map showing Capella, or Hircus (Alpha Auriga, at $\alpha$ ) in the constellation Auriga. The declination of the star is today calculated as $+45^{\circ} 59^{\prime} 53^{\prime \prime}$.

Figure 3.19. John Blagrave's portrayal of setting the eye at the North Pole so as to explain the drawing of the lines required for the stereographic projection of a standard astrolabe.

Figure 3.20. John Blagrave's summary of Stöffler's projection, which the

former used as a basis from which to suggest his own improvements.

Figure 3.21. Side-by-side images of the base disc found in Harvey's copy of the Mathematical Jewel, British Library Shelfmark 60.07, compared with a fully constructed volvelle from the Science Museum Library's copy of Peter Apian's Cosmographia, Science Museum Library Shelfmark Q O. B. GEM GEMMA 461575-2001.

Figure 3.22. A hand-drawn horological dial, appended on loose leaves to Gabriel Harvey's copy of The Mathematical Jewel. British Library Shelfmark 60.07.

Figure 3.23. An example of the calculations that could be tested with the previous diagram, taken from Gabriel Harvey's copy of John Blagrave's The Mathematical Jewel. British Library Shelfmark 60.07.

Figure 3.24. A hand-made volvelle replication of Blagrave's astrolabe, taken from Gabriel Harvey's copy of The Mathematical Jewel. British Library Shelfmark 60.07.

Figure 3.25. Horological and calendrical annotation using positional astronomy, excerpted from a user's 1639 annotations in their copy of Blundeville's Exercises (1636). Science Museum Library Shelfmark O. B. BLU BLUNDEVILLE 459578-2001.

Figure 3.26. A description of Number as akin to a 'glas of art' from the flyleaves of the Science Museum's 1636 edition of Blagrave's Exercises. Science Museum Library Shelfmark O. B. BLU BLUNDEVILLE 459578-2001.

Figure 3.27. Composite image of the exterior (left) and interior (right) of Science Museum Object 1938-371.

Figure 3.28. Composite image of the front (left) and back (right) of

Science Museum Object 1952-230, an ivory diptych sundial with a wind rose (with a hole to view the internal compass) and brass index to the front, and a brass volvelle to calculate nocturnal time and the epact to its rear.

Figure 3.29. The interior of Science Museum Object 1952-230, a diptych dial and compass. 
Figure 3.30: An example of a user finding the time with a nocturnal dial,

using Polaris and its 'Guard' stars in Peter Apian's Cosmographia (1524).

Figure 3.31. The 'Rectifier of the North Star', as constructed in Thomas

Blundeville's Exercises. Science Museum Library Shelfmark O. B. BLU BLUNDEVILLE 459578-2001.

Figure 3.32. Klaus Vopel's multi-faceted nocturnal dial. Science Museum

object 1883-131. Copyright The Board of Trustees of the Science Museum, London.

Figure 3.33. Robert Yeff's wooden nocturnal. Yeff's 1702 inscription is seen beneath the heart-shaped cut-out on the nocturnal's handle. Science Museum Object 1903-80. Copyright The Board of Trustees of the Science Museum, London.

Figure 3.34. A constructed volvelle aiding users of Blundeville's

Exercises to 'know (...) the tides at any place'. Science Museum Library Shelfmark O. B. BLU BLUNDEVILLE 459578-2001.

Figure 3.35. Example of navigational annotations written by John Beard found in the Science Museum Library's copy of Matthew Norwood's Norwood's System of Navigation (1685). Science Museum Library Shelfmark O. B. NOR NORWOOD 460785-2001.

\section{Chapter Four: Hydrography, Astronomy, Chronology: Knowing, Using and Collecting Mathematics in Early Modern England}

Figure 4.1. Composite image of provenance data from John Seller's

Pocket Book, belonging to S. Jenkinson, Edm. Withers, and Tho. Withers.

Science Museum Library Shelfmark O. B. SEL SELLER 30209019360995.

Figure 4.2. Excerpt of a user's trigonometric annotation from the Science

Museum Library's copy of John Seller's Pocket Book (1685), Science Museum Library Shelfmark O. B. SEL SELLER 30209019360995.

Figure 4.3. Composite image of John Seller's zodiacal man and the title page of Robert Fludd's Utriusque Cosmi Historia.

Figure 4.4. Image of John Seller's printed table for the sun's rising and setting for every hour of the day, with 'J. S. fecit' below the title. Science Museum Library Shelfmark O. B. SEL SELLER 30209019360995.

Figure 4.5. Expanded image of 'J. S. fecit' from the previous printed table. 
Figure 4.6. An example of John Seller's double-page copperplate

printing: in this case, an engraved table on the use of the almanac.

Figure 4.7. An example of John Seller's use of italic type in the

instructional, letterpress section of the Pocket Book.

Figure 4.8. Mathematical annotation referencing ' $P$. Herigoino' as

excerpted from Isaac Barrow's edition of Euclid, Euclidis Elementorum

(1655). Science Museum Library Shelfmark O. B. SEL SELLER 30209019360995.

Figure 4.9 An excerpt from the reading list, titled 'Controv. Nat. Ph.'.

Science Museum Library Shelfmark O. B. SEL SELLER 30209019360995.

Figure 4.10. From the reading list, 'Galtruchii, Instit. Mathemat.', likely referring to Pierre Gautruche's Mathematicae totius institutio (1653).

Science Museum Library Shelfmark O. B. SEL SELLER 30209019360995.

Fig 4.11. Exploded chart showing the percentage breakdown of the annotated leaves of John Seller's Pocket Book, as owned by Simon Jenkinson and Edmund Withers.

Figure 4.12. A copied astronomical diagram, excerpted from

Burgersdijk's commentary on De Sphaera, taken from the Pocket Book, Science Museum Library Shelfmark O. B. SEL SELLER 30209019360995.

Figure 4.13. Image displaying annotations in the Pocket Book copied from

Book 1, Chapter 13 of Pierre Gassendi's Institutio astronomica (1647).

Science Museum Library Shelfmark O. B. SEL SELLER 30209019360995.

Figure 4.14. Image copied in manuscript into the Pocket Book from Book

1, Chapter 24 of Gassendi's Institutio astronomica, 'De Hebdomade'.

Science Museum Library Shelfmark O. B. SEL SELLER

30209019360995.

Figure 4.15. Edmund Withers's calendrical annotation. Science Museum

Library Shelfmark 0 .

O. B. SEL SELLER 30209019360995.

Figure 4.16. Annotations from John Seller's Pocket Book instructing a reader on how to find the moon's age by use of epacts: reference is also made to other pages of notes ('vid pag. 12 infra') in the volume. Science Museum Library Shelfmark O. B. SEL SELLER 30209019360995.

Figure 4.17. Examples of extensive chronological narrative and

mathematical working by 'Edmund Withers'. Science Museum Library

Shelfmark O. B. SEL SELLER 30209019360995. 
Figure 4.18. An example of a juvenile hand - possibly a later user than

'Edmund Withers', annotating on the finding of 'a true meridian line'.

Science Museum Library Shelfmark O. B. SEL SELLER

30209019360995.

Figure 4.19. Images of manuscript annotation 'working out' trigonometric

questions, and of a table of positional astronomy. Science Museum

Library Shelfmark O. B. SEL SELLER 30209019360995.

Figure 4.20. Annotation on the circumscription of regular polyhedra within a sphere, excerpted from Isaac Barrow's Euclidis Elementorum (1655). Science Museum Library Shelfmark O. B. SEL SELLER, 30209019360995.

Figure 4.21. 'Edmund Withers's' list of 'Astron. Questions' expressing

the relations shared by various parts of the celestial sphere. Science

Museum Library Shelfmark O. B. SEL SELLER, 30209019360995.

Figure 4.22. Annotations concerning multiple ways to find the time using spherical triangles, with a reconstitution of a sphere of latitude $51^{\circ} 32^{\prime}$.

Science Museum Library Shelfmark O. B. SEL SELLER, 30209019360995.

Figure 4.23. Manuscript excerpt taken from Mark Forster's

Arithmetical Trigonometry (1690), with additional material on

time-finding below. Science Museum Library Shelfmark O. B.

SEL SELLER 30209019360995.

\section{Chapter Five: The identities and institutional afterlives of early modern} and modern libraries

Figure 5.1. Composite image of the Sion College Book of Benefactors and a sample donation from Henry and Katharine Fetherstone, written by John Simson on vellum, 1629. London, Lambeth Palace Library, Sion College Collection. L40.2/E64.

Figure 5.2. Composite image of John Spencer's entry for Nathaniel

Torporley's 1633 bequest in the Book of Benefactors and in Spencer's parallel manuscript catalogue.

Figure 5.3. The donation label appended to the front pastedowns of a

number of Nathaniel Torporley's texts. London, Lambeth Palace Library. Sion College Collection Shelfmark A51.2/D92T(1).

Figure 5.4. Graph detailing the top five broad subject groupings identified

from an analysis of Nathaniel Torporley's donations to Sion College. 
Figure 5.5. Specific mathematical disciplines as identified by texts found to be in Nathaniel Torporley's donations to Sion College.

Figure 5.6. Nathaniel Torporley's proposed division of the celestial sphere in his Diclides coelometricae, with alternative circles drawn to those of the accepted great circles of ecliptic, zodiac, and so on.

Figure 5.7. Diclides coelometricae's first theorem, drawn according to

Torporley's alternative circles as mapped onto the celestial sphere.

Figure 5.8. Torporley's semi-circular instrument, printed at the conclusion of Diclides coelometricae's first book, Polyxestae.

Figure 5.9. Torporley's redrawing of Menelaus's theorem as applied to spherical trigonometry via a bishop's mitre in Diclides coelometricae's second book, Pandectes.

Figure 5.10. Composite image showing the stamp of Sion College library and the red acquisition stamp of the Science Museum Library.

Figure 5.11. Composite image showing the donation imprint of the

Educational Museum, the bookstamp of the Museum of Economic Geology, and the Educational Museum's 1846 donation bookstamp, as found in books held by the Science Museum library today.

Figure 5.12. Image of Robert Brodhead Honeyman's ex libris bookplate. Science Museum Library Shelfmark O.B. RAM RAMUS 30209019362784.

Figure 5.13. James Musgrave's bookplate, bearing the motto

'Philosophemur' and the Barnesley Park shelfmark. Huggins's bookplate can just be seen beneath. Science Museum Library Shelfmark O. B. EVE EVERARD 459930-2001.

Figure 5.14. Graph showing texts purchased from the Honeyman sale by the Science Museum, classified in broad mathematical subject groupings. 


\section{$\underline{\text { Introduction }}$}

This thesis utilises the Science Museum Library's Rare Books Collection to study the transformation and growth of the mathematical culture of early modern Europe. The mathematical disciplines' re-emergence in the period between 1500 and 1750 was galvanised, in Jacqueline Stedall's description, by the recovery and translation of ancient texts, by engagement with ideas contained in Islamic sources, and by the technical practicalities of endeavours central to exploration, trade, and conquest. ${ }^{1}$ Neglected during the Middle Ages and given little weight in the hierarchy of academic disciplines, the mathematical disciplines increasingly came to be seen as central to natural philosophy, the study of the natural world, and as key to accomplishing useful and practical tasks in the realms of commerce, navigation, warfare, and land management. As part of this transformation, mathematics and most prominently physics were recast as the discipline most capable of providing certainty to almost any form of theoretical or practical branch of enquiry relevant to our understanding of the natural world. ${ }^{2}$

Aided by the technology of printing, developments in both theory and practice helped to increase the daily practice of mathematics across European society. Whether ancient or contemporary, in Latin, Greek, or the vernacular, the mathematical texts produced as part of a booming print trade enjoyed comparably huge increases in production relative to their counterparts in other genres. ${ }^{3}$ Combined with a new emphasis on the importance of instruments to practices of observation and measurement, these texts (and their printed counterparts of maps and

\footnotetext{
${ }^{1}$ Jacqueline Stedall, Mathematics Emerging: A Sourcebook, 1540-1900 (Oxford: Oxford University Press, 2008), p. 1. The emergent mathematics Stedall speaks of refers mainly to developments in arithmetic, geometry, number theory, algebra and calculus. The current thesis considers a wider concept of mathematics in its many premodern forms, including, for example, astronomy. Historians' of science and historians' of mathematics contrasting definitions of which 'mathematics' are worthy of study are discussed on pp. 4-8 of the current chapter.

${ }^{2}$ Mathematics' relevance to the search for epistemological certainty in the service of early modern natural philosophy is treated in Niccolò Guicciardini, Isaac Newton on Mathematical Certainty and Method (Cambridge, MA: Massachusetts Institute of Technology Press, 2009), particularly pp. 233290. For a detailed summary of the mathematization of nature pre-Newton, see Geoffrey Gorham, Benjamin Hill, and Edward Slowik, 'Introduction', in Geoffrey Gorham, Benjamin Hill, Edward Slowik, and C. Kenneth Waters, eds., The Language of Nature: Reassessing the Mathematization of Natural Philosophy in the Seventeenth Century (Minneapolis: University of Minnesota Press, 2016), pp. 1-28, particularly pp. 1-8.

${ }^{3}$ Quantitative increases in mathematical literature relative to increases in other genres are considered in Chapter One of the current thesis.
} 
charts) were used to reposition mathematics as practical, useful, and necessary to natural philosophy and the 'new science', to technological improvements, and to the advancement of national interests in trade, discovery, and warfare. As a consequence, the transformation of mathematical culture cut across many aspects of early modern life.

However, as Michael Sean Mahoney argued in his ground-breaking monograph on the French mathematician Pierre de Fermat (1601-1655) nearly half a century ago, mathematics in the sixteenth and seventeenth centuries was less a unified and coherent overarching discipline, and more an ill-defined and contested assemblage of contrasting and competing sub-disciplines, one that 'meant many different things to many different people'. ${ }^{4}$ Attempts to elevate the status of mathematical study in the period thus took different forms, and were to some extent dependent on the disciplinary identity and purposes of their promoters; so much so that only in the later seventeenth century could mathematics be termed a professional pursuit. Mahoney helpfully proposed six broad categories of mathematician at work in the sixteenth and early seventeenth centuries, ranging from classical geometers to cossist algebraists, from applied mathematicians to mystics, and from artisans to analysts. $^{5}$

Yet a range of other roles were available to the mathematically literate. The use of the term mathematicus up to and including the late sixteenth century denoted only that its holder possessed understanding of any branch of mathematical study including the quadrivial arts of arithmetic, geometry, music and astronomy, as well as optics, statics, and astrology. ${ }^{6}$ Learned astronomers, in Robert S. Westman's term, acted as 'discipline bridgers', involved in dynamic and strategic negotiations over the expectations and disciplinary boundaries that came with their post. ${ }^{7}$ Cosmographers, meanwhile, could by choice similarly cast themselves as authors

\footnotetext{
${ }^{4}$ Michael Sean Mahoney, The Mathematical Career of Pierre de Fermat, $2^{\text {nd }}$ edn (Princeton, NJ: Princeton University Press, 1994), p. 2.

${ }^{5}$ Mahoney, ibid, pp. 2-14. Stephen Johnston has noted that Mahoney explicitly debarred mathematici (astronomers and astrologers) from this typology, ascribing such figures to the history of science. Stephen Johnston, 'Making Mathematical Practice: Gentlemen, Practitioners and Artisans in Elizabethan England', Unpublished Ph.D. dissertation, University of Cambridge, 1994, p. 6. ${ }^{6}$ Robert S. Westman, The Copernican Question: Prognostication, Skepticism, and Celestial Order (Berkeley, Los Angeles, and London: University of California Press, 2011), p. 31.

7 Robert S. Westman, 'The Astronomer's Role in the Sixteenth Century: A Preliminary Study', History of Science, 18.2 (1980), pp. 105-147, p.106.
} 
and/or as part of a much wider group of practitioners, utilising their mathematical capabilities for cartography, surveying, and the production of a range of instruments, activities which along with authorship might improve the wider perception of their endeavours. $^{8}$

Naturally, individuals from each of these categories sought to enhance their positions by publishing mathematical or quasi-mathematical texts. Their output included translations and new editions of the works of classical authors; commentaries on existing popular works; educational textbooks; philosophicomathematical treatises; texts presenting innovative theories or unique observations; materials on the construction, use, and theory of instruments; and works of prognostication, calendrical calculation, or esoteric numerology and magic. Although the intended audience for these works undoubtedly consisted of fellow experts and authors, a wider readership of varying abilities must also have existed: one served by the various levels of instruction offered in the workplaces of the guilds and shipyards; at institutions such as scholae triviales, gymnasia, and universities; via individual tutoring; and even auto-didactic reading. This wider audience for mathematical texts has yet to be satisfactorily recovered. Historians of both science and mathematics have only recently begun to capture the role of users in the making of early modern mathematical culture. As a result, our knowledge of these more quotidian users - the reasons behind their demand for materials, the ways in which they came to practice mathematics, and, indeed, their important role in effecting wider changes in this mathematical culture - remains significantly underdeveloped.

\section{Analysis of the Science Museum Library's Rare Books Collection - a} collection consisting of a wide variety of technical, disciplinary, and philosophical literature related to early modern mathematics and the mathematical sciences therefore has the potential to shed new light on transnational communities of readers participating in the consumption and use of early mathematical culture, as well as the intellectual ecosystems of these less-heralded users. Furthermore, investigations into the multiple premodern and modern acquisition practices of individuals, institutions, and the Science Museum itself each help to characterise the Museum's mathematical

\footnotetext{
${ }^{8}$ Adam Mosley, 'The Cosmographer's Role in the Sixteenth Century: A Preliminary Study', Archives Internationales d'Histoire des Sciences, 59 (2009), pp. 423-439, p. 438.
} 
holdings and qualify their representativeness, contributing in the process to our understanding of the history of collecting. In order to most fully analyse the Museum's printed holdings, three discrete but interlinked questions crucial to our understanding of the demand for printed mathematical literature in early modern Europe run through this thesis. First of all, how was mathematical culture constructed and practised through print in this era? Secondly, to what extent can the subsequent collection of mathematical texts and other printed ephemera inform our understanding of the consumption of this literature, its perceived value, and its use? Finally, how do the multiple processes of collection and preservation which sustain this mathematical sample inform or challenge our understanding and evaluation of the users of early modern mathematical literature?

To answer these questions, I consider how and why users read (and responded to) specific texts in a historical period marked by the increasing prevalence of mathematical methods and modes of thought to a number of disciplines; how these users valued mathematical practice and its material products as a means to improve their personal and professional standing; and how the study of mathematics came to be reified as a marker of cultural and intellectual capital, its products commodified as objects of economic, personal, and historical value. In short, the current study provides new perspectives on the transformation of the role enjoyed by mathematics and the mathematical sciences in the period by redirecting attention away from the producers of its intellectual culture and attendant materials, and instead toward the less-expert consumers of early modern mathematical culture.

\section{Trends in the Twentieth-Century Writing of the Histories of Mathematics and Science}

There are several methodological and conceptual reasons why the users and consumers of early modern mathematical culture have yet to be fully brought to light. As Stephen Johnston highlighted twenty-five years ago, the diversity of mathematical arts and sciences of the early modern period (and the diversity of their propagators) represents a historical terrain repeatedly carved up and reallocated, its shifting cartography used to map the modern contours of science, mathematics, and 
technology - as well as those of art, music, and architecture. ${ }^{9}$ Often co-opted in the research of others, the field of the history of mathematics - and what might usefully be termed the study of the historical culture and experience of mathematics ${ }^{10}$ - is itself a still-maturing discipline. Much of the research to date has been highly technical, assuming to some extent a level of capability (or at least a high level of genre-specific understanding) commonly associated with those possessed of an existing professional interest or background. This work has often concerned the development of a narrow set of sub-disciplines, namely arithmetic, geometry, trigonometry, and algebra; even more recent source-books, written with the best of intentions and often with introductory aims in mind, can seem daunting. ${ }^{11}$

This is not to say, however, that historians of mathematics have steered clear of writing rich and detailed accounts of the development of the discipline and its key figures. While the roots of such efforts can be traced to the eighteenth century and to Etienne Montucla, the discipline's 'golden age' is today linked to Moritz Cantor's four-volume opus Vorlesungen über Geschichte der Mathematik (Lectures on the History of Mathematics). ${ }^{12}$ Written and compiled between 1894 and 1908, Cantor's opus attempted a comprehensive history of the subject and the transmission of its

\footnotetext{
${ }^{9}$ Johnston, 'Making Mathematical Practice', p. 5. The interconnected nature of mathematics and early modern material, technological and artistic cultures has been expertly treated most recently in Alexander Marr, Between Raphael and Galileo: Mutio Oddi and the Mathematical Culture of Late Renaissance Italy (Chicago and London: University of Chicago Press, 2011). See also Erwin Panofsky, Idea: A Concept in Art Theory, trans. Joseph J. S. Peak (New York: Harper and Row, 1968); Svetlana Alpers, The Art of Describing: Dutch Art in the Seventeenth Century (Chicago: University of Chicago Press, 1983); Martin Kemp, The Science of Art: Optical Themes in Western Art from Brunelleschi to Seurat (New Haven, CT: Yale University Press, 1990). On mathematics and music, see E. G. McClain, The Myth of Invariance: The Origins of the Gods, Mathematics and Music from the Rig Veda to Plato (York Beach, ME: Nicolas-Hays, Inc, 1976); Benjamin Wardhaugh, Music, Experiment and Mathematics in England, 1653-1705 (Aldershot: Ashgate, 2008); Roger Matthew Grant, Beating Time and Measuring Music in the Early Modern Era (Oxford: Oxford University Press, 2014). For the associations drawn between architecture and early modern mathematics, see Rudolf Wittkower, Architectural Principles in the Age of Humanism (London: Studies of the Warburg Institute, 1949), and George Hersey, Architecture and Geometry in the Age of the Baroque (Chicago: University of Chicago Press, 2000).

${ }^{10}$ This term was suggested to me by Benjamin Wardhaugh in personal email correspondence.

${ }^{11}$ Recent efforts to combat these factors include works such as Stedall, Mathematics Emerging, as well as Benjamin Wardhaugh, How to Read Historical Mathematics (Princeton and Oxford: Princeton University Press, 2010).

${ }^{12}$ Ivor Grattan-Guinness, 'Talepiece: The History of Mathematics and its own History' in Ivor Grattan-Guinness, ed., Companion Encyclopedia of the History and Philosophy of the Mathematical Sciences, Vol. 2 (London and New York: Routledge, 1994), pp. 1665-1675, particularly pp. 16661668.
} 
technical elements. ${ }^{13}$ In doing so, he catalysed a sustained professional interest amongst his colleagues in Germany and further afield, influencing both immediate peers such as Anton von Brauhmühl and later scholars including Otto Neugebauer, Florian Cajori, David Eugene Smith, and Morris Kline. ${ }^{14}$

Importantly, although Cantor acted in keeping with his educational background and the prevailing contemporary academic attitude by prioritising 'pure' mathematics over the applied branches of the discipline, he championed the value of history to the teaching, learning, and ultimately understanding of mathematics. ${ }^{15}$ Moving beyond E. T. Bell's curious treatment of the historical 'great men' of mathematics, meanwhile, modern scholars including Kline and Ivor GrattanGuinesss have sought to bring to the technical history of mathematics a cultural and sociological appreciation of its heritage. ${ }^{16}$ Elements underpinning the re-emergence of mathematics as part of the variegated intellectual ecosystems of the Renaissance and early modern periods have long been of interest to both historians of mathematics and historians of science: so much so that the relation of the former to the latter has been described as indicative of the vexed relationship shared by the two historical disciplines. ${ }^{17}$

\footnotetext{
${ }^{13}$ Moritz Cantor, Vorlesungen über Geschichte der Mathematik, 4 vols. (Leipzig: B. G. Teubner, 1894-1908). Cantor was the sole author of the first three volumes, and the editor, later in life, of the collection of articles found in the fourth volume. Otto Neugebauer, The Exact Sciences in Antiquity, $2^{\text {nd }}$ edn (Providence R.I: Brown University Press: 1957; first published Copenhagen: Ejnar Munksgaard, 1951); Florian Cajori, A History of Mathematical Notations, Two Volumes Bound as One (New York: Dover Publications, 1993; originally Chicago: Open Court, 1928-1929); David Eugene Smith, A Source Book in Mathematics (New York: Dover Publications, 1959; originally published 1929); Morris Kline, Mathematics in Western Culture (Oxford: Oxford University Press, 1953).

${ }^{14}$ Menso Folkerts, Christoph J. Scriba, and Hans Wussing, 'Germany' in Joseph W. Dauben and Christoph J. Scriba, eds., Writing the History of Mathematics: Its Historical Development (Basel, Boston and Berlin: Birkhäuser Verlag, 2002), pp. 109-150, particularly pp. 123-125.

${ }^{15}$ Hélène Gispert, 'The German and French Editions of the Klein-Molk Encyclopedia: Contrasted Images' in Umberto Bottazzini and Amy Dahan Dalmedico, eds., Changing Images in Mathematics: From the French Revolution to the New Millennium (London: Routledge, 2001), pp. 93-112, pp. 1045.

${ }^{16}$ E. T. Bell, Men of Mathematics: The Lives and Achievements of the Great Mathematicians from Zeno to Poincaré, 2 vols. (London: Penguin, 1953; first published 1937); Kline, Mathematics in Western Culture; Ivor Grattan-Guiness, The Rainbow of Mathematics: The Fontana History of the Mathematical Sciences (London: Fontana, 1997). See also Ivor Grattan-Guinness, 'On Certain Somewhat Neglected Features of the History of Mathematics', in Ivor Grattan-Guinness, Routes of Learning: Highways, Pathways and Byways in the History of Mathematics (Baltimore: The Johns Hopkins University Press, 2009), pp. 83-103.

${ }^{17}$ Jeremy Gray, 'Histories of Modern Mathematics in English in the 1940s, 50s and 60s' in Volker R. Remmert, Martina R. Schneider, and Henrik Kragh Sørensen, eds., Historiography of Mathematics in the 19th and 20th Centuries (Cham: Birkhäuser, Springer International Publishing, 2016), pp. 161-
} 
With a view towards better understanding the mathematical culture of the early modern period, a useful point of departure is found in the middle decades of the twentieth century and in a series of important historical works pertaining to mathematical practice. Drawing scholarly attention to the use of the mathematical sciences in seventeenth-century England, a trio of British historians focussed largely on the interactions of expert or highly-capable theorists, authors and producers of mathematical material. A. Rupert Hall studied the role of ballistics in theory and practice to the methods of warfare of the period; E. G. R. Taylor's seminal prosopographical research identified (and, to some degree, invented) clusters of 'mathematical practitioners' at work in Tudor, Stuart, and, later, Hanoverian England; and David A. Waters produced three volumes of illuminating scholarship on the art of navigation, its theories, products, and communicators. ${ }^{18}$ These works joined existing historical studies of mathematical culture such as those of Ernst Zinner, whose work on the mathematical and the astronomical culture of early modern Germany remains influential. ${ }^{19}$

Despite the continuing importance of these works to present-day scholarship, studies attending to the component parts of early modern mathematical culture have regrettably drifted in and out of focus. To some extent, attempts to characterize the theoretical, social and material underpinnings of this culture have been beset by issues which have troubled the twentieth-century historiography of science more generally. These issues are directly connected to the conceptualization of the 'Scientific Revolution', and one of its attendant, defining features, the 'mathematization of nature', perceived in this understanding to have occurred in the

\footnotetext{
183, p. 162. For a treatment of the issues facing the history of mathematics as a stand-alone discipline (or otherwise), see Michael N. Fried, 'The Discipline of History and the "Modern Consensus in the Historiography of Mathematics", Journal of Humanistic Mathematics, 4.2 (2014), pp. 124-136. Similar arguments have also been made regarding the study of the history of mathematics in the United Kingdom in Tony Mann, 'History of Mathematics and History of Science', Isis, 102.3 (2011), pp. 518-526.

${ }_{18}$ A. Rupert Hall, Ballistics in the Seventeenth Century. A Study in the Relations of Science and War with reference particularly to England (Cambridge: Cambridge University Press, 1952); E. G. R. Taylor, The Mathematical Practitioners of Tudor and Stuart England (Cambridge: Institute of Navigation at the University Press, 1954); id., The Mathematical Practitioners of Hanoverian England, 1714-1840 (Cambridge: Institute of Navigation at the University Press, 1966); David W. Waters, The Art of Navigation in England in Elizabethan and Early Stuart Times (London: Hollis and Carter, 1958).

${ }^{19}$ Ernst Zinner, Leben und Wirken des Johannes Müller von Königsberg gennant Regiomontanus (Munich: C. H. Beck, 1938); id., Deutsche und Niederländische Astronomische Instrumente des 11.18. Jahrhunderts (Munich: C. H. Beck, 1956).
} 
period between 1500 and $1700 .{ }^{20}$ Consistently identified by many historians as the origin of modern science and its practices of hypothesis, experimentation, repetition and quantification, the idea of the 'Scientific Revolution' exerted significant influence on the works of the past century. ${ }^{21}$ In the mid-twentieth century, a grand narrative was shaped to celebrate this revolution in thought as the displacement most prominently in the seventeenth century - of an existing, premodern epistemology dominated by Aristotelian teaching in favour of a mathematized, mechanical and experimental natural philosophy. ${ }^{22}$ This conceptual framework gave rise to what Margaret J. Osler in 2000 dubbed a canonical group of individuals working on a largely canonical set of subjects: chief amongst them, the interrelated studies of astronomy, physics and mathematics. ${ }^{23}$

The origins of this narrative and its interest in the mathematical sciences reach back to the foundations of the history of science as an academic discipline. In the first edition of his journal Isis, published in 1913, George Sarton outlined his vision for the nascent discipline of the history of science as an aggregational synthesis building toward a common 'humanist' viewpoint - built predominantly by

\footnotetext{
20 The literature on both of these concepts is vast, and an exhaustive list is beyond my capabilities. For the promotion and alteration of the 'Scientific Revolution' as a concept, see, for example, Alexandre Koyré, 'Galileo and the Scientific Revolution of the Seventeenth Century', Philosophical Review, 52.4 (1943), pp. 333-348; A. Rupert Hall, The Scientific Revolution, 1500-1800: The Formation of the Modern Scientific Attitude (London: Longmans, Green and Co, 1954); and I. Bernard Cohen, Revolution in Science (Cambridge, MA, and London: The Belknap Press of Harvard University Press, 1985). For a historiographical review of the concept, see Steven Shapin, The Scientific Revolution (Chicago and London: University of Chicago Press, 1996), pp. 1-12. On the 'mathematization of nature', see Edmund Husserl, The Crisis of European Sciences and Transcendental Phenomenology: An Introduction to Phenomenological Philosophy, trans. David Carr (Evanston: Northwestern University Press, 1970; originally published as Die Krisis der europäischen Wissenschaften und die transzendentale Phänomenologie: Eine Einleitung in die phänomenologische Philosophie, 1936), pp. 23-59. For a detailed treatment of Husserl's concept, see Dermot Moran, Husserl's Crisis of the European Sciences and Transcendental Philosophy: An Introduction (Cambridge: Cambridge University Press, 2012), particularly pp. 66-98.

${ }^{21}$ For example, William Shea, ed., Nature Mathematized. Historical and Philosophical Case Studies in Classical Modern Natural Philosophy, 2 vols (Dordrecht, Boston and London: D. Reidel, 1983); Joella G. Yoder, Unrolling Time: Christiaan Huygens and the Mathematization of Nature (Cambridge: Cambridge University Press, 1989); Geoffrey Gorham, Benjamin Hill, Edward Slowik, and C. Kenneth Waters, eds., The Language of Nature: Reassessing the Mathematization of Natural Philosophy in the Seventeenth Century (Minneapolis: University of Minnesota Press, 2016).

${ }^{22}$ Richard S. Westfall, The Construction of Modern Science: Mechanisms and Mechanics (New York: John Wiley \& Sons, 1971), pp. 30-31.

${ }^{23}$ Margaret J. Osler, 'The Canonical Imperative: Rethinking the Scientific Revolution' in Margaret J. Osler, ed., Rethinking the Scientific Revolution (Cambridge: Cambridge University Press, 2000), pp. 3-24, p. 3.
} 
scientists and their theories, yet in collaboration with historians and philosophers. ${ }^{24}$ Sarton was inspired by the work of the nineteenth-century positivist philosopher Auguste Comte, who in his Cours de Philosophie Positive (1839) outlined the belief that each branch of human knowledge had invariably passed progressively through 'Theological (fictitious)' and 'Metaphysical (abstract)' phases, prior to its arrival at the final and most appropriate phase of 'Scientific (positive)'.${ }^{25}$ Comte's formulation and advocacy of this 'law' of epistemological progress yoked knowledge to rationality and observation by a process of ever-decreasing connections of phenomena to general and then to specific parts, with the ideal end result a single, all-encompassing theory or fact that might encapsulate all aspects of these constituent phenomena. ${ }^{26}$

Although Sarton can be highlighted as crucial to the invention and spread of the history of science as an academic discipline, within twenty years of its launch the 'internalist' programme he advocated - one which argued for the autonomy of scientific theory and method via internal dynamics of thought and procedural action as quasi-independent from their socio-cultural or economic trappings, its theoretical findings reified from within a like-minded and self-regulated scientific community ${ }^{27}$ - was rejected by a number of scholars who, motivated in certain cases by Marxist teaching, proposed instead an 'externalist' history of science. 'Externalism' in this context held that scientific knowledge in both content and direction was shaped by technological pulls that were themselves dependent on overarching economic and social superstructures. ${ }^{28}$ The roots of this interpretation are commonly identified as belonging to a paper by Boris Hessen, titled 'The Social and Economic Roots of Newton's Principia', delivered at the Second International Congress of the History of Science in London in 1931.

\footnotetext{
${ }^{24}$ George Sarton, 'L'histoire de la science', Isis, 1.1 (1913), pp. 3-46; Gerald Holton, 'George Sarton, His Isis, and the Aftermath', Isis, 100.1 (2009), pp. 79-88, particularly pp. 80-82.

${ }^{25}$ Auguste Comte, The Positive Philosophy of Auguste Comte, trans. Harriet Martineau (Kitchener: Batoche Books, 2000; originally New York: Calvin Blanchard, 1855), pp. 27-28.

${ }^{26}$ Comte, Positive Philosophy, p. 28.

${ }^{27}$ John Schuster, 'Internalist and Externalist Historiographies of the Scientific Revolution' in Wilbur Applebaum, ed., The Encyclopedia of the Scientific Revolution: From Copernicus to Newton (New York: Routledge, 2008) pp. 334-336, p. 334

${ }^{28}$ Schuster, ibid.
} 
Hessen's argument proposed that the Newtonian synthesis - the syncretisation of the principles of Copernican and Keplerian astronomy, Galilean physics, and Newton's own work on the force of gravity in service of the mathematization of physics and natural philosophy ${ }^{29}$ - was in fact a theoretical consolidation of the artisanal knowledge and working practices previously utilised in service of technology for economic gain. Seventeenth-century merchants and capitalists were for Hessen the motors of scientific progress, with a booming global trade bringing with it technical problems in navigation, ballistics, mining, naval and military activities, and commerce: in summary, the 'main technical and physical problems of the era (...) were primarily determined by the economic and technical problems that the rising bourgeoisie placed on the agenda' ${ }^{30}$ Merchant capitalism, cast as something of a demanding schoolmaster, "presented science with a number of practical tasks and urgently demanded their solution'. ${ }^{31}$ Isaac Newton's Philosophice Naturalis Principia Mathematica (1687) was, in this idiosyncratic thesis, written in response to these demands; yet at the same time, its author was inherently bound by the social, theological and intellectual conditions under which its author worked.

Much ink has been spilled over the manner in which Boris Hessen's hypothesis influenced his peers and colleagues on both sides of the Atlantic, for either good or ill. ${ }^{32}$ From its debut in 1931, the impact of the Hessen thesis can be retrospectively witnessed in the disciplinary and geo-political arguments which recurred into the 1950s and to the present day. Furthermore, Hessen's influence was of direct relevance to subsequent works by Robert K. Merton and Edgar Zilsel, and to the later rejection of works of this nature by 'idealist' historians. To differing

\footnotetext{
${ }^{29}$ I. Bernard Cohen, The Newtonian Revolution: With Illustrations of the Transformation of Scientific Ideas (Cambridge: Cambridge University Press, 1980), pp. 160-161. Cohen argues that the concept of 'Newton's synthesis' has at least two meanings; the first the unification of within a single theoretical structure previously divorced concepts, the second the synthesizing of the laws and principles derived from Galileo, Kepler, and others.

${ }^{30}$ Boris Hessen, 'The Social and Economic Roots of Newton's "Principia", reproduced in Gideon Freudenthal and Peter McLaughlin, eds., The Social and Economic Roots of the Scientific Revolution: Texts by Boris Hessen and Henryk Grossman (Dordrecht: Springer, 2009), pp. 41-102, p. 53.

${ }^{31}$ Hessen, ibid.

32 Anna K. Mayer, 'Setting up a discipline, II: British history of science and "the end of ideology", 1931-1948', Studies in History and Philosophy of Science, 35 (2004), pp. 41-72; Steven Shapin, 'Discipline and Bounding: The History and Sociology of Science as seen through the ExternalismInternalism Debate', History of Science, 30.4 (1992), pp. 333-369; Simon Schaffer, 'Newton at the Crossroads', Radical Philosophy, 37 (1984), pp. 23-28; Nathan Reingold, 'History of Science Today, 1. Uniformity as Hidden Diversity: History of Science in the United States, 1920-1940', British Journal for the History of Science, 19.3 (1986), pp. 243-262.
} 
degrees, Merton and Zilsel each used 'The Social and Economic Roots of Newton's Principia' to delve more deeply into the socio-economic and, for that matter, the sociological connections of scientific praxis in the $1600 \mathrm{~s}$.

\section{While Merton's Science, Technology and Society in Seventeenth Century} England (1938) did not engage in sufficient detail with mathematics and its relevance to the rise of mechanical philosophy in the seventeenth-century, it did treat in detail the developments pre-modern scientific methodology and practice of experiment and observation brought to what is today termed the 'knowledgemaking' processes of the period. Additionally, by drawing attention toward the previously under-appreciated role of confessional identities as part of scientific practice, Merton suggested a new perspective for future research. While the precise workings of Merton's contention that puritanical English Protestantism was specifically suited to scientific endeavour were flawed, his overarching position that the achievements of figures across a range of non-homogeneous fields of early modern intellectual activity may be explained through study of the "combinations of sociological circumstances, of moral, religious, aesthetic, economic and political conditions ${ }^{33}$ - has remained a topic for heated debate well into the current century.

Edgar Zilsel's thesis, meanwhile, expanded on Boris Hessen's work by more securely grounding the mathematically- and technically-capable artisans, craftsmen and mechanicians of the early seventeenth century as examples of skilled workers whose interactions with scholarly humanists were central to the creation of the "new sciences' of the early modern era. These groups came to interact thanks to urbanization and commercial interests which led to professional conditions and innovations which encouraged causal and quantitative ways of thinking, with the results seen in methodical, proto-scientific praxis. ${ }^{34}$ In Zilsel's argument, the interaction of figures such as Galileo, Bacon and Gilbert with a population of skilled craftsmen was cemented around 1600 . The overall result was such that:

\footnotetext{
${ }^{33}$ Robert King Merton, 'Science, Technology and Society in Seventeenth Century England', originally published in Osiris: Studies on the History and Philosophy of Science, and on the History of Learning and Culture (Burges: St. Catherine Press, 1938), 4.2, pp. 360-632, p. 364.

${ }^{34}$ Edgar Zilsel, 'The Sociological Roots of Science', republished in Diedrick Raven, Wolfgang Krohn, and Robert S. Cohen, eds., The Social Origins of Modern Science (Dordrecht: Springer Science + Business Media, 2003), pp. 7-21.
} 
The technological revolution transformed society and thinking to such a degree that the social barrier between liberal and mechanical arts began to crumble, and the experimental techniques of the craftsmen were admitted to the ranks of the university scholars. ${ }^{35}$

Having established this position, Zilsel then pointed toward a new dynamism in early modern print technology, with the medieval liberal arts teachings of physics and natural philosophy portrayed as stagnant, in contrast to the exciting new texts presenting the theory and practice of the mechanical arts as essential to various occupational endeavours. ${ }^{36}$

As Anna K. Mayer's detailed analysis of the 'transformative decade' the academic discipline of the history of science experienced in the 1940s demonstrates, the at-times vituperative anti-Marxist reaction to these studies occurred in precisely the period when the academic idea of the scientific work as the product of a linear, universal rationality - and with that, a cultivated, intellectual disinterestedness of the practical at the expense of the theoretical - was institutionalised. Though the longer influence of George Sarton on the history of science is now viewed as limited, ${ }^{37}$ the continued efforts of the Belgian émigré from his academic seat at Harvard served, in John F. M. Clark's depiction, to create a bridge between the positivist philosophers of the late nineteenth century and the internalist and idealist historians of science who came to prominence in the $1940 \mathrm{~s} .{ }^{38}$ The longer process of this institutionalisation and the impact of the internalist outlook is traced by Mayer to the careers of Alexandre Koyré, Herbert Butterfield, and, later in the twentieth century, Butterfield's protégé A. Rupert Hall. Hall exerted an enduring influence upon the history of science for much of the second half of the twentieth century from his

\footnotetext{
${ }^{35}$ Zilsel, ibid, p. 15. Zilsel expanded on this position in Edgar Zilsel, 'The Methods of Humanism', republished in Diedrick Raven, Wolfgang Krohn, and Robert S. Cohen, eds., The Social Origins of Modern Science (Dordrecht: Springer Science + Business Media, 2003), pp. 50-65.

${ }^{36}$ Zilsel, ibid, particularly pp. 15-18.

${ }^{37}$ Bert Theunissen, 'Unifying Science and Human Culture: The Promotion of the History of Science by George Sarton and Frans Verdoorn', in Harmke Kamminga and Geert Somsen, eds., Pursuing the Unity of Science: Ideology and Scientific Practice from the Great War to the Cold War (London and New York: Routledge, 2016), pp. 182-206, p. 203; Peter Dear, 'The History of Science and the History of the Sciences: George Sarton, Isis, and the Two Cultures', Isis, 100.1 (2009), pp. 89-93, p. 91.

${ }^{38}$ John F. M. Clark, 'Intellectual History and the History of Science' in Richard Whatmore and Brian Young, eds., A Companion to Intellectual History (Chichester: John Wiley and Sons, 2016), pp. 155169 , p. 158. For Sarton's rejection of Hessen and Marxist scholarship in correspondence with his near-contemporary Johan Nordstrom, see Tore Frängsmyr, 'Sarton and Nordstrom', Isis, 75.1 (1984), pp. $49-55$, pp. 50-51.
} 
position of pre-eminence at the University of Cambridge: one which helped to undercut the Marxist, 'externalist' programme in part by demonstrating that ballistics was a mathematical rather than a military science. ${ }^{39}$

For Butterfield, A. Rupert Hall, and the American historian Marie Boas, the appearance of 'externalism' post-Hessen had been effectively and terminally outflanked by the near-parallel emergence of Alexandre Koyré's Études Galiléennes (Galileo Studies, 1939). Presenting himself as a Platonic idealist rather than an internalist, Koyré eschewed the earlier positivism of Auguste Comte and his followers, choosing instead to found his theory of the history of science upon the mathematical realism of Galileo and Descartes. In H. Floris Cohen's lively if at times essentialist account, written in the mid-1990s, Koyré's enunciation of the coterminous concepts of the mathematization of nature and the seventeenth-century 'Scientific Revolution' had been pioneered to a lesser degree in Eduard Jan Dijksterhuis's Val en Worp (Free Fall and Projectile Motion, 1924) and, somewhat remarkably in the same year, E. A. Burtt's Metaphysical Foundations of Modern Physical Science (1924). ${ }^{40}$

Central to Alexandre Koyré's concept of this revolution was a metaphysical change in attitude. Utilising his understanding of Platonic thought, Galileo conceived of the geometrization of space as relative; a conception which (in this argument) was then further used by Galileo himself, Descartes, and Newton to develop motion as a state in time. This refutation of Aristotelian principles of physics was elaborated in Etudes Galiléennes and From the Closed World to the Infinite Universe (1957) and inspired, in Koyré's view, a revolution in thought which destroyed the 'finite and hierarchically ordered, therefore qualitatively and ontologically differentiated, whole' premodern cosmos, and replaced it with 'an open, indefinite, and even infinite universe, united not by its immanent structure but

\footnotetext{
${ }^{39}$ Mayer, 'Setting up a discipline, II', particularly pp. 60-61.

${ }^{40}$ H. Floris Cohen, 'The Mathematization of Nature': The Making of a Concept, and how it has Fared in Later Years', in Volker R. Remmert, Martina R. Schneider, and Henrik Kragh Sørensen, eds., Historiography of Mathematics in the $19^{\text {th }}$ and $20^{\text {th }}$ Centuries (Cham: Birkhäuser, Springer International Publishing, 2016), pp. 143-160. See also H. Floris Cohen, The Scientific Revolution: A Historiographical Inquiry (Chicago and London: University of Chicago Press, 1994). Adding Annaliese Maier to Dijksterhius, Burtt, and Koyré as the 'Big Four' of post-Duhemian proponents of the 'Scientific Revoluton', Floris Cohen offers a much more detailed treatment of these concepts in his at times iconoclastic survey of the history of the Scientific Revolution as both historical event and historiographical concept.
} 
only by the identity of its fundamental contents and laws'. ${ }^{41}$ A. Rupert Hall's appreciation for the Koyréan position was rarely more succinctly apparent than in his own treatment of Galilean idealist physics:

Idealism (or abstraction) is not delusion because it ignores the complexities and discrepancies of reality; on the contrary, only through idealism can the reality explaining the complexities and discrepancies be discerned. [...] The supreme instance of idealism or abstraction in scientific method is the use of mathematics, especially (in Galileo's time) geometry for the study of physical events. ${ }^{42}$

In seeking to establish the means by which mathematical concepts, in Morris Kline's later phrase, 'supplied the essence of remarkable scientific theories' through theoretical predictions relevant to the observational and experimental study of nature and the physical world, ${ }^{43}$ Koyré's work was crucial to the writing of the midtwentieth-century grand narrative of scientific progress. As Osler has succinctly noted, historians such as Koyré, Butterfield, A. Rupert Hall and, more recently, Richard S. Westfall followed the nineteenth-century positivist Ernst Mach by prioritising the achievements of Galileo so as to effect in the minds of their readers a clean break with previous epistemic outlooks. ${ }^{44}$ The remarkable discontinuity outlined by these arguments was crafted so as to further highlight the radical departure - borne on mathematical principles - supposedly engendered by the 'Scientific Revolution'. Early modern mathematics was evoked almost sui generis in these arguments: a de-centering, revolutionary discipline identified as the motivator behind the remarkable developments of Copernicus' and Kepler's astronomy, Galileo's work on motion, and, finally and perhaps most gloriously, the Newtonian synthesis of the mathematical principles of nature.

Furthermore, Koyré's lionization of theory above all other aspects of scientific progress relegated the sociological elements of early modern science as proposed by Hessen, Zilsel and others to a position of near-irrelevance for some time. Thus, by the early 1960s, A. Rupert Hall could be found confidently asserting

\footnotetext{
${ }^{41}$ Alexandre Koyré, 'The Significance of the Newtonian Synthesis' in Alexandre Koyré, Newtonian Studies (Cambridge, MA: Harvard University Press, 1965), pp. 3-24, pp. 6-7.

${ }^{42}$ A. Rupert Hall, From Galileo to Newton (London: Collins, 1963), p. 63. Hall's emphasis.

${ }^{43}$ Morris Kline, Mathematics: The Loss of Certainty (Oxford and New York: Oxford University Press, 1980), pp. 3-4.

${ }^{44}$ Osler, 'Canonical Imperative', pp. 10-11.
} 
across a range of platforms that 'externalist' and particularly Marxist histories of science were, along with the study of their associated socio-economic concerns, dead in the water. ${ }^{45}$ Yet in establishing a chronology for the mathematization of nature which ran from the publication of Copernicus's De revolutionibus to that of Newton's Principia, Butterfield, Hall, and other historians indebted to Koyré fell into a trap of their own making. ${ }^{46}$

Widening his historical lens to incorporate a Duhemian concept of fourteenth-century impetus theory, ascribed by Duhem to Buridan and Nicole Oresme as a precursor to the canonical theories of the seventeenth century, ${ }^{47}$ Butterfield weakened the force of his argument by defocusing the special relevance this metaphysical thought-process of seventeenth-century mathematization had held for Koyré, Burtt and Dijksterhuis: a movement which Butterfield then compounded by postponing a similar revolution in chemistry. ${ }^{48}$ Hall and Boas Hall followed Butterfield in loosening the periodization of the 'Scientific Revolution' further, with Hall plotting a course which saw medieval magic and 'superstition' gradually relegated from the minds of early modern philosophers and theorists in favour of the rationality of exact science. ${ }^{49}$ Duly mathematized, Nature was conceived of not through theology nor esoteric mysticism, but through standardised laws of action and reaction, of cause and effect: laws which were inevitably codified by the Newtonian

\footnotetext{
${ }^{45}$ Shapin, 'Discipline and Bounding', particularly pp. 341-342. For Hall's rejection of Merton's thesis, see A. Rupert Hall, 'Merton Revisited, or Science and Society in the Seventeenth Century', History of Science, 2.1 (1963), pp. 1-16.

${ }^{46}$ Floris Cohen, 'Mathematization of Nature', pp. 154-155.

${ }^{47}$ Herbert Butterfield, The Origins of Modern Science 1300-1800, revised edn (New York: The Free Press, 1997; first published London: Bell, 1950; new edition first published London, G. Bell and Sons, 1957), pp. 13-28; Pierre Duhem, 'Research on the History of Physical Theories', in Roger Ariew and Peter Barker, trans. and eds. Essays in the History and Philosophy of Science (Indianapolis : Hackett Publishing Company, 1996; originally published in 1913 as part of Pierre Duhem, Le système du monde, histoire des doctrines cosmologiques de Platon à Copernic, 10 vols, Paris: Hermann, 1913-1959), pp. 239-250. For Koyré's rejection of Duhem's argument, see Alexandre Koyré, Galileo Studies, trans. John Mepham (Hassocks: The Harvest Press, 1978), p. 3 and p. 31. For appraisals of Duhem as a continuity theorist, see Roger Ariew and Peter Barker, 'Duhem and Continuity in the History of Science', Revue internationalle de philosophie, 46.182 (1992), pp. 323-343, and Horia-Roman Patapievici, 'The 'Pierre Duhem Thesis'.A Reappraisal of Duhem's Discovery of the Physics of the Middle Ages', Logos \& Episteme, 6.2 (2015), pp. 201-218.

${ }^{48}$ Butterfield, Origins of Modern Science, pp. 203-221.

${ }^{49}$ Floris Cohen, 'Mathematization of Nature', pp. 154-155. For Hall's dismissal of the 'magical view of nature', see Hall, From Galileo to Newton, p. 25.
} 
philosophy, whose mathematical rationality won it its subsequent, central position in modern science. ${ }^{50}$

Two clear difficulties with this narrative and its variants have suggested themselves, and each are relevant to developments in the historiography of early modern science from the 1970s onward. First of all, ascribing to Galileo (or, indeed, to any individual theorist or group of theorists) the role of agent of change almost entirely independent of previous theoretical discoveries risks over-emphasising to an extreme degree the revolutionary aspects their theories might possess. Pierre Duhem, Alastair C. Crombie and Peter Dear have all at various points identified how such a dismissive position neglects the existing continuities such innovators shared with their classical or medieval forebears $;{ }^{51}$ moreover, such arguments deliberately obscure the cultural, educational and social contexts such supposedly discontinuous thinkers shared with their predecessors and with one another. As Richard J. Oosterhoff has recently noted, Galileo and Descartes borrowed heavily from the same Jesuits they derided, and the so-called 'new sciences' of the seventeenthcentury resembled nothing so much as the disciplinary traditions they emerged from. ${ }^{52}$

Secondly, these factors are particularly problematic when we consider the primacy afforded to the mathematization of physics in the seventeenth century. By focussing on histories of individual virtuosi and their outstanding departures from the norm, such narratives resolutely failed to advance our understanding of the general mathematical practices and culture of the period - or, indeed, of the aftereffects of these epoch-making mathematical revolutions on a wider population of less-expert users and consumers. A master-narrative which moves from Copernicus to Galileo to Descartes to Newton (occasionally via Kepler), in pursuit of the foundations of modern physics, has elided the socio-cultural commonalities shared

\footnotetext{
${ }^{50}$ Hall, Scientific Revolution, p. 365.

${ }^{51}$ Duhem, 'Research on the History of Physical Theories'; A. C. Crombie, Augustine to Galileo: The History of Science, A.D. 400-1650 (London: Falcon Press, 1952); id., Medieval and Early Modern Science, 2 vols, revised $2^{\text {nd }}$ edn (Garden City, New York: Doubelday, 1959); Peter Dear, Revolutionizing the Sciences: European Knowledge and its Ambitions, 1500-1700 (Houndmills: Palgrave Macmillan, 2001).

52 Richard J. Oosterhoff, Making Mathematical Culture: University and Print in the Circle of Lefèvre d'Étaples (Oxford: Oxford University Press, 2018), p. 4.
} 
by these great thinkers, the lesser developments which occurred between their innovations and, perhaps most importantly, the wider reception of their works.

Furthermore, the prevalence afforded to the mathematization of physics assumes that the boundaries, epistemic concerns and disciplinary methods of modern science can be mapped coherently onto those of pre-modern enquiry. This issue is itself two-fold. As we have already seen, the prioritisation of certain types of mathematical sciences risks painting an incorrect or incoherent picture of the use and value ascribed to mathematics in the early modern period: one which conceives of mathematical physics as uppermost in its importance to today's science. A corollary of this is that such problematic historical enquiry disassociates specific mathematical disciplines from their true cultural positions, promoting those which can be mostly clearly linked to the modern understanding of the discipline to the status of heralds of scientific progress. A consequence of these evaluations was that work on noncanonical yet mathematical or pseudo-mathematical subjects such as astrology and numerology was relegated to near-obscurity. Even as the historical environment and outlook began to change in the 1960s and 70s, historians such as Lynn Thorndike were sidelined as scholars such as Frances Yates came to prominence - despite the latter's continuation of this problematic master-narrative in the service of noncanonical subjects. ${ }^{53}$

In summary, prior to the 1980s, many historians' understanding of the place of mathematics in the early modern period was influenced by roughly a century of work in the history of science whose proponents had: celebrated the discoveries of a

\footnotetext{
53 The 'Yates thesis' is expounded in Frances A. Yates, Giordano Bruno and the Hermetic Tradition (London: Routledge and Kegan Paul, 1964); id., 'The Hermetic Tradition in Renaissance Science' in Charles S. Singleton, ed., Art, Science and History in the Renaissance (Baltimore: The Johns Hopkins University Press, 1967), pp. 255-274. A range of scholars have since taken Yates to task in her conflation of Hermeticism with Neoplatonism and natural magic, both of which exerted influence on pre-modern science, including Robert S. Westman, 'Magical Reform and Astronomical Reform: The Yates Thesis Reconsidered', in Robert S. Westman and J. E. McGuire, eds., Hermeticism and the Scientific Revolution (Los Angeles: William Andrews Clark Memorial Library, 1977), pp. 1-91; Charles B. Schmitt, 'Reappraisals in Renaissance Science', History of Science, 16 (1978), pp. 200214; Paolo Rossi, 'Hermeticism, Rationality, and the Scientific Revolution' in M. L. Righini Bonelli and William R. Shea, eds., Reason, Experiment and Mysticism in the Scientific Revolution (New York: Science History Publications, 1975), pp. 247-273. See also Lynn Thorndike, The History of Magic and Experimental Science, 8 vols (New York: Columbia University Press, 1932-1958. For a historiographical review of the 'rationality' of magic and its place in modern scholarship, see Richard Kieckhefer, 'The Specific Rationality of Medieval Magic' in Brian P. Levack, ed., New Perspectives on Witchcraft, Magic and Demonology, Volume 1: Demonology, Religion, and Witchcraft (New York and London: Routledge, 2001), pp. 59-82, particularly pp. 59-61.
} 
set of canonical theorists as relevant to the foundation of modern science; situated these canonical theorists within a progressive narrative of development characterised as little less than a universal revolution in rational thought; utilised this narrative to establish the central value of theory over social, economic, and other cultural elements; and, finally, utilised this idea of rationality to downplay any supposedly irrational endeavours undertaken by figures in the period - for example, alchemy or astrology, both of which utilised the mathematical and experimental processes and modes of thought so central to the master narrative of scientific revolution.

\section{Characterizing the Social Context of Early Modern Mathematics}

Whether intentionally or otherwise, a number of significant works written in the last fifty years have worked to undo several of the problems listed above. A key element of these works has been their recognition of the need for a greater contextual awareness of sixteenth- and seventeenth-century modes of thought and practice, and the relevance of these plural modes to the social processes of knowledge-making in the early modern period. The culmination of much of this scholarship has contributed to a now widely-accepted 'de-centering' of the concept of the 'Scientific Revolution'; ${ }^{54}$ so much so that in 2006 Katharine Park and Lorraine Daston argued:

It is no longer clear that there was any coherent enterprise in the early modern period that can be identified with modern science, or that the transformations in question were as explosive and discontinuous as the analogy with political revolution, or that those transformations were unique in intellectual magnitude and cultural significance. ${ }^{55}$

From the 1980s onwards, sociological studies of science have in particular been influential in sparking in the history of science a renewed interest in the social elements relevant to the construction and practice of scientific knowledge. Inspired by the re-evaluation of the concept of the 'Scientific Revolution' provided in Thomas Kuhn's The Structure of Scientific Revolutions (1962), a generation of

\footnotetext{
${ }^{54}$ Andrew Cunningham and Perry Williams, 'De-Centring the 'Big Picture': "The Origins of Science" and the Modern Origins of Science', The British Journal for the History of Science, 26.4 (1993), pp. 407-432. Brian P. Copenhaver, 'Did Science have a Renaissance?', Isis, 83.3 (1992), pp. 387-407.

${ }^{55}$ Katharine Park and Lorraine Daston, 'Introduction: The Age of the New', in Katharine Park and Lorraine Daston, eds., The Cambridge History of Science. Volume 3: Early Modern Science (Cambridge: Cambridge University Press, 2006), pp. 1-17, p. 13.
} 
historians applied constructivist approaches to the history of science, ${ }^{56}$ and to the cyclical paradigms of 'normal' and 'revolutionary' science Kuhn had identified even in the face of disparagement from Kuhn himself. ${ }^{57}$ Jan Golinski has since distinguished three aspects of the Kuhnian model of historiography that the constructivist approach latched onto: firstly, that scientific practice in its various forms is moderated by the relations of authority and social discipline through which consensus among communities of practitioners is maintained; secondly, that scientific practices are governed by adherence to set model problem solutions and their attendant methods, concepts, and instruments. The application of modes of thought or instruments to new problems comes, in this argument, from a kind of pragmatic approach to problem-solving akin to that of the skilled craftsman. Finally, the core values governing scientific practice may be extremely small-scale and local, implicitly linked to the social lives of a set of practitioners and, in certain cases, established or tried only by controversy. ${ }^{58}$

If to some extent these studies met with their apogee in Steven Shapin and Simon Schaffer's Leviathan and the Air-Pump (1985), the field of the history of science has undoubtedly turned since the 1970s increasingly toward studying local subcultures of science, their craft processes and practices, their immediate and wider modes of legitimation, and their often narrow chronological and geographical specificity. ${ }^{59}$ While the spectre of the internalist/externalist debate has arisen again

\footnotetext{
${ }^{56}$ Shapin, 'Discipline and Bounding', p. 353 and pp. 357-358. Shapin argued for the rejection of the false dichotomy of the internalist-externalist debate in favour of a 'historicist perspective on scientific boundaries as a good vehicle for moving forward both the sociology of scientific knowledge and a naturalistically-conceived history of scientific culture.' For a later appraisal of the state of the field of Sociology of Scientific Knowledge (SSK) (albeit by Shapin himself), see Steven Shapin, 'Here and Everywhere - Sociology of Scientific Knowledge', Annual Review of Sociology, 21 (1995), pp. 289321.

57 Thomas S. Kuhn, The Structure of Scientific Revolutions, $2^{\text {nd }}$ edn, enlarged (Chicago: University of Chicago Press, 1970; originally published 1962). Kuhn's treatment of 'normal' and 'revolutionary' science - and the 'anomalies' in normal science that bring about 'paradigm shifts' can be found from pp. 35-82. For Kuhn's repudiation of the sociological approach, see Thomas S. Kuhn, 'The Trouble with the Historical Philosophy of Science', Robert and Maurine Rothschild Distinguished Lecture 19 November 1991. An Occasional Publication of the Department of the History of Science (Cambridge, MA. Harvard University Press, 1992). A detailed discussion of Kuhn's 'internalism' is found in Alexander Bird, 'Kuhn, Naturalism, and the Social Study of Science', in Vasso Kindi and Theodore Arabatzis, eds., Kuhn's The Structure of Scientific Revolutions Revisited (New York: Routledge, 2012), pp. 205-230.

58 Jan Golinski, Making Natural Knowledge: Constructivism and the History of Science, $2^{\text {nd }}$ edn (Chicago and London: University of Chicago Press, 2005; first published Cambridge: Cambridge Univeristy Press, 1998), p. 22.

${ }^{59}$ Golinski, ibid, p. 26.
} 
on occasion, many historians have chosen instead to utilise the best parts of each approach with a view to correctly identifying and explaining changes in scientific theory and practice. ${ }^{60}$ Seen in this sociological, constructivist light, the aforementioned trio of works by Taylor, Hall and Waters has become foundational to much of this recent historiography.

In particular, E. G. R. Taylor's work - akin to an extensive database of those she dubbed the 'mathematical practitioners' working as teachers, authors, instrument makers, and in other technically-proficient roles in England between the fifteenth and early nineteenth centuries - has achieved classic status, and has frequently been invoked to combat the history of science's persistent tendency to return to canonical theorists. Though nebulous and still open to clarification, her broad identification of these practitioners represents for many historians a stereotype functioning as a useful gateway through which to approach the histories of the celebrated and lesscelebrated individuals belonging to geographically-clustered communities of mathematically-literate producers of texts and instruments and most often working largely in the vernacular. ${ }^{61}$

\section{Characterizing the Communities of Early Modern Mathematical Practice}

The biographical and bio-bibliographical evidence amassed by Taylor and subsequent historians has provided a model by which to identify the proponents of mathematics in other early modern environments and localities. Central to these efforts has been the reappraisal, post-Taylor, of how mathematical practice was itself fashioned by its adherents - adherents who themselves often possessed contesting views of what mathematics was, and indeed what it was for. Several of these studies

\footnotetext{
${ }^{60}$ John Nnaji and José Luis Luján, 'The Content of Science Debate in the Historiography of the Scientific Revolution', International Studies in the Philosophy of Science, 30.2 (2017), pp. 99-109, p. 106.

${ }^{61}$ The term 'mathematical practitioner' is itself problematic. Commonly utilised by historians following Taylor, it remains something of a nebulous catch-all for the individuals who engaged in a huge variety of practical, mathematically-related endeavours, most particularly in early modern England. It is intended here as an introductory term prior to a more specific handling of those engaging with mathematical culture across Europe in the early modern period. For contrary views on the usefulness of the term, see Stephen Johnston, 'Review of Eric H. Ash, Power, Knowledge and Expertise in Elizabethan England', Isis, 97.2 (2007), pp. 348-349, and Adam Mosley, 'Early Modern Cosmography: Fine's Sphaera mundi in Content and Context' in Alexander Marr, ed., The Worlds of Oronce Fine: Mathematics, Instruments and Print in Renaissance France (Donnington: Shaun Tyas, 2009), pp. 114-136, pp. 129-130.
} 
have addressed the supposed intellectual discontinuity of the pivotal innovators of the 'Scientific Revolution' present in the historiographical narratives of Koyré and his followers by studying disparate groups of professional and non-professional mathematical thinkers within their socio-cultural, intellectual and economic structures. While such communities should not necessarily be conceived of as tightly-knit or even particularly coherent, the goals and perspectives of their members evince the manifold ways by which such individuals came to learn, practice, and disseminate mathematical material. ${ }^{62}$

Mahoney's pioneering biography of Pierre de Fermat and the later scholarship of Johnston have explained the diversity of these communities and their constituent individuals by emphasising both the ambiguity of mathematics' contemporaneous disparate disciplinary identities and, simultaneously, the personal motivations disparate practitioners brought to their studies. In a similar vein, and appearing two years after the first publication of Mahoney's monograph in 1975, Paul Lawrence Rose's expert study of the scholarly communities of Renaissance Italy demonstrated how the fifteenth- and sixteenth-century recovery of the subject which preceded Galileo was in every way a humanist enterprise: one in which expert philosophical, philological and literary skills travelled hand-in-hand with an aptitude for mathematics. ${ }^{63}$

A series of landmark studies written in the 1980s brought together several of these strands, in the process deepening the historical understanding of the mathematical communities of sixteenth- and seventeenth-century England and Italy respectively. The first of these was Mordechai Feingold's research into the teaching and learning of the mathematical sciences in English universities between 1560 and 1640, which brought to light how the discipline's public emergence owed much to

\footnotetext{
${ }^{62}$ Mahoney, Mathematical Career of Fermat, p. 22. Mahoney has argued that mathematics in the seventeenth century was dependent on individual personalities and their reasons for appropriating specific methods or conforming to a given school of thought. In this argument, the biographical background of an individual - and his reasons for pursuing mathematics - was at least as important as the school of mathematics in which he chose to operate.

${ }^{63}$ Paul Lawrence Rose, The Italian Renaissance of Mathematics: Studies on Humanists and Mathematicians from Petrarch to Galileo (Geneva: Librarie Droz, 1975). On the philosophical debates regarding the position of mathematics that had dominated a section of Italian humanism, see Paul Lawrence Rose and Stillman Drake, 'The Pseudo-Aristotelian Questions of Mechanics in Renaissance Culture,' Studies in the Renaissance, 18 (1974), pp. 65-104; and Paolo Mancosu, Philosophy of Mathematics and Mathematical Practice in the Seventeenth Century (Oxford: Oxford University Press, 1996), particularly pp. 10-15 and pp. 25-28.
} 
its cross-pollination by university-educated and mathematically-literate individuals. Rather than rigidly adhering to official decrees demanding that Aristotelian teaching retain its primacy, universities could instead function as arenas tacitly open to the dissemination and debate of new ideas, with professors and tutors teaching from a wider and more vibrant set of texts than those officially recognised on curricula. ${ }^{64}$

The proposed inclusivity of the nascent profession of mathematics inside and outside of the universities and learning institutions of the period has remained a subject for debate: one in which the individuals and groups of the period are exhumed to participate. Jim Bennett's contribution to these debates has long been central to our present-day understanding of the continuing tension which existed between the advocates of the study of pure mathematics and those arguing for improvements to the status of the so-called practical or 'mechanical' use of the mathematical sciences for commercial and technological progression. In a series of defining articles, beginning with 'The Mechanics' Philosophy and the Mechanical Philosophy' in 1986, Bennett further secured for the makers of philosophical, mathematical and scientific instruments a central position in the mainstream historiography of science. ${ }^{65}$ In doing so, Bennett - along with earlier historians such as Paolo Rossi, Arthur Clegg and A. C. Crombie ${ }^{66}$ - aided the re-establishment of mechanicians' craft practice as a key part of early modern knowledge making, experiment, and technological invention. ${ }^{67}$

\footnotetext{
${ }^{64}$ Mordechai Feingold, The Mathematicians' Apprenticeship: Science, Universities and Society in England, 1560-1640 (Cambridge: Cambridge University Press, 1984).

${ }^{65}$ See particularly J. A. Bennett, 'The Mechanics' Philosophy and the Mechanical Philosophy', History of Science, 24.1 (1986), pp. 1-28; id., 'The Challenge of Practical Mathematics' in Science, Culture and Popular Belief in Renaissance Europe, ed. by Stephen Pumfrey, Paolo L. Rossi, and Maurice Slawinski (Manchester and New York: Manchester University Press, 1991) pp. 176-90; and id., 'Knowing and Doing in the Sixteenth Century: What were instruments for?', British Journal for the History of Science, 36.2 (2003), pp. 129-150.

${ }^{66}$ Paolo Rossi, Philosophy, Technology, and the Arts in the Early Modern Era, trans. Salvator Attanasio, ed. Benamin Nelson (New York: Harper and Row 1970; originally published as I filosofi e le macchine: 1400-1700, Milan: Feltrinelli, 1962); Arthur Clegg, 'Craftsmen and the Origin of Science', Science and Society, 43 (1979), pp. 186-201; A. C. Crombie, 'Science and the Arts in the Renaissance: The Search for Truth and Certainty, Old and New’, History of Science, 18 (1980), pp. 233-46.

67 Aspects of this debate were pre-empted in A. Rupert Hall, 'The Scholar and the Craftsman in the Scientific Revolution' in Marshall Clagett, ed., Critical Problems in the History of Science (Madison, Milwaukee, and London: University of Wisconsin Press, 1969), pp. 3-23; and in Thomas S. Kuhn, 'Mathematical Versus Experimental Traditions in the Development of Physical Science', Journal of Interdisciplinary History, 7 (1976), pp. 1-31.
} 
Taking something of a middle ground between these positions, meanwhile, Mario Biagioli's 1989 exploration of the social status of Italian mathematicians at work between 1450 and 1600 illuminated the ways in which the epistemic legitimation of mathematical methods was predicated upon the social legitimation of its practitioners. To gather evidence for this position, Biagioli eschewed the anachronistic classification of types of mathematician, choosing instead to map the genealogical pattern of their professional roles and movements. To do so, he employed an holistic approach which considered almost every social aspect of mathematics in Italy in the round: its teaching at universities and its curricular status relative to other disciplines; the public teaching of its practical elements; its role in military engineering; biographies of mathematical practitioners; the status afforded to astrology; changes in the liberal arts; the role and function of the Italian courts in supporting practitioners; and the interplay between humanists and mathematicians. ${ }^{68}$

Whether in pursuit of patronage, social and commercial recognition, or academic advancement, the necessity for scholars and practitioners to negotiate and, indeed, self-fashion their expert identities has been held up as a by-product of the struggle for status experienced by both 'practical' and 'academic' mathematicians in English and European contexts. In this context, Katharine Hill and Katherine Neal have more recently revealed how authors and instrument-makers were often called upon to defend the utility of their output as much as their precise interpretation of its use; in fact, their success in doing so could depend on demonstrations of mathematical expertise as much as appropriately persuasive rhetoric. ${ }^{69}$ Robert Goulding, meanwhile, has through close reading of texts, addresses and lecture notes excavated the ways in which early modern educational reformers, such as Phillip Melanchthon, Henry Savile and Petrus Ramus were called upon to defend the mathematical disciplines in similar fashion; such figures used the controversies

\footnotetext{
${ }^{68}$ Mario Biagioli, 'The Social Status of Italian Mathematicians, 1450-1600', History of Science, 27 (1989), pp. 41-95, p. 41.

${ }^{69}$ Katherine Hill, “'Juglers or Schollers?” Negotiating the Role of a Mathematical Practitioner', British Journal for the History of Science, 31.3 (1998), pp. 253-274; Katherine Neal, 'The Rhetoric of Utility: Avoiding Occult Associations for Mathematics through Profitability and Pleasure', History of Science, 37.2 (1999), pp. 151-178.
} 
surrounding the role of mathematics in natural philosophy to redefine the history, teaching, and identity of mathematics in Germany, England and France. ${ }^{70}$

Undoubtedly, sixteenth- and seventeenth-century communities of learning such as the Lutheran astronomers of Wittenberg, the 'Fabrist Circle' of Jacques Lefèvre d'Étaples at the Collège Royal in Paris, and the Jesuit proto-scientists influenced by the teachings of the Collegio Romano helped to bring about what Peter Dear has called the 'mathematical way' of the new science. ${ }^{71}$ Yet cast as crucial to our present understanding of early modern mathematical culture are the practitioners: an almost bottomless and non-homogeneous group of technically innovative disruptors who helped effect a successful challenge to the existing orthodoxy of Aristotelian physics through the real-world application of physics on the battlefield or at sea; whose dissemination of texts and instruments made knowledge replicable through observation, experiment, and measurement, and who could be found at an increasingly large number of sites of practice, including the court, the university, the artisan's workshop and the shipyard..$^{72}$

By presenting detailed accounts of these individuals, their communities, and their contributions to the construction of mathematical culture and practice, the roles occupied by the mathematically-literate have been brought into sharper focus, even as the supposed boundaries between early modern scholars and craftsmen have been blurred. ${ }^{73}$ We have learned how these individuals participated directly in the vibrant ecclesiastical, courtly, and mercantile centres of the early modern period whilst they

\footnotetext{
${ }^{70}$ Robert Goulding, Defending Hypatia: Ramus, Savile and the Renaissance Rediscovery of Mathematical History (New York: Springer, 2010).

${ }^{71}$ Robert S. Westman, 'The Melanchthon Circle, Rheticus, and the Wittenberg Interpretation of the Copernican Theory', Isis, 66.2 (1975), pp. 164-193. For Philip Melanchthon's use of mathematics in the Lutheran reform of natural philosophy, see Sachiko Kusukawa, The Transformation of Natural Philosophy: The Case of Philip Melanchthon (Cambridge: Cambridge University Press, 1995), particularly pp. 134-144. On the Parisian 'Fabrist' circle, see Oosterhoff, Making Mathematical Culture; for the Jesuit influence on early modern mathematics and science, see Peter Dear, Discipline and Experience: The Mathematical Way in the Scientific Revolution (Chicago: University of Chicago Press, 1995), particularly pp. 32-62.

${ }^{72}$ Marr, Between Raphael and Galileo, p. 16.

${ }^{73}$ Introducing a collection of essays on practitioners and the transformation of natural philosophy, Lesley B. Cormack in 2017 wrote that 'an investigation of the interplay between useful mathematics and its practitioners on one hand, and natural philosophers on the other, seems in order.' Lesley B. Cormack, 'Introduction: Practical Mathematics, Practical Mathematicians, and the Case for Transforming the Study of Nature', in Lesley B. Cormack, Steven A. Walton and John A. Schuster, eds., Mathematical Practitioners and the Transformation of Natural Knowledge in Early Modern Europe (Cham: Springer, 2017), pp. 1-8, p. 2.
} 
were embedded in the broader occupational cultures of theology, medicinal 'physic', scholastic natural philosophy, teaching, princely prognostication, and artisanal craft. Following Taylor in affording sustained scholarly attention to the figure of the mathematical practitioner, the work of Bennett and subsequent historians of science has won for these practitioners a central role in the making of early modern mathematical and pre-modern science.

\section{Characterizing the Social Context of Early Modern Mathematics: Places of Practice}

The polyvalent utility of mathematics promoted by these practitioners has since been used by historians of science to explain the high degree of mobility intrinsic to these professional figures. Writing in 1998 on the sites of early modern astronomical practice, Nicholas Jardine acknowledged that the division of such arenas into university, court, and urban locations was often overly simplistic; nevertheless, increased professional mobility between these arenas and between branches of mathematics was very much the rule rather than the exception. ${ }^{74}$ Yet the problematic distinctions applied in the partitioning of scholars and craftsmen includes the locations of their appropriate sites of practice, and the attendant debate inspired between Feingold, Bennett and others, has yet to be fully resolved.

It should therefore come as no surprise that historians have worked diligently to correctly place mathematically-literate producers in arenas within and beyond the tripartite matrix of university, court and market so useful to our initial classification of their sites of practice. Following in the footsteps of A. Rupert Hall, there have been extensive studies on those in military occupations, who worked on and with technologies relating to firearms, ballistics, and fortification. ${ }^{75}$ In a similar fashion, professional communities gathered in the service of the state provide evidence of the

\footnotetext{
${ }^{74}$ Nicholas Jardine, 'The Places of Astronomy in Early Modern Culture', Journal for the History of Astronomy, 29 (1998), pp. 49-62, p. 52.

${ }^{75}$ William H. McNeil, The Pursuit of Power: Technology, Armed Force, and Society since A.D. 1000 (Chicago: University of Chicago Press, 1982); Mary (Henninger) Voss, 'Between the Cannon and the Book: Mathematics and Military Culture in Cinquecento Italy', Unpublished Ph.D. Dissertation, The Johns Hopkins University, 1995; Alfred W. Crosby, The Measure of Reality: Quantification and Western Society, 1250-1600 (Cambridge: Cambridge University Press, 1997), particularly pp. 129137 and pp. 230-237; Mary Henninger-Voss, 'How the New Science of Cannons Shook up the Aristotelian Cosmos', Journal of the History of Ideas, 63.3 (2002), pp. 371-397; Jochen Büttner, Peter Damerow, Jürgen Renn and Matthias Schemmel. 'The Challenging Images of Artillery: Practical Knowledge and the Roots of the Scientific Revolution' in Wolfgang Lefèvre, Jürgen Renn, and Urs Schoepflin, The Power of Images in Early Modern Science (Basel: Birkhäuser, 2003), pp. 3-27.
} 
value of mathematics to large-scale, national engineering projects - for example, the sixteenth-century remaking of Dover Harbour, treated first by Stephen Johnston in 1994, returned to view in Eric H. Ash's exploration of the copper miners, the practitioners at Dover Harbour, and the navigators who established a communal culture of expertise in Elizabethan England. ${ }^{76}$

We have learned of the networks of expertise, influence and patronage which promoted experimentation and technical innovation at English, Tuscan and French courts and academies. ${ }^{77}$ The co-dependence of mobility and status in the careers of many practitioners can be witnessed in Biagioli's longitudinal work on Galileo, written between 1993 and 2010, wherein the subject's search for social, economic and intellectual legitimation was witnessed first in his move from university to court, and then in his fashioning of tools, texts, theory and teaching into 'instruments of credit' that could secure his ascension to the unique role of the Medici's philosophermathematician. $^{78}$

The multiplicity of these environments, not to mention the numbers of producers and consumers that might pass through them, has in the past ten years been visualised by Pamela O. Long as akin to melting-pot 'trading zones' wherein pre-professionalized tradesmen, trained on-site in artisanal workshops, guilds, or construction yards and unbound by standardized practice in a range of trades met with and exchanged expertise with those taught at educational institutions. ${ }^{79}$ Existing

\footnotetext{
${ }^{76}$ Johnston, 'Making Mathematical Practice', particularly pp. 218-286. Eric H. Ash, Knowledge, Power and Expertise in Elizabethan England (Baltimore and London: The Johns Hopkins University Press, 2004), particularly pp. 55-86.

${ }^{77}$ R. J. W. Evans, Rudolf II and his World: A Study in Intellectual History, 1576-1612 (Oxford: Oxford University Press, 1973); Guy Fitch Lytle and Stephen Orgel, eds., Patronage in the Renaissance (Princeton, N.J., Princeton University Press, 1981); Sharon Kettering, Patrons, Brokers and Clients in Seventeenth Century France (Oxford and New York: Oxford University Press, 1986); David C. Goodman, Power and Penury: Government, Technology and Science in Philip II's Spain (Cambridge: Cambridge University Press, 1988); Bruce T. Moran, ed., Patronage and Institutions: Science, Technology and Medicine at the European Court, 1500-1750 (Rochester, N.Y.: The Boydell Press, 1991).

${ }^{78}$ Mario Biagioli, Galileo, Courtier: The Practice of Science in the Culture of Absolutism (Chicago: University of Chicago Press, 1993); id., Galileo's Instruments of Credit: Telescopes, Images, Secrecy (Chicago: University of Chicago Press, 2006).

${ }^{79}$ Pamela O. Long, 'Trading Zones in Early Modern Europe', Isis, 106.4 (2015), pp. 840-847. Long adapts the concept of trading zones proposed by Peter Galison: see Peter Galison, Image and Logic: A Material Culture of Microphysics (Chicago: University of Chicago Press, 1997), pp. 781-844; see also Peter Galison, 'Trading with the Enemy', in Michelle E. Gorman, ed., Trading Zones and Interactional Expertise: Creating New Kinds of Collaboration (Cambridge, MA: Massachusetts Institute of Technology Press, 2010), pp. 25-52.
} 
beyond the relationships commonly entered into by patrons and clients, from these meetings could evolve 'bricolagic' craft processes and constructions of knowledge that, as they grew in number, encouraged both the skilled artisan and the learned scholar to gradually learn from one another in outlook and application. ${ }^{80}$

Long's work is part of a longer strand of modern historiography which has taken as its focus not only the artisans and practitioners but also their craft processes and the market for manufactured instruments, texts, and objects, both practical and ornate. A focus on artisanal practice is witnessed particularly in the scholarship of Pamela H. Smith, who has made clear the relationship shared between the making of objects and the making of knowledge about the natural world. Across different areas in early modern Europe, those involved in the making of instruments, tools, buildings and other materials gradually came to participate in the making of knowledge, bringing with them artisanal epistemologies to the exchange of ideas and practice. ${ }^{81}$ Importantly, as a result of the transition of economic value from a given product to the knowledge required for its production, printing also aided the codification and diffusion of practical knowledge: a diffusion that was further increased by non-uniform economic expansion across early modern Europe.

This economic growth was itself based upon technological innovation, and supported by 'diverse, yet highly-connected, constellations of political, economic and geographical entities', including, in Matteo Valleriani's example, the Dukedom of Florence and the Este Family principalities based in Ferrara and Modena. ${ }^{82}$ The development of similar bodies and their reciprocal trading zones in the commercial and urban centres of Europe was coupled with the movement of technically superior artisans: skilled workers who moved countries for opportunity; because of local shortages of employment or food; to avoid war or religious and political persecution; or for any of a host of personal and professional reasons.

\footnotetext{
${ }^{80}$ Pamela O. Long, 'Multi-Tasking "Pre-Professional" Architect / Engineers and Other Bricolagic Practitioners as Key Figures in the Elision of Boundaries between Practice and Learning in SixteenthCentury Europe: Some Roman Examples' in Matteo Valleriani, ed., The Structures of Practical Knowledge (Cham: Springer International Publishing, 2017), pp. 223-246, p. 224.

${ }^{81}$ Pamela H. Smith, The Body of the Artisan: Art and Experience in the Scientific Revolution (Chicago: University of Chicago Press, 2004), particularly pp. 67-82.

${ }^{82}$ Matteo Valleriani, 'The Epistemology of Practical Knowledge', in Matteo Valleriani, ed., The Structures of Practical Knowledge (Cham: Springer International Publishing AG, 2017), pp. 1-21, particularly pp. 12-14.
} 
Yet if the diversity argued for as central to the spread of mathematical culture and practice brings with it a complication in ascribing set locations to mobile figures whose professional and non-professional reasons for studying mathematics were entwined with the political, philosophical, and religious issues of their day, we now possess a range of scholarly methods to trace these figures and their instruments of credit much more effectively. As the literature attests, studies of instruments illuminate both the communities and the places of practice of early modern mathematical culture: a fact borne out in studies such as Penelope Gouk's research on The Ivory Sundials of Nuremberg, 1500-1700 (1989) and, more recently, in Susan Dackerman and Suzanne Karr Schmidt's treatment of the construction and use of printed instruments for measurement and time-finding. ${ }^{83}$

\section{Characterizing the Social Context of Early Modern Mathematics: Products of Practice}

The movements of instrument-makers and their instruments - whether across Europe, in more local settings, or into the museum or the collection - has long been enlivened by the social, economic, practical and theoretical contexts of printed or engraved knowledge-making objects and their makers. In this subfield of the history of science, the work of Gerard L'Estrange Turner, Jim Bennett, D. J. Bryden, and A. J. Turner has proven crucial to our understanding of what we now call scientific instruments; an anachronistic categorisation which we should yet approach with appropriate caution. ${ }^{84}$ As Bennett has identified in a number of articles, mathematical instruments - the sundials, quadrants, staffs, theodolites and rules which provided measurements predicated on geometrical theory-were the prevalent category of instruments in the early modern period. Trends in philosophical and proto-scientific enquiry, commerce, and nation-building changed to incorporate them, rather than the other way around. ${ }^{85}$

\footnotetext{
${ }^{83}$ Penelope Gouk, The Ivory Sundials of Nuremberg, 1500-1700 (Cambridge: Whipple Museum of the History of Science, 1989); Suzanne Karr Schmidt, with Kimberley Nichols, Altered and Adorned: Using Renaissance Prints in Daily Life (Chicago and New Haven: Art Institute of Chicago, distributed by Yale University Press, 2011); Susan Dackerman, Prints and the Pursuit of Knowledge in Early Modern Europe (Cambridge, MA: Harvard University Art Museums, 2011).

${ }^{84}$ J. V. Field, 'What is Scientific about a Scientific Instrument?', Nuncius, 3.2 (1988), pp. 3-26; Deborah Jean Warner, 'What is a scientific instrument, when did it become one, and why?', British Journal of the History of Science, 23 (1990), pp. 83-93.

${ }^{85}$ See, for example, J. A. Bennett, 'Early Modern Mathematical Instruments', Isis, 102.4 (2011), pp. 697-705, p. 698; id., 'Geometry in Context in the Sixteenth Century: The View from the Museum',
} 
The reference catalogues and synoptic histories assembled by L'Estrange Turner, Bennett, Bryden and Turner form essential resources for our understanding of early modern science. ${ }^{86}$ To these works can be added important publications emanating from the National Maritime Museum at Greenwich, London. ${ }^{87}$ Such studies have helped to guide and inspire research into the use of instruments for the education of gentlemen; for professional and disciplinary legitimation; as models for the communication for novel cosmological theories; and, most recently, in service of the repositioning of mathematics itself as an inherently practical discipline. ${ }^{88}$ Additionally, the outlook of the aforementioned scholar-curators and their successors brings with it its own site of methodological practice. The view from the museum has undeniably been of central importance to the revival of interest in instruments; furthermore, it has been afforded a unique place in the transformation of the history of science as a corrective to the theory-driven mindset of idealist historians.

Introducing a special volume of the journal Osiris in 1994, Albert van Helden and Thomas L. Hankins elevated instruments from the subordinate position gifted them by theorists such as Alexandre Koyré, arguing instead that instruments occupy a mediatory role in both the practice and the historical study of science. Not

Early Science and Medicine, 7 (2002), pp. 214-230; id., 'Knowing and Doing in the Sixteenth Century', particularly pp. 131-134.

${ }^{86}$ Gerard. L'Estrange Turner, Elizabethan Instrument Makers. The Origins of the London Trade in Precision Instrument Making (Oxford: Oxford University Press, 2000); J. A. Bennett, The Divided Circle: A History of Instruments for Astronomy, Navigation and Surveying (Oxford: Phaidon and Christie's, 1987); D. J. Bryden, Scottish Scientific Instrument Makers (Edinburgh: Royal Scottish Museum, 1972); A. J. Turner, Early Scientific Instruments, Europe 1400-1800 (London: Sotheby's, 1987).

${ }^{87}$ H. O. Hill and E. W. Paget-Tomlinson, Instruments of Navigation: a catalogue of instruments at the National Maritime Museum with notes upon their use (London: National Maritime Museum and Her Majesty's Stationery Office, 1958); Gloria C. Clifton, Directory of British Scientific Instrument Makers, 1550-1851 (London: Zwemmer in association with the National Maritime Museum, 1995); Hester Higton, Sundials at Greenwich: a catalogue of the sundials, nocturnals, and horary quadrants in the National Maritime Museum, Greenwich (Oxford, New York, and Greenwich: Oxford University Press and National Maritime Museum, 2002); W. F. J Mörzer Bruyns, Sextants at Greenwich: a catalogue of the mariner's quadrants, mariner's astrolabes, cross-staffs, backstaffs, octants, sextants, quintants, reflecting circles and artificial horizons in the National Maritime Museum, Greenwich (Oxford: Oxford University Press, 2009).

${ }^{88}$ A. J. Turner, 'Mathematical Instruments and the Education of Gentlemen', Annals of Science, 30.1 (1973), pp. 51-88; Stephen Johnston, 'Mathematical Practitioners and Instruments in Elizabethan England', Annals of Science, 48.4 (1991), pp. 319-344; Adam Mosley, 'Objects of Knowledge: Mathematics and Models in Sixteenth-Century Cosmology and Astronomy’ in Sachiko Kusukawa and Ian Maclean, eds., Transmitting Knowledge: Words, Images, and Instruments in Early Modern Europe (Oxford: Oxford University Press, 2006), pp. 193-216; Katie Taylor, 'A "Practique Discipline"? Mathematical Arts in John Blagrave's The Mathematical Jewel (1585)', Journal for the History of Astronomy, 41.3 (2010), pp. 329-353. 
merely tools for the investigation of ideas or the testing of theory, instruments were instead to be recognised as things that could determine what can be done, what can be thought, and, finally, as possible initiators of investigation. ${ }^{89}$ The impact of studies of the history of mathematical, philosophical and scientific instruments was such that van Helden and Hankins were emboldened to state that Koyré's views on such instruments as secondary or rhetorical reifiers of theory were now proven incorrect:

The important question to ask is not whether Koyré was right or wrong about the importance of instruments. Subsequent historians and philosophers have proved him wrong. What we need to ask is, rather, how instruments have worked to determine and, perhaps, even to define the methods and content of science. $^{90}$

Aside from the impact of these studies and the associated alteration of the theoretical viewpoint historians focussing on mathematical instruments may have effected, two important points on the history of instruments and their collection in museums may here be made. Each is germane to our understanding of the changing character of early modern mathematical culture, and to our understanding of the makers, consumers, and users of that same culture. Firstly, the discipline of the history of science in England has particularly strong roots in the museum and its collections. Both the Museum of the History of Science at Oxford and the Whipple Museum of the History of Science predate the foundation of academic departments in the subject at these universities.

To differing ends, Bennett and Seb Falk have taken the history of these institutions to add to our understanding of the journey taken by the discipline, tracing a thread from Robert T. Gunther, to Herbert Butterfield, A. Rupert Hall, Derek J. de Solla Price and their successors. ${ }^{91}$ In doing so, the battles waged between internalist and externalist theories of science; between Marxist and idealist inspirations, and between the collection of instruments as 'mere antiquarianism' or essential part of

\footnotetext{
${ }^{89}$ Albert van Helden and Thomas L. Hankins, 'Introduction: Instruments in the History of Science', Osiris, 9 (1994), pp. 1-6, p. 4.

${ }^{90}$ van Helden and Hankins, ibid, p. 6.

${ }^{91}$ J. A. Bennett, 'Museums and the Establishment of the History of Science at Oxford and Cambridge', British Journal for the History of Science, 30.1 (1997), pp. 29-46; Seb Falk, 'The Scholar as Craftsman: Derek DeSolla Price and the Reconstruction of a Medieval Instrument', Notes and Records of the Royal Society, 68 (2014), pp. 111-134.
} 
research are given fresh perspectives by detailed study of the personal motivations of their combatants. Understanding these developments aids our understanding of what historians of science do when studying and/or contextualising a historical instrument, whilst simultaneously adding depth to the methodological and ideological standpoints still exerting conspicuous influence on the wider discipline.

A second point is of relevance to instruments, texts, and their collection in many museums of science and technology today. Concluding his investigation into de Solla Price's construction of a model of a planetary equatorium through study of a preserved Chaucerian manuscript, Falk noted that, from its point of origin, the Whipple Museum had always intended for its research to bridge the divide between text and object: as the museum's founding memorandum expressed, historical instruments and tools were so often illustrated in manuscripts and books. ${ }^{92}$ This point has previously been emphasised in Silvia de Renzi's recent collection contextualising instruments and their accompanying texts, their use and application, and their histories of collection inside and outside of the museums in which they now reside. ${ }^{93}$ It has been made again by Alexander Marr, who has used the example of practical mathematical and instrumental treatises to lay emphasis on the breadth of consumers in the market for such texts: the instrument makers, architects, surveyors, military engineers and gentlemen who might benefit from this vibrant intersection of print, instrument and practice. ${ }^{94}$ Despite acknowledgements of the commercial power of this audience, and, indeed, of its preference for more introductory, vernacular texts, the evidence of this audience and its response to the mathematical materials of the period is still a largely untapped resource.

\footnotetext{
92 Falk, 'Scholar as Craftsman', p. 127. For Price's study of Chaucer's manuscript, see Derek de Solla Price, The Equatorie of the Planetis (Cambridge: Cambridge University Press, 1955).

${ }^{93}$ Silvia de Renzi, Instruments in Print: Books from the Whipple Collection (Cambridge: Whipple Museum for the History of Science, 2000). See also Adam Mosley, 'Spheres and texts on spheres: the book-instrument relationship and an armillary sphere in the Whipple Museum of the History of Science', in Liba Taub and Frances Wilmoth, eds., The Whipple Museum of the History of Science: Instruments and Interpretations, to Celebrate the Sixtieth Anniversary of R. S. Whipple's Gift to the University of Cambridge (Cambridge: The Whipple Museum of the History of Science, 2006), pp. 301-318.

94 Alexander Marr, 'The Production and Distribution of Mutio Oddi's Dello Squadro (1625)', in Sachiko Kusukawa and Ian Maclean, eds., Transmitting Knowledge: Words, Images and Instruments in Early Modern Europe (Oxford: Oxford University Press, 2006), pp. 165-192, p. 166. See also Marr, Between Raphael and Galileo, pp. 109-130.
} 


\section{Characterizing the Social Context of Early Modern Mathematics: Collections and Cultures of Commerce}

That studies attending to the sociological contexts of early modern knowledgemaking grew consistently in their influence throughout the 1980s is undoubted.

Following historians in a number of related fields who sought to classify the early modern period as one in which market forces and trends in consumption became the principal drivers of social and economic development, historians of science writing in the decades after 1990 have since invested time and effort into carefully detailing the commercial realities which underpinned the early modern interest in products through which to evaluate, measure, and master the natural world. This turn toward what Richard Goldthwaite dubbed in 1987 the 'empire of things' (with specific reference to Renaissance Italy) can, ${ }^{95}$ to some degree, be seen as a modern attempt to restructure the core concerns of the Marxist studies that inspired so much vitriol in the 1930 s. $^{96}$

Following Goldthwaite, many historians now argue that the purchase and retention of things, and their attendant display of wealth publically and privately was actively promoted in the early modern period as central to the self-fashioning of social and economic identity. Areas that witnessed identifiable periods of consumer change, market development, and, by proxy, economic growth - for example, Renaissance Italy, or the Dutch Republic of the early modern period - have been celebrated as evidence of the seedbeds of modern consumer society, ${ }^{97}$ with personal

\footnotetext{
${ }^{95}$ Richard A. Goldthwaite, 'The Empire of Things: Consumer Demand in Renaissance Italy', in F. W. Kent and Patricia Simons, eds., with J. C. Eade, Patronage, Art, and Society in Renaissance Italy (Oxford: Clarendon Press, 1987), pp. 153-175.

${ }^{96}$ In addition to the aforementioned works by Hessen and Zilsel, see also Franz Borkenau, Der Übergang vom feudalen zum bürgerlichen Weltbild: Studien zur Geschichte der Philosophie der Manufakturperiode (Paris: F. Alcan, 1934); Henryk Grossman, 'The Social Foundations of the Mechanistic Philosophy and Manufacture' in Gideon Freudenthal and Peter McLaughlin, eds., The Social and Economic Roots of the Scientific Revolution. Texts by Boris Hessen and Henryk Grossman (Dordrecht: Springer, 2009), pp. 103-156. Originally published as 'Die Gesellschaftlichen Grundlagen der Mechanistischen Philosophie und die Manufaktur', Zeitschrift fur Sozialforschung, 4 (1935), pp. 161-231. For a detailed treatment of the Marxist historiography of science, see Richard W. Hadden, On the Shoulders of Merchants: Exchange and the Mathematical Conception of Nature in Early Modern Europe (Albany: State University of New York Press, 1994), pp. 8-62.

${ }^{97}$ Richard A. Goldthwaite, Wealth and the Demand for Art in Italy, 1300-1600 (Baltimore: The Johns Hopkins University Press, 1993); Jan de Vries, The First Modern Economy: Success, Failure, and Perseverance of the Dutch Economy, 1500-1815 (Cambridge: Cambridge University Press, 1997); for a more recent example, see H. J. Cook, Matters of Exchange: Commerce, Medicine, and Science in the Dutch Golden Age (New Haven and London: Yale University Press, 2008).
} 
reports, trade figures and probate inventories held up as evidence of the ever-more conspicuous consumption a growing portion of society began to enjoy. ${ }^{98}$

Within these developments, specific communities of producers and consumers relevant to the history of mathematics can be identified, as in, for example, the sixteenth-century Northern European courts which fed and encouraged the growth of a class of expert, professional instrument-makers. The products sold by these instrument-makers (and their representation of the tastes and fashions of a moneyed elite) were then desired by a growing market of consumers: consumers who could be satiated with less-ornate and more affordable iterations of the same. As this class of consumers grew, more instrument-makers (of varying degrees of skill) entered the marketplace, thereby widening the circle of commerce. The identification of communities and individuals who put their mathematical expertise toward gainful employment, and the sites and arenas at which such figures were to be found, has thus been stimulated by the integration into the history of science of histories of instruments and of histories of both collecting and material culture.

That the instruments of intellectual culture are worthy of study - or that these objects are at least worthy of collection - is an idea long established, and one that can be traced back in its various forms to the Renaissance and early modern periods. As the previous sections have shown, there is by now a large body of literature presenting evidence of early modern scholars and princes collecting in parallel, patronising in the process a growing merchant class which provided and, thereafter, themselves desired such paraphernalia, spawning a mimetic circuit which incorporated both presentational and practical utility. This self-conscious aping of the collection practices of leisured classes has been used to delineate four main contexts for Renaissance collecting: the collection of antiquities; collection of

\footnotetext{
98 There now exists a wide array of literature on early modern and historical consumerism, and its means of testing. Examples can be found in John Brewer and Roy Porter, eds., Consumption and the World of Goods (London: Routledge, 1993); Lisa Jardine, Worldly Goods: A New History of the Renaissance (London: Macmillan, 1996); Sara Pennell, 'Consumption and Consumerism in Early Modern England', Historical Journal, 42.2 (1999), pp. 549-564. On the specific use of probate inventories, and the problems associated therewith, see Lena Cowen Orlin, 'Fictions of the Early Modern Probate Inventory' in Henry S. Turner, ed., The Culture of Capital: Property, Cities, and Knowledge in Early Modern England (New York and London: Routledge, 2002), pp. 51-84.
} 
curiosities; collections of savants or practitioners, and didactic collections - those of schools and teachers. ${ }^{99}$

Microcosmic cabinet collections - with their resemblances, signifiers and curios of the wider world - were, in this argument, usurped and then cannibalized by a practical culture in which instrumentation, rationalisation and classification saw value move away from wonder and amazement and instead toward ordered knowledge and understanding. ${ }^{100}$ The trend toward utilitarian, practical and communal knowledge-making identified in the period has been cited as evidence of a change in the focus of the observational gaze: one moving away from the cabinet and instead mediated by the text and the instrument, as put to use at specific sites of practice. $^{101}$

In this manner, Bruce T. Moran's study of the prince-practitioners of sixteenth century northern Europe has remained influential in its depiction of how such individuals used artistic and mechanical novelties as displays to communicate their support for novel inventions and artisanal creativity as representative of regal power. Combining elements of the vogue for courtly mannerism with princely interests, the nobility of early modern Europe saw (or were convinced by ideas of) the uses of technical or mechanical work for territorial exploration or commercial expansion. ${ }^{102}$ Prototypical early modern museum and collection practices suggest that collectors saw their assemblages through the lens of specific types of utility. Scholars including Carol Duncan have extrapolated the growth of the modern museum from sixteenth-, seventeenth- and eighteenth-century princely reception rooms: rooms designed to dazzle and overwhelm local and foreign dignitaries with

\footnotetext{
${ }^{99}$ A. J. Turner, 'From Mathematical Practice to the History of Science', Journal of the History of Collections, 7.2 (1995), pp. 135-150, p. 139.

100 Turner, 'Mathematical Practice to History of Science', p. 141.

${ }^{101}$ Gianna Pomata, 'Observation Rising: Birth of an Epistemic Genre, 1500-1650', in Lorraine Daston and Elizabeth Lunbeck, eds., Histories of Scientific Observation (Chicago: University of Chicago Press, 2011), pp. 45-80, p. 69.

102 Bruce T. Moran, 'German Prince-Practitioners: Aspects in the Development of Courtly Science, Technology, and Procedures in the Renaissance', Technology and Culture, 22.2 (1981), pp. 253-274, p. 259. See also Nicholas Dew, "A Gymnosophist at Versailles: The Geography of Knowledge in the Iconography of Louis XIV” in Joan Pau Rubiés, Melissa Calaresu, and Filippo de Vivo, eds., Exploring Cultural History: Essays in Honour of Peter Burke (Farnham: Ashgate, 2010), pp. 249264 , p. 250.
} 
the magnificence and might of the sovereign, communicating in the process the legitimacy of that sovereign's rule. ${ }^{103}$

Collection for representation and collection for advancement were by no means mutually exclusive and, subsequently, are not easily untangled. In their public demonstrations of rhetorical imitatio, exempla and inventio, early modern Italian collectors deployed the entirety of their social and intellectual talents in the service of creating a dazzling bricolage: a mosaic of the fragments of cultural inheritance, both unique and insurmountably derivative. ${ }^{104}$ Inspired by the work of Moran, and, more prominently, by that of Paula Findlen, subsequent scholarly explorations of the early modern scientific marketplace have sought to amplify its communal aspects, drawing attention to the complex systems of exchange, patronage and commerce in which princes, scholars, merchants and other agents engaged as indicative of a social network in which everyone from the nobility to a craftsman could participate. ${ }^{105}$ Contrasting the ostentatious science of sixteenth-century Prague and Hesse-Kassel to the supposedly more utilitarian practices of seventeenth-century England, Stephen Pumfrey and Frances Dawbarn have proposed that this utilitarian scientific market was shaped less by princely self-image and more by the practitioners of lower social order and visibility. ${ }^{106}$

Similar processes of ostentatious representation are argued to have been at work in the book-collections and private libraries of the early modern period. Prior to his aforementioned monograph on the scholarly practices of Italian humanistmathematicians, Rose has elsewhere argued that one model for representation through the intellectual recovery of rare or important texts was to be found in the libraries of fifteenth-century humanists such as Paolo dal Pozzo Toscanelli (13971482) in Quattrocento Italy and its vibrant culture of literary transmission, centred on the recovery, translation and restitution of classical mathematical theory. ${ }^{107}$ In early

\footnotetext{
${ }^{103}$ Carol Duncan, Civilizing Rituals: Inside Public Art Museums (London: Routledge, 1995), p. 22.

${ }^{104}$ Paula Findlen, Possessing Nature: Museums, Collecting, and Scientific Culture in Early Modern Italy (Berkeley, Los Angeles, and London: University of California Press, 1994), p. 296.

${ }^{105}$ See, for example, Mark A. Meadow, 'Merchants and Marvels: Hans Jacob Fugger and the Origins of the Wunderkammer' in Pamela Smith and Paula Findlen, eds., Merchants and Marvels: Commerce, Science, and Art in Early Modern Europe (New York: Routledge, 2002), pp. 182-200, p. 184.

${ }^{106}$ Stephen Pumfrey and Frances Dawbarn, 'Science and Patronage in England, 1570-1625: A Preliminary Study', History of Science, 42.2 (2004), pp. 137-188, p. 142.

${ }^{107}$ Paul Lawrence Rose, 'Humanist Libraries and Renaissance Mathematics: The Italian Libraries of the Quattrocento', Studies in the Renaissance, 20 (1973), pp. 46-105, p. 47.
} 
modern England, meanwhile, practices of recovery, representation and advancement were in frequent interplay. Declamations of the treasures of one's erudite collection could, in William H. Sherman's assertion, reflect the fact that the image of the English private library and its solitary scholarly reader were 'less representations of early modern reality than rhetorical strategies by which early modern subjects negotiated their place in society'. ${ }^{108}$ At the same time, with university curricula slow to respond to the contemporaneous authoring of mathematical and scientific texts and institutional libraries beholden to the textual and disciplinary interests of their donors, the personal library became all the more important for the theorist or practitioner. ${ }^{109}$

\section{Characterizing the Social Context of Early Modern Mathematics: Books, Readers and Mathematical Culture}

The breadth of the market for mathematical texts and instruments in a number of commercial centres was a boon to the booming print and artisanal culture of the early modern period more generally. Books, meanwhile, were malleable carriers of value both inside and out, their size, shape, binding, ornamentation and contents all evidence of a complex and interlocking interface of the socio-cultural worth of information and object. Early modern printed texts were not always bound prior to sale, and many surviving examples display how owners were given the opportunity to select particular styles of binding for themselves. Consequently, as the work of David Pearson has shown, binding preferences - the choice of material, its decoration, the gilt or dye applied to a finished product, or the addition of stamped heraldry - can all fruitfully be used as evidence to situate a text as belonging to a given person or family, as well as to a given century, decade, or even year. ${ }^{110}$ Similarly, globes, maps, and dials - and the accompanying texts that taught their use - were simultaneously cast as objects of desire and objects of necessity depending on the market being served. These material goods, constructed and inscribed according

\footnotetext{
${ }^{108}$ William H. Sherman, 'The Place of Reading in the English Renaissance' in James Raven, Helen Small \& Naomi Tadmor, eds., The Practice and Representation of Reading in England (Cambridge: Cambridge University Press, 1996) pp. 42-76, p. 76.

${ }^{109}$ Giles Mandelbrote, 'Scientific Books and Their Owners: A Survey to c. 1720' in Andrew Hunter, ed., Thornton and Tully's Scientific Books, Libraries, and Collectors: A Study of Bibliography and the Book Trade in Relation to the History of Science, $4^{\text {th }}$ edn (Aldershot: Ashgate, 2000), pp. 333-366, p.335.

${ }^{110}$ David Pearson, Provenance Research in Book History: A Handbook (London: The British Library, 1998).
} 
to geometrical theory, were duly collected and invested with personal, professional, and intellectual value by their users.

Of pronounced importance to the outlook of the current study, then, is the successful integration into the history of science of the techniques, methodologies, and, indeed, the concerns of historians of the book and of reading. In many ways, these fields are entirely complementary, and their convergence has been a natural byproduct of both the move toward the social and material contexts of early modern knowledge-making and, indeed, of the wider appeal of inter- or multi-disciplinary studies. Furthermore, both fields have in the past thirty years actively contributed to a wider change in focus: one moving from an image of erstwhile producers distributing printed media to receptive consumers, to a narrative wherein readers actively shape and appropriate works in manuscript and in print.

Rather than following Elizabeth L. Eisenstein by celebrating fixity, standardization, mass-production and distribution as guaranteed by the immediate terminus a quo of printing technology, a range of scholars have successfully argued that these properties were instead outcomes gradually negotiated only through lengthier exposure to the worlds of print. ${ }^{111}$ The emergence (and eventual primacy) of print was a product of exchanges of credit between communities of producers and users: exchanges which brought with them variety and complexity in relationships and, indeed, to the final product. ${ }^{112}$ As Rosamond McKitterick has argued, it is particularly appropriate for historians of science to counteract the assumption that printing brought with it a paradigmatic revolution in ideas by attending instead to the reading and understanding of books, their use in teaching, the methods of their

\footnotetext{
${ }^{111}$ Elizabeth L. Eisenstein, The Printing Press as Agent of Change: Communications and Cultural Transformations in Early Modern Europe, 2 vols (Cambridge: Cambridge University Press, 1979); particularly vol. 1, pp. 116-120. For the seminal rebuttal of Eisenstein's thesis with regards to the history of science, see Adrian Johns, The Nature of the Book: Print and Knowledge in the Making (Chicago and London: University of Chicago Press, 1998); see also Anthony Grafton, 'The Importance of Being Printed', Journal of Interdisciplinary History, 11 (1980), pp. 265-86; Anne Goldgar, Impolite Learning: Conduct and Community in the Republic of Letters, 1680-1750 (New Haven, CT: Yale University Press, 1995); Roger Chartier and Guglielmo Cavallo, eds., History of Reading in the West (Amherst: University of Massachusetts Press, 1999).

112 Johns, Nature of the Book, pp. 31-32; David McKitterick, Print, Manuscript and the Search for Order, 1450-1830 (Cambridge: Cambridge University Press, 2003), p. 117.
} 
production and dissemination, and, crucially, the ways in which those in the book trade were able to utilize patterns of distribution predating the printing press. ${ }^{113}$

Uniting manuscript and print technologies, many such texts bring to mind Peter Stallybrass's term 'discontinuous reading', coined following his research into the practices of early modern Bible-readers. Stallybrass posited the concept of the 'navigable book' as a culmination of developments in the presentation of the codex from the thirteenth century onwards. Such codices permitted a reader to move back and forth between sections, and used headings, consistent foliation, bookmarks and other reading tools to facilitate this. ${ }^{114}$ Whilst mathematical books doubtlessly benefitted from tables of contents, indexes, and referenceable foliation alongside printed marginal and other 'bookmarking' tools, the examples present in the Science Museum's collection also include codices that were intended to be used instrumentally, as part of their readers' mathematical endeavours. We should recognise that these texts may disrupt the more modern notion of continuous reading by encouraging a guided making and application of the materials at hand. With their incorporation of instruments into codices, printers and publishers used these works to continue the legacy of previous manuscript ages. ${ }^{115}$

Texts presented breath-taking, artistic frontispieces which depicted the adoption of mathematical practice; fold-outs unfurled diagrams and tables much larger than the containing book itself. These diagrams could themselves become instruments, intended to be constructed from paper, card or brass, exteriorising the contents of a mathematical volume through direct application. Their encouragement of discontinuous reading is further highlighted by the presence of volvelles and other instruments occasionally seen in educational texts and used either for computation or instruction. Depending on the desires of the producer or the buyer, such instruments could be elaborately decorated or entirely quotidian; they could be constructed by stationers and publishers prior to sale, or, offering the user the opportunity to learn

\footnotetext{
${ }^{113}$ Rosamond McKitterick, 'Books and Sciences before Print', in Marina Frasca-Spada and Nicholas Jardine, Books and the Sciences in History (Cambridge: Cambridge University Press, 2000), pp. 1334.

${ }^{114}$ Peter Stallybrass, 'Books and Scrolls: Navigating the Bible' in Jennifer Andersen and Elizabeth Sauer, eds., Books and Readers in Early Modern England: Material Studies (Philadelphia: University of Pennsylvania Press, 2002), pp. 42-79.

${ }^{115}$ Laurel Means, 'The Vulnerability of Volvelles in Medieval Manuscripts', Manuscripta, 25 (1991), pp. 43-54.
} 
by doing, could be left for the reader to complete later. As historians of the book and of science such as Sten G. Lindberg, Owen Gingerich, and Richard L. Kremer have reflected upon, these printed instruments encourage us to consider the ludic value of paper mobiles to mathematical - and, particularly, instrumental - application. ${ }^{116}$ When considered as part of a continuum of knowledge incorporating equatoria, manuscript treatises, instruments, and fabrica et usus and Instrumentbuch titles, such examples highlight a unification of mathematical culture present in the evidence of manuscript, text and instrument over a much longer history than that of the printed word.

Although the past three decades have witnessed extensive scholarship on early modern marginalia, scribal technologies and reading strategies by historians and literary scholars alike, few studies have considered the relationships developed between the reader and the mathematical text. Many users of such books and their attendant instruments therefore remain unseen, their responses to mathematical literature, practice, and culture sadly undocumented. As a study combining evidence of the use of texts and instruments (paper or otherwise) through marks of provenance and annotation, the current work therefore has the potential to advance our appreciation of mathematical culture and its place in the intellectual culture of the early modern period more generally.

It is clear that a wide variety of occupational users were in the market for tools and texts that might aid their day-to-day work or, in the case of the welleducated purchaser, their intellectual practice. As we might expect, this audience existed on a spectrum of literacy and numeracy which differed depending on their location and era. Whilst divining meaningful evidence from the decontextualized calculations that often litter early modern volumes has previously proven difficult, the existence of such a varied readership in combination with the huge range of mathematical texts printed in the early modern period suggests that evidence of users

\footnotetext{
${ }^{116}$ Sten G. Lindberg, 'Mobiles in Books: Volvelles, Inserts, Pyramids, Divinations, and Children's Games', Private Library, $3^{\text {rd }}$ Series, 2 (1979), pp. 49-82; Owen Gingerich, 'Astronomical Paper Instruments with Moving Parts' in R. G. W. Anderson, J. A. Bennett, and W. F. Ryan, eds., Making Instruments Count: Essays on Historical Scientific Instruments Presented to Gerard L'Estrange Turner (Aldershot: Variorum, 1993), pp. 63-74; Richard L. Kremer, 'Playing with Geometrical Tools: Johannes Stabius's Astrolabium imperatorium (1515) and Its Successors', Centaurus, 58 (2016), pp. 104-134, particularly p. 106. See also Nick Kanas, Star Maps: History, Artistry, and Cartography, $2^{\text {nd }}$ edn (Berlin: Springer, 2009), particularly pp. 234-239.
} 
of all abilities await our discovery, whether in pocket-books, practical treatises and educational textbooks, or in the ornate presentational folios exchanged as gifts between practitioner and patron.

To what extent, then, can these texts demonstrate evidence not only of use, but of use for particular action? In 1990, having researched Gabriel Harvey's (ca.1552/3-1631) copious marginalia, Lisa Jardine and Anthony Grafton convincingly argued that the activity of scholarly reading in early modern England could be employed toward specific actions. Instruments and techniques were adapted to achieve this goal, and the enterprise was conducted in conditions that encouraged almost total attentiveness. ${ }^{117}$ While forms of self-fashioning undoubtedly ensured that a range of collectors, readers and users of texts saw the value in recovering and preserving intellectual literature for social benefit, humanist scholarship has itself been characterised, most prominently in the work of Ann Blair, in part by practices of the composition and later circulation of key texts within a reading culture conceptualized and practiced (through reading practices including commonplacing) as a process of collection. ${ }^{118}$

The importance of an accessible store of materials close to hand, a common educational and intellectual trope in the early modern period, soon filtered down to the individual text itself. Those unable to utilise institutional collections or afford substantial private libraries were encouraged to participate in this literary culture, with trusted authorities pitching their mathematical texts as compendia of useful information made easy for the untutored user, or as collections of mathematical exercises or recreations to train the pupil or auto-didact. Thus users of all abilities made collection part of their mathematical practice, storing their mathematical texts and excerpts into collections of all shapes and sizes, many of which could be kept about a user for swift retrieval.

\footnotetext{
${ }^{117}$ Lisa Jardine and Anthony Grafton, “'Studied For Action”: How Gabriel Harvey Read his Livy', Past and Present, 129 (1990), pp. 30-78.

118 Ann Blair, 'Humanist Methods in Natural Philosophy: The Commonplace Book', Journal of the History of Ideas, 53.4 (1992), pp. 541-551; id., 'The Rise of Note-Taking in Early Modern Europe', Intellectual History Review, 20.3 (2010), pp. 303-16. See also Marjorie Swann, Curiosities and Texts: The Culture of Collecting in Early Modern England, (Philadelphia: The University of Pennsylvania Press, 2001), p. 149.
} 
Building upon this taxonomy of 'active reading', and upon the evidence collated in Roger Stoddard's exhibition of marks in books, scholars such as Blair and Sherman have produced pivotal works on the marginalia of early modern readers; ${ }^{119}$ however, evidence of readers turning their attention specifically toward mathematical practice has remained thin on the ground. ${ }^{120}$ Works published in the last five years by Benjamin Wardhaugh, Richard J. Oosterhoff and Renée Raphael have begun to fill these gaps, and the current thesis is written in dialogue with such studies. ${ }^{121}$ It is to be noted that these enquiries occasionally suffer from the issues common to previous attempts to research the reading practices relevant to the history of science. Their first port of call is often by necessity the well-educated, erudite virtuoso - a figure characterized by inveterate note-taking ${ }^{122}$ - yet the prevalence of such annotators need not act as a stumbling block to continuing efforts to identify the types of mathematical practice at play in the period. Instead, by utilising scholars' identifications of the communities, sites of practice, and tools and products of such practitioners, it is possible to find the previously-unseen users of mathematics who populate these same areas as consumers, readers, experimenters and collectors.

\section{Conclusion}

As this brief review has shown, the study of the historical culture of the mathematical sciences has been invigorated by the successful integration of research into its technical elements with enquiries into three interlinked areas of people, places, and things: namely, the larger population of individuals and communities

\footnotetext{
${ }^{119}$ Roger Stoddard, Marks in Books, Illustrated and Explained (Cambridge, MA: Houghton Library, Harvard University, 1985); H. J. Jackson, Marginalia: Readers Writing in Books (New Haven and London: Yale University Press, 2001); Ann Blair, 'Reading Strategies for Coping with Information Overload, ca. 1550-1700', Journal of the History of Ideas, 64, 1 (2003), pp. 11-28; William H. Sherman, Used Books: Marking Readers in Renaissance England (Philadelphia: University of Pennsylvania Press, 2008).

${ }^{120}$ Examples of research into the annotations of active 'mathematical' readers include William $\mathrm{H}$. Sherman, John Dee: The Politics of Reading and Writing in the Renaissance (Amherst, MA: University of Massachusetts Press, 1995); Owen Gingerich, The Book Nobody Read (New York: Walker, 2004). A mathematical reader who annotated his copy of John Wells's dialling text Sciographia, or The Art of Shadows (1635) is also briefly detailed in Sherman, Used Books, p. 9. ${ }^{121}$ Benjamin Wardhaugh, 'Consuming Mathematics: John Ward's Young Mathematician's Guide (1707) and Its Owners', Journal for Eighteenth-Century Studies, 38 (2015), pp. 65-82; Richard Oosterhoff, 'A Pen, a Book, and the Sphere: Reading Sacrobosco in the Renaissance', History of Universities, 28.2 (2015), pp. 1-54; Renée Raphael, Reading Galileo: Scribal Technologies and the Two New Sciences (Baltimore: The Johns Hopkins University Press, 2017).

${ }_{122}$ Richard Yeo, Notebooks, English Virtuosi, and Early Modern Science (Chicago and London: University of Chicago Press, 2014), pp. xi-xii.
} 
identified as the practitioners and producers of early modern mathematics; the learned and occupational arenas, sites of practice and trading zones where these figures met; and, finally, the instruments, books, maps and material goods produced by these practitioners. Clearly, the thrust of much of this research has been to develop our understanding of the cultural role enjoyed by the mathematical and wider intellectual culture of the period by attending to the interwoven narratives of people, places and things in their correct sociological and anthropological environments.

At the same time, the cumulative effect of these invaluable studies has been to disestablish a prior positivist narrative of the 'Scientific Revolution' by turning instead to the spatial, material, and social contexts of knowledge-making and its attendant craft processes. Nevertheless, the mathematization of natural philosophy and the practices of 'proto-science' have remained central elements to both of these narratives. Efforts to more precisely understand and explain the role of this mathematization to the epistemological transformations natural philosophy underwent in the period continue, with the great theorists prevalent in earlier studies now studied as, and alongside, practitioners enmeshed in the politicized arenas of education, trade, technology and the court. ${ }^{123}$

Numerous studies have shown beyond doubt that coteries of expert mathematical readers purchased materials written and produced (sometimes, on demand) by their peers. Having integrated histories of commerce, material culture, and intellectual practices, much of our current understanding and techniques of investigation have thus served to classify these figures as worthy of study both on their own terms and, in a methodological sense, as a means of redrawing, or moving away from, the canonical theorists so well-treated by earlier narratives.

While this is an understandable reaction to previous trends in the history of science, such a focus risks painting a false - or at best misleading - picture of the making of, and the demand for, early modern mathematical culture and its products.

\footnotetext{
${ }^{123}$ Lesley B. Cormack, 'Handiwork and Brainwork: Beyond the Zilsel Thesis', in Lesley B. Cormack, Steven A. Walton and John A. Schuster, eds, Mathematical Practitioners and the Transformation of Natural Philosophy in Early Modern Europe (Cham: Springer, 2017), pp. 11-35, p. 17. An example of the recasting of a great theorist placed among the practitioners is Matteo Valleriani, Galileo Engineer (Dordrecht: Springer, 2010), particularly pp. 12-69.
} 
In their failure to develop new techniques by which to identify and examine the juvenile, amateur, and more quotidian audiences of this culture, historians risk neglecting mathematical practice in its many forms. Without a greater awareness of these users, our understanding of the mathematical culture of the early modern period can only remain incomplete; with users' attendant reading practices of mathematics, whether for learning, rehearsal and performance, scholarly erudition, occupational needs or simply leisure unexamined, we are left with little understanding of these users' motivations as to how and why they participated in early modern mathematical culture. Identifying and interrogating the reading practices pursued by the active readers of early modern educational institutions will thus help us to identify the transmission of materials and ideas between individuals and communities at various trading zones and sites of practice. In turn, this will lead us to a fuller understanding of the position of mathematical literature in educational, commercial and domestic arenas.

In a spirited essay on the future relationship of the history of science and the history of mathematics written in 2011, Amir Alexander returned to the founding father of the former as an academic discipline, George Sarton. In The Study of the History of Mathematics (1937), Sarton had argued:

Take the mathematical developments out of the history of science, and you suppress the skeleton that supported and kept together the rest. Mathematics gives to science its innermost unity and cohesion, which can never be entirely replaced with props and buttresses or with roundabout connections, no matter how many of these may be introduced. ${ }^{124}$

For Alexander, the Sartonian idea of mathematics as the rational skeleton of scientific activity today appears untenable to historians for whom science is best seen as a cultural activity. Yet this disjunct presents an opportunity to recast mathematics: not as the transcendent epitome of rationality applied to empirical investigations of the natural world, but instead a dynamic and evolving study, one which 'is shaped by — and in its turn shapes - human values, institutions, and systems of

\footnotetext{
${ }^{124}$ George Sarton, The Study of the History of Mathematics (New York: Dover, 1957; originally Cambridge, MA.: Harvard University Press, 1937), p. 4. Cited in Amir Alexander, 'The Skeleton in the Closet: Should Historians of Science Care about the History of Mathematics?', Isis, 102.3 (2011), pp. 475-480, p. 476.
} 
knowledge'. ${ }^{125}$ Such a new history would interrogate, historicise and contextualise mathematics just as the theories and practices of science had been, with technical aspects co-existing with the historical contingencies of mathematics, the changes in its standards and practices, and its interaction with other cultural factors. ${ }^{126}$

By treating scholars, practitioners and users as the reciprocal creators and participants of early modern mathematical culture, the current study contributes to this new history of mathematics by utilising the methodological tools and techniques integrated into the history of science over the past forty years. A comprehensive analysis of the demand for mathematical literature and its subsequent use and collection in early modern Europe cannot be accommodated by any single study. Rather than attempting this, the current thesis instead investigates the mathematical holdings of Science Museum Library's Rare Books Collection as representative of this period's mathematical culture.

This mathematical subset, consisting of texts encompassing the disciplines considered mathematical according to pre-modern disciplinary classifications, is characterized in Chapter One's detailed methodology. The subset incorporates texts belonging to the study of arithmetic, geometry, astronomy, music, and optics as pertaining to the curricula of early modern universities. Equally, materials defined as belonging to the 'mixed' mathematics - studies such as optics, mechanics, hydrostatics, navigation, and gunnery - and similar pursuits read for both practice and leisure, such as surveying, dialling, geography and cosmography are all included. Disciplines created in the period - for example, the analytical art of algebra, or the calculus of Leibniz and Newton - are represented, alongside the more esoteric practices of astrology and numerology. It is the product of multiple smaller libraries and collections, and as such reflects the collecting strategies of both individuals and institutions. These factors serve to minimize the likelihood that the mathematical subset of the collection under study is uniquely unrepresentative of the culture that produced it.

\footnotetext{
125 Alexander, 'Skeleton in the Closet', p. 478.

${ }^{126}$ Alexander, ibid, pp. 477-479.
} 
Having defined and characterised this mathematical subset through an analytic survey in the first chapter of this thesis, I then present three case studies based on unique findings from the collection. Tackling the position of mathematics in the educational and literary humanist culture of the early sixteenth century, Chapter Two presents evidence of the readers of Petrus Ramus's mathematical texts, visible in both the printed text and marginal annotations of a multi-volume mathematical Sammelband constructed in 1586. By extracting the material evidence of the Wittenberg Sammelband - specifically, the interplay between its printed texts and its readers' manuscript engagements - networks of early modern mathematical teaching, learning, and theory are more clearly illuminated. The physical construction of this volume tells a shared story of the educational experiences of young learners in the gymnasia and universities of Leipzig, Wittenberg and elsewhere. Evidence from the manuscript annotations of the volume, meanwhile, makes it possible to clarify precisely how users and readers handled works by mathematical authorities after the advent of educational developments linked to Ramism.

The repackaging of continental instruments, tables, and theoretical literature into mathematical compendia in Tudor and Stuart England forms the basis for Chapter Three's enquiry into Thomas Blundeville's Exercises in Sixe Treatises (1594) and its users. Initially aimed at the genteel audience circulating amongst the universities and Inns of Court, Blundeville's text celebrated the use of arithmetic and geometry to knowledge of the wider world, incorporating treatises on geography, navigation, astronomy and cosmography. Printed instruments including maps, globes, compasses, tide tables and nocturnals all featured as part of this compendium, whether in text, illustration, or paper iterations, making the volume itself a hybrid instrument for the transmission of disciplinary theory. Uniting text, instrument, and, of particular importance to our understanding of early modern users, annotations, two marked copies of Blundeville's work bear evidence of early modern readers actively adopting the theory and practice of their texts.

Chapter Four continues this focus by considering the nautical stationer and instrument maker John Seller, and his Pocket Book of 1677. Presenting 'several choice selections' from a number of mathematical disciplines, Seller's octodecimo 
was ostensibly intended to provide an occupational class of users with the mathematical materials to navigate their way in the world. As analysis of one copy of this volume demonstrates, however, readers had other intentions, using Seller's collections as the foundation for their own practice of collecting and commonplacing mathematical information at the University of Cambridge and beyond. The uses Seller's text was put to reflect both the vogue for utilitarian practical mathematics identified in seventeenth-century England, as well as the transmission of humanist reading practices and scribal technologies. That Seller's occupational manual was repurposed to serve the needs of late-seventeenth century students, is, I suggest, part of wider evidence that demonstrates the dichotomy between universities and other sites of practice has been over-represented in previous historiography on the topic.

Book-ending these case studies, and acting as a companion piece to Chapter One's analysis of the Science Museum's Rare Books Collection, Chapter Five focuses on the formation and identity of individual and institutional collections. Identifying specific works owned by particular readers through investigation of their provenance, this chapter establishes the routes these titles have taken before their acquisition by the Science Museum. Attending first to the Anglican clergyman Nathaniel Torporley's bequest to the nascent Sion College in 1632, this chapter explores how Torporley's books formed a key part of the institution's first library, before tracing the dispersal and diffusion of this collection. Torporley's collection is then contrasted with that of the twentieth-century American antiquarian Robert Brodhead Honeyman, culminating in a discussion on the identity of these individual collections and their subsequent entry to - and subsumption by - larger institutional libraries.

Understanding the Science Museum's processes of identification, acquisition, and conservation, both historical and contemporary, provides a unique insight into its Rare Books Collection as a malleable accumulation of individual and idiosyncratic purchases; an agglomeration of personal and institutional libraries, and, as such, ultimately a preservation of collectors and their collections. By situating the Library and its holdings in their correct historical contexts, this research offers novel contributions to our understanding of mathematical culture in the early modern period, to the history of collecting mathematical objects in the modern era, and to the 
Science Museum's understanding of its own holdings. Thus Chapters 1 and 5 of the current thesis attend to both the representativeness of the collection itself to a study of early modern mathematical culture, and to the multiple processes of collection and preservation of its literature. Chapters 2, 3, and 4 each detail the construction, practice, and collection of mathematical knowledge in the period, and help to inform our understanding of the owners and users of such material. Finally, Chapter 6 offers concluding remarks on the findings of this study, and suggests a number of avenues for future enquiry relevant to each of the histories of mathematics, science, reading, and collection. 


\section{Source materials}

As Chapter One details, the main body of material surveyed as part of the present study is the Rare Books Collection of the Science Museum Library. The majority of the analytic survey of this collection was undertaken at the Museum's Library and Archives at the National Collections Centre in Wroughton, Wiltshire, between February 2016 and June 2017. Volumes were classified through initial research and spreadsheets compiled by Nicholas Wyatt, Head of Library and Archives, and associated library staff. This cataloguing took place prior to the current project; classification data was made available as part of the Collaborative Doctoral Award commenced in January 2016.

As the analytic survey continued, volumes identified as suitable for detailed examination on occasion travelled the Science Museum Library's reading room in London, the Dana Research Centre and Library, for further study. These materials were supplemented by exploratory research into other collections, including materials from the Bodleian Library, Oxford; the British Library, London; Cambridge University Library; the Whipple Library at the Department of History and Philosophy of Science at the University of Cambridge; the Huntington Library, San Marino; Lambeth Palace Library, London; the Library of St Andrews University, and the Library of Trinity College Dublin. Where unique materials belonging to either the Science Museum Library's Rare Books Collection or to these external institutions feature, the holding institution and shelfmark or identifying barcodes are provided. 
Chapter One. A Return to Rara Arithmetica: The Science Museum Library's Rare $\underline{\text { Book Collection }^{1}}$

Established in 1883 as a repository to house technical and scientific materials for the benefit of expert readers, Museum staff, the students of the 'Normal School of Science', and the general public, the Science Museum Library has grown to one of the larger libraries of its type in Europe. Home today to some 500,000 volumes across two sites in London and in Wroughton, Wiltshire, these holdings have been extensively utilised over the past 135 years. ${ }^{2}$ Whether under the threat of war, in the face of widespread social upheaval, or in periods of remarkable technological change, the Library has continued to provide readers with access to both the historical and current literature relevant to their needs - helping to advance both the actual practice of science, and our subsequent study of its history.

Of the materials present at the beginning of this analytic survey in February 2016, 3,330 titles printed between 1486 and 1800 constituted the Science Museum's Rare Books Collection, supplemented by a further 1,419 periodical volumes from the same period. Drawing from this repository of rare books, the current study is an analysis of a subset of close to 1,700 titles deemed directly applicable to the history of mathematical culture in the early modern era. This subset comprises printed texts from England, France, Germany, and Italy, and from as far afield as Japan.

As I have discussed in the introduction, historians have shown that precisely what mathematics was, as well as what or who it was for, was the subject of recurrent debates in the early modern period. The variety of uses mathematical knowledge was put to can be seen in a collection containing volumes which evince the protean character of mathematics as theoretically understood and operatively practised by a wide-range of producers and consumers. Authors and their readers

\footnotetext{
${ }^{1}$ This title is borrowed from David Eugene Smith, Rara Arithmetica: A Catalogue of the Arithmetics Written Before the Year MDCI, with a Description of Those in the Library of George Arthur Plimpton of New York, Fourth Edition, including Augustus De Morgan's Arithmetical Books (New York: Chelsea, 1970). Although not directly cited in this thesis, I have made frequent returns to Rara Arithmetica throughout my research.

${ }^{2}$ Nicholas Wyatt, 'Waves of Change: How the Science Museum's Library Rose, Fell and Rose Again', in Peter J. T. Morris, ed., Science for the Nation: Perspectives on the History of the Science Museum (Houndmills: Palgrave Macmillan, 2010), pp. 136-156; p. 154. The establishment of the Science Museum Library and its acquisition of rare books are considered in more detail in Chapter Five of the current thesis.
} 
engaged with significant overlaps between disciplines in terms which may not at first glance appear recognisably 'mathematical' to the modern reader. Titles the modern reader might appreciate as inherently mathematical - for example, a first edition of Isaac Newton's Philosophice Naturalis Principia Mathematica of 1687 - accompany those such as Girolamo Cardano's De subtilitate: a work combining the metaphysical, mathematical and pseudo-mathematical ideas at play in the preceding century's intellectual culture. ${ }^{3}$ The complexity of the collection under study testifies to the vibrant intertextuality of early modern intellectual culture, and to the role of mathematical works within that broad culture.

To introduce the intensive case-studies which follow, this chapter begins with a large-scale analysis of this mathematical subset of the collection in order to test its representativeness with respect to the discipline's culture and practice in the period. To achieve this goal, three simple hypotheses are suggested. The first hypothesis is that there was a growth in the publication of mathematical and mathematicallyadjacent literature in the period commensurate with the growth in early modern printed literature more generally. Over the past fifteen years, scholarly attention in the field of economic history has been drawn toward the micro-foundations of both population density and economic growth as witnessed in the centuries immediately prior to the Industrial Revolution. Central to a number of these studies is the role literacy played in the formation of 'human capital'.

With this concept in mind, such research has built upon existing histories of reading in previous eras, most prominently David Cressy's seminal investigation into the role of literacy to social order in early modern England..$^{5}$ In many respects, the

\footnotetext{
${ }^{3}$ Isaac Newton, Philosophice Naturalis Principia Mathematica (London: J. Streater for the Royal Society, 1687), Science Museum Library Shelfmark Q O. B. NEW NEWTON 30209019359067; Girolamo Cardano, De subtilitate libri XXI (Lyon: Apud Gulielmum Rovillium, 1559), Science Museum Library Shelfmark O. B. CAR CARDANO 459700-2001.

${ }^{4}$ Research in this field is vast. For an introductory review of literacy's impact on human capital as part of a range of other indicators, see Robert. C. Allen, 'Progress and Poverty in Early Modern Europe', Economic History Review, 56.3 (2003), pp. 403-443, particularly pp. 414-415.

${ }^{5}$ Raouf Boucekkine, David de la Croix and Omar Licandro, 'Early Mortality Rates at the Dawn of Modern Growth', The Scandinavian Journal of Economics, 105.3 (2003), pp. 401-418; Raouf Boucekkine, David de la Croix and Dominique Peeters, 'Early Literacy Achievements, Population Density, and the Transition to Modern Growth', Journal of the European Economic Association, 5.1 (2007), pp. 183-226; Joerg Baten and Jan Luiten van Zanden, 'Book Production and the Onset of Modern Economic Growth', Journal of Economic Growth, 13. 3 (2008), pp. 217-235; David Cressy, Literacy and the Social Order: Reading and Writing in Tudor and Stuart England (Cambridge: Cambridge University Press, 1980).
} 
handling of pre-modern literacy offered by more recent research covers well-trodden ground, advancing little beyond R. A. Houston's careful analysis of reading as a geographically-determined hierarchy of skills whose effects were modulated by a range of personal, social and institutional attitudes. ${ }^{6}$ What these studies $d o$ help to establish, however, is a more developed sense of the macro-economic demand for printed material in the early modern period, and it is in this light that the demand for mathematical literature (and, beyond this, the representativeness of the subset under study) must first be situated.

As part of their detailed study into the growth of textual culture in manuscript and print, Eltjo Buringh and Jan Luiten van Zanden have estimated that the production of printed copies across Western Europe rose from more than 12 million in the half-century 1454-1500 to a remarkable 628 million printed between 1751 and 1800, with an estimated 20 million copies alone printed in $1790 .^{7}$ This data has been used to advance the existing hypothesis that demand for books across Europe increased dramatically in the early modern period, even in inverse proportion to both income levels and to living standards. As large-scale access to the printed word made possible by mass production met with an ever-growing market of literate consumers, a growing merchant-class and an existing elite readership were joined by a wider population encouraged to read for devotional, economic and educational purposes.

Regardless of its precise rate of production, it is clear that between 1450 and 1800 a mammoth amount of literature saturated Western Europe. The invention of the moveable type printing-press in 1439 brought a new technological capability to the mass manufacture of books, disestablishing some of the existing dynamics of

\footnotetext{
${ }^{6}$ R. A. Houston, Literacy in Early Modern Europe: Culture and Education 1500-1800, $2^{\text {nd }}$ edn (Abingdon and New York: Routledge, 2013).

${ }^{7}$ Eltjo Buringh and Jan Luiten van Zanden, 'Charting the "Rise of the West". Manuscripts and Printed Books in Europe, A Long-Term Perspective from the Sixth through Eighteenth Centuries', Journal of Economic History, 69.2 (2009), pp. 409-445, particularly p. 420 and p. 443. Febvre and Martin estimated that in the first fifty years of printing some 15 to 20 million copies were produced, whereas Eisenstein, citing Clapham, argues for a figure of circa 8 million. Pettegree suggests that by 1601, 100 million copies of texts had been produced. See Lucien Febvre and Henri-Jean Martin, The Coming of the Book: The Impact of Printing, 1450-1800 (London: Verso, 1976; first published as L'Apparition $d u$ Livre, Paris: Editions Albin Michel, 1958), p. 258; Eisenstein, Printing Press as Agent of Change, vol 1., p. 45; Andrew Pettegree, The Book in the Renaissance (New Haven: Yale University Press, 2010), p. 218.
} 
scribal book production yet strengthening others in the process. ${ }^{8}$ The increase in available literature, and, more importantly, its effect upon the transmission and reception of disciplinary knowledge, was readily noted in the period itself. In $D e$ Stella Nova (1606) Johannes Kepler remarked that:

After the birth of printing, books became widespread. Hence everyone throughout Europe devoted himself to the study of literature...Every year, especially since 1563 , the number of writings published in every field is greater than all those produced in the past thousand years. ${ }^{9}$

Pre-empting the content of John Donne's laments in An Anatomy of the World (1611) in rather more positive terms, Kepler remarked that disciplines were being remade as a result, with a new theology, jurisprudence, medicine and astronomy being created. ${ }^{10}$ Whilst mathematical texts may not have proven quite as popular as other scholarly works, nor as widespread as devotional or calendrical materials (the latter of which were calculated according to mathematical principles), a similarly substantial increase in the subject's disciplinary literature over time occurred alongside a remaking of its intellectual culture. As a consequence, the current dataset should present a significant growth in materials printed across the period selected for study. Any such rise need not be exponential, owing to the rather mundane fact that certain decades may be under-represented owing to the Museum's inability, lack of opportunity, or disinclination to purchase specific literature from these timeframes.

The second hypothesis is that this growth should be represented in the identifiable existence of core European print locations known for producing mathematical literature, and that the ascendance of London as a site of growing importance to first the English and then the European book markets in the seventeenth and eighteenth centuries be recognisable in the subset. Although it is

\footnotetext{
${ }^{8}$ McKitterick, Print, Manuscript and the Search for Order, particularly p. 21, pp. 32-33, and p. 58. Challenging Eisenstein's arguments for the printing press as an agent of cultural revolution, McKitterick characterises print and manuscript traditions as complementary long beyond the first flourishes of the printing press.

${ }^{9}$ Translated in Nicholas Jardine, The Birth of History and Philosophy of Science: Kepler's A Defence of Tycho against Ursus with Essays on its Provenance and Significance, corrected edition (Cambridge: Cambridge University Press, 1988), pp. 277-278.

${ }^{10}$ John Donne, An Anatomy of the World, Wherein, by Occasion of the Untimely Death of Mistress Elizabeth Drury, the Frailty and the Decay of this Whole World is Represented (London: Printed for Samuel Macham, 1611).
} 
correct to speak of the transformative impact of the printing-press in terms of numerical output - either generally, across the entire historical period of the early modern, or more specifically, for example in the first phase of its adoption in the mid-fifteenth century - if the mathematical subset of the Rare Books Collection is to be deemed truly representative of mathematical literature in the period between 1480 and 1800 , and, by dint of this, of production trends in literature more generally, then specific locational variations in the materials published should be visible.

One such trend would, for example, reflect the concentration of printing amongst a small number of firms in cities familiar with major trade in the first decades of the 1500s. Often dynastic, these organisations were defined by their ability to withstand the risks inherent in the European book trade. Financially secure enough to bring an edition to print, to ride out complex productions, to transport goods over lengthy trade-routes by way of networks of influence and exchange, and, should all of these capabilities lapse, to keep ephemeral goods in long-term storage, these large establishments connected Venice, Lyon, Paris, Basel and Cologne, and account for the production of the majority of Latin texts which ultimately supported print technology through the growing pains of its adolescence. ${ }^{11}$

A significant core of Latin texts from key trading cities is therefore to be expected, supplemented by diverse vernacular texts from printers in a wider range of locations unable to benefit from such economies of scale. By the turn of the seventeenth century the centrality of businesses in these core locations of the international market was assured, with smaller, provincial businesses surviving on combinations of pamphlets, vernacular and niche materials, and the distribution of literature produced in these print metropolises. The development of such commercial arenas, local and international, is best understood through their interlocking domains: a series of dynamic settings defined by physical environments, economic surroundings, and social qualities. ${ }^{12}$

\footnotetext{
${ }^{11}$ Andrew Pettegree, 'Centre and Periphery in the European Book World', Transactions of the Royal Historical Society, 6th series, 18 (2008), pp. 101-128, particularly p. 104 and p. 127.

12 Johns, Nature of the Book, p. 59. Johns makes the comparison between these interlocking domains' and the emergent cultures, their contributors, and locations depicted in Howard Saul Becker, Art Worlds (Berkeley, Los Angeles, and London: University of California Press, 1982) and Mary Poovey, Making a Social Body: British Cultural Formation, 1830-1864 (Chicago: University of Chicago Press, 1995).
} 
Although London was an outlier to this concentrated and centralised sixteenth-century network, the city's gross metropolitan expansion between 1550 and 1750 brought with it developments in the information and knowledge economies previously witnessed in other major European trade centres. The changes wrought upon the physical, economic, and social environments of the English capitalparticularly in the seventeenth century - are likely to be represented in the collection; ${ }^{13}$ owing to the Science Museum's identity as a heritage institution and collector for the nation, however, it must also be noted that the Library's Rare Books Collection is likely to contain a disproportionately large number of English materials.

The third and final hypothesis used to test this material is that, if printed mathematical texts reached ever-broader audiences as the early modern period progressed, then this literature should present material evidence of readers at work in keeping with historical studies of other genres of literature. As the previous examples have shown, the mathematical subset under study mirrors the general growth in literature in the period, and can be tied to the continued success of key printing locations and their networks of production - first in mainland Europe, and latterly in early modern London. The third test of this subset is therefore one of use. As the early modern period witnessed an expansion in readership of all disciplines and a growth in the vernacular literature of the period, we should expect to see the collection under study gradually moving away from an over-emphasis on scholarly or expert Latinate texts, encompassing more and more quotidian and practical works in the process. With the educated population of various early modern European countries increasing over time, it would be reasonable to suppose that the numbers of books printed for higher study likely grew in kind. At the same time, however, it is to be recognised that the majority of the European population did not attend institutions of higher learning.

More literate and numerate than past generations, early modern users still required explanatory literature for educational and economic purposes. The market for mathematical texts changed to meet the needs of this wider population. Evidence of these readers is found in the form of users signing, marking and annotating a

${ }^{13}$ Pettegree, 'Centre and Periphery', p. 119. 
range of volumes, commonplacing key materials inside and outside their texts, and using the reading practices of the period to develop intellectual and interpretative ways of thinking. Although testing this use is inherently complex, existing studies point to marks in texts as proof of engagement with printed materials, and, to some extent, proof of their use. Prior to a series of discrete case-studies in which evidence of individuals and their texts are intensively examined whether in educational, occupational or domestic surroundings, the current chapter outlines the methodology underpinning the large-scale data collection behind this thesis. It presents statistical trends present in the collection concerning the production of texts, quantitative analysis of their use, and information concerning the later valuation of such literature, relevant to its subsequent collection by individuals and institutions.

\section{Methodology}

To most effectively define and characterise the materials under study prior to testing their representativeness to early modern mathematical culture, existing catalogue data was used to outline a classification of 78 general subject groupings present in the Rare Books Collection, ranging from Aeronautics to Zoology via Medicine and Volcanology. 48 of these 78 groupings were identified as sub-disciplinary classifications presenting as probable to highly relevant to the early modern culture of mathematics. From these 48 mathematical, mathematically-adjacent and related groupings, approximately 1,648 titles have been analysed, with all but two texts dating from between 1486 and $1800 ;{ }^{14}$ these 1,648 titles form the data-set utilised for the current study.

A detailed process of data mining then took place: one by which volumes could be classified according to their publication and their physical characteristics, compared to existing bibliographical and catalogue data, and then analysed in detail for evidence of use and ownership. Owing partly to the existence of the comprehensive Science Museum cataloguing spreadsheet 'Rare Books - Complete List' (Figure 1.1), and partly to my personal experience in handling specific

\footnotetext{
${ }^{14}$ These groupings, and the number of texts reviewed in each, can be found in Appendix 1. A further 33 texts from the period present in the Science Museum's Rare Books Collection were unavailable for analysis due to display and conservation issues. Information on this group of texts is provided in Appendix 1.
} 
software, the creation of a relational database using Structured Query Language (SQL) or a similar technique was deemed to be unnecessarily time-consuming. Instead, the data of the existing spreadsheet functioned as a useful starting point, containing as it did information on the entire rare books collection: its subject breakdowns; strengths; accompanying periodicals; and collection management identification numbers. Following early visits to the Rare Books Collection at the Science Museum Library and Archives in Wroughton, a mixed-method approach was decided upon in order to capture data which could reasonably be quantified - for example, counts of publication places, text languages, and types of marginalia - and data which could not, such as descriptions of bindings, or notes on the detail of specific annotation.

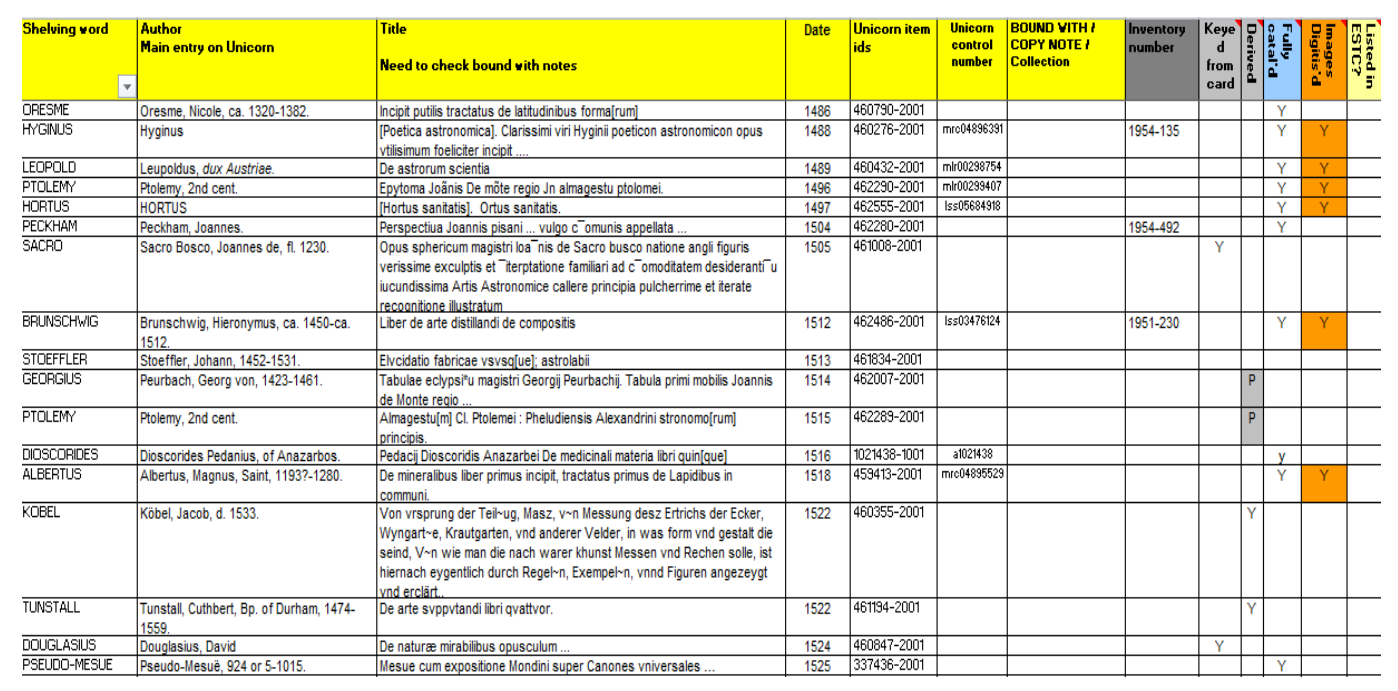

Figure 1.1. Sample image of 'Sheet 1, Pre-1800 Books, A-Z', from the 'Rare Books - Complete List' spreadsheet. Individual titles have been demarcated by unique identification numbers generated by the Sirsi 'Unicorn' library management system.

Several amendments were made to the existing spreadsheet as this broadspectrum analysis progressed. Initially, the key criteria of an adequate data-set required integrating qualitative and quantitative data in such a way that it would allow the return of appropriate sample sizes of evidence from both. Varieties of evidence, relating to the dates and places of publication; the locations of printers, sellers, and users; the properties of editions, including size and binding style; and, finally, to identifiable provenance data; are all crucial to the current study. The 18 fields created to incorporate statistical analysis alongside descriptive notation are shown in Figure 1.2 below. 


\begin{tabular}{|c|c|c|c|c|c|}
\hline $\begin{array}{c}\text { Publication } \\
\text { Place }\end{array}$ & $\begin{array}{c}\text { Modernised } \\
\text { Publication } \\
\text { Place }\end{array}$ & Publisher & $\begin{array}{c}\text { Binding } \\
\text { Information }\end{array}$ & $\begin{array}{c}\text { Size (e.g } \\
\text { Quarto, } \\
\text { Folio) }\end{array}$ & Size (cm) \\
$\begin{array}{c}\text { Text } \\
\text { Language }\end{array}$ & $\begin{array}{c}\text { Marginalia } \\
\text { Type }\end{array}$ & $\begin{array}{c}\text { Marginalia } \\
\text { comments }\end{array}$ & $\begin{array}{c}\text { Signatures / } \\
\text { Ownership }\end{array}$ & $\begin{array}{c}\text { Armorial / } \\
\text { Bookplate }\end{array}$ & $\begin{array}{c}\text { Collection } \\
\text { Information }\end{array}$ \\
\hline Study Use & $\begin{array}{c}\text { Study } \\
\text { Comments }\end{array}$ & $\begin{array}{c}\text { Science } \\
\text { Museum } \\
\text { Library } \\
\text { Stamp } \\
\text { Colour }\end{array}$ & $\begin{array}{c}\text { Science } \\
\text { Museum } \\
\text { Library } \\
\text { Stamp Date }\end{array}$ & $\begin{array}{c}\text { Alternate } \\
\text { Library } \\
\text { Stamp (1) }\end{array}$ & $\begin{array}{c}\text { Alternate } \\
\text { Library Stamp } \\
(2)\end{array}$ \\
& & & & \\
\hline
\end{tabular}

Figure 1.2. The categories added to pre-existing data to allow for qualitative and quantitative data collection and subsequent analysis.

Additional sub-categories with the ability to support quantitative aggregation were then created. A series of data-validation options was applied to specific subcategories with a view to improving the spreadsheet interface. Utilising datavalidation tools in this manner ensured that entries could be restricted to identified types occurring throughout the collection: these options were reviewed and tested as the scoping process continued to assure their suitability. Lists of valid entry options, as shown in Table 1.1, were added to sub-categories and then restricted to guarantee that only these entries could be inputted by the user.

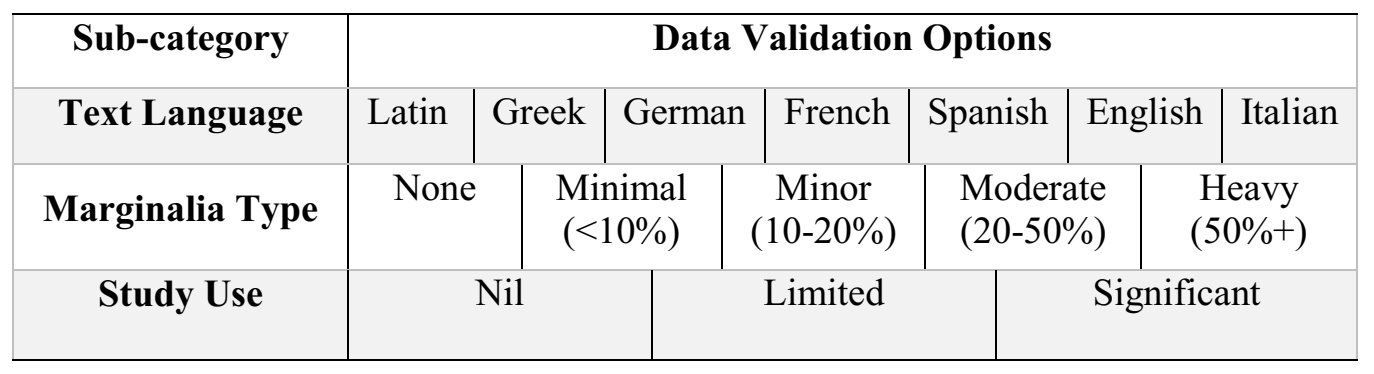

Table 1.1 Examples of data validation applied to sub-categories to return quantitative data.

If alternate or blank values were entered within these fields, an error message was generated automatically. The use of restricted values to return only previouslyidentified data types reduced the user errors common to large-scale data entry, ultimately assuring the likelihood of higher quality data being gathered across the study. Values were audited and cross-checked using data-recognition formulae, highlighting possible errors across thousands of entries. Moreover, data validation assisted in swiftly identifying and grouping similar types of evidence, enabling 
immediate overviews of the statistical proportion of large, discrete groupings within a field. Users can, for example, filter data according to individual items common to a subset (e.g. [Latin] within [Text Language]), confident in the knowledge that the data returned has already been tested and audited using data validation tools. Multilanguage or macaronic texts were classified under the grouping [Mixed], with the printed languages used noted elsewhere. A pictorial example of data validation within the field [Text Language] is provided in Figure 1.3 below.

\begin{tabular}{|c|c|c|c|c|}
\hline $\begin{array}{l}\text { Size Category (initial } \\
\text { scope) }\end{array}$ & $\begin{array}{l}\text { Sizing (cm) } \\
\text { (Koha) }\end{array}$ & Text Language & None & Margir \\
\hline Sml Quarto / lg Octavo? & - & Latin & $\begin{array}{l}\text { Moderate }(<50 \%) \\
\end{array}$ & $\begin{array}{l}\text { Latin. Gothic print. } 74 \mathrm{pgs} \text {.. Consistent Latin annot } \\
\text { through frst half of book. Some would appear to } \\
\text { conversation with text }\end{array}$ \\
\hline Folio & $33 \mathrm{~cm}$ & \begin{tabular}{|l} 
Latin \\
Greek \\
Gemman \\
French \\
Sparish \\
Enqlish \\
teatisn \\
Mired \\
\end{tabular} & or $(<20 \%)$ & 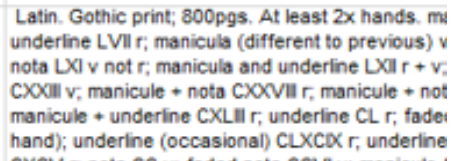 \\
\hline Folio & $29 \mathrm{~cm}$ & Latin & Minor (<20\%) & 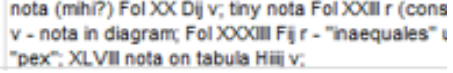 \\
\hline
\end{tabular}

Figure 1.3. An example of data validation applied to the [Text Language] field, taken from the adapted 'Rare Books - Complete List' spreadsheet.

The spreadsheet created to accommodate this data set was then tested and finalised with four essential requirements in mind:

1. The spreadsheet must allow utilisation 'in the field' when gathering data relevant to the project.

2. The spreadsheet must allow interrogation on an as-and-when basis to display preliminary findings statistically and graphically as required.

3. The spreadsheet must return information in a manner that supports the swift identification and recovery of information relevant to the project aims of discovering proof of ownership, use, and collection of mathematical books.

4. The spreadsheet must be able to retain information that can be used to guide future data collection. 
The adapted copy of the Science Museum spreadsheet 'Rare Books Complete list' has therefore been manipulated to: filter subject categories relevant to the current study; include new sub-categories to aid the working goals of the current study; include data validation and unique referencing tools to allow for quantitative analysis; and to create a data set which could be cross-referenced against existing Science Museum Library catalogue data. Information accrued from the analysis of texts was grouped and subjected to data validation to allow for immediate metaanalysis. Data was reviewed, tabulated, and plotted to appropriate graphs allowing for the extraction of trends: these trends were then analysed in order to identify examples of particular significance from a growing data set. Further data fields were included to cross-reference data collected against the online Science Museum library catalogue. $^{15}$

Information held in the online catalogue fields [Material Type], [Publisher], [Description], [Title Notes] and [ISBD View] for each text analysed was then compared with the data collected on site and marked accordingly (Figure 1.4). Wherever conflicting information arose, priority was given to the library catalogue, with the conflicts noted for future exploration. To further ensure the validity of publication and title data, this information was also consistently checked against large-scale, online bibliographical tools, including the Universal Short Title Catalogue (USTC), the English Short Title Catalogue (ESTC), and the Karlsruher Virtueller Katalog (KVK). ${ }^{16}$

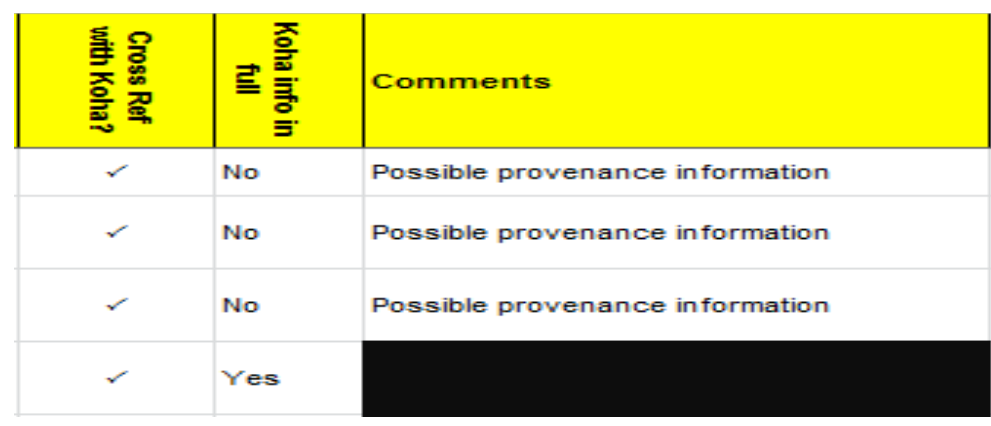

Figure 1.4. Image of the adapted 'Rare Books - Complete List' spreadsheet displaying additional cross-referencing with Science Museum library catalogue.

\footnotetext{
15 The Science Museum Library Online Catalogue is available via https://smg.koha-ptfs.co.uk/ ${ }^{16}$ Universal Short Title Catalogue, https://www.ustc.ac.uk/index.php, hosted by The University of St Andrews; English Short Title Catalogue, http://estc.bl.uk, hosted by the British Library; Karlsruher Virtueller Katalog, https://kvk.bibliothek.kit.edu, hosted by the Library of the Karlsruher Institut für Technologie.
} 
Alongside the creation of an illustrative provenance index to display examples found within the collection, further fields were added to the data-set to indicate only the presence of signatures, ownership inscriptions, armorials, and bookplates (aka 'Provenance Markers'): qualitative data collated for these occurrences remains highly descriptive, difficult to pin down, and, consequently, resistant to quantitative grouping and analysis. As a result, single-use identifiers (in the form of typographical ticks) have been utilised to identify both the presence and type of provenance, and whether it has been indexed, with block-filled fields utilised both to indicate instances of non-occurrence (Figure 1.5) and as a visual aid.

Additional efforts to produce broad-brush groupings - for example, to group texts by [Publication Place (Modernised)] and [Date] - led to the creation of a [Decade] field; further analysis of findings suggests additional fields of [Periodization], for example [Early Modern: 1450-1750]. The value of these additions will arguably be seen beyond the current study, when the data accrued from this analysis is added to the existing catalogues of the Science Museum Library.

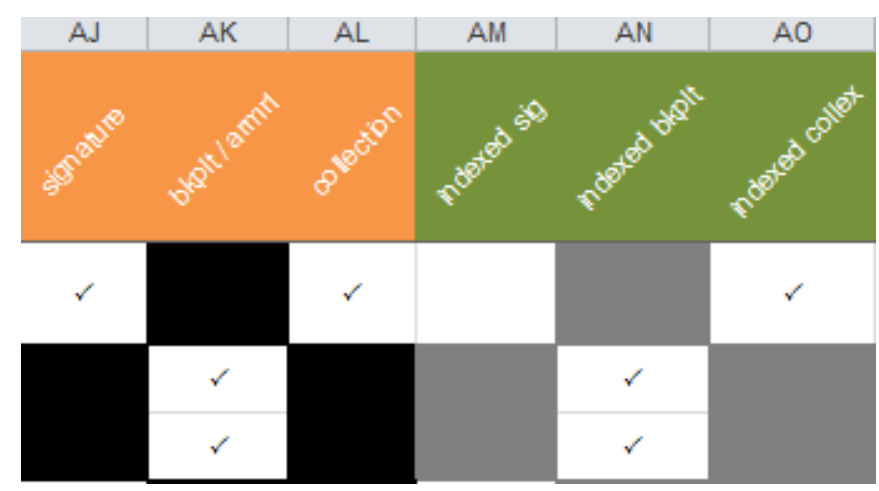

Figure 1.5. Sample image of 'Provenance Markers' data from the adapted 'Rare Books - Complete List' spreadsheet. Block filled fields have been used to aid visual recognition.

\section{The growth of mathematical culture and the growth of print}

As Figure 1.6 below illustrates, a steady rise in the number of mathematical or mathematically-adjacent titles published per decade is witnessed in the collection over more than three centuries. ${ }^{17}$ This data corresponds to the wider expansion of

\footnotetext{
${ }^{17}$ A particularly noticeable spike in the subset is seen in the decade grouping $1650-1659$, where the texts collected leaps from 37 in the previous decade to 94 . The numbers of texts collected gradually tail off in the subsequent groupings, dropping from 92 (1660-1669) to 84 (1670-1679) to 68 (16801689 ) before returning to the previous growth curve by the decade grouping 1690-1699. This sudden
} 
early modern European publishing, and, as previously discussed, mirrors the growth of literature of almost every genre in the period.

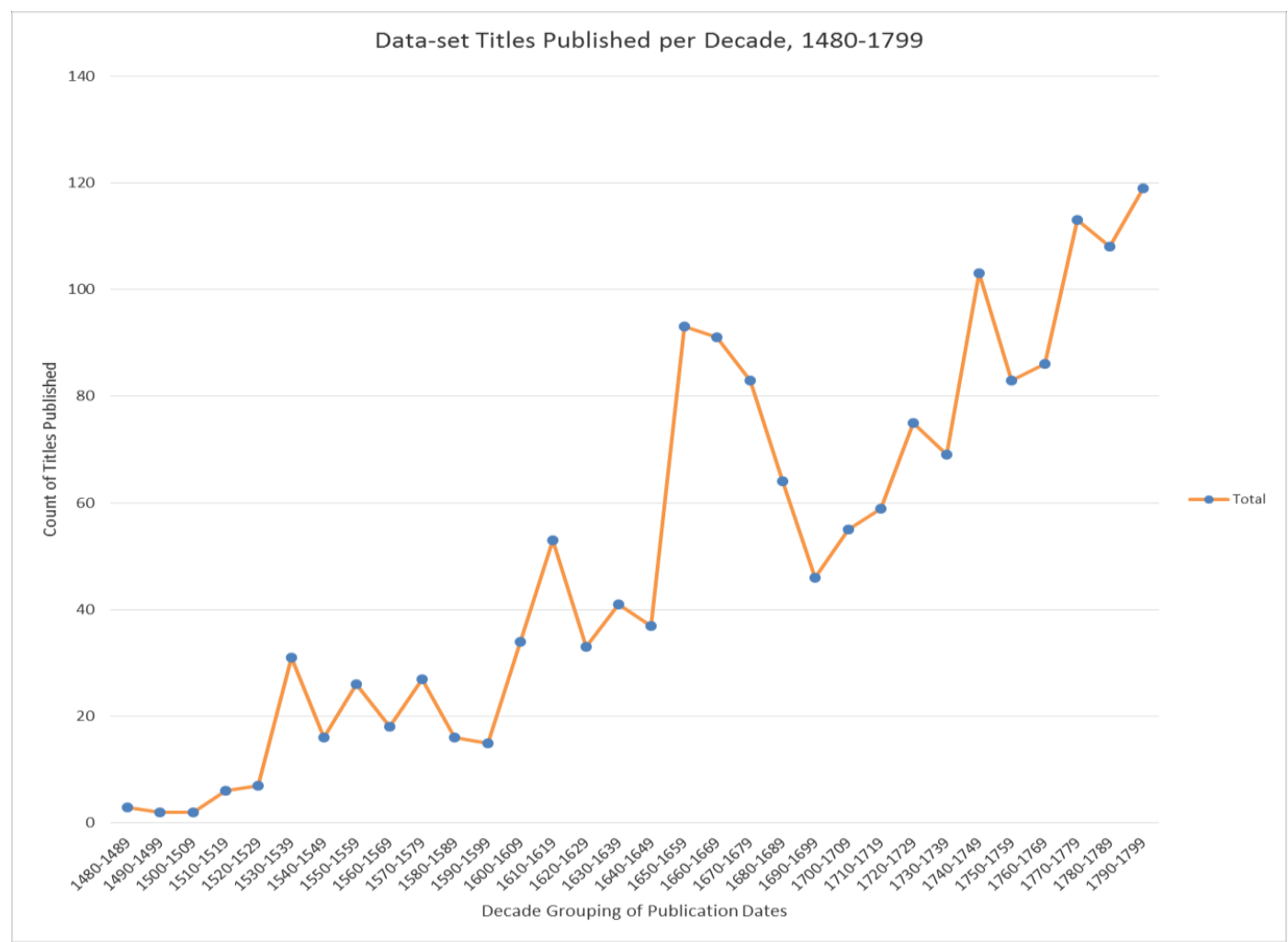

Figure 1.6. Line graph showing the rise in printed mathematical literature per decade, 1480-1799.

Of the 1,648 texts constituting this data-set, the leading 10 frequencies of texts published between 1486 and 1800 are presented in Table 1.2, representing 57\% (946 of 1,648 ) of books examined. In the first instance, these subject groupings should first and foremost be regarded as guides to help visualise the collection at a macroscopic level. Useful for the purposes of bibliometric analysis and as findingaids, by necessity their sub-classes serve to stratify the interdependent nature of various forms of mathematical practice, dividing, for example, surveying from geometry, and instruments such as globes and astrolabes from astronomy. At the same time, whilst it is to be recognised that these broad-brush numbers rely upon modern disciplinary and sub-disciplinary classifications whilst simultaneously

increase can largely be explained by an influx into the collection of both new and reissued editions of texts printed in London, which account for 42 titles printed in the decade grouping 1650-1659, 35 titles in the grouping 1660-1669, 42 titles in the grouping 1670-1679, and 33 titles in the grouping 1680-1689. London's growth in relation to the book trade of early modern Europe is discussed in more detail between pp. 73-86 of the current chapter. 
striving to respect the categories of the period a text belongs to, they nonetheless suggest that this subset of literature is suitably representative of the culture of which it was a product.

\begin{tabular}{|c|c|l|c|c|c|}
\hline Scoping Rank & $\begin{array}{c}\text { Subject } \\
\text { Acronym }\end{array}$ & \multicolumn{1}{|c|}{ Title } & Count & $\begin{array}{c}\text { \%age of } \\
\text { Mathematical } \\
\text { Subset }\end{array}$ & $\begin{array}{c}\text { \%age of } \\
\text { Total } \\
\text { Collection }\end{array}$ \\
\hline 1 & ASTR & Astronomy & 178 & 10.8 & 5.3 \\
2 & PHYS & Physics and Natural Philosophy & 174 & 10.6 & 5.2 \\
3 & MATH & Mathematics & 139 & 8.4 & 4.2 \\
4 & ARTH & Arithmetic & 71 & 4.3 & 2.1 \\
4 & SCIE & Science - General and Societies & 71 & 4.3 & 2.1 \\
6 & ASTI & Astronomical Instruments & 53 & 3.8 & 1.9 \\
7 & OPTC & Optics & 52 & 3.4 & 1.7 \\
8 & GEOM & Geometry & 48 & 2.2 & 1.6 \\
9 & WGMS & Weights and Measures; Metrology; Money & 47 & 2.9 & 1.4 \\
10 & SHIP & Ships, Shipbuilding, Naval History & 47 & 2.9 & 1.4 \\
10 & SURV & Surveying & $\mathbf{9 4 6}$ & $\mathbf{5 7 . 4}$ & $\mathbf{2 8 . 4}$ \\
\hline
\end{tabular}

Table 1.2. Table showing the leading frequencies of texts printed between 1486 and 1800 belonging to subject groupings identified as mathematical or mathematically-adjacent.

As might be expected, subjects common to educational curricula—arithmetic, geometry, astronomy, optics and natural philosophy — are all well-represented in the collection, and are joined by materials in keeping with the Science Museum's identity as an institutional collector of the practice of science. Thus literature on astronomical instruments, contemporary and historical reports on the foundation and development of scientific societies, literature produced by such societies, and works on the development of existing technologies crucial to early modern state-building, warfare, and trade, such as shipping, feature prominently.

Of these ten subject groupings, Astronomy is the most consistently represented in the collection across decade groupings between 1480 and 1799, with texts belonging to this subject grouping absent only in the periods 1520-1529 and 1590-1599. A peak of 14 [ASTR] titles is witnessed in the period 1660-1669, with the 58 titles produced in the half-century between the periods 1610-1619 and 16601669 representing the zenith of the subject grouping in the collection. Every other subject grouping presents null values in at least six decade groupings; in only two decade groupings (1500-1509 and 1520-1529) did the highest-ranked subject grouping come from outside of these ten most featured groupings. Figure 1.7 highlights how titles belonging to these 10 subject groupings appear consistently in 
most decades, with only texts grouped as related to Shipping, Ship-Building and Naval History (SHIP) absent entirely prior to the decade grouping 1610-1619.

The data presented in Figure 1.7 below offers a useful entry point to the dataset as a whole, helping us to witness how mathematical literature gradually transitioned from texts used mainly in educational arenas to become representations of an intellectual culture encompassing all aspects of the theoretical, occupational, and applied practice of the subject. This should not, however, lead us towards focussing on a false bifurcation between practical and theoretical learning-between a 'low' mechanical or practical mathematical culture, written in the vernacular, and a 'higher' Latinate market focussed on learned studies of astronomy, optics, or the mathematics deemed relevant to natural philosophy. Instead, macroscopic analysis of these titles suggests that we should instead seek further evidence of the ways in which users of these texts witnessed and participated in the gradual creation and maintenance of the mathematical culture of the early modern period. Such evidence would help us to further identify more clearly the precise contours of a culture in which practitioners moved freely between sites of practice and between the trading zones shared by princes, courtiers, artisans, and publishers. 


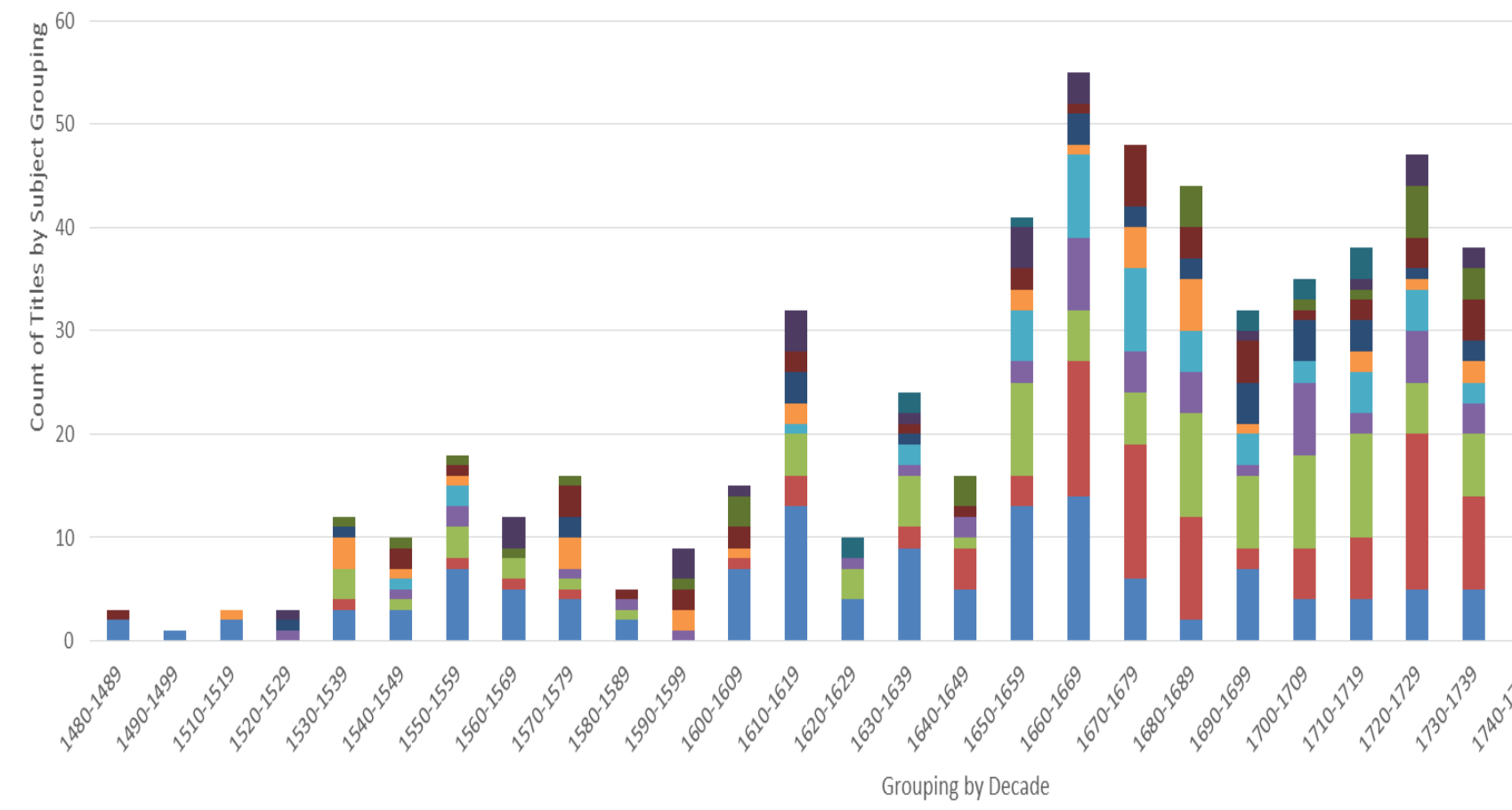

Figure 1.7. Stacked bar chart showing the top ten subjects across the entirety of the mathematical subset 
The development of this culture can be further evaluated by comparing the genres of titles present in the dataset according to their periodization by decade. Analysis of the mathematical texts printed across all locations between 1480 and 1599 , for example, displays a number of variations from the leading frequencies presented in Table 1.3 below. In total, $10.6 \%$ of the entire dataset $(175$ of 1,648$)$ comes from this period; the scholarly roots of early modern mathematical practice are shown by the fact that $68 \%$ of these 175 texts (119) were printed in Latin. The ten most frequent broad subject groupings are provided below. Alongside subjects previously witnessed as popular, such as Astronomy [ASTR], Geometry [GEOM], Arithmetic [ARTH] and Weights, Measures and Metrology [WGMS], the disciplines of cosmography [CSMO], astronomical instruments [ASTI], dialling [SUND] and surveying [SURV] are all well represented.

\begin{tabular}{|c|c|c|c|c|c|c|c|c|c|c|c|}
\hline \multirow[b]{2}{*}{ Decade } & \multicolumn{10}{|c|}{ Broad subject } & \multirow[b]{2}{*}{ Decade Total } \\
\hline & ASTR & ASTI & CSMO & MATH & GEOM & SUND & ARTH & SURV & GEOG & WGMS & \\
\hline $1480-1489$ & 2 & & - & - & 1 & - & - & - & - & & 3 \\
\hline $1490-1499$ & 1 & - & - & - & - & - & - & - & - & - & 1 \\
\hline $1500-1509$ & - & & 1 & - & - & - & - & - & - & - & 1 \\
\hline $1510-1519$ & 2 & 1 & - & - & - & - & - & - & - & - & 3 \\
\hline $1520-1529$ & - & - & 1 & - & - & - & 1 & 1 & - & - & 3 \\
\hline $1530-1539$ & 3 & 3 & 2 & 3 & - & 1 & - & - & 2 & 1 & 15 \\
\hline $1540-1549$ & 3 & 1 & 1 & 1 & 2 & - & 1 & - & 1 & 1 & 11 \\
\hline $1550-1559$ & 7 & 1 & 2 & 3 & 1 & - & 2 & - & - & 1 & 17 \\
\hline $1560-1569$ & 5 & - & - & 2 & - & 2 & - & 3 & - & 1 & 13 \\
\hline $1570-1579$ & 4 & 3 & 2 & 1 & 3 & 1 & 1 & - & 2 & 1 & 18 \\
\hline $1580-1589$ & 2 & - & 1 & 1 & 1 & 2 & 1 & - & - & - & 8 \\
\hline $1590-1599$ & - & 2 & 1 & - & 2 & 2 & 1 & 3 & 1 & 1 & 13 \\
\hline Subject Total & 29 & 11 & 11 & 11 & 10 & 8 & 7 & 7 & 6 & \begin{tabular}{l|l}
6 \\
\end{tabular} & 106 \\
\hline
\end{tabular}

Table 1.3. Table showing the leading frequencies of texts printed between 1486 and 1599 belonging to subject groupings identified as mathematical or mathematically-adjacent.

Although the data presented in Table 1.3 is not in itself demonstrative of modes of practice in early modern Europe, it does suggest a cultural interest in materials relating to the theory and practice of astronomy, whether for philosophical, theological, or mathematical reading, or for practical problem-solving, and the relevance of distinct texts to those studies. The sixteenth-century interest in time-finding has been cited as one instance of a craft tradition in astronomical practice common to the period: an active setting in which producers integrated 
learning, skill, mathematical knowledge and innovation. ${ }^{18}$ Texts and instruments were utilised by a range of actors to make and to promote mathematical culture itself, with Germanic regions key points in this sixteenth-century print and instrument network. 65\% (69 of 106) of the titles numbered in Table 1.3 were published in either German or Swiss regions, including Basel, Cologne, Frankfurt, and Nuremberg and, as we shall see, the prevalence of Germanic regions in relation to the production of mathematical culture should not be underestimated.

Valuable techniques were to be improved and passed on, and the mathematical materials that remain perhaps tell us of the importance of specific types of practice within this broader culture. Dating from at least the thirteenthcentury, inventions such as naviculae - miniature, ship-shaped portable sundialsrelied on the manipulation of the geometrical construction described in Ptolemy's Analemma, putting applied geometrical theory (if not understanding) directly into users' hands. ${ }^{19}$ If the foregoing discussion implies that the prevalence in the collection of Latinate works in these decades suggests a well-educated readership, it should not necessarily be assumed that the audience for such materials automatically valued theory over practice. Instead, when allied to titles which represented the theory and practice of dialling [SUND], these figures help to present a picture of mathematical culture as predicated mainly on the reading and use of texts and instruments marrying geometry and spherical astronomy.

Citing the utilitarian and everyday importance of the sundial, Turner identified the tool as an example of the growing importance of mathematics to the early modern user. These quotidian properties naturally led to an increase in the demand for the instruments and texts which accompanied the practice. ${ }^{20}$ Utility, delight, play, presentation, teaching, demonstration and problem-solving were all parts of the development of this culture; developments which were harnessed and

\footnotetext{
18 J. A. Bennett, 'Cosmography and the Meaning of Sundials' in Mario Biagioli and Jessica Riskin, eds., Nature Engaged: Science in Practice from the Renaissance to the Present (New York: Palgrave Macmillan, 2012), pp. pp. 249-262, particularly pp. 251-252.

${ }^{19}$ Catherine Eagleton, Monks, Manuscripts and Sundials: The Navicula in Medieval England (Leiden and Boston: Brill, 2010), pp. 3-5.

${ }^{20}$ A. J. Turner, 'Interpreting the History of Scientific Instruments', in R. G. W. Anderson, J. A. Bennett, and W. F. Ryan, eds., Making Instruments Count. Essays on Historical Scientific Instruments presented to Gerard L'Estrange Turner (Aldershot: Variorum, Ashgate Publishing Ltd, 1993), pp. 1726.
} 
cultivated by the producers of such instruments: not only the texts of the sixteenth century, but also the globes, paper instruments and dials attached to practices such as cosmography, horology, and dialling.

The twelve publishing locations most represented in the collection are shown in Table 1.4, with the numbers of texts printed in each location present in the collection per decade appearing in Figure 1.8. ${ }^{21}$ Although the data is skewed by the frequency of texts produced in London, core locations central to the early modern print trade are well represented, including Paris, Amsterdam, Venice and Basel. The cosmopolitan nature of the collection reflects the existence of substantial print cultures in France, Italy, Germany and the Low Countries. Even if factors both local and national periodically impinged on the early modern book trade, with social instability, war, destitution and religious upheaval all depressing the wider economy and, in turn, the trade in books and other luxury products, the general trend was that a growing audience of readers of mathematical and scientific texts generated an increased demand for these material products.

\begin{tabular}{|c|c|c|c|c|}
\hline Rank & Modernised Location & Count & $\begin{array}{c}\text { \%age of } \\
\text { Mathematical Subset }\end{array}$ & $\begin{array}{l}\text { \%age of Total } \\
\text { Collection }\end{array}$ \\
\hline 1 & London & 650 & 39.4 & 19.5 \\
\hline 2 & Paris & 225 & 13.7 & 6.8 \\
\hline 3 & Amsterdam & 66 & 4.0 & 2.0 \\
\hline 4 & Venice & 51 & 3.1 & 1.5 \\
\hline 5 & Frankfurt & 37 & 2.2 & 1.1 \\
\hline 6 & Leiden & 31 & 1.9 & 0.9 \\
\hline 7 & Basel & 30 & 1.8 & 0.9 \\
\hline 8 & Bologna & 29 & 1.8 & 0.9 \\
\hline 9 & Leipzig & 28 & 1.7 & 0.8 \\
\hline 10 & Nuremberg & 26 & 1.6 & 0.8 \\
\hline 10 & Oxford & 26 & 1.6 & 0.8 \\
\hline \multirow[t]{2}{*}{10} & Rome & 26 & 1.6 & 0.8 \\
\hline & Total & 1225 & 74.3 & 36.8 \\
\hline
\end{tabular}

Table 1.4. Table showing the leading frequencies by location of texts printed between 1486 and 1799 belonging to subject groupings identified as mathematical or mathematically-adjacent.

\footnotetext{
${ }^{21}$ Robert L. Maxwell, RBMS/BSC Latin Place Names File, http://rbms.info/lpn/. This facility incorporates both R. A. Peddie, Place Names in Imprints: An Index to the Latin and Other Forms Used on Title Pages, $2^{\text {nd }}$ edn (Detroit: Gale Research Company, 1968), and J. G. T. Graesse, F. Benedict, and H. Plechl, Orbis Latinus: Lexikon lateinischer geographischer Namen des Mittelalters und der Neuzeit, $4^{\text {th }}$ edn (Braunschweig: Klinkhardt \& Biermann, 1972).
} 
Thanks to a mixture of the scuola d'abaco, a vogue for humanist learning, and its geographical position on a number of trade routes, Venice had by the beginning of the sixteenth-century established itself as a major centre of the European book trade, its cosmopolitan community of merchants, scholars, artists and artisans marrying commerce with learning and new technology. ${ }^{22}$ A centre of early modern commerce, Venice is well represented in the mathematical collections of the Science Museum dating from before 1600, and is joined in the subset by educational and commercial hubs such as Paris, Basel and Nuremberg. One surprising omission from this list is the city of Antwerp. Home to mathematical artisans, instrumentmakers, and cartographers including Michiel Coignet, Jodocus Hondius and Willem Janszoon Blaeu, the city, then under the control of the Duchy of Brabant as part of the Spanish Netherlands, was well-known in the early decades of the seventeenthcentury both as a dominant publishing location and for the production of luxury goods linked to the mathematical sciences. ${ }^{23}$

Whilst the influence of the aforementioned practitioners is noted elsewhere in the collection - for example, in English materials authored by Thomas Blundeville and Joseph Moxon, which owed much to Coignet and Blaeu respectively_only nine mathematical texts printed in Antwerp are present in the entire collection. Six of the nine texts printed in Antwerp present in the collection appeared prior to the year 1600, including three works by Gemma Frisius and two from Peter Apian. Closer inspection of these trends serves to highlight the importance of stratifying our largescale data into both subject and decade groupings (as seen in Figure 1.8 below), thereby affording a means to further explore the construction of mathematical culture across the distinct regions and zones of early modern Europe.

\footnotetext{
${ }^{22}$ On the scuola d'abaco tradition, see James Bruce Ross, 'Venetian Schools and Teachers Fourteenth to Early Sixteenth Century: A Survey and Study of Giovanni Battista Egnazio', Renaissance Quarterly, 39 (1976), pp. 521-566; Grahame Thompson, 'Early Double-Entry Bookkeeping and the Rhetoric of Accounting Calculation' in Anthony G. Hopwood and Peter Miller, eds., Accounting as Social and Institutional Practice (Cambridge: Cambridge University Press, 1994), pp. 40-66, p. 41; Paul F. Grendler, Schooling in Renaissance Italy: Literacy and Learning, 1300-1600 (Baltimore and London: The Johns Hopkins University Press, 1989). See also Bronwen Wilson, The World in Venice: Print, the City, and Early Modern Identity (Toronto: University of Toronto Press, 2005).

${ }^{23}$ Sven Dupré, 'Trading Luxury Glass, Picturing Collections and Consuming Knowledge in Early Seventeenth-Century Antwerp' in Sven Dupré and Christoph Lüthy, eds., Silent Messengers: The Circulation of Material Objects of Knowledge in the Early Modern Low Countries (Berlin: Lit Verlag, 2011), pp. 261-292.
} 


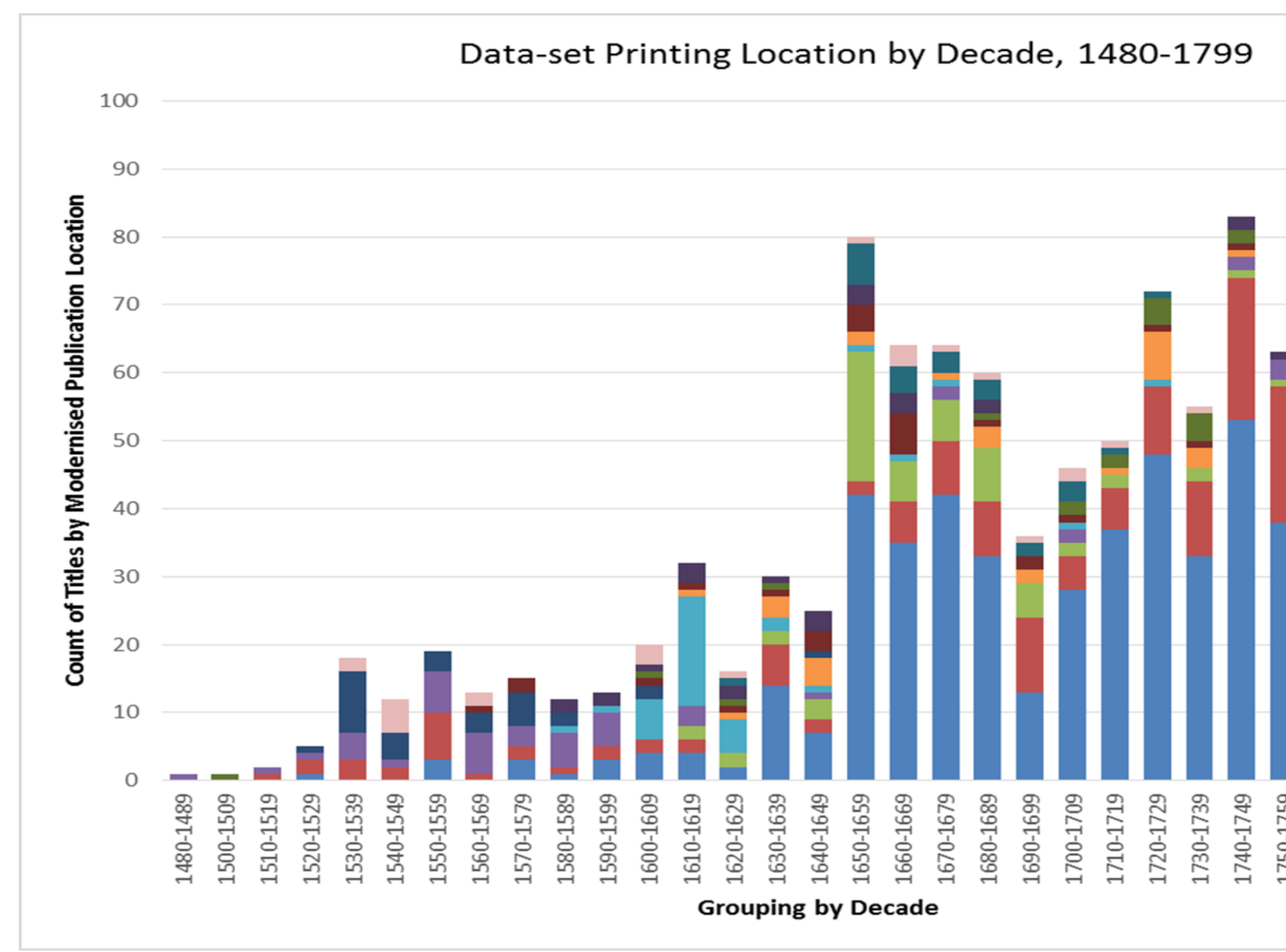

Figure 1.8. Stacked bar chart showing the top ten publishing locations across the entirety of the mathem: 
As previously shown in Table 1.4, Basel is the seventh most represented publishing location in the collection, presenting 30 mathematical titles. 25 of these were printed between 1480 and 1599, a period for which Basel is the second-most represented location in the collection (Figure 1.9, below), producing $15 \%$ of the mathematical titles (25 of 164); more specifically, these titles were published in the 54 years between 1529 and 1583. This frequency of materials produced in Basel attests to the free imperial city's position as one of the foremost outposts of the early printed-book market; beyond this, it is also evidence of an appreciation of mathematical culture in Northern Europe at the time.

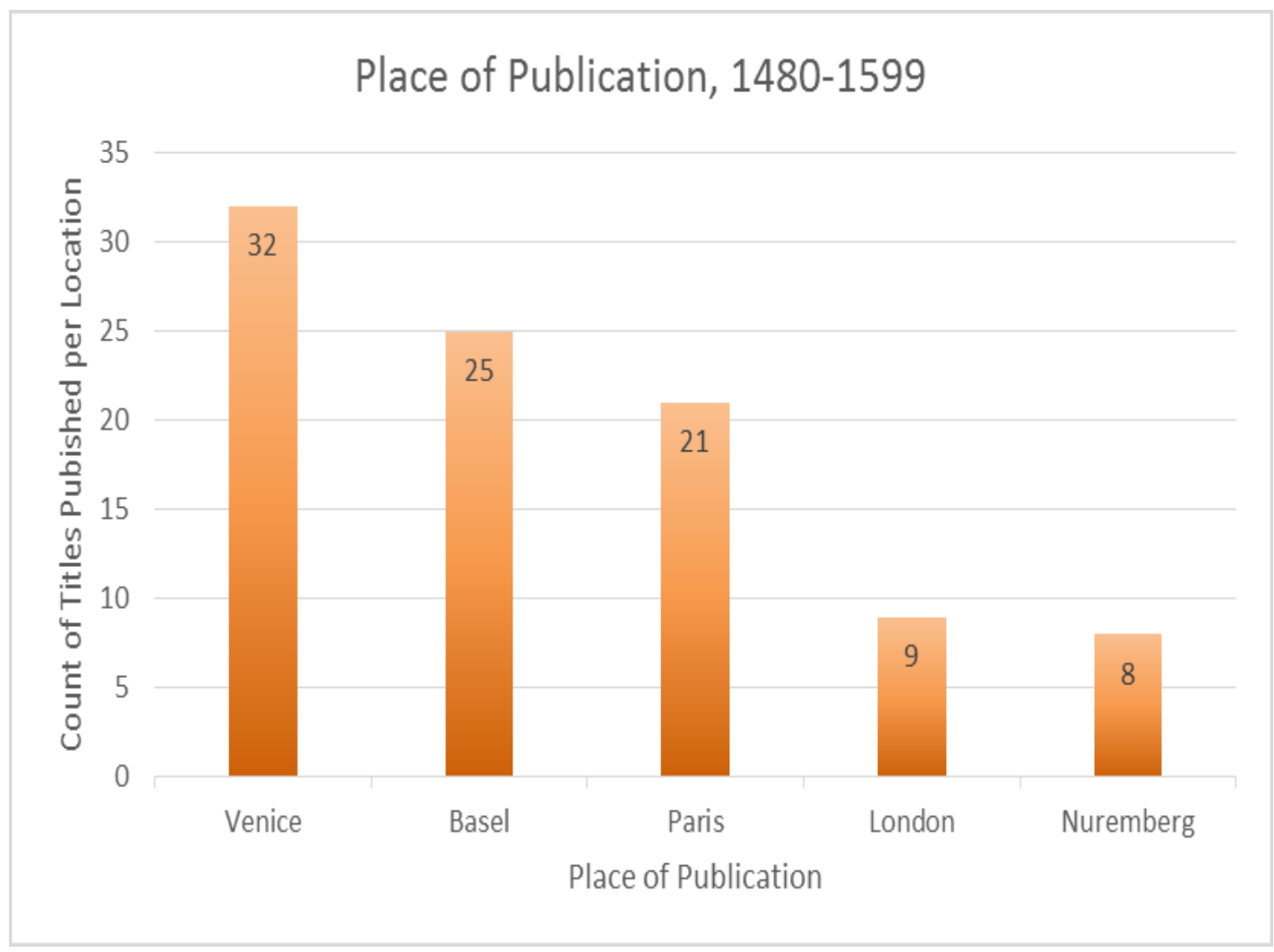

Figure 1.9. Bar chart showing the five most popular print locations by frequency of texts published, 1480-1599.

Well-placed to benefit from traders travelling well-trodden routes between Italy, France, and Germany, Basel was where far-sighted merchants such as Johann Froben established printing-houses to both serve and benefit from this footfall. The printer and his son, Hieronymus (1501-1563) opened their own home to the influential humanist Desiderius Erasmus (1466-1536): taking advice on which books to publish, as well as providing lodgings for the famed humanist, the firm cultivated 
a mutually-beneficial relationship with the Dutch scholar. In turn, the publishers basked in the glow of Erasmus's renown. The Frobens' name and products were made widespread by association, and their living quarters became a meeting place for a mathematically-literate community of editors, authors, and correctors affiliated to Erasmus, including the Basel professor Simon Grynaeus, editor of the editio princeps of Euclid's Elements (1533), and Sebastian Münster (1488-1522), who would go on to publish a Latin edition of Ptolemy's Geographia, as well as his own works on dialling and his Cosmographia (1544). ${ }^{24}$

Sebastian Münster's mathematical and mathematically-adjacent works were published not by Froben, but by the author's step-son, Heinrich Petri (1508-1597), and the author's hugely successful Cosmographia proved the golden goose for the Petri printing house for generations, with 35 editions of Münster's text issued between 1544 and 1628 in five different languages. ${ }^{25}$ Earlier in the sixteenth century, Heinrich's maternal uncle, the Nuremberg printer Johann Petri (Johannes Petreius, ca. 1497-1550), had been entrusted with printing the first edition of Nicolaus Copernicus's De Revolutionibus orbium coelestium (Nuremberg, 1543); Petreius also published the mathematical works of Michael Stifel and Girolamo Cardano, amongst others. This Johannes was himself merely the latest scion of a printing family, nephew to one part of the hugely successful Basel publishing collective of Johann Amerbach, Johann Froben, and Johannes Petreius the elder. ${ }^{26}$

The business practices of generations of both the Froben and Petri families elucidate the interlocking domains of printing-houses and the wider market at work in cities such as Basel in the sixteenth century. Clearly, the dynastic continuation of

\footnotetext{
${ }^{24}$ Richard J. Oosterhoff, 'The Fabrist Origins of Erasmian Science: Mathematical Erudition in Erasmus' Basle', Journal of Interdisciplinary History of Ideas, 3.6 (2014) Item 3, pp. 1-37.

${ }^{25}$ Matthew McLean, 'Between Basel and Zurich: Humanist Rivalries and the Works of Sebastian Münster' in Malcolm Walsby and Graeme Kemp, eds., The Book Triumphant: Print in Transition in the Sixteenth and Seventeenth Centuries (Leiden and Boston: Brill, 2011), pp. 270-294, p. 289. A search of the Universal Short Title Catalogue shows that 27 editions of Cosmographia, in three languages, were published by the Petri firm between 1544 and 1600 .

${ }^{26}$ For the mechanics of this relationship, the role of authors, and the importance of international bookfairs such as that of Frankfurt, see correspondence between January and April 1506 between Amerbach, Petri, and Johann Koberger, in Barbara C. Halporn, trans. and ed., The Correspondence of Johann Amerbach: Early Printing in Its Social Context (Ann Arbor: University of Michigan Press, 2000), pp. 267-269. On Amerbach and Petri's patronage of Froben, see Valentina Sebastiani, Johann Froben, Printer of Basel: A Biographical Profile and Catalogue of his Editions (Leiden and Boston: Brill, 2018), pp. 24-30.
} 
mathematical printing interests in specific firms was a product of a number of factors. The domesticity of printing enterprises is made apparent by the Frobens having Erasmus as a lodger both at the site of their business and their home. With the printing-press and the home inseparable, texts and their producers could literally be kept in-house, with a cottage industry of correctors and future authors in close proximity. As the experiences of the Petri printing house shows, the creation of professional identity could be secured on a familial connection (or, in other cases, an ecclesiastic or economic one), as much as it might be linked to technical proficiency in manufacturing, or to the fame of having printed ground-breaking works in a given discipline. Beyond these domestic matters, Basel benefited immensely from its proximity to scholarly networks present at the local university and beyond, with a steady flow of scholars moving between the city, its institutions, and the universities and important trade routes which lay further afield. ${ }^{27}$

Quantitative analysis of the texts produced in Basel present in the collection between 1486 and 1599 consolidates our view of its printers servicing the scholarly market. The collection houses 12 individual works from the Basel printing house of Henricus Petrus and his son Sebastian Henric Petri (1546-1627), including the Finean edition of Gregor Reisch's Margarita Philosophica (1535), Erasmus Oswald Schreckenfuchs' Commentaria in novas theoricas planetarum Georgii Purbachii (1556), bound together with the same author's Primum mobile (1567) and Commentaria in sphaeram Ioannis de Sacrobusto (1569), as well as imprints of works by Copernicus, Münster, and others. 84\% (21 of 25) of the Basel texts are in Latin, with the remaining 16\% (4 of 25) printed in Greek. Their titles reflect intermediate university treatments of theoricae planetarum in discourse with the traditions of classical mathematics, with contemporary and near contemporary authors such as Peurbach, Schreckenfuchs, and Christian Wurstisen ballasted by Euclid, Archimedes, Ptolemy and Alhazen.

\footnotetext{
${ }^{27}$ See Earle Hilgert, 'Johann Froben and the Basel University Scholars, 1513-1523', The Library Quarterly: Information, Community, Policy, 41.2 (1971), pp. 141-169. Richard J. Oosterhoff notes that the Amerbach and Froben printing enterprises were particularly successful in enticing to Basle scholars from Venice, Nuremberg, and Paris. Oosterhoff, 'The Fabrist Origins of Erasmian Science', pp. 16-17.
} 
$60 \%$ (15 of 25 ) of these books were folios, a size common to the university study, princely collection and private library, rather than the more portable quarto textbooks that would come to flood marketplaces around European schools and universities. In this instance, the size of the text is no less important than its language or contents: large, unwieldly folios cost more to produce and were difficult to transport, with the result that their physical characteristics necessarily had an effect upon the mechanisms of their trade and the price paid by customers. Each of these factors serves to elucidate the relationships entered into by printers, traders, and scholarly customers. Publishers required assurances that a market existed for these works; similarly, traders sought evidence that transporting them across Europe was worthwhile; finally, scholars, as both authors and users of such literature, wished to maintain and profit from their access to such intellectual materials, as well as to guarantee the existence of a market for any future offerings of their own. Basel functions merely as one nodal point of the European-wide printing network. The factors at play in the city are comparable to its fellows of Venice, Paris, and Antwerp at different points in time in the period.

By way of contrast to these cities, London was a minor and peripheral printing location in the sixteenth century. How, then, did the English capital come to be the significant locational outlier dominating the collection? Local interest and national promotion make it reasonable to assume that the Science Museum's location in South Kensington, London, has been a contributory factor in the collection of significantly more texts from the city than from anywhere else; at the same time, it is equally possible that similar bias might be reflected in the equivalent collections present in national repositories today held in other European countries. Putting the acquisition policies of the museum to one side, the printed text in early modern England took a different path to that of its continental neighbours. Geographically isolated from mainland Europe, English printing merchants could not benefit from the trade-routes, footfall, and free movement of scholars, artisans and tradesmen in quite the same way as Antwerp, Basel or Venice. Indeed, there is evidence that Antwerp printers viewed the English market as an area ripe for expansion, its 
readers' needs ill-met by its printing infrastructure stunted in comparison to those of major European hubs. ${ }^{28}$

Though the English reading audience may well have been influenced by exports from Dutch printers, London's identity was more irrevocably altered by the Franco-Flemish influence wrought in the late sixteenth century by a huge influx of Protestant refugees seeking safe haven from religious persecution in their homelands of Belgium, the Netherlands, and France. Skilled émigrés brought with them a range of expert technical and artisanal skills which helped to accelerate the city's economic, artistic, and intellectual development, ${ }^{29}$ and these developments were clearly witnessed in the printed products of the age. Elizabeth Evenden has stressed the centrality of Flemish and Dutch printers and artists to John Day's publication of John Foxe's Book of Martyrs (Actes and Monuments) (1563), itself a hugely important work to Elizabethan religious identity; importantly, Day had four years previously presented ornate woodcut illustrations and fine type in his printing of William Cunningham's The Cosmographical Glasse (1559) to secure not merely a mathematical readership but also a patent from Queen Elizabeth covering all new works printed at Day's expense. ${ }^{30}$

Day's production of The Cosmographical Glasse impressed its (relatively few) readers with the skills now available to English printers, but this text is only one example of the influence of Franco-Flemish artifice particularly relevant to the development of mathematical culture in England. Not only did such skilled workers work to advance printing technology and paper-making: expert craftsmen such as Thomas Gemini helped to implant the trade in mathematical instruments. Indeed, Gemini's publication of Leonard Digges's Tectonicon presented on its title page perhaps the first printed advertisement for mathematical instruments, noting that the printer-instrument maker was 'ready exactly to make all the instruments appertaining

\footnotetext{
${ }^{28}$ Ben Parsons, 'Dutch influences on English literary culture in the early Renaissance, 1470-1650', Literature Compass, 4 (2007), pp. 1577-1596, particularly p. 1583.

${ }^{29}$ George Unwin, The Guilds and Companies of London, 4th edn (London: Frank Cass, 1963).

${ }^{30}$ Elizabeth Evenden, 'The Fleeing Dutchmen? The Influence of Dutch Immigrants upon the Print Shop of John Day', in David Michael Loades, ed., John Foxe at Home and Abroad (Bodmin: MPG Books, 2004), pp. 63-78. On Day's acquirement of printing privileges, see Elizabeth Evenden, Patents, Pictures and Patronage: John Day and the Tudor Book Trade (Aldershot: Ashgate, 2008), particularly pp. 59-67.
} 
in this book'. ${ }^{31}$ Thus the input of technical expertise from Continental Europe soon became visible — and, indeed, a source of tension — in a wide range of industries serving all walks of life, from brewing to finance to medicine. The book trade was no different, with developments in printing and production influencing both the quality of texts produced and the content of materials available.

Despite these changes, the English book trade had remained small and selfregulated, existing in tandem with a more prominent circulation of manuscripts between readers keenly aware of political and religious tensions. From the 1480s onwards printing in the capital was an upwardly-mobile enterprise, and one in which an increasing number of printers traded in close proximity to the Guildhall, the Inns of Court, and the educational and religious establishments found in the City of London. These locations allowed printers and print-sellers to benefit from the close networks of production which sprung up in tandem, with skilled craftsmen, artisans and other trained or well-educated workers readily available. At the same time, these locations gave stationers and book-sellers valuable access to the transitory customers who may have had business elsewhere in Europe. ${ }^{32}$

Escalations in print activity in sixteenth-century England, conjoined with the demands of an increasingly literate clientele, helped to bring a variety of texts from across Europe into the English marketplace. This nascent commercial arena supplied its consumers with access to devotional literature, political texts, playbooks and pamphlets: so much so that efforts by the long-extant Stationers' Company to police the trade had gained official sanction by Royal Charter in 1557. A nascent vernacular market duly followed, albeit somewhat slowly to begin with. 416 titles of any genre have been identified as printed in England before 1500, with as few as seven printers in operation before the turn of the century. ${ }^{33}$ These figures escalate to a further 4,373

\footnotetext{
${ }^{31}$ Leonard Digges, A Boke Named Tectonicon (London: John Day for Thomas Gemini, 1556), title page.

32 Julia Boffey, Manuscript and Print in London c.1475-1530 (London: British Library, 2012), p. 125.

${ }^{33}$ Valerie Hotchkiss and Fred C. Robinson, English in Print from Caxton to Shakespeare to Milton, (Urbana and Chicago: University of Illinois Press, 2008), p. 9; Ian Maxted, 'Impressorie Arte: The Impact of Printing in Exeter and Devon' in Benito Rial Costas, ed., Print Culture and Peripheries in Early Modern Europe: A Contribution to the History of Printing and the Book Trade in Small European and Spanish Cities (Leiden: Brill, 2013), pp. 127-146, p. 127.Valerie Hotchkiss and Fred C. Robinson reference seven printers - Caxton, Wynkyn de Worde (d. ca. 1534), Robert Pynson (14481529), Theodoric Rood (fl. 1480-1484?), Thomas Hunt (fl. 1480?), John Lettou (fl. 1475-1483) and William de Machlinia (fl.1483-1490) - operating prior to 1500. Maxted suggests that perhaps as
} 
titles recorded as printed between 1500 and $1550,{ }^{34}$ one of which was the first English vernacular mathematical text, the anonymously-authored An introduction for to lerne to recken with the pen or with the counters of 1537.

English presses made little physical impact on continental trends, with their output accounting for just 1.5\% of editions published in Europe before 1501, rising to circa 4\% in the sixteenth century; furthermore, Andrew Pettegree's estimates suggest that prior to 1601 English vernacular titles in print outnumbered Latin ones by a ratio of more than $5: 1$, with the consequence that the learned book trade was almost entirely an import-only affair. ${ }^{35}$ More than twenty printing-houses were officially recognised as being in operation in the half-century between 1580 and 1630, with that number doubling to 40 by 1649 and around 55 by 1686. In the first decades of the seventeenth century, printers were reliant on publishing patents, permissions, and the registered titles of the Stationers' Company, while the presses of the Company themselves, and the royal Printing House, maintained significant market shares. ${ }^{36}$

These figures are reflected in the mathematical subset of the Science Museum's holdings. Although London makes its first appearance in the collection in the decade 1520-1529, we do not find it present in subsequent decades until the periods 1590-1599 and 1600-1609. The city then appears consistently thereafter, and is most strongly represented in the collection in the decades 1650-1659, 1720-1729, and 1770-1779, with mathematically-related publications numbering 42, 48 and 57 titles respectively. Unsurprisingly, the majority of London imprints present in the collection were printed in the eighteenth century, with $68 \%$ (443 of 650) titles printed between 1700 and 1799, by which time the printed word had long established itself as central to English society. A single mathematical volume published in England prior to 1550 exists within the collection: Cuthbert Tunstall's arithmetical text, De arte supputandi libri quattuor (1522), printed in London by Richard Pynson

many as twenty printers were active in 12 English locations prior to 1557 , when printing was prohibited outside of London.

${ }^{34}$ James Raven, The Business of Books: Booksellers and the English Book Trade 1450-1850 (New

York; London: Yale University Press, 2007) pp. 14-20.

${ }^{35}$ Pettegree, 'Centre and Periphery', p, 118.

${ }^{36}$ Raven, Business of Books, pp. 46-47; Mark Bland, 'The London Book Trade in 1600' in David Scott Kastan, ed., A Companion to Shakespeare (Oxford; Blackwell, 1999), pp. 450-463, particularly pp. 451-452. 
(1488-1529). That no mathematical texts appear in the collection prior to Tunstall's work of 1522 is therefore in keeping with the low number of texts produced in England, and, more specifically, mathematical texts produced in England, compared to continental Europe up to 1550 .

Although printers would come to cater for the learned and the barely-literate alike, the low status of the English language in the sixteenth century ensured that few European intellectuals concerned themselves to learn it. At the same time, there were little by way of English expatriate communities to be found in European universities or courts prior to 1620, meaning that the general exportation of English texts was unnecessary. ${ }^{37}$ In advance of the large-scale growth of a literate public, lacking the travelling scholars produced by Italy and Germany, and represented by relatively few printers, the low number of mathematical texts printed in England prior to 1550 in the collection ( 1 out of 67 , or $1.5 \%$ ) is therefore statistically unsurprising, particularly given the extensive importation of texts from continental locations witnessed in England in the period. Equally, the collection's accumulation of mathematical texts printed in England matches their rising rate of production between 1550 and 1600. An additional ten texts from this period appear in the subset, charting a rise in the proportion of texts that were printed in England to $9.26 \%$ (10 of 108$)$.

It would be incorrect to claim that English-produced texts held such a foothold in the market; in this case, this development should instead be marked as evidence of the Science Museum collecting according to national interests. Yet in their separate ways these texts should nevertheless be seen as representative of the English consumption of mathematical literature. ${ }^{38}$ They include Robert Recorde's series of mathematical textbooks on arithmetic, geometry, and spherical astronomy; also two editions of Leonard Digges's A geometrical practise, named Pantometria issued in 1571 and 1591, as well as an edition of the same author's An arithmetical warlike treatise named Stratioticos of 1590. Alongside these works is an

\footnotetext{
${ }^{37}$ Ian Maclean, Learning in the Marketplace: Essays in the History of the Early Modern Book (Leiden: Brill, 2009), pp. 341-346.

${ }^{38}$ Perhaps the most oft-referenced example of English mathematical culture, John Dee's preface to Henry Billingsley's 1570 translation of Euclid's Elements, also exists as part of the collection. However, owing to display it is one of the 32 texts which I have been unable to access.
} 
astronomical treatise written by Digges's son, Thomas, Alae seu scalae mathematicae (1573), bound up with his teacher John Dee's Parallaticae commentationis praxeosque (1573). Each concerning the comet or 'new star' of 1572, these two texts were linked not only by their topic but by the almost familial relationship enjoyed by their authors. Surviving copies suggest that these works were, in fact, consistently issued together. ${ }^{39}$

A tradition of instrumental innovation, seen in books and tools of mathematical practice produced throughout Europe, was also witnessed in England, and is seen once again in the early entries in the collection. Although a first edition of Digges' Tectonicon as printed by Gemini is absent (albeit with a 1630 edition of the text present), these materials are joined by John Blagrave's state-of-the-art works on the astrolabe, or 'mathematical jewel', and the Jacob's staff. As we would expect, the increasing number of texts in the collection printed in English, seen in Figure 1.11 , is most prominent from 1650 onwards and parallels London's rising importance in the European book trade. Mathematical subjects naturally benefited from this growing demand for print, with one notable by-product relevant to mathematical and technical texts an increasing awareness (played upon by producers) of such literature's usefulness to employment or commerce. Figure 1.10 illustrates the rising to prominence in the collection of London imprints across the seventeenth-century. Of the 586 texts printed between 1600 and 1699 identified, 196 (33.4\%) were printed in London; in this period, the city's publications comfortably outstrip those of Amsterdam (53, or 9.16\%), Paris (47, or 8.13\%) Frankfurt (33, or $5.7 \%)$ and Bologna $(20$, or $3.5 \%)$.

\footnotetext{
${ }^{39}$ Stephen Johnston, 'Like Father, Like Son? John Dee, Thomas Digges and the Identity of the Mathematician' in Stephen Clucas, ed., John Dee: Interdisciplinary Studies in English Renaissance Thought (Dordrecht: Springer, 2006) pp. 65-84, p. 65.
} 


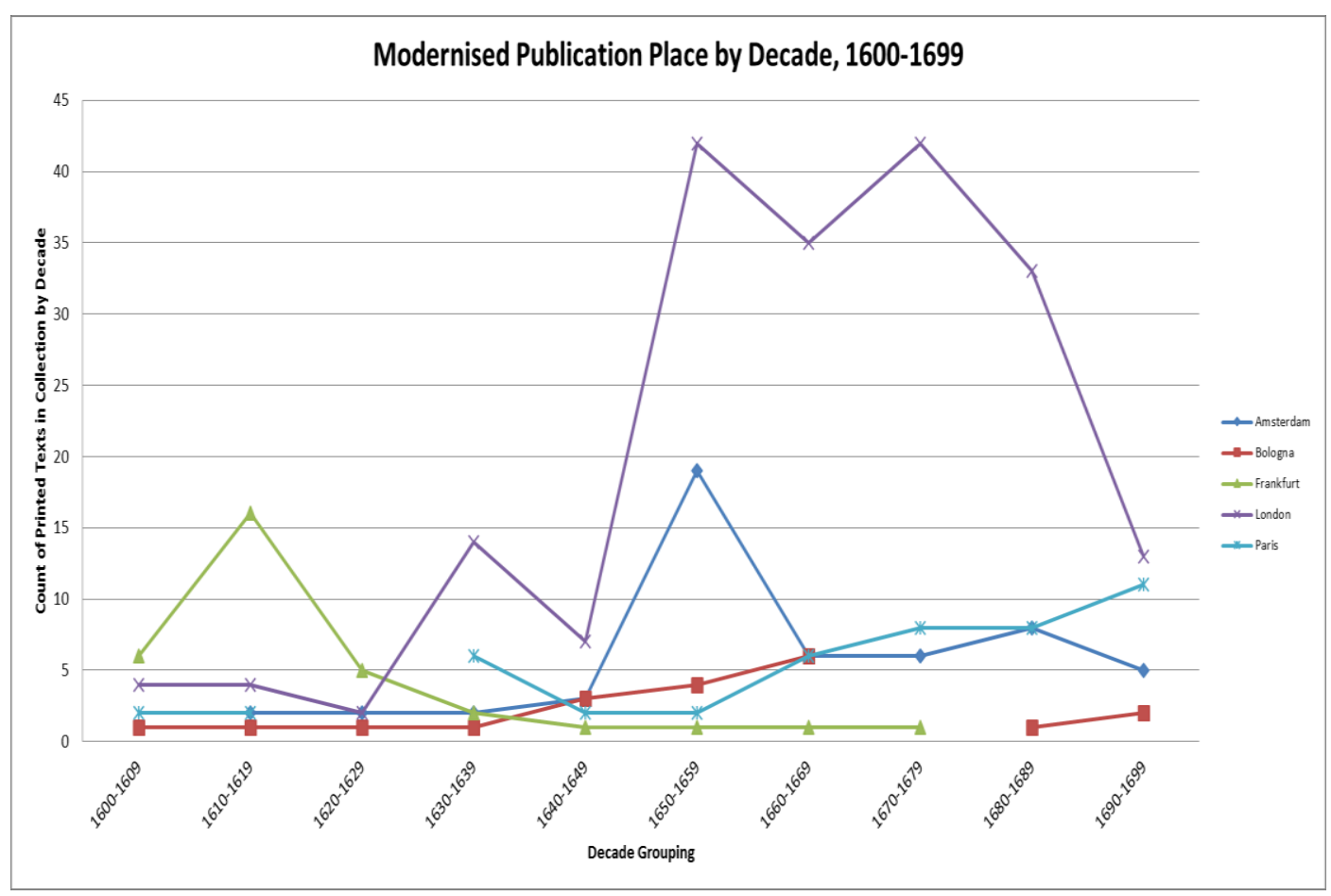

Figure 1.10. Line graph contrasting growth and decline of publishing locations identified in the collection by count of texts published, 1600-1699.

Just as five cities dominate the holdings in this period, five subjects are visibly more prominent in the holdings from this century: accounting for $40 \%$ (236 of 586) of titles printed between 1600 and 1699, the groupings of astronomy (ASTR), physics and natural philosophy (PHYS), mathematics (MATH), science and scientific societies (SCIE), and texts relating to mathematical instruments (MTHI) are prominent (Table 1.5).

\begin{tabular}{|c|c|c|c|c|c|c|}
\hline \multirow[b]{2}{*}{ Decade } & \multicolumn{5}{|c|}{ Broad subject } & \multirow[b]{2}{*}{ Decade Total } \\
\hline & ASTR & PHYS & MATH & SCIE & MTHI & \\
\hline $1600-1609$ & 7 & 1 & - & - & 2 & 10 \\
\hline $1610-1619$ & 13 & 3 & 4 & 1 & 2 & 23 \\
\hline $1620-1629$ & 4 & - & 3 & - & 2 & 9 \\
\hline $1630-1639$ & 9 & 2 & 5 & 2 & 5 & 23 \\
\hline $1640-1649$ & 5 & 4 & 1 & - & - & 10 \\
\hline $1650-1659$ & 13 & 3 & 9 & 5 & - & 30 \\
\hline $1660-1669$ & 14 & 13 & 5 & 8 & 4 & 44 \\
\hline $1670-1679$ & 6 & 13 & 5 & 8 & 1 & 33 \\
\hline $1680-1689$ & 2 & 10 & 10 & 4 & 4 & 30 \\
\hline $1690-1699$ & 7 & 2 & 7 & 3 & 5 & 24 \\
\hline Subject Total & 80 & 51 & 49 & 31 & 25 & 236 \\
\hline
\end{tabular}

Table 1.5. Printed texts grouped by most prominent subjects, 1600-1699. 
It is no surprise to see that astronomical texts continue to be well represented in this period: the utility of astronomical study to philosophy, dialling, navigation and a wide range of other fields has already been discussed. Works in the Science Museum's collection relating to physics and natural philosophy (PHYS) published in the early- to mid-1600s include Galileo's text on floating bodies, the Discorso intorno alle cose che stanno in sù l'acqua (1612) - a text which directly refuted Aristotelian theory - as well as Athanasius Kircher's Magnes, sive de arte Magnetica (1641), which featured a clock combining magnets with a sunflower. In Kircher's argument, the dynamics of this floating, botanical mechanism proved the spiritual, attractive relationship existing between the sun, the flower, and a component magnet. ${ }^{40}$

Each of these works uses instrumentation and experimentation in their own way, and both authors promote a method of 'doing' mathematics that may serviceably advance (or upset) traditional natural philosophy. The collection holds additional theoretical texts which appropriated these ideas: for example, Giuseppe Biancani's (Blancanus) work, Aristotelis Loca mathematica ex universis ipsius operibus collecta et explicata (1615), wherein the author lamented the state of mathematical enquiry and the lack of respect granted to Galileo, his friend and peer. ${ }^{41}$ Notably, a growing number of texts advancing the worth of mathematical instruments to a number of practical endeavours appear. New geometrical instruments for navigation, fortification and warfare are presented in Leonard Zubler's Nouum instrumentum geometricum (1607) and a second edition of Edmund Gunter's The description and use of the sector, crosse-staffe, and other instruments (1636).

As titles from the Rare Books Collection illustrate, English authors and printers had noted and encouraged the growing interest in practical treatises from the beginning of the seventeenth century. Pocket-books, 'friends', and other texts

\footnotetext{
${ }^{40}$ Roberto Buonanno, The Stars of Galileo Galilei and the Universal Knowledge of Athanasius Kircher, trans. Roberto Buonnano and Giuliana Giobbi (Cham: Springer, 2014), p. 98; Koen Vermeir, “'Bent and Directed Towards Him': A Stylistic Analysis of Kircher's Sunflower Clock' in Ofer Gal and Raz Chen-Morris, eds., Science in the Age of the Baroque (Dordrecht: Springer, 2013) pp. 47-76, p. 63.

${ }^{41}$ Francesco Paolo de Ceglia, 'Additio illa non videtur edenda: Giuseppe Biancani, Reader of Galileo in an Unedited Censored Text', in Mordechai Feingold, ed., The New Science and Jesuit Science: Seventeenth Century Perspectives (Dordrecht: Kluwer Academic Publications, 2003), pp. 159-186.
} 
claimed to make various disciplines easy or approachable to those of the "meanest capacitie', and, alongside their more expert works, mathematically-capable stationerauthors including William Leybourn produced entry-level titles such as A platform for purchasers, guide for builders, mate for measurers (1668). These developments proved so popular that by the time of its printing in 1726, the most recent imprint of John Ayres's Arithmetick made easie: for the use and benefit of trades-men, first published in 1693, had reached no less than 17 editions. That there was an intensifying recognition of mathematical disciplines and what they might provide is further supported by Benjamin Wardhaugh's bibliometric analysis of the incidence of mathematical terms in English book titles between 1473 and 1800. Use of the word 'mathematics' itself climbed markedly between 1510 and 1690; not only were higher numbers of mathematical texts being produced, but more identifiably mathematical terms, used both positively and negatively, were seeping into the titles and texts of the period. ${ }^{42}$

Changes in terminology and the frequency of its use bring us to analysis of the linguistic breakdown of the collection under study. Whilst the development of a vernacular market, particularly in England, can be referenced as proof of the growing audience for printed literature in early modern Europe, there remain factors requiring exploration to fully define and characterize this change, several of which are of particular relevance to mathematical, mathematically-adjacent, and scientific works. Examining the mathematical subset of the collection in its periodic entirety, the most represented languages are English (669 of 1,648, or 40.6\%), Latin (487, or 29.6\%), French (263, or 16\%), then, following a significant drop-off, German (89, or 5.4\%) and Italian (78, or 4.7\%). Marking the scholarly nature of many of the volumes as well as the dominant position it held with regard to printed materials in the early modern period, Latin is well represented. The frequency of literature printed in the language goes into steady decline only from 1660 onwards, at which point the print runs in the vernacular languages of English and French begin to take precedence, visible in Figure 1.11 below. By comparison, texts printed in French and English are

\footnotetext{
42 Benjamin Wardhaugh, 'Mathematics in English Printed Books, 1473-1800: A Bibliometric Analysis', Notes and Records of the Royal Society, 63 (2009), pp. 325-338, particularly p. 331.
} 
extremely poorly represented until at least the decades 1630-1639 (French) and 1670-1679 (English).

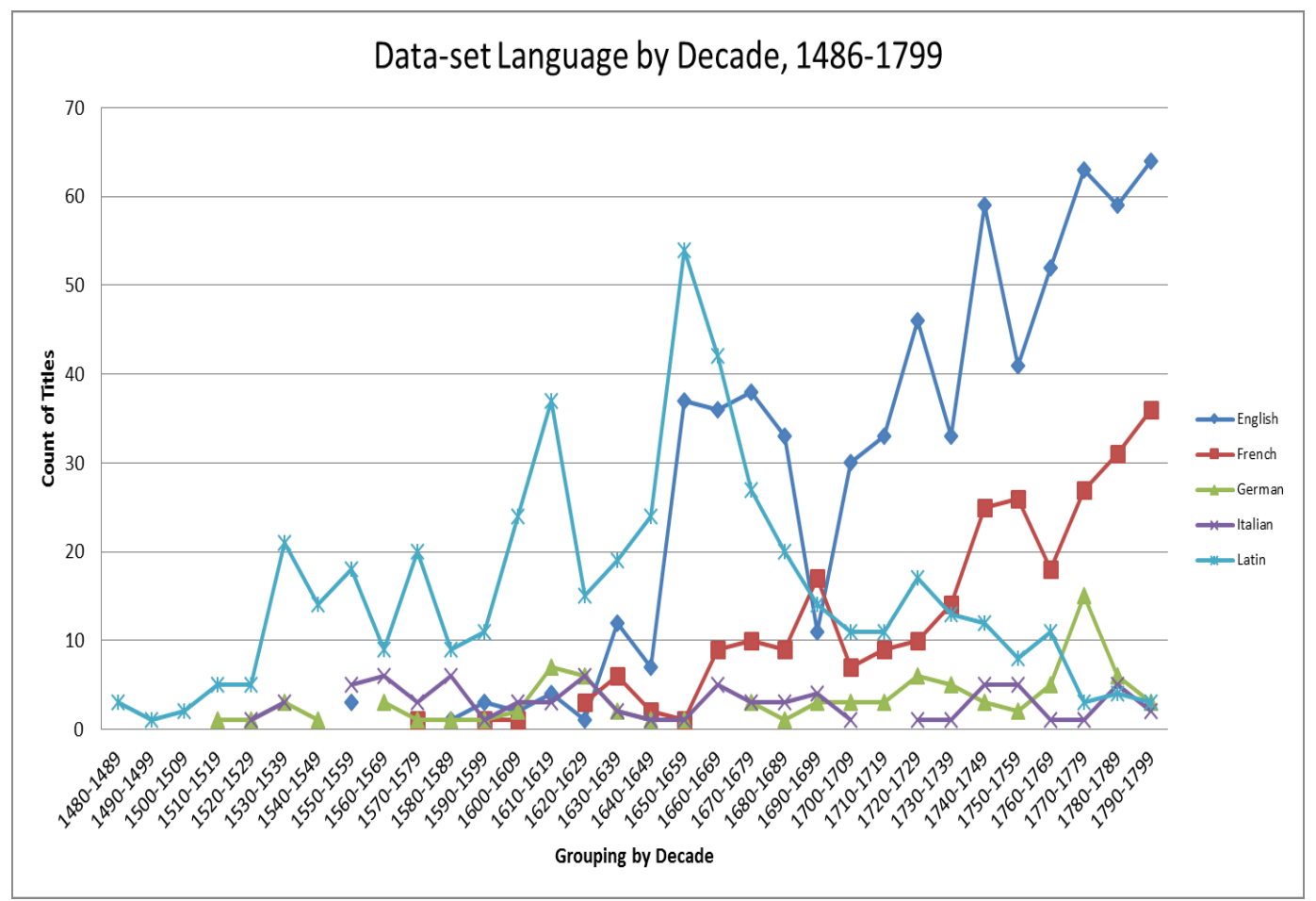

Figure 1.11. Line graph displaying frequencies of textual language occurrence identified in the collection by decade between 1480 and 1799.

It would seem reasonable to expect that the number of Latinate books produced in the period would begin to drop as that of vernacular texts rose, with increases in literacy, access to education, and indeed the growth of the general population all contributing factors; to these may be added the development and promotion of national interests, and the importance of language to those interests. ${ }^{43}$ There are, however, strong arguments that we should not see linguistic changes in early modern printed texts in terms of a triumphalist narrative of 'rise and fall', but rather as evidence of the competition of languages within various multi-linguistic communities - a competition in which Latin retained its presence as a lingua franca and as the language of educational, ecclesiastical, diplomatic and academic domains

\footnotetext{
${ }^{43}$ Margaret Spufford, 'First Steps in Literacy: The Reading and Writing Experiences of the Humblest Seventeenth-Century Spiritual Autobiographers', Social History, 4 (1979), pp. 407-435, p. 408; James Raven, Publishing Business in Eighteenth-Century England (Woodbridge: Boydell and Brewer, 2014), pp. 17-32. On the relationship between print, language, and national interests, see Kevin Sharpe, Reading Authority and Representing Rule in Early Modern England (London: Bloomsbury Academic, 2013), particularly pp. 103-120.
} 
well into the eighteenth century. ${ }^{44}$ These factors were of particular relevance to early modern authors of scientific texts, for whom the choice between publishing in Latin or a given vernacular often came down to one's philosophical or political aims, and to the audience intended for those aims.

Even in the latter decades of the seventeenth century, widespread appreciation of a work was guaranteed only by providing an international community access in the common tongue of Latin, which had retained intellectual hegemony through early modern educational systems, and further analysis of the journals produced by the Royal Society and the Académie des sciences bears this out. ${ }^{45}$ Both the Philosophical Transactions and Journal des Sçavans continued to publish articles in Latin and vernacular languages, and to commission book reviews of Latinate works, until at least the end of the seventeenth century. ${ }^{46}$ Whilst vernacular texts gradually came to prominence across Europe from mid-century onwards, the particular expansion of printed scientific, mathematical and mathematically-adjacent materials in the native languages of England and France from the 1660s should not necessarily be seen in terms of direct replacement, but rather as evidence of a growing market of literate consumers, the changing role of mathematics in society, and, to a lesser extent, the establishment of the Royal Society in 1660 and the Académie des sciences in 1666.

The evidence of these figures suggests the repetition in England of an earlier continental pattern of development, in which circles of professionalised practitioners and educators acted reciprocally, sharing information and skills at court and the marketplace which helped to foster a wider demand for mathematical objects, instruments, texts and tuition. The data yielded by this analytical survey would appear to indicate that the dichotomy of town and gown remained, with the publication of Latinate mathematical works in the middle and late decades of the seventeenth-century suggesting something of a cottage industry incorporating the

\footnotetext{
${ }^{44}$ Peter Burke, The Historical Anthropology of Early Modern Italy: Essays on Perception and Communication (Cambridge: Cambridge University Press, 1987), p. 84-85; Peter Burke, Languages and Communities in Early Modern Europe (Cambridge, Cambridge University Press, 2004), particularly p. 46 and pp. 62-64.

${ }^{45}$ Sietske Fransen, 'Latin in a Time of Change: The Choice of Language as Signifier of a New Science?', Isis, 108.3 (2017), pp. 629-635.

${ }^{46}$ David Banks, 'Starting Science in the Vernacular. Notes on Some Early Issues of the Philosophical Transactions and the Journal des Scavans, 1665-1700', ASp, la revue du GERAS, 55 (2009), pp. 5-22.
} 
consumers of the universities of Oxford and Cambridge, whilst vernacular works turned their user's vision towards the high seas, low fields, and damp fens to be sailed, surveyed and drained respectively. A closer look indicates however that any such bifurcation of vernacular and Latinate material may well have been of interest to printers or book-sellers only inasmuch as it affected the market he or she had targeted.

It is clear that the number of texts printed in London identified in the collection thus far significantly outweighs all other locations: nonetheless, points of convergence between Latin, English and French appear in the collection's seventeenth-century materials. The period between 1650 and 1679 is a suitable point from which to begin. Analysis of the data collected demonstrates, in this thirty-year period, a point of intersection between Latin and English. The mathematical books in the collection published in this period were predominantly printed in England. When combined, London, Oxford and Cambridge account for 49.6\% (134 of 270) of these volumes. The next closest national grouping across the period 1650-1679 is modernday Holland, with 15\% (41 of 270) of collected books published in Amsterdam, Rotterdam, and The Hague.

Of the 134 books printed in England, the vast majority - 82\% (110 of 134) were printed in the vernacular. This can be contrasted to the figures identified between 1500 and 1550, and goes some way toward highlighting the growth in the English-language book market up to this time. A significant amount of these works lean towards the practical: representative titles published in London include John Collins's Navigation by the mariners plain scale newly plain'd (1659) and Joseph Moxon's Mechanick Dyalling (1668). The 22 remaining texts (21 of which are in Latin, with a single text presenting both Latin and Greek typography), meanwhile, are skewed significantly toward the academic centres of Oxford and Cambridge. Seth Ward (1617-1689), and John Wallis (1616-1703), Savilian professors of Astronomy and Geometry, feature as authors, alongside their earlier tutor and correspondent William Oughtred (1574-1660).

It is the appearance in the collection of individual author-practitioners such as William Oughtred which should however most give us pause when considering the language of printed texts in England in the mid-seventeenth century. Oughtred's 
mathematical career was something of a culmination of piecemeal endeavours built around various domains involving mathematical practice, rather than a planned and repeatable professional pathway. ${ }^{47}$ The author, and many of his peers, can instead be placed as a liminal figure, traversing the boundaries of practical and theoretical spheres: one servicing the needs of both university student and apprentice sailor, as well as their respective masters. Oughtred and his fellow practitioners were ultimately utilitarian in outlook, and simply put mathematics to work to whatever ends were required - developing strategies to overcome any hurdles (including language) that might be encountered.

For this reason, the titles of Oughtred's works are instructive. Within the collection, we find his commitment to practice, pedagogy and instrumentation in works such as an improved and reissued edition of The circles of proportion and the horizontall instrument (1660), first published in 1632. The text features both a circular slide rule and its horizontal equivalent, demonstrated to aid navigation (through, for example, logarithmic calculation) and to assist troop formations in battle. Of his Latin works, it would appear that a contemporaneous user has bound together four titles, including the author's Elementi decimi Euclidis declaratio and Theorematum in libris Archimedis de sphaera et cylindro declaratio, both printed in Oxford in 1652, and likely to have been intended for use by university students. There is no reason to believe that these students did not then go on to engage in the multifarious interests and career paths apparent in the biographies of several mathematically-minded individuals: it would be incorrect to suppose that every Latinate reader of mathematics was uninterested in practical and vernacular expressions of the discipline.

Accordingly, we may question why a large number of mathematical works promise personal improvement alongside swift results (and, frequently, short-cuts), and what this may tell us of the consumers or audiences of the period. As we lack a comprehensive understanding not only of how users saw and interpreted these books and instruments, but also of how the texts were actually used, it is crucial that examples of marginalia and ownership are explored in conjunction with the printed

${ }^{47}$ Frances Willmoth, Sir Jonas Moore: Practical Mathematics and Restoration Science (Woodbridge: The Boydell Press, 1993), pp. 44-48. 
material in order to establish just how active readings of the text affected - positively or negatively - a given consumer's mathematical understanding.

There can be no doubt that the styles of presentation chosen by agents within the production process of these texts, and the typographical layout of the finished product, had some effect on the early modern user. Printed textual examples, relevant to actual application, were worked through by users seeking to calculate the precise costings of tilling acres and yards; to calculate the volumes of cylinders; to navigate or find the time by sun, moon and stars. By adding annotation to printed marginalia as provided by the printer, users inscribed evidence of their handling of geometrical, arithmetical and algebraical problems and, in some cases, broke away from the problems presented in texts by working out examples drawn either from daily life or their reading of other books.

\section{Proof of Use, Collection, and the Identity of the early modern Mathematical Consumer}

As the introduction to this thesis has shown, recent studies of Renaissance and early modern books and their readers have consistently emphasized the importance of understanding the role and function of books to their users. By discovering the 'et amicorum' lending lists, gauger's purchase orders, and sailor's navigational declinations added in manuscript, today's reader comes face to face with modes of early modern life and practice, and sees evidence not only of the development of genres of the codex, but also historical evidence of our cultural development as readers and users of books. Practical engagement with these volumes helped users to reify core elements of mathematical theory; by analysing large numbers of such source materials, our awareness of these centuries-old texts and instruments as 'carriers' of mathematical and scientific information - as well as unique material objects - cannot help but grow.

Viewing the many forms of the early modern mathematical (and, at times, quasi- or pseudo-mathematical) book over a period of several centuries allows us to witness the operative uses of texts as the wider disciplinary culture to which they belonged transformed and came to prominence. These texts exhibit, for example, evidence of how annotated replications and corrections of diagrams, tables and instruments aided mathematical interpretation and reasoning. They indicate how 
extra-textual elements grew to be central to both the mathematical text and its application, and their owners' actions reveal reading and usage strategies as discontinuous, disruptive, acquiescent and performative. Strategies that directly enacted the author or printer's intentions with practical outcomes are found; equally, readers who overruled the intentions of the author or printer through correction, amendment and erasure present themselves. Rather than bundle these points of departure together into wide-ranging, generalised forms of practice, these differences should be explored in greater detail, even if their liminality generates problems for both qualitative and quantitative expression.

To establish an overarching quantification of several discrete types of ownership evidence, examples of provenance - signatures, inscriptions, bookplates and armorials - were tallied and given unique identifiers, with these groups of 'Provenance Markers' - for example, [Signature / Ownership Inscription], [Armorial/Bookplate] and [Collection] - categorised and applied to volumes according to the number of such markers displayed. In this manner, a text presenting an individual signature, bookplate or collection mark but no other provenance markers would be categorised in the provenance grouping ' 1 type'. Likewise, a text presenting signatures and a bookplate - even if belonging to the same individual would be categorised as possessing ' 2 types', and so on. It should be noted that evidence of ownership by municipal and academic libraries was collated elsewhere and is not included in these statistics. From this, a notable $55.9 \%(923$ of 1,648) of the texts reviewed thus far were found to present some form of provenance data. Data concerning marginalia has not been specifically counted as evidence of provenance in and of itself: thus, texts with marginalia but lacking provenance data fall into the 'No Provenance' grouping. The stratification of this data is shown in detail in Figure 1.12. 


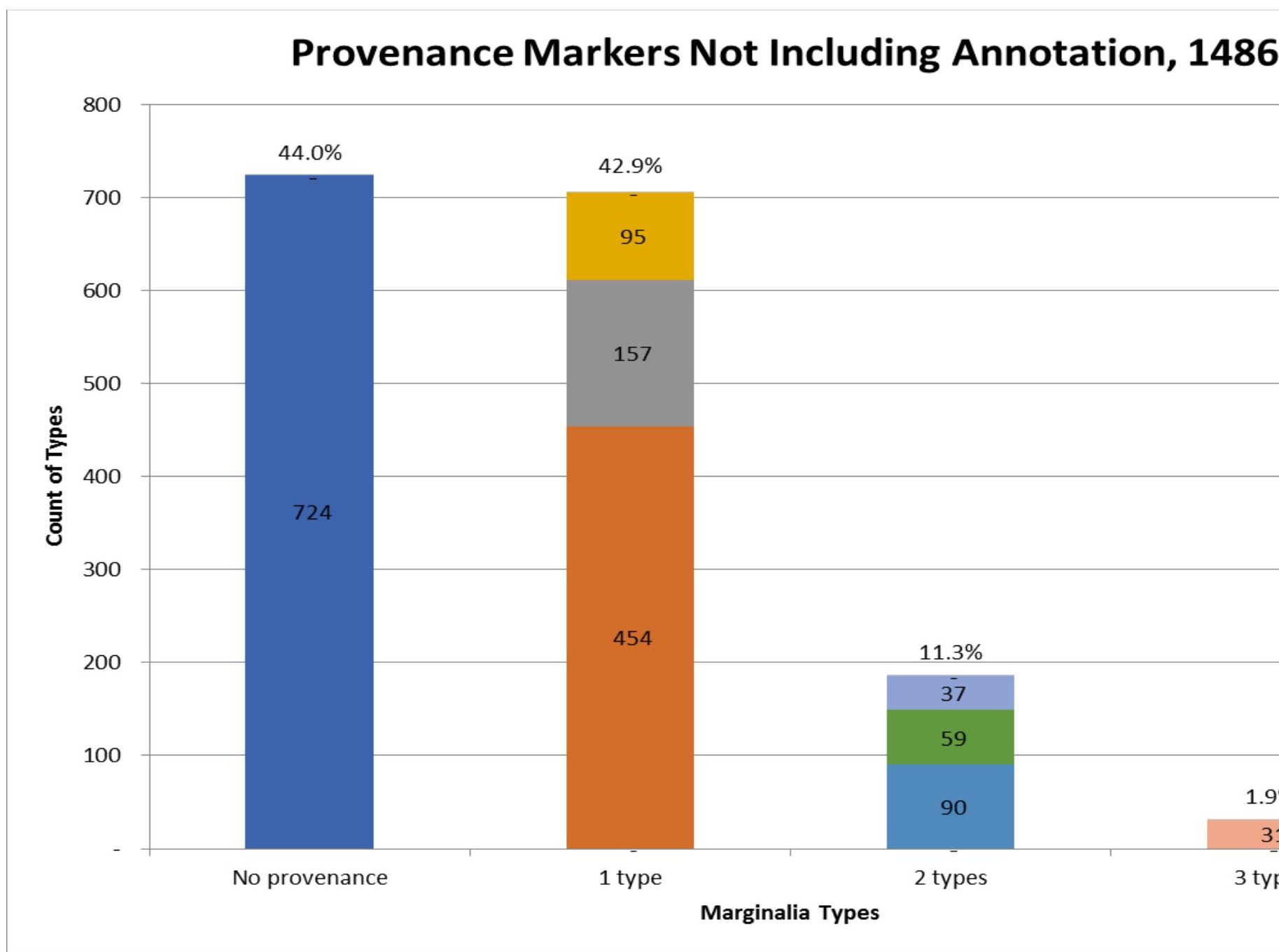

Figure 1.12. Stacked bar chart displaying identified provenance markers, 1486-1799. 
The 31 texts carrying three separate provenance markers make up a statistically insignificant proportion of the texts surveyed. This figure reflects the fact that, for any text to have survived, passed through several owners - each of whom quite literally put their stamp upon it - and then be found in the Science Museum's collection today is likely to be suitably famous, or of significant collectable value. Accordingly, within these 31 examples we find two dominant modern collectors: Robert Brodhead Honeyman (1897-1987) and the mathematician and historian of science Michel Chasles (1793-1880), alongside bookplates belonging to early modern gentlemen and nobility. Amongst the texts themselves are famed authors often considered to be of specific interest to later collectors, including Euclid, John Dee, and Johannes Kepler.

Whilst every identified type of provenance marker is valuable in its own regard, it is particularly important for the purposes of the current study that precise owners of given texts be located. Although decorated bookplates are largely more identifiable than an individual's signature, my investigation of the Science Museum's collection suggests that a signatory was more likely to annotate (and to use) a text than the individual who pasted an armorial bookplate inside a book's front cover. This pattern, whereby an owner is identified by their bookplate and then subsequently nowhere to be found throughout the rest of the volume, suggests that such users saw their texts as valuable objects with which their personal qualities might be identified and associated: physical examples of their learning and erudition, and often part of an even greater personal library collection constructed in part to achieve the same. This process of valuation may in turn have meant that those owners who adorned their texts with bookplates were less likely to 'spoil' the same text by annotating it. Against these suppositions, we must also note that bookplates can be pasted into volumes fraudulently, with a view to enhancing the value of the material for sale.

Nevertheless, each and every provenance marker identified advances the possibility of pairing a given individual with their purchase or donation, to their own era, and, wherever possible, within their particular socio-cultural milieu.

Furthermore, detailed provenance information can improve the study of annotation and marginalia on text - for example, by clearly identifying a hand at work - thus 
increasing the reach of the current study and its conclusions. The figures produced above, although useful in their own right, tell us only of the provenance markers indicating ownership or collection of texts. The question remains; how many volumes within the Science Museum's holdings present examples of direct usage? To identify this, data validation was again used to separate examples of marginalia into five discrete packets of information (Figure 1.13).

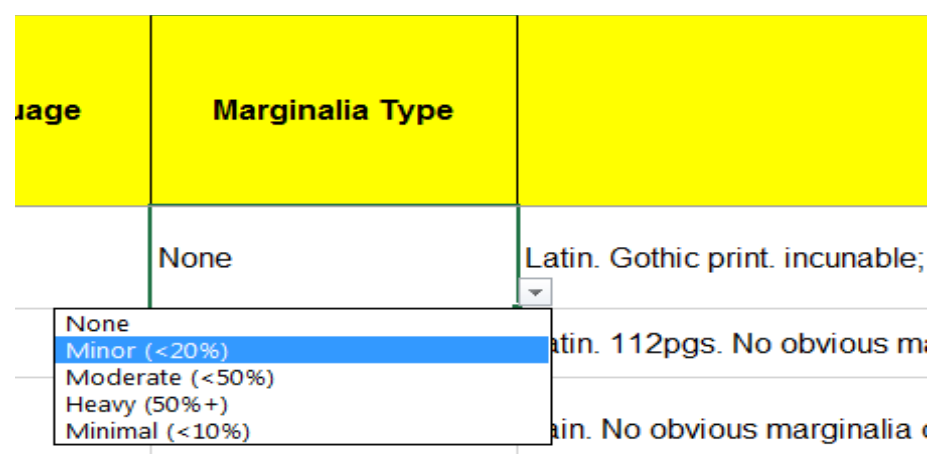

Figure 1.13. Image of [Marginalia Type] data validation from the adapted 'Rare Books - Complete List' spreadsheet.

Unsurprisingly, these results return much lower numbers than the aforementioned provenance markers. As Figure 1.14 shows, $80.9 \%(1334$ of 1,648) titles display no evidence whatsoever of annotation or marginalia. Whilst this is not the sole marker for 'use' of a text, such a figure is naturally disheartening. Nevertheless, $19 \%$ (313 of 1,648$)$ of texts displaying proof of use is a figure not to be sniffed at, particularly across a large collection. Furthermore, this figure may be reasonably compared to at least one similar study: in his investigation of the socalled Short-Title Catalogue (STC) collection held at the Huntington Library in San Marino, California, William H. Sherman reported that just over one fifth of all texts sampled - more than 7,500 volumes, dating between 1475 and 1640 - displayed some form of ownership inscription or annotation. ${ }^{48}$

${ }^{48}$ Sherman, Used Books, p. 5. 


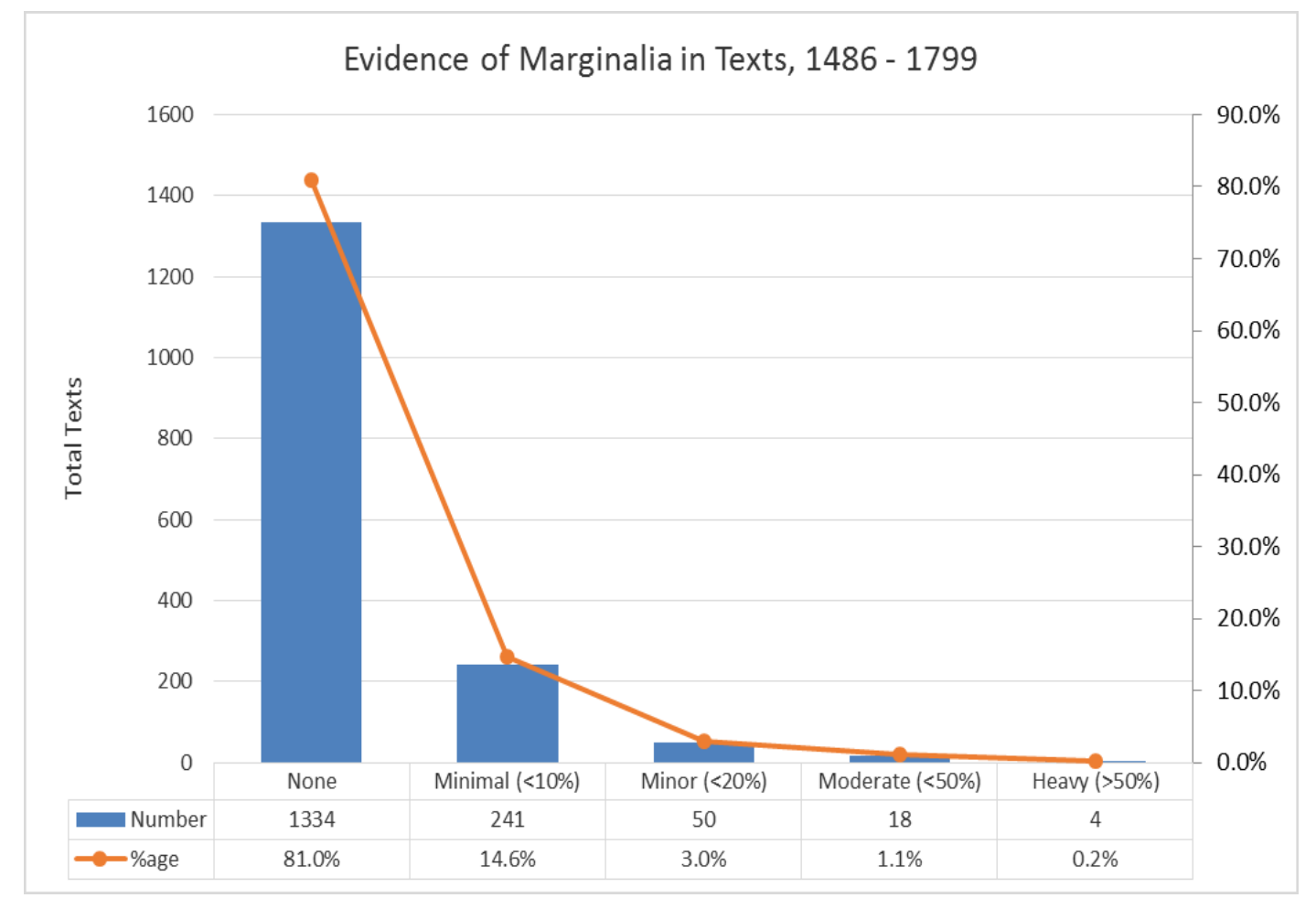

Figure 1.14. Combined line / bar diagram displaying total number and percentage of marginalia found in titles printed, 1486-1799.

This $19 \%$ of texts presenting annotation clusters significantly toward the lesser end of the spectrum. Drilling down into these 313 texts, gross data indicates that $93 \%$ (291 of 313 ) of the titles surveyed possess marginalia identified as belonging to either 'Minimal' or 'Minor' groupings: that is to say, possessing marginalia on less than $20 \%$ of the entire text. Indeed, just how skewed some of this data is can be best represented pictorially (Figure 1.15). Combined with the previously identified provenance markers of inscriptions, bookplates, armorials, and other indicators of ownership, however, these figures are somewhat instructive of practices of ownership and use. The most common evidence of ownership involved a signature: in 56\% (175 of 313) of cases where provenance was identified a signature was present, whilst signatures as the sole evidence of prior ownership account for no less than $40.3 \%$ (126 of 313 ) of examples of provenance uncovered. 


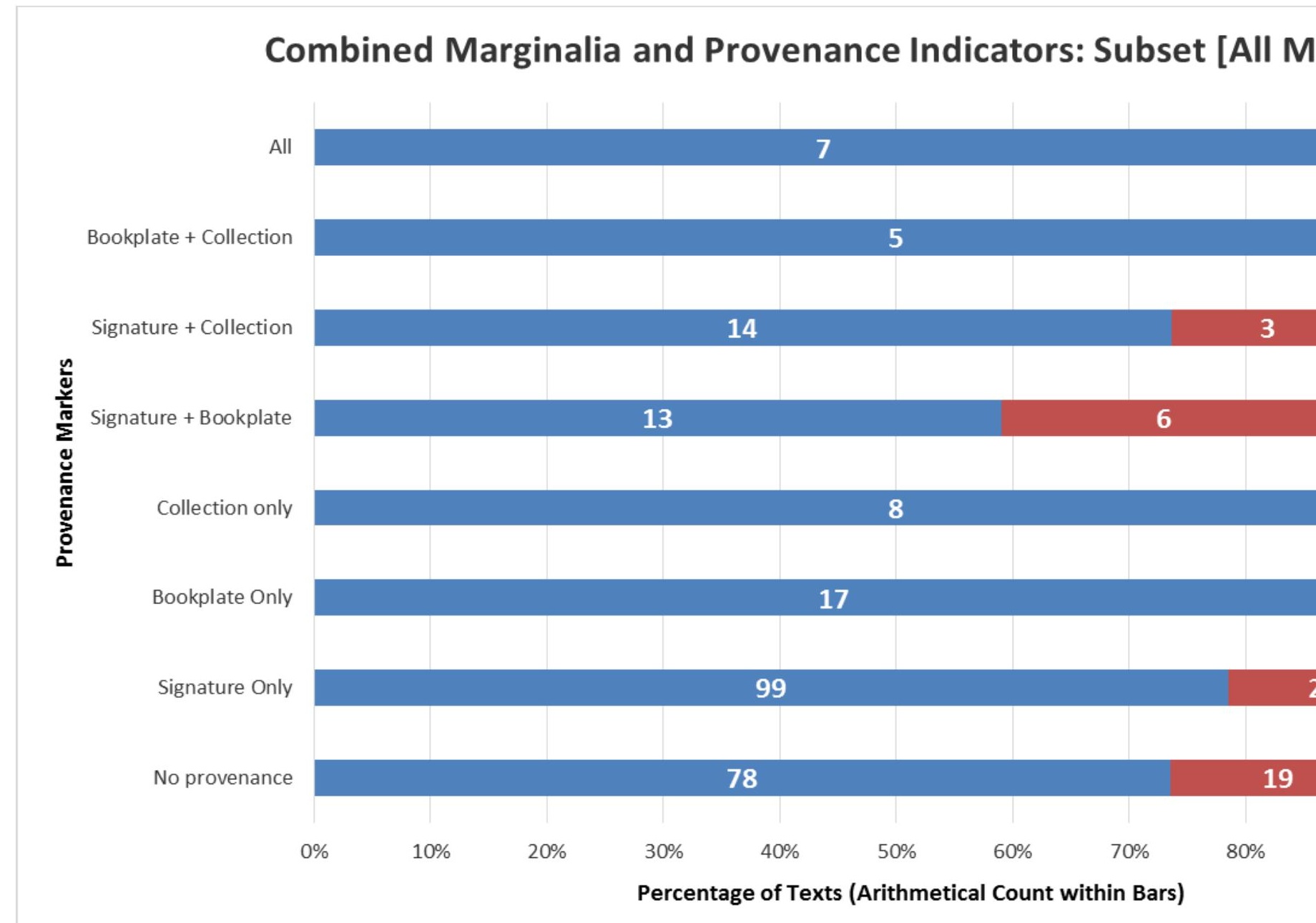

Figure 1.15. Stacked bar chart displaying total distribution of texts with marginalia discovered, 1486-1799. 
On the face of things, the suggestion that individuals who signed their texts appear statistically more likely to mark them in other ways is hardly groundbreaking. But the superficiality of this conclusion should not belie its relevance to our identification of communities of users and their individual proclivities, and two further points can be made to strengthen this point. First of all, it should be repeated - as the data from this analytic survey has shown already - that the majority of users in both the early modern and modern periods chose not to mark their texts in any meaningful way, or even at all. The appearance of any inscription that aids our identification of a user is therefore of value: each pen mark, scribble or nota bene deserves some sort of classification if we are to gain the fullest picture possible of the manifold interactions enjoyed between text and user.

Furthermore, the separation of different types of owner may yet reveal more about practices of reading, annotation, and collection in different historical periods. Extracting the hands of multiple annotators from signatures, bookplates, and armorial stamps is necessarily painstaking and often fruitless work. However, evidence of the values that past owners attached to specific genres of texts is liable to be found only in the material remnants of the works themselves, and in the tools of analytical bibliography. Contributions to the public identification of users and their practices through techniques utilised by digital humanities projects - whether in online provenance projects, or crowd-sourced efforts in transcription, for example or through more traditional scholarship are to be welcomed, and may prove reciprocally advantageous. Whilst high numbers of texts within this subset fall into either 'No Provenance' or 'Signature' markers, it is not the case that, when signatures and annotations are both present, the identity of signature and the annotating hand are always the same. Equally, instances where provenance information is entirely lacking means that analysis must either focus on other clues (such as, for example, binding styles) or instead turn entirely toward a reading of the content of the marginalia itself.

Further excavation of quantitative data on incidences of marginalia found in this collection, identified by decade grouping and subject, is presented respectively in Table 1.6 and Figure 1.16 below. The rank of most popular disciplines of texts presenting annotation unsurprisingly bear a high degree of similarity to that of the 
most popular disciplines present in the subset as a whole, seen previously in Table 1.2; despite this, the presence of annotations to titles on dialling [SUND] and cosmography [CSMO], as previously discussed, should be noted. When considered alongside annotations in surveying texts, geometrical works, and general mathematical compendia, this evidence suggests that attending to the communal and quotidian practices of scientific and mathematical texts remains key to our understanding of users' practices.

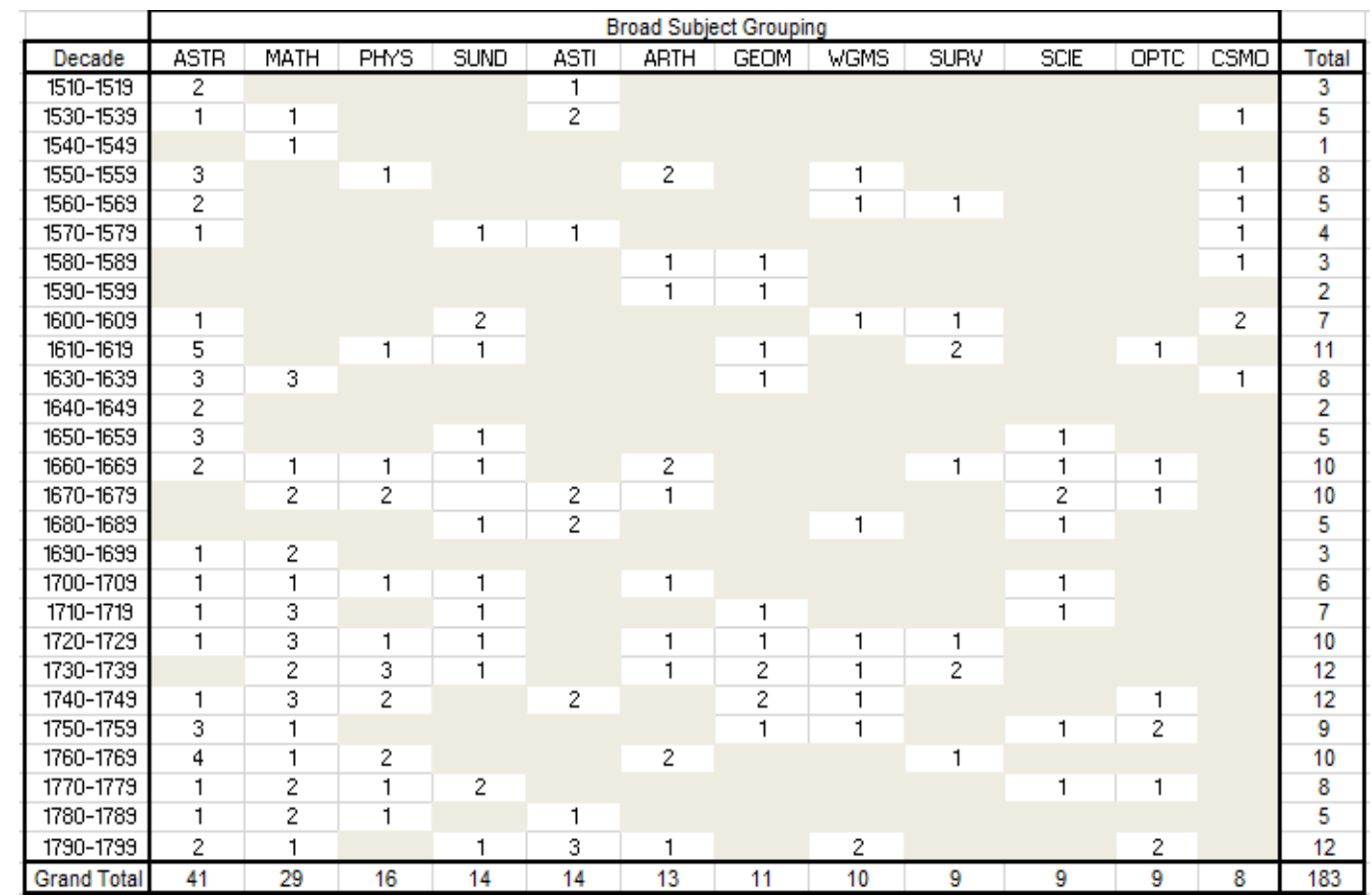

Table 1.6. Frequency of texts annotated by sub-discipline per decade, 15101799.

Finally, the combination of provenance markers and annotation (and, independently, the presence of provenance markers such as bookplates and armorials on their own terms) has much to tell us of the owners of mathematical material in and beyond the early modern period. As we shall see in Chapter Five of the current thesis, tracing how specific texts came to be part of individual and institutional collections helps to highlight their use, acquisition, and rarity, and further serves to characterise the Science Museum's mathematical holdings both en bloc and individually. Understanding these processes adds to our understanding of the history of collection and, ultimately, to the shifting socio-cultural values invested in these material products. 


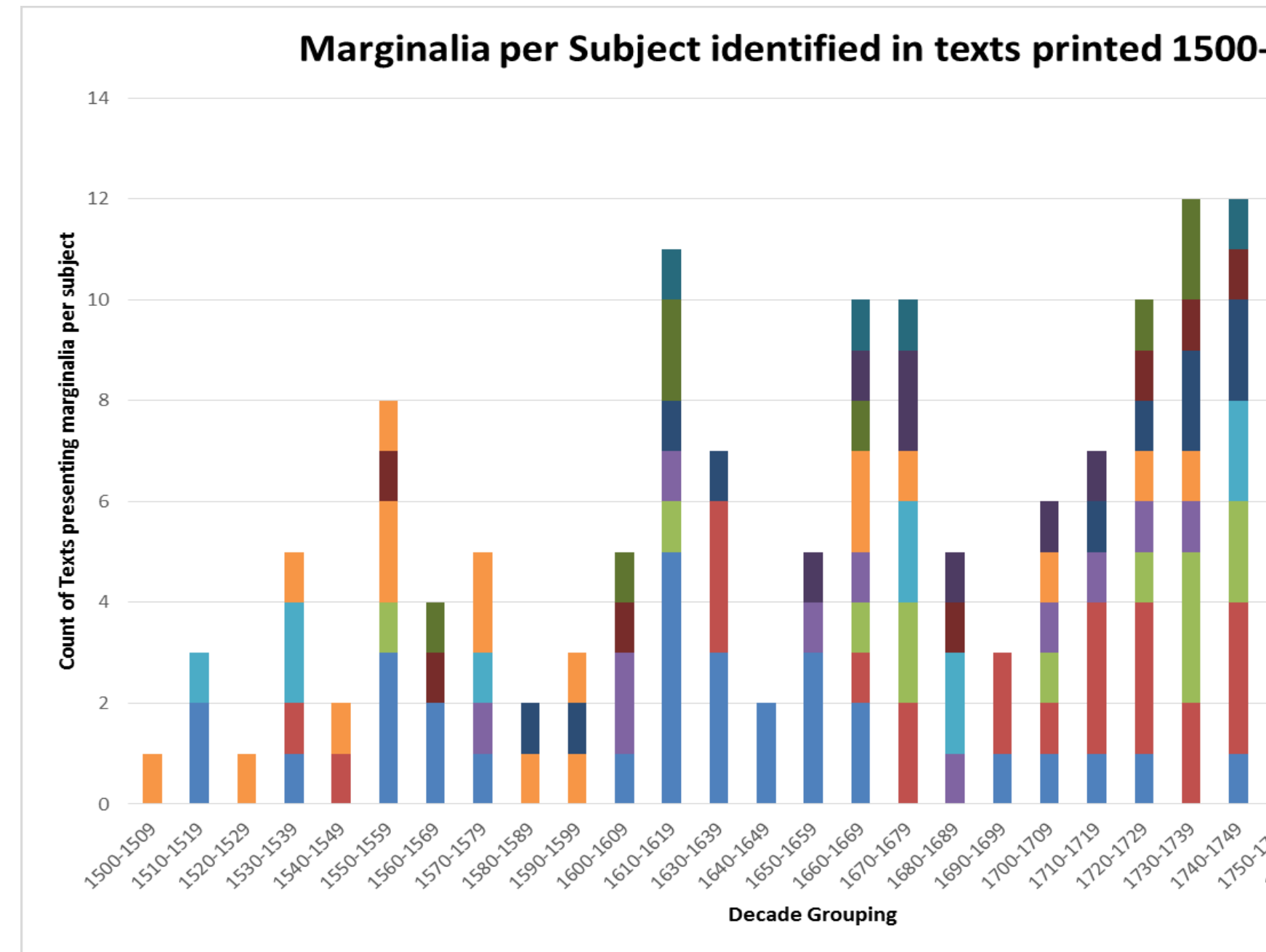

Figure 1.16. Stacked bar chart showing the incidence of annotation by most popular sub-discipline acros: subset by decade, 1480 to 1799 . 


\section{Conclusion}

The educated sixteenth-century purchaser of printed texts was likely to have acquired both literacy and numeracy owing to existing connections to either ecclesiastical, academic or, latterly, urban elites. Although the market for texts would change as the increased availability of literature across the continent engendered a steady drop in prices, the early purchasers of mathematical printed literature would (perhaps obviously) have needed to possess a certain level of literacy and numeracy to make any headway whatsoever with these materials. Intrepid traders set out their stalls in the vicinity of educational institutions, providing newly-established schools with relatively standardised textbooks and expert literature. Outside the university, courtroom, or the church, however, books in the first phase of print culture remained luxury items, professionally unnecessary and financially unaffordable to the majority of people. Beyond commercial mechanisms of distribution, even greater opulence was conferred upon the works presented to would-be patrons, their ornately-bound, decorated, and/or personally dedicated pages offered by the author partly so as to recognise or solicit financing and patronage, partly so as to establish and maintain cordial relations with other scholars.

Presentation copies of books were often enhanced with a special binding or by colouring of any illustrations; dedications, which might be printed in the book or added in manuscript, were widely employed as another way of making a present of a work $^{49}$

The intellectual culture of mathematics underwent a series of distinct changes in the early modern period, aided primarily by the expert appropriation of printing technology. Initially, this appropriation served the goals of a variety of communities including theorists, instrument makers, and educators, many of whom saw printing as a unique opportunity to secure their professional status by improving the social position of their disciplines. The commercialization of intellectual labour was a core part of such practices. Changing trends in demand reflect the changing identities of

\footnotetext{
${ }^{49}$ For one example of the multi-faceted role of books as gifts in one early modern European setting, see Natalie Zemon Davis, 'Beyond the Market: Books as Gifts in Sixteenth-Century France: The Prothero Lecture', Transactions of the Royal Historical Society, 33 (1983), pp. 69-88.
} 
European book consumers between 1486 and 1800, and appetites for mathematical literature are no different.

As the first hypothesis proposed demonstrates, the mathematical subset of the Science Museum's Rare Books Collection currently under study is correlative with the general growth in early modern printed literature. Growth is witnessed across all sub-disciplines present in the collection, and is not limited to more erudite, theoretical works common to higher level education in the period, nor to the textbooks, practical manuals, ready-reckoners and calendrical materials intended for more amateur users. The specific emphasis placed on technological, engineering, and mechanical treatises can be explained by the Science Museum's institutional identity as a collector of the application of scientific principles to a wider progressivist narrative of cultural and intellectual development, particularly across Western Europe, in the period under study. The second hypothesis, which stated that this growth should be represented in the identifiable existence of core European print locations known to produce specifically mathematical literature (of which London began as an outlier and then moved to a position of primacy) in the seventeenth and eighteenth centuries, has been proven with particular reference to production practices in locations including Basel and London itself.

The third and final hypothesis used to test this material considered the breadth of this content, and, as a corollary, its subsequent use and collection. Macroscopic analysis of the mathematical subset highlights a significant number of readers marking their texts in keeping with the data presented in other, larger studies. Though rates of annotation across the period appear to be relatively consistent, and, to some extent, reject large-scale statistical analysis, the fuller analysis of individual works featuring annotations, and their growing presence in the texts of the period, is highlighted in the following chapters of the current thesis. Looking past evidence of annotation, the significant number of provenance markers, including but not limited to binding styles, armorials, and bookplates, helps to bring to light the value more modern owners and collectors saw in owning these works. The properties of the texts, their contents, and later fame can all be witnessed in the collecting practices of both working mathematicians, such as Michel Chasles, and of antiquarian collectors of the history of science like Robert Brodhead Honeyman. 
The Science Museum Library's mathematical holdings can, in summary, be said to be representative of the intellectual culture of which they were a product. As the data presented in this chapter clearly indicates, such holdings, ranging across sub-disciplines, locations, languages and uses, represent an accumulation of notable value to the study of the use and collection of mathematical literature in the early modern period. The product of multiple collectors both individual and institutional, they are also ripe with evidence of the later acquisition of such materials, and as a result have much to tell us of the valuation of mathematics in both the early modern and modern eras. 
Chapter Two: Reading mathematics in sixteenth-century Germany: The 'Wittenberg Sammelband' as an instrument of knowing ${ }^{1}$

In 1583, the precocious Dane Thomas Fincke (1561-1656) announced his mathematical ability at a mere twenty-two years old with the publication of Geometriae rotundi libri XIIII. Comprised of 14 chapters, this textbook guided readers through a novel presentation of spherical geometry, moving from the form of the circle and sphere, to the relationships between their radii, diameters, and sines, before fully explicating the 'law of tangents' later developed algebraically by François Viète. ${ }^{2}$ Twelve years before Bartholomaeus Pitiscus (1561-1613) presented a new name for the study in Trigonometria (1595), Fincke introduced the words 'tangent' and 'secant' to the study of triangles, offering a new means of conceptualising trigonometric functions. Having drawn extensively upon the works of Regiomontanus and Ptolemy, the author advised studious readers to follow his lead by profiting from the lessons of the German mathematician in particular. ${ }^{3}$

Acknowledging his debt to Regiomontanus amidst a clutch of mathematical authorities old and new, Thomas Fincke identified himself as part of a rich lineage of practitioners motivated by the revival and improvement of classical mathematics. ${ }^{4}$ Yet it should be noted that the Dane also took his authorial lead from the period's most important pedagogical reformers. A pupil of the Strasbourg Academy of

\footnotetext{
${ }^{1}$ This phrase is taken from Walter J. Ong, quoting Johann Heinrich Alsted's 1609 dictum from Clavis artis Lulliane, 'Ergo dialectica est ars tradens modum sciendi et per consequens docens instrumentum sciendi'. Ong argued that Alsted's assimilation of the methods of Aristotle, Ramon Lull, and Petrus Ramus marked something of a victory for the Ramist art of pedagogy in particular. Walter J. Ong, Ramus, Method, and the Decay of Dialogue: From the Art of Discourse to the Art of Reason, $2^{\text {nd }}$ edn (Chicago and London: University of Chicago, 2004; originally Cambridge, MA: Harvard University Press, 1958), p. 160.

${ }^{2}$ For a summary of the mathematical relationship between Viète's and Fincke's trigonometry, see Enrique A. Gonzalez-Velasco, Journey through Mathematics: Creative Episodes in Its History (New York: Springer Science + Business Media, 2011), particularly pp. 74-76. For the key sections in Fincke's work, see Thomas Fincke, Thomae Finkii Flenspurgensis Geometriae rotundi libri XIIII (Basel: Sebastian Henric-Petri, 1583), particularly pp. 73-76.

${ }^{3}$ Fincke, Geometriae rotundi, p. 295: 'Regiomontanus aliquot casus in secondo libro de triangulis collegit (...) Cujus certe libri à studiosus avidè legi debent; \& cum fructu legi possunt.'

${ }^{4}$ For Regiomontanus's famed 'Padua Oration' of 1464, see Regiomontanus, 'Oratio Iohannis de Monteregio, habita in Patavii in praelectione Alfragani' in Opera collectanea, ed. Felix Schmeidler (O. Zeller: Osnabruk, 1972), pp. 43-53. Regiomontanus's oration has been situated both in the humanist educational culture of the fifteenth-century and within a wider historiography of mathematics from a mathematician's perspective; see James Steven Byrne, 'A Humanist History of Mathematics? Regiomontanus's Padua Oration in Context', Journal of the History of Ideas, 67 (2006), pp. 41-61.
} 
Johannes Sturm (1507-1589), and heavily influenced by the works of Petrus Ramus (Pierre de la Ramée, 1515-1572), Fincke ensured that his own textbook bore many of the hallmarks of Northern European humanism in which he had been schooled: one that had radiated outwards from the Wittenberg of Philip Melanchthon (1497-1560). ${ }^{5}$

Amid ecclesiastical and educational reform and counter-reform, further pedagogical territory was yet to be won. With this goal in mind, Thomas Fincke therefore made Petrus Ramus's methodical presentation of mathematical theory central to Geometria rotundi. Combining the lessons of a nomadic education undertaken in Strasbourg, Wittenberg, and elsewhere with Petrus Ramus's dialectical method, Fincke sought to promulgate a new model for mathematical pedagogy. 'Disturbed' by the Euclidean presentation of geometry, ${ }^{6}$ the author sought to recover his discipline's classical foundations in part by expunging the supposedly artificial and abstruse syllogistic structures that Euclid had erected. Geometriae rotundi was thus designed to help new generations of mathematical readers break free from theorems and from deductive reasoning as demonstrated by the Elements, presenting instead Ramist dichotomies of definition and proposition as a means to more effectively (and expeditiously) teach spherical geometry.

The copy of Geometriae rotundi held in the Science Museum Library's Rare Books Collection reflects these goals, as well as the relationship shared by Ramus and Fincke's texts. ${ }^{7}$ As part of a unique early modern artefact, Geometriae rotundi is one of three printed quartos bound up in what I have termed the 'Wittenberg Sammelband', named for the University linking the authors, teachers, and students found within its pages. Three-quarter bound in intricately tooled vellum on painted wooden boards with 'M K G - 1586' stamped on its front cover, the volume comprises Petrus Ramus's Arithmeticae libri duo, Geometriae septem et viginti libri

\footnotetext{
${ }^{5}$ Peter Mack, A History of Renaissance Rhetoric, 1380-1620 (Oxford: Oxford University Press, 2011), p. 104.

${ }^{6}$ Fincke, 'Praefatio ad Lectorem', Geometriae rotundi, f. 1 v: 'methodum vero in ubertate tanta nullam, aut vix ullam videre potui Quam id me perturbarit'.

${ }^{7}$ The volume is comprised of the following titles: Petrus Ramus, P. Rami Arithmeticae libri duo: Geometriae septem et viginti (Basel: haer. Nikolaus II Episcopius, 1580) Science Museum Library Shelfmark O. B. RAM RAMUS 30209019362784; Thomas Fincke, Thomae Finkii Flenspurgensis Geometriae rotundi libri XIIII (Basel: Sebastian Henric-Petri, 1583), Science Museum Library Shelfmark O. B. RAM RAMUS 30209019362777; John Peckham, Perspectivae communis libri tres (Cologne: Arnold Birckmann, 1580), Science Museum Library Shelfmark O. B. RAM RAMUS 30209019362791. This copy is hereafter referred to as Wittenberg Sammelband, with individual texts referenced according to their shelfmark.
} 
(1580), Fincke's aforementioned Geometriae rotundi (1583) and a contemporary edition of John Peckham's optical text Perspectiva communis libri tres (1580), printed in Cologne.
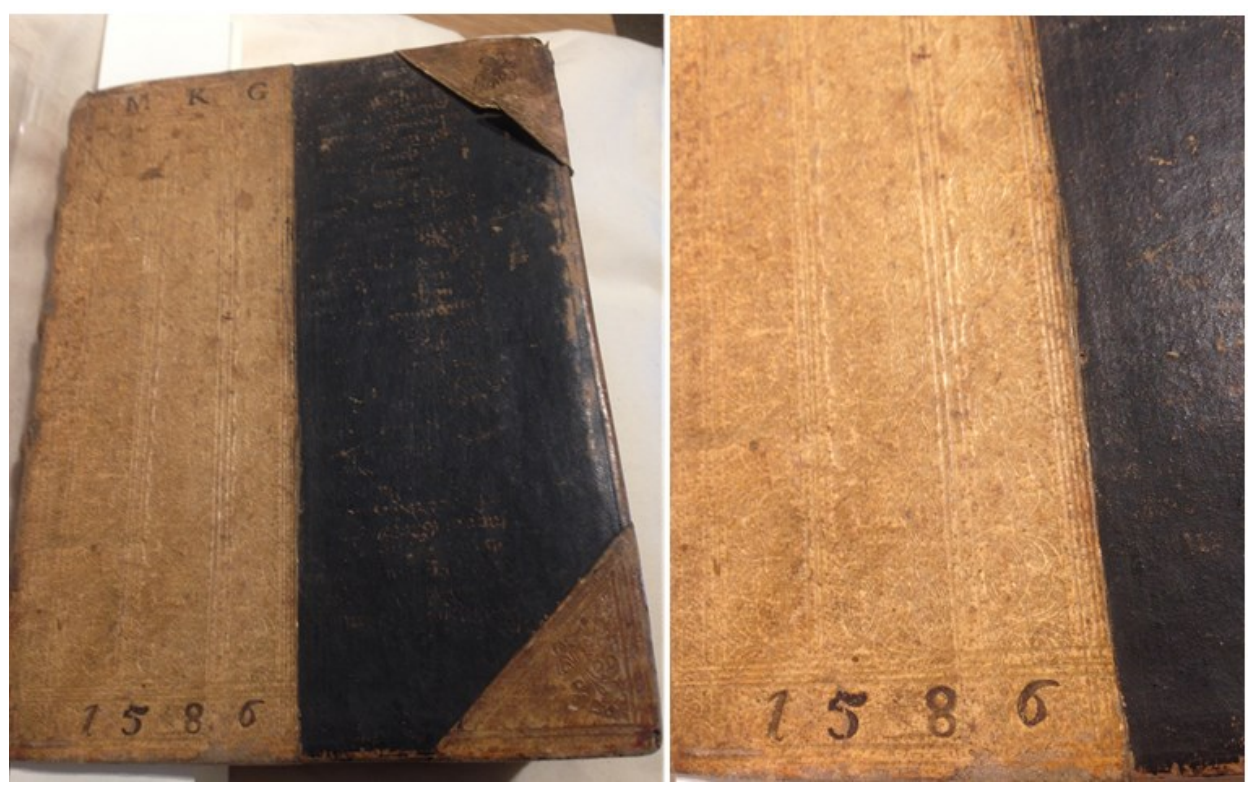

Figure 2.1. Composite image of the outer binding of the Wittenberg Sammelband, containing Petrus Ramus' Arithmeticae libri duo: Geometriae septem et viginti (1580), Thomas Fincke's Geometriae rotundi libri XIIII (1583), and a 1580 reprint of John Peckham's Perspectiva communis libri tres. Science Museum Library Shelfmark O. B. RAM RAMUS 30209019362784.

Following these printed works is a contemporary manuscript summary entitled De Logistice Astronomica seu sexagenaria. Written as a series of axioms covering the importance of sexagesimal arithmetic to the study of astronomy, these papers appear to have been lecture notes cribbed from sources such as Caspar Peucer's Logistice Astronomica Hexacontadon et Scrupulorum Sexagesimorum (1556), Edo Hildericus von Varel's Logistice Astronomica (1568), and Lazarus Schöner's De Logistice sexagenaria liber (1569), the first two of whom were Wittenberg professors. Perhaps the most closely related of these sexagesimal texts to the end notes of the Wittenberg Sammelband is that of Lazarus Schöner, the Nuremberg mathematician and Wittenberg alumni who edited and further popularised Ramus's mathematical works. ${ }^{8}$ Schöner emphasised the value of the

\footnotetext{
${ }^{8}$ Schöner's De Logistice sexagenaria liber of 1569 was re-issued as part of the author's edited version of Petrus Ramus' Petri Rami Arithmetices Libri Duo, et Algebrae totidem (1586). The notes on sexagesimal astronomy appended to the Wittenberg Sammelband bear a relatively high degree of
} 
French author's pedagogical method from a position of authority: initially as a teacher in the gymnasia of Schmalkalden and Marburg, and then as Rector of the Korbach grammar school. His promotion of Ramist mathematics from within such educational institutions tallies with recent identifications of early modern Germany as a crucial hothouse of Ramism more generally. ${ }^{9}$

The Renaissance teaching of 'mathematics for astronomy' of the midfifteenth century has been characterized by reference to a quadripartite hierarchy, consisting of the use of fractiones physicae, or sexagesimal positional fractions; the arithmetic of large numbers; theories of proportions as applied to plane and spherical trigonometry, and to fractions; and a particular interest in trigonometric canons and tables of sines. ${ }^{10}$ Studies of Wittenberg textbooks have demonstrated that materials authored by university professors were bound together with those on related subjects, and that the mathematical teachings of these professors on topics such as Copernican heliocentrism could treat both rudimentary and complex mathematics without engaging in cosmological controversy. ${ }^{11}$ As a consequence, the Sammelband's combinations of introductory and more complex mathematics, coupled with Thomas Fincke's spherical trigonometry and canons, and manuscript materials on sexagesimal astronomy, appear to be entirely in keeping with the mathematical curriculum as experienced at the University of Wittenberg.

similarity to De Logistice sexagenaria liber; given that Schöner's work was re-issued in the same year in which the Sammelband was bound, I believe that the notes on sexagesimal astronomy are an owner's inexact paraphrase predominantly of Schöner's work and of other sources. See Lazarus Schöner, De Logistice sexagenaria liber, in Petrus Ramus, Petri Rami Arithmetices libri duo, et Algebrae totidem (Frankfurt: Andreae Wechelus, 1586), pp. 364-406.

${ }^{9}$ Alastair Hamilton, William Bedwell the Arabist, 1563-1632 (Leiden: Published for the Sir Thomas Browne Institute by E. J. Brill and The University of Leiden Press, 1985), p. 61. Howard Hotson, Commonplace Learning: Ramism and its German Ramifications, 1543-1630 (Oxford: Oxford University Press, 2007).

${ }^{10}$ Grazyna Rosínska, "Mathematics for Astronomy” at Universities in Copernicus' Time: Modern Attitudes toward Ancient Problems', in Mordechai Feingold and Victor Navarro-Brotons, eds., Universities and Science in the Early Modern Period (Dordrecht: Springer, 2006), pp. 9-28, p. 11.

${ }^{11}$ Pietro Daniel Omodeo, Copernicus in the Cultural Debates of the Renaissance: Reception, Legacy, Transformation (Leiden and Boston: Brill, 2014), p. 68; Stefan Kirschner and Andreas Kühne, 'The Decline of Medieval Disputation Culture and the 'Wittenberg Interpretation' of the Copernican Theory', in Wolfgang Neuber, Thomas Rahn and Claude Zittel, eds., The Making of Copernicus: Early Transformations of the Scientist and his Science (Leiden and Boston: Brill, 2015), pp. 13-41, p. 16. For a discussion of the methodological outlook shared among astronomers at the University of Wittenberg in the sixteenth century and the impact of this outlook on the transmission of Copernican theory, see Westman, 'The Melanchthon Circle'. 
As I have alluded to in the previous paragraphs, I have chosen to term the volume as the 'Wittenberg Sammelband' for the associations shared between the University and between its authors and readers. Although evidence found within the Sammelband demonstrates that its first owners and users were located in Leipzig rather than Wittenberg, I believe that the volume was constructed to serve the needs of students who intended to attend the university or similar institutions. For Petrus Ramus, Wittenberg, thanks to the erudite leadership of Philip Melanchthon, was the jewel in the crown of German mathematics. ${ }^{12}$ His autodidactic reader, Thomas Fincke, author of the second of the texts found in the volume, followed both his father and uncle in attending the august institution prior to returning to Flensburg to write Geometriae rotundi in $1583 .{ }^{13}$ The topics of the texts match the early modern curriculum as undertaken at the university, and it appears that the annotator who constructed the volume's notes on sexagesimal notation was aware of the works of figures affiliated to Wittenberg such as Peucer, Hildericus, and Schöner. Finally, as we shall see, there is clear evidence of the volume being utilised (and, in all likelihood, shared) by students who attended the University of Wittenberg in the early 1590s.

To all intents and purposes, then, the print and manuscript contents collated in the Sammelband made for an enlarged type of textbook. Its printed works were ordered by their increasing complexity, and by the progress students might be expected to make as they ascended the quadrivium: moving from arithmetic, to geometry, to astronomy. As the current chapter will go on to argue, each of these materials might have been put to use by readers at prefatory gymnasia, scholae triviales and at university. Study of these readers reveals something of how the volume's material form was constructed and adapted by individual users who sought to make use of new developments in early modern pedagogical and mathematical culture. Furthermore, the Sammelband displays one complex though coherent form of the 'active' making and reading of mathematics: one whereby the rhetorical and

\footnotetext{
${ }^{12}$ For a helpful summary of Ramus's admiration of Wittenberg (and German mathematics more generally), see Westman, The Copernican Question, pp. 168-170

${ }_{13}$ Jürgen Schönbeck, 'Thomas Fincke und die Geometriae rotundi' NTM Zeitschrift für Geschichte der Wissenschaften, Technik und Medizin, 12.2 (2004), pp. 80-89, p. 82 and p. 83.
} 
methodological presentation of mathematical sub-disciplines, rather than any notable theoretical ability on the part of students or masters, took priority.

The spread of the philosophical and pedagogical movement known today as 'Ramism' is most commonly seen through the lens of Walter J. Ong's seminal works on the French educator. Even when criticised, this interpretation of Petrus Ramus continues to provide the backdrop against which many scholars have operated. One outcome of this dominance is that the depiction of Ramus as possessive of a unique understanding of early modern information transmission - and of the swing from an oral to a visual culture of learning - obscures almost entirely the less-expert readers of his texts. Scant attention has thus been paid to Ramus's audience and their role in the spread of his thought, with only rare, if valuable, exceptions. ${ }^{14}$

In this chapter, I propose to show how readers read, understood, and replicated Ramist pedagogy with specific relation to the introductory mathematical disciplines of arithmetic and geometry. By taking Thomas Fincke and his Geometriae rotundi as a point of departure, I aim to situate the author first as a student himself, then as a mathematician, and finally as a pedagogical reformer influenced by Petrus Ramus. A product of the Strasbourg gymnasium which so influenced Ramus, Fincke also, via his time in Wittenberg, belonged to the German school of mathematics the French pedagogue had previously celebrated. Yet the precocious Dane had been so taken with his autodidactic reading of Ramus's introductory works that he strove to utilise his education and erudition to reformulate Euclidean gemoetry for the benefit of future students. Ramus's method of mathematical presentation provided Fincke with the tools to unseat Euclid and make his own fame at the same time. By exploring the interplay between Ramus, Fincke, and a second layer of readers - the owners and annotators of the Sammelband which contained the works of both authors - Ramist methods for early modern mathematical teaching and learning are more clearly illuminated. Furthermore, analysis of these later readers explores the processes of textual transmission,

\footnotetext{
${ }^{14}$ See particularly Hotson, Commonplace Learning; also James Veazie Skalnik, Ramus and Reform: University and Church at the End of the Renaissance (Kirksville, MO: Truman State University, 2002).
} 
collection, and preservation central to the Wittenberg Sammelband's use in the late sixteenth-century and beyond.

\section{Book use, book theory, and the Wittenberg Sammelband}

As collections of discrete, often independently produced printed texts and/or manuscript works bound together, early modern sammelbände are significant for our understanding of the modes of reading in the early modern period. ${ }^{15}$ Literary scholars and historians of the book alike have been exercised by evidence of collection, collation, and use found in sammelbände comprised of early modern devotional literature, plays and poetry, and political pamphlets; in a similar fashion, analysis of collated mathematical and scientific works informs our understanding of their intellectual and material cultures. ${ }^{16}$ Leaving to one side their specific contents, sammelbände can offer us insight into the idiosyncratic ways individuals saw their reading materials, revealing much of how sellers and consumers perceived, organized and consumed similar texts. They help us situate the early modern readeruser in direct relation to their books, and to situate the contents of those volumes alongside each other, thematically as well as in terms of utility, economy, and geography.

Historians of reading and historians of the book are today increasingly cognizant of the material choices on offer to the early modern book-buyer, and a growing body of evidence points toward the personalization available to such consumers. Early modern printed books survive as remnants of entirely different modes of production than those that generated their modern counterparts. These texts were not always bound prior to sale, and many surviving examples display how owners were given the opportunity to select particular styles of binding for themselves. Consequently, binding preferences - the choice of material, its

\footnotetext{
${ }^{15}$ Peter Beal, A Dictionary of English Manuscript Terminology, 1450-2000 (Oxford: Oxford University Press, 2008), p. 356.

${ }^{16}$ For literary histories of early modern sammelbände, see Gudya Armstrong, 'Print, Paratext and a Seventeenth Century Sammelband: Boccaccio's Ninfale Fiesolano in English Translation’ in Sara K. Barker and Brenda M. Hosington, eds., Renaissance Cultural Crossroads: Translation, Print and Culture in Britain, 1473-1640, (Leiden and Boston: Brill, 2013), pp. 79-99; and, particularly, Seth Lerer, 'Medieval Literature and Early Modern Readers: Cambridge University Library Sel.5.515.63', Papers of the Bibliographical Society of America, 97.3 (2003), pp. 311-332.
} 
decoration, the gilt or dye applied to a finished product, or the addition of stamped heraldry - can all fruitfully be used as evidence to situate a text as belonging to a given person or family, as well as to a given century, decade, or even year. ${ }^{17}$

Owners commissioned individually-tailored bindings illustrative of their status as well as their personal taste, and repeated examples of a distinct binding style can perhaps suggest a desire for uniformity applied to a personal library or collection. Many book-buyers were content to purchase texts bound in the predominant style of the time, in serviceable, undecorated calf leather; equally, many were happy to acquire texts bound in the manner judged best by book-sellers. In some cases, multiple texts came to be bound together according to a complementary interest in their contents as perceived by the book-seller, or as demanded by the purchaser.

Often constrained by the limitations of their purse and by what local craftsmen could offer, the material properties of historical book-bindings showcase that early modern consumers exercised choice in their selection from the wide variety of bindings available to them: choices which varied according to location, supply and demand, price-point, and prevailing trends. The bound volume as final product was therefore an expression of the economic and personal values consumers invested in these choices, and in their books more generally. The physical evidence of these evaluative processes contributes further to our understanding of the methods of book production and sale at work in given locations, the social making of tastes, and the purchasing power of early modern consumers. ${ }^{18}$

At the same time, it has become equally apparent that the physical violence visited upon books as material objects has obscured and rendered problematic histories of the ways in which early modern texts were produced, organized, read,

\footnotetext{
${ }^{17}$ Pearson, Provenance Research in Book History, p. 128; Nicholas Pickwoad, 'Onward and Downward: How Binders Coped with the Printing Press Before 1800' in Robin Myers and Michael Harris, eds., A Millennium of the Book: Production, Design \& Illustration in Manuscript \& Print 900 1900 (Winchester and Delaware: St. Paul's Bibliographies and Oak Knoll Press, 1994), pp. 61-106, p. 63.

${ }^{18}$ Kathleen Lynch, 'Devotion Bound: A Social History of The Temple', in Jennifer Andersen and Elizabeth Sauer, eds., Books and Readers in Early Modern England: Material Studies (Philadelphia: University of Pennsylvania Press, 2002), pp. 177-198; Graham Pollard, 'Changes in the Style of Bookbinding, 1550-1830', The Library, $5^{\text {th }}$ series, 11 (1956), pp. 71-94.
} 
and retained, by sellers and buyers alike. Participants in the rare book and incunabula trades have been guilty of unbinding, rebinding, cutting, pasting, aggressively cleaning, and, generally, decontextualizing the artefacts of early modern reading. ${ }^{19} \mathrm{~A}$ lamentable by-product of such practices has been to obscure evidence of the agency of both producers and readers at work in the making of their texts; often, to the point of complete erasure. The urge that grasped the collectors of the nineteenth century, in particular - an organizational impulse favouring discrete and uniform texts, and leading away from untidy or unclassifiable mongrel volumes - often denies today's researcher the opportunity to explore the texts joined together in multiple, unique, and ultimately personal combinations. ${ }^{20}$ For the early modern owner, bindings were more akin to book-seller's suggestions than to the fixed object of the modern book. Understood as objects to be reconfigured as was seen fit, bindings, in Jeffrey Todd Knight's apothegm, were much less binding than they are today. ${ }^{21}$

The relevance of such factors to our understanding of the demand for mathematical products in the early modern period is demonstrated by idiosyncratic artefacts like the Wittenberg Sammelband. Studies that combine Genettian ideas of print and paratext, ${ }^{22}$ the book as a material object, and readers' agency in the construction and use of their volumes, are few - perhaps with some justification. ${ }^{23}$ Nonetheless, paratextuality is of specific relevance in considering how texts, as material objects, carried their contents into new cultural sites and arenas. Such

\footnotetext{
${ }^{19}$ Monique Hulvey, 'Not so Marginal: Manuscript Annotations in the Folger Incunabula', The Papers of the Bibliographical Society of America, 92.2 (1998), pp. 159-176, p. 161; H. J. Jackson, Marginalia: Readers Writing in Books (New Haven and London: Yale University Press, 2001); William H. Sherman, 'Soiled by use' or 'enlivened by association'? Attitudes toward marginalia' in Rosalind Edwards, John Goodwin, Henrietta O'Connor, and Ann Phoenix, eds., Working with Paradata, Marginalia, and Field Notes: The Centrality of By-Products of Social Research (Cheltenham and Northampton, MA: Edward Elgar Publishing, 2017), pp. 134-153.

${ }^{20}$ See, for example, Thomas Frognall Dibdin, Bibliomania: Or Book-madness, $2^{\text {nd }}$ edn (London: Henry G. Bohn, 1832), p. 136. On eighteenth and early nineteenth-century vogues for 'bibliomania', see James Raven, 'Debating Bibliomania and the Collection of Books in the Eighteenth Century', Library \& Information History, 29.3 (2013), pp. 196-209, and Edward Potten, 'Beyond Bibliophilia: Contextualizing Private Libraries in the Nineteenth Century', Library \& Information History, 31.2 (2015), pp. 73-94.

${ }^{21}$ Jeffrey Todd Knight, 'Fast Bind, Fast Find: The History of the Book and the Modern Collection', Criticism, 51.1 (2009), pp. 79-104, p. 83.

${ }^{22}$ Gérard Genette, Paratexts: Thresholds of Interpretation, trans. Jane E. Lewin (Cambridge: Cambridge University Press, 1997; originally published in French as Seuils, Paris: Editions de Seuils, 1987).

${ }^{23}$ One notable exception to this is Helen Smith and Louise Wilson, eds., Renaissance Paratexts (Cambridge: Cambridge University Press, 2011).
} 
theoretical studies of the making of material objects help us to understand the reflexive remaking of intellectual cultures in which authors, readers and users participated and this can be further illustrated by two concepts central to Genette's idea of paratextuality.

Firstly, the peritext: the materials located within the physical volume of the book itself, its title page, dedicatory epistles, style of printing, and footnotes, for example. Secondly, the epitext: 'distanced elements (...) messages that, at least originally, are located outside the book'. ${ }^{24}$ Genette offers a number of possible examples of external epitextual communication, including public advertisements, prospectuses, catalogues, and articles, ${ }^{25}$ as well as an example of 'embedded enunciating: the situation for all notes that include quotations (third party cited by author) or for critical notes mentioning, for example, an epitextual authorial commentary (author cited by third party) ${ }^{\prime} ;{ }^{26}$ to these examples, we might add the authentication of use in educational arenas. Each of these elements was subsequently interpreted (and, to various degrees, deliberately remade) by the volume's owners and users: highlighted, amended, corrected, with manuscript notes appended, their printed texts and paratexts reorganised by multiple variations of print, paratext, and palimpsestic annotations and over-writings so as to be entirely changed from that 'ideal' copy initially constructed .Yet even though these works were refashioned by use and collection, the same body texts lie beneath the palimpsests of underline and strikethrough, of correction and amendment.

Hence the cross-pollinated texts of the Wittenberg Sammelband, replete with printed and marginal notes, colophons, dedicatory epistles and references to external texts now bound up internally in the same volume, provide ample evidence of the remarkable and multifaceted functionality of early modern peritexts and epitexts. Clearly, the paratextual practices enacted by early modern producers and readers altered how they engaged with already 'reformatted' texts. Indeed, such volumes go beyond the agency exhibited simply by personalized collection, and by conjoining discrete texts, early modern sellers and users created unique compendia of information to suit a perceived need. As the declarations of friendship and the

${ }^{24}$ Genette, Paratexts, p. 5.

${ }^{25}$ Genette, ibid, p. 38.

${ }^{26}$ Genette, ibid, p. 323. 
autographs inscribed in the front leaves of the Wittenberg Sammelband help show, printed materials were circulated amongst fellow-users, with traces of utility inscribed in provenance and marginal annotations left behind. Such markings help to bring to light overlapping networks of education, commerce, friendship, and influence.

\section{The Wittenberg Sammelband: provenance and construction}

Given the inclusion of Thomas Fincke's Geometriae rotundi, the Wittenberg Sammelband could not have been bound before late 1583 . The physical appearance of its contents would instead suggest that it was collated and bound in 1586 (as its cover stamping indicates) and that the quartos comprising the finished product enjoyed only minimal circulation, if any, prior to this date. Each text has retained its title page and colophon, and no leaves have been found to be wanting from any individual work. The pages are consistently trimmed, with the exception of the manuscript leaves, all of which are slightly larger than those of the printed text. This minor difference notwithstanding, there is little to suggest that De Logistice astronomica seu sexagenaria was not included with the other texts as part of the volume's 1586 binding. Tellingly, the fore-edges of its final leaves feature the same blue-green paint washing as the printed works. Distinguished by its ornate threequarter vellum binding, the Wittenberg Sammelband may have been produced with a tutor or lecturer in mind; it is equally possible that the volume was designed as a gift. When compared with like examples from late sixteenth-century Northern Europe, particularly those of Basel, it is clear that this volume, with its ornate, panel-stamped vellum coverings and decorated fore-edges, was an object upon which time, money, and effort had all been spent. ${ }^{27}$

Bearing this evidence in mind, the ' $\mathrm{M} \mathrm{K} \mathrm{G}$ ' stamped to the vellum binding of the Sammelband is likely to be the identifying mark of a bookbinder rather than that of an owner. Though rare, similar stamps have been discovered on books bound in

\footnotetext{
${ }^{27}$ Edith Diehl, Bookbinding: Its Background and Technique, Volume 1 (New York: Dover, 1980) (originally New York: Rinehart and Co., 1946), p. 132; Janet E. Scinto, 'The Panel Stamp in Early and Modern Bindings', Library Quarterly: Information, Community, Policy, 85 (2015), pp. 106-111, particularly p. 107. Earlier evidence of panel stamped bindings surrounding texts printed in Basel is discussed in Ernst Kyriss, 'Parisian Panel Stamps between 1480 and 1530', Studies in Bibliography, 7 (1955), pp. 113-124, particularly p. 116 and p. 123.
} 
Germany and Northern Europe in this period. ${ }^{28}$ We can place the volume with some precision in Leipzig between 1587 and 1590, in the hands of Nicholas Hommer (Nicolaus Hommero) of Copenhagen. Hommer signed and dated the front pastedown of the volume ' 17 November, 1587', locating himself in Leipzig in the process (Figure 2.2).

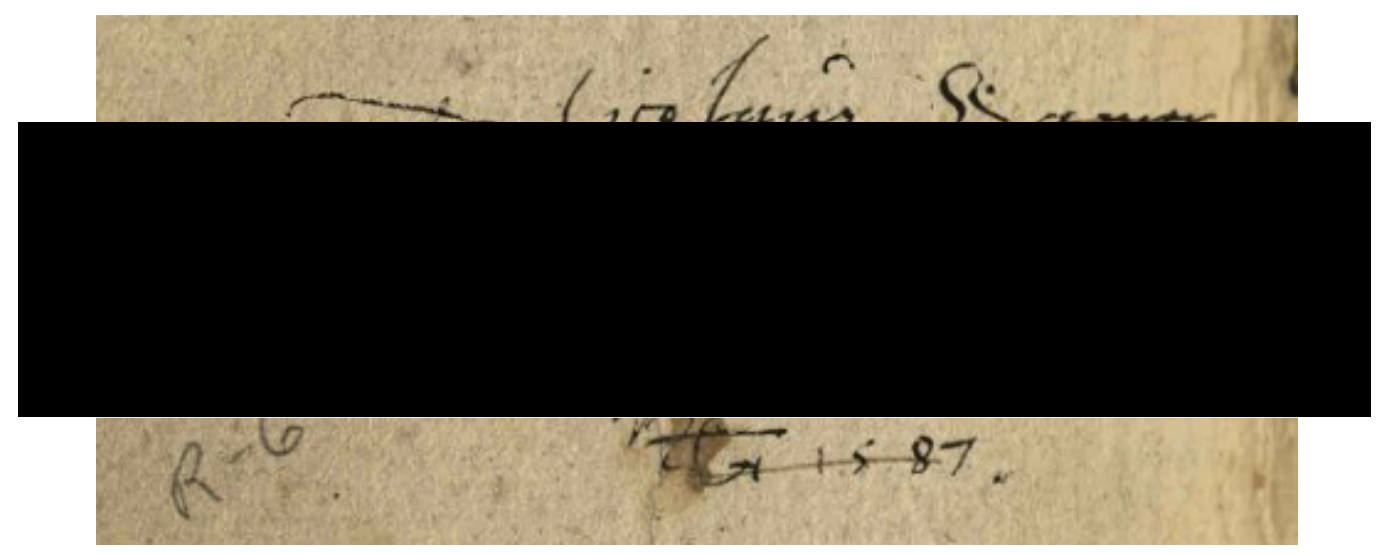

Figure 2.2. Ownership inscription of Nicholas Hommer, Haf(niae) Danus., Lipsiae, 17 Nov[embr]ib: 1587, found in the front pastedown of the Wittenberg Sammelband. Science Museum Library Shelfmark O. B. RAM RAMUS 30209019362784.

A salutation written to Hommer by Johannes Coppius, of Leisnig, Saxony, suggests that the former was still in possession of the Sammelband in 1589. The inscription, shown in Figure 2.3 below, is translated as:

(To the) Most decorated and learned young master Nicolao Hommero, of Copenhagen, writing with love and goodwill. Leipzig, M(aster) Johannes Coppius of Leisnig, 17 January (15)89. ${ }^{29}$

\footnotetext{
${ }^{28}$ J. Basil Oldham, English Blind-Stamped Bindings (Cambridge: Cambridge University Press, 1952), particularly pp. 33-37; Diehl, Bookbinding: Its Background and Technique, p. 28. Oldham points out that English and German binders of the late sixteenth-century (and other agents in the binding process) often 'signed' their work in this fashion, whilst Diehl also refers to the German market's predilection for 'rolls with a pattern divided by segments (...) on (which) were frequently engraved the initials of the bookbinder'.

${ }^{29}$ The text shown in Figure 2.3 reads: 'Ornatiss(im)o et doctiss(sim)o juveni Domino Nicolao Hommero Hafniensi amoris et benevolentiae ergo scribebat Lipsiae M. Joh. Coppius Leisnicensis, 17 Jan. 89.
} 


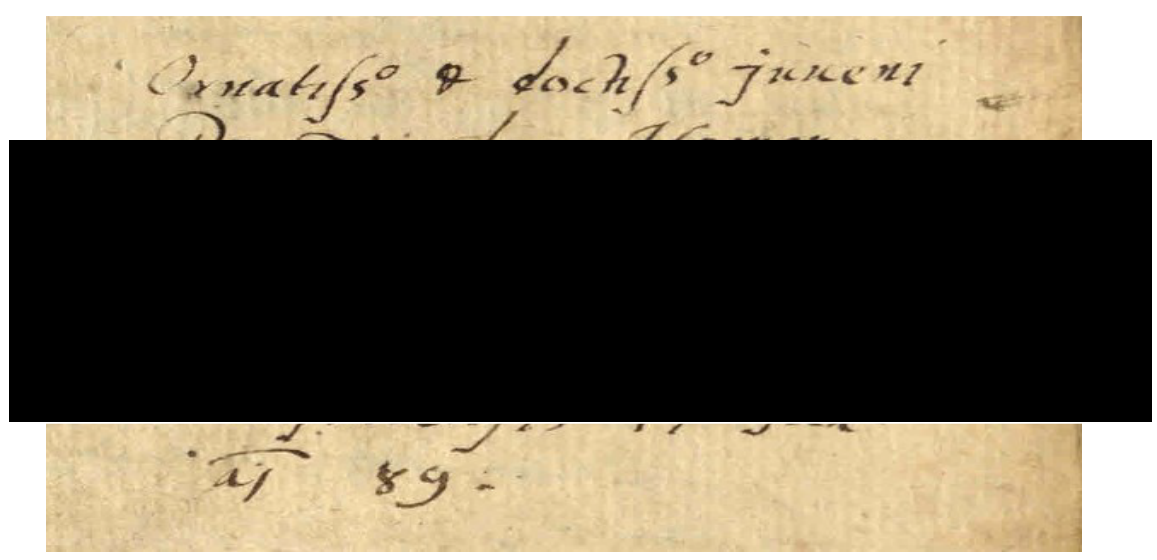

Figure 2.3. Possible album amicorum inscription from Johannes Coppius to Nicholas Hommer. Science Museum Library Shelfmark O. B. RAM RAMUS 30209019362784.

The manuscript notes of De Logistice astronomica appear to be largely in Coppius's hand, with occasional commentaries from Hommer interposed. The inscription shown above is perhaps evidence of a friendship between two students with a shared interest in mathematics or possibly that of a master and his student, written in the fashion of the album amicorum - literally, 'books of friends' - popular in the period. These scrapbooks contained inscriptions, devotional poems, academic notes, portraits and sketches, and reports of local and international fashions. Their entries were written from one student to another, and often circulated amongst a wider network of friendly scholars. While mottoes fell in and out of use and fashions changed, a fellow pupil's autograph or heraldry was a stamp of loyalty and of lasting friendship. ${ }^{30}$ As scholars moved between institutions, these books remained evidence of the companionship they had enjoyed on their travels.

Travelling well beyond its point of origin, the value of this particular sammelband was not restricted to one individual. By 1593, the volume had passed through two further sets of hands: those of another Dane, David Johannes Klynaeus, and his Wittenberg contemporary, Johannes Lobhartzberger, with each name scored widely through, though not entirely obscured (Figure 2.4). ${ }^{31}$ It need not necessarily be assumed that Nicholas Hommer had lost ownership of his sammelband by this

\footnotetext{
${ }^{30}$ Margaret F. Rosenthal, 'Fashions of Friendship in an Early Modern Illustrated Album Amicorum: British Library, MS Egerton 1191', Journal of Medieval and Early Modern Studies, 39.3 (2009), pp. 619-641, p. 622.

${ }^{31}$ Petrus Ramus, Arithmeticae Libri Duo, Gemoetriae Septem et Viginti, title page. Wittenberg Sammelband, O.B. RAM RAMUS 30209019362784.
} 
point. The palaeographic similarities shared between these ownership inscriptions suggest that Hommer may have loaned his annotated text out to friends and countrymen at university, scoring their names out upon its successful return - a common practice in the early modern period. That this activity likely took place at the German institution is in keeping with the roots of the album amicorum, which can be traced back to mid-sixteenth century Wittenberg. ${ }^{32}$

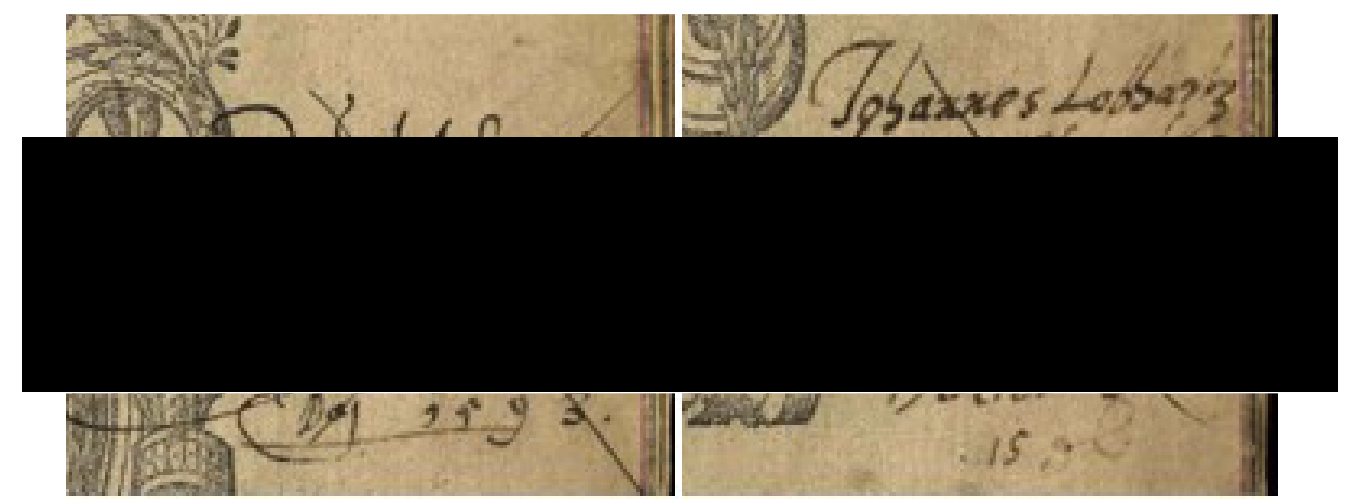

Figure 2.4. Composite image of possible lending or amicorum inscriptions from David Johannis Klynaeus (left) and Johannes Lobhartzberger (right), Wittenberg, 1593. Klynaeus identifies himself as a Dane, from Copenhagen, whilst Lobhartzberger was from Kłodzko (then Glacio, in Lower Silesia). Science Museum Library Shelfmark O. B. RAM RAMUS 30209019362784.

Both Klynaeus and Lobhartzberger can be located at the University of Wittenberg in the early 1590s, though the trail of Hommer has petered out by this point. David Johannis Klynaeus is one subject of a ribald collection of Latin poetry penned by Friedrich Taubmann (1565-1613), a Wittenberg professor, poet, and something of a jester at the court of the Duke of Saxe-Weimar, Friedrich Wilhelm I (1562-1602). ${ }^{33}$ Johannes Lobhartzberger, meanwhile, was a companion to Daniel Sennert (1572-1637), and a dedicatee of Sennert's Templum Mnemosynes (Wittenberg, 1599), a poem lauding the Brunian application of the art of memory. ${ }^{34}$

\footnotetext{
${ }^{32}$ Wolfgang Klose, Wittenberger Gelehrtenstammbuch (Halle: Mitteldeutscher Verlag, 1999). See also Jason Harris, 'The Practice of Community: Humanist Friendship during the Dutch Revolt', Texas Studies in Literature and Language, 47.4 (2005), pp. 299-325.

${ }^{33}$ Friedrich Taubmann, Melodaesia sive Epulum Musaeum (Leipzig: Thomas Schurer, 1597), pp. 453454. For a summary of Taubmann's life and endeavours, see H. C. Erik Midelfort, A History of Madness in Sixteenth-Century Germany (Stanford, CA: Stanford University Press, 1999), pp. 270275.

${ }^{34}$ Daniel Sennert, Templum Mnemosynes (Wittenberg: M. Henkel, 1599), title page. See also Christoph H. Lüthy and William R. Newman, 'Daniel Sennert's Earliest Writings (1599-1600) and Their Debt to Giordano Bruno', Bruniana and Campaneliana, 6 (2000), pp. 261-279, particularly pp. 274-275.
} 
Ultimately the precise identities of these annotations' authors are of less importance than what they suggest about the transmission of the volume's contents. Nicholas Hommer was reading, copying, and rearranging the mathematical texts of Petrus Ramus and Thomas Fincke in Leipzig, perhaps under the tutelage or in the company of Johannes Coppius. While Ramus's texts were of a rudimentary bent, Fincke's work moved toward a higher level of sophistication, and it is notable that the marginal notes that cover these works attend much more to the former than the latter. That Johannes Lobhartzberger and David Klynaeus then had cause to avail themselves of this compendium whilst at Wittenberg suggests the continuing value of the collection to university students, and perhaps even to those preparing for disputations.

By the time Klynaeus and Lobhartzberger encountered the Sammelband in 1593 Thomas Fincke had begun to move away from mathematical study, gravitating instead toward a career in medicine. ${ }^{35}$ A mere three years after its original publication, his Geometriae rotundi was bound up alongside the works which had so influenced its author and was used with these texts to advance the ideas of a pedagogical coterie inspired by ideas concerning the utility of mathematics. Nevertheless, Fincke's brief authorial career should not distract attention from the fact that he was a near-contemporary of the owners of the Sammelband that featured his work, and nor should it go unrecognised that the author was just as much a product of the self-same Northern European educational system as Nicholas Hommer and his peers. The pre-eminence of Ramist method shared by the first two titles of the Sammelband - Petrus Ramus's own Arithmeticae libri duo, Geometriae septem et viginti and Thomas Fincke's Ramus-inspired Geometriae rotundi - is significant for understanding both the authorship of the texts and their subsequent use and transmission; the promotion of dialectic was central to the educational

\footnotetext{
${ }^{35}$ Between 1583 and 1601 Fincke published works on mathematics and astronomical calculation, including Theses de constitutione philosophiae mathematicae (Copenhagen: Mads Vingaard, 1591) and Horoscographia (Schleswig: Nikolaus Wegener, 1591). By 1594, he had taken charge of the University of Copenhagen's curriculum, publishing Theses Logicae (Copenhagen: Mads Vindgaard, 1594), Theses Philosophicae (Copenhagen: Mads Vindgaard, 1594), as well as Bachelor's and Master's programmes - Programma universitatis Hafniensis in promotionem baccalaureorum 15.3.1594 (Copenhagen: Mads Vingaard, 1594) and Programma universitatis Hafniensis in promotionem magistrorum (Copenhagen: Mads Vingaard, 1594) - all in the same year.
} 
philosophies of Melanchthon, Sturm, and Ramus and, ultimately, to the paratexts of the Wittenberg Sammelband.

\section{The Influence of Ramus}

By the 1590s, the teachings of the French pedagogue, logician, and philosopher Petrus Ramus had become entrenched in the schools of Northern Europe, despite continued attempts to halt its diffusion. ${ }^{36}$ Even as the universities of Leipzig (1591), Rostock (1592), and, eventually, Wittenberg itself (1602) clamped down on Ramism and its methods, students nonetheless arrived expecting to continue their education in a manner delivered at least somewhat in keeping with that of the French philosopher. ${ }^{37}$ In 1597, the decree of Duke Julius of Helmstedt - created to vet and ultimately expunge Ramist teaching - acknowledged that students came with little else in their heads. Allowances were therefore made so that tutors might teach using Ramist materials, albeit in private. ${ }^{38}$

It should therefore come as no surprise to see Petrus Ramus's textbooks being put to use by students such as Nicholas Hommer in late-sixteenth-century Leipzig. One leading authority has claimed that Germany was very much the 'seedbed' for Ramism after the murder of its creator; ${ }^{39}$ indeed, the philosophical works of the pedagogue and his ally Omer Talon (ca. 1510-1562) gained their strongest foothold in German-speaking regions (including Switzerland and Alsace) between 1570 and 1600. Joseph S. Freedman's analysis of Walter J. Ong's Ramus and Talon Inventory (1958) show that almost 70\% of editions and adaptations (155 of 225) of Ramus's La Dialectique (1555) and Ramus-Talon's Rhetorica (1548) published between 1555 and 1600 originated in one of these regions. ${ }^{40}$ Though not

\footnotetext{
${ }^{36}$ Ong, Ramus, Method and the Decay of Dialogue, p. 299. Ong claimed that attempts to ban Ramism in the 1590s led to the development a group of scholars who syncretised Ramist, Aristotelian, and Melancthonian thought. According to Ong, this group were somewhat confusingly known to contemporaries as either 'mixts', 'Philippo-Ramists', and/or 'Systematics'.

${ }^{37}$ For the Aristotelian backlash against Ramism in Germany, and specifically in Helmstedt, see Pietro Daniel Omodeo, 'Hoffmanstreit' in Pietro Daniel Omodeo and Karin Friedrich, eds., Networks of Polymathy and the Northern European Renaissance (Leiden and Boston: Brill, 2016), pp. 82-85.

${ }^{38}$ Hotson, Commonplace Learning, p. 94.

${ }^{39}$ Ong, Ramus, Method and the Decay of Dialogue, p. 298.

${ }^{40}$ Joseph S. Freedman, 'The Diffusion of the Writings of Petrus Ramus in Central Europe, c.1570 c.1630', Renaissance Quarterly, 46.1 (1993), pp. 98-152, p. 100. The Latin edition of Ramus's La Dialectique, titled Dialecticae libri duo (1556) is included in Freedman's wider analysis.
} 
quite as popular, Ramus's mathematical textbooks followed a similar trajectory. With the popularity of Ramism growing throughout the educational institutions of northern Europe, the teachers and pupils affiliated with large-scale gymnasia turned to works of a Ramist bent in every branch of the curriculum. ${ }^{41}$ Though arithmetic and geometry ostensibly belonged to the medieval quadrivium, and were intended to be studied at university level, in practice introductory mathematical studies joined the trivium of grammar, rhetoric and dialectic on the pre-university curriculum of Protestant scholae triviales, where Ramist materials were making steady progress. ${ }^{42}$

First issued together in $1569,{ }^{43}$ Ramus's mathematical textbooks on arithmetic and geometry were constructed in such a way as to guide readers to the easy and immediate truth of their contents. In this manner, they were envisioned as the reorganization of a discipline that Petrus Ramus had himself previously failed to grasp. Between 1551 and 1555, the author had suffered a debilitating crisis of confidence in his own mathematical capabilities. Unable to comprehend the tenth book of Euclid's Elements, Ramus admitted to being literally crippled by the difficulties of the discipline - at least, mathematics as they were expressed in Euclidean form. ${ }^{44}$ Rather than products of a subject defined by clarity and perfection, ready to be grasped immediately by those who would study its principles, Petrus Ramus's mathematical textbooks were instead proof of their author's defeat. The pedagogue's original view that mathematics exhibited a perfect form of logical dialectic was irrevocably altered. ${ }^{45}$ In its place rose the idea that authors such as Euclid had so obscured the truth of mathematics that a new method - one more in keeping with natural reason - had become essential. Whether or not the students and

\footnotetext{
${ }^{41}$ Hotson, Commonplace Learning, p. 115. Hotson's analysis of the Ramus and Talon inventory shows that more than 80 per cent of Ramus's works on grammar, mathematics, physics, metaphysics and theology between the author's death in 1572 and 1620 originated in Germany or Basel.

42 Joseph S. Freedman, Diffusion of the Writings of Peter Ramus, p. 123. See also Joseph S. Freedman, 'Philosophy Instruction within the Institutional Framework of Central European Schools and Universities during the Reformation Era', History of Universities, 5 (1985), pp. 117-166.

${ }^{43}$ Walter J. Ong, 'Christianus Ursitius and Ramus's New Mathematics', Bibliothèque d'Humanisme et Renaissance, 36.3 (1974), pp. 603-610, pp. 608-609. The 1569 edition of Arithmeticae libri duo, Geometriae septem et viginti was the first to combine Ramus's works on arithmetic and geometry; two previous editions of his Arithmeticae libri duo had already been published by this point. ${ }^{44}$ Robert Goulding, 'Method and Mathematics: Peter Ramus's Histories of the Sciences', Journal of the History of Ideas, 67.1 (2006), pp. 63-85, p. 74. Ramus's apologia Oratio de professione sua (written in 1563), relates how the pedagogue, reading Euclid, 'felt all the muscles in my back seize up', and moments later 'burst out in a rage against mathematics'.

${ }^{45}$ Goulding, ibid, p. 76.
} 
teachers of early modern Germany shared either the author's pain or, for that matter, his lofty goals, is a discussion for another time.

It is much more apparent why these texts proved as popular as they did: their emphasis on simplicity is evident in the opening lines. The educator starts from perhaps the most introductory position possible in each, famously stating that arithmetic 'is the art of numbering [counting] well'; ${ }^{46}$ geometry, 'that of measuring well' ${ }^{47}$ Such reductive brevity helps in part to show how and why Ramist methods gained ground in late sixteenth-century Europe. As one early English translator of Ramus had it, these pedagogical texts were 'most conuenient and fit for the master to teach and the scholler to learn, not only the art, but also the use of the art.' ${ }^{48}$ Those who had previously read Ramus's works on mathematics to develop their own disciplinary expertise often retained an admiration for the texts' methodological lucidity as well as the step-by-step definitions offered by the author. In one such instance, John Napier opened the second book of Mirifici logarithmorum canonis descriptio (1614) by directly praising Ramus's succinct definition of geometry, before incorporating a number of lessons taken from his Geometriae septem et viginti libri on magnitude and on the figure of the triangle. ${ }^{49}$

As its title makes clear, Arithmeticae libri duo consists of two books, with the fourteen chapters of the first moving from basic instruction on the numeration and notation of addition, subtraction, multiplication and division of whole numbers, to an explication of compound numbers and the numerators and denominators of fractions. The seventeen chapters of Book Two commence with arithmetical and geometrical proportion before gradually presenting more complex examples of arithmetical and geometrical progression. Practical examples for the calculation of compound interest

\footnotetext{
${ }^{46}$ Petrus Ramus, Arithmeticae libri duo (Basel: haer. Nikolaus II Episcopius, 1569), p. 1: 'Arithmetice est doctrina bene numerandi'.

${ }^{47}$ Petrus Ramus, Geometriae septem et viginti (Basel: haer. Nikolaus II Episcopius, 1569), p. 1. 'Geometria est ars bene metiendi'.

${ }^{48}$ Petrus Ramus, The Art of Arithmeticke in Whole Numbers and Fractions, trans. William Kempe (London: Richard Field for Robert Dexter, 1592), f. a iiij.

${ }^{49}$ John Napier, Mirifici logarithmorum canonis descriptio (Edinburgh: Andreae Hart, 1614), p. 21: 'Quum Geometria sit ars bene metiendi, dimensio sit magnitudinum propositarum, magnitudines figuram (potentia saltem) constituent, figura sit Triangulum, at triangulatum'.
} 
over time, involving multiplication and addition of whole numbers and fractions, are representative of the content of this second book.

In Walter J. Ong's opinion, this work, and its sister text on geometry, was Ramus at his best: elementary, organised, and to-the-point. ${ }^{50}$ More recent studies on Ramus and his philosophy have identified that the unifying theme of the French pedagogue's work was an overwhelming desire to combat the rigid oligarchy exhibited by the French Ancien Régime; accordingly, his depiction and consequent teaching of mathematics was characterized by the supposedly accessible, utilitarian, practical and meritocratic qualities of the discipline. His interest in educating pupils more expeditiously was motivated by these social concerns, rather than by any more coherent or distinctive philosophical outlook. ${ }^{51}$

Following on from the Arithmeticae libri duo, Ramus's Geometriae septem et viginti libri provided a cursory introduction to the foundations of geometry before devoting ever more attention to the discipline's practical application. In essence, its goal was to inspire the reader to unite their natural faculties with the many worthwhile pursuits improved by geometrical knowledge: Ramus listed the praxis of astronomers, navigators, surveyors and architects as the fruits of geometry's vines. ${ }^{52}$ The author's desire to kindle a love of practical application in his students is reminiscent of a comment made in his 1545 translation of Euclid's Elements; the student who plays at imitating the construction of geometric figures by first drawing them in the dust would, in Ramus's view, be more worthy of praise than one simply gazing at printed figures. ${ }^{53}$

Ever the logician, Petrus Ramus's efforts in popularising mathematical disciplines were tied to pedagogical and philosophical reforms following his

\footnotetext{
${ }^{50}$ Walter J. Ong, Ramus and Talon Inventory: A Short-Title Inventory of the Published Works of Peter Ramus (1515-1572) and Omer Talon (Ca. 1510-1562) in their Original and Variously Altered Forms (Cambridge, MA: Harvard University Press, 1958), p. 370.

${ }^{51}$ Skalnik, Ramus and Reform, p. 157; Hotson, Commonplace Learning, pp. 39-51.

${ }^{52}$ Ramus, Geometriae septem et viginti, p. 1: 'hic sinis geometriae usu atque opera geometrico multo splendidior apparebit, quám praeceptis, cum animadvertes astronomos, geographos, geodetas, nautas, mechanicos, architectos'.

${ }^{53}$ Petrus Ramus, Euclides (Paris: apud Lud. Grandinum, e regione gymnasij Mariani sub signo galli, 1545), p. 4: 'quódque ad figuras attinet, magis laudabo discipulum in abaco et pulvere figuras sibi demonstratas imitantem, quàm ociose et inutiliter alienas picturas aspectantem'. Originally cited in Peter Sharratt, 'La Ramée's Early Mathematical Teaching', Bibliothèque d'Humanisme et Renaissance, 28.3 (1966), pp. 605-614, p. 608.
} 
debarment from teaching in 1544 . His interest in mathematics was primarily a product of a desire to promote the learning and use of any art according to his own proposed method, itself a mélange of humanist reading and Aristotelian analysis. To this end Ramus wished to see the artes mechanicae (hereafter, the mechanical arts), including agriculture, architecture, trade, tailoring and the military, achieve equal standing with the liberal arts of the trivium and quadrivium in theory and in practice. This celebration of the mechanical arts was motivated by Petrus Ramus's long-held belief that the application of any given art - liberal or mechanical - was key to both the user's practice of that art, and to the intrinsic identity of the art itself. For Reijer Hooykaas, this belief is to be set against Ramus's rationalistic metaphysics as outlined in Dialecticae institutiones (1543), in which the pedagogue argued that human knowledge was predicated on reason, the artifex exercising our innate abilities to speak, count, measure, and so forth. ${ }^{54}$ It was essential that reason not be obstructed by improper or incorrect teaching. Any 'artificial' material obscuring the faculty of natural reasoning was unnatural or - in Ramus's most cutting term 'fabricated' and was to be swept away. ${ }^{55}$

As a corollary of this, the presentation of propositions without synthetic demonstration afforded Ramus the space to present mathematical results expeditiously and, in his view, as they might be best grasped by the mind. The visiospatial organisation of dichotomies was the engine driving this progress, with the end destination improvements in the clarity and order of language-orientated dialectic via the inculcation of a more mathematically-guided thought process. This outlook was then adapted in participation with the four key constants of Ramus's philosophical tenets: method, practicality, simplicity, and accessibility. ${ }^{56}$ Mathematics was therefore prized by Ramus for its theoretical utility to the liberal arts, in which it aided the innate abilities of counting and measuring, and for its comparability to logical dialectic as a tool for the application of natural reasoning. At the same time,

\footnotetext{
${ }^{54}$ Petrus Ramus, Dialecticae institutiones (Paris: Jacobus Bogardus, 1543), ff. 3r - 3v; Rejier Hookyaas, 'Humanities, Mechanics and Painting (Petrus Ramus; Francisco de Holanda)', Revista da Universidade de Coimbra, 36 (1991), pp. 1-31, p. 3.

${ }^{55}$ Goulding, 'Method and Mathematics', p. 65.

56 Timothy J. Reiss, 'From Trivium to Quadrivium: Ramus, Method and Mathematical Technology' in Timothy J. Reiss and Jonathan Sawday, eds., The Renaissance Computer: Knowledge Technology in the First Age of Print (London: Routledge, 2000), pp. 43-56, pp. 47-48; Skalnik, Ramus and Reform, p. 57.
} 
the use of mathematical practice as applied to the more mechanical elements of commerce, architecture, the military arts, and so on, was further proof of the discipline's worth.

The methodical rigour of Ramus's pedagogic style is met with early in Geometriae septem et viginti libri's second chapter. With the necessary treatment of points and magnitude dealt with, the author delineates his method for the rest of the text: the common properties of magnitudes are defined, then the species are dichotomised accordingly. For Ramus this model applied to all discursive enquiry: definition was demonstration. ${ }^{57}$ Hence the diction of Geometriae septem et viginti was brusque and immediate, resulting in the reader being given little more in each definition than was deemed absolutely necessary. The pedagogue subjected classical authorities to this process of reduction, setting his abbreviated reading of their works against each other in his texts and so rearranging more detailed treatments of mathematical theory into what he perceived as a more expeditious, bite-sized selection of materials, with proofs eschewed for illustrative examples.

Upon these squat foundations, more definitions could be heaped, and, once the definitions had been clarified, Ramus expected that his mathematical rules would be understood, piece by piece. The effect of this was to present what has been termed an observational geometry: one which encouraged pupils to witness the construction of the art and then methodically practice and repeat its rules for their own education and later application. ${ }^{58}$ As part of this method, whereby sufficient instruction and practical application would most clearly direct students' minds to the correct use of the art of mathematics, the author highlighted the centrality of simple tools:

Whether straight shanked or bow-legg'd (...) its skilleth not, are for all purposes and practise in this case the best and readiest. And indeed the

\footnotetext{
${ }^{57}$ An example of this is found early in Ramus, Geometriae septem et viginti, p. 10, where magnitude is defined before being dichotomised: 'Communes affectiones magnitudinis expositae sunt: sequitur dichotomia, quae adhuc nobis occurrit'. Ong stated that, for Ramus, 'to demonstrate something is to define it. [...] As Ramus's textbook on the subject shows, even geometry will consist not of demonstrations, but of definitions, or "rules" '. Ong, Ramus, Method and the Decay of Dialogue, pp. 188-189.

${ }^{58}$ Marta Menghini, 'From Practical Geometry to the Laboratory Method: The Search for an Alternative to Euclid in the History of Teaching Geometry' in Sung Je Cho, Selected Regular Lectures from the $12^{\text {th }}$ International Congress on Mathematical Education (Heidelberg, New York, Dordrecht, London: Springer International Publishing, 2015), pp. 561-587, p. 565.
} 
Compasses, of all geometricall instruments, are the most excellent, and by whose help famous Geometers have taught: That all the problems of geometry may be wrought and performed. ${ }^{59}$

Ramus continued by noting that 'Joan. Baptistae' - Giovanni Battista Benedetti (1530-1590) - had written a book 'teaching how by one opening of the Compasses all the problems of Euclide may be resolved' ${ }^{60}$ English readers were admonished by William Bedwell to think upon how the theoretical problems of Euclid's geometry were enacted daily with the simple tools and methods of a 'cooper', a cask and barrel maker, 'or other like artists'. ${ }^{61}$ The implication was clear: using the ancient instruments of ruler and compass while ignorant of Euclidean theory, these untutored minds had, for some time, been as close to the correct practice of geometry's art as any abstruse theoretician. Students therefore had little to fear from abandoning Euclid's methods: the art remained the same. Petrus Ramus's mathematical method was merely a tool to sweep away the Elements's logical detritus in favour of a style of presentation which might allow for the mathematical arts to be practiced more in keeping with the French pedagogue's idea of natural reason.

Elsewhere in Geometriae septem et viginti, Petrus Ramus continued to enforce his conception of the art as an ideal combination of practical usage and natural reason. A few pages before his description of the form and use of compasses, the philosopher advocated for the use of instruments as a form of practice entirely in keeping with natural capabilities. Though the leitmotif of the text is found in its first commandment - learning to measure well - the instrument for doing so is already present in the mind of the learner. This can loosely be represented by Ramus's treatment of instruments in relation to geometrical practice. Whether wielded by the theoretician or the cask-maker, the aforementioned compass could resolve every

\footnotetext{
${ }^{59}$ Peter Ramus, Via Regia ad Geometriam, or The Way to Geometry, trans. William Bedwell, (London: Printed for Thomas Cotes, 1636), p. 56. Ramus, Geometriae septem et viginti, p. 42: 'Ut vero regula fuit instrumentum ducendae recte, sic modo est circinus peripheriae describendae, cruribus rectis an valgis nihil interest, ut hic vides. Circinus vero é geometricis instrumentis instrumentum longe praestantissimum est, cujusque machinatione nobiles geometerae prodiderunt omnia geometriae problemata consici posse'.

${ }^{60}$ Ramus, Way to Geometry, trans. William Bedwell, , p. 57; Ramus, Geometriae septem et viginti, p. 42: 'et extat Joan Baptistae liber, quod una circini aperture omnia Euclidis problemata resoluantur'.

${ }^{61}$ Ramus, Way to Geometry, trans. William Bedwell, p. 56.
} 
proposition of Euclidean geometry; the humble ruler was equally capable of performing similar feats. Explicating how a line of set measurement (the line IO) may be subtracted sufficiently from a longer line (line AE) to create a new portion (line AU), Ramus (in Bedwell's words) claimed that 'if any man shall think that this ought only to be don in the minde, hee also, as it were, beares a ruler in the mind, that he may do it by the help of the ruler. ${ }^{62}$

Though the author frequently covered his thought in a thin veneer of Platonism, he did not here intend the mind's instrument to be taken as concomitant with a pre-existent understanding of the entire 'art' of geometry. ${ }^{63}$ Instead, by internalising the physical processes of geometry in the ruler and the compasses, Ramus appended the mathematical discipline to the tripartite system of his dialectic: one of nature, art, and practice. Nature and the ability to practice are both innate: art, however, requires either didactic or auto-didactic teaching, and can be corrupted as a result. ${ }^{64}$ The Ramist dialectic, itself an 'instrument of oration and reason', utilised physical and imagined instruments in the theory and practice of a given art (in this case, geometry) to obtain knowledge of every thing - a belief previously expounded in Dialecticae institutiones. ${ }^{65}$ For Petrus Ramus, method as applied to any art was an instrument of knowing: one supplemented by the external instruments of text and tool.

\section{Ramus and Fincke's shared dialectical influences: Melanchthon and Sturm}

Themselves readers of Petrus Ramus, Thomas Fincke and the late sixteenth-century pupils who studied the Wittenberg Sammelband encountered mathematics as part of

\footnotetext{
${ }^{62}$ Ramus, Way to Geometry, trans. William Bedwell, p. 55. Ramus, Geometriae septem et viginti, pp. 41-42: 'Nam si quis mente tantum id fieri putat oportere, is etiam regulam mente complectatur, ut regula opera faciat'.

${ }^{63}$ Ramus enjoyed a complicated relationship with both Plato's works and the historical figure of the philosopher. See Robert Goulding, Defending Hypatia: Ramus, Savile, and the Renaissance Rediscovery of Mathematical History (Berlin: Springer, 2010), pp. 42-48.

${ }^{64}$ Reijer Hookyaas, Fact, Faith and Fiction in the Development of Science: The Gifford Lectures given in the University of St Andrews 1976 (Dordrecht: Springer Science + Business Media, 1999; first edition Kluwer Academic Publishers, 1999), p. 270.

${ }^{65}$ Ramus, Dialecticae instituiones, f. 38 r: 'itaque cum in hoc rationis, et orationis instrument clarissimos divini luminis radios dialectica deprehenderit'. See also Ramus, ibid, f. 39 v: 'age vero physicis regionibus ingentibus peragratis eadem lux dialectica persectiores imagines perscrutetur. Mathematicas artes ingrediatur: quas pro quantitatis natura distribues, arithmeticam discretae: geometriam continuae principes videbit'.
} 
an educational culture transformed by early modern humanism. Though Ramus's philosophical reforms were inarguably presented as improvements to the humanist teaching of figures such as Rodolphus Agricola (ca. 1444-1485), the particulars of the Ramist way of thinking have most recently been characterised as more a loose and shifting assemblage of 'largely commonplace ideas and techniques' than one coherent and consistent philosophical phenomenon grafted en bloc onto a range of early modern intellectual cultures. ${ }^{66}$ To this point, I have argued that the French pedagogue's desire to promote the mathematical disciplines of the quadrivium in both theory and practice was comparable to his appreciation for the value of dialectic and its role within the trivium. This view of dialectical logic as integral to theory and practice of any given art is central to understanding Ramus's pedagogical outlook an outlook that was brought to bear on his mathematical works as much as it affected his works on the various parts of the trivium.

In Petrus Ramus's interpretation the discursive arts of the trivium were tangled up together, with their constituent parts intertwined and too often overlapping. To pare back these untended vines, Ramus insisted upon pruning these arts to their essential and most logical components: grammar to syntax and etymology, rhetoric to style and delivery, and dialectic to invention, arrangement, and judgement. Doing so would return a sense of order to the whole endeavour, and would remove rhetoric from its false position at the peak of the trivium (as taught by classical authors such as Quintilian, and agreed upon by Agricola), its place taken instead by dialectic, the art which could most effectively divine the truth of a given statement.

With this reorganisation realised, the Ramist student could philosophise more effectively by arranging and comprehending terms through grammar, using the dichotomous branches common to Ramist method (as appropriated from Johannes Sturm) to organize material for effective recognition and thereafter delivery, and then utilising dialectic to attain and judge the logic and validity of statements, thus arriving at truth, or, more correctly, philosophical certainty. ${ }^{67}$ A devotee of Erasmian and Agricolan forms of humanism, Ramus based his ideas on the more general

\footnotetext{
${ }^{66}$ Hotson, Commonplace Learning, p. 16.

${ }^{67}$ Thomas M. Conley, Rhetoric in the European Tradition, $2^{\text {nd }}$ edn (Chicago and London: University of Chicago Press, 1994), pp. 128-133.
} 
humanist practices of hypercritical close reading, of allying logic to theoretical knowledge, and of inculcating the use of text and arts for a vita activa. Each of these were practices which Johannes Sturm and Philip Melanchthon inherited and altered, with the latter educator advocating the particular value of mathematical study for intellectual, civic, and social use. It is in this Northern European, and particularly Germanic, context that the roots of Ramus's dialectical philosophy truly belonged.

Students matriculating at the University of Wittenberg in the second half of the sixteenth-century - including Fincke, Lobhartzberger, and Klynaeus - therefore entered an environment rooted in the edicts of Philip Melanchthon, the Lutheran reformer and pedagogue who came to be known as the Praeceptor Germaniae, yet brought with them their experience (and, perhaps, their preference) for educational materials as presented in the Ramist format. Early in his career, Melanchthon had seen dialectic and rhetoric as intertwining subjects, each essential to the other. His youthful vision of dialectic was espoused in Compendiaria dialectica ratio (1520), where the worth of the study to pedagogy was made clear:

(Dialectic) shows the nature and parts of any subject simply and describes the proposed subject in such clear words that the audience cannot fail to understand what it contains, whether it is true or false. ${ }^{68}$

This understanding of dialectic made it ideally suited for educational purposes. Although Philip Melanchthon himself would later return to scholastic logic, motivated at least in part by the need for the ideas of the Reformation to triumph in ongoing theological debates, ${ }^{69}$ the idea that dialectic was a foundational educative element remained influential among the pedagogues who succeeded him; Melanchthon's marriage of rhetoric and humanist dialectic duly influencing, among others, Martin Crusius (1526-1607), Johannes Sturm (1507-1589) and, ultimately, Petrus Ramus and his ally Omer Talon. ${ }^{70}$ For the Praeceptor Germaniae, the dual

\footnotetext{
${ }^{68}$ Peter Mack, A History of Renaissance Rhetoric 1380-1620 (Oxford: Oxford University Press, 2011), p. 109; originally, Philip Melanchthon, Compendiaria dialectica ratio, Libri XX (Wittenberg: Melchior Lotther Junior, 1520). The original text reads: 'Simpliciter enim cuiusque thematis naturam et partes ostendit, et quod proponitur, adeo certis verbis praescribit, ut non possit non deprehendi, quicquid inest, sive veri, sive falsi'.

${ }^{69}$ Mirella Capozzi and Gino Roncaglia, 'Logic and Philosophy of Logic from Humanism to Kant', in Leila Haaparanta, ed., The Development of Modern Logic (Oxford: Oxford University Press, 2009) pp. 78-158, particularly p. 92-93.

${ }^{70}$ Mack, History of Renaissance Rhetoric, p.123, p. 129, and pp. 136-153.
} 
mobilization of dialectic for learning and rhetoric for oratorical persuasion was deployed so as to win hearts and minds. In tandem with Martin Luther, Melanchthon's objective was to reform Christendom so that the knowledge and understanding of God as man's creator, judge, and ruler was paramount.

Mathematics became part of this programme; taught with specific emphasis to learners working toward careers in medicine, law, and theology, its study was propaedeutic to the acquisition of higher types of knowledge. ${ }^{71}$

In 1545, the Reformation scholar had written new statutes for the teaching of natural philosophy; these regulations called for two lecturers to deliver lessons on mathematics. One tutor was to instruct on arithmetic and Euclid's Elements; the other, preparing students for the master's degree, on Sacrobosco's De Sphaera and Ptolemy's Almagest. ${ }^{72}$ Preceded by intensive study of philosophy, Latin, rhetoric, and dialectic, students were to be taught to synthesise these mathematical lessons into a more complete understanding of the Gospel as the Word of God. Melanchthon saw the study of mathematics as one of several ways to encourage recognition of the orderliness supplied by divine providence, and he supported this idea with frequent appeals to Platonism; indeed, the reformer's predilection for Plato's supposed apothegm 'God always geometrizes' and its variants is well attested in modern scholarship. ${ }^{73}$ In his preface to Johannes Vogelin's 1536 book on geometry, the Lutheran humanist went further still, informing readers that they would be 'admonished by the voice of Plato' every time they turned the pages of Vogelin's work. $^{74}$

Elsewhere, the overall goal of Melanchthonian mathematics was rarely made clearer than in a preface to Georg Peurbach's Theoricae novae planetarum

\footnotetext{
${ }^{71}$ Kusukawa, Transformation of Natural Philosophy, pp. 134-144.

72 Kusukawa, ibid, p. 176.

${ }^{73}$ Friedrich Ohly, 'Deus Geometra: Skizzen zur Geschichte einer vorstellung von Gott' in Norbert Kamp and Joachim Wollasch, eds., Tradition als Historische Kraft: Interdiziplinare zur Geschichte des Fruheren Mittelalters (Berlin: Walter de Gruyter, 1982), pp. 1-41. See also Charlotte Methuen, 'Interpreting the Books of Nature and Scripture in Medieval and Early Modern Thought: An Introductory Essay' in Jitse M. van der Meer and Scott Mandelbrote, eds., Nature and Scripture in the Abrahamic Religions: Up to 1700, Volume 1 (Brill: Leiden and Boston, 2008), pp. 179-218, p. 206.

${ }^{74}$ Philip Melanchthon, 'Preface to Johannes Vogelin's Book on the Elements of Geometry (1536)' in Sachiko Kusukawa, ed., and Christine F. Salazar, trans., Orations on Philosophy and Education (Cambridge: Cambirdge University Press, 1999), pp. 98-104, p. 99.
} 
(Wittenberg, 1535). Taking the form of a letter to the printer Simon Grynaeus, this preface was initially intended for an earlier edition of the work, published in 1532. Comparing the turbulence of recent upheavals to a long and bitter civil war in ancient Greece, Melanchthon told of an entreaty to the Apollonian oracle at Delos. According to the oracle, lasting peace would be secured only by the building of a cubic altar in greater dimensions than that which currently existed. Baffled, the Delians sought the help of Plato, who resolved the mathematical problem before interpreting for them the true meaning of the oracle's words. ${ }^{75}$

By making the civic and spiritual values of Platonic geometrizing apparent in his introductory epistle, Philip Melanchthon first of all highlighted the discipline's practical utility to the measurement and correct construction of the altar. Beyond this, the more tacit property of geometry was to create a lasting and intangible value far beyond that of its original use, with its practitioners sowing peace and moderation instead of disharmony and discord. In doing so, they come closer to acknowledging the thoughts of the divine. Undoubtedly, Melanchthon wished for university students to incorporate the lessons of Plato (subservient to the reformers' theological instruction) into their own practices so as to heal the Europe of the 1500s. Conceived of as part of an ideal curriculum - the definitive goal of which was a greater understanding of God and His works - Melanchthon's use of mathematics contributed to the reformative process which underpinned Lutheran education, whilst remaining propaedeutic to the higher (and even more curative) studies of medicine and theology.

In his elevation of the position of mathematical study in the early modern curriculum through a recasting of its relationship to philosophy and theology, Philip Melanchthon helped to stimulate a growth in mathematics that was replicated elsewhere in Germany. His influence spread outwards, guiding the precepts of the universities of Tübingen, Leipzig and Heidelberg, and the newer institutions founded

\footnotetext{
${ }^{75}$ Philip Melanchthon, Preface, Georg Peurbach, Theoricae Novae Planetarum (Wittenberg: Joseph Klug, 1535), f. aij r: 'ad Platone, qui docet qua in re sit erratum, videlicet nescisse eos cubi et quadranguli discrimen, nec ex cubo fuisse quadrangulum faciendem, monstrat qua ratione cubus duplicandus sit. Caeterunt admonet hac oraculi sententiam esse, ita demum Graeciam futuram tranquillam, si se ad Philosophiam Graeci convertissent, quia haec studia animos ab ambitione, et caeteris cupidatibus, ex quibus bella et caetera mala existent, ad amorem pacis, et moderationem in ombinus rebus abducerent.'
} 
in the sixteenth century, such as Marburg and Helmstedt. ${ }^{76}$ Citing Johannes Sturm as a key disciple of Melanchthonian doctrine, Kees Meerhoff has convincingly argued that Ramus's dialectic was the product of a combination of method, practice, and humanist study of classical texts as taught by Melanchthon and Sturm, and itself a distinctive form of Northern Humanism. ${ }^{77}$

In keeping with the educational currents of his time, Johannes Sturm's pedagogical model conditioned pupils to amass inexhaustible troves of mnemonic material, from individual words upwards, which were later to be analysed and combined stylistically (often via imitation of approved authorities) before being practised and delivered to prove mastery of a given subject. ${ }^{78}$ Sturm encouraged students to employ the commonplace books familiar to the era from an early age, and advised masters to dictate commentaries contextualising and explaining single key words found in classical texts. ${ }^{79}$ Once more, the educator was faced with a dilemma: how to educate students swiftly, reliably, but comprehensively? Sturm settled on three methods, culled from reading Galen, Aristotle, and Plato: an analytic method, which moved from the perception of objects to the principles guiding an art; a synthetic method, moving from principles to specifics; and, finally, and most importantly for the current study, a logical method characterized by definition and

\footnotetext{
${ }^{76}$ Westman, 'The Melanchthon Circle', p. 169. Westman develops the ideas of both Pierre Duhem and Lynn Thorndike; see Pierre Duhem, To Save the Phenomena: An Essay on the Idea of Physical Theory from Plato to Galileo, trans. Edmund Dolan and Chaninah Masler (Chicago: University of Chicago Press, 1969), particularly pp. 75-78 and pp. 88-98, and Lynn Thorndike, A History of Magic and Experimental Science, 8 Volumes (New York: Columbia University Press, 1923-1958), Volume 5 , p. 378.

${ }^{77}$ Kees Meerhoff, 'International Humanism' in Winifred Bryan Horner and Michael Leff, eds., Rhetoric and Pedagogy: its History, Philosophy and Practice: Essays in Honour of James J. Murphy, (New York: Routledge, 1995), pp. 213-226, particularly pp. 216-219. Walter Ong and John Monfasani have separately argued for Rhenish and Dutch influences as central to the Northern European humanists' fascination with 'method'. See Ong, Ramus, Method and the Decay of Dialogue, p. 232; John Monfasani, George of Trebizond: A Biography and Study of his Rhetoric and Logic (Brill: Leiden, 1976), pp. 325-326.

${ }^{78}$ Pierre Mesnard, 'The Pedagogy of Johann Sturm (1507-1589) and its Evangelical Inspiration', Studies in the Renaissance, 13 (1966), pp. 200-219, particularly pp. 209-211.

${ }^{79}$ Anja-Silvia Goeing, Storing, Archiving, Organizing: The Changing Dynamics of Scholarly Information Management in Post-Reformation Zurich (Leiden: Brill, 2017), p. 207.
} 
division, in which an art was divided and subdivided into constituent parts, with each part defined so as to demonstrate its relevance to the whole. ${ }^{80}$

If such a methodology sounds familiar, Petrus Ramus certainly left little doubt as to the inspirational effect of his colleague's teaching. Referring to Sturm's time in Paris from 1529 to 1536 , Ramus recalled that the educator:

excited in the (Collége Royal) an incredible ardour for the art [of logic] whose utility he revealed. It was at the lessons of this great master that I first learned the use of logic, and since then I have taught in an entirely different spirit from that of the sophists $(\ldots) .{ }^{81}$

It is easy to imagine that Ramus was particularly taken with Sturm's lauding of a tripartite approach to teaching focussing on the simplification of terms, on brevity and on diaresis, or the division of definitions into smaller parts. ${ }^{82}$ However, Johann Sturm was rather less enamoured of Ramus. Though the latter was invited to visit the Strasbourg academy (then under Sturm's aegis) in 1569, Ramus's texts were not introduced to the curriculum. ${ }^{83}$ Johann Sturm was still in post as the director and $d e$ facto leading light of Reformation education when Thomas Fincke arrived at Strasbourg some eight years later, ${ }^{84}$ and the Sturmian methodical fixation on textual analysis, oratory, and practice were communicated in no uncertain terms to the teachers working in his institution, including the mathematics instructor Conrad Dasypodius (1532-1600). ${ }^{85}$

Of further significance is the fact that Sturm, unlike Melanchthon and, indeed, the pedagogues of Zurich and Wittenberg who followed him, believed that subjects such as mathematics (along with jurisprudence and medicine) could be

\footnotetext{
${ }^{80}$ Mack, History of Renaissance Rhetoric, pp. 133-134. See also Lewis W. Spitz and Barbara Sher Tinsley, Johann Sturm on Education (St Louis, MO: Concordia Publishing House, 1995), particularly pp. 45-58.

${ }^{81}$ Petrus Ramus, Preface to Scholae in Liberales Artes: 'academiam academiarum principem incredibili tam insperatae utilitatis desiderio inflammavit: tum igitur tanto doctore logicam istam ubertatem primum degustavi, didicique longe alio fine consilioque juventuti proponendam esse (...).' I have taken this translation from Skalnik, Ramus and Reform, p. 31, fn. 72.

${ }^{82}$ Monfasani, George of Trebizond, p. 326.

${ }^{83}$ Hotson, Commonplace Learning, p. 22.

${ }^{84}$ Fincke was enrolled at Strasbourg from 1577 to 1582 . See Schönbeck, 'Thomas Fincke und die Geometriae rotundi', p. 83.

${ }^{85}$ Pierre Mesnard, 'The Pedagogy of Johann Sturm (1507-1589) and its Evangelical Inspiration', Studies in the Renaissance, 13 (1966), pp. 210-219, p. 212.
} 
introduced to pupils from a young age. ${ }^{86}$ Writing to Dasypodius in 1569, Sturm earnestly confirmed his wish that mathematics be taught to the two eldest classes, using the first mathematical textbook approved for use in the Strasbourg Gymnasium, Dasypodius's 1567 collection of lectures on geometry, astronomy, and geography. ${ }^{87}$ Along with this Sturm counselled that pupils should read the Elements, and Sacrobosco's De Sphaera; should Dasypodius wish, he could also furnish pupils with examples from Ptolemy, Proclus, Hipparchus, and Theodosius. ${ }^{88}$ For Sturm, mathematics offered certainty beyond the phenomenological world:

things that our senses cannot even count, nor grasp, our spirit can nevertheless embrace, like the whole world, the sky, the seas, land. [...] Did Euclid describe the finite or the infinite? Euclid's problems and mathematicians' axioms are finite, but how many propositions one can deduce from them that have not been dealt with by the doctors! ${ }^{89}$

Dasypodius, himself a graduate of the Strasbourg gymnasium, undoubtedly shared many of Sturm's ideas and at least some of his pedagogical zeal. Towns possessing large schools and universities soon became breeding grounds for printing-presses, followed soon after by the production and sale of textbooks. It is notable that Conrad Dasypodius's return to Strasbourg from Louvain in 1562 kickstarted a period of his life that was characterised by a significant increase in his publishing efforts. In particular, Dasypodius, in conjunction with his predecessor as professor of mathematics, Christian Herlin, was responsible for the translation and publication of a number of Greek works, including those of Euclid, Aristotle, Theodosius, and Autolycus. ${ }^{90}$

\footnotetext{
${ }^{86}$ Goeing, Storing, Archiving, Organizing, p. 129.

${ }^{87}$ Conrad Dasypodius, Volumen primum mathematicum. Prima, et simplicissima mathematicarum disciplinarum principia complectens: Geometriae. Logisticae. Astronomiae. Geographiae. Per Cunradum Dasypodium in utilitatem academiae Argentinensis collectum (Strasbourg: Josias Rihel, 1567). See also Anton Schindling, Humanistische Hochschule und freie Reichsstadt: Gymnasium und Akademie in Strassburg 1538-1621 (Wiesbaden: Steiner, 1977), pp. 206-7.

${ }^{88}$ Letter from Johann Sturm to Conrad Dasypodius, 1569, in Spitz and Tinsley, Johann Sturm on Education, p. 321.

${ }^{89}$ Letter from Johann Sturm to Conrad Dasypodius, March 1565 in Spitz and Tinsley, ibid, p. 295.

${ }^{90}$ C. Doris Hellman, The Comet of 1577: Its Place in the History of Astronomy (New York: Columbia University Press, 1944), p. 237. For an extensive list of Dasypodius's publishing endeavours, see Hellman, The Comet of 1577, p. 238, fn. 24.
} 
On the face of things, the motivations for this were simple. Conrad Dasypodius prefaced his Euclidean works by drawing attention to long-standing curricular regulations, and to the fact that all students were to learn the Elements from their first classes onward. The teacher argued that it would be best, then, if pupils were to have access to a small though complete treatment of Euclid's work - a position few could disagree with. ${ }^{91}$ By happy accident, any such translation would also advance Conrad Dasypodius as a mathematician and a humanist: the recovery of classical Greek texts remained a feather in the cap for humanists of any stripe. At a deeper philosophical level, however, Dasypodius's efforts were part of a more general movement to present Euclidean proofs as Aristotelian syllogisms: ${ }^{92} \mathrm{a}$ movement that would ultimately be rejected as abstruse and unnecessary by Ramus and the Oxford mathematician Henry Savile, amongst others. ${ }^{93}$

\section{Print, paratext, and epitext: Fincke's Geometriae rotundi and its influences}

Existing one after the other as part of a pedagogical network influenced by the educational reforms of Philip Melanchthon and located at Johannes Sturm's Strasbourg Gymnasium, Conrad Dasypodius and Thomas Fincke nonetheless differed entirely in their appreciation of how geometry might best be presented dialectically. For Dasypodius (and his teacher and now colleague, Herlin), Euclid's Elements would be improved by transforming proofs into syllogisms, bringing the axiomatic structure of the text into agreement with the first principles of Aristotelian logic. ${ }^{94}$ For Fincke, following Ramus rather than the Strasbourg tutor, little more than a methodical redrawing of Euclidean geometry would do: the Dane therefore chose not to syllogize Euclid, but sought instead to ally himself with Petrus Ramus's more radical departure from the Greek mathematician by means of methodological presentation and an extensive use of other mathematical texts, following largely in

\footnotetext{
${ }^{91}$ Neal Ward Gilbert, Renaissance Concepts of Method (New York: Columbia University Press, 1960), p.84.

${ }^{92}$ Gilbert, ibid, p.89.

${ }^{93}$ Giuliano Mori, 'Mathematical Subtleties and Scientific Knowledge: Francis Bacon and Mathematics, at the Crossing of Two Traditions', British Journal for the History of Science, 50.1 (2017), pp. 1-21, p. 11.

${ }^{94}$ Vincenzo de Risi, 'The development of Euclidean axiomatics. The systems of principles and the foundations of mathematics in editions of the Elements in the Early Modern Age', Archive for History of Exact Sciences 70. 6 (2016), pp. 591-676, p. 598. See also H. D. P. Lee, 'Geometrical Method and Aristotle's Account of First Principles', The Classical Quarterly, 29.2 (1935), pp. 113-124.
} 
the process the French pedagogue's method of mathematical presentation. The contrasting positions taken by Dasypodius and Ramus were a reflection of ongoing debates on the relationship of dialectic to mathematical certainty, and on the very idea of mathematical certainty more generally. ${ }^{95}$

Thomas Fincke's reasons for writing Geometriae rotundi were, however, tied to more personal goals. Positioned as an introductory, Ramist textbook, Fincke's work offered students and their teachers an expeditious yet complete guide to the art of spherical geometry. At a higher level, the tables presented as improvements to Georg Joachim Rheticus's astronomical canons were a vehicle for the author to demonstrate his own abilities to an expert audience. Having proven his command of geometrical theory, Fincke's intention was to use his calculation of sines, tangents and secants to greater levels of precision as a platform from which to definitively evaluate the computations of a range of prior mathematical authorities. Reared as he was on the pedagogical traditions of Melanchthon and Sturm, the young author introduced his volume with learned oratory and intensive textual analysis so as to participate in an ongoing philological process of mathematical reconstruction. Doing so would, in his estimation, allow him to reformat the presentation of geometry according not to the received wisdom of Euclid, but rather to a new approach popularised by Petrus Ramus.

It is in this context that Geometriae rotundi's peritextual materials-a dedicatory epistle to Frederick II of Denmark (1534-1588); the Praefatio ad Lectorem addressed to the English mathematician Thomas Digges and to a host of Fincke's near-contemporaries; and, at the threshold of the text, the branching, diagrammatic visualisations specifying the division of topics into their composite parts common to 'Ramist' texts of the early modern period (Figure 2.5, below) helped to mediate readers' understandings of what followed. ${ }^{96}$

\footnotetext{
${ }^{95}$ For a detailed summary of these debates, see Chikara Sasaki, Descartes's Mathematical Thought (Dordrecht, Boston, and London: Kluwer Academic Publishers, 2003), pp. 333-358.

${ }^{96}$ Ong, Ramus, Method and the Decay of Dialogue, particularly pp. 307-314. Ong has consistently and, at times persuasively, argued for the conceptualisation of Ramism as a visual methodology: one diffused as part of an 'aural to visual shift' made possible by the printing press.
} 


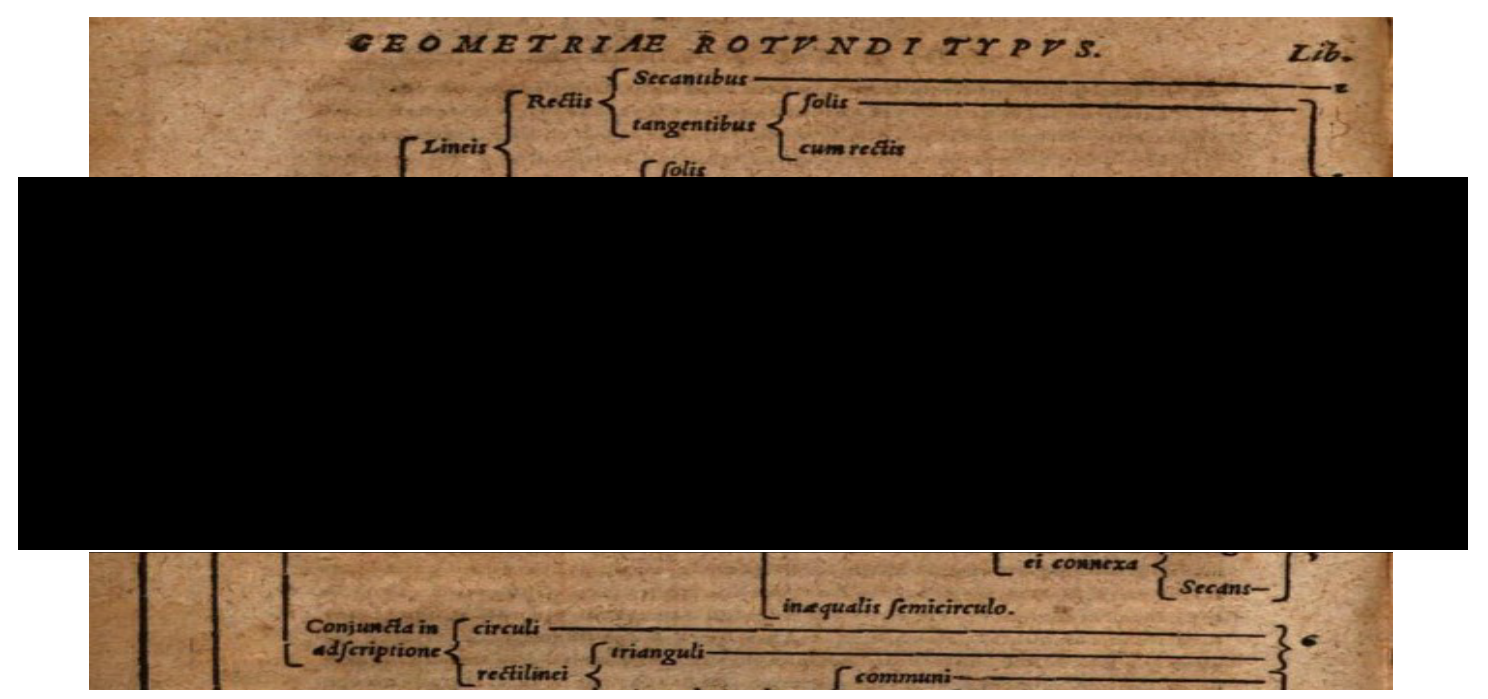

Figure 2.5. Excerpt from a diagram explicating the Ramist organisation, chapter by chapter, of Thomas Fincke's Geometriae rotundi (1583).

Fincke began by citing a number of prestigious mathematical authorities, old and new, as belonging to the cultural epitext surrounding his own intellectual development, before offering readers his own synthesis of a methodological presentation of spherical geometry from within a vision of mathematics predicated on dichotomies and definitions. ${ }^{97}$ These introductory epistles took their place within the author's humanist adherence to persuasive oratory, and it should be noted that the tone of each letter was altered according to their intended audience. A consequence of this is that the paratextual elements of Fincke's text are as much a part of his mathematical presentation as any other page of print: as Brian Vickers has counselled, the discipline of rhetoric taught in the Renaissance and early modern periods encouraged would-be orators and authors to be sensitive to their reader's likely intellect, emotions, judgement, and response when gauging how best to frame their epistles. ${ }^{98}$ Addressing (and celebrating) Frederick II, Fincke's prose was marked by a pomposity rarely seen elsewhere in his text. ${ }^{99}$ Treating Digges and his

\footnotetext{
${ }^{97}$ Fincke, 'Epistola Nuncupatoria', Geometriae rotundi, f. 4 r.

${ }^{98}$ Brian Vickers, 'Epideictic and Epic in the Renaissance', New Literary History, 14.3 (1983), pp. 497-537, p. 498.

${ }^{99}$ See, for example, Fincke, 'Epistola Nuncupatoria', Geometriae rotundi, f. 2 r: 'Videre id cum aliis in rebus, tum literis humanioribus licet: maxime vero iis in artibus: quae ob certam suam, quam pariunt scientiam [...] mathematicae solae vocantur.' For Fincke's celebration of Frederick II's patronage, see Fincke, ibid, f. 4 v: 'Quin et aequum esse arbitrates sum: ut grata Mathemata suos maxime Mecaenates et Patronos celebrarent. In quorum numero regiam T. M. consistere: vel insignis illa erga nobilissium et in Mathematis excellentissimum virum Dn. Tychonem Brahe magnificentia docere satis poterit: Academia vero Hafniensis nunquam tacebit.'
} 
fellow mathematicians as intellectual equals, the Danish mathematician's praise for his ideal readership was more understated, if occasionally still fulsome.

Importantly, the prefatory letter addressed to his ideal readership serves to highlight the manner in which Thomas Fincke utilised the rhetorical writing strategies and intensive collation taught as part of his humanist education to marry together two key issues which had inspired the creation of Geometriae rotundi. In dialogue with his fellow mathematicians, the cautious Dane was able to situate his desire to restructure the Euclidean method of presentation by couching his experience with the Greek author as unsettling and confusing. Blaming Euclid for perturbing him so, Fincke turned to praise Ramus for recovering the art that was there all along. The former's harmonization of the luminescent qualities of reason with the dialectical qualities of mathematics was most clearly invoked in his Prefatio ad Lectorem:

Therefore, thinking of another means of coming to know this divine knowledge than the one presented to me - for with this latter way, one would succeed little - I turned myself to Petrus Ramus's book of geometry, where I found immediately that which I had long desired in Euclid. Traces of the clearest methods presented themselves, and that particular art itself is seen to be taught more abundantly, and more brilliantly. ${ }^{100}$

This quest for clarity had led to the creation of Geometriae rotundi: Ramus, as the autodidactic Fincke's textual teacher, had shown the way through a humanist method marshalling copious authorities and definitions into a coherent, logical order. In doing so, the practically-minded French pedagogue had (in Fincke's eyes) made his methods and results congruent to reason, uncovering the building blocks of the art of geometry as he went - and revealing to his autodidactic charge the importance of logical structure to mathematics. ${ }^{101}$ The visual, illuminating nature of such a description of method distinctly echoed Petrus Ramus's celebration of the discipline as coterminous with dialectic in Dialecticae institutiones, in which the author argued

\footnotetext{
${ }^{100}$ Fincke, 'Praefatio ad Lectorem', Geometriae rotundi, f. 1 v: 'Alia itaque ad perscrutandam divinam hanc scientiam, via insistendum mihi putabam: cum hac successisset parum, itaque ad $\mathrm{P}$ Rami me volumen Geometricum converti. inveni illico quod in Euclide desideraram diu, nam et methodi sese clarissima offerebant vestigia: et ars quoque ipsa copiosius aliquanto et luculentius instructa videbatur.'

${ }^{101}$ Fincke, Geometriae rotundi, f. b 1 v: 'Apuerit mihi vir hic mentis oculos: quod Logices usum in Mathematis egregiè monstrate est visus'.
} 
that the mathematical arts, understood through the correct use of dialectic, would both illuminate and purify all other disciplines and so elevate the understanding of all things. ${ }^{102}$

By way of this introductory dialogue, Fincke subtly deprecated his ambition to compare the astronomical calculations of Geber, Regiomontanus, and Copernicus, with those of Ptolemy, Rheinhold, and Fincke himself, with a view to gauging which were most concise and efficacious. Instead, Thomas Digges (or, indeed, any similarly expert reader) would be the judge. ${ }^{103}$ Fincke could thereby be absolved of any accusations of arrogance, whilst still encouraging his audience to place him alongside the great theorists of his discipline. Immersing readers thereafter in a distinctly Ramist presentation of spherical geometry throughout his work, the author's peritext was crafted to bring the epitextual values of his education to bear in two specific ways. Fincke's employment of a respectable, epideictic rhetoric was crafted so as to encourage readers to witness him as an altruistic reformer, seeking to recover and advance mathematical thought in equal measure. To this end, Geometriae rotundi's introductory epistles were in keeping with the style of literary rhetoric advocated by a range of humanists, amongst whom Sturm and Melanchthon were the latest inheritors. At the same time, Fincke's advocacy of Ramus's logical style and organisation of mathematical material over that of Euclid (and, indeed, Aristotle and the scholastic tradition) marked him as an active member of a new school of thought: one influenced by Melanchthon, Sturm, and Ramus, in which mathematics could be allied to dialectic as a method for discerning certainty.

Whilst it is difficult to state with absolute confidence that sixteenth-century readers of Fincke recognised themselves as part of this school of thought, it can at least be marked that the growth in Ramist literature previously referred to had a

\footnotetext{
102 Ramus, Dialecticae institutiones f. 39 v: 'Itaque cum has disciplinas lumine suo dialectica lustraverit, quanto iam plenius naturalium principia rerum, et umbrarum illarum causae cernentur.' Goulding has argued that this section of Ramus's work outlines the author's view that mathematics is both improved by and identical with dialectic, with the discipline's lofty position owing to mathematics' ability to assess truth and certainty. Goulding, Method and Mathematics, p. 68. ${ }^{103}$ Fincke, 'Praefatio ad Lectorem', Geometriae rotundi, f. a 3 r: ‘(...) alis Mathematicis notum mihi primum factum est nomen tuum. Fac quaeso: ut sicuti scalas coelo compendiosas admovisti: sic brevissimos ad sydera in calculo accessus eligas. Quod utinam Copernici problemata praestarent. Ego enim quo pacto praestent videre nondum possem. Tu itaque, mi Thoma judicabis: et calculum Gebri, Regiomontani, itemque Copernici, cum eo, qui hisce in libris ex Ptolomaeo atque, Rheinholdo deducitur, conferes.'
} 
lasting impact on educational trends in Northern Europe. The method of division, definition, repetition and construction offered by Ramus's works was naturally applied to his texts on the trivium and quadrivium alike, and Thomas Fincke's debt to the French pedagogue in this respect is readily apparent. Written consistently in the style of Geometriae septem et viginti, when Fincke's Geometriae rotundi does not borrow wholesale from Petrus Ramus's works the latter (or, occasionally, Fincke's other key influence, Regiomontanus) was afforded the final or definitive word amongst a host of authorities.

Geometriae rotundi's first five chapters take the form of an introduction to the geometry of the sphere, with particular focus granted to the radius: its relationship to methods of dividing the circle in right lines and triangles (Book I), and that same relationship to the creation of sines, tangents and secants of a semicircle (Book V). From Book VI onwards Fincke presented plane trigonometry, including methods to square the circle (Book VIII) and the trigonometric canons (Books IX and X), based on the calculations of Georg Joachim Rheticus (15141574), which dominate much of the volume. Geometriae rotundi then concluded with lessons on the construction and measurement of spherical triangles (Books XIII and XIV).

Introducing the form of the circle in Book I, Fincke referenced Thales of Miletus, Ptolemy, Aristotle, and Euclid to demonstrate the proposition that the shape in either plane or solid form provides a maximum area compared to that of any other polygon with an equal perimeter. ${ }^{104}$ Authorities were stacked higher and higher, with the author adding Theon of Alexandria's commentary on the Almagest as proof of the mathematical demonstration of this fact; but the bluntest proof is that of Ramus, expressed diagrammatically, in which the perimeters and areas of an equilateral triangle, a square, and a circle are presented (Figure 2.6). ${ }^{105}$

\footnotetext{
${ }^{104}$ Fincke, Geometriae rotundi, p. 6: 'Nam ut in planis circulus quolibet rectilineo ordinato, sic in solidis sphaera ordinatis quibuslibet corporibus est ordinatior (...) Et vero axioma illud et principium Geometricum est: ex isoperimteris homogeneis ordinatius est majus, ex heterogeneis ordinatis terminatius.'

${ }^{105}$ For Ramus's treatment of isoperimetric figures, see Ramus, Geometriae septem et viginti, Book IV, pp. 19-33, and Book XIX, pp. 130-134. The diagram illustrated in Figure 2.6 is found in Fincke, Geometriae rotundi, p. 7, and is based on that of Ramus, Geometriae septem et viginti, p. 133.
} 


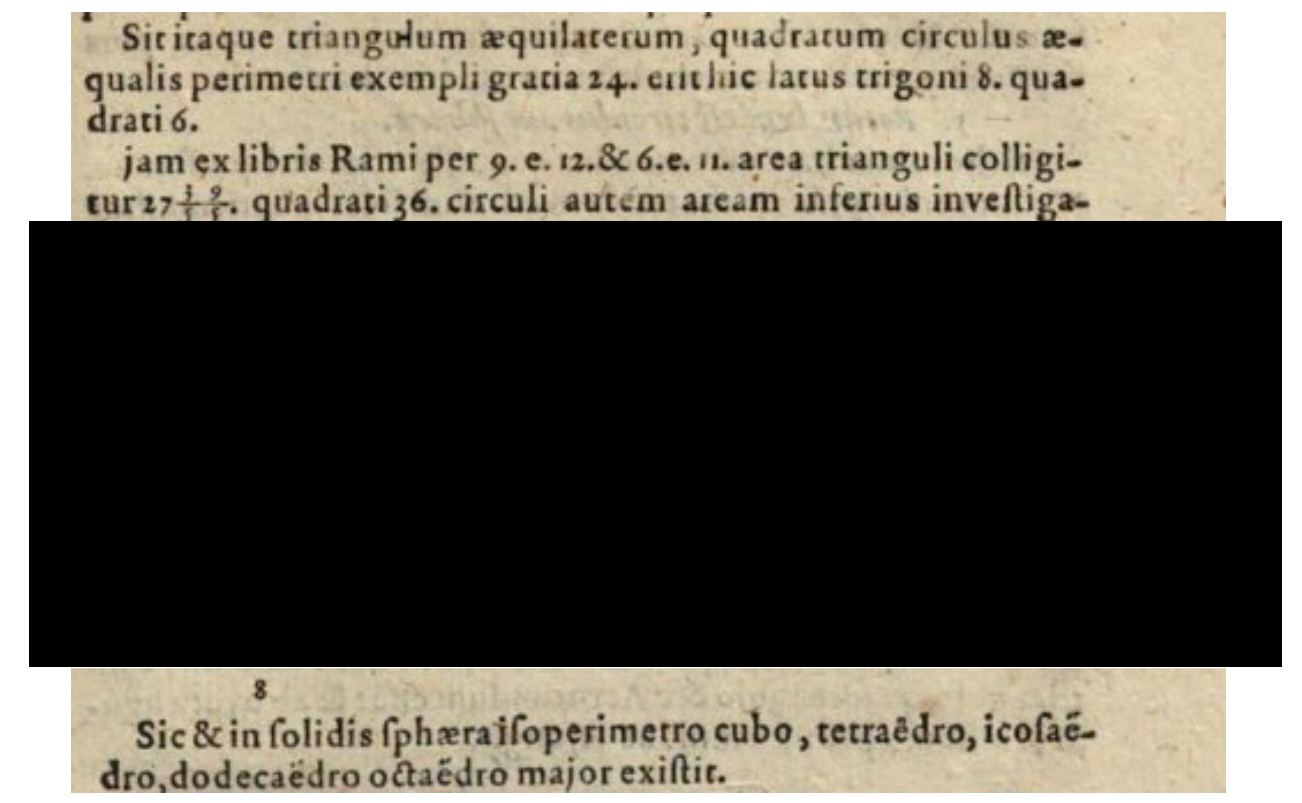

Figure 2.6. An example of Thomas Fincke excerpting material directly from Petrus Ramus's Geometriae septem et viginti, in this case detailing isoperimetric figures. As can be seen (though the diagram is not drawn to scale) the perimeter of each shape is given as 24; the areas of the triangle and quadrilateral are both less than that of the circle.

The organisation of this proposition followed Ramus's explanatory mode of mathematical presentation in its use of definition, enunciation, and construction. Aided by copious authority, the mental cognizance advocated by Fincke's presentational method chimes with the aforementioned identification of Ramism as an 'observational' methodology: ${ }^{106}$ the reader is encouraged, thanks in no small part to the supposed clarity of this method, to mentally recognise the truth of these written propositions swiftly, and without significant difficulty. ${ }^{107}$ As is frequently seen to be the case elsewhere in Geometriae rotundi, the composite parts of the argument were defined previously, with each conclusion built upon the foundations of the preceding one. Diagrams, used consistently (if sparingly, as in Ramus's own work), were secondary to the structure of the printed text. ${ }^{108}$

\footnotetext{
${ }^{106}$ Menghini, 'From Practical Geometry to the Laboratory Method', p. 565.

107 This chimes with Pierre Duhamel's assertion that 'one of the more or less explicit assumptions of the Ramist dialectic was the inevitability of the mind's assent to a true proposition, once it was presented to the mind'. Pierre Albert Duhamel, 'The Logic and Rhetoric of Peter Ramus', Modern Philology, 46.3 (1949), pp. 163-171, p. 169.

${ }^{108}$ It should be noted that in this example the diagram which follows the proposition is visibly erroneous. Although the area of the circle is numerically significantly larger than the square or triangle, as the printed numbers indicate, the diagram itself was not drawn to scale. It is possible that Fincke's printer was so convinced by the methodical presentation of the proposition that the errors in
} 
Thomas Fincke then bookended his mathematical material with additional philosophical excerpts from Plato, Aristotle, and Quintilian; each selected to portray the perfectability of circle and sphere and their value to the study of geometry - and, beyond that, to the study of natural order. ${ }^{109}$ This is but one example of the way in which the arguments of Geometriae rotundi were consistently built from a cascade of sources. Their series of definitions were most often succeeded by blunt, explanatory sequiturs expressed in precisely the same format and diction as Fincke's mathematical proofs almost without fail: the implication being that many of these proofs were self-evident by observation of their preceding parts - a position that follows that adopted by Petrus Ramus. Fincke's commitment to the lessons of the French pedagogue might even at times be termed arch-Ramist, given the way the Dane abbreviated his authorities even more succinctly than might be thought necessary.

Such presentations shared two points of convergence, each crafted to secure the author's mathematical authority. Firstly, the author was careful to consistently reference authorities such as Euclid, ${ }^{110}$ Regiomontanus, ${ }^{111}$ and (most frequently) Ramus $^{112}$ by chapter and verse, indicating the precise points where readers might pick up his predecessors' work. This conscientious approach served in part to convince the reader that Fincke's conclusions might be verified by comparison with

\footnotetext{
the diagram escaped his attention....though perhaps more likely that the diagram was simply incorrectly copied from Ramus's source material before going to print.

${ }^{109}$ Fincke, Geometriae rotundi, p. 7. This section is compiled from references cross-pollinating and supporting one another. The paraphrasing of Plato's Timaeus, for example ('Atque hinc Plato dixit, rotundam figuram omnium esse perfectissimam: ideoque Deum mundum Sphaericum figurasse: ut suo complex cuncta contineret') supports Ptolemy's idealisation of the sphericity of the heavens, in which the sphere is the figure with the 'freest motions', and therefore most suitable for the form of the heavens. Ptolemy's Almagest, trans. G.J. Toomer (Princeton, NJ: Princeton University Press, 1998; originally London: Duckworth Press, 1984) pp. 39-41.

110 Euclid's work is well represented throughout Geometriae rotundi in the italicised definitions and propositions strewn throughout each book. Mostly, material taken from the Elements is provided without naming the author, as, for example, in Fincke, Geometria rotundi, p. 8: ' 6 . Circulus est rotundum planum. 15. d.1'. Euclid's fifteenth definition in the Elements's Book I stated: 'A circle is a plane figure, conteyned under one line, which is called a circumference, unto which all lynes drawen from one point within the figure and falling upon the circumference thereof are equal the one to the other'. Henry Billingsley, The Elements of Geometrie of the Most Auncient Philosopher Euclide of Megara (London: John Daye, 1570), f. b iij.

${ }^{111}$ Similarly, Regiomontanus's work was used both within the text and to provide introductory definitions and guidance: see, for example, Fincke, Geometriae rotundi, p. 67: 'Radius aeque potest sinibus peripheriae et complementi. 1.p. Regio de sinib,'.

${ }^{112}$ Fincke, ibid, p. 83: 'Nam quadratum semissis lateris de quadrato radii relinquit quadratum perpendicularis per 5. e. 12. R. (...)'.
} 
his voluminous sources; assuredly, this approach also worked to convince readers that his work was enough of a compendium to be trustworthy. Secondly, and more importantly, the author was just as careful to situate himself alongside classical mathematicians when subtly critiquing more recent theory, mounting stirring defences of the mathematical art as a product of rediscovery rather than novelty. In this manner, Fincke concluded his fourth book by marking how Hipparchus, Menelaus and Ptolemy improved the theory of chords only by abbreviation; ${ }^{113}$ likewise, Copernicus, in his 'marvellous' work, had, along with Peurbach, succeeded by retaining much of the classical mathematicians' thought. ${ }^{114}$

By this token, the effects of Johannes Sturm's influence on the young mathematician should not be underestimated, even if Sturm's professional interest in mathematics was limited. As a well-educated product of the Strasbourg model of education, Thomas Fincke presented his work within a context of rhetorical and mathematical appeals to key classical authorities, as taught by the humanist gymnasia and universities of his era. At the same time, the author utilised Geometriae rotundi as a theatre in which to rehearse and perform his extensive learning for reputational gain. Before presenting the sine canons which he hoped would help make his name, Fincke had to first of all guide his reader through their geometry of their construction. To do so, Geometriae rotundi's Book VII defined how a circle circumscribed a series of regular polygons - including the equilateral triangle, pentagon, hexagon and decagon - and then used the sides of each polygon to compute the chords of the circle's circumference from a given radius. ${ }^{115}$ Having obtained these chords, the mathematician could then follow Regiomontanus and Rheticus by decimalising the radius and its sines to ever greater degrees of accuracy.

Prior to his explication of the decimalisation of the radius, Fincke followed Ramus in situating his methodical presentation amongst a clutch of classical and contemporary authorities, buttressed by evidence from nature herself. ${ }^{116}$ Citing

\footnotetext{
${ }^{113}$ Fincke, ibid, p. 63: 'Atque sic Ptolemaeo, quae debere ipsi volvi, exolvi: referens ipsius theoremata de subtensis: et ad suum locum ut puto referens. Hipparchus de subtensis scripsisse refertur libros 12 . Menelaus (...) de iisdem libros sex consecerat. (...) Tantum in eo, hoc quidem in loco, brevitatis fuisse studium videmus. Brevitas hec tam grata accidit: ut a posteris Ptolemaica theoremata retenta fuerint.'

${ }^{114}$ Fincke, ibid: 'Retinuit Purbachius: retinuit Copernicus in opere suo mirando: retinuere alii'.

${ }^{115}$ Fincke, ibid, pp. 89-104.

${ }^{116}$ For Fincke's source material, see Ramus, Geometriae septem et viginti, p. 128.
} 
Varro's conjecture on industrious bees, their busy feet, and their tiling of constructions of hexagons within the hive, both Ramus and Fincke spoke of nature and geometry as being in perfect accordance in the circumscription of the hexagon within the circle. Importantly, however, the Danish mathematician diverged from, and then returned to, Ramus's source material and its form of demonstration in his treatment of the triangle and hexagon.

As he had elsewhere, Petrus Ramus used Geometriae septem et viginti's eighteenth book to edit and reorder several of the propositions of the Elements. Expanding on Euclid's work, the French pedagogue appended a summary of Varro's conjecture to Book XVIII's seventh proposition - a proposition which recapitulated the Elements' XIII:12 by stating that, if an equilateral triangle is inscribed in a circle, then the square is triple the square on the radius of the circle. ${ }^{117}$ From there, the French pedagogue cited Pappus and Campanus of Novara to show that, if the side of a circumscribed hexagon is cut proportionally, then the larger segment would be the side of a decagon. ${ }^{118}$ Ramus used this information to introduce the Elements' proposition XIII: 9, in which Euclid demonstrated that 'if the side of the hexagon and that of the decagon inscribed in the same circle are added together, then the whole straight line has been cut in extreme and mean ratio, and its greater segment is the side of the hexagon'; ${ }^{119}$ the pedagogue then considered (as Euclid had) the relationships between the figures of an equilateral pentagon, hexagon, and decagon inscribed within a circle.

In his adaptation of Ramus's geometry, Thomas Fincke retained much of his key source's order, content, and style. Yet rather than move exactly from the inscription of an equilateral triangle and its squares to the sides of a hexagon and decagon as the French pedagogue had, Fincke in Geometriae rotundi's Book VII instead inserted two additional propositions: proposition fifteen, detailing the

\footnotetext{
${ }^{117}$ Ramus, Geometriae septem et viginti, p. 128. Thomas L. Heath, trans., The Thirteen Books of Euclid's Elements, Volume III, $2^{\text {nd }}$ edn (Cambridge: Cambridge University Press, 1926; reissued in paperback 2014), pp. 466-467.

${ }_{118}$ Ramus, ibid: 'Si latus sexanguli secetur proportionaliter, majus segmentum erit latus decanguli.'

${ }^{119}$ Heath, ibid, p 455. Ramus introduced this proposition with reference to a right line continued beyond the sides of the inscribed hexagon and decagon, cut proportionally. Ramus, ibid, p. 129: 'Si decangulum et sexangulum inscribantur eidem circulo, recta é latere utriusque continuata secabitur proportionaliter, et majus segmentum erit latus sexanguli: et si majus segmentum rectae proportionaliter sectae est latus sexanguli, reliquum erit latus decanguli. 9 p 13.'
} 
construction and relationship of lines and triangles drawn from the end point of the side of an inscribed equilateral triangle, ${ }^{120}$ and proposition 16, on the inscription of the heptagon from a point perpendicular to the centre of a circle and the side of an inscribed hexagon. ${ }^{121}$ Proposition 15 was, in the author's argument, 'most noble for the construction of the canon of sines'. ${ }^{122}$

Displaying his own learning and the importance of continued inquiry, Fincke concluded his fifteenth proposition with Ramus's retelling of Varro's conjecture, before reporting how the great mathematician Pappus of Alexandria went beyond the hexagon in demonstrating that a series of other regular polygons were similarly circumscribed. Although the heptagon and nonagon could not be constructed in the same fashion, Pappus taught that they could be constructed from triangles, and their ratios calculated thereafter. This labour of the ancients had been passed down, with the authority of Pappus contrasted to Euclid, Proclus, Archimedes and Ramus; but as many had written, this art was difficult, with a variety of proposed solutions. ${ }^{123} \mathrm{In}$ the following proposition (proposition 16), the author went on to offer something of a resolution by outlining how 'mechanics' drew a heptagon by aid of the hexagon. ${ }^{124}$

As Ramus had, Fincke's seventeenth proposition of Book VII prefaced his treatment of proposition XIII:9 of the Elements by first treating the sides of a hexagon and decagon. As the image of Book VII's seventeenth proposition below (Figure 2.7) shows, Geometriae rotundi followed the order of operations previously set out in Geometriae septem et viginti. Aping the presentational method of the

\footnotetext{
${ }^{120}$ Fincke, Geometriae rotundi, p. 101: 'Si la termino lateris trianguli aequalteri inscripti duae rectae in puncta peripheria aequalitier a reliquo dicti lateris termino remota inscribantur: differentia inscriptarum aequatur inscriptae inter reliquum terminum et alterutram inscriptam.'

${ }^{121}$ Fincke, ibid, p. 102: 'Perpendicularis a centro in latus inscripti sexanguli, est latus inscripti septanguli.'

${ }^{122}$ Fincke, ibid, pp. 101-102: 'Differentia sinuum peripheriarum á sextante totius peripheriae aequali differentia majoris et minoris aequatur sinui differentiae. Consectarium certe pro constructione canonis sinuum nobilissimum'.

${ }^{123}$ Fincke, ibid, p. 102: 'Apis enim, ait alicubi Varro, sexangulam cellam sibi architectatur, quot habet

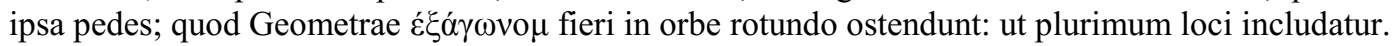
Hoc idem Pappo in Proemio libri quinti copiosius demonstratur. Et ita adscriptionem habemus trianguli, quadrati, quinquanguli, sexanguli, octanguli. Jam ad septangulum et nonangulum opus esset triangulo, cujus uter(que) angulus ad basin esset illic triplus hic quadruplus reliqui. In hujus inventione multum posuisse operae atq(ue) studii Geometras veteres accepimus. Quidam, ait Proclus, ab Archimedis, helicibus incitati in datam rationem datum angulum rectilineum secuerunt. Conatus illos Geometricos P. Ramus scholis suis Mathematicis inseruit lib. 12. in 4, Euclidis. Qui illic perlegi possunt: artificium est difficile, multiplex et varium.'

${ }^{124}$ Fincke, ibid: 'Mechanici tamen septangulum inscribunt opera sexanguli hoc modo.'
} 
French pedagogue, Fincke began with a definitive statement detailing the problem, headed by italic type. Beneath this, brief statements of fact on the constituent parts of the topic were collated. As I have previously suggested, the overall effect was to inculcate a similar kind of 'observational' geometry to that of Ramus: one in which the truth of the matter is laid out systematically before the reader. Theory gave way to blunt, abbreviated definition, with copious authorities providing the necessary scaffolding.

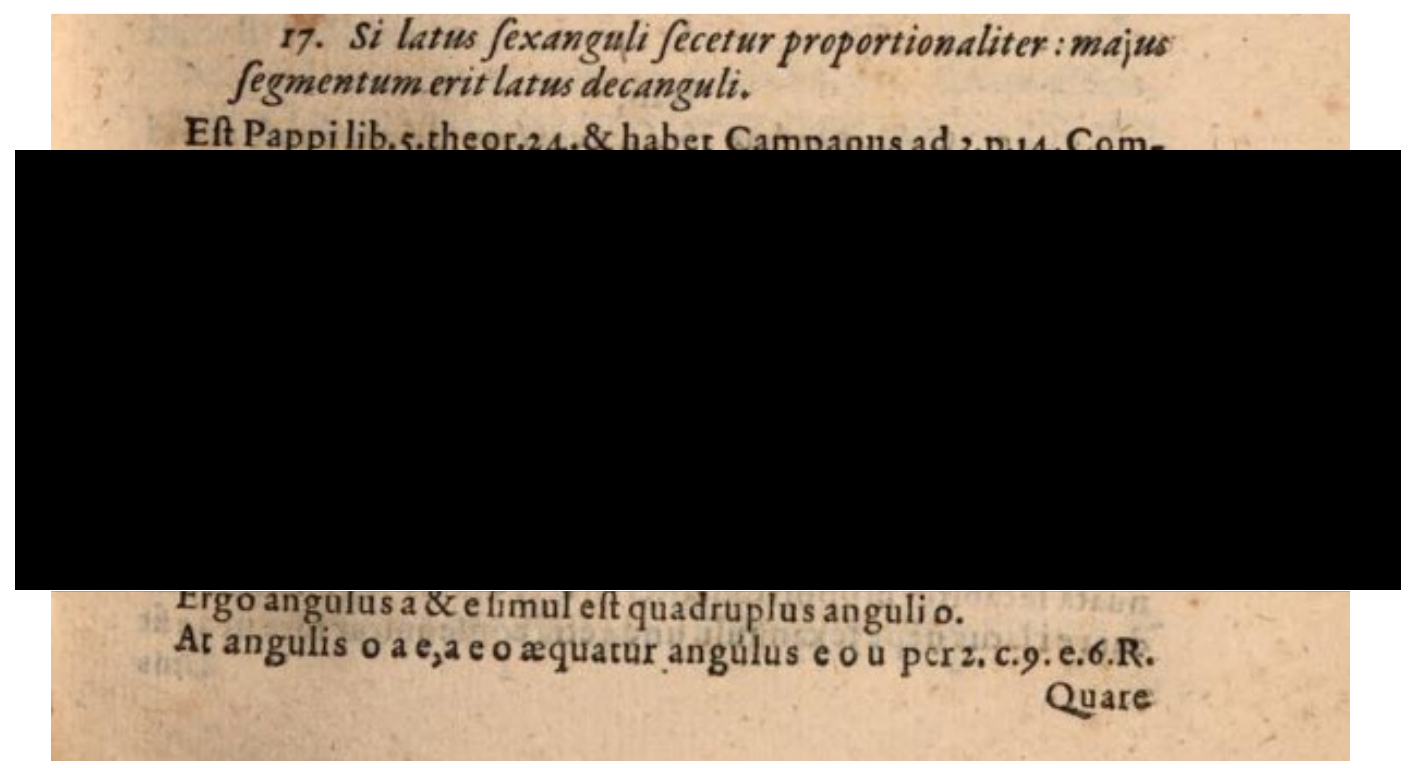

Figure 2.7. The seventeenth proposition of Geometriae rotundi's Book VII. The proposition was headed by italic type, beneath which authorities and definitions were arranged in a similar presentational style to Petrus Ramus's work. 


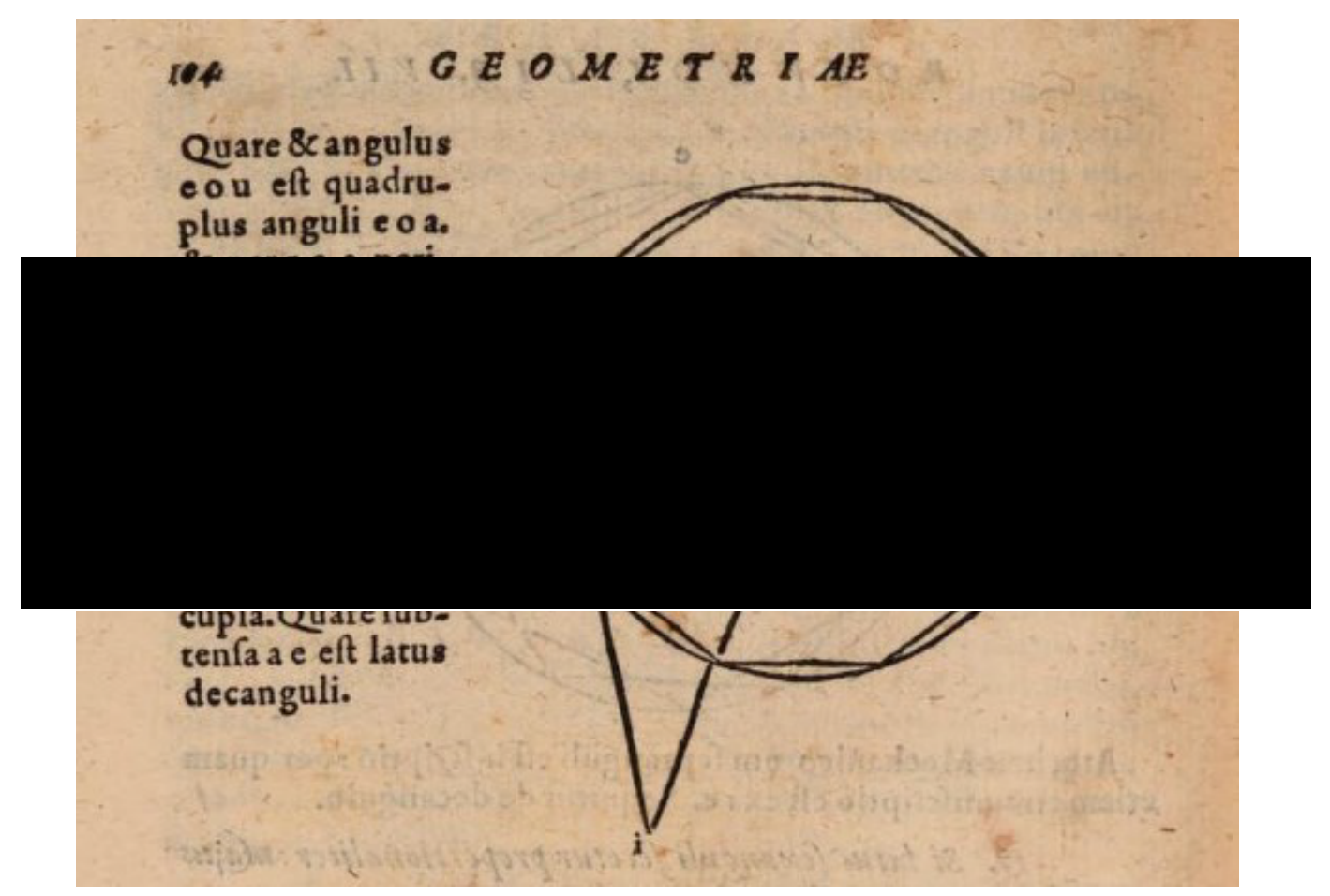

Figure 2.8. The proposition continued to the following page, working through the diagram shown in a demonstrative, apodictic fashion more common to Greek mathematical texts - including Euclid's Elements.

Although most often content to rely on his readership's ability to follow a step-by-step process whereby the factuality of the materials presented was recognised most frequently by brusque classification, it is clear from the example of proposition 17 that Fincke on occasion saw the need for a more classical form of demonstration than that offered by Ramus. Despite his professed discomfort with the Euclidean presentation of geometry, the author incorporated a more demonstrative mode than that advised by Ramist method where Fincke deemed it necessary.

Whereas the first two paragraphs of this proposition followed Ramus's source text in content, in order and in presentation, the third paragraph broke from the pedagogue's method by clearly directing the reader's attention to the apodeixis, or proof, which followed. ${ }^{125}$ Fincke's presentation in this section of the proposition thus belongs to a more classical style of mathematics common to works such as the Elements: one in

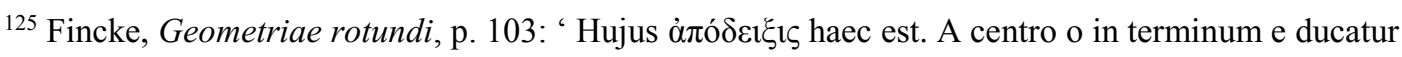
radius: fiet triangulum aequicrurum a o e cujus anguli ad a et e per 10. e. 6 . aequantur: et uterque duplus est anguli a o e per 7. e. Nam a o ex thesi secatur proportionaliter et a e et majus segmentum.'
} 
which the proof is provided through a sustained exposition of the particular objects of a given diagram. ${ }^{126}$

Thomas Fincke's infrequent blending of Euclidean and Ramist forms of presentation is perhaps best understood in the context of his wider goals and the rhetorical strategies he applied in their pursuit. In defining and demonstrating how chords and their sines were found through the construction of polygons within a circle, Fincke demonstrated that his mathematical practice varied little from the methods of Ptolemy, Peurbach and Regiomontanus. He could nonetheless point to improvements in the precision of his calculations; by framing Geometriae rotundi in this way, Thomas Fincke cautiously plotted something of a precarious path for his textbook. ${ }^{127}$ Making clear his knowledge and understanding of the works of Copernicus and Rheticus by comparison to their classical sources, the Dane strove to carve out for himself an uncontentious position as an expert humanist improver of spherical geometry, from which he might encourage his readers to see him as an altruistically-minded author whose comprehensive abbreviations and evaluations of his predecessors were for the benefit of teachers and students alike. In doing so, the author led his audience to see his work as part of a programme for the greater understanding and recovery of those sources, even as the discipline progressed.

At the same time, Fincke, himself an adherent and autodidactic reader of Ramus, sought to promote both the Ramist method as an ideal means to test the truth and validity of mathematical calculations, and the use of this method to interpret the mathematical elements of Copernican theory. Through this methodical reading and application of geometry, Thomas Fincke intended to present his own canons as improvements upon those of Rheticus, and, even more ambitiously, to evaluate the trigonometric calculations of a wider range of authorities. Wrapped in the garb of Petrus Ramus's pedagogical method, however, Geometriae rotundi was itself part of

\footnotetext{
${ }^{126}$ Reviel Netz, 'Proclus' Division of the Mathematical Proposition into Parts: How and Why Was It Formulated?', The Classical Quarterly, 49.1, pp. 282-303, p. 286.

${ }^{127}$ Considering the Dane's use of Copernican theory, Kristian Peder Moesgaard has described Thomas Fincke as a 'cautious' mathematician, and this term is suited to his work more generally. Kristian Peder Moesgaard, 'How Copernicanism Took Root in Denmark and Norway', in Jerzy Dobrzycki, ed., The Reception of Copernicus' Heliocentric Theory: proceedings of a symposium organized by the Nicolas Copernicus Committee of the International Union of the History and Philosophy of Science, Toruń, Poland, 1973 (Dordrecht: Springer Science + Business Media BV, 1972), pp. 117-152, p. 119.
} 
another, much more cautious attempt at reform; one conceived in an attempt to keep the baby from being thrown out with the bath-water.

Thomas Fincke may have argued for the methodical presentation of mathematics to be altered according to the precepts of Ramus, but at the same time he wished to guarantee that classical works remained ennobled in the schools of early modern Europe. ${ }^{128}$ The Dane admitted as much in the final lines of the tenth book of Geometriae rotundi, by which point he had largely abandoned one part of his original goal as put forward in his prefatory letter to Digges. If Ramus had charged Euclid with obscuring the natural reason of readers through abstruse constructions, Fincke could not afford the same accusation to be levelled at him. To avoid any possibility of Geometriae rotundi sowing confusion, students were strongly advised to remain in constant dialogue with their discipline's immortal masters, Regiomontanus and Ptolemy amongst them. ${ }^{129}$

In gathering up theoretical predecessors and saturating his text with reference to their works, Thomas Fincke had already expressed his intimacy with, and command of, the totality of their mathematical theory. The Dane's grafting of humanist learning on to the Ramist dialectical method was in one sense intended to provide pupils and their teachers with access to a style of presentation that he himself had found applicable, clear, and expeditious. As this was the method to which he attributed his own mathematical successes, the promotion of Ramist dialectic was thus intrinsically bound up with Fincke's astronomical calculations. In seeking to garner the disciplinary legitimacy required for his evaluation of astronomical authorities to be widely appreciated, Fincke had also used Geometriae rotundi to unseat one key authority in the teaching of early modern mathematics: Euclid, his supposed bête noire.

Seeing as it featured new approaches to spherical geometry in both terminology and, to a greater extent, methodological presentation, Thomas Fincke

\footnotetext{
${ }^{128}$ Fincke, Geometriae rotundi, p. 63: 'Et nos retinere voluimus ob pleniorum textus Ptolemaici intellectum: qui miseré hodie é scholis, superioribus tamen annis a vide receptus, exclusus videtur'. ${ }^{129}$ Fincke, ibid, p. 295: 'Habui id quidem in animo ut calculum Regiomontani itemque Ptolomaei et Copernici cum hoc praesenti conferrem: Verum ego hinc tyrones turbari existimavi: nec ab horum artificum immortalitati consecratorum monumentis abducere studiosos volui. Ubi hic perceptus fuerit: facile collatio institui poterit'.
} 
could hardly define his work as the epitome of a pre-existing and well-defined field of study. He could, however, present his text as a unique and forward-thinking synthesis of geometric knowledge, classical and modern: one that eschewed the dialogues, scholastic arguments, and other vestigial remnants of earlier texts, and advanced the discipline in the process. Furthermore, Fincke's sprawling, selfadvertised learning was a tactic to appeal both to those younger students seeking swift yet authoritative guidance in mathematics, and to fellow mathematicians. Consequently, the Danish author's command of mathematics was likely to be at the very least the equal of most of his readership.

Geometriae rotundi's paratextual materials, placed before and within the text itself, serve as appropriate frames through which to view the author's trigonometric and pedagogic constructions: through these frames, the author exercised his control over his reader's interpretation of his work. Crucially, an edifice built from copious reference to external authorities served to elevate Fincke himself to a position from where he could most appropriately present his mathematical textbook. Set against a growing number of classical and contemporary scholars, Euclid was often introduced as a lone voice: the engine which had moved the mathematician to the point of publication. On the one hand, Fincke could legitimately assail or correct the Greek author wherever necessary, destabilising where necessary Euclidean order, presentation and proof in the process; ${ }^{130}$ on the other, the Elements functioned as the foundation of an art requiring intensive recovery.

As a result, Euclid's dual role as Geometriae rotundi's progenitor and its preeminent antagonist was an authorial sleight of hand. Content to borrow the Euclidean definitions common to all who had studied mathematics in the period even as he decried what he perceived as the incorrect method of their presentation, Thomas Fincke nonetheless recognised the necessity of introducing readers to geometry through the terminology (and, occasionally, the mode of demonstration) used by the classical author. Only after the first five elementary books of Geometriae rotundi are

\footnotetext{
${ }^{130}$ Schönbeck, 'Thomas Fincke und die Geometriae rotundi', pp. 89-90. Jürgen Schönbeck notes that Fincke offered an alternative and more elegant solution to Thales's inscribed angle theorem as postulated in Book III, Proposition 31 of Euclid's Elements. This solution found its way into mathematical teaching literature, and was popularised in the eighteenth and nineteenth centuries.
} 
completed do we see Fincke openly acknowledge that Euclid's teachings (along with those of Ramus, unsurprisingly) had functioned as a cornerstone on which to build sufficient understanding for a novel presentation of the geometric and trigonometric relationships between circles and rectilinear lines. ${ }^{131}$ Without Euclid and Ramus, it would have been impossible (in Fincke's argument) to arrive at the point from which a more complex spherical geometry could be taught.

That Petrus Ramus was indispensable to the creation of Geometriae rotundi is apparent; nevertheless, the precise ways in which Thomas Fincke combined humanist reading with Ramist dialectic for the purposes of advancing mathematical teaching require further consideration. Though the Dane can be correctly positioned as a follower of Ramus, Geometriae rotundi's rather half-hearted treatment of the practical uses of mathematics would appear to indicate that the unification of theory with real-world practice was not amongst Fincke's uppermost concerns. Although willing to follow the French pedagogue by promoting geometry's worth to mathematical practice in the field or at sea, Thomas Fincke rarely convinces the reader that utilitarian application is of central importance. His calculated canons might certainly have been of use to navigators, but as a theoretician the author more often gave the impression that he wanted to improve the study of spherical geometry for the astronomer rather than the sailor. The practical value of his work lay in the clear and succinct elucidation of mathematical theory and its methodology, which could then be applied as the user saw fit.

Instead, Fincke's construction of a methodological commonality with Petrus Ramus consisted largely of utilising the latter's dialectical method to present advances in both the method and practice of mathematics. At the same time, he presented himself as a follower of Regiomontanus, and of the Germanic school of mathematics more widely, presenting his work to ideal readers such as David Wolkenstein, Conrad Dayspodius, Christian Ursitius, Michael Maestlin and Tycho Brahe, as well as the aforementioned Thomas Digges. ${ }^{132}$ Such authorities were at any

\footnotetext{
${ }^{131}$ Fincke, Geometriae rotundi, p. 80: 'Geometriam circularem nobis duplicé proposuimus: simplicem quidem solius circuli cum suis lineis et segmentis: conjunctam vero in adscriptione circuli et rectilinei ponimus. Cognitionem rectilineorum é Geometria vel Euclidis vel Rami huc adferri necesse est: nos ea saltem docebimus quae circulum attingunt'.

${ }^{132}$ Fincke, 'Praefatio ad Lectorem', Geometriae rotundi, ff. b 2 v - b 3 r.
} 
rate among the experts Thomas Fincke thought an appropriate audience for Geometriae rotundi's reception, but such a receptive hearing was somewhat out of kilter with the student readership for whom the text was initially constructed.

\section{Using the Wittenberg Sammelband: Reading print, paratext and marginalia}

A granular example of this audience can be approached by looking in on the early modern German classroom or university lecture through the marginalia found in the Wittenberg Sammelband's pages. Though sixteenth-century German students met with Ramist educational materials in their droves, both prior to and during their attendance at educational arenas such as sixteenth-century Wittenberg, evidence of the use of these materials has received little scholarly attention. As a result, our understanding of the transmission of Ramist teaching is lacking; more importantly, our understanding of the teaching and reception of mathematics in a culture devoted to literary models is significantly under-developed.

Up to this point, I have attempted a three-part historical reconstruction of the pedagogical milieu of the Sammelband: first of all, by showing how the material object presents evidence of Ramist and post-Ramist methods and their effects on early modern German pedagogy; secondly, by discussing how the volume was circulated amongst secondary school and university students; and, thirdly, by demonstrating how Thomas Fincke's mathematical thought, witnessed in one text of the Sammelband, was forged by and embodied these same cultural factors. How, then, did users respond to the volume's epitextual and paratextual representations of mathematics as clothed in Ramist dialectic and humanist rhetoric? What, if anything, can we untangle from readers' responses to this collection?

In situating the authors of the texts found in the Wittenberg Sammelband within their correct educational context, it bears repeating that the volumes which constitute this material object reflect the progression of students from gymnasium to university in late sixteenth-century Germany. By first utilising Ramus's mathematical texts for autodidactic or pedagogic practice, students such as Nicholas Hommer and Johannes Coppius would have acted entirely in the same fashion as large swathes of the school-going population of 1580s Germany. Pupils at Northern European gymnasia were introduced to basic arithmetic and geometry through 
Ramist and proto-Ramist teaching: this method would, if nothing else, provide learners with the tools to manipulate basic mathematical terminology, while emphasising the utility and practicality of the discipline. Petrus Ramus's systematic method, by which readers were encouraged to observe the branching relationships between the parts and the whole of a given art, could at least offer learners the simulacra of knowledge. Definitions were learned and parroted, even if true understanding remained absent.

For many, this method became an ideal mode of learning, its definitions and dichotomies affording users a means by which to visualise, comprehend, and recall the key elements of a variety of disciplines expediently. Where Ramus's works served as a suitable introduction to mathematical study (introductions that many would never graduate beyond), Thomas Fincke's textbook was intended for a moderately more advanced audience, and one that might have at least some existing knowledge of geometry. Furthermore, by consistently cross-referencing Ramist material, Fincke's text quite specifically suggested that Ramus's Geometriae septem et viginti libri be close to hand. It is difficult to imagine a student making much headway otherwise. For readers of Thomas Fincke, then, the Geometriae rotundi existed in an epitextual and mediatory conversation with Petrus Ramus's works.

If we take the Wittenberg Sammelband as indicative of an idiosyncratic crash-course in early modern mathematics in 1580s Germany, the purpose of binding texts from Petrus Ramus and Thomas Fincke together in a single, multi-faceted volume is clear. In their teaching of the rudiments of arithmetic and geometry via this expeditious and accessible method, a tutor (perhaps Johan Coppius) also appears to have used the volume as a springboard for the introduction of topics more appropriate for university study, including in his copy a sheaf of notes on sexagesimal notation and its value to astronomy. As a result, the reading practices and scribal technologies found therein are important examples of the types of public and private instruction delivered prior to, and, in many cases, alongside university tuition.

The presence of John Peckham's Perspectiva communis, along with the manuscript notes on sexagesimal notation, suggests that the Sammelband was intended to function as a guide to a significant portion of the early modern 
quadrivium. As has previously been shown, introductions to more rudimentary arithmetic and geometry were common, if poorly taught, at secondary and tertiary institutions across Europe, and the study of the sphere was elementary to early modern astronomy. Writing to Conrad Dasypodius in March 1565 to outline the year's mathematical course, Johann Sturm instructed Dasypodius to introduce pupils to the study of the physical world through Proclus's Sphere, Aratus's Phaenomena, Euclid, Aristotle, and arithmetic; ${ }^{133}$ reading Ramus's texts could aid with several of these works, with Geometriae rotundi something of a bridge between these introductory materials and the more demanding sub-disciplines of spherical geometry and the study of triangles. In these surroundings Peckham's text is rather the odd man out, belonging to both an older tradition of perspectival optics and to a more advanced study of mathematics than the volume as a whole appears to have witnessed. Its inclusion may indicate an attempt by a book-seller or purchaser to include material that would be of use should a subsequent owner achieve high standards in their reading of mathematics. The almost total lack of annotation on its leaves, contrasted to printed materials consistently written on, over, and around suggests that this was not to be.

It is certain that the second batch of users after Hommer and Coppius, namely Joseph Lobhartzberger and David Klynaeus, were at least in attendance at an institution that taught mathematics alongside the mathematical precepts of astronomy, and optics thereafter. That the users of the Wittenberg Sammelband were educated within the parameters of Melanchthonian doctrine is evident from the date and locations of their ownership inscriptions, and even more clearly from a declaratory statement prior to the final, manuscript notes at the rear of the volume. Immediately preceding the volume's manuscript notes on sexagesimal astronomy is a reproduction of Plato's oft-paraphrased maxim 'God always geometrizes' ('ó $\theta \varepsilon o ́ s$ ácí $\gamma \varepsilon \omega \mu \varepsilon \tau \rho \varepsilon \tilde{\imath})$ as seen in Figure 2.9 below.

\footnotetext{
${ }^{133}$ Letter from Johann Sturm to Conrad Dasypodius, March 1565, in Spitz and Tinsley, Johann Sturm on Education, p. 295.
} 


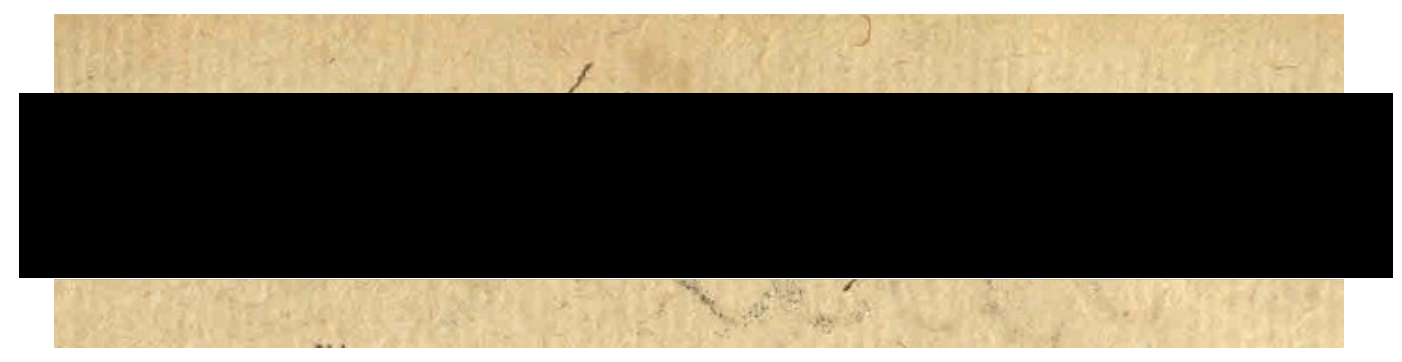

Figure 2.9. Plato, 'God always Geometrizes', prior to manuscript notes on sexagesimal astronomy, as found in the front leaves of Peckham's text in the Wittenberg Sammelband. Science Museum Library Shelfmark O. B. RAM RAMUS 30209019362791.

For us, this citation of Plato's apothegm immediately prior to notes on sexagesimal calculation appears demonstrative of an owner or users' familiarity with the place of mathematics in Melanchthonian educational doctrine. As we have previously seen, in his preface to Vogelin's geometry the Praeceptor Germaniae identified the foundations of natural philosophy and Aristotelian physics in mathematics; it was this same discipline that would guarantee man's correct understanding of the natural world, the heavens, and the Deity beyond. ${ }^{134}$ The two latter works bound to the rear of the Wittenberg Sammelband were by-products of the study of mathematics as inspired by that influence. Students at Wittenberg and other Lutheran institutions would have studied 'lower' mathematics (arithmetic and geometry) and, depending on their progress, 'higher' mathematics (astronomy and astrology) as part of the arts course undertaken prior to the elevated disciplines of medicine, law and theology. ${ }^{135}$ Although classical and medieval texts such as Euclid's Elements and Sacrobosco's De Sphaera remained predominant, the increased availability of print meant that students could supplement lecturers' notes (either distributed and copied, or taken by dictation in the classroom) with popular amended editions which included up-to-date commentaries - some, as in the case of those written by Conrad Dasypodius at the Strasbourg Gymanisum, authored by tutors themselves.

In this vein, students at Wittenberg might have encountered Sebastian Theodoricus Winshemius's Novae questiones spherae, hoc est, de circulis coelestis,

\footnotetext{
${ }^{134}$ Goulding, Defending Hypatia, p. 15.

135 Jardine, 'Places of Astronomy', p. 50.
} 
primo mobile (Wittenberg, 1564), reprinted six times between 1567 and $1605 .^{136}$

Earlier, in mid-century, the university itself had attracted astronomers such as Georg Joachim Rheticus, whose sine canons would form the basis of Thomas Fincke's Geometriae rotundi. When Fincke sat down to write his own textbook on the circle and sphere, he combined the Ramist method insistent on clear and expeditious definitions with a rhetoric which prioritised classical authority and noble use. Lessons from his recent past on dialectic, rhetoric, and the value of mathematics were surely fresh in his mind.

Thus the works of Ramus and Fincke contained in the Sammelband were textbooks constructed according to their authors' interpretations of an intellectual movement engineered by dint of Philip Melanchthon's pedagogical reforms in dialectic and mathematics and by Johann Sturm's teaching on method. By the 1580s, the motivations of this educational structure were twofold. It combined the centuriesold teaching traditions and structure of the liberal arts - a tradition familiarising learners with the rudiments of rhetoric, grammar, dialectic, arithmetic, geometry, and astronomy, before ascending toward natural philosophy - to a more recent pedagogical approach tested over the preceding decades: one focussed on definition, division, and topical reorganisation. The gymnasia of early modern Germany, swept up in the vogue for Petrus Ramus's works, thereby produced learners taught according to the precepts of a dialectical model broadly in agreement with the earlier sixteenth-century reorganisation of the liberal arts as championed by Agricola and further emended by Melanchthon, Sturm, and others. ${ }^{137}$

To what extent did the late sixteenth-century readers of the Wittenberg Sammelband recognise Ramus and Fincke's works as part of a cohesive educational movement? The fact that these materials were bound up with Peckham's thirteenthcentury scholastic work on optics and a sheaf of notes on sexagesimal notation - in use since the Babylonian era - would suggest that the Wittenberg Sammelband is

\footnotetext{
${ }^{136}$ Owen Gingerich, 'From Copernicus to Kepler: Heliocentrism as Model and as Reality', Proceedings of the American Philosophical Society, 117.6, Symposium on Copernicus (1973), pp. 513-522, p. 516.

137 Ong, Ramus, Method and the Decay of Dialogue, pp. 29-32. Ong divided Petrus Ramus's intellectual career into four main phases: rhetorical, methodical (focussed on dialectic and rhetoric), mathematical, and theological. Though a neophyte of Ramus's mathematical works, Thomas Fincke should be considered as influenced most strongly by the 'methodical' precepts of Ramus rather than his mathematical arguments.
} 
evidence of an inherently pragmatic educator, rather than a teacher at the bleeding edge of controversial, Northern European pedagogical developments. Even if this was the case, however, evidence of such pragmatism is nonetheless a valuable addition to our appreciation of the ways in which early modern mathematics was transmitted and received. We know that the French pedagogue's methods proved popular, yet intensive, reader response-led studies of Ramist materials remain thin on the ground.

Defining the marginalia found in mathematical texts as indicative of evidence of readers' mathematical literacy is a complex task. In a recent article considering annotators of Sacrobosco's Sphere in Paris and Cologne in the late sixteenth-century, Richard Oosterhoff has considered the means by which we may define marginalia found in mathematical texts as indicative of evidence of readers' mathematical literacy, proposing heuristically three broad categories of reading in response: the mining of mathematical or astronomical texts for material related to other, literary works; critical comparison of authorities on astronomical or mathematical knowledge; and, finally, calculations. ${ }^{138}$

Whereas many of the annotations found in the Wittenberg Sammelband fall uncomfortably between each of these helpful categories, they can nonetheless be redefined to serve my similar analysis of the two key texts of this volume. Following Oosterhoff's template, three broad categories of heuristic reading are proposed to assist our interpretation of the reading strategies at work in the Wittenberg Sammelband. The first is a 'mining' of key sections, with their contents redacted and paraphrased in summaries in the text's margins. The second category takes the form of a visual restructuring of these printed materials, with textual content reduced to the dichotomous schema so familiar to historical studies of the printed Ramist method. The third strategy features occasional amendment to, and conversation with, the volume's printed content - at work both within the text and on the margins just beyond. One annotator peppered the margins of the Sammelband with manuscript notes, their inscriptions appearing frequently in both Ramus and Fincke's works, and

\footnotetext{
${ }^{138}$ Richard J. Oosterhoff, 'A Book, A Pen, and the Sphere: Reading Sacrobosco in the Renaissance', History of Universities, 28.2 (2015), pp. 1-54, particularly p. 17.
} 
it is this annotator who will be considered in detail from this point onwards (Figure 2.10).

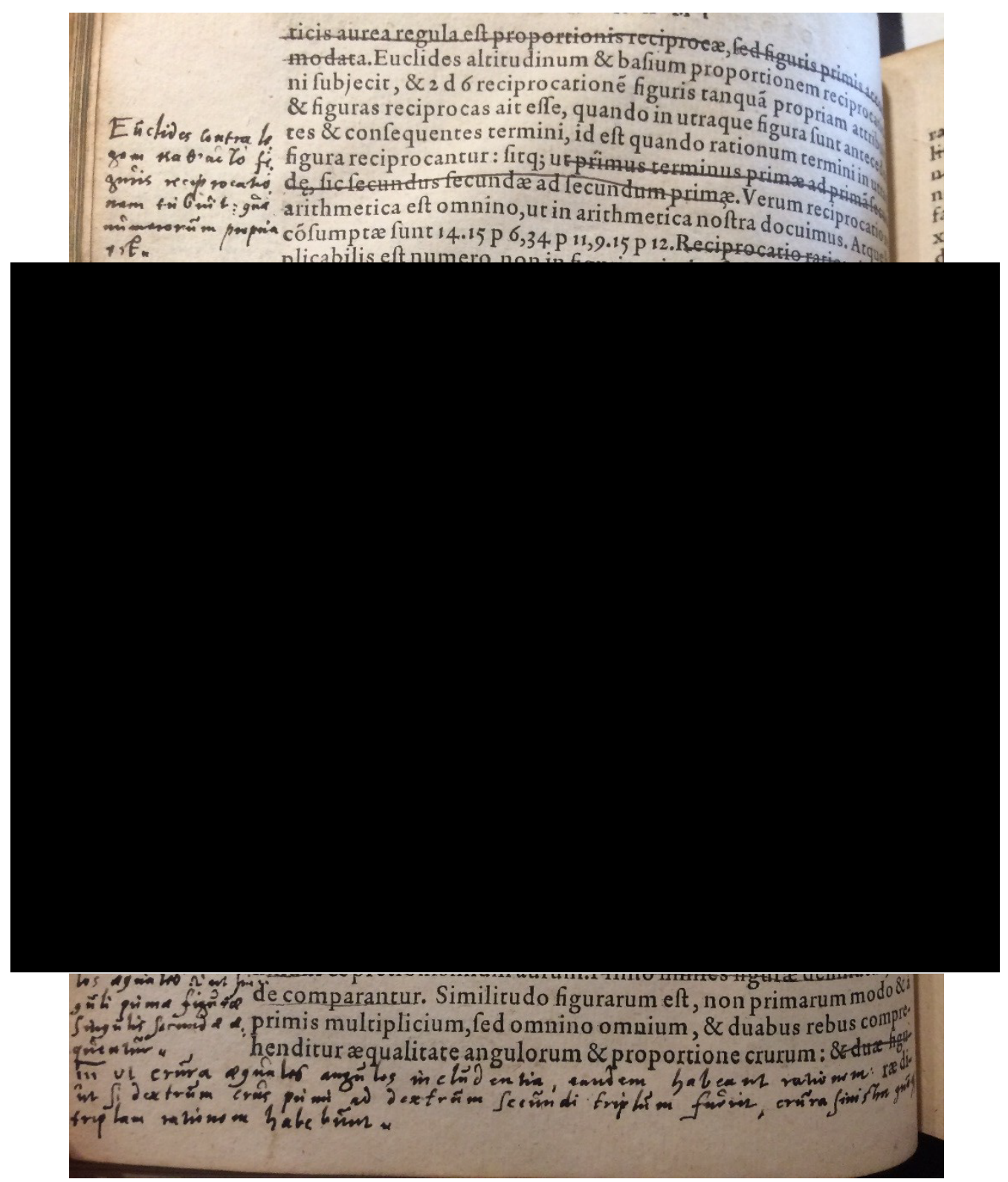

Figure 2.10. The annotating style most commonly found in the Wittenberg Sammelband. Sections are highlighted, struck through and paraphrased; occasional 'NB's specify important parts of the texts, and additional commentary (seen here under the section marked 'Demonstratio') reframes the printed text of Ramus, Geometriae septem et viginti. Science Museum Library Shelfmark O. B. RAM RAMUS 30209019362784.

The volume's opening Ramist and proto-Ramist texts were annotated by a user displaying a keen eye for the reconstruction of mathematical practice.

Commonplacing authorities, our annotator studiously collected the names of the mathematicians identified in Thomas Fincke's Praefatio ad Lectorem prior to 
Geometriae rotundi. In contrast to the other annotated sections of the volume, these names are not scored through, but underlined and then listed in the margins, as shown in Figure 2.11 below. ${ }^{139}$ Such readers would have met with and understood such paratextual elements on their own terms: whereas the authoritative names listed in the Praefatio ad lectorem fulfil the role of dedicatees for the author, the contemporary reader would more likely have used these figures as points of reference by which to situate Geometriae rotundi's mathematical theory.

Ultimately, identification of authority served the early modern reader mainly for the purposes of collection and recall of information. Where reference is made to such theoreticians, the brief notes that accompany their reference perform the function of an index rather than a commentary, and one akin to existing reading practices by which the gathering and framing of authorities and their texts were central to the entire educational edifice of thinking, reading, teaching, speaking and writing. ${ }^{140}$ Indeed, Thomas Fincke was as much a product of this practice as he was a proponent.

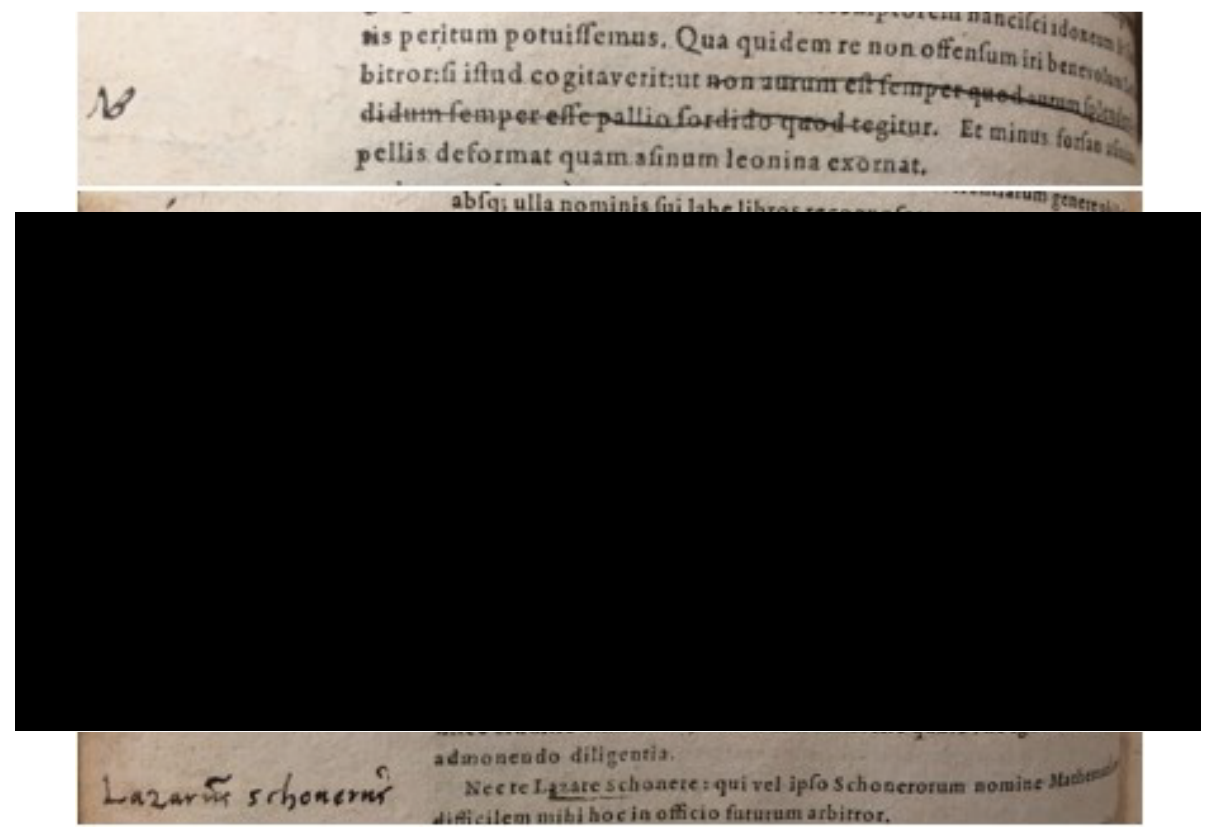

Figure 2.11. Composite image showing 'nota bene' ('NB') with text lined through, and, on the same page, a range of mathematical authors underlined in Fincke's Praefatio ad Lectorem. Science Museum Library Shelfmark O.B. RAM RAMUS 30209019362777.

\footnotetext{
${ }^{139}$ Fincke, 'Praefatio ad Lectorem', Geometriae Roundi, f. a 2 v, Wittenberg Sammelband, O.B. RAM RAMUS, 30209019362777.

${ }^{140}$ Mary Thomas Crane, Framing Authority: Sayings, Self, and Society in Sixteenth-Century England (Princeton, NJ: Princeton University Press, 1993), p. 12.
} 
Collating mathematical authorities is merely one example of the way in which the Wittenberg Sammelband bears evidence of modes of mathematical study rather than any notable mathematical proficiency. For this individual, 'mining' the Sammelband's works was a process characterized by extraction, collection, and reorganization intended for their own pedagogical purposes. Redaction and repetition of the printed text dominate the marginalia of Arithmeticae Libri Duo, Geometriae Septem et Viginti and Geometria rotundi alike. Largely content to refrain from deconstructing literary and rhetorical allusions or arguments with the scholastic logic common to the universities, as might be expected, the main annotator of the Wittenberg Sammelband has instead sought to replicate much of the volume's mathematical content in the abbreviated style of the volume's authors. The form of this 'mining' is likely to have been the product of a master, with pupils copying dictation or written notes into their texts and notebooks: a clear example of this, rich in detail, occurring at the beginning of the first chapter of the second book of Arithmeticae Libri Duo, can be seen in Figure 2.12.

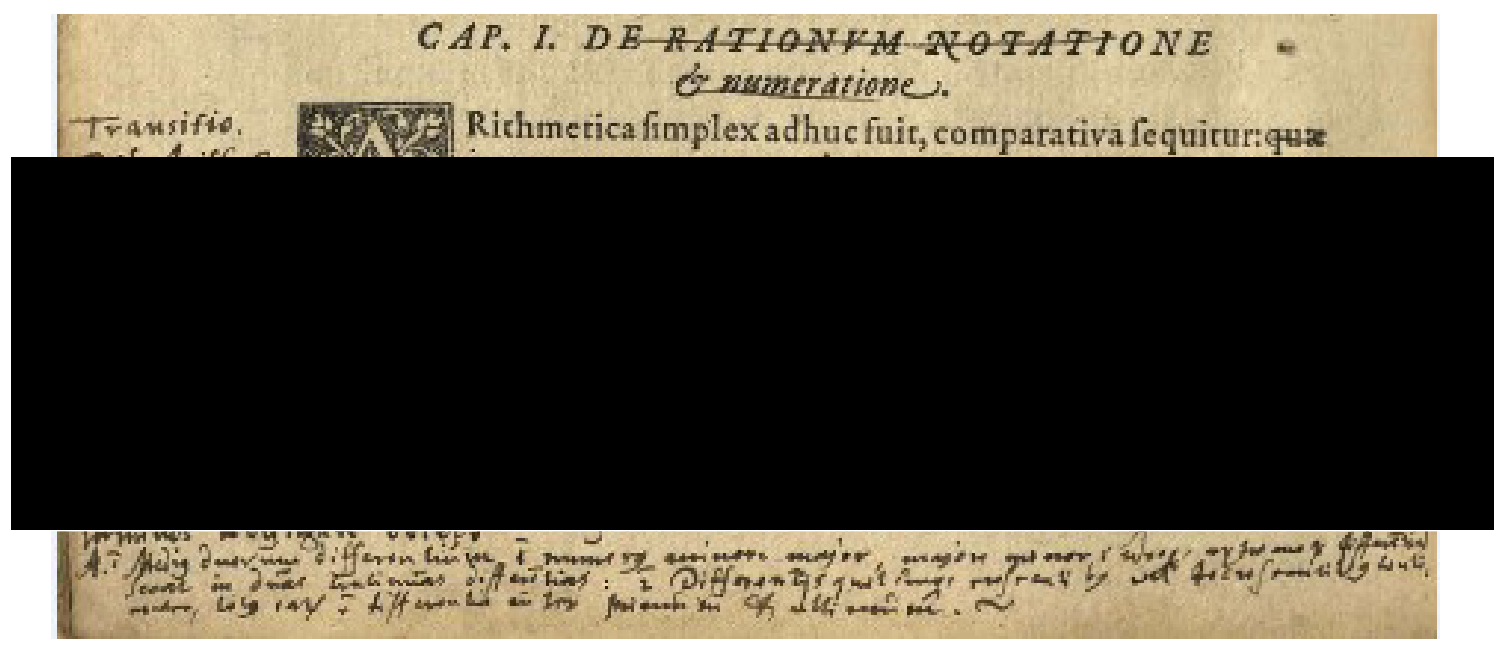

Figure 2.12. Excerpt of marginalia covering a third of a page of Petrus Ramus's Arithmeticae Libri Duo. Science Museum Library Shelfmark O.B. RAM RAMUS 30209019362784.

This particular example is typical of the annotating style brought to bear upon Ramus's text in particular, and several identifiable features common to the entire volume's marginalia can be seen. First of all, the title of the chapter - De rationum notatione et numeriatione - has been struck through for emphasis: wherever annotation is present in the Sammelband, the majority of titles are found redacted in this manner. The volume's body text bears the same marking, with clauses lined 
through and then repeated in similar diction in the left-hand margin of the page. In this instance, the term 'transitio' serves as an important directive from the annotator, intended to aid future readers (or, perhaps, those listening to the annotator himself). Ciceronian rhetoric taught that through transitio the orator could recall what had been and introduce what would follow, its stylistic movement serving both to remind and to prepare. ${ }^{141}$ Thus the marginal addition is a close analysis of the printed passage's stylistic movement, with the annotator's notes shepherding readers (or listeners) through three separate but interlinked definitions extracted from the text: the first, marking the definition of comparative arithmetic, whereby comparisons of quantity are defined either in terms of equality or inequality (Figure 2.12, below); the second, marking the rules by which differences in unequal numbers may be analysed; the third drawing attention to how numerical ratios may be used to illustrate the two previous axioms. ${ }^{142}$

The goal of this practice was twofold. First of all, in their process of extracting core definitions from the text and repeating them in the plain space of the margins, an authoritative reader has demonstrated their understanding of Ramus's key mathematical terms, and, more importantly, the importance of their order to building arithmetical understanding from more general parts to particulars. Secondly, whether for the purposes of lecturing, emphasis, or memorization, this annotator has further abbreviated the text through close reading, using the skills taught as part of the trivium to analyse the textual units of mathematics so that they might better present these units to younger and less capable learners.

\footnotetext{
${ }^{141}$ Cicero, Rhetorica ad Herennium, trans. Harry Caplan (Cambridge, MA: Loeb Classical Library and Harvard University Press, 1954), p. 319.

${ }^{142}$ Ramus, Arithmeticae Libri Duo, p. 22, Wittenberg Sammelband, O.B. RAM RAMUS 30209019362784.The annotation reads: 'Transitio. Def(initione): Arith(metica) C(omparativa): et comparatione quantitate est vel aequalitatis vel in[ae]qualitalis; Def(initione): differentiae quae illustrator regula proprietatis de genesi et analÿsi differ; $\operatorname{Def}($ initione): Rationis illustrato duplici axiomate: quorum prius rationis analÿsin (docet): posterius datae rationis terminos investigare docet.'
} 


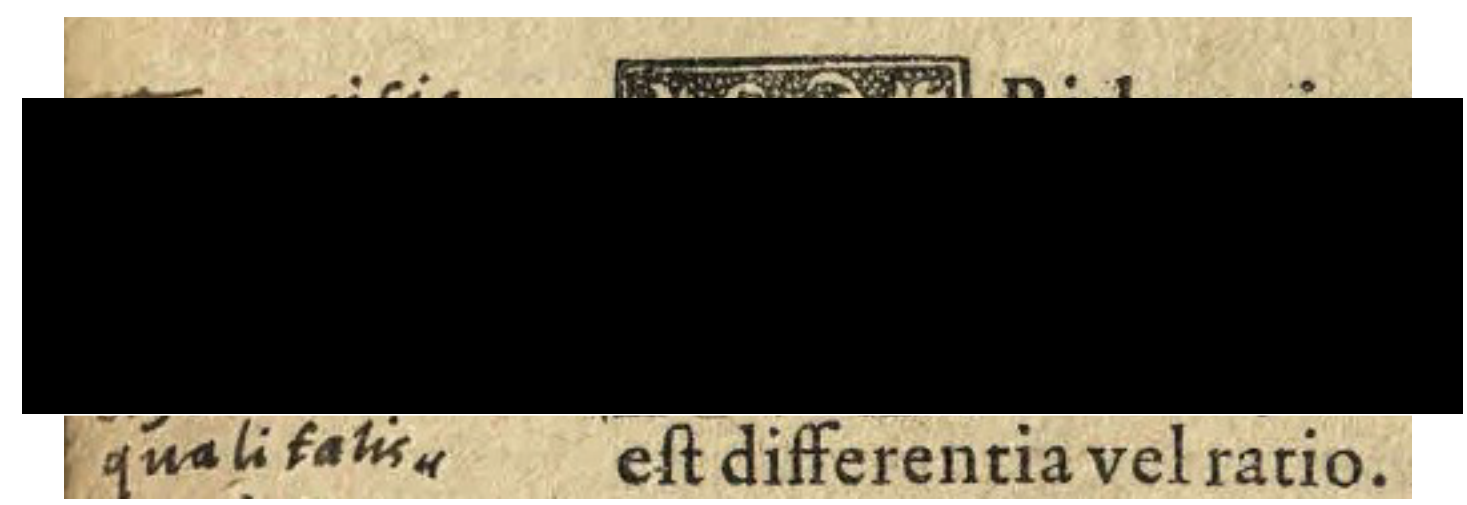

Figure 2.13. Expanded section of marginalia shown previously in Figure 2.12, detailing excavation and repetition of definitions from Petrus Ramus's printed text on arithmetic. Science Museum Library Shelfmark O.B. RAM RAMUS, 30209019362784.

The bulk of the marginal notes filling the blank spaces of the Wittenberg Sammelband were written in similarly abbreviated fashion. Although the lengthy notes surrounding the body text bear some resemblance to the commentary scholia written by Renaissance and early modern students in textbooks, their contents run exactly parallel to the text from which they are drawn with little in the way of critique or deviation and showcase more the contents, stylistic movement and presentation of the material to hand. In delineating how triangles of equal angles but different dimensions may be compared, Petrus Ramus had initially constructed his argument concerning equilaterals through a series of definitions aided by of simple geometrical figures. Following suit, our annotator used the margins of the printed work to unpack precisely the same argument verbally: although the form of the triangles was defined in terms similar to the Euclidean $u r$-text shared by both Geometriae septem et viginti and the later Geometriae rotundi, the logical structure of text and annotation is reorganised by a process of division and definition. 


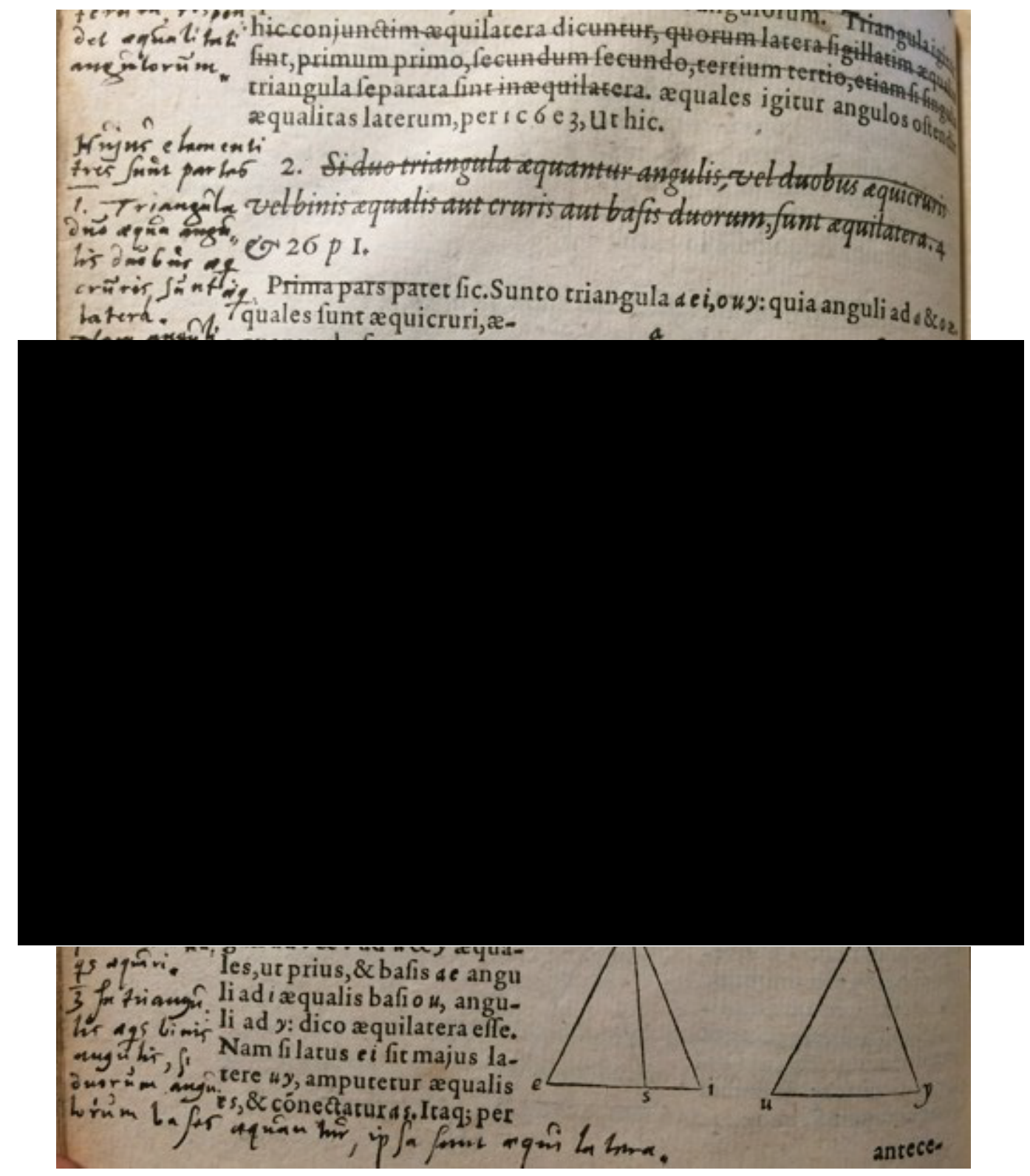

Figure 2.14. Annotations on equilateral triangles from Petrus Ramus's Geometriae septem et viginti. In the left-hand margin of the page, a tripartite system of division, definition and recast propositions can be seen. Science Museum Library Shelfmark O.B. RAM RAMUS 30209019362784.

At times, these distillations highlight perfectly how the Ramist presentation of geometry could be ever more compacted by the 'active' techniques of Renaissance reading. Throughout Ramus's Geometriae Septem et Viginti this particular annotator was content to redact entire, introductory lines of propositions, occasionally indexing their contents only in the briefest possible terms. Headings 
such as Book II's 'fabrica peripheria' ${ }^{143}$ (the drawing of a circumference by extending a radius outwards from its central point) or Book VI's 'fabrica generalis omnis trianguli', ${ }^{144}$ on the various ways of constructing triangles, serve as indexical bookmarks for the swift identification of various (and slightly more verbose) theoretical definitions. Rather than any meaningful commentary on Ramus's text, or, indeed, any significant efforts to draw its contents toward the other mathematical, philosophical or literary works these arguments might be compared with, such marginalia instead evince a user's systematic desire to parse the key elements of arithmetic and geometry to only the most essential units, most likely for swift identification and recovery.

The preponderance of summary and, though rarely, explanatory notation on Ramus's texts is evidence of the repackaging of materials into ever more manageable packets of information best suited to more juvenile learners. This practice was undertaken in detail consistently throughout the edition of Ramus's work found in the Sammelband, and continued, in the same hand, in marginalia added to the opening chapters of Thomas Fincke's Geometriae rotundi. Definitions were extracted from the text, their sources lined through, and their contents rewritten in the marginalia. However, as the volume's texts grew in complexity, a more interpretative style of annotation began to appear.

As we have already seen, the first five chapters of Geometriae rotundi took the form of a Ramist-influenced reconstruction of introductory Euclidean geometry. Thomas Fincke presented these materials to inculcate in students a foundational understanding of the discipline, so that he might then move on to advanced treatments of spherical geometry and the importance of the radius to the calculation of trigonometric canons. Despite the author's best intentions, marginalia found in the Wittenberg Sammelband evince that students—-somewhat understandably—required from their instructors a little more interpretation of geometrical theory than Fincke's text had initially provided. This user's interpretative additions to the volume's textual materials is witnessed only occasionally across the two key texts of the Sammelband, and most frequently in relation to Fincke's spherical geometry. Where

\footnotetext{
${ }^{143}$ Ramus, Geometriae septem et viginti libri, p. 12, Wittenberg Sammelband, O.B. RAM RAMUS, 30209019362784.

${ }^{144}$ Ramus, ibid, p. 55, Wittenberg Sammelband, O.B. RAM RAMUS 30209019362784.
} 
the printed text of Geometriae rotundi gave definitions of the diameter and radius as rectilinear lines inscribed within the figure of the circle, this was immediately followed by a manuscript reworking of the printed propositions: one which aimed to make clear more precisely what these propositions themselves had shown, and one in spite of Ramus's identification of apparent problems of logical method in Euclid's presentation.

This tension is witnessed in the eleventh and twelfth propositions of Geometriae rotundi's Book I. ${ }^{145}$ The first of these propositions defined how a right line [eu] equal to a given line [a] drawn from the end point of the diameter [ei] of a larger circle radius could then be used to draw the circumference of a lesser circle, with the right line [eu] equal to both the given line [a] and the radius [eo]. The second demonstrated how, if the line [ui] bisected the line [ae] perpendicularly, then [y] would be the middle point of the diameter and the centre of its circle. ${ }^{146}$ Seeking to expand upon Fincke's eleventh proposition with reference to its source, the marginalia present benevolently reworded the text to instruct readers that 'this proposition demonstrates in what manner a right line equal to a given line is to be inscribed in a circle' - a definition quoted from Book XV of Geometriae septem et viginti libri. ${ }^{147}$ Furthermore, the annotator has added a Tironian symbol to the following proposition, ${ }^{148}$ circled in red in Figure 2.15 below, expanding on the printed reference to Book III, Proposition 1 of Euclid's Elements. To more fully explain how this proposition is proven, the annotator expands on the printed text by adding the referenced Euclidean corollary: 'if, in a circle, two lines are cut one another at right angles, and in fact at the centre, that is into two equal parts, then in this way the diameter (of the circle) is found. ${ }^{149}$ Fincke, however, had directly

\footnotetext{
${ }^{145}$ Fincke, Geometriae rotundi, p. 11: 'Si a termino diametri ex eaque radio aequante datam rectam peripheria describatur: recta a dicto termino in concursum peripheriarum inscribetur dato circulo, aequalis datae'.

${ }^{146}$ Fincke, ibid, p. 11 .

${ }^{147}$ Fincke, Geometriae rotundi, p. 11, Wittenberg Sammelband, O.B. RAM RAMUS 30209019362777. The annotation reads: 'Haec propositio docet quodmodo recta data sit inscribenda circulo aequalis datae'.

148 The Tironian symbol for 'est', shown in Figure 2.14, is listed by Michelle P. Brown in A Guide to Western Historical Scripts from Antiquity to 1600 (London: The British Library, 1990), p. 136.

${ }^{149}$ Fincke, Geometriae rotundi, p. 11, Wittenberg Sammelband, O.B. RAM RAMUS

30209019362777. The annotation reads: 'si in circulo duae rectae ad angulus rectos se intersecant, et medio quidem hoc est in duo aequalia, (...) via erit diameter circuli.'
} 
followed Ramus by expressing the view that Euclid wished this definition impossible, and thus sought its antithesis through reductio ad absurdum. ${ }^{150}$

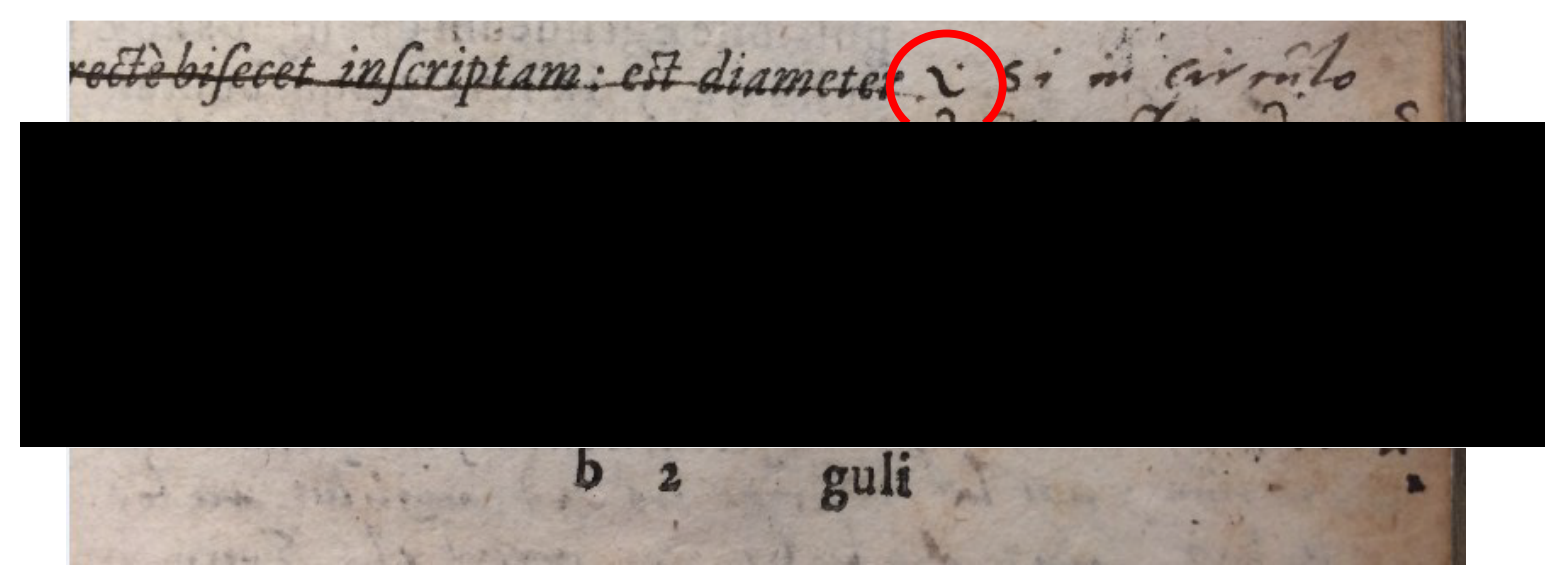

Figure 2.15. The annotator's use of the Tironian symbol for 'est', circled in red, followed by a brief note adding a Euclidean reference to Thomas Fincke's Geometriae rotundi. Science Museum Library Shelfmark O. B. RAM RAMUS 30209019362777.

In some respects, this reflects a pragmatic approach to learning that even modern teachers would no doubt recognise. Whilst every effort was made to situate mathematical learning within a Ramist structure, we can easily imagine why the annotator of these particular texts felt that it may have been necessary to succinctly adumbrate materials culled from external sources - even if these materials were, for the authors, a bone of some contention. This practice is even more understandable if we conceive of the notes as being copied from the dictation or writings of a lecturer. Given that both Ramus and Fincke sought to educate expeditiously, the author of these marginal notes may not have had the time for his students to consult Euclid under their own steam. Emending the text with missing chunks of Euclidean theory and definition is likely to have been an educator's attempt at widening his pupils' understanding rather than any evidence of exasperation with the text itself, and the glosses which accompanied the text worked to supplement its original authors' deliberate elisions.

Where Fincke recognized Plato, Aristotle and Quintilian as being in agreement on the perfection of the form and of the sphere, his annotator followed

\footnotetext{
${ }^{150}$ Fincke, Geometriae rotundi, p. 12: 'Euclides impossibile maluit, et ita cogit: quae est deductio ad sententiam absurdam'. See also Ramus, Geometriae septem et viginti libri, p.115.
} 
suit, redacting key statements in the texts and citing their sources by name alone. In a section treating isoperimetric figures, Fincke showed that a circle (in plane) has a greater area than any other polygon with the same perimeter. Thales of Miletus, Ptolemy, Theon (via Zenodorus) and Ramus were all cited before the author railed against those wilfully ignorant of geometry; ${ }^{151}$ despite the presence of these formidable thinkers, only the individual names of Plato and Aristotle recur in the margins, before a single repetition of the term ' $\psi \varepsilon v \delta \delta \gamma \rho \alpha \varphi \alpha^{\alpha} \alpha$ ' (pseudographia) marks the vulgar errors formed by ignorance of geometrical theory. ${ }^{152}$ Our reader's interest in the force of these terms seems limited to summary, and not discussion. Mathematical material was considered on its own terms, with little evidence to suggest that this user was keen to read arithmetic or geometry in conversation with literary, philosophical, or spiritual authorities.

The second element of this user's scribal practice builds upon such pragmatic pedagogy. 'Mining' the text in the manner witnessed thus far was preparation for the second form of textual interaction most prominently witnessed in the Sammelband the visual restructuring of theory. The body text of the volume was summarised and structured in such a way as to be more immediately accessible, and to retain the order of its source works. Textual material was then recast depending on the content of the information communicated: structured either by numbered points, or in the dichotomous trees of Ramus's organizational system. Both styles drew from the mode of presentation valued by Ramus and Fincke, even where the content of the texts being copied showed minor divergences from these authors. An example of this multi-level process of citation is seen in the first book of Fincke's Geometriae Rotundi, on 'cutting' the circle with intersecting right lines. ${ }^{153}$ Rather than replicate the diagram in the broad marginal space surrounding the text, an annotator has instead redacted the proposition's title and a key section of the text, before constructing a tripartite syllogism from the printed material (Figure 2.16).

\footnotetext{
${ }^{151}$ Fincke, Geometriae rotundi, pp. 6-7: 'Qui vel propterea cognoscendus est: ut constet quanto cum pudore philosophos sejactentii, qui elegantem hunc Geometriae usum ignorant: cum homini etiam rhetoric non sit ignotus'.

${ }^{152}$ Fincke, Geometriae rotundi, p. 7, Wittenberg Sammelband, O.B. RAM RAMUS 30209019362777. The manuscript annotation reads 'Plato', 'Aristoteles', and ' $\psi \varepsilon v \delta o \gamma \rho \alpha \varphi i ́ \alpha$ ignoratione rationis in isoperimetris'.

${ }^{153}$ The first book of Fincke's Geometriae rotundi is titled 'De circulis rectis secantibus'. Fincke, Geometriae rotundi, p. 5.
} 


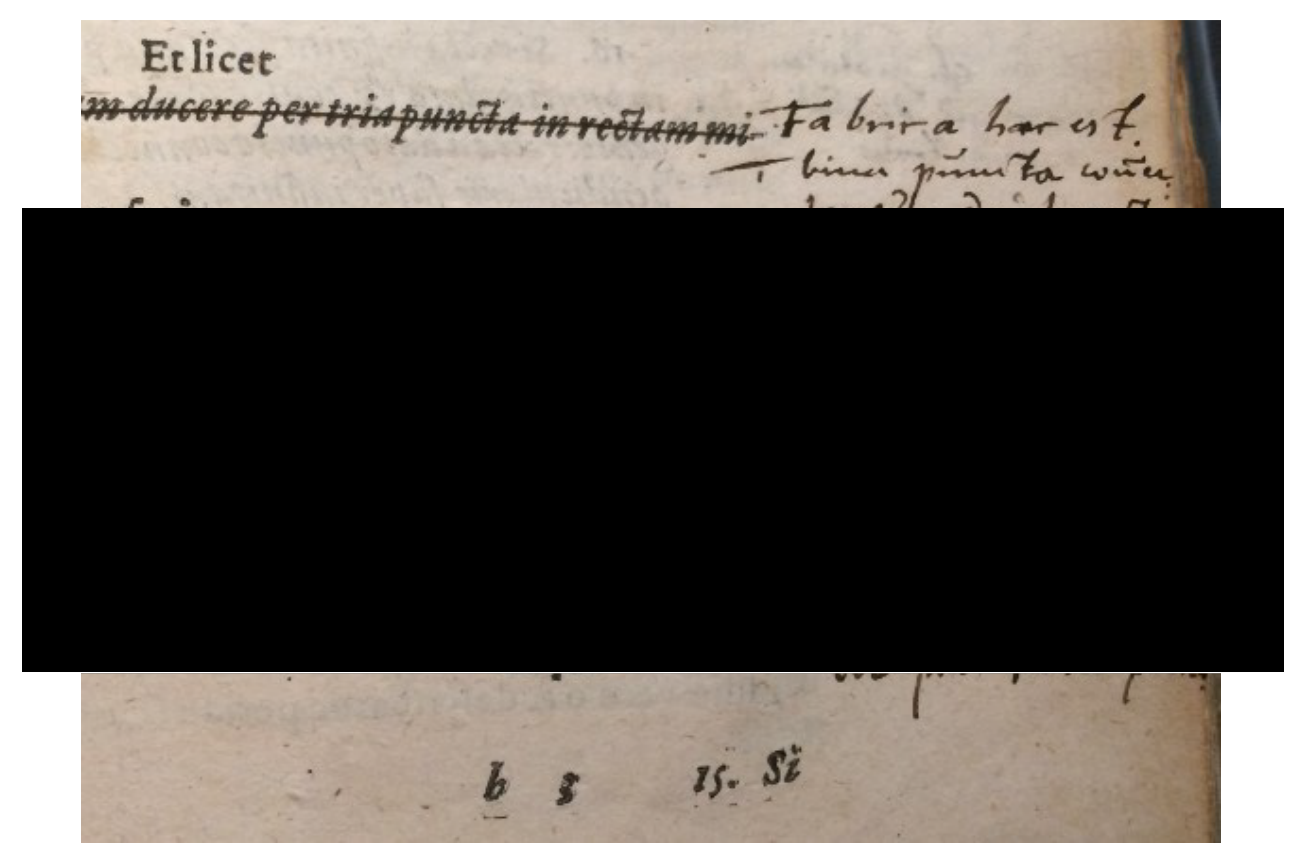

Figure 2.16. Annotations to Thomas Fincke's Geometriae Rotundi gloss the printed text with additional references, in this case from Petrus Ramus's Geometriae septem et viginti. Science Museum Library Shelfmark O.B. RAM RAMUS 30209019362777.

The printed text of Fincke's fourteenth proposition concerns the construction of the right-angle [aei] within the wider circumference of a circle. ${ }^{154}$ The lines [ae] and [ei] are secants, each intersecting with two points on the circumference's curve. Each are themselves bisected at the central point, [o], with a vertical diameter bisecting [ei] and a misprinted, skewed line bisecting [ea]. ${ }^{155}$ The marginal annotation here recasts the printed text without disagreement, advising that, to construct the example, right lines would need to be drawn from two points. ${ }^{156}$ Its author went on to repeat the postulation's connection of the points [a], [e], and [i] by two right lines. ${ }^{157}$ Exceeding even Fincke's printed citations, the annotator has notably glossed this section with a cross-reference to the seventh proposition of

\footnotetext{
${ }^{154}$ Fincke, Geometriae rotundi, p. 13.The proposition is entitled 'Peripheriam ducere per tria puncta in rectam minimè cadentia'.

${ }^{155}$ Fincke, Geometriae rotundi, p. 13, Wittenberg Sammelband, O.B. RAM RAMUS

30209019362777. The annotator has seen fit to redact (for emphasis) the lines 'Rectas enim interbina puncta inscriptas bisecantes duae in concursu suo centrum habent. Radius est a concursu in punctum.' ${ }^{156}$ Fincke, ibid, Wittenberg Sammelband, O.B. RAM RAMUS 30209019362777. The annotation reads: 'Fabrica haec est: 1) linea puncta connectantur duobus rectis (...)'.

${ }^{157}$ Fincke, ibid, Wittenberg Sammelband, O.B. RAM RAMUS 30209019362777. The annotation reads: '2) Recta ductae bisecentur recte p[er] 7.e.5. Rami, et bisecantes producantur donec concurrant'. For the relevant section in Ramus's work, see Ramus, Geometriae Septem et Viginti, p. 43. Ramus used the centre point of two separate yet coalescing circles to demonstrate how segments could be drawn between peripheral points using the equality of triangles.
} 
Ramus's fifth book of Geometriae septem et viginti, where the bisection of right angle triangles within circumferences had previously been treated so as to further support Geometriae rotundi's printed conclusions. Finally, the third description details (again, in keeping with the text) how the arc of the circle, held between these aforementioned points, is bisected by lines traversing its circumference. ${ }^{158}$

More eye-catching than the numbered summaries of logically ordered data are examples of the branching relationships drawn between thematically linked topics. There is little theoretical basis for the ways in which these flattened dichotomies have been presented: they are simply binaries, branching from a shared stem, presented visio-spatially for swift referral. By further subdividing the volume's texts into ever-more abbreviated parts, the users of the Wittenberg Sammelband displayed their willingness to think within the dialectical method espoused by the very authors they were handling. To some extent, this can be seen as evidence of the successful inculcation of the Ramist method: users, be they teachers or students, adopted Petrus Ramus's ideas so entirely that they returned to pare down his texts according to the very methods of their instructor.

At a number of points, this reorganisation of Ramus's own text is present. Dichotomous branches proliferated amongst geometrical propositions, separating objects by name and then by key properties. So it is that in Geometriae septem et viginti's third book the annotator, following the author's terms and logical disposition almost to the letter, counsels that triangles must be considered first in terms of their sides and overall shape ${ }^{159}$ and then afterwards by the homogeneity (or otherwise) of their angles within these lines (Figure 2.17). ${ }^{160}$

\footnotetext{
${ }^{158}$ Fincke, ibid, Wittenberg Sammelband, O.B. RAM RAMUS 30209019362777. The annotation to reads: '3. $\mathrm{E}(\mathrm{t})$ concursu bisecantium inter vallo alterius puncti describatur peripheria: hac transibit per dicta puncta'.

${ }^{159}$ Ramus, Geometriae Septem et Viginti, p. 17, Wittenberg Sammelband, O.B. RAM RAMUS 30209019362784. The annotation reads: 'In angulu(m) considerantur \{ crura / species'. Ramus's examples constructed the 'legs' (lines) or superficies of a triangle or triangular pyramid around a given angle (e or o) before using these terms to further define the formation of angles within plane and solid shapes. 'Crura' in this annotation refers to the definition of the lines, and 'species' to the more general shape thereafter.

${ }^{160}$ Ramus, ibid, Wittenberg Sammelband, O.B. RAM RAMUS 30209019362784. The annotation reads: 'Basis est latus cujus angulus insistit: seu qui crura anguli connectit. Hic considerantur'.
} 


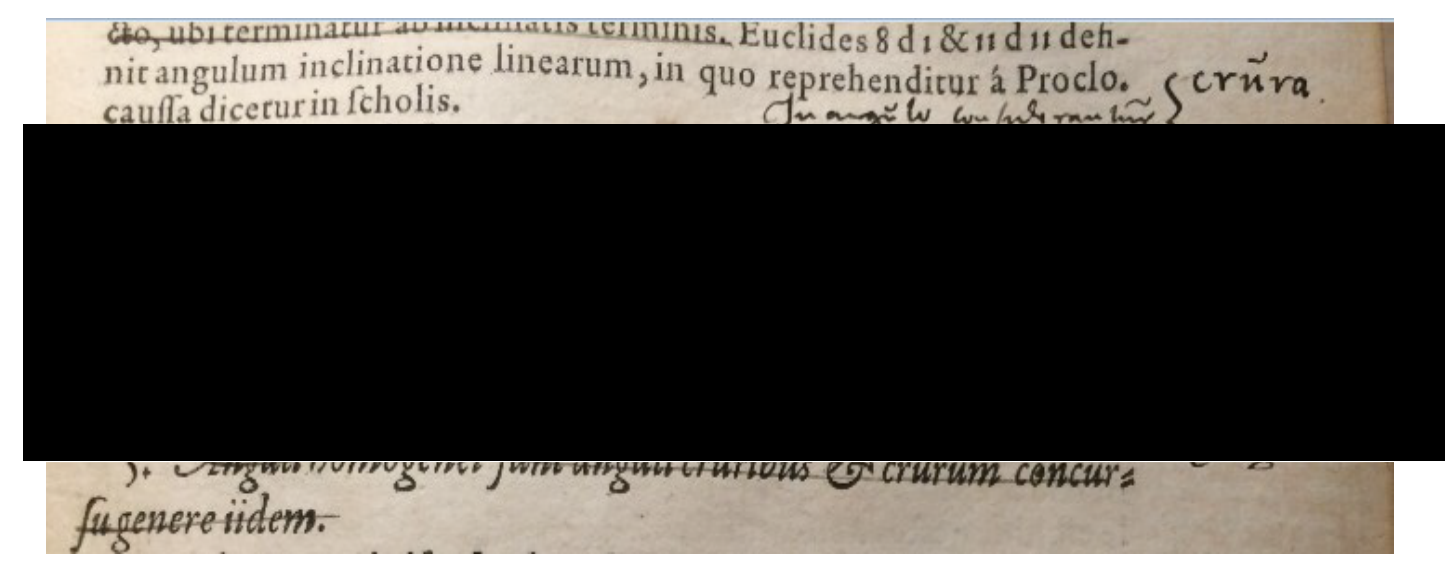

Figure 2.17. An example of branching, Ramist dichotomies drawn within Ramus's text. Science Museum Library Shelfmark O.B. RAM RAMUS 30209019362784.

Use of these graphic devices for mnemonic and organisational purposes is apparent in a number of additional examples from the Wittenberg Sammelband, and the practice is perhaps most apparent in the second book of Ramus's Arithmeticae Libri Duo. Books IV to VIII of the work move from the 'golden rules' of geometric proportion ${ }^{161}$ to the explication of a method of inverse reciprocation, whereby the calculation of ratios is discussed with reference to the relationships of various figures and their common denominators. ${ }^{162}$ Amidst the lined sections of text, an annotator selectively excerpted key phrases to keep in mind; thus a printed sentence comparing the structural importance of the golden rule and its analogical proportion to arithmetic as akin to syllogistic reasoning in logic ${ }^{163}$ is encapsulated as 'aurea regula: syllogismus' in the marginal space beside. ${ }^{164}$

Directly opposite this definition, appearing in the right-hand margin of the printed text, the quadripartite system of definitions that follows is distilled into a branching diagram illustrating proportion as composed of 'simplex' and 'multiplex'

\footnotetext{
${ }^{161}$ Ramus, Arithmeticae libri duo, p. 26: 'Proportio arithmetica sic est, geometrica sequitur, in ratione $(\mathrm{m})$ aequalitate (...) Si quatuor numeri sunt proportionales, factus a mediis, aequat factum ab extremis: et contra si equat, sunt proportionales. Haec proprietas propter admirabilem usum, vulgo regula aurea dicitur'.

162 Ramus, ibid, pp. 32-38.

${ }^{163}$ Ramus, ibid, p. 27: 'Est enim analogismus proportionis in arithmetica, quod syllogismus argumentationis in logica'.

${ }^{164}$ Ramus, Arithmeticae Libri Duo, p. 27, Wittenberg Sammelband, O.B. RAM RAMUS 30209019362784 .
} 
types: 'simple' proportion is then further constituted of direct and reciprocal proportions, as seen in Figure 2.18 below:

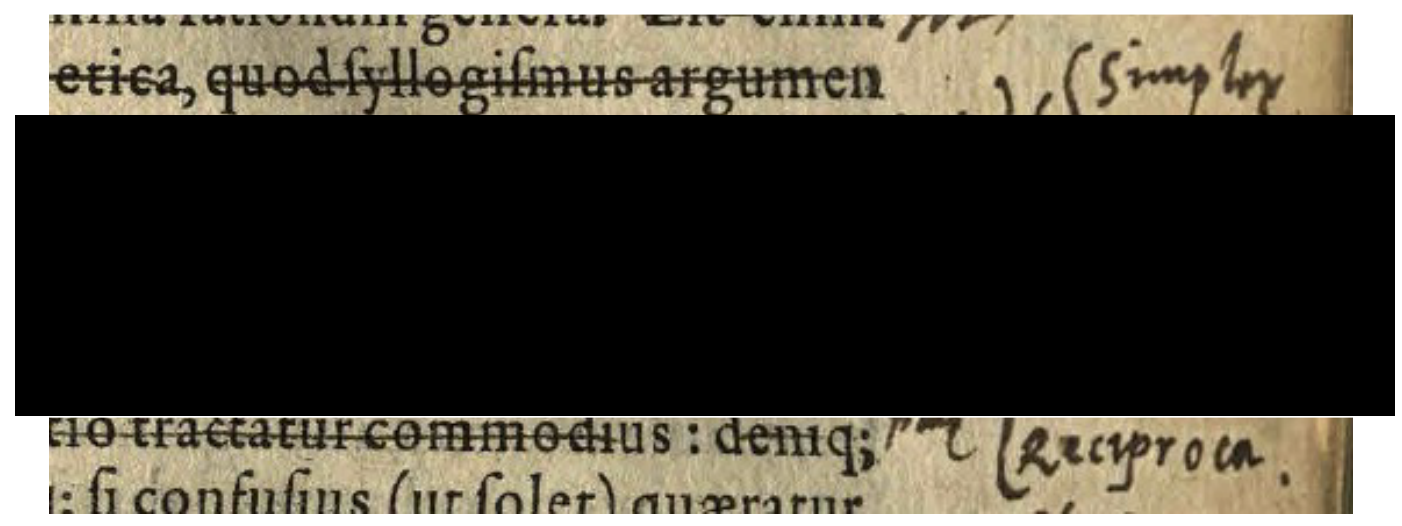

Figure 2.18. Further examples of the printed text of the Wittenberg Sammelband being dichotomised according to both Ramist method and the content of the text itself. Science Museum Library Shelfmark O.B. RAM RAMUS 30209019362784.

The recursive circuit of Petrus Ramus's dialectical method from teacher to student was repeated logically in its transmission from Ramus to the autodidact Fincke to the Sammelband's reader-annotator, and then beyond. In making Ramist dialectic instrumental to his presentation of spherical geometry, Thomas Fincke had explicitly praised the French pedagogue's method as the route by which he came to know mathematics. As the product of this knowledge, Geometriae rotundi was placed beside Ramus's works in the Wittenberg Sammelband as part of a constructed 'instrument of knowing' - one utilised to further inculcate and promote the value of Ramist pedagogy to the teaching and learning of mathematics. These lessons lasted long in the mind of the annotator of the Wittenberg Sammelband. As the text of Geometriae rotundi sheds its more elementary garb, the annotator nevertheless retains a system of dichotomy and definition to organise his reading materials, marking the first page of Book VI with Ramist diagrams and their excerpted definitions (Figure 2.19). 


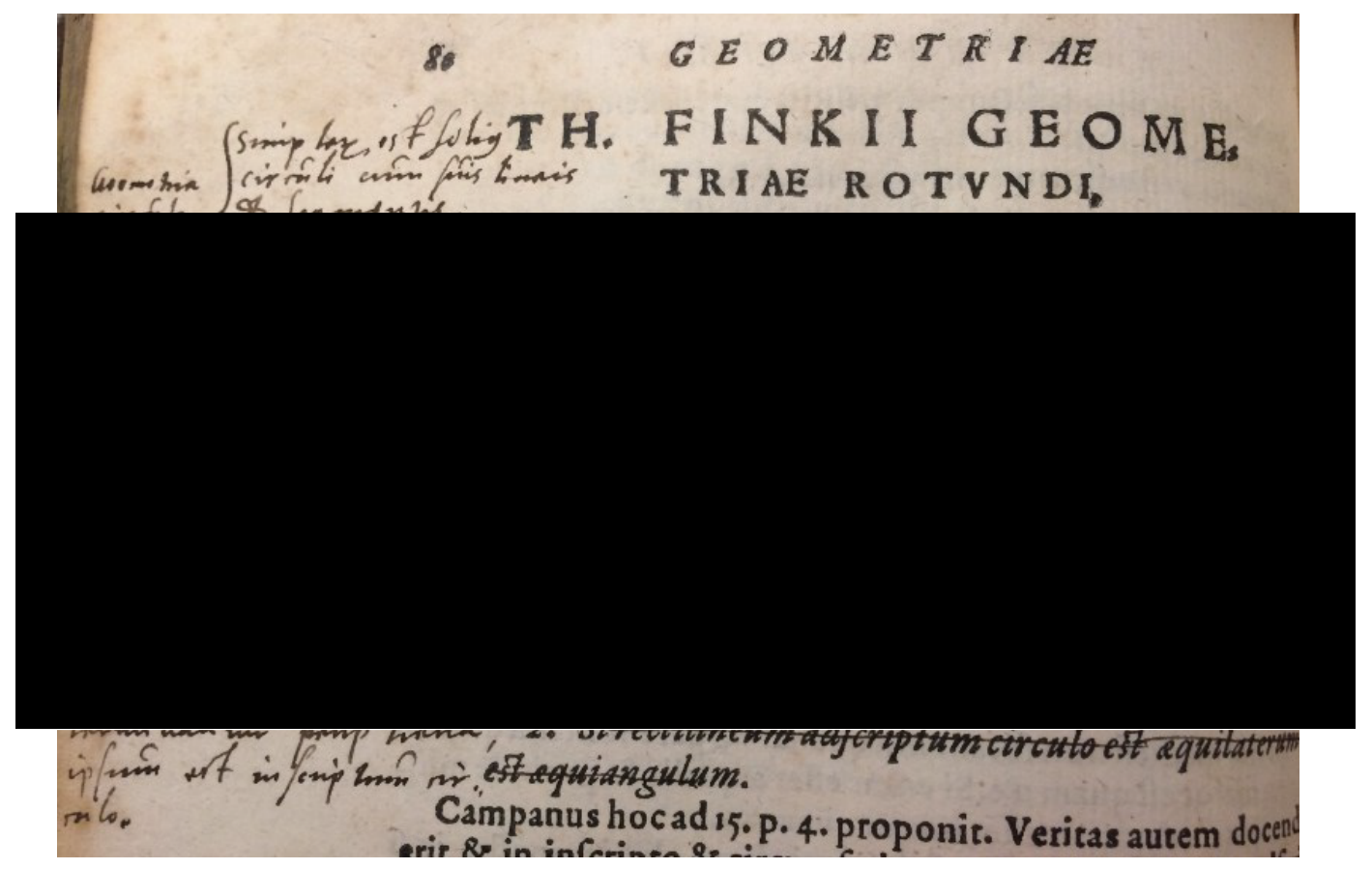

Figure 2.19. The system of dichotomy, division and definition continued throughout the Wittenberg Sammelband, as can be seen in the opening pages of Thomas Fincke's Geometriae rotundi, Book VI. Science Museum Library Shelfmark O.B. RAM RAMUS 30209019362777.

Ramus's structure of logical organisation was proposed as but one part of the method by which the mind could be cleared of the obfuscatory syllogisms and vestigial remnants of fabricated scholastic argument. This reorganisation could be brought to bear upon any art, theoretical or practical: its divisions, allied to correct definition, would clear the way for the more difficult propositions to come, paving the way for certainty in all things. The attentive reader at work in the Sammelband constructed familiar, branching diagrams in miniature to aid the recognition of these pathways; what these annotations serve to demonstrate is not so much an expressly critical or comparative form of mathematical reading, but rather one whereby the userannotator accepted the materials on display as a viable means for the teaching and learning of mathematics, and practiced their teachings accordingly.

This evidence need not lead us toward speculating, however, that readers were senseless automatons, cutting definitions into dichotomies as their books specified. It is instead proof - discoverable in any number of the annotations found in this volume - that the readers of the Wittenberg Sammelband were largely ensconced in the pedagogical system of Ramism, and saw no reason to stray from the path of his mathematical presentations. This much is true even when authorities 
beyond those specified by the text are introduced in marginal commentaries. By gilding portions of Ramus's and Fincke's works with rare excerpts from other authors, the user identifiable throughout the Sammelband conveyed their acceptance of the printed mathematical models to their students or readers. As the third part of a reading practice which incorporated 'mining' the text for key definitions, representing those definitions and their relationships diagramatically or hierarchically, and glossing the structure with occasional notae from exterior authors, this final practice is of particular relevance when we consider how these annotations helped to organise and demonstrate mathematical theory for teaching purposes.

Though the manuscript notes surrounding the text focus most predominantly on applying the lessons of a logical, Ramist dialectic to the printed material at hand, their author was not so fixated on brevity as to leave his readers floundering (or himself stranded, should he return to the texts after any absence). On rare occasions, additional or indeed contrary information to aid the learner's development was provided, and in these moments the idea of a lecturer broadening students' horizons in conversation with the text is suggested. Arithmeticae Libri Duo Book 2's tenth chapter, on alligation, an arithmetical method used to calculate using mixed properties or denominations (for example, fluids commingled according to their ratios), ${ }^{165}$ displays each of the two styles of annotation dealt with thus far: the text has been extensively redacted and repeated, although, somewhat curiously, the definition of alligation has escaped emphasis, ${ }^{166}$ despite being dichotomised in the margin (figures 2.20 and 2.21).

\footnotetext{
${ }^{165}$ Petrus Ramus, The Art of Arithmetike, trans. William Kempe (London: Richard Field for Robert Dexter, 1592), p. 61. Kempe titled this section 'Mixture', and followed Ramus by explaining the practice as 'the mingling of divers sorts, whereof a meane is tempered: as in divers kinds of graine, liquid, mettall, pieces, weights, measures, and in all such things as may be mingled and tempered'. Similar terminology introduces the term in Robert Recorde, The ground of artes teachyng the worke and practise of arithmetike (London: Reynold Wolff, 1552), f. u 6 r. For a history of alligation for mercantile and medicinal calculation, see Alvan Bregman, 'Alligation Alternate and the Composition of Medicines: Arithmetic and Medicine in Early Modern England', Medical History, 49.3 (2005), pp. 299-320.

${ }^{166}$ Ramus, Arithmeticae libri duo, p. 38: 'Alligatio est medii quaesiti vel dati'.
} 


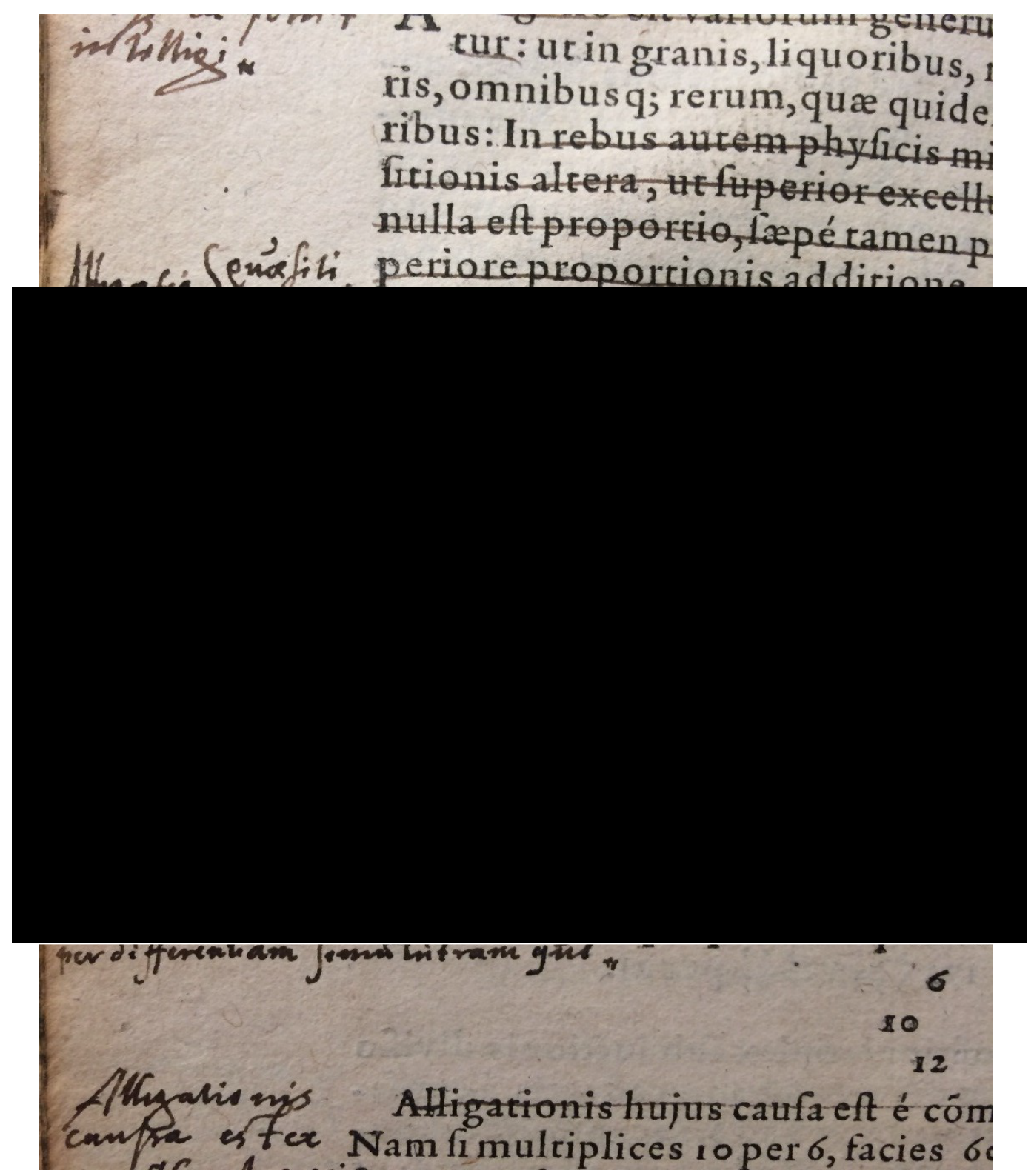

Figure 2.20. The text of Petrus Ramus' Arithmeticae libri duo, showing the styles of marginalia common to the Sammelband. Science Museum Library Shelfmark O.B. RAM RAMUS 30209019362784.

ribus: In rebus awn $\mathrm{r}=\mathrm{J}$. frionis altera, ut fuperior excelltitin poticicis. Per fe vero alligatio

Prima daris extremis quærtt medium divilıone additorum per ipfori

Figure 2.21. The statement 'Alligatio est medii quaesiti vel dati' has escaped redaction, somewhat curiously given the standard practice in operation throughout the Sammelband. Wittenberg Sammelband, Science Museum Library Shelfmark O.B. RAM RAMUS 30209019362784. 
Prior to these schematic marginalia, however, a point of contention with the main text was noted, even as the annotations themselves were dominated by a script which summarised (and tacitly bolstered) Ramist doctrine. An alternative voice was interjected to critique the veracity of the printed work. As Figure 2.22 below illustrates, the marginal space was used to cite Lazarus Schöner's understanding of alligation as a method, and his concern over its value to the teaching of the doctrine of proportions. ${ }^{167}$

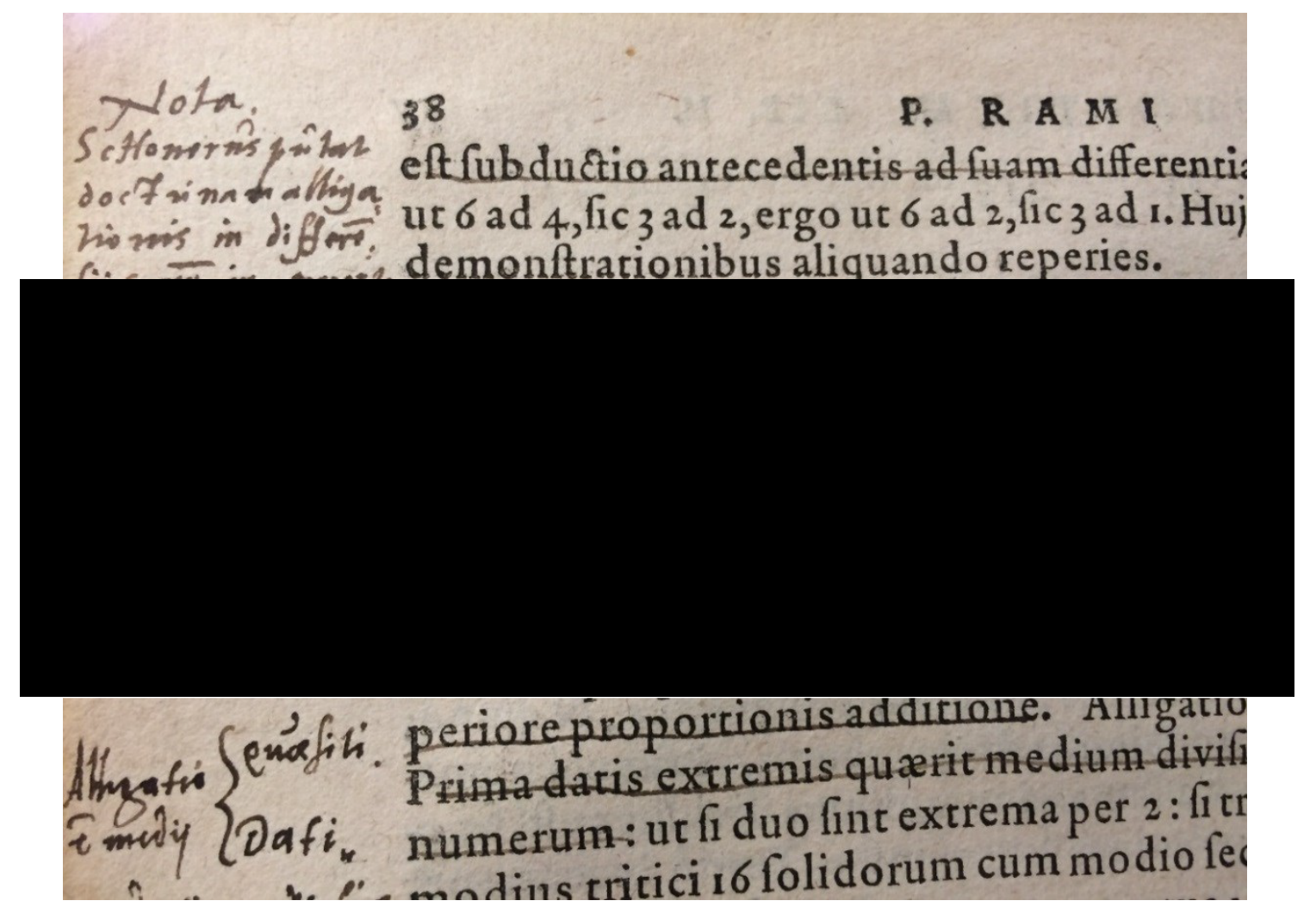

Figure 2.22. Additional information, provided in contrast to that of the printed text: here the work of Schonerus (Lazarus Schöner) is referenced on alligation ('Nota...'). Science Museum Library Shelfmark O.B. RAM RAMUS 30209019362784.

The introduction of Schöner illustrated a contemporaneous appreciation of the currents of mathematical theory in early modern Germany, and the citation of the respected mathematical educator again gives weight to the supposition that the

\footnotetext{
${ }^{167}$ Ramus, Arithmeticae libri duo, p. 38, Wittenberg Sammelband, O.B. RAM RAMUS 30209019362784. The annotation reads: 'Nota: Schonerus putat doctrina alligationis in differentis non in proportionibus locum habere, quia nec proportio est, nec proportionis necessario utitur, sed absque ea potuit intelligi'. I have to date been unable to precisely trace this remark. However, given Schöner's contemporary editing of Ramus's texts, and the presence of notes similar to Schöner's $D e$ Logistice sexagenaria in the Wittenberg Sammelband mentioned previously, I argue that this annotator was familiar with, and excerpting from, the works of Lazarus Schöner.
} 
content of these notes was ultimately the product of a lecturer. Excerpts drawn from additional alternative sources further support this view: in these notes are the hint of unasked questions, and of an educator constructing material so that it might be close to hand - whether to further elucidate a point or to head off a challenge. In this manner, the second page of Ramus's arithmetical text was inscribed with an alternative example on addition, adumbrating Euclid's first 'common notion', that things which are equal to the same thing are also equal to one another. The annotator chose to demonstrate this principle arithmetically rather than geometrically, constructing a monetary example of the ratios of asses to aurei, and aurei to libella, that was unmentioned in either the text or its Euclidean predecessor. ${ }^{168}$

In addition to this habit, further examples demonstrate that the annotator was content to diverge from the strict order of the printed text by introducing more advanced topics from an early stage, safe in the knowledge that they could complement learners' understanding as it was improved piece by piece. Hence a succinct summary of arithmetical prosthaphaeresis appeared in the margins of the printed text as an example of the effective use of the models of addition, subtraction, and arithmetical notation discussed immediately prior (Figure 2.23). ${ }^{169}$

\footnotetext{
${ }^{168}$ Ramus, Arithmeticae libri duo, p. 2, Wittenberg Sammelband, O.B. RAM RAMUS 30209019362784. The annotation reads: 'Euclides 1 axiomate 1. Numeri eidem aequales sunt inter se aequalibus: ut 2 et 2 sunt aequales tertie 2, s[un]t igitur inter se aequales. Hoc axiomate valoris aequalibus indicantur, quos numeros idem arguit: (...?) totidem é partibus hoc et unitatibus (...?) ut 260 asses faciunt 13 libellas: 5 aurei ft. 260 asses, ergo 5 aurei faciunt 13 libellas'.

${ }^{169}$ Ramus, Arithmeticae libri duo, p. 7, Wittenberg Sammelband, O.B. RAM RAMUS

30209019362784. The quotation marks on either side of this marginalia suggest that it has been excerpted from another text; however, owing perhaps to difficulties in precisely transcribing the manuscript, I have as yet been unable to locate the origin of the text quoted.
} 


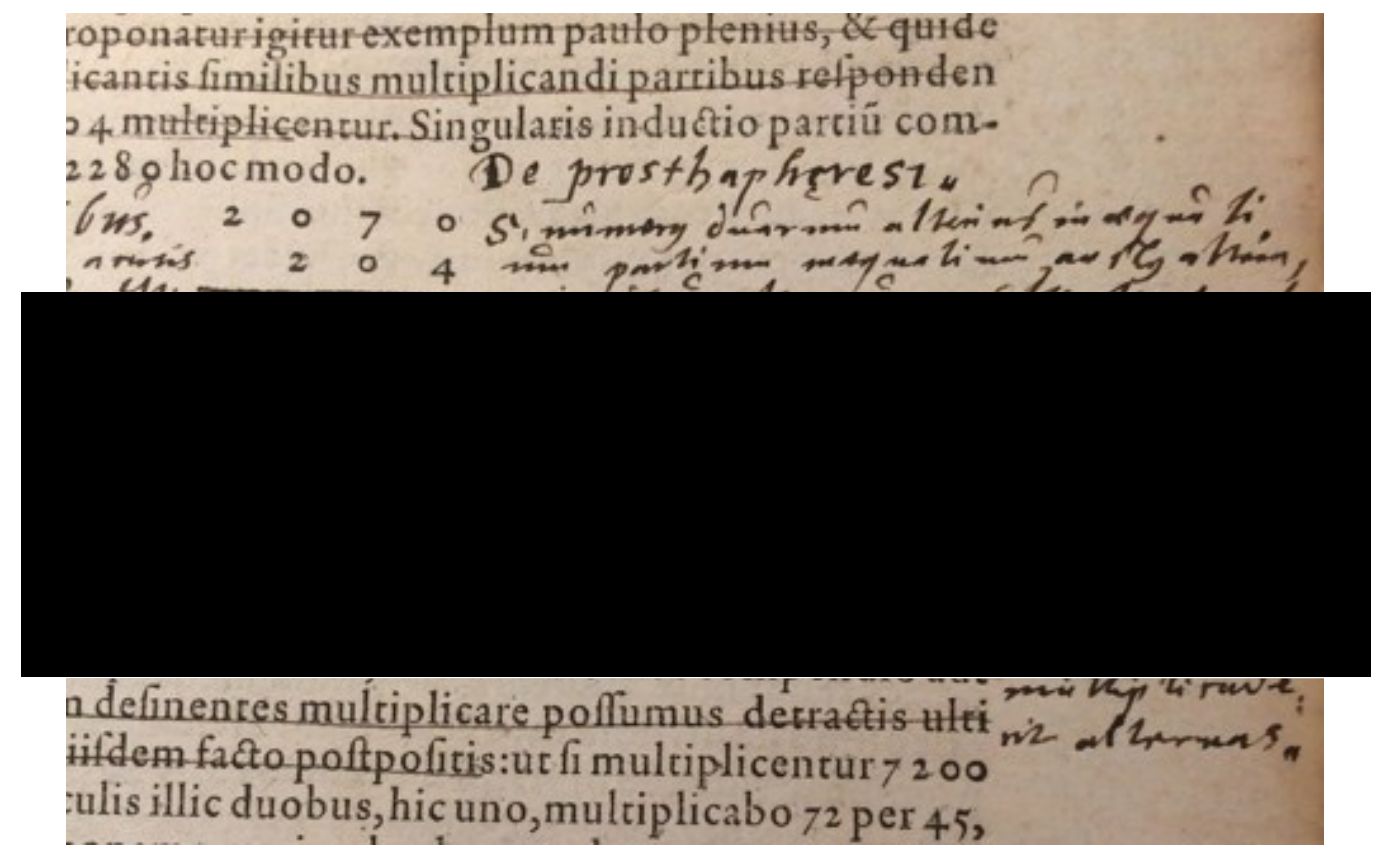

Figure 2.23. A summary of the method of prosthaphaeresis in Petrus Ramus's Arithmeticae libri duo. Science Museum Library Shelfmark O.B. RAM RAMUS 30209019362784.

This reference effectively foreshadowed the parallels drawn elsewhere in the text between the more complex methods of prosthaphaeresis and alligation, and their relationships to the simpler functions of addition and subtraction: a relationship that went untreated in the text, and reappears only when the annotator has cause to correct the printed work. ${ }^{170}$ Whilst prosthaphaeresis would later be used in an astronomical context in the late $1580 \mathrm{~s}$, in this instance the use of the term is considerably more likely to be in keeping with its etymological origins as a Greek portmanteau of addition and subtraction. ${ }^{171}$ Such minor corrections notwithstanding, the overall effect of the annotation found in the Wittenberg Sammelband was to construct and demonstrate a coherent practice of mathematical operations in agreement with the printed text. In this style of précis, occasional, minor emendations worked to assure readers of the suitability of method and outcome advocated by the two key texts of the volume. By drawing brief and occasional

\footnotetext{
${ }^{170}$ Ramus, Arithmeticae libri duo, p. 38, Wittenberg Sammelband, O.B. RAM RAMUS 30209019362784. In this instance, the phrase 'Alligationis hujus causa est é communibus regulis mutiplicationis' is lined through, and rewritten in the margin as 'Alligationis cause est ex prostaphaeresi'. An erratum was not provided for Ramus's work, and elsewhere in the text minor corrections appear to be the product of a reader acting of their own volition.

${ }^{171}$ For a detailed summary of prosthaphaeresis in the priority debates in late sixteenth-century astronomy, see Victor E. Thoren, 'Prosthaphaeresis Revisited', Historia Mathematica, 15 (1988), pp. 32-39.
} 
examples from the wider field of mathematics, the lecturer who annotated or delivered this information further assured their students of the suitability of these texts for study. Occasional, additional references to Euclid and Schöner in no way invalidated the conclusions of either Petrus Ramus or Thomas Fincke, as each theorist had shown themselves willing to utilise such classical and contemporary sources throughout their works.

Whilst more than one annotating hand is present at the beginning of the Sammelband, it is clear that the vast majority of markings belong to a single individual. As close inspection of this dominant annotating hand has indicated, the markings found throughout the Sammelband do not betray disagreement with the authors but rather evince a structured re-making of the text: one in keeping with the instructive syllabus of a teacher or lecturer. Although it is entirely credible to view the volume as a classroom textbook, it seems unlikely that the marginalia found in Ramus's and Fincke's texts are the product of a student. This annotator can be seen correcting his own notes on only three occasions throughout the volume, and there is no evidence to suggest that space has been left for text to be added later (having, for instance, consulted another student's notes with regard to portions that may have been missed). The manuscript notes on sexagesimal astronomy do present a further level of marginal commentary that may have belonged to a student or later reader, but the consistency and clarity presented in the vast majority of notes to the printed texts point toward a mature and knowledgeable author.

The minutiae of these manuscript materials suggest that a lecturer or tutor covered their own text with summaries of key sections, and that this marginalia was intended either as a script for dictation or as notes to be copied into students' commonplace books, notebooks, or, in some cases, more cheaply-bound copies of the texts themselves. Naturally, such a script would be of value to later university students delivering disputations, and in this light the annotations which further compartmentalize the writing of Ramus and Fincke into smaller chunks may have been of great value to students gorging on information prior to such performances. Additionally, when considered beside the material quality of the volume's binding, the complexity of the latter texts can be seen as further proof of a mature and salaried owner: likely one with a professional interest in mathematics and its instruction. 
When seen in this light, a number of properties of the manuscript text come into clearer focus. The authoritative quality of the marginalia leaves little room for performativity or experimentation. Rather, key sections were only minimally refashioned outside of the boundaries of the printed text, their importance highlighted and further clarified, for consumption by at least one additional reader. Although these were literal rewritings of the printed works, contradictory or comparable treatments are missing, indicating that neither the methods nor the conclusions of the printed texts came into question. If anything, these texts are marked by users' unquestioning acceptance of their doctrines. As such they are not only Ramist materials, but literal evidence of attempts to think and reason within a Ramist model. Whilst I have been unable to uncover examples of didactic address to a reader which might further substantiate the supposition of a teacher-pupil relationship, the blunt direction provided throughout - particularly in Ramus's works - suggests that the brusque nature of the text was appreciated and further distilled by an educator operating within this pedagogical style.

\section{Conclusion}

The teaching and study of mathematics in the sixteenth century was by no means independent of ongoing debates concerning dialectic, reason, and correct pedagogy. Such disputes wrought significant change in the teaching of the liberal arts curriculum in early modern Germany, where educational institutions from scholae triviales to gymnasia to the elite universities - under the influence of reformers such as Sturm and Melanchthon - re-established the value of the mathematical disciplines. An integral part of this shifting educational landscape was the educational output of Petrus Ramus, marked by their rejection of existing scholastic principles and available to students in almost every branch of the liberal arts. The spread of Ramus's teachings on dialectic, rhetoric and mathematics and the response of expert and novice readers to this literature remain an understudied area in recent scholarship; it is relevant, therefore, to analyse artefacts such as the Wittenberg Sammelband as evidence of both the textual transmission of mathematics, and of the interlinked transmission of educational currents such as Ramism.

The reshaping of this printed material and the style and structure of such active manipulation is indicative of the making of mathematical culture in the early 
modern period, and to the transmission and reception of this culture through social institutions. By way of his controversial dialectical method, the French philosopher Petrus Ramus drew mathematics into a wider programme of philosophical and pedagogical reform. Ramus's presentational style, regulated strictly by definition, rule, and diagrammatic constructions, was succinct and practically-minded. His mathematics were not intended for philosophical abstraction, but instead to educate swiftly: for regurgitation by some, and application by others.

At the very least, Ramus's elementary works offered a coherent means by which to inculcate in students an ability to recognise and manipulate mathematical terms, rather than their true understanding. Dispensing with Euclidean order and demonstrations, he applied his dialectical method as an 'instrument of knowing' to the study of arithmetic and geometry. In this way, the French pedagogue's sallies against Euclid in his Scholae mathematicae (1569) became a touchstone for the 'divergent philosophical and methodological stances' of the next generation of mathematicians. ${ }^{172}$ Thomas Fincke was one such tyro, but, as the material form of the Wittenberg Sammelband shows, he was not alone in being guided by Ramist dialectic.

In a more cautious fashion, Fincke's Geometriae rotundi was crafted so as to reform mathematical pedagogy according to the lessons he had taken from the French pedagogue. For Fincke, Ramist presentation would help to construct the platform from which he announced his skill in astronomical calculation. Though the latter was undoubtedly influenced by the former, it is important to note that the texts each author created shared a common well-spring in the humanist educational movements of the mid sixteenth century. As we have seen, Ramus's texts had gained a significant foothold in the German secondary education system by the late 1580 s. Their impact had left humanist educators fighting a rear-guard defence of the scholastic philosophy of education, lest universities become infected by wave after wave of ill-prepared undergraduates reared on such insufficient methods. The intellectual coalescence of authors, consumers, and users on display inside the

\footnotetext{
${ }^{172}$ Stephen Johnston, 'John Dee on Geometry: Texts, Teaching and the Euclidean Tradition', Studies in History and Philosophy of Science, 43 (2012), pp. 470-479, p. 474.
} 
Wittenberg Sammelband is further evidence of the impact of this movement, and of its mode of transmission.

On the one hand we have an author - Thomas Fincke - who, under the tutelage of Johannes Sturm and Conrad Dasypodius at the Strasbourg academy, read the works of classical mathematical authors and, prior to this, learnt from Ramus's logical and mathematical works. Fincke appropriated Ramist method and terminology to promulgate a new model for mathematical pedagogy: one which challenged the importance of Euclid, just as it advanced the case for Regiomontanus as the ideal mathematical praeceptor. Much like Ramus, Fincke was himself a learner who found the mathematical discipline incomplete, obfuscatory, and unfit for his purposes. Much like Ramus, he drew upon the experiences of his background and education to resolve these matters. ${ }^{173}$

On the other hand, the annotations populating the Wittenberg Sammelband embody the worst fears of the university lecturers of early modern Germany. The ownership inscriptions of Hommer, Coppius, Klynaeus, and Lobhartzeberger carry us from Leipzig to Wittenberg via Leisnig and Copenhagen. The bacillus of the Ramist educational method had infected these learners prior to their matriculation, and the transmission of this unique volume helps in part to demonstrate the hold Ramist methodology would exert on both students and educators. How this cultural phenomenon altered the minds and products of generations of learners remains under-explored, particularly in the history of mathematics.

Despite his best efforts, Thomas Fincke's 'improvement' of Euclidean geometry and development of a new theory of tangents garnered him praise only from a very particular audience. It is notable that although mathematical luminaries including John Napier, Christoph Clavius, and Johannes Kepler all recognised the

\footnotetext{
${ }^{173}$ Ramus's socio-economic and meritocratic motivators are considered in Hotson, Commonplace Learning, p. 42. Given the nepotistic fiefdom Fincke later created for himself at the University of Copenhagen it is difficult to claim that he shared Ramus's zeal for social reform as based on absolute meritocracy. On Fincke's Copenhagen cabal, see Ole Peter Grell, 'Caspar Bartholin and the Education of the Pious Physician', in Ole Peter Grell and Peter Cunningham, eds., Medicine and the Reformation (London: Routledge, 1993), pp. 78-100, particularly pp. 89-91.
} 
Dane's contribution to trigonometry in his own lifetime, ${ }^{174}$ Geometriae rotundi made little impact beyond the already mathematically literate. Anton Elder von Braumühl's supposition that it was a well-read work would appear to be based more upon the response of a small though geographically diverse coterie of famed mathematicians and astronomers (several of whom Fincke was in direct correspondence with) rather than on evidence of a sustained and widespread audience. ${ }^{175}$ Though it occasionally appears on book lists - for example, in the lateseventeenth century library of Trinity College, Dublin, and in the auction of the libraries of the physicians Sir Thomas Browne and his son, Edward - Fincke's textbook does not appear to have been translated into any European vernacular, and achieved only similar print runs to his single edition works on astrology and astronomy. ${ }^{176}$

Historians of mathematics have understandably focussed on the relative importance of Thomas Fincke's work with reference to developments in the growing sub-discipline of trigonometry in the late sixteenth-century, and, in this light, it can be argued that Fincke has been granted a position not entirely in keeping with his merits. Few would disagree that Thomas Fincke was by some degrees a superior mathematician to Petrus Ramus; but as a logician, and a proponent of 'method', the latter was clearly a significant influence upon the former. Fincke is often named by historians of science as a disciple of Ramus's method, even though to date little effort has been made to dig deeper into Fincke's particular use of Ramism. It is not enough to acknowledge Ramus's influence on Fincke without further questioning the ways in which the autodidactic student interpreted the mathematical intentions of his teacher. Conclusions that Fincke saw in Ramism a useful pedagogical model for the teaching and presentation of mathematics, and subsequently sought to utilise this method for the presentation of his own novel mathematical theory, remain convincing though incomplete.

\footnotetext{
${ }^{174}$ Anton Elder von Braumühl, Vorlesungen über Geschichte der Trigonometrie, Erster Teil (Leipzig: B. G. Teubner, 1900-1903), p. 4.

175 von Braumühl, ibid, p. 186.

${ }^{176}$ K. Theodore Hoppen, The Common Scientist in the Seventeenth Century: A Study of the Dublin Philosophical Society, 1683-1708 (London: Routledge and Kegan Paul, 1970), p. 60. Thomas Ballard, A catalogue of the libraries of the learned Sir Thomas Brown, and Dr. Edward Brown, his son (London: Thomas Ballard, 1711), p. 29.
} 
The limited popularity of Fincke's text, particularly when compared to the growth in Ramist material more generally, suggest that his work achieved little by way of a significant foothold in the educational institutions of northern Europe. But this does not mean that its place in the Wittenberg Sammelband is irrelevant to the story of mathematics in the early modern period. Instead, we should consider how one recently published book was deemed important to the distinctive experience of the makers and users of the Sammelband, and how the evidence of active reading found within the volume helps to broaden our historical understanding of the consumption and use of Ramist and post-Ramist mathematical materials in the period.

As a result, the public nature of Fincke's education and his later adoption of Ramist principles together require further exploration, not least as Genettian epitexts surrounding Geometriae rotundi. More importantly, analysis of the network of influences present in Thomas Fincke's educational biography encourages us to search for the rhetorical commonalities consistent in the presentation of innovative and novel mathematical ideas in the textual culture of the late sixteenth century. Existing research concerning the relevance of rhetoric to mathematical presentations has, understandably, focussed primarily upon the rhetoric of the mathematical 'author' rather than the possible response of the mathematical 'reader' ${ }^{177}$ But the importance of textual rhetoric must be considered a vital part of readers' responses, particularly when discrete texts are compiled and annotated as part of a single compendium.

We can only imagine how readers and users of the Wittenberg Sammelband interpreted the educational and intellectual epitexts which surrounded their learning. Nonetheless, in both its physical construction and in the intellectual effects the literature contained within it inspired, it is clear that the Wittenberg Sammelband itself functioned as an 'instrument of knowing'. Given the sparsity of evidence of its users engaging with John Peckham's Perspectiva communis, this definition is most

\footnotetext{
177 These issues have most recently been brought to light by Giovanna Cifoletti. See, in particular, Giovanna Cifoletti, 'Mathematics and Rhetoric: Introduction', Early Science and Medicine, 11 (2006), pp. 369-389; and, in the same issue, Giovanna C. Cifoletti, 'From Valla to Viète: The Rhetorical Reform of Logic and its Use in Early Modern Algebra', Early Science and Medicine, 11 (2006), pp. 390-423.
} 
appropriately applied to the volume's two introductory Ramist texts, each of which helped promulgated a methodological dialectic that made significant gains in the pedagogical landscape of late sixteenth-century Northern Europe. The rhetorical value of the peritextual elements surrounding Ramus and Fincke's contemporary works should not be overlooked when we consider how these advances were gained. Furthermore, the Sammelband's annotations transformed these opening texts into a type of palimpsest, one which further enforced the value of Ramist method for the learning of mathematics, and which could, at times, be read almost independently of the printed works themselves. Whilst we may never know if these factors were deemed to be of worth to the owners and collectors of the Wittenberg Sammelband beyond the early modern period, there can be little doubt that the object itself deserves celebration as proof of the multi-faceted ways in which mathematics were 'read' in the period. 
Chapter Three: 'A Key to the Whole Art': ${ }^{1}$ Instruments and Instrumental Knowledge in Print and Practice

By the time Thomas Blundeville's Exercises containing Sixe Treatises was first published in London in 1594, Thomas Fincke's tables of sines, tangents and secants had already been appropriated to some fanfare by the famed German Jesuit Christoph Clavius (1538 -1612). ${ }^{2}$ Blundeville placed Clavius's canons between the more complex, final chapters of the Exercises's introductory arithmetic, and that of the text's second treatise, introducing cosmography and the first principles of the sphere. The English humanist and tutor prefaced his description and use of Clavius's trigonometrical canons with a brief history of their construction, albeit one omitting Thomas Fincke by name. Blundeville stated that, in superseding the trigonometric work of Ptolemy and Ibn Al-Haytham (Alhazen, ca. 965-1040) by dividing the diameter of a circle into 'a far greater number of parts', Georg Peurbach (1423-1461) and his student Regiomontanus (1436-1476) had significantly advanced the study of the proportions shared by a circle, its diameter, and any chord pertaining to that circle. $^{3}$

Regiomontanus had set down new calculations in unwieldy folios, best suited to the study or library; Clavius then improved these tables, before printing them in much more accessible and affordable quartos. ${ }^{4}$ According to his own account, Thomas Blundeville went further still, repackaging the calculations of 'our modern geometricians [who] have of late invented two other right lines belonging to a circle called lines Tangent, and lines Secant ${ }^{\prime 5}$ in an accessible and affordable vernacular manual in quarto. This manual described a range of practical, mathematical tasks and, where the author deemed appropriate, their underlying theory (Figure 3.1).

\footnotetext{
${ }^{1}$ John Holwell, Clavis Horologiae; or, A Key to the Whole Art of Arithmetical Dyalling, in two parts (London: William Bonny for Thomas Hawkins, 1686).

${ }^{2}$ Augustus de Morgan, 'On the first introduction of the words Tangent and Secant', in David Brewster, Richard Taylor, Richard Phillips, and Robert Kane, eds., The London, Edinburgh, and Dublin Philosophical Magazine and Journal of Science, 28, January - June 1846 (London: Richard and John E. Taylor for the University of London, 1846) pp. 382-387, p. 385. De Morgan suggested that, as a Jesuit, Clavius abrogated mention of Fincke's efforts due to his need to suppress the Dane's twin Protestant and Copernican identities.

${ }^{3}$ Thomas Blundeville, M. Blundeuile his Exercises in Sixe Treatises (London: John Windet, 1594), f.

$47 \mathrm{r}$. Further references will be taken from this edition unless otherwise stated.

${ }^{4}$ Blundeville, ibid.

${ }^{5}$ Blundeville, ibid, f. 47 v.
} 


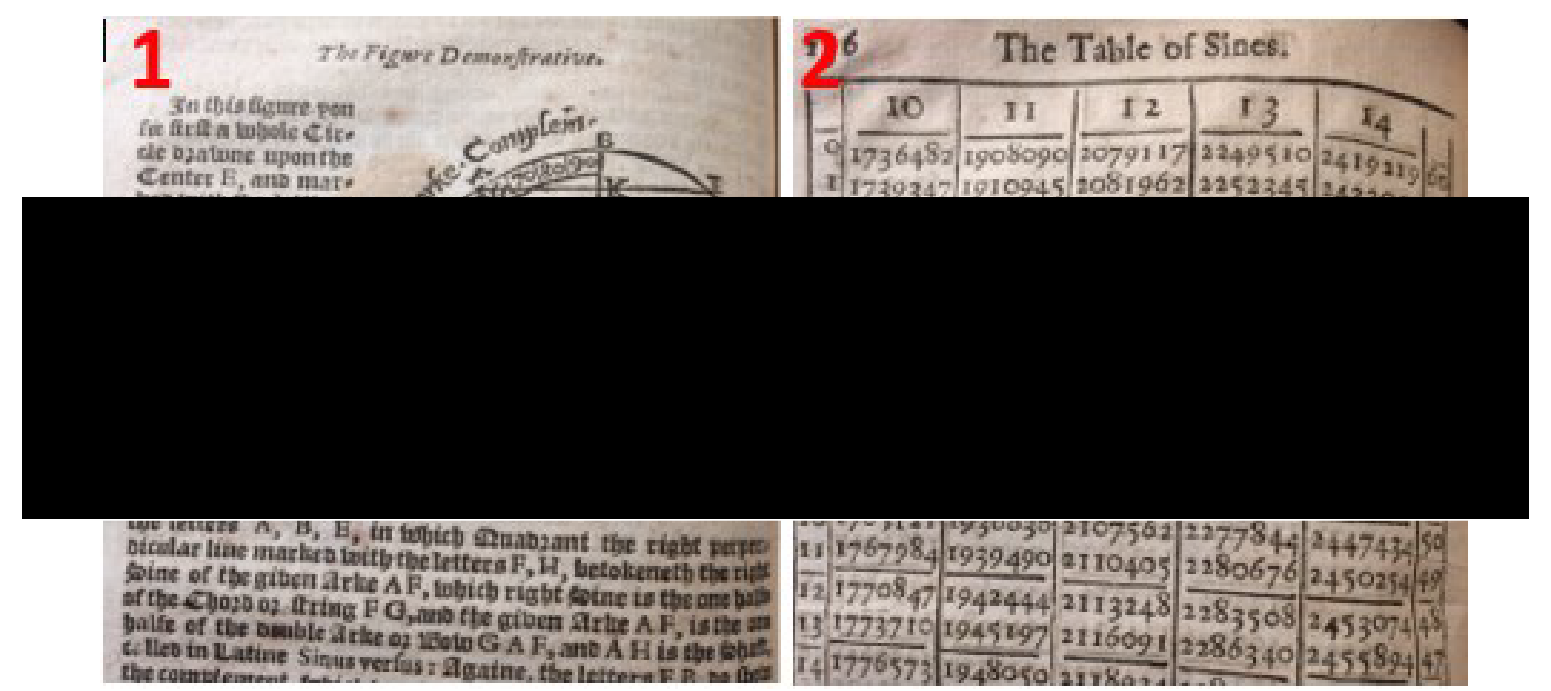

Figure 3.1. Composite image of Thomas Blundeville's trigonometric work as found in his Exercises, encapsulating (1) its basis in theoretical geometry and (2) the canons of sines made widely available by Christoph Clavius.

As the previous chapter's study of Thomas Fincke's Geometriae Rotundi has shown, developments in geometry and trigonometry were marshalled as but one part of assorted late sixteenth-century efforts to improve the theory, teaching, and practice of mathematics across the continent. The first English work to feature plane trigonometry, ${ }^{6}$ Blundeville's Exercises is indicative of a growing European interest in the study of triangles, and of the particular relevance of that study to practical knowledge of the celestial sphere and the terrestrial globe

Advances in the mathematical understanding of plane and spherical trigonometry imbued the interlinked disciplines of astronomy, geography, navigation, and dialling (or time-finding) with gradual but ever greater quantitative accuracy. The utilisation of trigonometric functions in order to increase calculatory precision impacted directly upon economic, naval, military and socio-cultural understandings of time and space. Texts written by mariners, mathematical practitioners, theoreticians and patrons all acknowledged the flow of their shared cultural capital in loose communication with one another, with authors of navigational manuals in particular acknowledging their debt to the domestic and continental authors they had borrowed from, and were in many cases in competition

\footnotetext{
${ }^{6}$ W. W. Rouse Ball, A History of the Study of Mathematics at Cambridge (Cambridge: Cambridge University Press, 1889), p. 22. Augustus de Morgan identified Blundeville as the 'first introducer of a complete trigonometrical canon into English'. Augustus de Morgan, Arithmetical Books from the Invention of Printing to the Present Time (London: Taylor and Walton, 1847), p. 30.
} 
with. In Eric H. Ash's reading, the glut of navigational treatises published in England immediately prior to 1600 took such authorial efforts beyond mere selfpromotion and highlighted instead the public acknowledgment of the value of collaboration or the sharing (approved or otherwise) of technical knowledge within a blossoming culture of expertise. ${ }^{7}$

Whereas the theory of plane and spherical triangles had previously been the province of individual, largely university-based scholars working on astronomy, its practical use was tested more and more in the open, vibrant 'trading zones' where the inhabitants of shipyards, workshops, guilds, schools, private libraries, mathematical clubs, and philosophical societies all interacted. ${ }^{8}$ On the one hand, the mathematically adept may have already been liable to incorporate instruments into their existing practice to ensure ever-greater precision or to resolve problems without the need for calculation, their efforts thereby coming to embody a growing prioritisation in the common use of instruments as a necessary part of that practice. On the other, a larger, more amateur population of respondents within and beyond the aforementioned trading zones required a softer introduction to the theory and application of geometry, and to plane or spherical trigonometry thereafter.

It was therefore a matter of growing commercial necessity for the mathematical practitioners of Elizabethan England to engender public awareness of the value of mathematical aptitude and instruments as part of their consumers' daily lives. Advertising the purported utility of mathematics - not to mention the individual practitioner's concomitant expertise in teaching or making manifest that utility — was a key factor in this grouping's self-fashioning and, accordingly, in their subsequent economic success or lack thereof. ${ }^{9}$ One suitable means to do so was to write a manual that simplified mathematical practice for the broadest possible audiences: an intermediary text, sympathetic to the requirements of the learner, the

\footnotetext{
${ }^{7}$ Ash, Knowledge, Power and Expertise, pp. 200-201.

${ }^{8}$ Long, 'Trading Zones in Early Modern Europe', pp. 840-847. On the reciprocity of these exchanges, see Long, 'Multi-Tasking "Pre-Professional” Architect / Engineers', pp. 223-246.

${ }^{9}$ Stephen Johnston, 'The Identity of the Mathematical Practitioner in 16th-Century England' in Irmgarde Hantsche, ed., Der "mathematicus”: Zur Entwicklung und Bedeutung einer neuen Berufsgruppe in der Zeit Gerhard Mercators, Duisburger Mercator-Studien, vol. 4 (Bochum: Universitätsverlag Dr. N. Brockmeyer, 1996), pp. 93-120, particularly pp. 107-108.
} 
novice (possibly themselves some form of mathematically literate practitioner) and the educator alike. ${ }^{10}$

Thomas Blundeville's Exercises was archetypal of the most successful of such manuals. Though undoubtedly aimed initially at the well-heeled members of the Inns of Court and their ilk, its continuing popularity and use into the eighteenth century demonstrated the breadth of its appeal to a wider community beyond that of the well-educated Elizabethan gentry. Despite the Exercises's ongoing popularity in the Elizabethan and Stuart eras, the manner in which consumers responded to Thomas Blundeville's efforts remains less well understood. The repetitious advertisement of the utility of mathematics as found in the texts and printed ephemera of the period suggests that appealing to the desire for a multi-faceted intellectual capability paid off. ${ }^{11}$ By the seventh edition of Blundeville's work, the text - itself intended to advance its author's own prospects - had been fashioned into a promotional vehicle by the self-taught tutor of mathematics and navigation Robert Hartwell, a self-styled philomathematicus who was at pains to alert the reader to his expertise in astronomy, trigonometry, surveying, and book-keeping in an advertisement at the end of the volume (Figure 3.2, below).

${ }^{10}$ Feingold, Mathematician's Apprenticeship, p. 181.

${ }^{11}$ Neal, 'Rhetoric of Utility', pp. 151-178. 


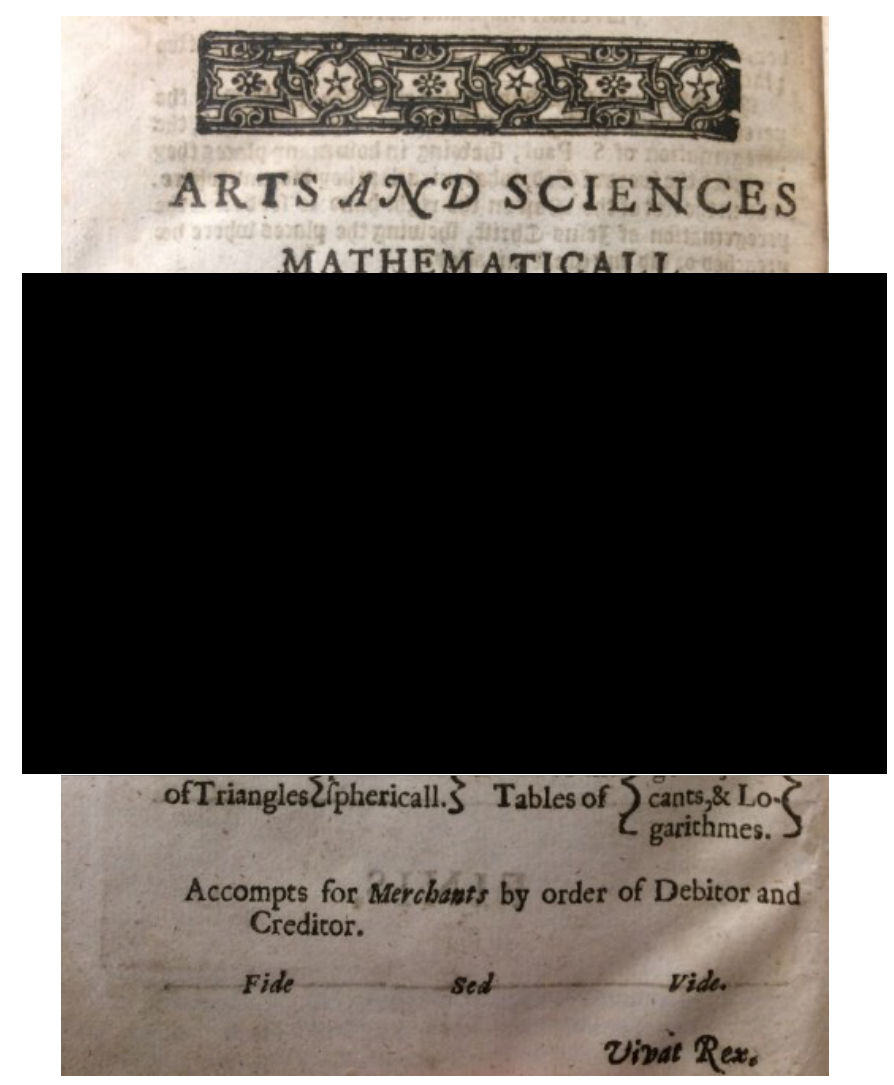

Figure 3.2. Robert Hartwell's advertisement, first appended to the final leaves of the seventh edition of $M$ Blundevile his Exercises contayning Eight Treatises (London: Richard Bishop, 1636).

Hartwell's advertisement highlighted the delights mathematical practice could bestow upon users in leisurely and in professional capacities, offering tuition in the pursuits of cosmography and horologiography (or dialling, i.e. time-finding) as well as more occupational training in book-keeping, navigation or architecture. Later in the seventeenth century, frontispieces such as that of Jonas Moore's New System of the Mathematicks (1681) encouraged buyers' belief that knowledge of arithmetic, geometry, cosmography and navigation would lead to adventure, success and prosperity. ${ }^{12}$ As the image's portrayal of a group of busy men at work implied, engraved instruments were the handmaids to such pursuits, with books, maps, dials, quadrants, sectors and globes embodying mathematical practice. Alongside books promoting externalised apparatus, a further subset of texts arrived from Europe,

\footnotetext{
${ }^{12}$ Volker R. Remmert, " "Docet parva pictura, quod multae scripturae non dicunt." Frontispieces, their Functions, and their Audiences in Seventeenth-Century Mathematical Sciences' in Sachiko Kusukawa and Ian Maclean, eds., Transmitting Knowledge: Words, Images, and Instruments in Early Modern Europe (Oxford: Oxford University Press, 2006), pp. 239-270, particularly pp. 265-267.
} 
containing within them paper tools to assist the intellectual (and practical) development of readers' mathematical abilities.

Whether in the form of frontispieces, title pages or advertisements, additional printed material was attached to the beginnings and ends of mathematical works printed in England from the sixteenth century onwards. These addenda promoted the utility of the mathematical sciences in times of both war and peace, and advertised authors, instrument makers and tutors as equally beneficial to mathematical study. As might be expected, mathematical instruments would also play their part in the advertisement of utility. ${ }^{13}$ Addressing an English audience envisioned as consisting of 'Surveyers, Landemeaters, Joyners, Carpenters, and Masons', amongst other interested parties, Leonard Digges's A Boke Named Tectonicon (1556) promised to liberate 'chiefly those rules hyd, and as it were locked up in straunge tongues' by publishing 'in this our tongue (...) a volume conteynynge the flowers of the Sciences Mathematical, largely applyed to our outwarde practice, most profitably pleasant to all manner men of this realme'. ${ }^{14}$

Pending the publication of such a work, these artificers were asked to instead to 'be contented with this lyttle boke' as something of a promissory note of what would come. ${ }^{15}$ Staking its claim for the English practitioner, Digges's text was in part a response to the huge number of mathematical treatises which had flooded the English book trade from the European market, their contents describing the construction and use of instruments intended for surveying, navigation, time-finding, and a host of other mathematically related endeavours. Vernacular English was merely one method by which to draw together a wider audience of tradesmen, gentlemen, and fellow practitioners. Directing attention to the idea of a shared and profitable 'outwarde practice' as his end goal, Digges's Tectonicon was an early and important iteration of the labour shared by the theorists, printers, and instrument makers at work in early modern England - albeit one that pressed forwards, its face

\footnotetext{
${ }^{13}$ D. J. Bryden, 'Evidence from Advertising for Mathematical Instrument Making in London, 15561714', Annals of Science, 49 (1992), pp. 301-336.

${ }^{14}$ Leonard Digges, 'L. D. to the Reader', A Boke Named Tectonicon (London: John Day for Thomas Gemini, 1556), unpaginated, A $1 \mathrm{r}$.

${ }^{15}$ Digges, ibid.
} 
towards a growing culture of practical mathematics shared by various strata of English society.

Published by the Flemish émigré, Thomas Gemini, himself one of the first and foremost of London's sixteenth-century artisans, ${ }^{16}$ Tectonicon was a multifaceted artefact in which print, instrument, and practice met. Digges grounded his mathematical theory in examples, diagrams, and true-to-life measurements that would be easily tested and repeated by owners of the instruments whose use he promoted. As the publisher, maker, and retailer of books as well as instruments, the importance of Gemini was also advertised: readers could visit the instrument maker, who, from his 'dwellynge within the Black Fryers', would be 'ready exactly to make all the Instruments apperteynynge to this Booke'. ${ }^{17}$ Possibly a graduate of the Louvain school of instrument making, Gemini has been referenced as a likely contemporary of the cartographer and engraver Gerard Mercator thanks to a number of similarities in their work. ${ }^{18}$ As a precedent of the later practitioners who combined their interests in theory, practice, and publishing, Gemini was himself adept at fashioning instruments for surveying, to locate celestial and terrestrial positions, and to find the time.

Whilst examples of frontispieces and advertisements are hugely beneficial to our understanding of the market for mathematical objects (particularly in seventeenth-century England), a clear picture of mathematical reading outside of university cloisters remains difficult to pin down. A gateway to such readers is suggested by studies of instruments and their makers and users, however. Emblematic of early modern mathematical practice more broadly, efforts to appropriately characterize mathematical instruments — and, in Jim Bennett's terminology, a suitable awareness of what they were for-remain fertile ground for enquiry. ${ }^{19}$ Central to the spread of early modern mathematical culture are the 'hybrid instruments' of texts containing paper tools, particularly when viewed as part of an additional subgenre of instrument-books and fabrica et usus texts.

\footnotetext{
${ }^{16}$ L'Estrange Turner, Elizabethan Instrument Makers, pp. 12-13.

${ }^{17}$ Digges, Tectonicon, title page.

${ }^{18}$ Turner, Elizabethan Instrument Makers, pp. 12-20.

${ }^{19}$ Bennett, 'Knowing and Doing', p. 131.
} 
By considering the book more generally as a hybrid object, particularly when in the hands of a user, the material artefact is recognised in its truest historical sense not simply as a vehicle for textual presentation, but as an item in which is found evidence of intention, interpretation, and use. ${ }^{20}$ Importantly, in their encounters with volumes containing figures of instruments to be made and then operated, users were first given the opportunity to avail themselves of instrumental technology through the printed page, rather than via more expensively-wrought materials. Concerns over cost, damage, and loss of these more expensive materials were therefore annulled or significantly ameliorated.

These objects helped to further promote the public and private use of mathematics, whether for the common good or for private entertainment, via a diverse, aesthetically pleasing material culture. To encourage wider participation in the systematised processes of observation, calculations and recording, print technologies and expertise were co-opted by practitioners and publishers to introduce new users to the worlds of mathematics through texts, images, and instruments. Existing within a continuum of print culture in which cartographers, instrument makers, and stationers all held fluid and interchanging roles, paper instruments sat comfortably beside globes, maps, staves and dials within a shared class of products available in a range of materials dependant on their users tastes and income. They could be used as objects of wonder and delight, teaching and modelling, or active enquiry: or, indeed, any mixture of all three.

In combining analysis of users' scribal technologies with our understanding of the operation of instruments made available by print technology, this chapter examines the interpretative practices of the users of early modern mathematical objects. I argue that the users of the material culture of mathematics benefited from an attendant type of coaching in two sequential ways. First, these users were encouraged in their operation of intermediary instruments and texts so as to aid their visualisation of the contours of mathematical theory. Secondly, in their use and application of more complex instruments, users came to actively 'practice'

\footnotetext{
${ }^{20}$ Adam Mosley, 'Objects, Texts and Images in the History of Science', Studies in History and Philosophy of Science, 38.2 (2007), pp. 289-302, p. 292.
} 
mathematical theory to more adequately measure, calculate, and quantify the natural phenomena surrounding them.

Of particular interest are the methods mathematically literate technicians and practitioners brought to the related studies of the sphere, to planispheric projection, and to plane and spherical triangles. Relying on shared geometrical principles, these theoretical studies were of specific importance to practices of the early modern mathematical user, conjoining as they did navigation, geography, astronomy, and time finding (or dialling). How users responded to the textual and instrumental presentations of the methods belonging to plane and spherical geometry - and, more importantly, any evidence of their operative use of such methods - is therefore key to understanding the transmission of mathematical culture of the early modern period.

To understand these factors in their appropriate historical context, this chapter takes Thomas Blundeville's Exercises as a lens through which to view both its predecessors and descendants. By collating his vernacular manual, the author presented to a broad readership mathematical theory from several European sources: tables and instruments from the Germans Peter Apian and Clavius; maps from the Dutch mathematician, cosmographer, and globe- and instrument-maker Gemma Frisius and the cartographer Petrus Plancius; as well as volvelles and instruments taken from the work of the Flemish practitioner Michiel Coignet. Equally keen to see English interests given their due, Blundeville was unequivocal in his praise of John Blagrave's astrolabe, and spoke in glowing terms of his friend the Cambridge mathematical professor, navigator and inventor Edward Wright.

Whilst text and instrument are married in Blundeville's work (and, indeed, in the works of Apian, Blagrave, and many other mathematical authors of the period) as materials to be read for improved mathematical comprehension, their creators' goals were equally to see the text used thereafter as part of a reification of that understanding through the use of the instruments as described or provided. Acknowledging the visual and mental apprehension of figures, diagrams, and instruments is therefore as appropriate to today's historians as it was to the early modern practitioner - a fact that a number of contemporary studies are keen to 
express. ${ }^{21}$ Central to these studies is the challenge of expressing the epistemological backgrounds from which images and figures were generated and functioned, and, afterwards, how their meaning was transmitted amongst the interpreters of that image. ${ }^{22}$ Imagining, thinking through, and manipulating the texts and instruments relevant to each of these interlinked mathematical disciplines became its own type of training: a training in which, I argue, many authors and practitioners utilised instruments to prioritise 'doing' over 'knowing' - but only after a point of theoretical representation had been won. ${ }^{23}$

To this end, the current chapter first presents Thomas Blundeville's humanist background and goals as relevant to his mathematical publications. I then move to detailed presentations of three instruments, each of which appears in some form in the multiple editions of the Exercises, and their use: a tool for finding solar declination, for navigation and time finding; Michiel Coignet's nocturnal dial, previous iterations of which can be found in both Peter Apian's Cosmographia (1524) and Sebastian Munster's Horologiographia (1553); and, finally, John Blagrave' astrolabe, as described in The Mathematical Jewel (1585). To highlight how individual users and practitioners saw their efforts as reflected in the material culture of the period, this chapter draws on separate editions of Blundeville's texts, on editions of his sources, and on the instruments of the Science Museum's wider collection where appropriate.

\footnotetext{
${ }^{21}$ A number of these studies are particularly relevant to explorations of the growth of mathematical culture in the early modern period. See, for example, Samuel Y. Edgerton, The Renaissance Rediscovery of Linear Perspective (New York: Basic, 1975); Michael S. Mahoney, 'Diagrams and Dynamics: Mathematical Perspectives on Edgerton's Thesis', in John W. Shirley and F. David Hoeniger, eds., Science and the Arts in the Renaissance (Washington, DC: Folger Shakespeare Library, 1985), pp. 198-220; Brian S. Baigrie, ed., Picturing Knowledge: Historical and Philosophical Problems Concerning the Use of Art in Science (Toronto: University of Toronto Press, 1996); more recently, Nicholas Jardine and Isla Fay, eds., Observing the World through Images: Diagrams and Figures in the Early-Modern Arts and Sciences (Leiden and Boston: Brill, 2014). A useful if by now slightly outdated historiographical survey is to be found in Renzo Baldasso, 'The Role of Visual Representation in the Scientific Revolution: A Historiographic Inquiry', Centaurus, 48 (2006), pp. 69-88.

${ }^{22}$ Christoph Lüthy and Alexis Smets, 'Words, Lines, Diagrams, Images: Towards a History of Scientific Imagery', Early Science and Medicine, 14 (2009), pp. 398-439, p. 437.

${ }^{23}$ Mosley, 'Early Modern Cosmography: Fine's Sphaera Mundi in Content and Context', p. 133. Mosley argues that Fine's Sphaera Mundi was 'practical mathematics of the theoretical sort'; whilst Blundeville is some degrees less of a theoretician, his goals (and attempts at popularisation) existed on a similar scale to that of the French author.
} 


\section{Thomas Blundeville's canon and the publication of the Exercises}

As a well-connected humanist, Thomas Blundeville was propitiously placed to profit from the surfeit of educational needs present at court, the university, and the wider trading zones of the English market at the turn of the seventeenth century. Having inveigled himself into the broader court of Elizabeth I (1533-1603) thanks to the support of her secretary William Cecil (1520-1598) and the patronage of Robert Dudley, $1^{\text {st }}$ Earl of Leicester (1532-1588), the author was able to parlay his linguistic and mathematical abilities into a career as tutor to the house of the Lord Keeper of the Great Seal, Nicholas Bacon (1510-1579). ${ }^{24}$ It was in this capacity, as instructor to Bacon's daughter Elizabeth, that Blundeville began writing the Exercises's introductory treatise on arithmetic. ${ }^{25}$

Prior to these efforts, the first phase of Blundeville's literary career had consisted of pedagogically minded translations directed toward Elizabeth and her courtiers. The tutor's early oeuvre included collations of Plutarchan morality, advice on the counsel of princes, and an instructional manual on horsemanship, the last of which would be published in four editions between 1570 and $1609 .{ }^{26}$ An abridged and adapted English version of Francesco Patrizi’s important Della Historia Diece Dialoghi (Venice, 1560) was combined with a translation of the Italian émigré Giacomo Aconcio's unpublished Delle osseruationi, et auuertimenti che hauer si debbono nel legger delle historie (1564) under the title The True Order and Methode of Wryting and Reading of Hystories in $1574 .^{27}$

At this time the author also worked on an Arte of Logick, a philosophical text predicated on Aconcio's reading of Aristotle contra Petrus Ramus's dialectical

\footnotetext{
${ }^{24}$ Thomas Blundeville, A New Booke containing the Arte of Ryding (London: William Seres, ca. 1561), Preface, f. A i r; Thomas Blundeville, The Fowre Chiefyst Offices belonging to

Horsemanshippe (London: William Seres, 1565), Epistle, f. A ij r. In his preface to The Arte of Ryding the author thanked William Cecil for reading a draft copy. His following work, The Fowre Chiefyst Offices, was dedicated to Dudley. Dudley's portrait also featured at the frontispiece of a separate publication of Blundeville's The Order of Dietynge of Horses (London: William Seres, 1565).

${ }^{25}$ Blundeville, Exercises, Preface, (unpaginated) f. A 5 r.

${ }^{26}$ For an exploration of Blundeville's use of translations of Plutarch to curry royal favour, see Robert Cummings, 'Versifying Philosophy: Thomas Blundeville's Plutarch' in S. K. Barker and Brenda M. Hosington, Renaissance Cultural Crossroads: Translation, Print and Culture in Britain, 1473-1650 (Leiden and Boston: Brill, 2013), pp. 101-120.

${ }^{27}$ Hugh G. Dick, 'Thomas Blundeville's The True Order and Methode of Writing and Reading Hystories (1574)', Huntington Library Quarterly, 3.2 (1940), pp. 149-170, p. 149; pp. 151-152.
} 
method..$^{28}$ In the later sixteenth century, an influx of Ramist texts into England had met with their equal and inevitable reaction, both in Latin and in the vernacular. ${ }^{29}$ Aconcio, a close friend of Blundeville's, was of value as both an Italian authority and an admitted foe of Catholicism. ${ }^{30}$ Entrenched as he was in English Protestant humanism, the translator met with no meaningful controversy in his use of his friend's work; however, his Arte of Logick remained unpublished until 1599. In between times, he fashioned the Exercises, dedicating the work to his employer Sir Nicholas Bacon and to his previous student, Elizabeth. By this time, in the final third of his career, he had turned to mathematics: following the tome's first publication of 1594, a further collaboration with the physician Lancelot Browne produced The Theoriques of the Seven Planets in 1602.

Although Thomas Blundeville later termed his Exercises 'simple pamphlets' written specifically for the benefit of the young gentry, ${ }^{31}$ the publication of such a large and technical work was a calculated risk for the stationer John Windet. After the establishment of their printing-house in January 1584, Windet and his partner Thomas Judson enjoyed a small share of an ever-expanding market. Mark B. Bland's analysis of Windet's output has shown that the stationer printed at least 70 books during the $1580 \mathrm{~s}$, with an average composition rate of 200 sheets per annum between 1584 and $1589 .{ }^{32}$

Entering into a complementary partnership with his fellow printer John Wolfe provided the stationer with the capital required to undertake three major publications between 1592 and 1594: namely, a revised edition of Sir Philip Sidney's Arcadia; Richard Hooker's Of the Lawes of Ecclesiasticall Politie; and the Exercises. With the latter retailing bound at a price of $4 s 6 d$ in $1595,{ }^{33}$ the ambitions of the author and the stationer were well served by their first edition's popularity.

\footnotetext{
${ }^{28}$ Thomas Blundeville, The Art of Logick (London: William Stansby, 1617; first published 1599), pp. 63-64.

${ }^{29}$ For a summary of these works, see Charles B. Schmitt, John Case and Aristotelianism in Renaissance England (Kingston and Montreal: McGill Queen's University Press, 1983), pp. 33-37.

${ }^{30}$ Marco Sgarbi, The Aristotelian Tradition and the Rise of British Empiricism: Logic and Epistemology in the British Isles (Dordrecht: Springer Science + Business Media, 2013), p. 30.

${ }^{31}$ Thomas Blundeville, The Theoriques of the Seven Planets (London: Adam Islip, 1602), f. A iij r.

${ }^{32}$ Mark B. Bland, 'John Windet and the Transformation of the Book Trade, 1584-1610', Papers of the Bibliographical Society of America, 102.2 (2013), pp. 151-192, p. 156.

${ }^{33}$ Francis R. Johnson, 'Notes on English Retail Book-Prices, 1550-1640', The Library, Fifth Series, 5.2 (1950), pp. 83-112, p. 97. Johnson notes that this copy was part of a Cambridge physician's library as inventoried in 1595 .
} 
The first of several enlarged editions appeared only three years later. William Stansby, an apprentice, partner, and then successor of Windet's, would take responsibility for the printing of subsequent editions in 1613 and 1622.

Each of these major works reflects the past and future direction of Windet's commercial interests, which shifted gradually from providing texts for church and court to serving the interests of a learned gentry and a more quotidian audience thereafter. The author, himself a member of the Inns of Court as well as a tutor to the nobility, knew these coteries well. However, Blundeville's work was not Windet's first foray into mathematical printing, and nor would it be his last. In 1588, the stationer had printed Valentine Leigh's surveying text, The moste profitable and commendable science, of surueying of landes, tenementes, and hereditaments, on behalf of Andrew Mansell, and in 1590 he published Thomas Hood's translation of Petrus Ramus's The Elementes of Geometry. Under his own steam, Windet also printed instructions for keeping accounts, ${ }^{34}$ and Francis Cook's adaptation of the work by the German physician, astronomer and professor Georg Henisch, The Principles of Geometrie, Astronomie, and Geographie (1591). After the success of Blundeville's first two editions of the Exercises, Windet made further strides in mathematical publishing with his issue of Hood's The Making and Vse of the Geometricall Instrument, called a Sector (1598).

We can draw several meaningful conclusions from Blundeville and Windet's author-publisher relationship. Both men clearly saw the value in providing an audience growing in literacy and numeracy with well-chosen guidance for the young gentleman, be that in statesmanship, navigation, or the care and rearing of horses. Both were able to marry a technical proficiency to the production of texts: Blundeville, in his selection of materials to replicate from European texts, and Windet who, having purchased material from the estate of John Day, possessed the technology and the expertise to successfully bring the Exercises to fruition. Their shared enterprise resulted in what David W. Waters, in his seminal study of the

\footnotetext{
${ }^{34}$ Hugh Oldcastle, A Briefe Instruction and Manner how to keepe Books of Accompts (London: John Windet, 1588).
} 
development of navigation in Elizabethan and Stuart England, marked as a crucial turning point in the development of English maritime science. ${ }^{35}$

Furthermore, the movements of Thomas Blundeville's career are illustrative of a growth in Protestant humanism as tended to by Dudley and orbiting, in the first instance, the Inner Temple of the Inns of Court. ${ }^{36}$ A product of the Inner Temple in the early 1560s, Blundeville was one of a group of author-translators who 'identified with the young queen and the Protestant leadership at court [...] [contributing] translations of the classics and of Continental writing to the new politics', be they on statecraft, the art of war, or the training of noblemen. ${ }^{37}$ The translator's adaptation of Italian models of historiography was a product of his earlier travels, as well as something cultivated from close proximity to Dudley. But even these interests were intended to ultimately serve for the benefit of the overarching state. ${ }^{38}$ To the service of this common wealth we may add the author's concern for the discovery of a wider world, as evinced by the intellectual coterie to which he ultimately returned.

Charting the spread of mathematical geography in Elizabethan England, Lesley B. Cormack has demonstrated that mathematically-minded geographers gathered in localised groups identifiable through associations, correspondence, and printed dedications. This argument demarcates congregations of like-minded individuals in four discrete but interlinking circles: those of Thomas Allen, at Oxford; Henry Briggs, at Oxford and Gresham College, London; of John Dee, in London and Mortlake, and, finally and more amorphously, between the foci of Henry Percy, $9^{\text {th }}$ Earl of Northumberland, and the University of Cambridge mathematician Edward Wright. ${ }^{39}$

\footnotetext{
${ }^{35}$ Waters, Art of Navigation, Volume II, p. 341.

${ }^{36}$ For an overview of Robert Dudley's various patronages of Protestant authors and their humanistically-minded translations, see Eleanor Rosenberg, Leicester, Patron of Letters (New York: Columbia University Press, 1955).

${ }^{37}$ Kent Cartwright, Theatre and Humanism: English Drama in the Sixteenth Century (Cambridge: Cambridge University Press, 2004), p. 110.

${ }^{38}$ Claus Uhlig, 'National Historiography and Cultural Identity: The Example of the English Renaissance', in Herbert Grabes, ed., Writing the Early Modern English Nation: The Transformation of National Identity in Sixteenth- and Seventeenth-Century England (Amsterdam and Atlanta, GA: Rodopi B.V., 2001), pp. 89-108, pp. 93-94.

${ }^{39}$ Lesley B. Cormack, Charting an Empire: Geography at the English Universities 1580-1620 (Chicago: University of Chicago Press, 1997), pp. 124-128. Cormack's descriptions of the PercyWright circles suggest that the figures belonging to this final coterie are linked more by loose association than direct assimilation. Wright's interactions with the Percy circle are perhaps best
} 
Whilst in most cases members of each circle were well-known to each other, and would have often interacted thanks in no small part to their shared interests, Blundeville belongs most clearly to the fourth and final circle and is linked particularly to Edward Wright. Though the author of the Exercises was a friend of the ubiquitous Dee, he marks himself in print as strongly affiliated to his 'loving friend' Wright, whose permission he had sought to print the latter's theories previously circulating in manuscript, and to his 'deare friend' William Gilbert another important member of the Cambridge mathematician's identified coterie. ${ }^{40}$

Blundeville's presence in this subset of mathematical geographers chimes with his previous career as a tutor and translator, and particularly with his patriotic desire to improve the next generation for the benefit of the nation. A key participant in Wright's circle, the author aspired to put his linguistic and mathematical sophistication to use on behalf of the state. Mathematical geography as taught by English universities took inspiration from classical sources and, possibly inspired by John Dee's wider connections to continental theoreticians including Gemma Frisius, Pedro Nunez and Gerard Mercator, English geographers added to these sources the best of contemporary European practice. ${ }^{41}$ If the wider outcome was, as Cormack argues, a spur to the development of methods crucial to imperial success improvements in cartography, the theory of magnetism, and navigational methods, for example - then a further corollary is surely found in Blundeville's improving of the readers of the nascent English empire: that is, the students and users served by the Exercises.

Whilst the text was undoubtedly aimed at the young gentleman (who might just as likely become an intrepid navigator as he might an armchair cosmographer), its popularity extended through eight separate editions between 1594 and 1638 . These later editions suggest that an even broader audience benefited from the author's wide-ranging compilation of mathematical technologies from across Europe

\footnotetext{
understood as overlapping relationships at one remove, as, for example, when Cormack points out that a figure such as the globe-maker Emery Molyneux can be linked to Wright's circle through his work on the latter's projection, or to Percy's circle through his links to Robert Hues.

${ }^{40}$ For Thomas Blundeville's references to Wright, see Blundeville, Exercises, f. 189 r; f. 276 v; ff. 277 v - 278 r; f. 326 v. For his references to Gilbert, see Blundeville, Theoriques of the Seven Planets, particularly f. 291 r. An appendix provided by Wright at Gilbert's suggestion was also provided in Theoriques of the Seven Planets, f. 293 r.

${ }^{41}$ Sherman, John Dee: The Politics of Reading and Writing, p. 5.
} 
than was initially expected. As Hartwell's advertisement illustrates, in its later iterations, the Exercises was only occasionally improved by those directly involved in the teaching and promotion of mathematics, its original contents still valued by users and editors alike. Retained for use long beyond its final edition, Blundeville's defining work remained of interest to generations of learners. A copy of the fourth edition, printed in 1613, can be placed with the classicist Thomas Tyrwhitt (17301786) in the late eighteenth century. ${ }^{42}$

Attracting the learner with promises of dominion over the studies of astronomy, geography, and horology with the tacit improvement of the individual and state in mind, Blundeville in fact provided a coherent mathematical foundation to each study by guiding the reader from basic arithmetic and geometry (taken mainly from the works of Robert Recorde) to more complex trigonometry, gradually conjoining instrument and theory in the process. Reproductions of the first edition of the Exercises suggest that the work remained popular and held its own against the later works it would have undoubtedly influenced, such as Vincent Wing's Practica Urania, or Practical Astronomie in VI Parts (1652) and the navigational guides of Samuel Sturmy (1633-1669) and Richard Norwood (ca. 1590-1675). The Exercises's combination of civically-minded mathematics with demonstrations of its physical application to the material world was echoed half a century later in Norwood's call that theoretical speculation and leisurely divertissement give way instead to 'more labour and difficulty (...) the Mechanicall and bodily exercises which some esteeme meane and unworthy'. ${ }^{43}$

Deploying every aspect of his education, career and social networks to their maximum value, Thomas Blundeville marketed his Exercises as a product of Protestant, humanistic improvement of English students, ultimately for the benefit of the state. In steering the young gentility toward a sharper understanding of mathematics, the author's work was motivated by its author's background in mathematical geography for practical ends. Blundeville's familiarity with continental

\footnotetext{
42 Thomas Tyrwhitt's copy of the Exercises was bequeathed to the British Museum after his death in 1786, and now resides in the British Library, London. Thomas Blundeville, M. Blundeuile his Exercises, containing Eight Treatises, $4^{\text {th }}$ edn (London: Imprinted by William Stansby, 1613). British Library Shelfmark C.145.C17.

${ }^{43}$ Richard Norwood, The Seaman's Practice (London: printed for George Hurlock, 1637), ff. B 2 r-v.
} 
sources and his time as a tutor to nobility were equally important factors behind the Exercises's wider uptake, and became a significant influence on the navigational and mathematical manuals that followed in his wake. To understand how users interpreted Thomas Blundeville's direction, then, it is necessary to view his work within a longer transmission of the prevailing geo-centric, Ptolemaic cosmology of the era.

\section{The Exercises and the doctrine of the sphere}

The 'Ptolemaic' conception of the universe was popularly explicated largely through the continuing transmission and reception of Sacrobosco's influential medieval textbook De Sphaera Mundi (ca. 1230), a work which was almost continuously repackaged, rewritten, commented upon, printed and adapted until the end of the seventeenth century. ${ }^{44}$ As the 1505 copy of the text owned by the astronomer, meteorologist and statistician Sir George Schuckburgh (1751-1804) illustrated in Figure 3.3 shows, the Sphere's appeal to the mathematically and astronomicallyminded endured into the late $1700 \mathrm{~s}$, even as its wider popularity dwindled. ${ }^{45}$ Regrettably, in this case, Schuckburgh (after whom a crater of the moon is named) appears to have chosen not to add another layer of annotation to the indexical headings with which a previous user had marked their copy (Figures 3.4 and 3.5, below). ${ }^{46}$

\footnotetext{
${ }^{44}$ Kathleen Crowther, Ashley Nicole McCray, Leila McNeill, Amy Rodgers, and Blair Stein, 'The Book Everybody Read: Vernacular Translations of Sacrobosco's Sphere in the Sixteenth Century', Journal for the History of Astronomy, 46 (2015), pp. 4-28, p. 6. The authors point to both the high occurrence of editions of Sacrobosco's text, with over 200 editions printed between 1453 and the early $1600 \mathrm{~s}$, and to the editions in which vernacular translations and sections on practical subjects including astrology, cartography and navigation were common. For a detailed introduction to Sacrobosco, De Sphaera Mundi and its early reception, see Lynn Thorndike, The Sphere of Sacrobosco and its Commentators (Chicago: University of Chicago Press, 1949), pp. 2-21. ${ }^{45}$ For further details on George Schuckburgh's mathematical career, see Taylor, Mathematical Practitioners of Hanoverian England, p. 296.

${ }^{46}$ Joannes de Sacro Bosco, Opus sphericum magistri Ioamnis de Sacro Busco natione angli figuris verissime exculptis et interpretatione familiari ad commoditatem desiderantium iucundissima Artis Astronomice callere principia pulcherrime et iterate recognitione illustratum (Cologne: Henrici Quentel, 1505), Science Museum Library Shelfmark O. B. SAC SACRO 461008-2001.
} 


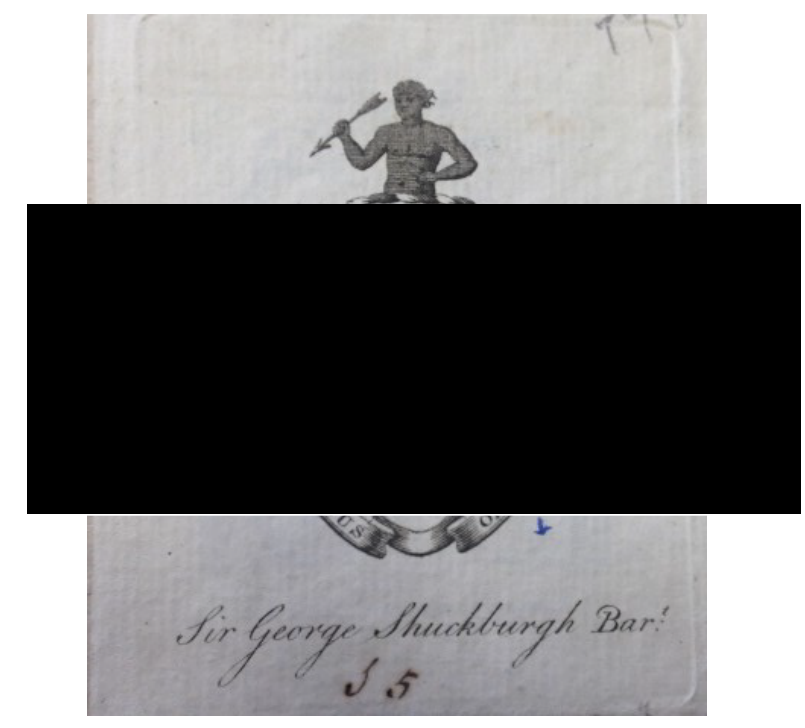

Figure 3.3. Bookplate of Sir George Schuckburgh-Evelyn, 6th Baronet, to the front pastedown of his copy of Sacrobosco's Sphere. Science Museum Library Shelfmark O. B. SAC SACRO 461008-2001.

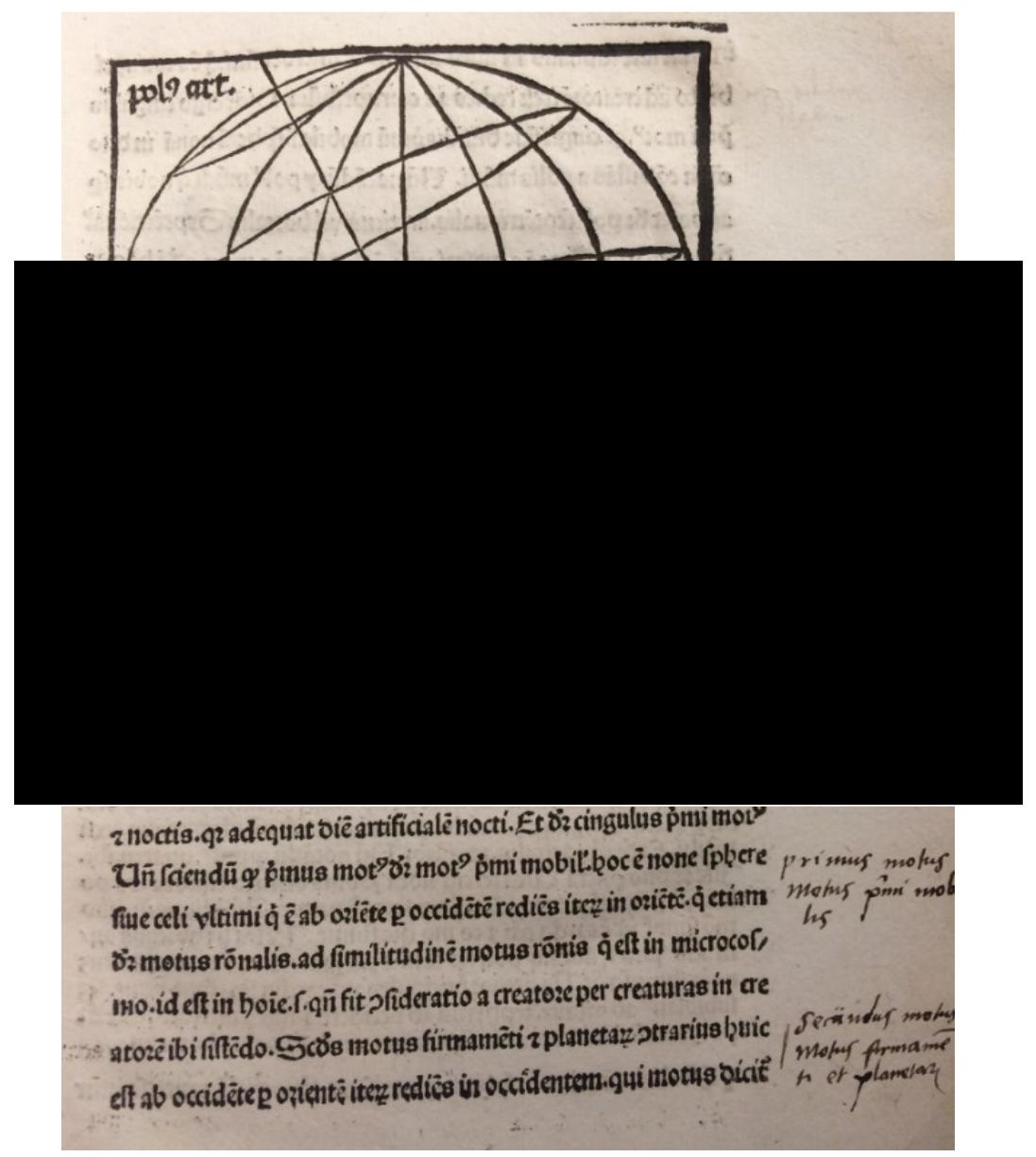

Figure 3.4. Indexical, marginal commonplacing of topics in the 1505 copy of Sacrobosco's Sphere. In this instance, the annotations mark the equinoctial and equatorial circles of the celestial sphere, and the motions of the first and second movements. Science Museum Library Shelfmark O. B. SAC SACRO 4610082001. 


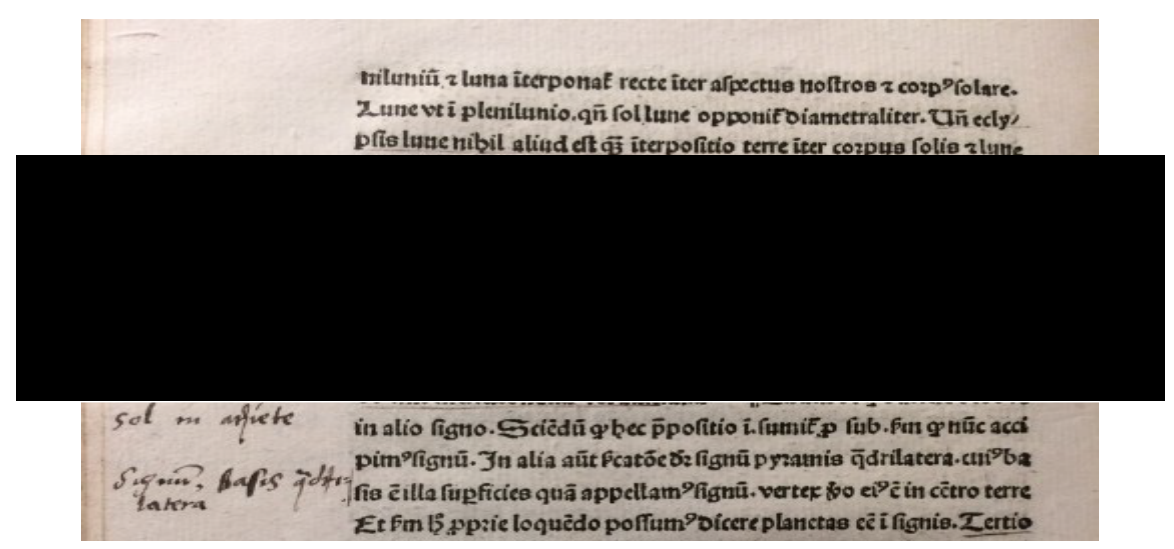

Figure 3.5. The indexical annotations in Schuckburgh's copy of the Sphere continued with a marking of the parts of the zodiac and the position of the sun in either hemisphere. Science Museum Library Shelfmark O. B. SAC SACRO 461008-2001.

The Sphere and its doctrine are distinguishable as one of the most crucial tools in the shared scientific and cultural identity that blossomed in Europe until the end of the seventeenth century; a manual common to multiple generations of learners both directly and through commentaries. ${ }^{47}$ Ptolemy's geocentric model as promoted by the Sphere taught that the earth was fixed at the centre of the universe, with celestial bodies orbiting it in daily and annual revolutions. Depending on their commitment to Aristotelian cosmology, medieval philosophers could speak in terms of between eight and eleven concentric spheres, eliding in the process the complexities of the eccentric orbits and epicycles introduced by the Almagest. ${ }^{48}$ Christoph Clavius's commentary on the Sphere, first published in Rome in 1570, achieved fame and praise for the depth of its learning; ${ }^{49}$ it was this commentary that Thomas Blundeville turned to for his own presentation of Sacrobosco's material.

Thus the Exercises taught, in keeping with Clavius's teachings, that beyond the sphere containing the earth and the four elements, a series of eleven concentric, interlocking spheres held the seven observable 'planets' - the Moon, Mercury, Venus, the Sun, Mars, Jupiter, and Saturn. The eighth sphere was the firmament of the fixed stars; the ninth, the crystalline heaven, also referred to as the Second

\footnotetext{
${ }^{47}$ Valleriani, 'The Tracts on the Sphere', p. 422. See also Olaf J. Pedersen, 'In Quest of Sacrobosco', Journal of the History of Astronomy, 12 (1981), pp. 113-123.

${ }^{48}$ Edward Grant, The Nature of Natural Philosophy in the Late Middle Ages (Washington, DC: The Catholic University Press, 2010), pp. 121-125.

${ }^{49}$ James M. Lattis, Between Copernicus and Galileo: Christoph Clavius and the Collapse of Ptolemaic Cosmology (Chicago and London: University of Chicago Press, 1994), pp. 37-38.
} 
Moveable, and the tenth the first movable or Primum Mobile. Finally, the model was crowned by the eleventh sphere - that of the Empyrean Heaven, inhabited by God and his angelic retinue (Figure 3.6)..$^{50}$

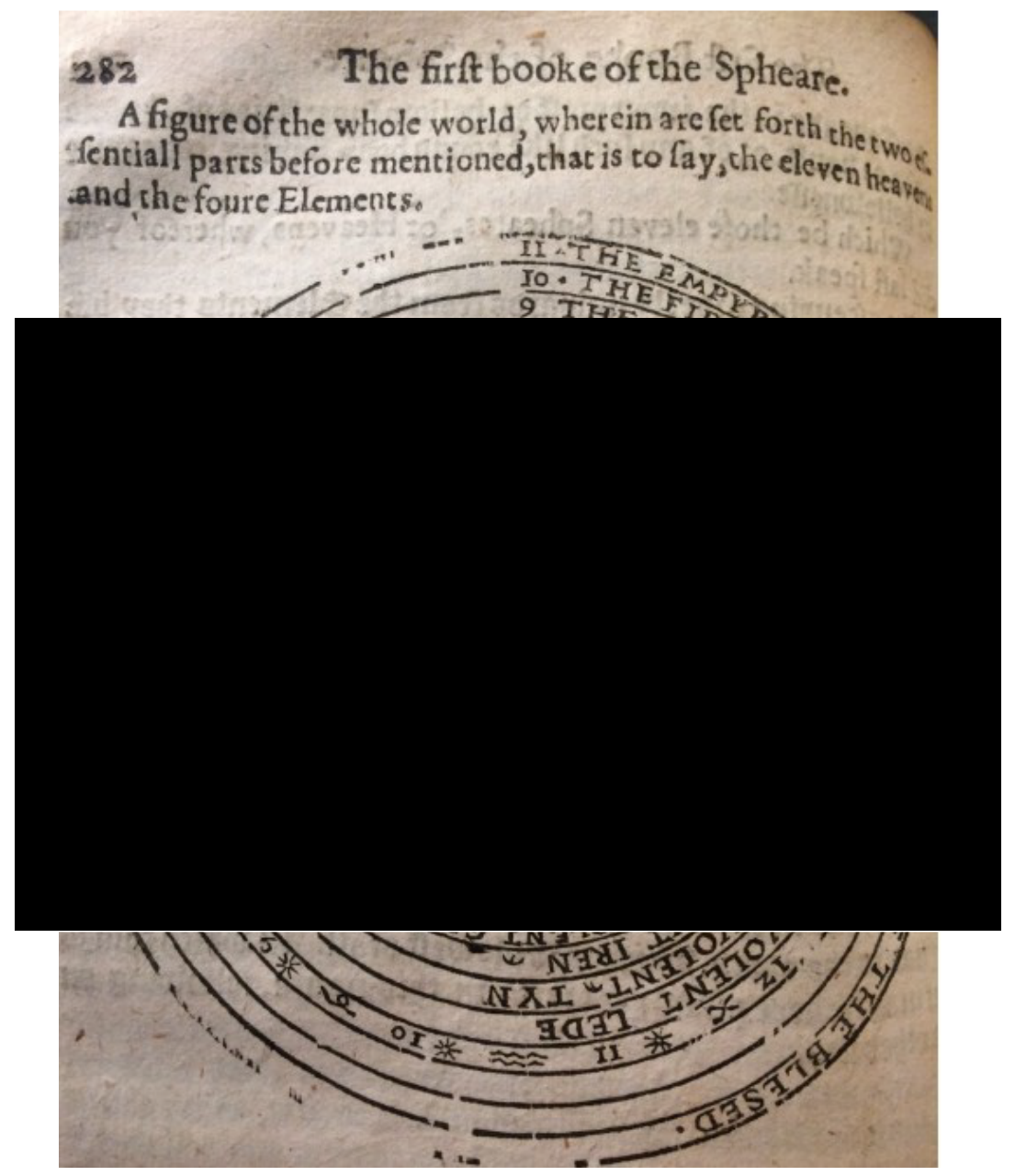

Figure 3.6. Blundeville's reprint of Sacrobosco's figure of the world, as featured in each edition of the Exercises.

Understanding or simply acknowledging the sphericity of the heavens was an important gateway to the operative application of mathematics through theory and through instruments. As a tradition, the doctrine of the sphere-with the repackaging of Sacrobosco's work a foundational element-successfully incorporated into itself a continuous process of the codification and integration of new subjects. ${ }^{51}$ Astrolabes and other instruments became central to the preparatory teaching of astronomy, and similarly aided the teaching of geography, cosmography, and navigation, with the

\footnotetext{
${ }^{50}$ Blundeville, Exercises, f. $136 \mathrm{r}$.

${ }^{51}$ Valleriani, 'The Tracts on the Sphere', p. 430.
} 
result that, in Matteo Valleriani's striking description, 'the nature of the knowledge connected with the Sphere was essentially practical (...) knowledge concerning the Sphere became completely instrumental to practical needs'. ${ }^{52}$ Whilst didactic instruments such as Ptolemaic armillary spheres could be used to introduce, model and demonstrate elementary astronomical principles and problems, the Sphere's doctrine was also presented alongside more practical fabrica et usus works featuring instruments such as astrolabes and quadrants, popular from the Middle Ages onwards. $^{53}$

The practical nature of such knowledge is immediately recognisable in the instruments that utilised the theory of spherical astronomy. Astrolabes and horary quadrants were based on projective geometry, and many popular iterations of each instrument aided their users to calculate local time and geographic position through either a local latitudinal or a universal planispheric projection. The mathematical technique of stereography ensured that by setting of a perspectival point, the circles of the celestial sphere were transposed into a series of curved lines on a plane with only minimal distortion. The doctrine of the sphere was further aestheticized in tandem with its practical use in the products - the astrolabes, geocentric armillary spheres for teaching and decoration, and dials - of what Pamela Smith has dubbed an 'artisanal epistemology': ${ }^{54}$ one emanating from Nuremberg, and one celebrated by German humanists enamoured with melding the mathematical and descriptive geographies of Ptolemy and Strabo respectively.

In their overlapping roles as mathematical professors, instrument makers, and printers, sixteenth-century German technicians such as Peter Apian, Johannes Stöffler and Georg Hartmann made use of spherical astronomy to continue Regiomontanus's legacy of utilising the technology of print to fashion new and mathematically exact instruments appropriate for teaching and use alike. These

\footnotetext{
${ }^{52}$ Valleriani, 'The Tracts on the Sphere', p. 438. Valleriani cites in particular the teaching practices of the aula de esfera at the Jesuit College of S. Antão in late-sixteenth century Lisbon; for the relevance of Sacrobosco's work to cosmographical teaching at the University of Salamanca in the sixteenth century, see María M. Portuondo, Secret Science: Spanish Cosmography and the New World (Chicago and London: University of Chicago Press, 2009), particularly pp. 42-49.

${ }^{53}$ Sara Schechner Genuth, 'Armillary Sphere' in Robert Bud and Deborah Jean Warner, eds., Instruments of Science: An Historical Encyclopedia (New York and London: The Science Museum, London and The National Museum of American History, Smithsonian Institution in association with Garland Publishing, 1998), pp. 28-31; Lattis, Between Copernicus and Galileo, p. 41.

${ }^{54}$ Smith, Body of the Artisan: Art and Experience in the Scientific Revolution, pp. 64-66.
} 
instruments could remain in books or pamphlets, or they could be fashioned into paper, wood, or brass instruments as their users desired. Apian had in fact specifically instructed that the leaves bearing prints of quadrants and dials should remain unbound, so as to encourage the consumer to fashion these prints into their instrumental forms as examples for instructional and practical purposes (Figure $3.7){ }^{55}$

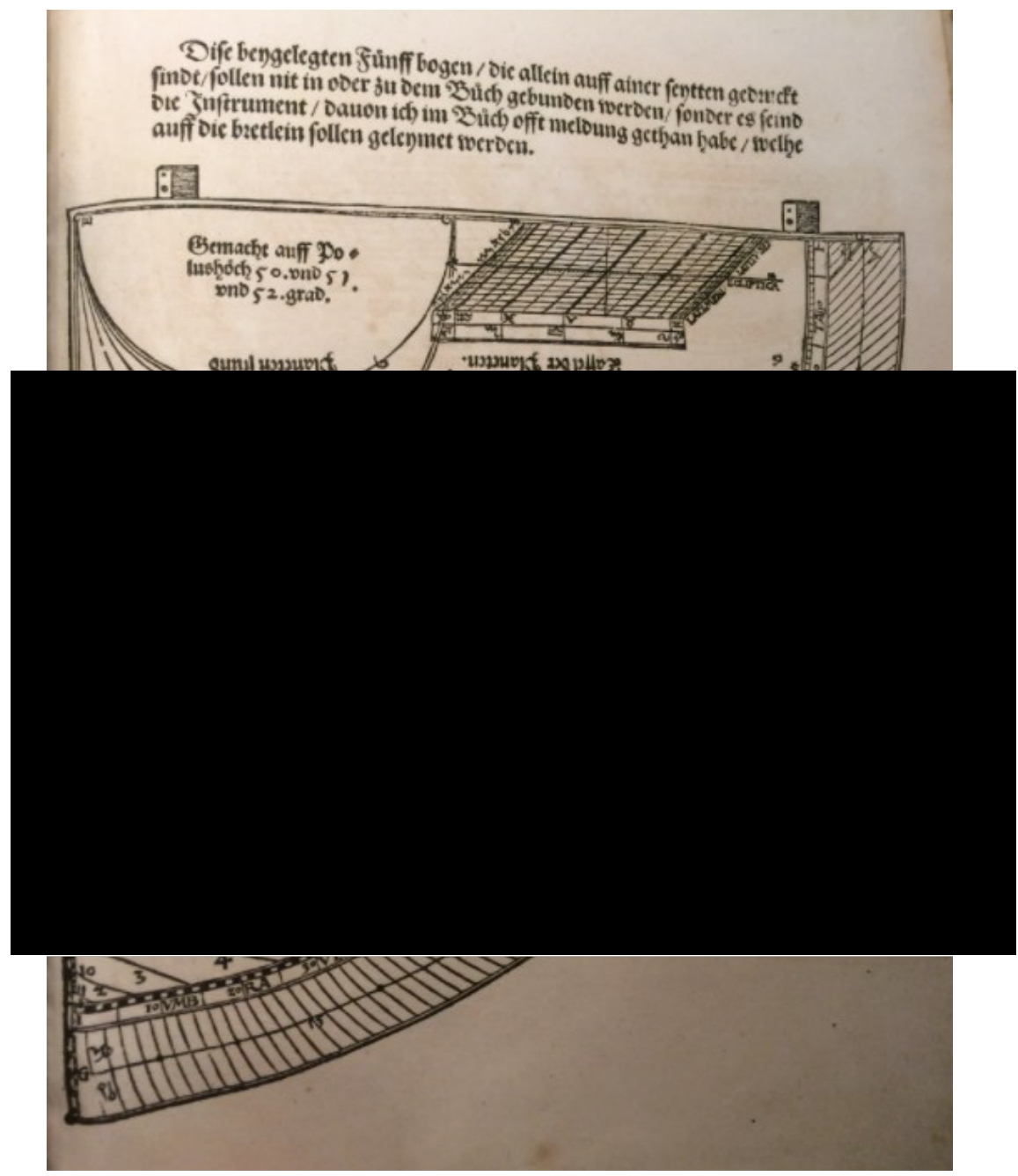

Figure 3.7. An example of one of Peter Apian's horary quadrants from Folium Populi (1533), created for use between 50 and 52 degrees of latitude.

When formed, Apian's quadrant served to aid users in finding the time at latitudes of 50 to $52^{\circ}$. The user would tilt the instrument toward the sun using the

\footnotetext{
${ }^{55}$ Peter Apian, Folium Populi. Instrumentum hoc a Pietro Apiano (Ingolstadt: Peter Apian, 1533), unpaginated. The text above the quadrant reads 'Diese beygelegten Funff bogen / die allein auff ainer feytten gedruckt finde / sollen nit in order zu dem Buch gebunden warden / sonder es seind die Instrument / davon ich im Buch offt meldung gethan habe / welche auff die bretlein sollen geleymet werden.'
} 
sights to the horizontal radius atop the quadrant. A thread with a plumb bob could be hung from the vertex, which, when the user was happy with their sighting, could be pinched tight to the instrument so as to read off the time on the 'folded' planispheric hour lines transposed to the quadrant's face. The graduated limb of the quadrant's quarter circumference was divided to show the sun's movement through the zodiacal constellations, with the $90^{\circ}$ arcs helping users to determine the altitude of celestial bodies. The quadrant, already by this stage an instrument with a long and popular history, embodied the geometrical properties underpinning positional astronomy for a huge variety of users. Inscribing the instrument with shadow squares also meant that it could be used to find the heights of objects and the lengths of distance from a given object. By making objects like the quadrant ever more accessible in cheaper if more ephemeral forms, instrument makers made geometrical practitioners of their consumers: practitioners who could easily marry the basic tools of a line of sight and the graduations of a divided circle.

Furthermore, the treatises accompanying these instruments ensured that users participating in a knowledge economy predicated upon the mathematics of positional astronomy were enabled to improve upon their epistemic practice. Instruments such as Apian's quadrant came with treatises explaining their use, introducing the user to an accessible (and somewhat demystified) treatment of the discipline, thus helping to popularize both disciplinary knowledge and its practical application. Earlier iterations were no different: Sacrobosco's description of the quadrant, written ca. 1245-1250, advocated, as so many later users would, the use of the instrument in conjunction with tables full of celestial data. ${ }^{56}$

Evidence of attempts to interact with this information can be witnessed in a number of annotations in the German instrument books of the early sixteenth century as present in the Science Museum's collection. A first edition of Peter Apian's Quadrans Apiani (Ingolstadt: Peter Apian, 1532) — a work featuring a do-it-yourself quadrant similar to that of the Folium Populi above-features a brief noting of the

\footnotetext{
${ }^{56}$ Wilbur R. Knorr, 'Sacrobosco's Quadrans: Date and Sources', Journal for the History of Astronomy, 28 (1997), pp. 187-222, p. 199. Knorr also provides a detailed survey of Sacrobosco's work on the quadrant in its medieval context in Wilbur R. Knorr, 'The Latin Sources of Quadrans Vetus, and What They Imply for Its Authorship and Date' in Edith Sylla and Michael McVaugh, eds., Texts and Contexts in Ancient and Medieval Science. Studies on the Occasion of John E. Murdoch's Seventieth Birthday (Leiden: Brill, 1997), pp. 23-67.
} 
names of various constellations beside their naturalistic, zodiacal portrayals. ${ }^{57}$ In this instance (and despite Apian's aforementioned recommendations to the contrary) the user has chosen not to construct the paper instrument, instead marking the text's accompanying depictions to internalise the names and depictions of the constellations above.

For other European users of German instrument-books, the goal of a deeper technical understanding through instrument and theory is readily witnessed. A lightly-annotated copy of Johannes Stöffler's Elucidatio fabricae ususque astrolabii (Oppenheim: Jacob Koebel, 1513) provides further evidence of early modern readers and would-be practitioners approaching mathematical theory. One individual user has marked the parts of the celestial sphere, noting the easterly and westerly cardinal points of the sun's rising and setting (the oriens and occidens), the movement of celestial bodies in twenty-four hour periods and, importantly, the construction of the astrolabe itself - both in the margins of the text (Figure 3.8) and upon a printed diagram of the instrument itself (Figure 3.9). ${ }^{58}$

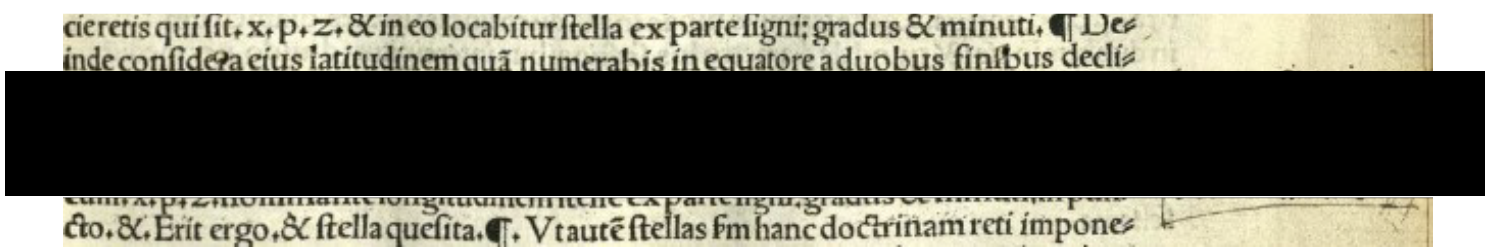

Figure 3.8. Annotation on the composite geometrical parts of Johannes Stöffler's astrolabe and their relation to the position of the earth within the celestial sphere. Science Museum Library Shelfmark Q. O. B. STO STOEFFLER 461834-2001.

\footnotetext{
${ }^{57}$ Peter Apian, Quadrans Apiani astronomicus et iam recens inventus et nunc primum editus (Ingolstadt: Peter Apian, 1532), ff. c 3 r - v. Science Museum Library Shelfmark Q. O. B. API APIANUS 461587-2001.

${ }^{58}$.Johannes Stöffler, Elucidatio fabricae ususque astrolabii (Oppenheim: J. Koebel, 1513), ff. 5 r-v and ff. 9 r -10 r. Annotation to Stöffler's printed instrument is found on f. 28 v. Science Museum Library Shelfmark Q. O. B. STO STOEFFLER 461834-2001.
} 


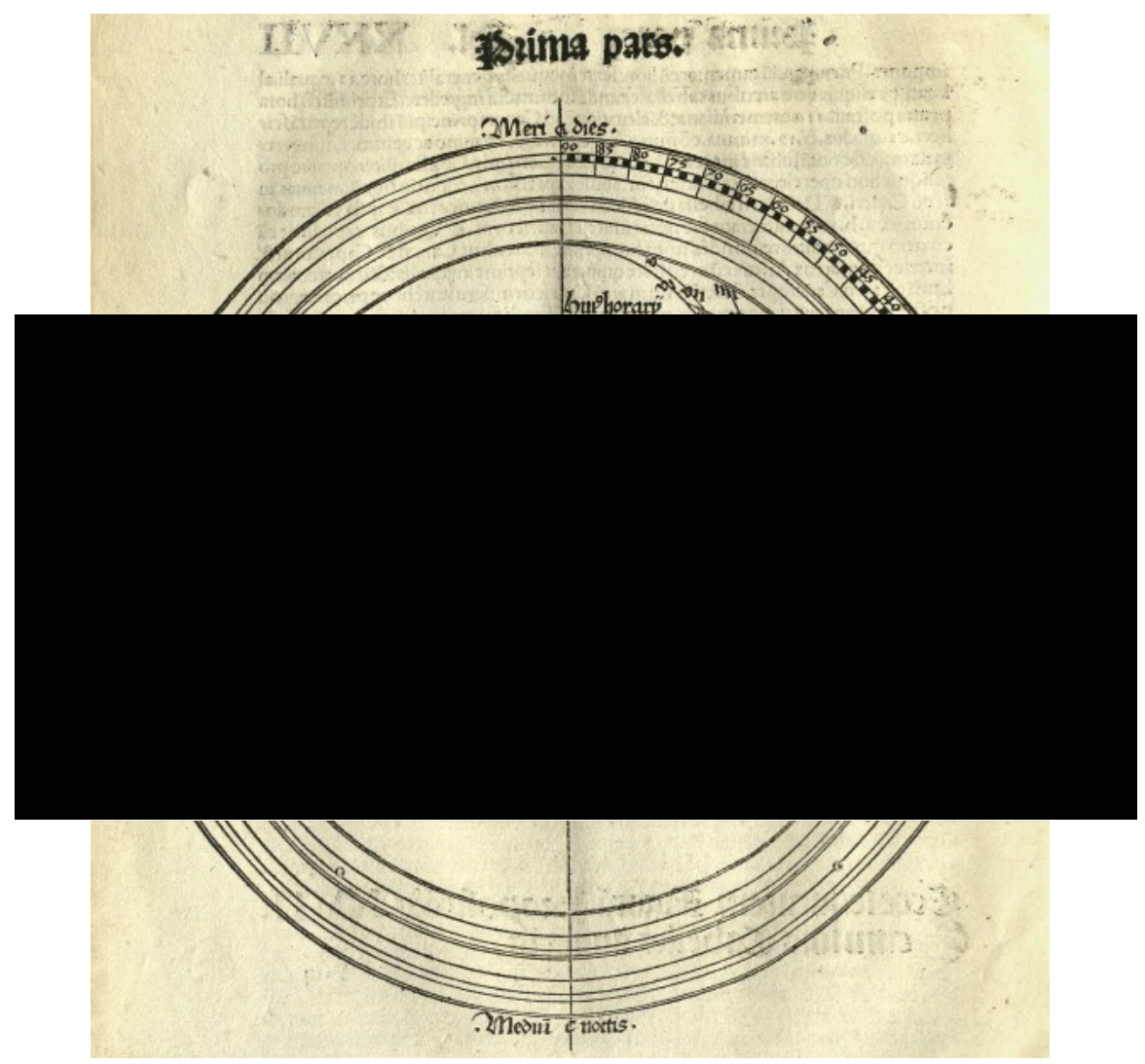

Figure 3.9. Annotation to a printed diagram marking the hour lines of Johannes Stöffler's astrolabe. Science Museum Library Shelfmark Q. O. B. STO STOEFFLER 461834-2001.

Stöffler's work was a cornerstone of the instrument and fabrica et usus texts of the early modern period. It presented, in two distinct sections, a schematic for the construction of the instrument, following this with true-to-life depictions of its use for time-finding, surveying, measurement, and astrological purposes. Large fold-out sections expanded the astrolabe's parts and inscriptions to make its construction and application as user-friendly as possible. The influence of the mathematician, instrument-maker, and Tübingen professor is obvious in the works of his famed pupil, Sebastian Münster, but also in any number of the works on astrolabes and instruments that came after him. Against these must be set the continuing popularity of Stöffler's own astrolabe text, a work that remained in publication from 1513 to the late seventeenth century.

As print and its influence spread across Europe, its associated proponents naturally sought new opportunities for patronage and influence throughout the continent. As Chapter One of the current thesis has already discussed, Thomas Gemini was at the forefront of the early 1540s influx of talented instrument-makers 
from Flemish and German regions to early modern London. Gemini and his peers brought with them a higher standard of mathematical instruments - instruments (and attendant practices) that were soon sold to the English consumer. Spurred to action by the increasing availability of mathematical texts, instruments, and education, indigenous practitioners soon established their own shop fronts, networks of production, and markets, profiting from this new class of skilled workers.

Importantly, these printed instruments existed in a continuum in which users were encouraged to conceive of their content in both plane and spherical forms. By depicting the relational, spherical structure of the earth and the heavens whilst simultaneously being capable of measuring quantities, such instruments helped users to strengthen the intellectual associations between the shared coordinates of the celestial sphere and terrestrial globe with practical endeavours relevant to one's everyday labour. These associations were put to work for seafaring, military, or commercial use. Whilst the aesthetic appeal of these objects to princes and wealthy collectors - an appeal undoubtedly milked by the instruments' creators - should not go unrecognised, it must also be noted that instrument makers were largely obstinate defenders of the functional use of their products. ${ }^{59}$

Works such as Thomas Blundeville's Exercises also afford us the opportunity to respond to A. J. Turner's challenge 25 years ago for historians of science to attend to 'the fullness of communal learning' presented by quotidian early modern instruments in their own age.$^{60}$ Novel appraisals of the mathematical and print cultures of early modern Europe have since brought to light the ways in which instruments such as sundials functioned as a suitable reflection of the movements and shape of the heavens. From their construction and use could be explicated geometrical theory and its practice. ${ }^{61}$ Blundeville's work is a further example of the presentation of amateur or everyday materials in participation with this communal making of knowledge as presented by continental and English experts. In such a

\footnotetext{
${ }^{59}$ Suzanne Karr Schmidt, 'Making Time and Space: Collecting Early Modern Printed Instruments' in Suzanne Karr Schmidt and Edward H. Wouk, eds., Prints in Translation, 1450-1750. Image, Materiality, Space (Abingdon: Routledge, 2017), pp 114-135; Karr Schmidt, Altered and Adorned, pp. 73-92.

${ }^{60}$ Turner, 'Interpreting the History of Scientific Instruments', p. 20.

${ }^{61}$ Catherine Eagleton, 'Oronce Fine's Sundials: The Sources and Influences of De solaribus horologiis' in Alexander Marr, ed., The Worlds of Oronce Fine: Mathematics, Instruments and Print in Renaissance France (Donnington: Shaun Tyas, 2009) pp. 83-99, p. 85.
} 
culture, the material objects of book and instrument acted as products and as participants.

To their users, navigational manuals, instrument books, fabrica et usus works, volvelles, globes, dials, and quadrants were all products of the inscribed materiality of early modern knowledge-making. Each type of object could supplement or, at times, substitute for the other, depending on the practices undertaken, their settings, and the outcomes desired. Of these objects, the book acted as a hybrid instrument. In Derek de Solla Price's playful summation,

the makers of scientific instruments begat the book trade, and the rise of the book in turn begat more scientists and more instruments to help their work (...) the book began to be the medium for a quite new activity in science that now completed the circle. The book itself became a sort of scientific instrument. ${ }^{62}$

It is to be noted that the early modern book-instrument hybrid - at least, as produced by Apian, Coignet, Blundeville and others - was a very particular type of instrument: one to be looked at, as well as looked through. At the cheaper end of the scale, the tools of these texts were marked by their material properties, with paper both a transparent bearer of marks, and something opaque, to be shaped and manipulated. ${ }^{63}$ Extant copies of the Exercises which bear evidence of use, whether in the making of these tools, or in accompanying annotations of manipulation and operation, therefore contain examples of more amateur readers unifying mathematical texts, instruments, and practice. Such users, however, had first to be trained in the visualisation, manipulation, and practical application of mathematical theory.

\section{The Exercises and their Instruments: Learning and Playing with Geometric Tools}

As we have seen, Thomas Blundeville's manual was intended for English readers to exercise their mathematical abilities mentally as well as physically. The Exercises's hybridity combined printed treatises full of textual instruction, diagrams, illustrations, and tables, with instruments both internal and external to the work. It

\footnotetext{
${ }^{62}$ Derek J. de Solla Price, 'Book Review: Astronomicum Caesarum, The Book as a Scientific Instrument', Science, 158.3797 (1967), pp. 102-104, p. 102.

${ }^{63}$ Boris S. Jardine, 'State of the Field: Paper Tools', Studies in History and Philosophy of Science, Part A, 64 (2017), pp. 53-63, p. 56.
} 
presented one unique instrument purportedly of Blundeville's creation, a protractor for calculating latitudinal position, and borrowed several others from Edward Wright, Michiel Coignet, and various other continental practitioners. Along with the tools common to early modern mathematical practice - compasses, cross-staves, globes, dials, and astrolabes - users (or the publishers and booksellers hawking the text) were encouraged to construct or operate paper volvelles from the leaves of the volume itself. ${ }^{64}$ Volvelles, a class of instrument made of fixed and moveable circles often incorporating graduated scales for analogue computation or the display of astronomical movements, ${ }^{65}$ had previously been put to use in a wide range of disciplines: including (but not limited to) educational, astrological, medicinal, and theological calculation.

A continuation of the material technology used in earlier manuscripts and codices, volvelles were beneficiaries of the opportunities afforded to producers by moveable type. The development of printing press and large-scale production contributed to the significant growth in popularity of volvelles in early modern printed texts, with examples most consistently found in astronomical and navigational textbooks of the period. ${ }^{66}$ Blundeville would himself return to a standard version of the tool in his later Theoriques of the Seven Planets, participating in the common lineage of astronomical teaching from earlier European and Latinate sources by presenting the circles, angles and relationships relevant to planetary positions as manipulable paper tools (Figure 3.10, below) ${ }^{67}$ Introducing his theorics, the author again established that he had borrowed from a wide range of sources, cadging materials 'partly out of Ptolomey, partly out of Purbachius, and of his

\footnotetext{
${ }^{64}$ As might be expected, surviving copies of Blundeville's text show examples of volvelles both constructed and unconstructed in the text. From an initial survey it does not appear that printers/publishers were given consistent instruction to construct the volvelles: however, the skill (and lack of damage to the bindings and surrounding sheets) of the constructed examples suggests that in several cases the instruments were constructed before purchase.

${ }^{65}$ Kanas, Star Maps: History, Artistry, Cartography, pp. 234-235.

${ }^{66}$ Gingerich, 'Astronomical Paper Instruments with Moving Parts', p. 73. On volvelles in manuscripts, see Laurel Braswell-Means, 'Vulnerability of Volvelles', pp. 43-54.

${ }^{67}$ Printed by Regiomontanus between 1472 and 1474 from manuscript lecture notes, Georg von Peurbach's Theoricae Novae Planetarum was a common source for the transmission of advanced Ptolemaic astronomy from the late fifteenth to at least the early seventeenth century, and incorporated paper tools in print from as early as 1482. See Olaf Pedersen, 'The Decline and Fall of the Theorica Planetarum: Renaissance Astronomy and the Art of Printing", Studia Copernicana, 16 (1978), pp. 157-185; Michael H. Shank, 'The Geometrical Diagrams in Regiomontanus's Edition of his own Disputationes (c. 1475): Background, Production, and Diffusion', Journal for the History of Astronomy, 43.1 (2012), pp. 27-55.
} 
Commentator Reinholdus, also out of Copernicus, but most out of Mestelyn, whom I have chiefly followed, because his method and order of writing greatly contenteth my humour. ${ }^{98}$

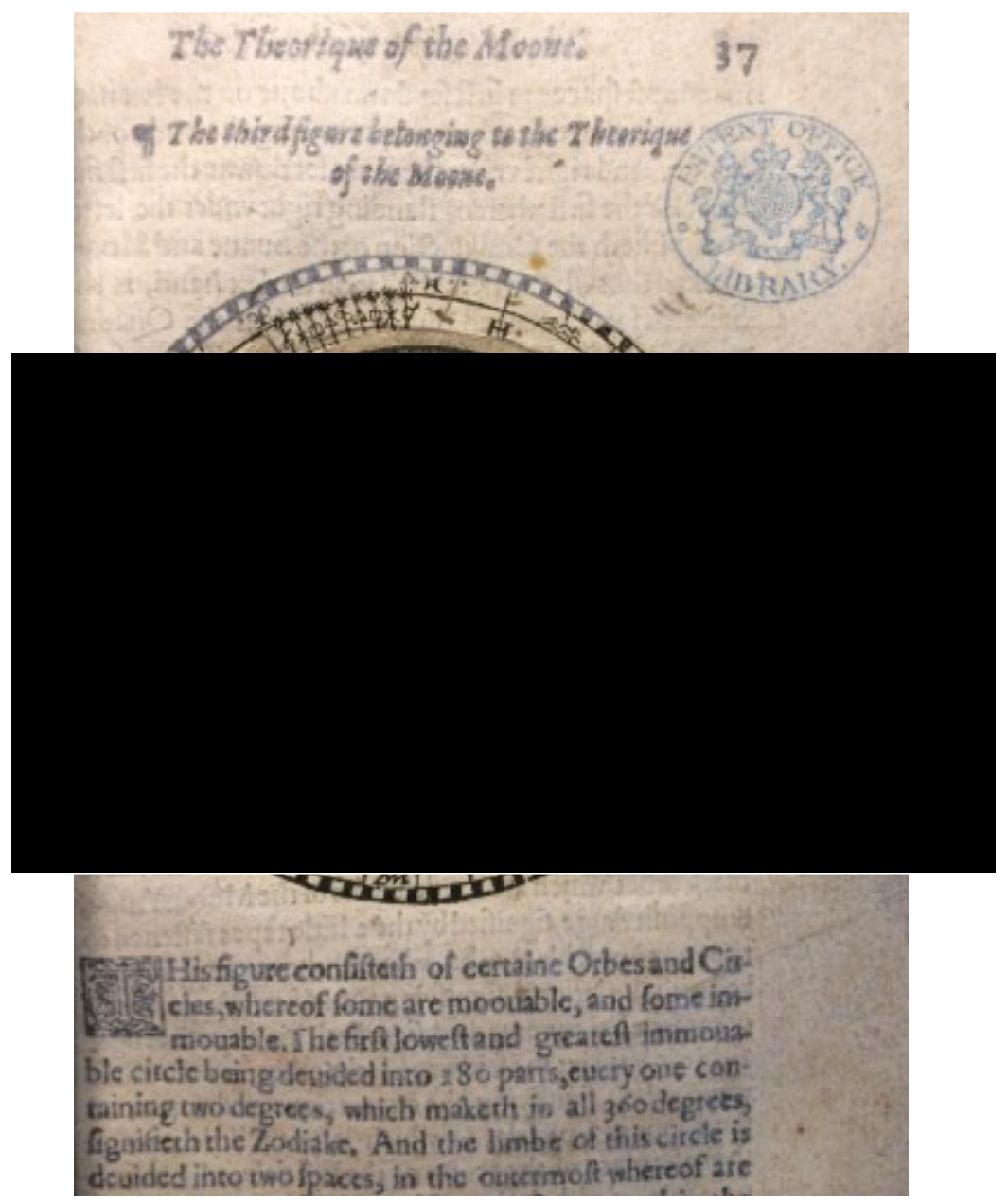

Figure 3.10. An example of a volvelle used to demonstrate the theoric of the Moon, in Thomas Blundeville's Theoriques of the Seven Planets (1602). British Library, Shelfmark C.184.d.2.

Attending to the intersection between books and instruments common in a variety of early modern 'knowledge-making' texts, scholars have sought to identify more precisely how and why volvelles were used in the early modern period. The suitability of the paper tools' overlapping discs to computation allowed their producers and users to circumvent astronomical tables and manual calendrical calculation with instruments of paper and thread. ${ }^{69}$ Particularly appropriate to the

\footnotetext{
${ }^{68}$ Blundeville, Theoriques of the Seven Planets, f. A iij r.

${ }^{69}$ Richard L. Kremer, 'Experimenting with Paper Instruments in Fifteenth- and Sixteenth-Century Astronomy: Computing Syzygies with Isotemporal Lines and Salt Dishes', Journal for the History of Astronomy, 42 (2011), pp. 223-258, p. 223.
} 
teaching of astronomy, navigation and cosmography, volvelles enabled the user to visualise and handle the essential concepts of the world-system underpinning each discipline. Such qualities meant that paper instruments were therefore used to teach or engender a basic understanding of the standard Ptolemaic conception of the universe common to introductory navigational and astronomical texts of the sixteenth and seventeenth centuries. ${ }^{70}$

Writing in 2003, Jim Bennett proposed the notion of the 'geometric theoric', suggesting that such a notion could be 'used to encapsulate a relationship between appearances, from which information could be extracted by the use of certain protocols' and, as such, be of general relevance to mathematical practice, characterizing planetary constructions, maps, and instruments. ${ }^{71}$ This has more recently been repurposed by Richard L. Kremer to expand upon the term 'geometrical tool'; in Kremer's conception, a mobile, easily-handled tool predicated on a particular configuration of graphical elements to allow users to solve a discrete geometrical problem. These tools could be added to existing instruments, combined together to form new instruments, or simply used on their own terms. Finally, such tools could operate on the basis of set geometrical techniques and could, if so desired, be used for ludic purposes, to test and solve problems, or for any combination thereof. ${ }^{72}$

The operation of the volvelles and paper tools presented in the initial edition of the Exercises was grounded upon their shared geometrical theory as applied to a geo-centric system initially modelled on the sphericity of the universe. Even as a more general shift toward the heliocentric theory occurred, however, users could nonetheless retain the lessons taught by these paper tools, with the mathematics of each theory broadly keeping the observer at the centre of his or her observations. The text's three volvelles encouraged the training of an intellectual visualisation to inculcate geometrical principles relevant to that system; each encouraged users to utilise graphical elements to return information, familiarising the reader with the

\footnotetext{
${ }^{70}$ Owen Gingerich, 'A Tusi Couple from Schoener's De Revolutionibus?', Journal for the History of Astronomy, 15 (1984), pp.128-133. See also Gingerich, 'Astronomical Paper Instruments with Moving Parts', p. 73; Steven A. Lloyd, 'Lunar Volvelles and Moondials in Baroque Germany', Journal for the History of Astronomy, 20 (1989), pp. 121-127.

${ }^{71}$ Bennett, 'Knowing and Doing', p. 142.

${ }^{72}$ Kremer, 'Playing with Geometrical Tools', p. 105.
} 
divided circle as a tool to return data and, simultaneously, as a tool that could be manipulated playfully or purposefully.

The first volvelle, demonstrating that an observer's latitude on earth is equal to the elevation of the pole above a local horizon, was taken directly from Peter Apian's Cosmographia. ${ }^{73}$ Another portrayed Michiel Coignet's Rectificatorium Stellae Polaris, or 'Rectifier of the North Star', a nocturnal dial with minor improvements to that of Sebastian Münster's. ${ }^{74}$ The third and final volvelle was an instrument to know the tides by the time of day and the age of the moon, also reproduced from Coignet's Instruction nouvelle des poincts plus excellents et nécessaires, touchant l'art de naviguer (1581). ${ }^{75}$ Falling somewhere between the depictions of external instruments and these paper volvelles, a further inclusion referred to by the author as both a figure and an instrument - aided the finding of solar declination. ${ }^{76}$

A key participant in the proliferation of university-based mathematical learning from his time at Cambridge as a humanist tutor and author, Blundeville made his disciplinary expertise serve the state through the promotion of geography and spherical astronomy as communicated in the Exercises. By adapting the cosmographical and navigational tools espoused by the mathematicians and instrument makers Peter Apian and Michiel Coignet, the author's goal was to improve his own users' abilities through mental and physical application. Before this could be achieved, however, it was necessary for the author to first teach a knowledge of the sphere that could be made instrumental to users' practical

\footnotetext{
${ }^{73}$ Blundeville, Exercises, f. 149 r. For Apian's horizontal polar volvelle, see Cosmographicus Liber Petri Apiani Mathematici Studiose Collectus (Landshut: Peter Apian, 1524), f. 17 r.

${ }^{74}$ Blundeville, ibid, f. 338 v. For Coignet's tool, see Michiel Coignet, Instruction nouvelle des points plus excellents et nécessaires, touchant l'art de navigeur (Anvers: Hendrick Hendersen, 1581), pp. 64-65.

${ }^{75}$ Blundeville, ibid, f. 350 r. A smaller, Dutch version of Coignet's text was first published in 1580 as an appendix to the Dutch translation of Pedro de Medina's Arte de Navegar (1585). Michel Coignet, Nieuwe Onderwijsinghe op de principaelste Puncten der Zeevaert (Antwerp: Hendrik Hendriksen, 1580). The adapted and improved French version appeared via the same publisher in 1581. See Ad Meskens, Practical Mathematics in a Commercial Metropolis: Mathematical Life in Late 16th Century Antwerp (Dordrecht: Springer Science \& Business Media, 2013), p. 139. Meskens elsewhere describes Coignet as 'the last representative of Frisius's school', and as a 'typical example of a high end mathematician of the Low Countries and indeed Western Europe (.,..) no longer contributing original work but focussing instead on the practical application of mathematical knowledge'.

Meskens, ibid, p. 211.

${ }^{76}$ Blundeville, ibid, f. 145 r.
} 
endeavours. To this end, Blundeville's 'students' were required to be able to first visualise the geometric movements and structures pertaining to the celestial sphere, and to then marry those imaginative visualisations to the observation and calculation of quantifiable data.

The pedagogical techniques utilised by the author chime with those discussed in recent arguments on the use of images and volvelles in early modern cosmography. In their discussion on the methods used by authors and readers to train the 'intelligent eye' required to perceive geometric and astronomical theory in the early modern period, Kathleen M. Crowther and Peter Barker identify four types of image common to editions of the Sphere after 1488: diagrams depicting geometric properties; hybrid images, combining diagrammatic and naturalistic elements; images of the entire cosmos; and, finally, volvelles. ${ }^{77}$ Each of these types were designed to aid the user in their imagination of schematic, non-corporeal forms, and to then train that user in conjoining the intellectual vision of the mind's eye with the physical apprehension of observable phenomena. ${ }^{78}$

Steven Vanden Broecke and Margaret Gaida have separately argued that training the mind's eye to be cognizant of phenomena in this way enabled an amateur and autodidactic audience to participate in the exciting new discipline of cosmography. ${ }^{79}$ For Vanden Broecke, the success of Apian and Frisius's Cosmographia, and, in particular, its autodidactic qualities, should not be seen as antithetical to the instruction of astronomy in the universities of the period. Instead, the abbreviated and abridged introduction to the doctrine of the sphere as offered by Apian's Cosmographia operated at the fringes of the university curriculum; it may also have supplemented institutional courses, ameliorating deficiencies in mathematical and astronomical teaching in the process. ${ }^{80} \mathrm{With}$ its tangible

\footnotetext{
${ }^{77}$ Kathleen M. Crowther and Peter Barker, 'Training the Intelligent Eye: Understanding Illustrations in Early Modern Astronomy Texts, Isis, 104.3 (2013), pp. 429-470, p. 442. Though Crowther and Barker reference volvelles, they do not treat them in their study, focusing instead on the previous three groups identified.

${ }^{78}$ Crowther and Barker, ibid, p. 453.

${ }^{79}$ Steven Vanden Broecke, 'The Use of Visual Media in Renaissance Cosmography: The Cosmography of Peter Apian and Gemma Frisius', Pedagogica Historica, 36 (2000), pp. 130-150, p. 133. Margaret Gaida, 'Reading Cosmographia: Peter Apian's Book-Instrument Hybrid and the Rise of the Mathematical Amateur in the Sixteenth Century', Early Science and Medicine, 21 (2016), pp. 277-302.

${ }^{80}$ Vanden Broecke, ibid, p.134.
} 
instruments and brief doctrinal instruction, the text co-opted and restructured Sacrobosco's Sphere as part of a mutable framework of practical knowledge - one later made practically applicable by sailors and pilots. In this conception the visual elements of cosmographical knowledge, so useful to autodidactic learners, were used to transmit astronomical data to every stripe of reader. Regardless of their eventual use of this training, these students could then be trusted to handle more complex mathematical practice as their intellectual development allowed. ${ }^{81}$

To be capable of doing so, however, Blundeville's readers needed to gather at least a smattering of numeracy and geometry. The author's decision to commence his treatises with a gradually more complex arithmetic — one culminating in astronomical fractions - is difficult to square with this picture; we may, however, assume that providing these calculations (and their trigonometrical roots) was something of a win-win situation for the author. At best, pupils, sailors or pilots would try their hand at a more difficult form of arithmetic before moving on to cosmography and navigation. At worst, the tables of sines would simply be ignored by the less adept, but remain appreciated by their tutors. Irrespective of the outcome, Blundeville's mathematical authority would stay in credit.

Before adapting Sacrobosco's work in his own presentation of the doctrine of the sphere, the author of the Exercises first guided his reader through the standard, elementary Euclidean geometry required by way of introduction to spherical astronomy. To introduce the practical use of the doctrine, Blundeville next prefaced his definitions of the 'great circles' of the celestial sphere - the zodiac, ecliptic, and equinoctial, with those of the tropics termed by the author as 'lesser circles' - with a graphical representation of the instrument which most embodied the celestial sphere's theory: a decorated armillary sphere, likely copied from the frontispiece of John Blagrave's The Mathematical Jewel (London: Walter Venge, 1585) (Figure $3.11)^{82}$

${ }^{81}$ Ash, Power, Knowledge and Expertise, pp. 201-202. Ash notes that many navigational authors made a point of lionising practical experience despite being themselves unfamiliar with sea-faring in practice if not in theory.

${ }^{82}$ Blundeville, Exercises, f. 126 r.; f. 140 v. 


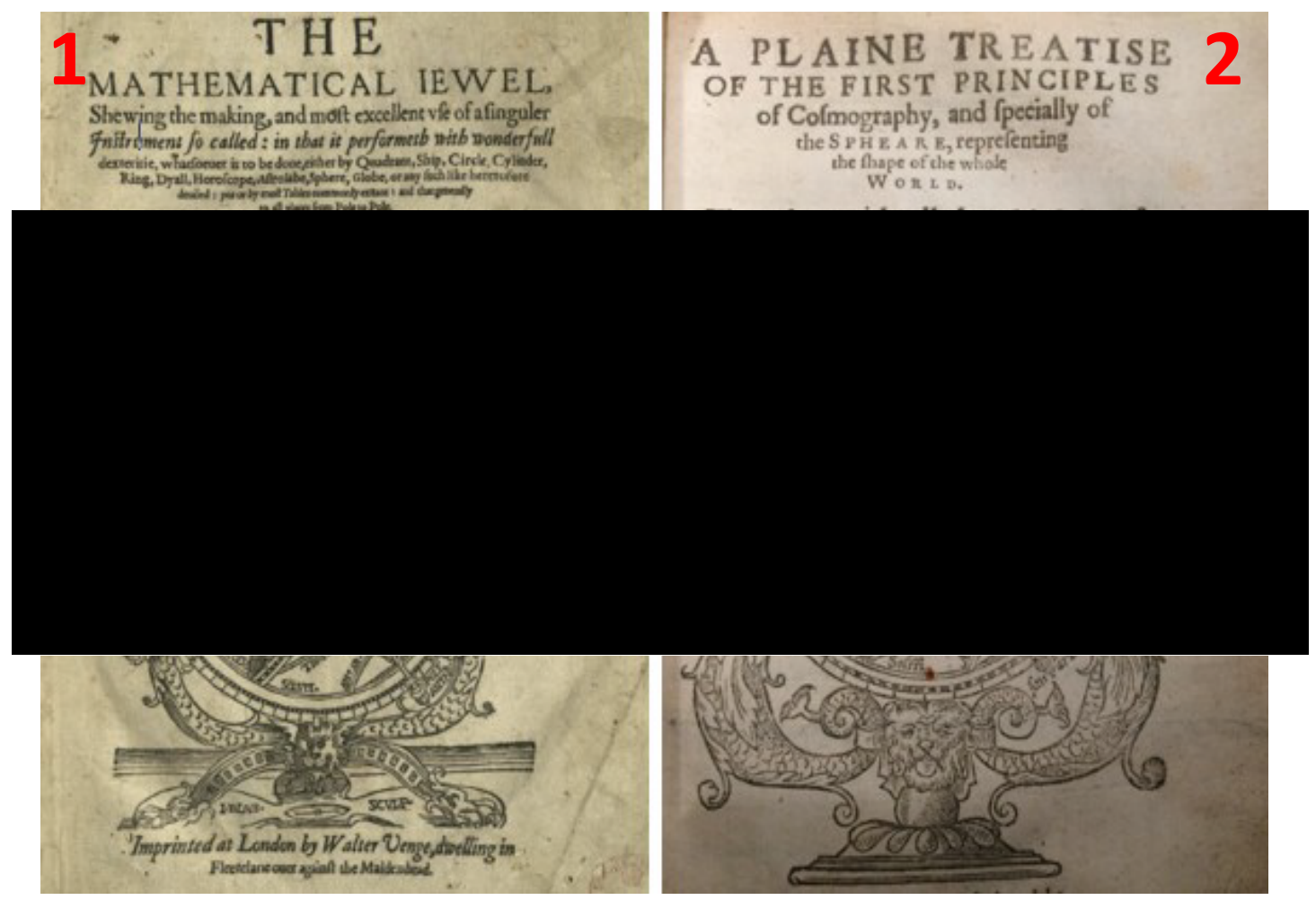

Figure 3.11. Side-by-side comparison of the armillary sphere printed to the title page of John Blagrave's The Mathematical Jewel (image 1, left) with that the armillary sphere featured in Blundeville's Exercises (image 2, left) some nine years later. The Latin declaration 'J. BLAG. SCULP.' can be seen at the feet of Blagrave's sphere.

To assist in his user's understanding of these circles as part of the celestial sphere, Blundeville moved from the naturalistic depiction of the instrument as seen above to a quasi-diagrammatical representation of two of its constituent circles: the equinoctial and zodiac, as can be seen in Figure 3.12. ${ }^{83}$ To this could be added mathematical specificity. In the seventh (1636) edition of Blundeville's work, today held in the Science Museum Library, an annotator glossed the erroneous printed declination of the ecliptic with an amendment of ' $23 \mathrm{dg} .30 \mathrm{~m}$ ' (Figure 3.13). ${ }^{84}$

\footnotetext{
${ }^{83}$ Blundeville, Exercises, f. 142 r; f. 144 r.

${ }^{84}$ Thomas Blundeville, $M r$ Blundevil his Exercises, contayning Eight Treatises, $7^{\text {th }}$ edn (London: Richard Bishop, 1636), p. 298. Science Museum Library Shelfmark O. B. BLU BLUNDEVILLE 459578-2001.
} 


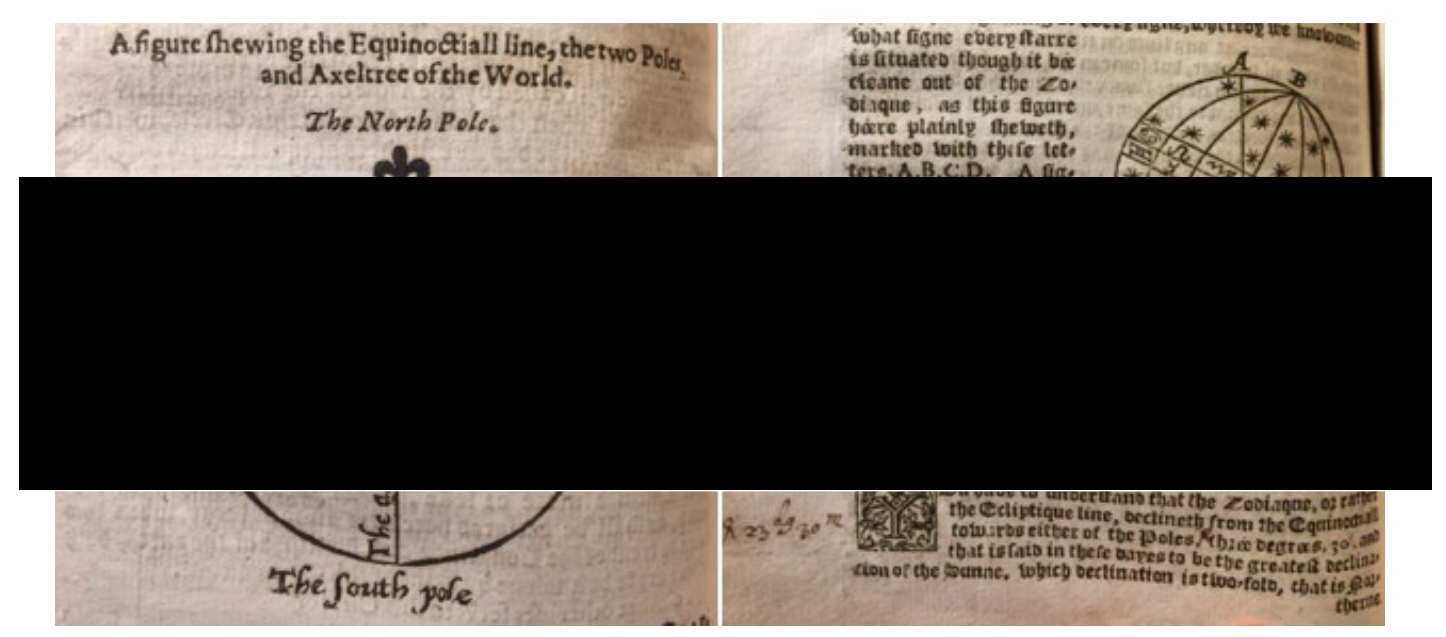

Figure 3.12. Composite image of Blundeville's diagrams of the equinoctial (left) and the zodiacal (right) circles of the celestial sphere.

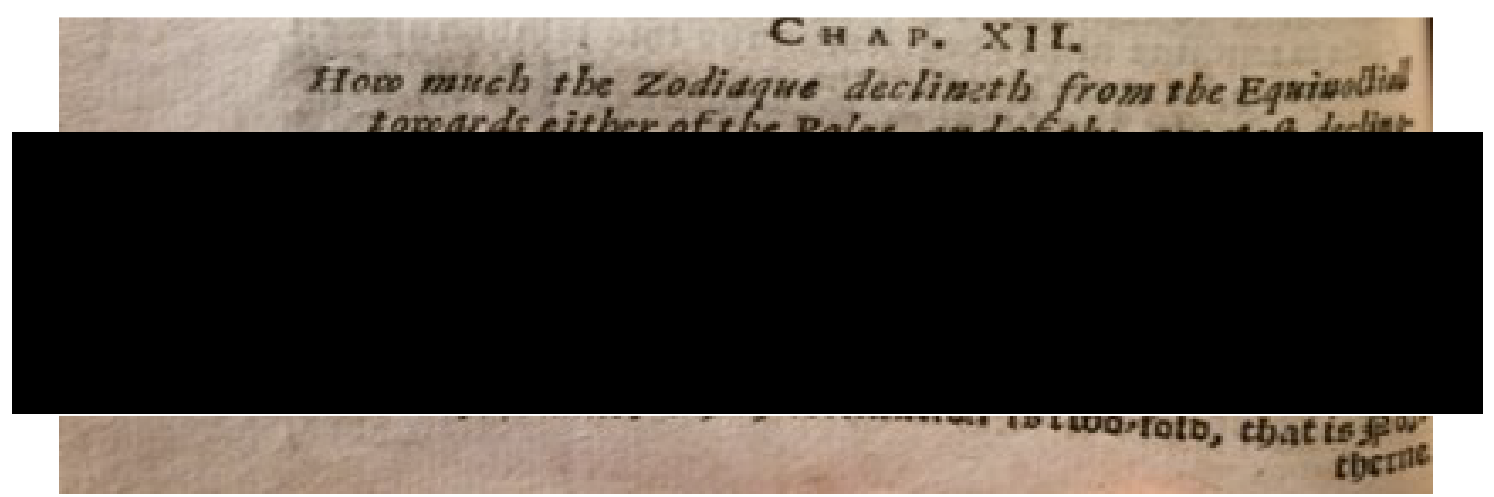

Figure 3.13. Expanded image of the gloss amending the sun's declination from 3 degrees to 23 degrees 30 minutes found in the Science Museum's copy of Thomas Blundeville's Exercises. Science Museum Library Shelfmark O. B. BLU BLUNDEVILLE 459578-2001.

With the author having briefly educated his reader on the figure of the celestial sphere with reference to a naturalistic picture and two diagrammatic representations, it is notable that the first manipulable instrument of the Exercises which immediately followed fell somewhat imperfectly between a table and a volvelle. Indeed, its author is himself unsure of how best to categorise it. In Blundeville's terms (perhaps a reflection on the less-than operative nature of the instrument's printed circles), the image can be thought of as either instrument or figure: ${ }^{85}$ a preliminary tool to finding the Sun's northward or southward declination using an instrument, a table, and spherical astronomy. Notably, it is a reformulation

${ }^{85}$ Blundeville, Exercises, f. 145 r. 
of the Instrumentum Theoricae Solis found in Apian's Cosmographia, with the shadow square and hour lines of the original replaced by a compass rose. ${ }^{86}$

To calculate solar declination, the tool first helped the user to identify the position of the sun via its apparent movement through the zodiac. Consisting of three immovable circles, the instrument's outermost dial was a graduated scale of the degrees and names of the zodiacal signs; a second, eccentric circle marked the days of the month, with the innermost circle containing a twenty-four-pointed compass rose, to the centre of which a piece of string was threaded (Figure 3.14).

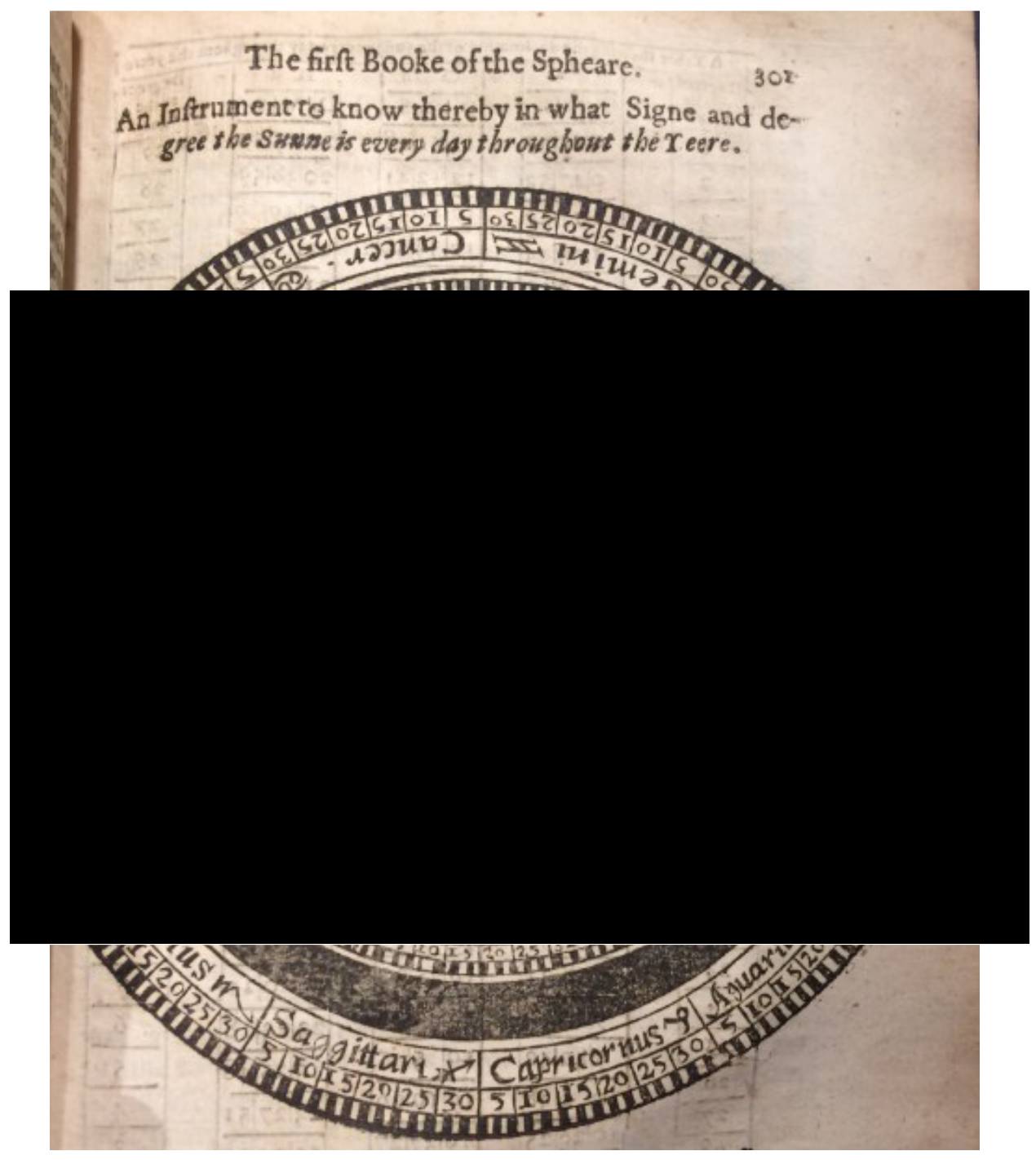

Figure 3.14. Thomas Blundeville's printed instrument to find the constellation and degree of the Sun daily, taken from Mr Blundevil his Exercises, $7^{\text {th }}$ edn, 1636. In this instance, the thread of the instrument is absent.

\footnotetext{
${ }^{86}$ Peter Apian, Cosmographicus Liber, f. 19 r.
} 
Manipulating the thread around the discs allowed for an intermediary form of astronomical calculation. When laid upon 'the day of the month which you seeke', the piece of string would 'straight direct you to the degree of the signe wherein the Sun is that day' ${ }^{87}$ A short table of ephemerides to the verso of the instrument was then used to find the degrees, minutes and seconds of declination.

Knowing the value of declination - the angular distance of the sun or another celestial body from the celestial equator ${ }^{88}$ - was an essential component in the finding of geographic latitude at land or sea, and belonged to a practical tradition put to use for centuries prior to the publication of Blundeville's text. An oft-used medieval method subtracted solar declination from the sun's altitude (the height of the sun above the horizon) at noon, giving a value of co-latitude which, when subtracted again from $90^{\circ}$, gave the latitude of the observer. ${ }^{89}$ This was complicated, however, by the fact that declination varied according to the 'passage' of the sun around the ecliptic circle, and by the fact that the tropical year gradually fell out of sync with the Julian calendar over time. As a result, medieval calculators resorted to providing two tables: one of daily solar longitude, and one providing for every degree of longitude of the ecliptic, a matter not simplified until the printing of more user-friendly tables in $1509 .{ }^{90}$

In his Almagest Ptolemy had provided a table of solar declination calculated on an arc as a function of solar longitude from 1 to $90^{\circ}$, with the angle of the obliquity of the ecliptic rounded down to $23^{\circ} 51^{\prime} .{ }^{91}$ This value was corrected to $23^{\circ}$ 30' by Pedro Nunes; it was used in 1599 by Thomas Harriot and Edward Wright for the improvement of mathematical navigation, and gradually came into common use as printed tables or manuscript copies thereof were brought on board. Blundeville, however, (along with several of his mathematical contemporaries), used the

\footnotetext{
${ }^{87}$ Blundeville, Exercises, f. 145 r.

${ }^{88}$ Thomas Sonar, 'The 'Regiments' of Sun and Pole Star: On Declination Tables in early modern England', GEM International Journal on Geomathematics, 1 (2010), pp 5-21, p11.

${ }^{89}$ John J. Roche, 'Harriot's 'Regiment of the Sun' and its Background in Sixteenth-Century Navigation', British Journal for the History of Science, 14, 3 (1981), pp. 245-262, p. 248.

90 Roche, ibid, pp. 248-9.

${ }^{91}$ Jose Chabás and Bernard R. Goldstein, A Survey of European Astronomical Tables in the Late Middle Ages, (Leiden, Boston: Brill, 2012), pp. 22-23.
} 
Copernican value of declination of $23^{\circ} 28^{\prime}$ as given by Erasmus Reinhold in the Prutenic Tables of $1551 .^{92}$

It must be said that Blundeville's figure and thread would only marginally improve users' practice by cutting down on the work required to cross-reference different tables. Nonetheless, understanding the division of the circle - and using it to return quantitative data - formed an essential part of the practical sciences of astronomy, navigation, and surveying from antiquity. ${ }^{93}$ As an introductory tool, this example is suggestive of the training of a user for two reasons. Firstly, it simplifies the calculation of declination by representation. By 'flattening' a spherical representation of phenomena - in this case, the sun's apparent journey along the ecliptic and through the houses of the zodiac, identified by various celestial bodies into two cross-sectional planar circles in a fashion similar to the diagrams of the great circles witnessed previously, the instrument encouraged the user to retain a sense of the sphericity of the heavens.

Keeping the user within such a model, one of these represented circles - the zodiac - exists as found on a standard, two-dimensional celestial sphere (as seen in print), or on a material, 3-dimensional armillary sphere, as previously introduced by the author. The second representational circle - the days and months of the calendar - is part of neither the celestial nor armillary spheres, yet, as Blundeville notes with reference to another flattened (or, more appropriately, planispheric) instrument namely the astrolabe - this data is calculated through knowledge of the various circles and the observation of celestial bodies.

Secondly, having encouraged the mental internalisation of the spherical world system, the use of the tool then trains a multi-layered operative process. Following the thread of this instrument taught users to manipulate and to scan a divided circle and its graduated scale. Moving from the eye to the hand, users drew the thread to the exact date required. Once the zodiacal reading was taken, they were instructed to then cross check this information with a further set of data: the table on

\footnotetext{
92 Roche, ibid, p. 249.

${ }^{93}$ For an introduction to the relevance of the division of the circle and its astronomical foundations, see Bennett, Divided Circle, pp. 7-9.
} 
the verso of the instrument, recording the angular position of the sun (its declination) in degrees, minutes and seconds.

As we can see in a representation of the example provided in the text (Figure 3.15), users were instructed to draw the thread from the fourth of May to the outermost circle: a practice which should result in finding the Sun to be in the $23^{\text {rd }}$ degree of Taurus. Cross-checking this data with the table printed on the reverse, the Sun in the $23^{\text {rd }}$ degree of Taurus results in a declination of 18 degrees 32 minutes 37 seconds, or $18^{\circ} 32^{\prime} 37^{\prime}$ '.

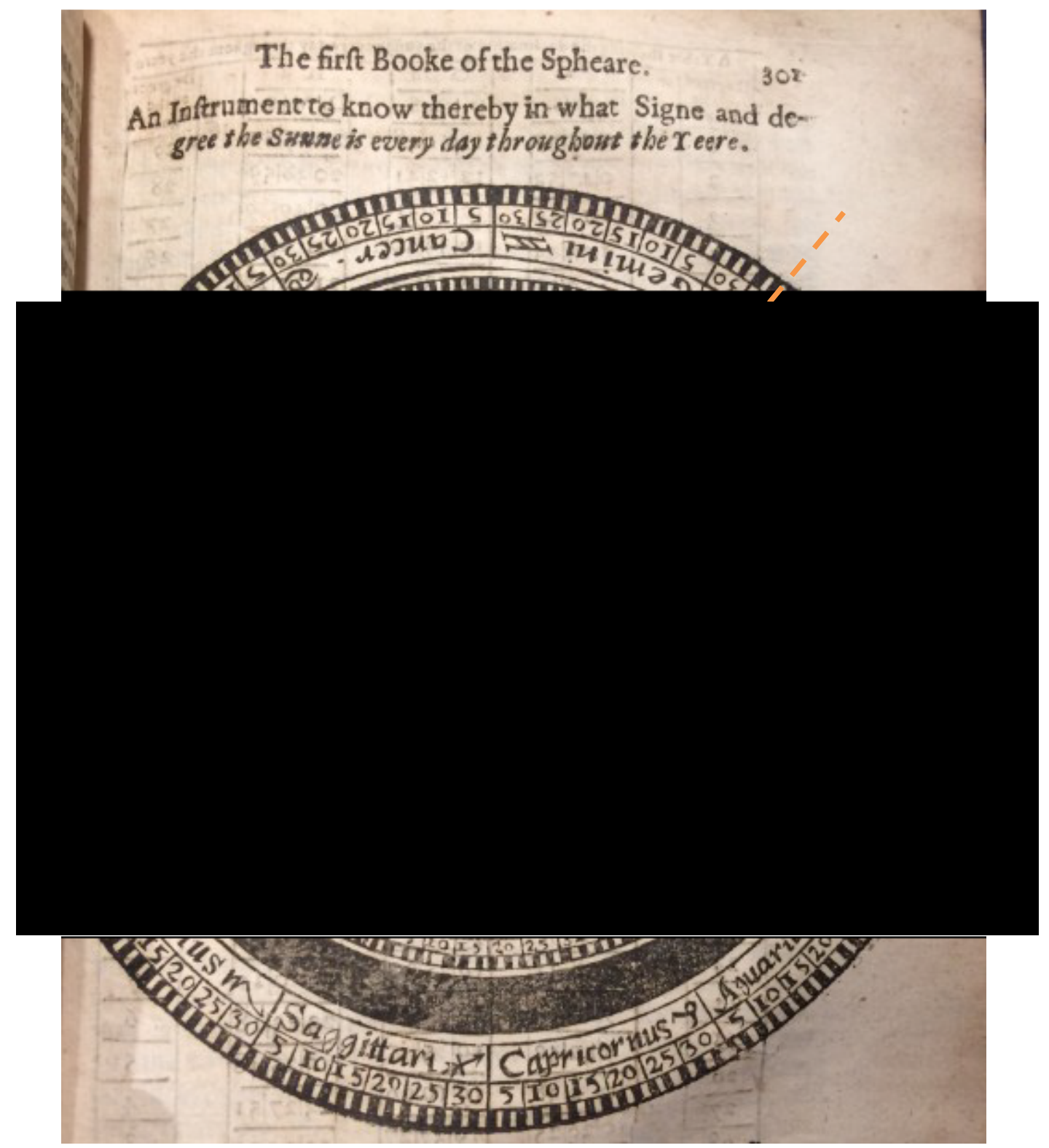

Figure 3.15. I have added the orange dashed line to show how the instrument's thread was intended to operate, intersecting the inner dial at May $4^{\text {th }}$ and returning a value of the Sun's position as $23^{\circ}$ in Taurus. 
In this manner, the tool for finding declination is both representational and informational. The eccentric zodiac calendar embodied the sun's theoric, indicating how its orbit gave rise to the inequality of the seasons. Although Thomas Blundeville did not reference this - nor describe the procedures used to calculate the attendant tables - the instrument could be utilised to engender 'knowing' in and of itself. Despite this, the author's intentions are perhaps best understood in the more general, introductory nature his text provided. By utilising the great circles of the zodiac and the ecliptic (with a directional compass set in the middle), the instrument offered its users testable proof of their location within a spherical world system. The geometrical and astronomical parameters of that system could serve to locate oneself with some precision. Finally, the instrument afforded its user brief training in the use of a simple tool to return and validate piecemeal information. It therefore encouraged the user to think in terms of circles and spheres, to appreciate the invisible lines overhead as usable parts of a systemic practice, and to expect results in numbers of degrees, minutes and seconds.

Evidence of the extent to which early modern users were convinced of the value of such an instrument is unfortunately lacking in the copies I have seen to date. One set of annotations in a first edition of Blundeville's Exercises, however, indicates that the information produced by this introductory instrument was something a user was keen to engage with, albeit with other, superior instruments close by. Held in the British Library and previously belonging to a G. Richardson of Ticknall, Derbyshire and to one John Butler, this edition's front flyleaves were heavily annotated with tables taken from Johannes Stadius's series of Ephemerides Novae et Auctae, first published in 1554 (Figure 3.16, below) ${ }^{94}$

Although intended primarily for astrological prognostication, Stadius's ephemerides were based on the Prutenic Tables calculated by Erasmus Reinhold

\footnotetext{
94 Thomas Blundeville, M. Blundeuile his Exercises containing Six Treatises (London: John Windet, 1594), British Library Shelfmark C.145.C.16. It is likely that Blundeville and his annotator used the third edition of Stadius's tables calculated to the year 1606, published in 1581, as the author referenced Stadius's ephemerides serving for 14 more years (i.e., from 1592, when the text was written, to 1606, when Stadius's third set of ephemerides ended). Johannes Stadius, Ephemerides Joannis stadii leonnouthensis mathematici, secundum antvverpiae longitudinem, ab anno 1554. Usque ad annum 1606. Iam recèns ab auctore auctae: adiecto quoque canone sinuum, vel semissium rectarum, in circulo, subtensarm, eodem auctore (Cologne: haer. Arnold I Birckmann, 1570).
} 
and, as such, remained a popular source for all varieties of astronomical inquiry well into the seventeenth century. ${ }^{95}$

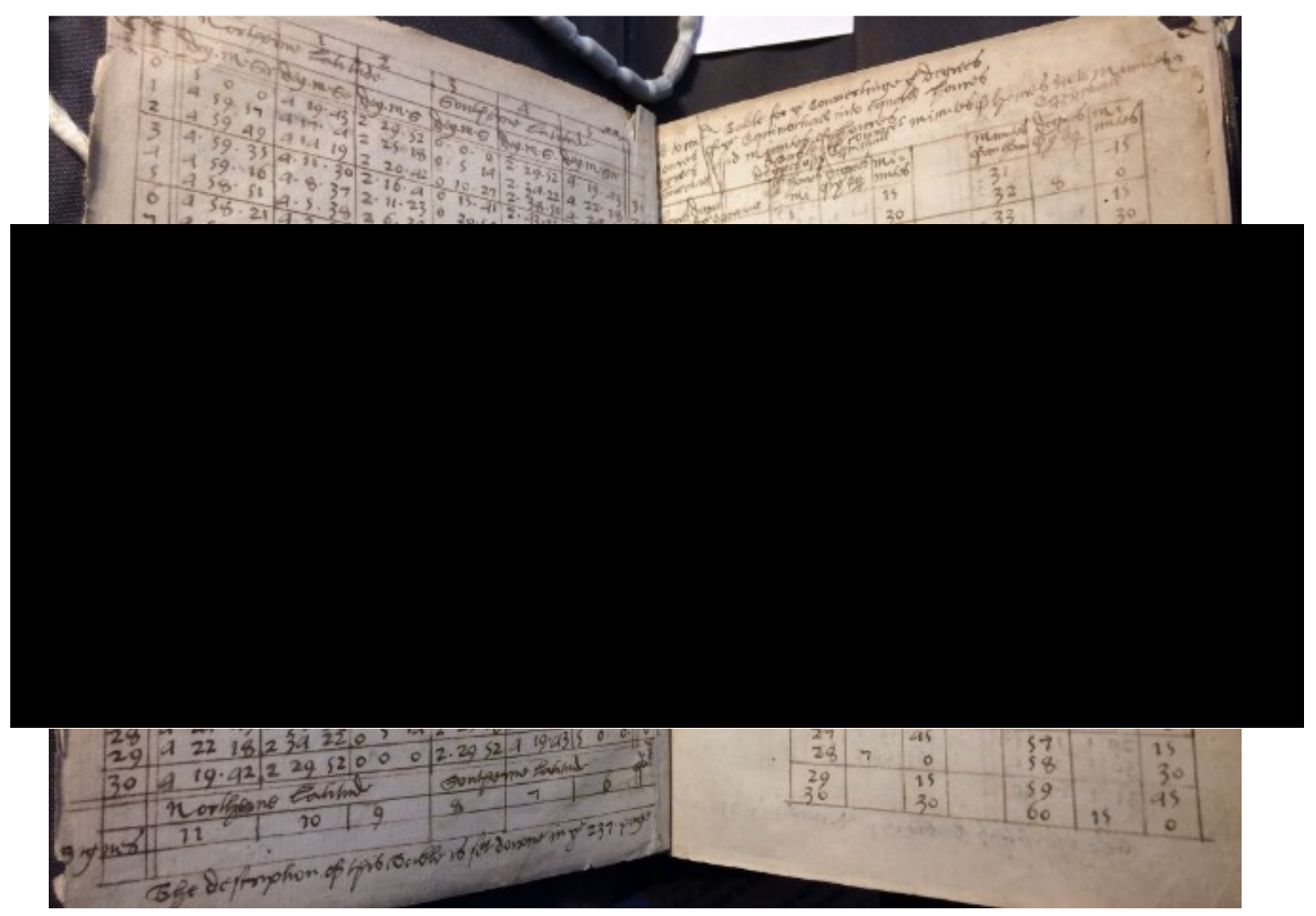

Figure 3.16. A user's addition of Johannes Stadius's ephemerides to the first edition of Thomas Blundeville's M. Blundeuile his Exercises (1594), British Library Shelfmark C.145.C.16.

A pupil of Gemma Frisius, Stadius prefaced his calculations with an introduction from his teacher which featured the assurance that their publication would bring glory both to their author and to the Copernican hypotheses underlying their calculation. ${ }^{96}$ Blundeville had cited Stadius's ephemerides approvingly from the Exercises's first pages, noting their value to locating the sun, moon, and other bodies on the celestial globe, and basing a series of sample problems on Stadius's calculations. ${ }^{97}$ The annotator of this copy of the Exercises added Stadius's tables, as

\footnotetext{
${ }^{95}$ J. D. North, The Universal Frame. Historical Essays in Astronomy, Natural Philosophy and Scientific Method (London and Ronceverte: The Hambledon Press, 1989), pp. 29-30. Tycho Brahe was unimpressed with Stadius, however, retrospectively reporting his teenage self a critic of errors in the latter's ephemerides. See Westman, The Copernican Question, p. 427.

${ }^{96}$ Pietro Daniel Omodeo, Copernicus in the Cultural Debates of the Renaissance: Reception, Legacy, Transformation (Leiden: Brill, 2014), pp. 127-131.

${ }^{97}$ Blundeville, Exercises, f. 235 v - 236 r; f. 237 r - 239v; f. 240 r; f. 293 r - v; f. 311 r - v.
} 
referenced on leaves 237 and 238 of the printed text, directly to the front of his volume.

As Blundeville had refrained from reprinting the Flemish astronomer's ephemerides, their presence in this copy of the Exercises can be considered evidence that our annotator intended to use them as part of his mathematical practice, replicating them for ease of access. Their inclusion is perhaps suggestive of this individual user's desire to extend their enquiry beyond that of the materials provided by Blundeville: the tables copied into this edition of the Exercises detail the latitude of the moon and more precise measurements of longitude, respectively. If the annotator of this first edition had access to the Exercises itself, Stadius's tables for reference, and a celestial globe, we are likely to be dealing with one of Thomas Blundeville's ideal audience: namely, a member of the gentility with access to some disposable income, perhaps even a teacher or lecturer. That a contemporaneous user was so motivated to replicate the portions of Stadius's tables referenced (cited, though unprinted, in the text) is perhaps evidence of an attempt to work through astronomical practice with a book, a pen, and a celestial globe close to hand. How, then, does the author suggest they do so?

In his treatise on the celestial and terrestrial globes, Blundeville first counselled his readers that knowledge of this particular instrument was best acquired via hands-on experience. The globe was required to be constructed and positioned so as to provide accurate data, and so it was imperative that its body 'doe not leane to the one side of the horizon more than the other' ${ }^{98}$ Blundeville recommended using a 'plummet of leade', often provided with globes, or alternatively a similar plumbline attached to a purposely-fashioned triangular level so as to set the horizon. Once the horizon was fixed, users should handle the globe '(w)ith (their) 2 handes laying holde of the 2 next pillers [and] turn the foot of the globe until it stand right North and South'. 99

To find the true meridian of the place where the globe was to be used, the erstwhile student was then faced with two choices. They could either consult the

\footnotetext{
${ }^{98}$ Blundeville, Exercises, f. 209 v.

${ }^{99}$ Blundeville, ibid.
} 
seventh chapter of William Burrough's Discourse of the Variation of the Needle (1581), which could at one stroke provide the values of the true meridian, the variation of the needle, and the true latitude of any place. Otherwise, the more practically-minded student (and, perhaps, the more patient) could embark on a voyage of discovery without leaving their home. Finding some open place, this user might follow Blundeville's instructions by drawing a large circle with their compasses on a smooth table or plank and constructing a gnomonic dial with a "pin of iron or latton wyer' ${ }^{\prime 100}$.

They would then need to wait diligently until the sun's passage across the dial allowed them to make a set of pricks on their board, and to divide their circle accordingly so as to identify their meridian. Having determined the meridian astronomically, users could then supplement their active practice by pressing the compass into service to allow for variation, so as to swiftly re-establish the meridian with the compass in future. ${ }^{101} \mathrm{~A}$ further method, taken from Gemma Frisius, was also provided, where the example latitude of Norwich was defined by manually turning and fixing the globe position of the sun in the zodiacal signs at points in a given day. ${ }^{102}$

After such an undertaking, solving astronomical problems with either globe was the next natural step. Again, as we might expect, the author sought to engender in his users a desire to exercise their mathematical practice through instrument and cognition. Proposition 30 of Blundeville's third treatise, On the Use of the Globe, gave as an example the star Hircus (the Goat, today known as Capella in the constellation Auriga). ${ }^{103}$ Hircus/Auriga is easily identifiable as part of the constellation of the 'Charioteer', and prominently visible in the east after sunset until the early morning: for this reason, Blundeville used the star for a number of problems. Manipulating a celestial globe, such as the example from the Science Museum Collection seen in Figure 3.17 below, the reader could marry instrument and observation, easily visualising then physically manipulating the component parts

\footnotetext{
${ }^{100}$ Latton, or latten, is a cheap alloy of copper and zinc that resembles brass and can be hammered into thin sheets. Harold M. Cobb, ed., Dictionary of Metals (Ohio: ASM International, 2012), p. 129. ${ }^{101}$ Blundeville, ibid. I am grateful to Stephen Johnston for providing further clarification on this point.

${ }^{102}$ Blundeville, ibid, f. 210 v.

${ }^{103}$ Blundeville, Exercises, f. 227 r.
} 
of their practice. They could thereby demonstrate, model, teach with, or learn from, this popular representation of the heavens.

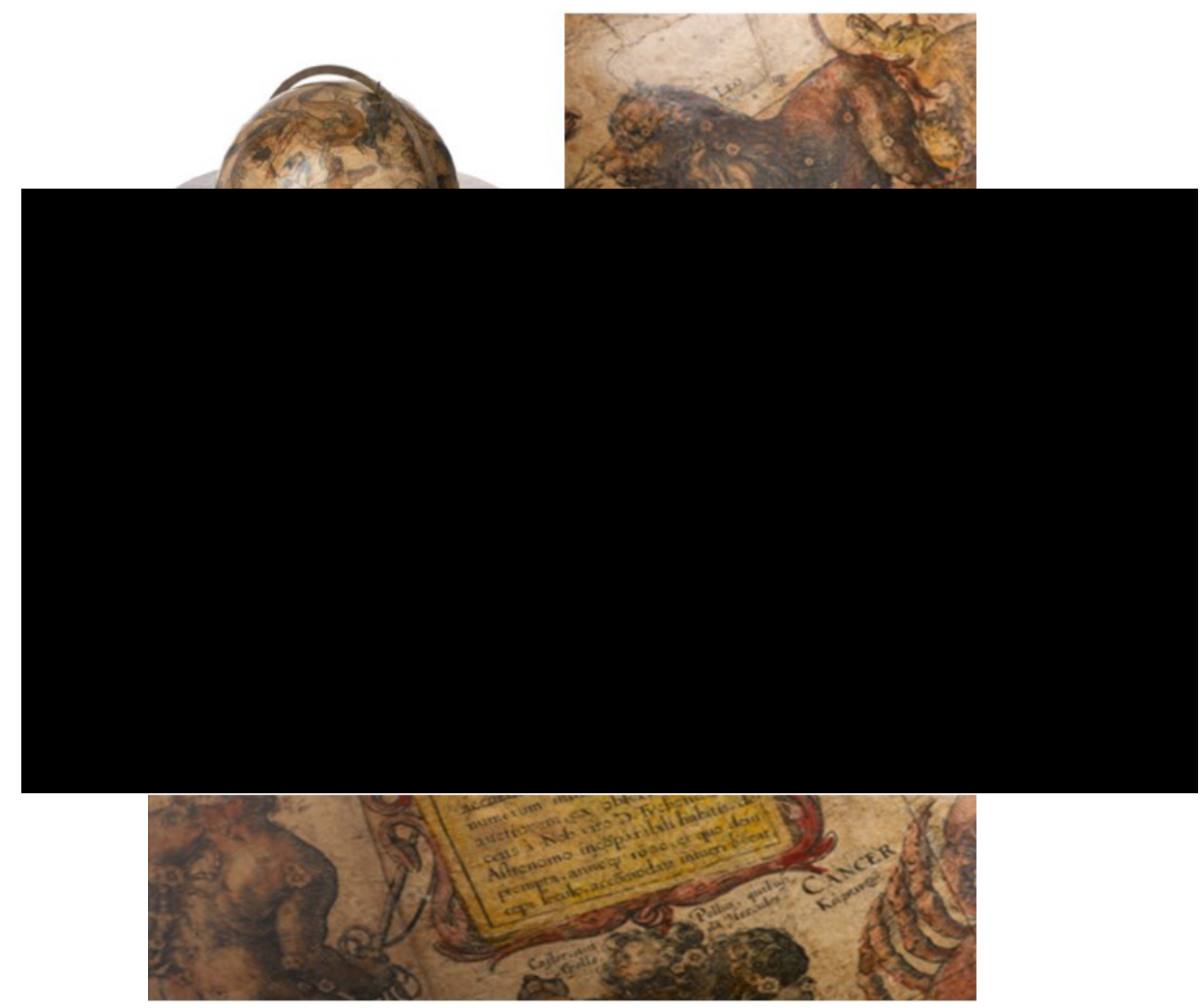

Figure 3.17. Composite image showing Science Museum Object 1980-1913, a celestial globe fashioned between 1603 and 1610 by Willem Janszoon Blaeu (1571-1638) and dedicated to Tycho Brahe. Copyright The Board of Trustees of the Science Museum, London.

Blundeville's instructions on finding the declination of any given star using the celestial globe are simple. The author directed users to rotate the globe until the star was 'right under the brazen Meridian', then,

there staying the globe, count the degrees of the said Meridian contained betwixt the saide starre and the Equinoctiall point or streeke of the said Meridian, and that shall be the declination of the starre. ${ }^{104}$

Following these instructions would, the author vouched, give a declination for Hircus of $45^{\circ}$ North $\left(+45^{\circ}\right)$ (Figure 3.18 , below). ${ }^{105}$ In the first edition of his $A$ Tutor to Astronomie and Geographie (1659), the printer and Royal Hydrographer Joseph

\footnotetext{
${ }^{104}$ Blundeville, Exercises, f. 225 v.

105 International Astronomical Union and Sky and Telescope Magazine, https://www.iau.org/static/public/constellations/pdf/AUR.pdf, accessed 14 February 2018.
} 
Moxon would use Hircus for similarly instructional purposes, calculating its right ascension and reporting, through example, its declination of $+45^{\circ} 40^{\prime}$. Moxon followed this example with a table of Tycho Brahe's calculations of the right ascensions and declinations of 100 'select fixed stars' for the years 1600 and 1700, with a further field highlighting their differences in $701 / 2$ years 'for the Stars moving upon the Poles of the Ecliptic go forwards in Longitude one whole degree in $701 / 2$ years $[\ldots]$ and so alter both their Right Ascension and Declination'. ${ }^{106}$

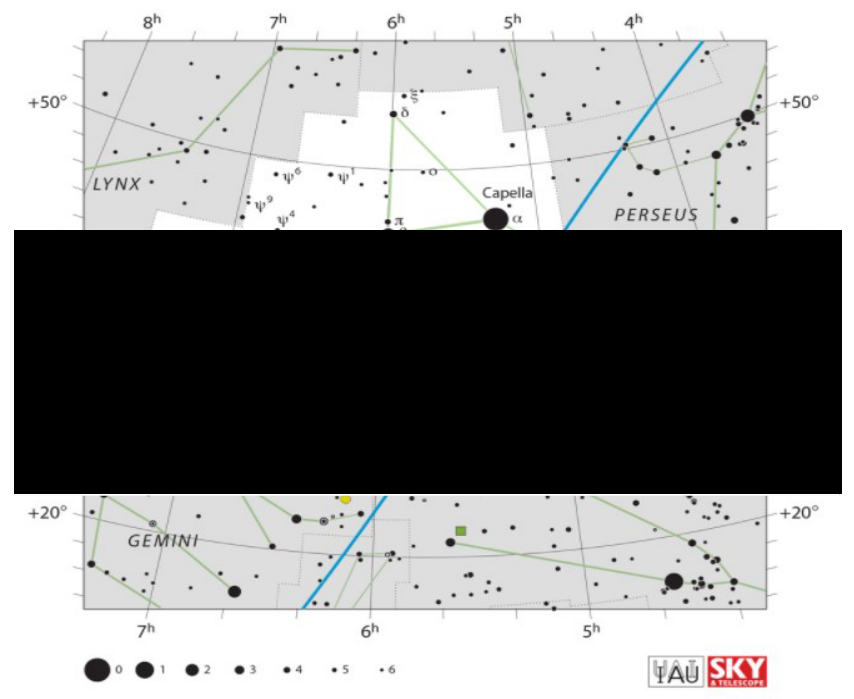

Figure 3.18. A modern-day star map showing Capella, or Hircus (Alpha Auriga, at $\alpha$ ) in the constellation Auriga. The declination of the star is today calculated as $+45^{\circ} 59^{\prime} \mathbf{5 3}^{\prime \prime}$.

Moxon would retain this table and its accompanying Tychonic, geoheliocentric cosmology in later editions, published from 1665 onwards. Somewhat confusingly to the modern reader, he also simultaneously published a closely-titled work which eschewed the Danish astronomer in preference for a more Copernican outlook. ${ }^{107}$ If nothing else, the mathematical practitioners of early modern England were open to fast-moving changes in their disciplines (or, more

\footnotetext{
106 Joseph Moxon, A Tutor to Astronomy and Geography: Or, an Easie and Speedy Way to Know the Use of Both the Globes, Celestial and Terrestrial (London: Joseph Moxon, 1659), p. 65.

${ }^{107}$ Joseph Moxon, A Tutor to Astronomy and Geography, or, The Use of The Copernican Spheres (London: Joseph Moxon, 1665). John L. Russell has suggested that the popularity of the Tychonic text over the Copernican is suggestive of a preference for the geocentric outlook in seventeenthcentury English astronomy. John L. Russell, 'The Copernican System in Great Britain' in Jerzy Dobrzycki, ed., The Reception of Copernicus' Heliocentric Theory: Proceedings of a Symposium Organized by the Nicolas Copernicus Committee of the International Union of the History and Philosophy of Science Toruń, Poland, 1973 (Dordrecht: Springer Science + Business Media, 1972), pp. 189-239, p. 224.
} 
likely, open to altering their principles as the market required). In a similar fashion, Blundeville, working some 70 years prior, acknowledged that the data he had provided could not keep pace with recent innovations. But even these changes could prove useful in training the learner in mathematical virtues. The tables of the Exercises's third treatise, intended for use with the globes, were calculated by the astrologer Johannes Garcaeus (1530-1574) for the year 1564 and were thus rendered invalid to users in 1594 by their imprecision.

Suitably unabashed, Blundeville merely refashioned incorrect data into an opportunity for hands-on practice. The erroneous calculations would 'serve to shewe you how to exercise your selfe in the said Globe, and you may correct this table [...] whereby you shall reape more pleasure than grief or paine'. The author went on to assure users that the inclusion of Garcaeus's outdated tables was deliberate: he had 'heere set it down more for your exercise, and to acquaint you with the fixed Starres that are described in the Celestial Globe, then for any other purpose'. ${ }^{108}$ Before they approached the precision of numerical measurement, users needed to once again mentally exercise their recognition and manipulation of the spherical form of the heavens.

Johannes Garcaeus's unwitting errors in declination and right ascension also provided the author with the opportunity to draw the attention toward what was, at the time, perhaps the most remarkable form of the globe yet constructed. A gift from the merchant-adventurer Thomas Sanderson to Queen Elizabeth, designed by the mathematician and instrument maker Emery Molyneux (d. 1598), with its gores engraved by Jodocus Hondius the Elder (1563-1612), Molyneux's two globes were the pride of early modern London. ${ }^{109}$ Blundeville's celebration of this instrument the first printed English globe - is of additional help in situating him at the Inns of Court, where the globe rested at the Middle Temple, and within a coterie of mathematical geographers such as Robert Hues, Thomas Hood, and Thomas Harriot, each of whom praised this new instrument in print. ${ }^{110}$

\footnotetext{
${ }^{108}$ Blundeville, Exercises, f. 227 v.

${ }^{109}$ H. M. Wallis, 'The Molyneux Globes', The British Museum Quarterly, 16.4 (1952), pp. 89-90, p. 89.

${ }^{110}$ Robert Hues, Tractatus de Globis et Eorum Usu (London, Thomas Dawson, 1594); Thomas Hood, The Use of both the Globes, Celestial and Terrestrial (London: Thomas Dawson, 1592).
} 
These great globes were models of contemporary improvement, demonstrating the advances made by English navigators, cartographers, and practitioners, all to the glory of the state. Through mathematical practice and its texts and instruments, Blundeville's readers were encouraged to see themselves as belonging to a national discipline that had recently superseded the work of Gerardus Mercator (1512-1592). Whether such readers made it aboard a ship or not, they remained calculators of distance, declination, and duration: concepts that the Exercises had first introduced through their arithmetical and cosmographical treatises. In celebrating the English development of the printed globe, Thomas Blundeville highlighted the vibrant and supposedly novel products of English mathematical practice: a practice which was circulated via print technology. The user who held a copy of the Exercises in their hands held access to mathematics and all its tools: first through printed text, then fashioned volvelles, and then through the imagination (and manipulation, where possible) of the globe itself.

By introducing the globe (and, indeed, the treatise on navigation) only after the basics of arithmetic, geometry, and spherical astronomy had been treated, the author subtly encouraged the theoretical development of his readers through text and instrument alike. Rarely willing to promote the globe as an instrument of a means to its own ends, Blundeville instead sought to adeptly position the tool within a practical framework of disciplines underpinned by spherical astronomy, and transmitted through an adapted, Sacroboscan presentation of the doctrine of the sphere. The introductory instruments taken from Apian were therefore to be seen as tools to training users' apprehension of divided and moving circles which could, with the appropriate scales, be related to the geometry of celestial movements, and used to return quantitative data thereafter. More importantly, though, the return of such data was in actual fact a reward for users' correct manipulation of the tool at hand. The successful operation of such tools would introduce a foundational understanding of the practical accessibility of spherical and positional astronomy, encouraging readers to continue on to more complex concepts and tools as the treatise progressed. As we shall see in the following section, this could involve denying the user an image of the instrument - John Blagrave's astrolabe - entirely. 


\section{From globes to dials: visualising and using 'universal' projection}

In a summary of the advantages of Blagrave's new astrolabe in comparison to those of Johannes Stöffler and Gemma Frisius, printed some ten years after, Thomas Blundeville suggested that his readers think of the novel instrument as secondary only to a celestial globe - an instrument which, 'for astronomicall matters is the perfectest instrument of all'. ${ }^{111}$ Eschewing the cumbersome and unwieldly globe as less likely to feature aboard ships, Blundeville suggested that Blagrave's astrolabe might be made even 'much more serviceable to the Sea men, then nowe it is' once the stars of the Southern Hemisphere had been correctly added to its rete. ${ }^{12}$ Should this be accomplished, the instrument would become truly representative of its type: a

handle or instrument of the Starres, by helpe whereof the manifolde motions and apparences of the heauens and the Starres therein contained or known [...] called of some a planispheare, because it is both flat and rounde, representing the Globe or Spheare, having both his Poles flatte both together $(\ldots) .^{113}$

The author's description of the astrolabe is germane to the current study for three reasons. In his treatment of Blagrave's Jewel, the author reduced the heavens ever further to something captured or contained in a hand-held instrument: one comparable to the technological artefact his reader now beheld - a book of exercises, containing mathematical and naturalistic representations of the earth and the cosmos between its boards. Furthermore, it should be noted that, perhaps to protect Blagrave's priority (as well as to advertise the latter's product), Blundeville decided against printing an image of the astrolabe, or of any of its constituent parts.

This made a description of the form, theory, and practical use of the astrolabe a necessity, as the author of the Exercises nonetheless deemed the instrument important enough to include it as part of his six original treatises. This decision perhaps points to the existing popularity still enjoyed by the Mathematical Jewel ten years after its debut, and to the mathematical value of the instrument to a diverse cast of users. The Exercises's creator sought to benefit from the best of both worlds:

\footnotetext{
${ }^{111}$ Blundeville, Exercises, f. 280 v.

112 Blundeville, ibid, f. $281 \mathrm{r}$.

${ }^{113}$ Blundevile, ibid.
} 
celebrating the value of Blagrave's astrolabe to English navigational learning and practice by making its use a key part of one of his series of exercises and problems, yet denying the user an image or figure of the instrument and directing them instead to purchase Blagrave's original work.

A second point, and one of greater importance to the current chapter, is that, regardless of the reader's prior understanding of astrolabes, Blundeville still felt it necessary to highlight the instrument's representative properties. The Exercises's authorial comparison of the planispheric astrolabe with the celestial globe seems unnecessarily glib, the key operational difference between the two being, in Blundeville's argument, one of material volume - an opinion perhaps influenced by the legendary origins of the astrolabe as the product of flattening a celestial globe or armillary sphere. ${ }^{114}$ The flattened disc of the astrolabe in its standard form simply could not fully represent the entirety of the heavens, and as a consequence was less useful than the celestial globe - an object which grew in representational value as its size increased. ${ }^{115}$ This apparently facile point reflected an issue that John Blagrave had shown himself keen to elucidate for his readers' understanding. Importantly, for both authors, users were to be encouraged to first visualise the spherical form of the heavens (and, to some extent, to handle the mathematical outcomes of such a system), before being led to flatten that same globe into a planar projection so as to understand the relationship between the instrument and the system it represented.

Introducing his new 'universal' astrolabe in 1585, the Tudor mathematician and instrument-maker John Blagrave (ca. 1561-1611) had dubbed the construction a 'jewel' not just for its ability to 'performeth with wonderfull dexteritie, whatsoeuer is to be done, either by quadrant, ship, circle, cylinder, ring, dyall, horoscope, astrolabe, sphere, globe, or any such like heretofore deuised'; nor, as might now be supposed, for its intuitive user-friendliness,

\footnotetext{
${ }^{114}$ Blagrave chose not to refer to the ancient Arabic anecdote which reported that Ptolemy's donkey accidentally created the astrolabe by stamping a celestial sphere dropped by its master under hoof. For a detailed history of the instrument, see Otto Neugebauer, 'The Early History of the Astrolabe. Studies in Ancient Astronomy IX', Isis, 40.3 (1949), pp. 240-256, particularly pp. 241-243. See also David A. King, 'Astrolabe' in Bud and Warner, eds., Instruments of Science, pp. 33-34.

${ }^{115}$ Blundeville, Exercises, f. 280 v. The author had argued that the celestial globe was 'for Astronomical matters the perfectest instrument of all [...] the greater [in size] the better', but noted that the astrolabe was a valuable asset at sea, where cumbersome globes were less than ideal.
} 
the use of which [...] is so aboundant and ample, that it leadeth any man practising thereon, the direct pathway (from the first steppe to the last) through the whole Artes of Astronomy, Cosmography, Geography, Topography, Navigation [...], Dyalling, Sphericall Triangles, Setting Figures, and briefly of whatsoever concerneth the Globe or Sphere [... ${ }^{116}$

Instead, Blagrave suggested that his customers think the jewel well-named for its particular combination of mathematical novelty and physical portability: a combination all of the aforementioned properties relied upon. Improving the astrolabes of Johann Stöffler (1452-1531) and Gemma Frisius (1508-1555) respectively, Blagrave's product was pitched as a more perfect iteration of its type by reducing the number of plates required to a single inscribed projection. Whereas other, planispheric astrolabes required that the projective plates between the mater and rete be changed depending on the user's latitude, the Mathematical Jewel was devised in such a way as to serve 'generally through the whole world from pole to pole, which [Stöffler's] could never doe, nor Gemma Frisius in all points' ${ }^{117}$

Briefly referencing the advantages and disadvantages of Stöffler and Frisius's efforts at the beginning of his second book, on the composition and fabrication of the new astrolabe, Blagrave then hitched his theoretical ability to an inherently more pragmatic outlook. Introducing imprecise and grubby-handed novices to the use of the astrolabe would be best done with a 'faire pastborde pasted on a massie borde', at least to begin with. Listing the various types of material he had fashioned astrolabes with himself, the practitioner used his personal experience to recommend humble paper and pasteboard as a more than suitable medium for the vast majority.

Removing the threat of a loss of quality or durability, Blagrave counselled that paper offered its own advantages to maker-learners, given that 'the circles may be so lively distinguished with coloured ynkes, and the Reete easily and exactly cut out'. ${ }^{118}$ Protection from overuse, 'brusing, soyling, and wet' was guaranteed by simply gluing the construction into a handy carry-case of bone or wood. Finally, Blagrave actively recommended that a deeper appreciation of the astrolabe was

\footnotetext{
${ }^{116}$ John Blagrave, The Mathematical Jewel, shewing the Making, amd Most Excellent Use of a Singular Instrument so called (London: Walter Venge, 1585), title page.

117 Blagrave, The Mathematical Jewel, p. 13.

118 Blagrave, ibid, p. 14.
} 
likely to be gained by those who made their own in paper, 'ere he proceede to work in metall, and let him make his pastboord of pure good paper himselfe'. ${ }^{119}$

To introduce the all-encompassing nature of this novel instrument, its inventor had his users imagine another type of material in order to visualise its working: neither metal nor paper, but glass. Introducing the long-held importance of planispheric projection to any astrolabe - the method by which a three-dimensional sphere was transposed onto a two-dimensional planar surface, with its circles and angles retained with minimal distortion - the mathematician and instrument-maker first adopted Albrecht Durer's work on perspective to train the mind's eye. The artist's perspectival method, as advocated by Blagrave, celebrated placing 'a plaine and cleare glass $[\ldots]$ between the eye and the thing seene or object: and so (the eye fixed in one very place) to draw vpon the glasse whatsoever [the artist] saw through the same' (Figure 3.19). ${ }^{120}$

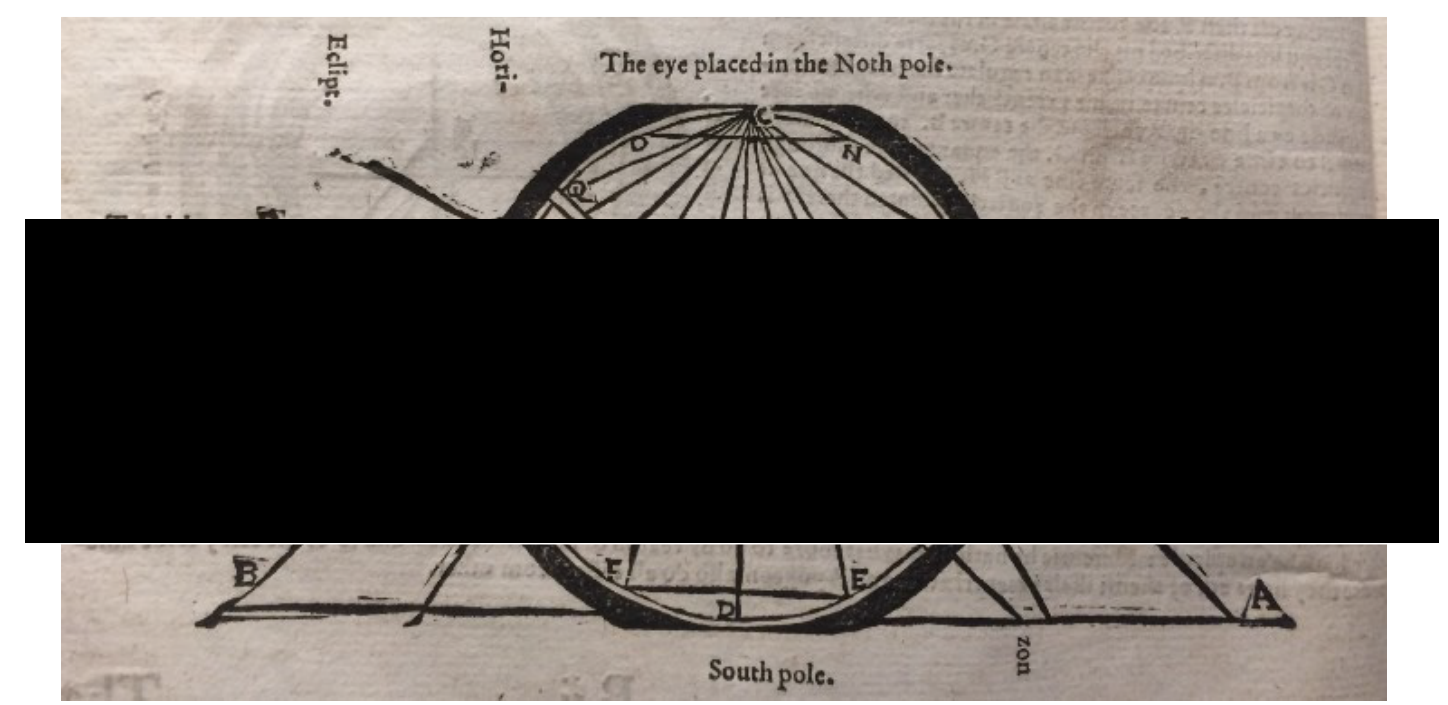

Figure 3.19. John Blagrave's portrayal of setting the eye at the North Pole so as to explain the drawing of the lines required for the stereographic projection of a standard astrolabe.

To explain the projection of the great circles of the celestial sphere onto the planar plates of an astrolabe, The Mathematical Jewel took for its example an eye fixed at the North Pole. Seeing that even the meanest geometricians knew that 'flat superficies cannot be equally answerable to a globes superficies in all points',

\footnotetext{
${ }^{119}$ Blagrave, ibid.

${ }^{120}$ Blagrave, ibid, p. 12.
} 
Blagrave highlighted the chief role of visual imagination in the process. The mind's eye was the mediator, bringing 'any thing that had thicknesse into a plaine flatte, [...] by prospective lineaments like to those which the eye by imagination maketh on the glasse set between the eye and the thing seene'. ${ }^{121}$

Placing the eye at $\mathrm{C}$, the North Pole, the user could then 'mark where the lines issuing from $\mathrm{C}$ do cut your plaine $\mathrm{AB}{ }^{\prime}{ }^{122}$ Each of the lines $\mathrm{AB}$ delimited the diameters of circles of the astrolabe, thus representing the tropics of Capricorn, Cancer, and the equinoctial, intersected by the ecliptic and the horizon at lines MG and QP in the above image respectively. From this figure, users would then gain a clearer understanding of the lines of Stöffler's projection (Figure 3.20), with the centre of the diagram representing the North Pole previously drawn at $\mathrm{C}$ in the previous diagram. This geometrical practice was in many ways the technical preface to Blagrave's succinct explanation, in the later Art of Dialling, of the technique of time-finding as:

Nothing else but the description of 24 hower-lines, which the Sunne by his diurnall revolution projecteth by the shade of a visible axtree line lying parallel to the invisible axtree of the world, on some visible plaine or other that lieth parallel to the invisible plaine of some one great cyrcle of the heavens or other. ${ }^{123}$

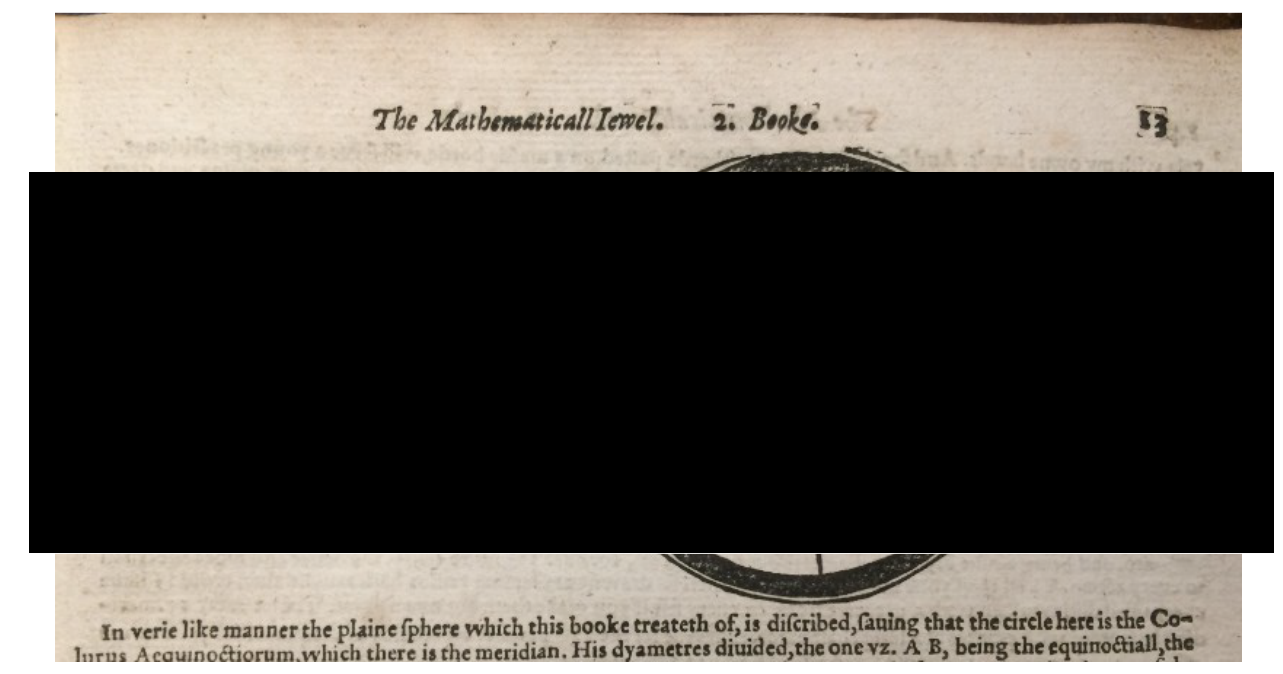

Figure 3.20. John Blagrave's summary of Stöffler's projection, which the former used as a basis from which to suggest his own improvements.

\footnotetext{
${ }^{121}$ Blagrave, Mathematical Jewel, p. 12.

${ }^{122}$ Blagrave, ibid.

${ }^{123}$ John Blagrave, The Art of Dialling in Two Parts (London: Nicholas Okes for Simon Waterson, 1609), p. 6.
} 
Users, then, were encouraged by authors such as Blagrave to visualise the imaginary lines of the great circles as indicative of geometric celestial movement on which direct calculations of time, location and distance could be made. The visible and invisible planes of these geometric forms afforded instruments such as astrolabes the ability to solve a diverse range of mathematical problems. So as to fully comprehend the theory behind this, users were challenged to harness their imaginative capabilities to visualise, to observe, and to then quantify.

Corroborating examples of users doing precisely this can be found in the annotations of early modern owners of both John Blagrave's The Mathematical Jewel and Thomas Blundeville's Exercises. In several instances, the evidence of users' annotations points to commonalities of purpose shared by discrete users. An example of attempts to conjoin visualisation and theory is found in markings to the print of the 'Margarita Mathematica' (the astrolabe's mater) and, printed on its verso, the rete of the new astrolabe. Unsurprisingly, several remaining copies of Blagrave's work are missing this print, their users (or printers) having cut it from their volumes to aid the construction of the instrument. In the case of one copy, bound up with six other mathematical works printed between 1616 and 1685, ${ }^{124}$ a user or bookseller has gilded the hour scales of the mater with the hours of the day (as requested by the author, who had provided the hours of night) and, in black ink, drawn the zodiac. On the rete, this individual has gone further still, shading the numbered stars in gold and, in a precise hand, adding the names so that they might identify these celestial objects more easily.

Other users chose not to mark their retes and maters in such fashion, although this should not be taken as evidence of their lack of practical interest. Gabriel Harvey is one such operator; he inscribed the print of the mater with an approving reference to the astrolabe as previously described by Chaucer, the basis of which was still 'in

\footnotetext{
${ }^{124}$ John Blagrave, The Mathematical Jewel, shewing the Making, amd Most Excellent Use of a Singular Instrument so called (London: Walter Venge, 1585), British Library Shelfmark 528 n.20.(1). The other works bound in the volume are Michael Dary, Gauging Epitomized: or, an abbreviation of solid geometry, so much as concerns the business of caskguaging, etc (1669); Aaron Rathborne, The Surveyour in Four Books (1616); Ioannis Della Faille, Theoremata de Centro Gravitatis (1632); Jacques Curabelle, Examen des Oeuvres du Sr Desargues (1644); John Pell, A Table of Ten Thousand Square Roots (1672) and John Caswell, An Account of the Doctrine of Trigonometry, Plain and Spherical (1685).
} 
esse. Pregnant rules to manie worthie purposes'. ${ }^{125}$ Harvey's oft-expressed desire to see the practical and theoretical aspects of astronomy and mathematics united was met by The Mathematical Jewel, a text in which he referenced a range of mathematical authors and practitioners - including Thomas Blundeville and, in a case perhaps demonstrative of the reading of trigonometry in university circles, Thomas Fincke. ${ }^{126}$

If Harvey's annotations are never quite convincing in their promotion of practical mathematics, one note at least is deserving of a re-reading. When John Blagrave told of the motivations behind his invention of the Jewel, his conversations with the vicar Thomas White were to the forefront. White's encouragement fulfilled a dual role in the instrument's origin. The clergyman's appreciation of Blagrave's practical skill in drawing, painting, and engraving had led him to contact an instrument maker in search of a new universal astrolabe. Blagrave, inspired by the vicar's library, then borrowed from the clergyman works by Andreas Schöner, Stöffler, Juan de Rojas y Sarmiento, and Gemma Frisius; above all else, the work of Frisius was commended by the clergyman. ${ }^{127}$

Marking this detail, Gabriel Harvey noted these names as '[Blagrave's] sole or principal Authors', before remarking that 'Schollars have the bookes: [..] Practitioners, the Learning'. ${ }^{128}$ This dictum has been termed disingenuous, particularly so given Gabriel Harvey's praise in the same volume of a number of Cambridge graduates, amongst their number Thomas Hood, few of whom could justifiably be placed alongside Blagrave according to either birth or education. ${ }^{129}$ However, it should perhaps instead be read as indicative of the transmission of theoretical expertise into the practical arena - a transmission that both makers and consumers could then benefit from. Blagrave himself was certainly grateful of the opportunity to improve upon Gemma Frisius; it seems more likely that Harvey was

\footnotetext{
${ }^{125}$ Gabriel Harvey’s copy of John Blagrave's The Mathematical Jewel (London: Walter Venge, 1585), annotation to title page. British Library Shelfmark 60.07.

${ }^{126}$ Blundeville and Fincke are both referenced in a list of mathematical authorities on the final page of Harvey's copy. Harvey's copy of The Mathematical Jewel, British Library, 60.07, p. 124.

${ }^{127}$ Blagrave, Mathematical Jewel, p. 19. For Blagrave's 'practical reading', see Taylor, 'A "Practique Discipline"?', pp. 332-340.

${ }^{128}$ Harvey's copy of Mathematical Jewel, p. 19.

${ }^{129}$ Jessica Wolfe, Humanism, Machinery, and Renaissance Literature (Cambridge: Cambridge University Press, 2004), p. 141.
} 
directly chiding the collection's owner, Thomas White, for making little use of his learning.

Harvey's copy of The Mathematical Jewel is of interest less for his occasional sallies on astronomical authors and their output than it is for the attending marginalia detailing the theory and use of the stereographic projection of the celestial sphere as replicated within its bindings. A series of extra leaves bound more recently into the copy bear evidence of instrumental material kept with the text. Included are a base disc from Peter Apian's Cosmographia, to be used as part of a volvelle by which the user could calculate the height of the sun, the height of the pole, the current time, and the length of day or night (Figure 3.21). ${ }^{130}$

The disc marks both poles and the hours of ante- and post-meridian along a latitudinal scale with the zodiacal signs graduated on either side. As Margaret Gaida has noted, Apian believed it imperative that the book's owner work through these operations diligently, and with a careful eye. The German author directed his reader in no uncertain terms to practice operating the instrument (when constructed in full) in daylight, with the book held upside down: the hybrid instrument thereby momentarily trumping the written word in communicating knowledge to its user. ${ }^{131}$

\footnotetext{
${ }^{130}$ Harvey's copy of Mathematical Jewel, unpaginated rear matter. Peter Apian, Cosmographia Petri Apiani (Paris: apud Vivantium Gaultherot, 1551), f. 9 v. Science Museum Library Shelfmark Q. O. B. GEM GEMMA 461575-2001.

${ }^{131}$ Gaida, 'Reading Cosmographia', p. 295.
} 


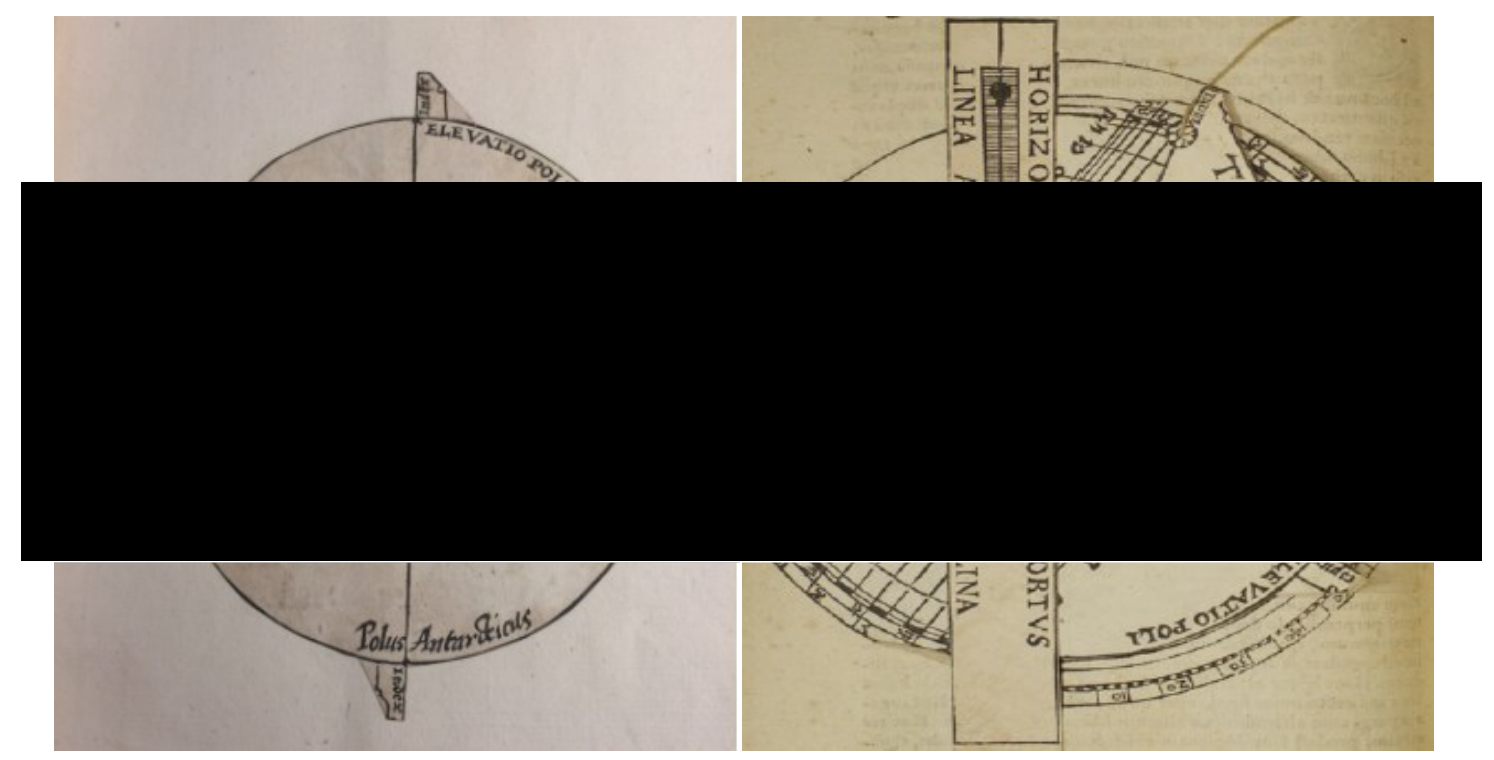

Figure 3.21. Side-by-side images of (left) the base disc found in Harvey's copy of the Mathematical Jewel, British Library Shelfmark 60.07, compared with (right) a fully constructed volvelle from the Science Museum Library's copy of Peter Apian's Cosmographia, Science Museum Library Shelfmark Q O. B. GEM GEMMA 461575-2001. As can be seen from the image, the disc turns around a scale and is beneath a moveable triangle and rule.

Also bound within Harvey's copy of the Jewel are a large, orthographic 'Rojas' projection, notes on using such a projection along with the points of the celestial sphere to find time, and, most interestingly, a hand-drawn, constructed, miniature volvelle version of the Jewel itself. The 'Rojas' projection, described in the sixth book of Juan de Rojas Sarmiento's Commentarium in Astrolabium libri sex (1550), transposed the celestial sphere onto the plane of the solstitial colures - so called because the colure, or circle of the sphere, 'passed through' the solstice points of the Tropics of Cancer and Capricorn marked by the sun's location directly over each in June and December respectively.

Figure 3.22 below is evidence of how the owner of this copy of The Mathematical Jewel sought to tease out their working understanding of this theory. The circle $E P A E S$ is given as the general meridian, with the line $P S$ the obliquity of the ecliptic, drawn to $23^{\circ} 30^{\prime}$ - the same value on which Regiomontanus had settled in Padua in $1464 .{ }^{132}$ This value was stated at points $E$ and $A E$ : $E$ marking the

\footnotetext{
${ }^{132}$ Ernst Zinner, Regiomontanus: His Life and Work, trans. E. Brown (Amsterdam and New York: Elsevier Science Publishers B.V, 1990), p. 74; N. M. Swerdlow, 'Tycho, Longomontanus, and Kepler on Ptolemy's Solar Observations and Theory, Precession of the Equinoxes, and Obliquity of the Ecliptic, in Alexander Jones, ed., Ptolemy in Perspective: Use and Criticism of his Work from Antiquity to the Nineteenth Century (Dordrecht: Springer Science + Business Media, 2010), pp. 151202, pp. 153-154; Edward Rosen, Copernicus and his Successors (London: The Hambledon Press,
} 
greatest maximal declination Northward, at the Tropic of Cancer $(E)$ and Southward at that of the Tropic of Capricorn $(A E) . P S$ was defined as both 'the axis of the world and circle of the hour of 6'. The circle of the celestial sphere was then further divided to delineate the zenith $(Z)$, nadir $(N)$, and horizon $(M A H)$, with instructions on points from which to calculate the altitude and azimuth of celestial objects. The latitudinal lines drawn between the tropics are parallel to the equator and serve to calculate time and location.

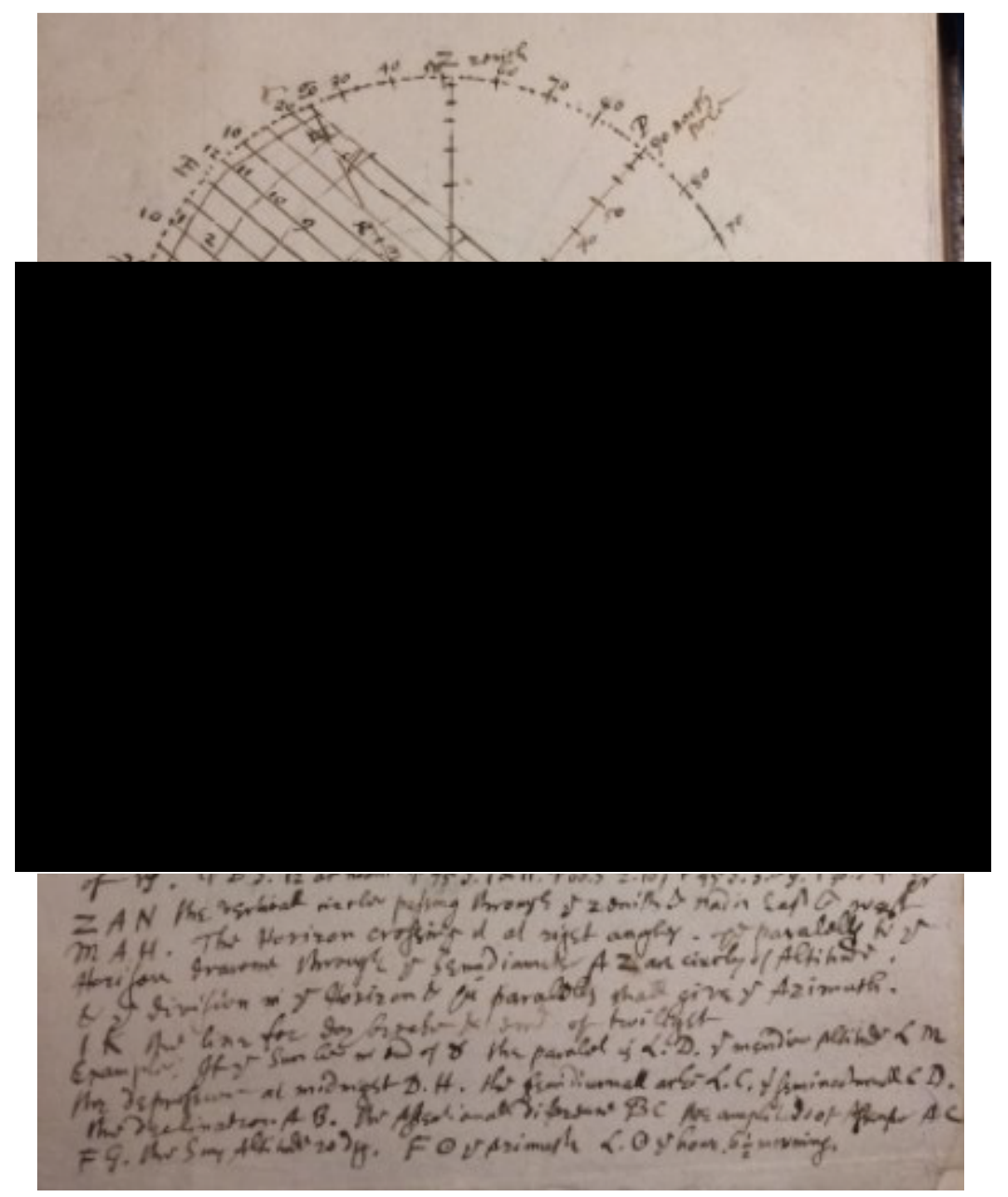

Figure 3.22. A hand-drawn horological dial, appended on loose leaves to Gabriel Harvey's copy of The Mathematical Jewel. British Library Shelfmark 60.07 .

There can be no doubt that this diagram was a figurative tool for the teaching, learning, and performance of spherical astronomy. Whilst it goes beyond the volvelles and figures of Apian's Cosmographia and Blundeville's Exercises in its 
mathematical specificity, however, it should not be denied the representative qualities afforded to the instruments and images found in these texts - as the example beneath the figure shows. Rather than calculate the position of points on the celestial sphere, the user instead annotated a cartography of the sky in a given situation: in this case, to derive the positions of various bodies to find the time. Thus, using the sun's position in relation to the sign of Taurus, the appropriate latitudinal parallel is identified as $L D$, after which can be plotted the "meridian altitude $L M,[\ldots]$ the declination $A B$, the ascentional difference $B C$, the amplitude of Ascent $A C, F G$ the Suns altitude 20 degrees, $F \odot$ your azimuth, $L \odot$ ye hour, 6 1⁄2 morning'.

On the verso of this leaf, the user appears to have gone a step further. Moving on from theoretical, imagined examples, the annotator has made a diary entry of their practice, marking that, on the $10^{\text {th }}$ of May, at $6: 30$ a.m., the sun was in the constellation Taurus and at an altitude of $20^{\circ}$. This passage reflects the efforts made by a user to think and reason in terms of celestial coordinates for largely practical aims. The ascensional difference, a measurement of the angular difference between a point's right ascension (its easterly distance from a vernal zero point on the celestial equator) and its oblique ascension (the angular distance between a point rising on the ecliptic and the equator), ${ }^{133}$ is calculated as being 2 hours from a solar declination of $20^{\circ}$ North.

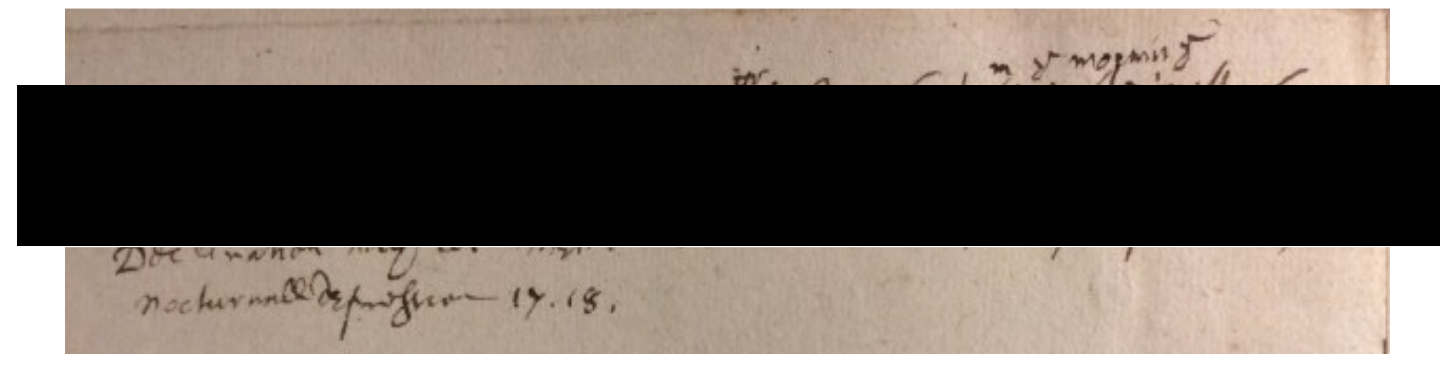

Figure 3.23. An example of the calculations that could be tested with the previous diagram, taken from Gabriel Harvey's copy of John Blagrave's The Mathematical Jewel. British Library Shelfmark 60.07.

By computing celestial coordinates in this way, our user demonstrated a number of skills that move from the interpretative to the calculative through the manipulation of a paper tool. They moved from imagining, to making, and there on

\footnotetext{
${ }^{133}$ Robin M. Green, Spherical Astronomy (Cambridge: Cambridge University Press, 1985), pp. 14-15; Chabás and Goldstein, Survey of European Astronomical Tables, pp. 28-30.
} 
from to knowing via doing. While it is unclear to what level this user had benefited from Apian and Blundeville's works, it is easy to imagine their moving between the instrument for locating the sun in a given constellation (such as Taurus) and then slowly improving their mathematical understanding through positional astronomy and subsequently time-finding.

As we can see from the hand-made volvelle astrolabe shown in Figure 3.24, one owner (likely Gabriel Harvey himself) of this copy of The Mathematical Jewel went so far as follow John Blagrave's instructions by constructing a paper instrument so as to further cement their understanding of its working. It is possible that this example is a later, more developed iteration of their mathematical practice, the instrument and its projection constructed only after the annotator shown at work in Figure 3.23 above was confident of the underlying theories of positional astronomy.

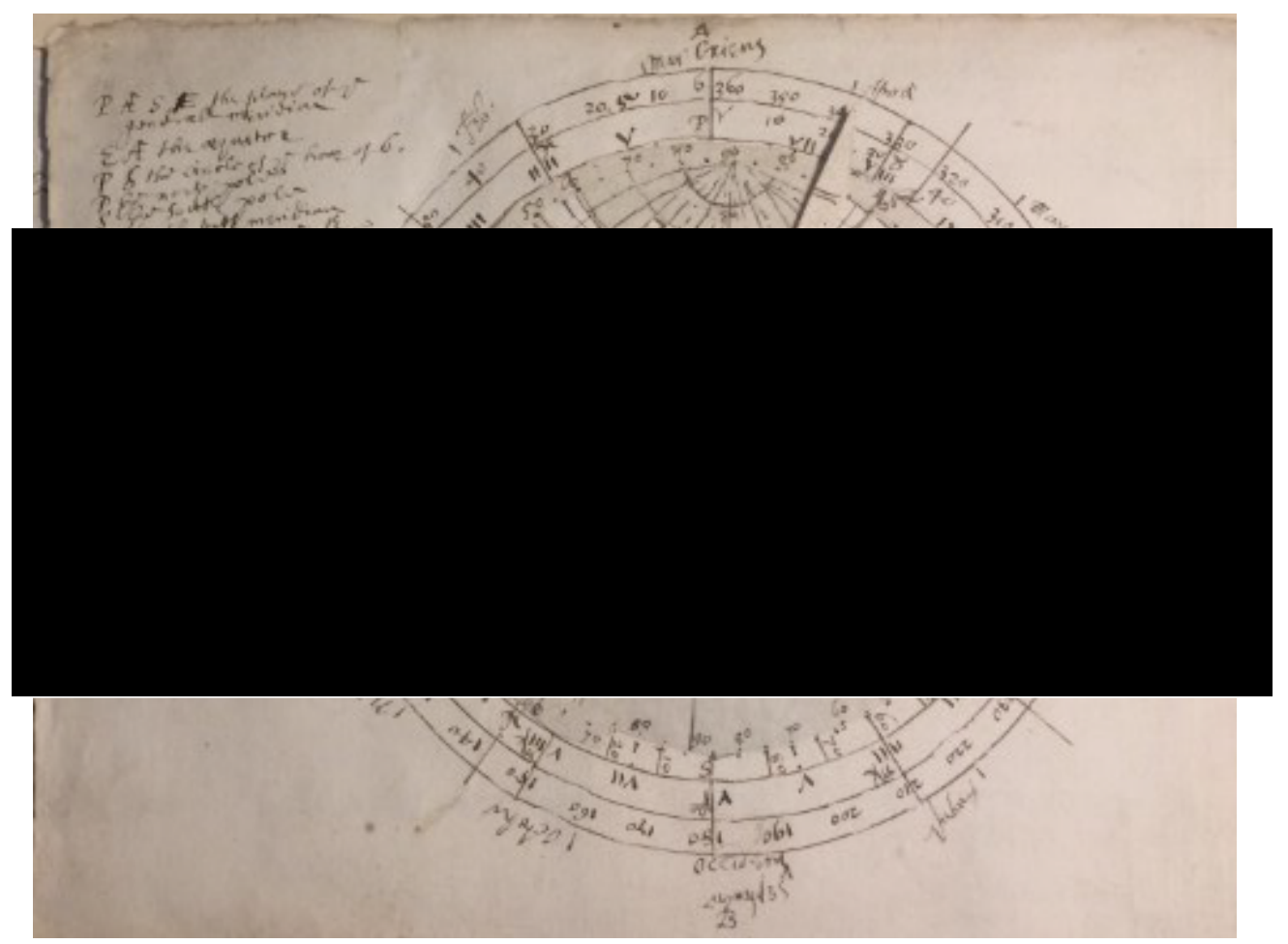

Figure 3.24. A hand-made volvelle replication of Blagrave's astrolabe, taken from Gabriel Harvey's copy of The Mathematical Jewel. British Library Shelfmark 60.07.

These examples help show how visual tools in cosmographical, navigational, and horological compendia could inspire in their users the development of an 
'intelligent eye': one which could visualise the structure and coordinates of the cosmos, use this understanding to plot celestial points, and then, as Apian had hoped, inform the calculation of time and place. As mathematical and cosmographical authors sought for ways to engender a visual apprehension of mathematical theory before moving on to precise, quantitative applications of that theory, users (in some cases) responded accordingly. In one final instance, an annotator, writing on the fourth edition of the Exercises in 1639, used the front and rear flyleaves of their copy to detail a number of calculations on the positions of the sun and moon throughout the year (Figure 3.25), with additional data, calculated at a distance of 45 minutes per compass point the celestial body moved through, taken from the location of London Bridge. ${ }^{134}$

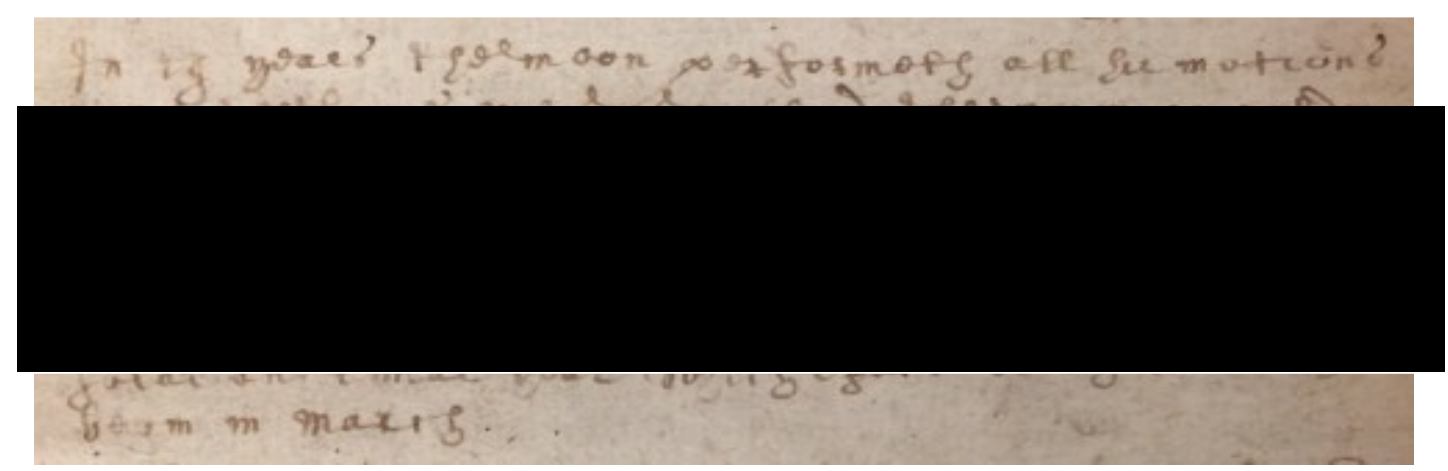

Figure 3.25. Horological and calendrical annotation using positional astronomy, excerpted from a user's 1639 annotations in their copy of Blundeville's Exercises (1636). Science Museum Library Shelfmark O. B. BLU BLUNDEVILLE 459578-2001.

For this user - as Apian, the creator of a Speculum Cosmographicum, and Blundeville and Blagrave, the adopters of such artifices, had no doubt hoped - the practical value of number was 'as a glass of art'. As Figure 3.26 highlights, this user was moved to decorate their book with literary efforts of their own. Whereas the drawing of the planispheric projection was a product of perspectival imagination for Blagrave, for this user, the very use of mathematics itself operated as the glass

\footnotetext{
${ }^{134}$ Blundeville, Exercises contayning Eight Treatises, unpaginated rear flyleaf, Science Museum Library Shelfmark O. B. BLU BLUNDEVILLE 459578-2001. This annotated section reads: 'In 19 years the moon performeth all the motions with the Soun which is called their tym or golden Number. At which tym Shee again beginneth at the sam(e) signe of the Zodiak Shee were at 19 Yeares before. The epact is 123 dayes difference betwixt the Solar and lunar year which epact doeth alwayeth begin in March.'
} 
through which the universe's form and figure could be ordered. Detailing their epistemic experience in rhyming couplets, they proclaimed:

Number did signe all the kyndes that be And gave form to the Chaos formerly All things in Number hath created bein As in a glas of art they may be sene This art surveyeth Thetis bed, the seas, It measures the hevens superficies And all the stars which in the spher moue on With a constant double revolution. ${ }^{135}$

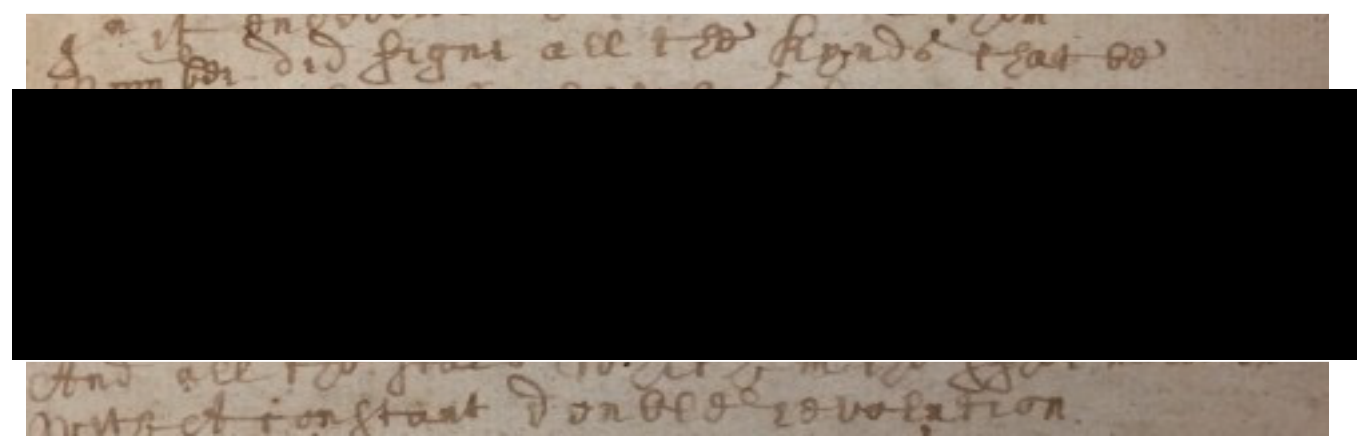

Figure 3.26. A description of Number as akin to a 'glas of art' from the flyleaves of the Science Museum's 1636 edition of Blagrave's Exercises. Science Museum Library Shelfmark O. B. BLU BLUNDEVILLE 459578-2001.

\section{Of Time and Tide: Using Instruments at Sea and on Land}

Finally, let us consider two instruments uniting several of the key elements this chapter has sought to discuss. By the sixth and final treatise of the Exercises, on navigation, Blundeville had introduced his users to arithmetic and to the doctrine of sphere, codifying its theory in service of the practical elements of exploration, seafaring, and time-finding. After attempting to train them in that doctrine using, in part, naturalistic and schematic figures, the author then encouraged his audience to make and apply planispheric projections to measure the differing, multi-dimensional properties of time and distance. It should be emphasised, however, that for the less numerate and literate users who nonetheless strove to improve their capabilities

\footnotetext{
${ }^{135}$ Blundeville, Exercises contayning Eight Treatises, unpaginated front flyleaf. Science Museum Library Shelfmark O. B. BLU BLUNDEVILLE 459578-2001. I am grateful to Stephen Clucas for his help in transcribing these lines.
} 
(aboard ships or otherwise), the volvelle retained its pedagogical and computational importance.

Just as Regiomontanus's calendrical volvelles aided the transmission and reception of astronomical and horological theory, so too did a more pastoral genre of print help to familiarise shepherds, sailors, and medical practitioners with mathematical and celestial data. We can therefore return to the Exercises's first instrument - a reprint of Peter Apian's Instrumentum Theoricae Solis - from an alternative perspective. Apian's zodiac calendar, consisting of fixed circles and thread, could be used to find longitude and, in conjunction with a separate table thereafter, to return declination. The benevolent, macrocosmic figure in Apian's print was a guide to the zodiacal signs with which users of many stripes would be familiar, whether through calendrical or medicinal prints. Blundeville, for his part, repurposed this figure with an even more 'practical' image - a simplistic compass. The author's text had then built toward exercising his readership's new imaginative and calculatory capabilities in their most applicable surroundings: namely, at sea. As we shall see, however, these final instruments offered the user perhaps the least mathematically-valuable training of the entire text.

The question of how seafaring users encountered the Exercises is a pertinent one. Ostensibly, Thomas Blundeville would have argued that his text was of most use to a group of readers with interests in navigation. The educational standards of many sailors were, however, both in 1594 and well beyond, some way below the gentry at whom the volume was assuredly pitched. Undeterred, the author used the title page of his first edition to declare that it was 'impossible to profit [in the Art of Navigation] without the help of these or such like Instructions' - indeed, it was for the furtherance of navigational science that any of the treatises had been collated, let alone the one specific to maritime pursuits. ${ }^{136}$ This declaration would remain to the fore of the Exercises's later editions and, while other treatises in the text spoke of their discipline's chief and necessary works, the sixth part of the volume was the only treatise to advertise both the breadth and simplicity of its learning. This portion of the text was 'lately collected out of the best Moderne Writers thereof [...] and by

${ }^{136}$ Blundeville, Exercises, f. 303 r. 
[the author] reduced into such a plaine and orderly forme of teaching as every man of a meane capacity may easily understand the same' [Blundeville's italics]. ${ }^{137}$

The author tackled the 'meane capacity' of these users head-on, and his introduction to the sixth treatise goes some way toward explaining why a discussion of navigational practice appeared so late in the volume - after those on arithmetic, cosmography, the globes, Petrus Plancius' map, and John Blagrave's astrolabe. As with any art, the method and practice was learned only through equal parts instruction and experience. ${ }^{138}$ The primary parts of Blundeville's instruction focused on instruments, under which fell ephemerides, cross-staves, globes, dials and compasses. However, in summarily dismissive fashion, the user is informed that these instruments serve little purpose without knowledge of the stars, 'their Longitudes, Latitudes, declinations $[\ldots]$ the course of the Sun $[\ldots]$ the times and seasons of the yeere, the hour of the day [...] and finally, the course of the Moone, whereon dependeth the knowledge of the tydes in all places' ${ }^{139}$ Although the author reaffirmed his commitment to teaching such knowledge in the forthcoming treatise, the implication remained. Even the reader of 'meane capacity' should recognise that they had been introduced to many of these concepts already. Furthermore, the use of instruments was neither a short-cut to nor a substitute for knowledge.

The first of the final two instruments presented in the Exercises was an instrument for finding the time at night; the 'rectifier' of the North Star. As the Science Museum's own collection demonstrates, consumers of various capabilities across early modern Europe could purchase horological and time-finding instruments in a range of materials, including paper, wood, and brass. Dials incorporating gnomonic, solar dialling and lunar time-finding were also fashioned from ivory (so as to better reflect sparse moonlight after dark), with brass volvelles to calculate the time and the age of the moon (Figure 3.27, below).

\footnotetext{
${ }^{137}$ Blundeville, Exercises, f. 303 r.

${ }^{138}$ Blundeville, ibid, f. 304 r.

${ }^{139}$ Blundeville, ibid, f. 304 v.
} 

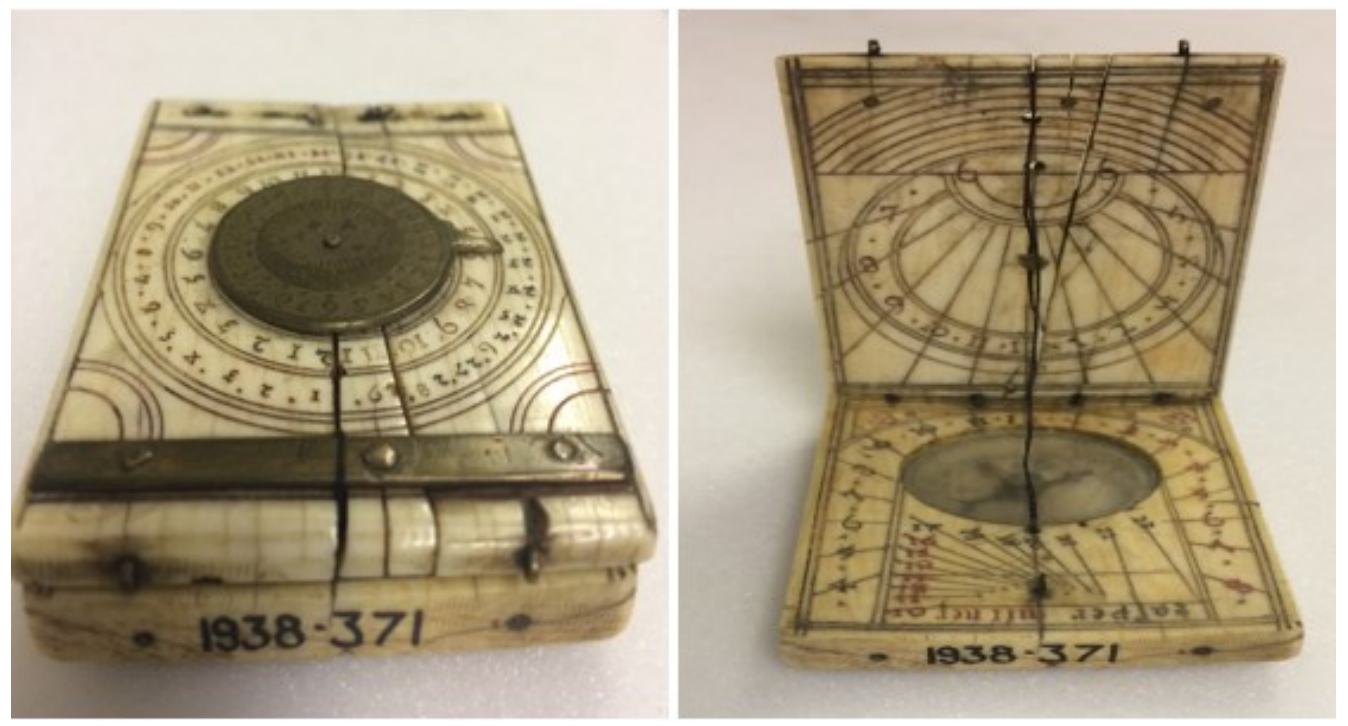

Figure 3.27. Composite image of the exterior (left) and interior (right) of Science Museum Object 1938-371. To the interior are horizontal and vertical dials and a pin-gnomon dial for Italian hours; to the exterior, a brass lunar volvelle which allowed time to be reckoned using the string gnomon dial by moonlight. The volvelle shows the age of the moon and two 24 -hour scales.

In one particularly striking example, a product of the horological instrument maker Paul Reinmann (ca. 1557-1609), the dial has been housed in a hinged diptych, no doubt playing on his consumers' understanding of the continuum of information (and its manufacture) made available by printing and engraving technologies. Although the diptych sundial was a common product of a relatively small number of expert Kompassmacher families working in close proximity to one another in sixteenthcentury Nuremberg, relatively few were decorated to resemble books in this manner. As Figures 3.28 and 3.29 below illustrate, Reinmann even went so far as to mimic the metal clasps and laced spinal ticketing witnessed in the codices of the era. ${ }^{140}$

\footnotetext{
${ }^{140}$ Steven A. Lloyd, Ivory Diptych Sundials, 1570-1750 (Cambridge, MA: Collection of Historical Scientific Instruments, Harvard University; Harvard University Press 1992), p. 6 and p. 45.
} 

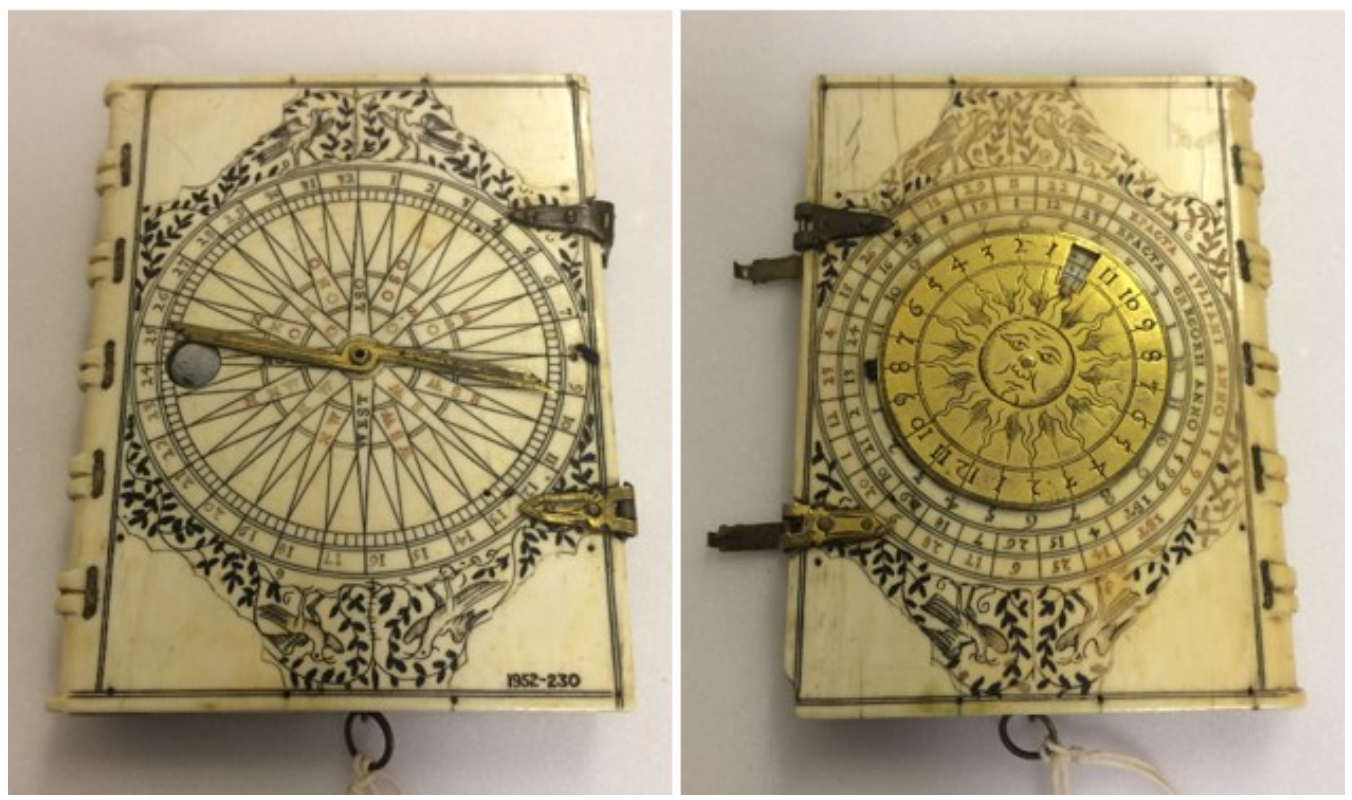

Figure 3.28. Composite image of the front (left) and back (right) of Science Museum Object 1952-230, an ivory diptych sundial with a wind rose (with a hole to view the internal compass) and brass index to the front, and a brass volvelle to calculate nocturnal time and the epact to its rear.

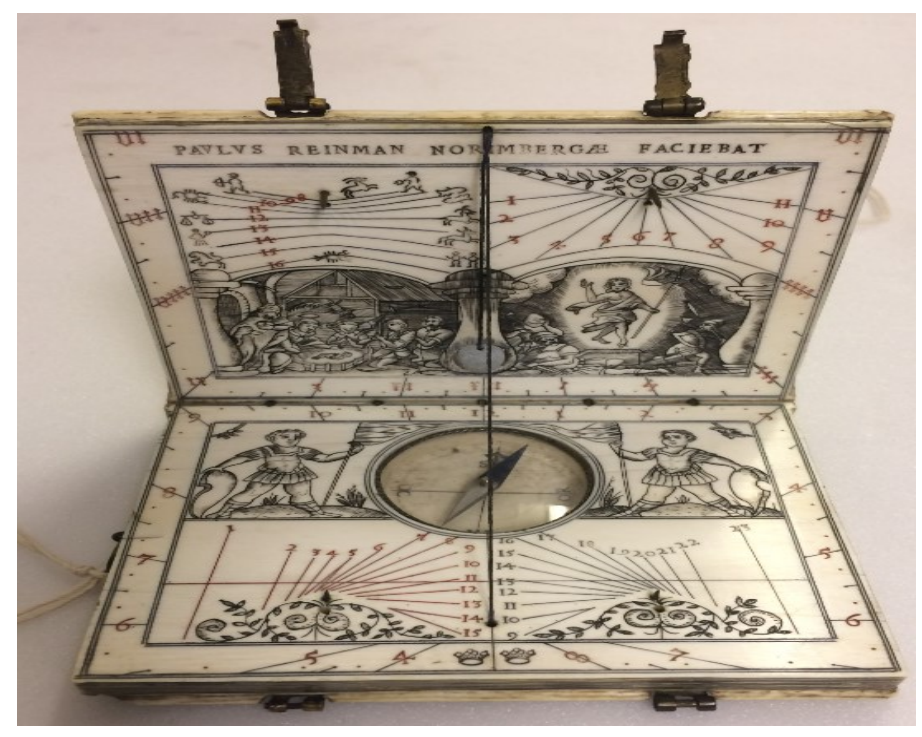

Figure 3.29. The interior of Science Museum Object 1952-230, a diptych dial and compass. The inscription 'Paulus Reinman Norimbergae Faciebat' can be seen to the uppermost horizontal edge of the ivory casing.

It is in this continuum of information - represented in interlinked prints, inscribed instruments, and analogue, computational volvelles - that Thomas Blundeville's contribution to nocturnal time-finding can be placed. In keeping with the previous paper instruments described and, in some cases, fashioned by the author, the user was advised to consider another volvelle - the 'rectifier' of the North Star, consisting of a circumpolar instrument for finding the time at night, when the 
sun could provide no assistance - as a tool with which to better understand geometrical and astronomical theory. The standard nocturnal consisted of a dial comprised of three concentric, rotating plates fitted to a handle. The bottom disc was a calendar, the middle disc a 24-hour clock and the innermost disc an alidade pointer that protruded beyond the edge of the plates. These were held together by a rivet that could be looked through so as to see the Pole Star. Having set the 12-hour mark to the date, the user then rotated the alidade until it met with the so-called Guard Stars of Ursa Major, Dubhe and Merak. ${ }^{141}$

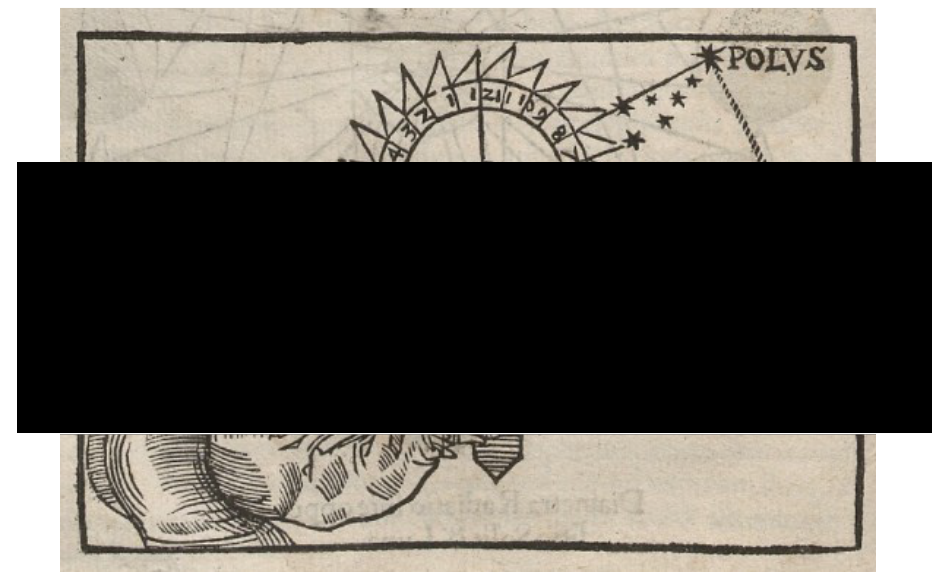

Figure 3.30: An example of a user finding the time with a nocturnal dial, using Polaris and its 'Guard' stars. Peter Apian, Cosmographia (1524).

To a certain extent, the paper construction presented by Blundeville held both ludic and pedagogical value. It was something to be manipulated at leisure, so as to formalise the relationship between sight and scale prior to the instrument's physical fabrication and use; yet the instrument provided in Blundeveille's text expanded on the standard nocturnal by also returning the declination of the Pole Star. The Exercises's nocturnal consisted of an exterior, fixed scale of declination in degrees and minutes (up to a maximum of $31^{1} 2^{\circ}$ ) of the declination of Polaris (the 'load-starre') from the North Celestial Pole. By consulting a table, the user could construct the scale of declination, and then return to the instrument to find the value to be added to or subtracted from the observed height of the Pole Star.

Concentric with the fixed disc is a circle of the 8 cardinal and inter-cardinal compass points - in Blundeville's terms, the principal rumbes or windes - within

\footnotetext{
${ }^{141}$ Günther Oestmann, 'On the History of the Nocturnal', Bulletin of the Scientific Instrument Society, 69 (2001), pp. 5-9; L’Estrange Turner, Scientific Instruments, 1500-1900, p. 17.
} 
which is a further, smaller disc of days and months of the year. The moving instrument fixed to this is a 24 hour clock, with a long, toothed alidade reaching beyond the circumference of the outermost circle. Below this is the handle of the instrument: when making their own copy, the author, again following Coignet to the letter, advises his users to ensure that they

alwaies set the 21 of October beneath towards the handle in the very line of North and South passing through the middest of the handle, so shall the Instrument shew the houre of the night more truely than when the 28 day of October standeth $[\ldots]^{142}$

as setting the position of the calendrical circle to the $28^{\text {th }}$ of October (as most nocturlabes were) would lead to errors of up to $7^{\circ} 18^{\prime}$ from celestial pole to star - a difference of almost 30 minutes.

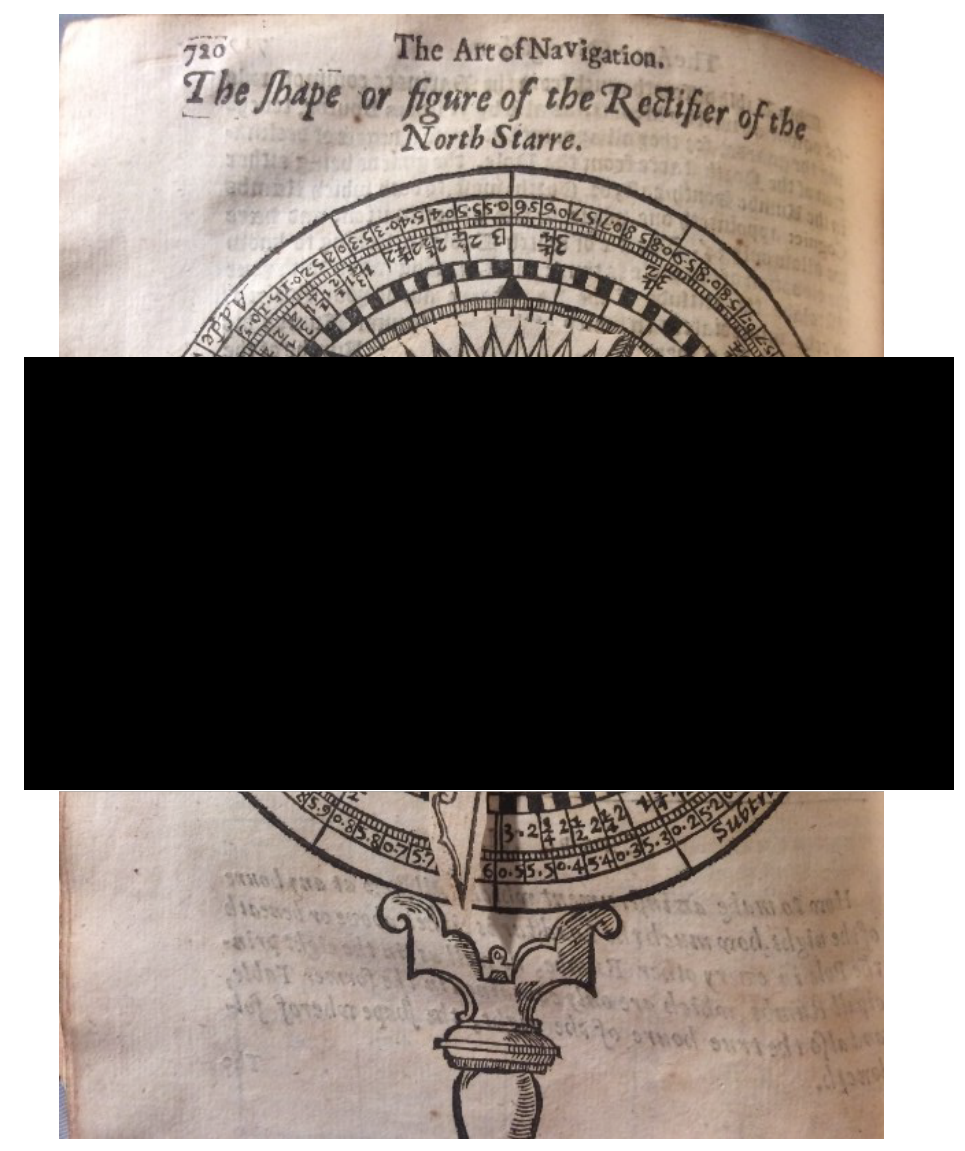

Figure 3.31. The 'Rectifier of the North Star', as constructed in Thomas Blundeville's Exercises. Science Museum Library Shelfmark O. B. BLU BLUNDEVILLE 459578-2001.

\footnotetext{
${ }^{142}$ Blundeville, Exercises, f. 340 r.
} 
However, it was nigh-on impossible for the user to test this without first making a physical version of the nocturnal. To use the instrument, it was essential to draw the tool by the handle 'right before your face [...] until you may see with the one eye, winking with the other, the North Starre through the hole of the pin, which is the Centre of the instrument'. ${ }^{143}$ As soon as the North Star was so located, the user was to move the alidade until the guards of the star were even with its toothed edges. Holding the alidade at this point would give the hour of night. To find the elevation of the celestial pole, the graduations on the exterior of the circular scale could then be added or subtracted to or from the altitude of the star.

Such nocturnal dials were frequently referenced in navigational manuals from the late sixteenth century onwards, ${ }^{144}$ with many decorative examples also fashioned as objets d'art. As with several instruments, whether intended for practical or leisurely pursuits, the mathematical and astronomical principles underlying nocturnal time-finding could be co-opted for various interlinked purposes. One example of how this could occur is found in an ornate nocturnal crafted by the German Caspar Vopel, which features on its reverse a Regiomontanus-type altitudinal sundial and, appended to the nocturnal, two additional alidades - one lunar, the other solar - the first of which could be used to define the phases and age of the moon. In combining the Regiomontanus dial, a version of which was first popularized by the mathematician in his Kalendarium (Venice: Erhard Ratdolt, 1474), with the aforementioned nocturnal and lunar instrument, Vopel offered his customers (likely of an aristocratic bent) an instrument somewhat akin to a Swiss Army knife of time finding.

Capable of being used at day or night, and at land or sea, Vopel's instrument (seen in Figure 3.32) is testament to the aesthetic appeal of the dial, which undoubtedly helped secure its admission to the genteel collections of early modern Europe. Designed by the mathematical practitioner for just such a purpose, Vopel's instrument remains a finer version of the very same nocturnals utilised by

\footnotetext{
${ }^{143}$ Blundeville, Exercises, f. 340 v.

${ }^{144}$ Oestmann, 'History of the Nocturnal', p. 7.
} 
mathematically weak seamen, as previously popularised in Peter Apian's

\section{Cosmographia.}

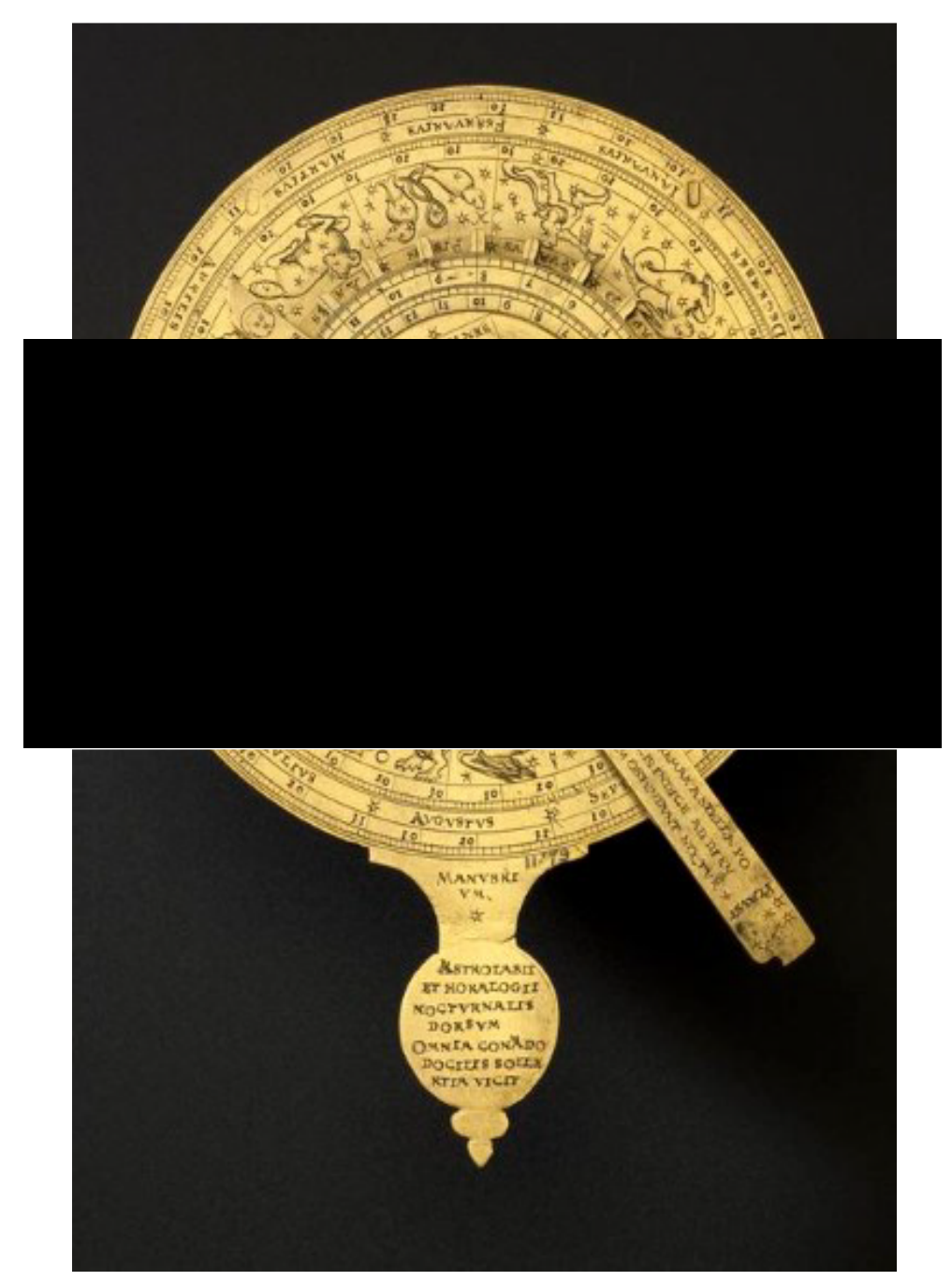

Figure 3.32. Klaus Vopel's multi-faceted nocturnal dial. Science Museum Object 1883-131. Copyright The Board of Trustees of the Science Museum, London.

A rather more utilitarian example of the nocturnal - and one similar to a type much more likely to have been used at sea - is found in Science Museum Object 1903-80, a wooden nocturnal bearing the inscription 'Robert Yeff in Bristol fecit 1702' (Figure 3.33). Robert Yeff (fl. 1693-1720) was one of a number of instrument-makers working in Bristol at this point, and his production of the nocturnal pictured below is evidence of a small community of practitioners and consumers at work outside of the English capital. 


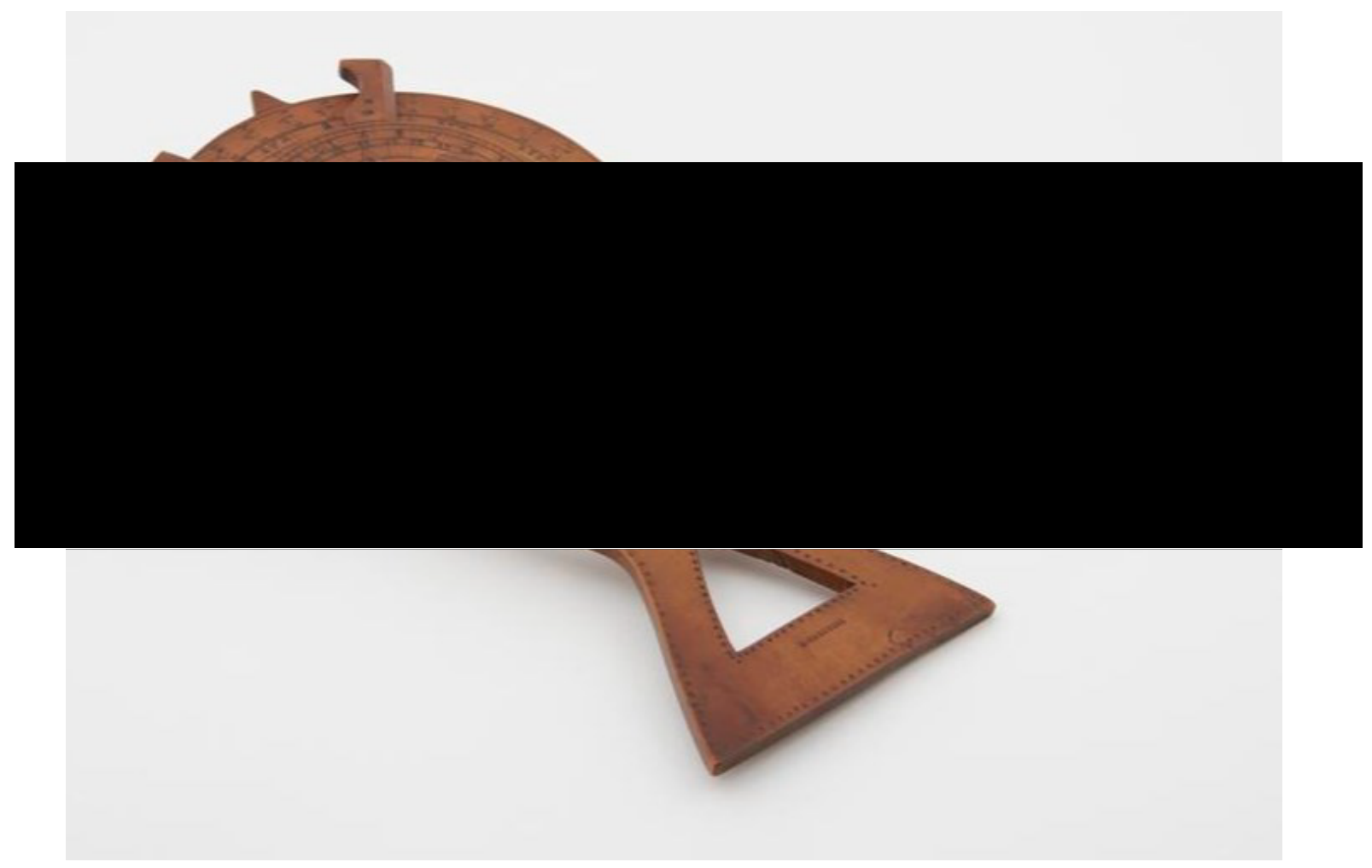

Figure 3.33. Robert Yeff's wooden nocturnal. Yeff's 1702 inscription is seen beneath the heart-shaped cut-out on the nocturnal's handle. Science Museum Object 1903-80. Copyright The Board of Trustees of the Science Museum, London.

As A. D. Morrison-Low has noted, Bristol was an important location for maritime trade and commerce in early modern England; at various times a safe harbour for the export of cloth and soap as well as for the import of Spanish wine, and, later in the seventeenth century, of sugar and tobacco from the West Indies. ${ }^{145}$ By the end of the seventeenth century, Bristol's commercial expansion had brought with it meaningful trading opportunities for mathematical and navigational practitioners. In Morrison-Low's argument, a growing demand for sea-faring instruments and their repair encouraged the transmission of tradesmen and of craft skills to areas outside of London. ${ }^{146}$

Further research into such communities may yet reveal previously unseen examples of users of both instruments and texts patronising the stores of figures such as Yeff, serving to elucidate more clearly the diffusion of mathematical skills, craft

\footnotetext{
${ }^{145}$ A. D. Morrison-Low, Making Scientific Instruments in the Industrial Revolution (Aldershot: Ashgate, 2007) p. 47.

${ }^{146}$ Morrison-Low, ibid.
} 
practices, and related products outwards from the capital. Yeff's near-contemporary, Anselm Jeffer (fl. 1685-1692) appears to have gone into business with the London practitioner Walter Hayes (ca. 1618-1696?); the pair produced mathematical instruments, and advertised their wares in Matthew Norwood's System of Navigation (1685). ${ }^{147}$ By uniting the gentility, the amateur, and the less-literate sailor in their mathematical practice, disparate makers - such as those embodied in the figures of Vopel and, later in the period, Yeff - provided the instrumental materials which authors and tutors such as Thomas Blundeville and his followers would seek to transmit to a wider audience in print. As Chapter Four of the current work goes on to highlight, seventeenth-century London instrument makers, amongst them Walter Hayes and John Seller, then expanded upon the efforts of their predecessors by utilising existing navigational instruments and texts so as to swell their share of a by then well-established market.

Along with the rectified nocturnal, the Exercises presented as its final instrument a volvelle with which users could find the height of the tide at any location (Figure 3.34). ${ }^{148}$ Though sixteenth-century naval pilots likely eschewed theory for the empirical data earned at sea, the result was much the same. Possessing the age and position of the moon at high tide, the pilot could use the 32 points of the compass as a kind of clock, with each point marking 45 minutes retardation of the tide from the date of the new moon, so as to safely approach or cast off from port. ${ }^{149}$ Sailors could find tables of these calculations in their pocket-books, full of navigational rules of thumb and practical methods; similarly, the impressive sea-atlas of the Dutch cartographer Lucas Janzoon Waghenaer (c. 1533 - 1606), Spieghel der Zeevaert (Leiden: Christophe Plantin, 1584), borne on the patronage of Philip II of Spain, incorporated much of the navigational manuals of the era, including tide tables, tables of solar declination, and guidance on using positional astronomy to find one's latitude at sea. ${ }^{150}$

\footnotetext{
${ }^{147}$ Morrison-Low, ibid, p. 49.

148 Blundeville, Exercises, ff. $349 \mathrm{v}-350 \mathrm{r}$.

${ }^{149}$ David Childs, The Warship Mary Rose: The Life and Times of King Henry VII's Flagship (London: Chatham Publishing, 2007), p. 76.

${ }^{150}$ Christine Marie Petto, Mapping and Charting in Early Modern England and France: Power, Patronage and Production (Lanham, MD: Lexington Books, 2015), p. 85.
} 


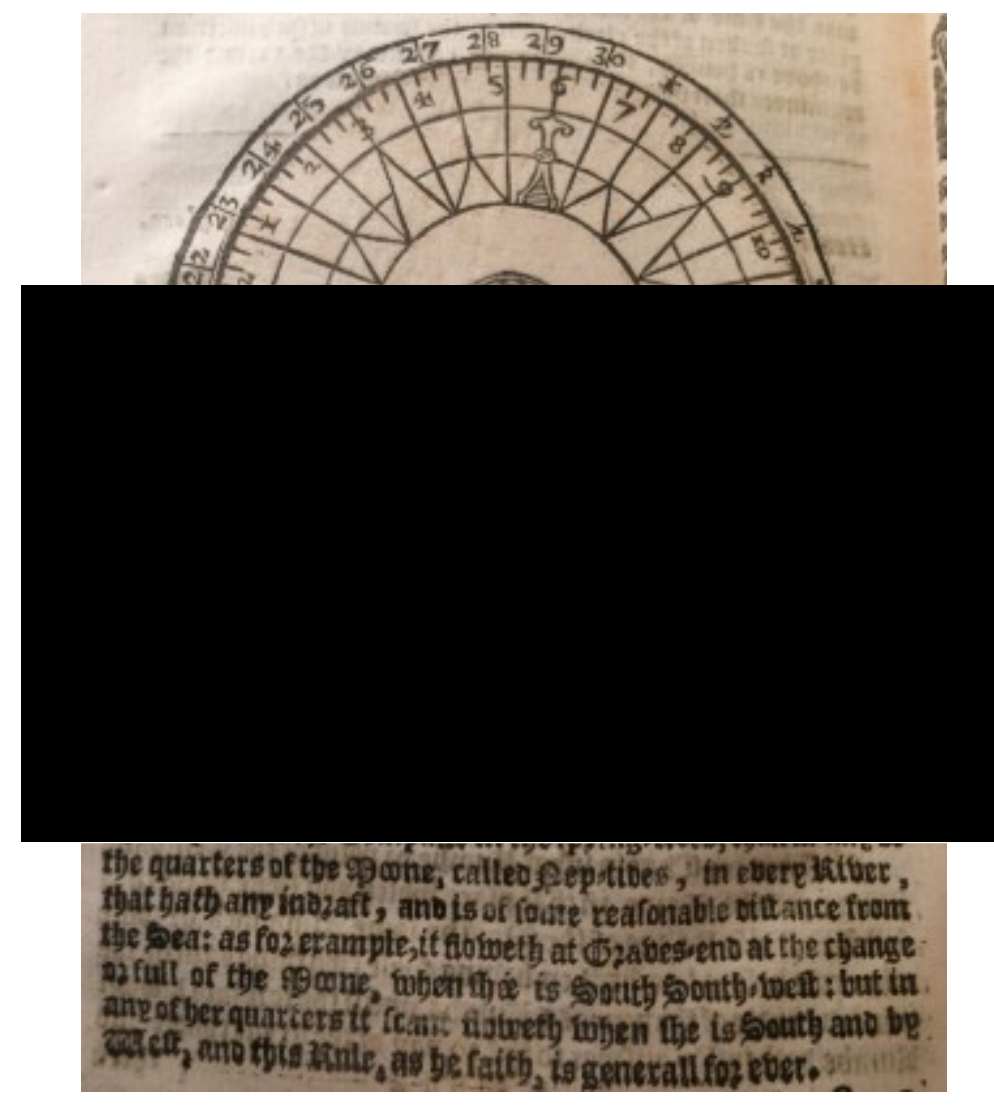

Figure 3.34. A constructed volvelle aiding users of Blundeville's Exercises to 'know (...) the tides at any place'. Science Museum Library Shelfmark O. B. BLU BLUNDEVILLE 459578-2001.

Blundeville's instructions for the application of this final volvelle point to the ready-reckoners and pocket books sailors would likely have had access to; for those marooned in the study or classroom, the data required was also close to hand. First of all, it was necessary to know the point of the compass 'upon the Moone in that place which you seeke maketh a full sea';151 additionally, users were advised to furnish themselves with an almanac 'or some other rule before taught' by which they might divine the Moon's age. ${ }^{152}$ Then, armed with these values, they could rotate the volvelle until the point of the compass (representing the position of the moon) met the $30^{\text {th }}$ day of the outer circle. Counting forwards or backward from 30 on the outer circle, the user could then read off the hour of high tide (on the inner circle) for their given location.

\footnotetext{
${ }^{151}$ Blundevile, Exercises, f. 349 v. The constructed volvelle illustrated in Figure 3.35 is taken from the Science Museum's copy of Blundeville, Exercises contayning Eight Treatises, p. 744. Science Museum Library Shelfmark O. B. BLU BLUNDEVILLE 459578-2001.

${ }^{152}$ Blundeville, Exercises, f. 349 v.
} 
Upon initial viewing, it is difficult to consider this final volvelle (more so than any other) as anything more than a playful diversion from tables and theory. It offers little by way of theoretical detail in explaining its workings, and the information it seeks to calculate could be more easily found in tables or by rules of thumb. Against these views, however, must be set a wider understanding of the use of volvelles within the doctrine of the sphere - an understanding that this chapter has sought, on the whole, to shed more light upon. Though of lesser importance than the other volvelles and instruments presented in the Exercises, the tide table nonetheless served a useful, three-fold purpose.

By delivering the times of high tide, it ensured the safe passage of sailors, offering (if nothing else) another means to calculate data which might separate a successful journey from disaster. Secondly, the instrument offered the tools of mathematical certainty from within a volume more generally interested in using celestial data to improve practical endeavours. Finally, and in keeping with the circular, planar instruments detailed elsewhere, the volvelle encouraged its users to think in terms of the celestial and terrestrial relationships codified by the division of geometric forms within an overarching world-system predicated upon the form of the sphere.

\section{Conclusion: Paper Instruments and Spherical Astronomy - looking at, looking through}

Writing in 1595, a year after the first edition of Blundeville's Exercises was published, the mariner John Davis left his reader in no doubt as to the value of a geometrical understanding of the circle and sphere. All instruments related to navigation 'of what form or shape soever they be, are described or demonstrated upon a Circle, or some portion of a circle, and therefore are of the nature of a circle'. ${ }^{153}$ This remained true for John Beard, an annotator of Matthew Norwood's System of Navigation (1685), and of his practice in the first decade of the eighteenth century. Appending his signature and sailing reports to Norwood's text—itself full of tables and a volvelle of the mariner's compass-Beard made his text an egodocument and a cross-referencing tool when navigating, calculating the length of his

${ }^{153}$ John Davis, The Seamans Secrets (London: Thomas Dawson, 1595), unpaginated, f. G 5 v. 
time at sea, and judging the time spent in travelling from London outward to key shipping locations. ${ }^{154}$

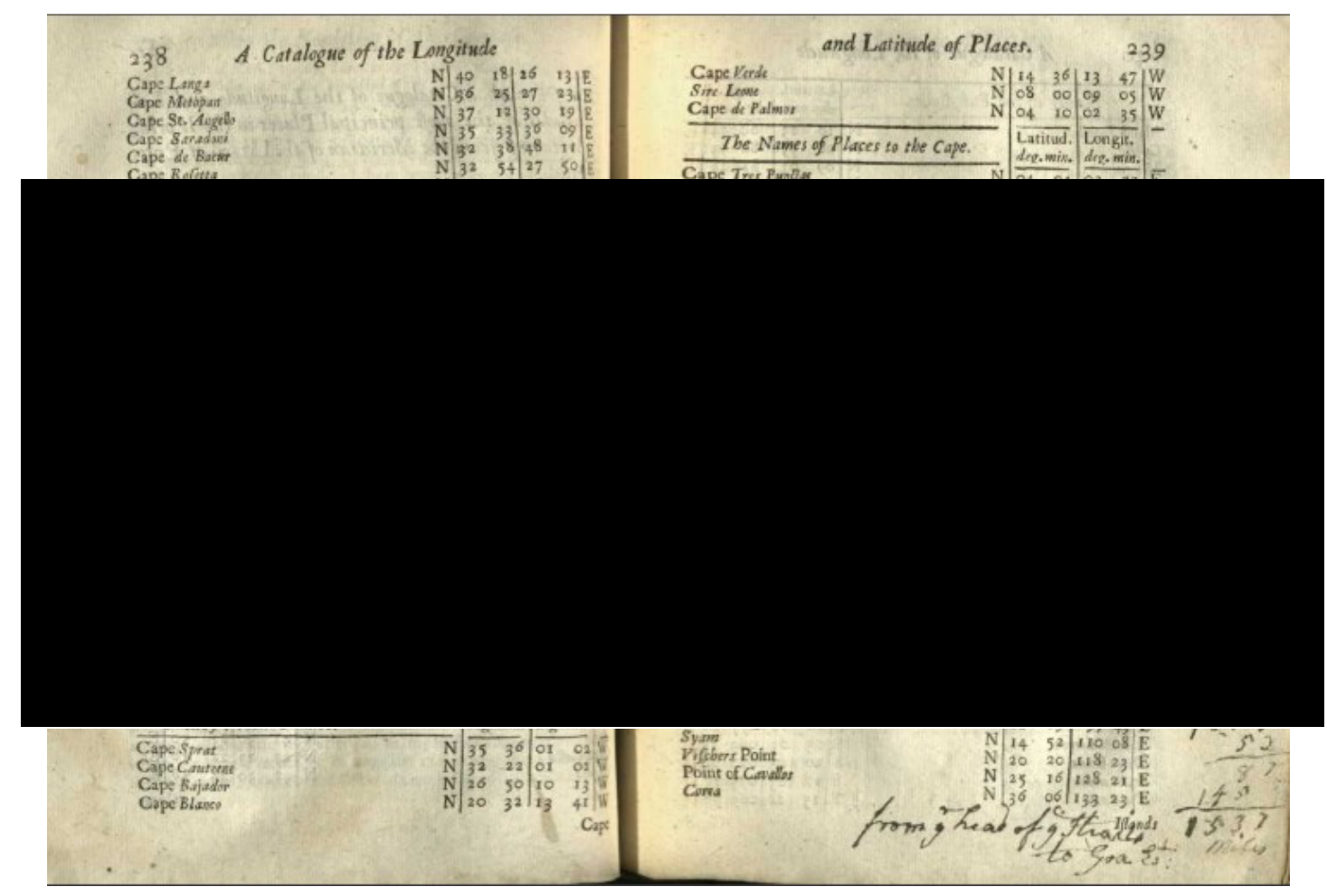

Figure 3.35. Example of navigational annotations written by John Beard found in the Science Museum Library's copy of Matthew Norwood's Norwood's System of Navigation (1685). Beard's marginalia can be dated to 1705 . Science Museum Library Shelfmark O. B. NOR NORWOOD 460784-2001.

Early modern navigational manuals, such as those written by Matthew Norwood, continued the efforts of Thomas Blundeville and his ilk. In constructing hybrid objects of text and instruments, they were geared towards mathematical readers of various stripes: to ensure the internalisation of geometrical theory applicable to practical endeavours, they followed Blundeville by presenting readers with paper tools for mathematical play, learning, problem-solving and practice. Whether read by amateur or professional, genteel or mechanic, texts such as the Exercises can be credited with inspiring significant advances in mathematical

\footnotetext{
${ }^{154}$ Matthew Norwood, Norwood's System of Navigation: teaching the whole art, in a way more familiar, easie, and practical, than hath been hitherto done (London: Printed for H Sawbridge and T Wall, 1685). Science Museum Library Shelfmark O. B. NORWOOD 460784-2001. Beard's signature can be found in the volume's front pastedown; his calculations and references to the dates of his visits to specific ports can be found occasionally between pp. 235-316.
} 
literacy through their cultural practice. ${ }^{155}$ Understood within the context of their author's membership of a coterie of sophisticated, university-educated mathematical geographers familiar with the technical and practical uses of the discipline of cosmography from continental sources, the instruments referenced in Thomas Blundeville's Exercises are nonetheless reflective of the protean doctrine of the sphere, and of the ways in which Sacrobosco's work was used by mathematicallyliterate authors to refashion mathematical practice and its recent advancements as part of a longer, coherent tradition. Depending on its user's goals, this tradition could then be put to social, profitable, national or simply leisurely ends.

\section{Blundeville's Exercises therefore comfortably meets Matteo Valleriani's} criterion of a continuous re-codifying of knowledge for practical ends within the aforementioned doctrine. The text book-ended a detailed adaptation of Sacrobosco's materials with an introductory section of arithmetic (practical and theoretical) and subsequent treatises on cosmography (to which the Sphere was foundational in the late sixteenth and early seventeenth centuries) and, more importantly, practical tools for navigation and dialling. In such light, the Exercises inhabits a similar cultural space to the works of authors such as Peter Apian and Oronce Finé, whose engagement with cosmography was itself a vehicle for the promotion of mathematical practice. ${ }^{156}$ In Blundeville's case, the cosmographical influence of Ptolemy's Geography was directed toward the education and betterment of the young learners who would take mathematics into navigational and military spheres.

Thomas Blundeville's Exercises is therefore an important text in the history of mathematics (and to the study of the use and collection of materia mathematica) for three key reasons. First of all, the materials collated by Blundeville are a reflection of best mathematical practice in a contemporary European context, manipulated into a primer of exercises for English students of the sixteenth and early seventeenth centuries: be they gentleman or mechanic, scholar or amateur. In this manner, they are indicative of both the transmission of such knowledge through

\footnotetext{
${ }^{155}$ Lesley B. Cormack, 'Glob(al) Visions', in Bronwen Wilson and Paul Yachnin, eds., Making Publics in Early Modern Europe: People, Things, Forms of Knowledge (Abingdon and New York: Routledge, 2010), pp. 138-156, p.146. Cormack suggests that the globes aided knowledge of place and the measurement of distance, and thus served partly to 'create a public that shared [personal access to globes] and an interest in the mathematical utility of these objects'.

${ }^{156}$ Mosley, 'Cosmographer's Role', pp. 427-428.
} 
printed text and instruments, and of the ways in which users at different sites of practice responded to such information. Secondly, in making his text a hybrid object of text and instrument, Blundeville used the mechanics of print to continue the manuscript legacy of the volvelle, continuing the theoretical and technological legacy of Regiomontanus in the process. Finally, in making instruments such as the globe, the nocturnal, and the compass readily available to his readership as part of a work recommending the practical exercise of mathematical theory, Blundeville encouraged the users of his work to adopt a hands-on approach to their own development as practitioners, regardless of their existing aptitudes.

Beyond the figure of the author, however, we may also conceive of the materiality of the text as relevant to its audience and to its types of use. The materiality of paper, either opaque or transparent depending on its use, played its own role in these endeavours. Simultaneously the bearer of information and a material with which a user could construct a tool, the leaves of the Exercises then became journals in which users might expand upon their text and document their practice. Rather than the transient and fragile material it is often depicted as, the high survival rate of paper in archives, texts, and instruments to the present day therefore presents us with the opportunity to identify such users and to trace their responses.

As the current chapter has shown, some of the paper tools presented in the Exercises were pedagogical instruments to introduce astronomical theory through intellectual visualisation. In other instances, they took the form of introductory iterations of physical instruments that could be bought ready-made or constructed by the user themselves to learn and to apply mathematical theory. As the annotations reporting back on this admixture of practices suggest, readers appreciated the text and its tools as hybrid instruments to be looked at as well as through: speculative material products that could help to learn and to teach, to measure, to solve problems, and to ameliorate tedious calculations. How users grappled with the paper iterations of such instruments requires further engagement on our part. The approaches we use must therefore re-engage with instruments by avoiding anachronistic attempts at reading, aestheticizing or fetishizing instruments in their many forms inside and outside of museums and library collections. ${ }^{157}$ As Ken

${ }^{157}$ Liba Taub, 'Introduction: Re-engaging with Instruments', Isis, 102.4 (2011), pp. 689-696, p. 695. 
Arnold and Thomas Söderqvist argue in their treatment of medical instruments, any such approaches will be energised by tactile experience and practical engagement (where possible) with the physical actuality of the instrument; beyond this, our engagement will only be improved by greater awareness of the cultural, imaginative and emotional values attached to these material products. ${ }^{158}$

${ }^{158}$ Ken Arnold and Thomas Söderqvist, 'Medical Instruments in Museums: Immediate Impressions and Historical Meanings', Isis, 102.4 (2011), pp. 718-729. 
Chapter Four: Hydrography, Astronomy, Chronology: Knowing, Using and Collecting Mathematics in Early Modern England

On or around December 10, 1685, one S. Jenkinson came into possession of a new edition of John Seller's A Pocket Book, containing several choice collections: in Arithmetick, Astronomy, Geometry, Surveying, Dialling, Navigation, Astrology, Geography, Measuring, Gageing, etc., stamping the octodecimo to reflect their purchase. First published in 1677, the volume was a compendium of 'useful' knowledge: mathematical and pseudo-mathematical, calendrical and mercantile, it offered its readers selections culled from a variety of the author's printed sources, intended to provide swift and somewhat trustworthy reference points for a range of occupations. Comprised of maps, tables, mathematical exempla and almanacs, the Pocket Book's contents were compressed so that the volume could be carried about as part of its owners' daily business. Made heavy with descriptive and technical annotation by Jenkinson and two later owners, this copy - today held in the Science Museum, London's Rare Books Collection - represents a unique example of late seventeenth-century English mathematical culture at discrete yet complementary sites of practice. ${ }^{1}$

The printed and manuscript contents of Jenkinson's Pocket Book plot the volume's trajectory from the busy maritime industry of early modern London to university tutorials at Oxford and Cambridge. Intersections of the production, transmission and reception of mathematical knowledge were negotiated by producers and consumers enmeshed in this vibrant intellectual culture. Found within the volume's pages, evidence of these meeting points elucidate how occupational and scholarly practices were aided by techniques which facilitated the use and collection of disciplinary information. As this chapter shows, this copy of the Pocket Book was

\footnotetext{
${ }^{1}$ John Seller, A Pocket Book, containing several choice collections: in Arithmetick, Geometry, Astronomy, Geometry, Surveying, Dialling, Navigation, Astrology, Geography, Measuring, Gageing, etc (London: John Seller, 1685), unpaginated, front-matter and title page. Science Museum Library Shelfmark O.B. SEL SELLER 30209019360995. Unless otherwise stated, the copy referred to hereafter is that of the Science Museum. This copy contains both printed and, more frequently, manuscript pagination. The numbering of the manuscript pagination is inconsistent. It initially runs from ff. 1-65; following the interpolation of the printed paginated section, running from pp. 1-40, the manuscript pagination recommences at ff. 41, running from ff. 41-166. For the avoidance of confusion, the manuscript pagination prior to the letterpress instructions will be denoted as I, followed by the page number(s), and, in similar fashion, the manuscript pagination following these instructions as II, with the page number(s) again provided.
} 
compiled as a unique paper instrument for knowing, doing, and collecting mathematics by its producer and users alike.

By 1677 the cartographer, instrument maker, and author-publisher John Seller (bap. 1630, d. 1697) had already experienced a great many of the peaks and troughs of London's maritime trade. Apprenticed to Edward Lowe of Whitechapel in 1644, Seller attained the role of Freeman in the Merchant Taylors' Company some ten years later. ${ }^{2}$ Fewer than half of early modern Britain's apprentices went on to establish their own businesses or to further apprentice others as masters: Seller, of Wapping born and bred, no doubt suffered less from the homesickness and isolation that so bedevilled his youthful indentured contemporaries. ${ }^{3}$ The artisanal nature of his role as an instrument maker was more in keeping with the Clockmakers' Company, to which Seller was later accepted, and though he remained affiliated to the Merchant Taylors throughout his career, in the last five years of his life Seller acted as a Warden of the Clockmakers. Prior to this, the erstwhile cartographic practitioner was jailed for alleged participation in a treasonous conspiracy, succeeded the respected Joseph Moxon to the role of Hydrographer to the King, and endured, by turns, alternating periods of penury and success.

It is tempting to imagine Jenkinson visiting either one of Seller's stores in 1685. Whether in the merchant's more permanent home at the Hermitage in Wapping, at the heart of a maritime community on the banks of the Thames, or his shop in Cornhill's vibrant Royal Exchange, customers could peruse the navigational charts, maps, and instruments for which the merchant was known. Advertisements published in the London Gazette, as well as in Seller's own printed works, suggested that patrons could expect to encounter a treasure-chest of mathematical materials: 'meridian compasses of all sorts and sizes'; 'cross-staves for forward and backward Observations'; 'rules for Carpenters, Gunners, and other artificers'; and, indeed, 'any

\footnotetext{
${ }^{2}$ Coolie Verner, 'John Seller and the Chart Trade in Seventeenth-Century England', in N. J. W. Thrower, ed., The Compleat Plattmaker: Essays on Chart, Map, and Globe Making in England in the Seventeenth and Eighteenth Centuries (Berkeley, Los Angeles, and London: University of California Press, 1978), pp. 127-158, particularly pp. 132-133.

${ }^{3}$ Chris Minns and Patrick Wallis, 'Rules and Reality: Quantifying the Practice of Apprenticeship in early modern England', Economic History Review, 65.2 (2012) pp. 556-579, p. 557. Further detail on map-making 'schools' and Seller's contemporaries can be found in Helen Wallis, 'Navigators and Mathematical Practitioners in Samuel Pepys' Day: The Eva G. R. Taylor Lecture', Journal of Navigation, 47.1, (1994), pp. 1-19, p.3.
} 
other Mathematical Instrument whatsoever'. Under 'Books', Seller listed three works of his own; one each by Thomas Street and John Brown; and, in an echo of his instrument collections, 'any other belonging to the Mathematicks'. ${ }^{4}$ A friend to naval officers and commoners alike, outright purchase was not mandatory. Books and charts were sourced for valued customers, and evidence exists of loan arrangements with patrons including Samuel Pepys. ${ }^{5}$

Stores like Seller's were filled with the inscribed materiality of early modern scientific and mathematical practice. Imprinted with numerical data, finished products of brass, wood and paper were sold on the basis of their functionality to an ever-growing market, and further layers of inscriptions exist beyond publishers' initial imprints. The examples of provenance information and marginalia found within the Science Museum's copy of the Pocket Book - the constructed bookplate of Edm(und) Withers dated October 23, 1692, and the title-page signature pertaining to Tho(mas) Withers, which accompany the marks of Jenkinson-encourage further explorations of early modern printed books as instrumental compendia, and objects for knowing and doing (Figure 4.1). ${ }^{6}$

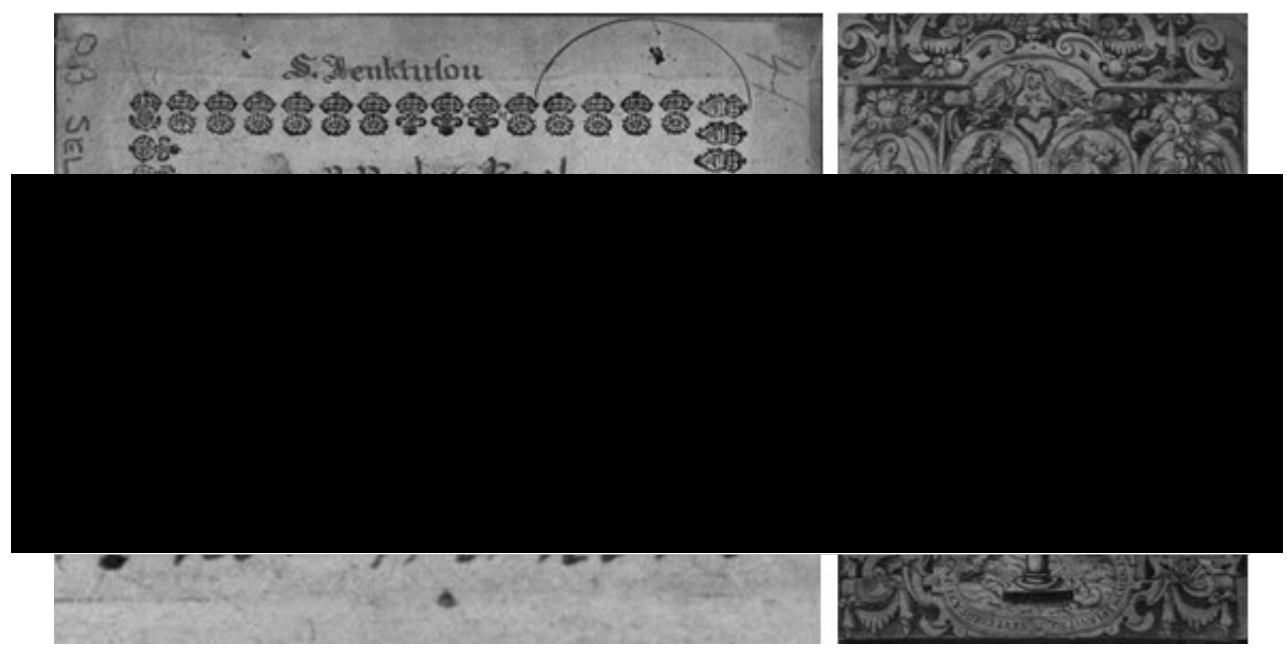

Figure 4.1. Composite image of provenance data from Seller's Pocket Book, belonging to (clockwise from left) S. Jenkinson, Edm. Withers, and Tho. Withers. Science Museum Library Shelfmark O. B. SEL SELLER 30209019360995.

\footnotetext{
${ }^{4}$ John Seller, The English Pilot (London: John Seller, 1671), p. 124.

${ }^{5}$ Natasha Glaisyer, The Culture of Commerce in England, 1660-1720 (Woodbridge: The Royal Historical Society and The Boydell Press, 2006), pp. 51-53. Kate Loveman, Samuel Pepys and his Books: Reading, Newsgathering, and Sociability, 1660-1703 (Oxford: Oxford University Press, 2015), p. 184.

${ }^{6}$ Seller, Pocket Book, front-matter and title page. Science Museum Library Shelfmark O. B. SEL SELLER 30209019360995.
} 
Amended so that it became a unique and personal compendium, this 1685 edition was arranged in a very different fashion to alternative versions: ${ }^{7}$ indeed, it is evidence of both its producer's and owners' attempts to create something of real utility. Bound in the weak, undecorated leather on thin pulp boards common to late seventeenth-century volumes of a similar cost, the volume is ordered so as to imply that the text was taken away loose-leaved, and bound thereafter. A paginated, letterpress section of instructions was placed en bloc at the middle of the book, rather than to the front as is more frequently found in other copies. Either side of these paginated instructions are a series of prints reproduced from engraved copperplates, around which indented 'plate-marks' are often clearly visible. ${ }^{8}$ The idiosyncratic (and, perhaps, bespoke) collation of this copy of the Pocket Book suggests that the work frequently took the form of a malleable construction: one that was intended to be ordered, supplemented, amended, and worked through according to an owner's wishes from the outset.

The 'choice collections' offered by the merchant were situated within a wider intellectual culture, wherein excerpting literary and educative copia as a means to access and understand a 'core body of knowledge' was a key learning strategy. ${ }^{9}$ To the blank spaces on the versos of its copperplate prints, users of this copy of the Pocket Book then assembled a wide range of calendrical and technical data in manuscript. Yet it should be noted that the spaces utilised for annotation existed, initially, a consequence of John Seller's printing and production practices - namely, his choice to utilise copperplate engravings to construct pocket-sized companions filled with visual and textual information. The presence of this annotation helps to further destabilise the idea of the printed text as fixed and inviolable; instead, with its

\footnotetext{
${ }^{7}$ Although I have to date been unable to undertake a systematic census of extant copies of Seller's Pocket Book, I have yet to see two examples presenting precisely the same contents in the same order. ${ }^{8}$ David Woodward, 'Techniques of Map Engraving, Printing, and Coloring in the European Renaissance', in David Woodward, ed., The History of Cartography, Volume Three: Cartography in the European Renaissance, Part One (Chicago: University of Chicago Press, 2007), pp. 591-610, p. 594.

${ }^{9}$ Kevin Joel Berland, Jan Kirsten Gillam, and Kenneth A. Lockridge, eds., The Commonplace Book of William Byrd II of Westover (Chapel Hill: Omohundro Institute of Early American History and Culture by the University of North Carolina Press, 2001), p. 30. Heidi Brayman Hackel has built on the work of Roger E. Stoddard and William H. Sherman to propose three 'classes' of reading and subsequently marking books: of these, marks of 'active reading. (which) (...) suggest that the book is to be engaged, digested, and re-read' are most applicable to this copy of Seller's Pocket Book. Heidi Brayman Hackel, Reading Material in Early Modern England: Print, Gender, and Literacy (Cambridge: Cambridge University Press, 2005), particularly p. 138.
} 
contents perhaps decided in conjunction with the purchaser and its blank spaces subsequently filled with additional information, the Science Museum's copy of the Pocket Book encourages us to consider the roles of both producers and users as active collaborators in the text's material construction.

Seen from this perspective, the author-publisher's identity and credibility as a mathematical practitioner was to a degree subverted by each manuscript example of reading, learning, using, and collecting. The original text, altered and improved by the deposit of supplementary materials, thus became a negotiated space where fixed type and printed images were utilised, overwritten, amended, and improved upon. ${ }^{10}$ The material features of this copy of the Pocket Book therefore complicate any ideas of fixity and authority that we may wish to attribute to scientific and mathematical texts. Mixing print, manuscript and practice, its physical properties serve to alter the distance between a reader or buyer of the text and the text itself, though perhaps not in the manner intended by Henry E. Lowood and Robin E. Rider. ${ }^{11}$ With the subtleties of this remarkable example in mind, the current chapter first explores the culture in which Seller's volume was produced, before turning to the annotation and use of the Science Museum's unique copy.

\section{The Idea of the Mathematical Pocket Book}

Acknowledging the breadth of the market he wished to draw commerce from, Walter Hayes's ca. 1670 advertisement was duly catholic in its appeal to customers. Rather than directly listing his wares as later examples of the genre would, Hayes instead promised as many mathematical materials as a buyer might be able to imagine:

If any Gentleman studious in the Mathematicks have, or shal have occasion for Instruments thereunto belonging, or Books to shew the use of them, they may be furnished with all sorts, usefull both for Sea or Land, either in Silver, Brass, or Wood (...) they may have all sorts of Maps, Globes, Sea-Platts, and Mathematical Paper, Carpenters Rules, Post and Pocket-Dyals for any

\footnotetext{
${ }^{10}$ Johns, Nature of the Book, p. 36.

${ }^{11}$ Henry E. Lowood and Robin E. Rider, 'The Scientific Book as a Cultural and Bibliographical Object' in Andrew Hunter, ed., Thornton and Tully's Scientific Books, Libraries, and Collectors: A Study of Bibliography and the Book Trade in Relation to the History of Science, $4^{\text {th }}$ edn (Aldershot: Ashgate, 2000), pp. 1-25, p. 19.
} 
latitude, Steel Letters, Figures, Signs, Planets, or Aspects, at reasonable rates. ${ }^{12}$

Hayes's mathematical store was intended to serve a broad church. In keeping with his contemporaries, the merchant saw no need to limit his market to the adept: for many in seventeenth-century England, mathematical ability was desired almost entirely on the grounds of utility, with practitioners, the gentry, students, and the common man all possible clients. Arithmetic, or, for that matter, basic numeracy, went neglected or untaught for many petty school pupils; grammar schools, in their turn, did little to pick up the slack, their curricula drawing instead from literary and rhetorical sources to best prepare young charges for university. ${ }^{13}$

It was in such a climate that earlier texts such as John Johnson's Iohnson's Arithmatick, in Two Bookes (1623) had held promise for literate, if not numerate, workers. Paraphrasing the 'Gentlemen, Merchants, and others of my very loving friends' who encouraged and abetted his endeavours, Johnson's dedicatory epistle to Sir Edward Barksham, Lord Mayor of the City of London, advised that arithmetic was to be freed from the 'Professors of Mathematick Sciences', and gifted instead to the Freemen of the City 'to the use and behoofe of those persons' so that they may be made yet freer still. ${ }^{14}$

Despite the incontestable worth of such a programme Johnson, a surveyor by trade and creator of annual almanacs between at least 1611 and 1625, conceded that the difficulties of arithmetic might yet leave his readership in some doubt as to its greater value. His own ability to summarise the key parts of his subject had been won only through 'long experience' and 'tedious studies': turning to his reader, the author confided with admirable tactlessness that his arithmetical labours were largely designed to produce a work of 'the most briefe, plaine, and easie manner that I could fit for the understanding of the weakest and meanest capacitie. ${ }^{25}$ This supposed brevity resulted in a 368-page duodecimo filled to the brim with problems, tables,

\footnotetext{
${ }^{12}$ Walter Hayes, Trade card (London: Walter Hayes, at the Crosse Daggers in Moore Fields, next door to the Popes-head Tavern, Bethlem Gate, 1680). Science Museum Collection, Object 1934$121 / 55$.

${ }^{13}$ Keith Thomas, 'Numeracy in Early Modern England: The Prothero Lecture', Transactions of the Royal Historical Society, 37 (1987), pp. 103-132, p. 109.

${ }^{14}$ John Johnson, Iohnson's Arithmatick in Two Bookes (London: Augustine Matthews, 1623) ff. a va $2 \mathrm{v}$.

${ }^{15}$ Johnson, ibid, f. a 3 r.
} 
and measures for the studious purchaser to grapple with. Apologising for the lack of arithmetical material on shot-weight and gunnery, the author conceded that these additional sections would have increased the volume's size (and likely cost) far beyond that of the average pocket. ${ }^{16}$

The popularity of Johnson's work can be measured in part by the fact that, at the publication of John Seller's Pocket Book in 1677, it had reached its ninth edition. Almanacs and books of religious computation in compact octavo and duodecimo formats were by this time familiar companions to a wide variety of early modern readers. ${ }^{17}$ As the output of many seventeenth-century English stationers testified, there existed a growing demand for more portable, and, crucially, more affordable technical titles printed in the vernacular. Guides like those produced by Johnson and Seller were advertised, and stood or fell, largely upon the basis of their easy utility, instructiveness, and convenience. It should be noted that the value of each of these factors could be long-lived. ${ }^{18}$ Promoted as accompanying advisors, portable books and their attendant instruments were often kept about a merchant, clerk, draughtsman or navigator's body, ready to reckon measurements, to solve problems, or to provide guidance whenever consulted; in short, to be ready to hand, and studied for action. A large number of these objects offered shortcuts to the novice, promising to make any number of complex disciplines - trigonometry, surveying, or gauging, to name a few-unfold simply, and at the reader's behest. ${ }^{19}$

\footnotetext{
${ }^{16}$ Johnson, ibid, f. a 4 v.

${ }^{17}$ Bernard Capp, Astrology and the Popular Press: English Almanacs 1500-1800 (London: Faber, 1979), p. 23; Keith Thomas, Religion and the Decline of Magic: Studies in Popular Beliefs in Sixteenth and Seventeenth Century England (Oxford: Oxford University Press, 1971), pp. 348-349. ${ }^{18}$ Natasha Glaisyer, 'Calculating Credibility: Print Culture, Trust and Economic Figures in Early Eighteenth-Century England', The Economic History Review, New Series, 60.4 (2007), pp. 685-711, p. 699.

${ }^{19}$ It is beyond the scope of the current chapter to outline a more complete history of the mathematical pocket-book and its users; however, a handful of example duodecimos such as John Martyn's posthumously published Mensuration made Easie: or, The way of measuring all solid and regular bodies, as of timber, stone, glass, \&c. Useful for surveyors of land, carpenters, joyners, glasiers, freemasons, plaisterers; and all other ingenious persons. Digested into a familiar tabular form, fitting the meanest, as well as the most pregnant capacities (London: James Cottrell, 1661); James Hodder, Hodder's Decimal Arithmetick: or, A plain and more methodical way of teaching the said art (London: Thomas Rooks, 1668); Jonas Moore, A Mathematical Compendium; or, Useful practices in arithmetick, geometry, and astronomy, geography and navigation, embattelling, and quartering of armies, fortification and gunnery, gauging and dialling (London: Printed for Robert Hardford, 1681) may help to partially highlight this popular genre.
} 
Previously, vernacular mathematical textbooks printed in quarto for the private study or classroom had encouraged consumers to build their understanding in a manner akin to the pedagogic methods favoured by schoolmasters. Encouraging his audience to build their intellectual castles from textual foundations upward, Robert Recorde's Pathway to Knowledg (1551) charged readers to elevate their understanding of the mathematical disciplines by reading, writing, and remembering: they were to 'practise their pennes, their eloquence to aduance, to register their names in the booke of memorie (...) whereon thei maie builde', and 'fashion them selves' by dint of Recorde's 'glimsinge dull light' ${ }^{20}$ Others decreed that the true worth of mathematics lay most in its practical application - albeit, an application similarly undertaken after periods of intense reading, study, and meditation.

Listing as many mathematical roles and their related tasks as he could think of, Arthur Hopton assailed the 'mathematical practizer' toward whom his Speculum Topographicum, or the Topographicall Glasse (1611) was intended, haranguing readers not to copy those 'plaine men' who, by lifting an instrument, 'presume they bee Geometritians' ${ }^{21}$ Hopton instead advised that true ability would be acquired by those willing to immerse themselves in theory and practice equally: such would-be mathematical practitioners were to 'learn by contemplation, to frame his proposition, and by action manage his instruments (...) (f)or as meditation causeth ability to understand, so action bringeth dexterity to performe'. ${ }^{22}$ In an often vituperative introductory epistle the author acidly observed that those who remained ignorant to such advice were akin to a horse who completes a journey 'though he be long and lame in performing it': the nag, he suggested, forever undeserving of the sobriquet 'Bucephalus'. ${ }^{23}$

Arthur Hopton's demand that learners meditated upon and thereby truly understood the mathematical elements of their work nevertheless cuts against the grain of the many volumes offering speedy workarounds for the practical man. It was perhaps his anger at seeing instruments and texts used improperly (their operators'

${ }^{20}$ Robert Recorde, The Pathway to Knowledg (London: Reynold Wolfe, 1551), f. g ii v.

${ }^{21}$ Arthur Hopton, Speculum Topographicum, or the Topographicall Glasse (London: Simon

Waterson, 1611), f. a $4 \mathrm{r}$.

${ }^{22}$ Hopton, ibid, f. a $2 \mathrm{r}$.

${ }^{23}$ Hopton, ibid. 
shoddy practices attacked in detail in the introduction to the Speculum Topographicum) that so stridently moved his pen. Unsurprisingly, variations on this theme recurred. For a growing number of mathematically-able writers, readers were to be guided into disciplinary rigour by the correct exercise of mental and practical dexterity. Arguments concerning correct practice went oft-rehearsed by the would-be authorities of mid-seventeenth century England, and, once again, the humble pocket book played its part.

In his correspondence with the intelligencer Samuel Hartlib (ca. 1600-1662) in 1638, the mathematician John Pell (1611-1685) proposed a methodology by which the study of his discipline could be pared down to a series of indispensable, advisory 'means'. ${ }^{24}$ Combining a catalogue of the texts most deserving of study, a repository of these texts along with all relevant mathematical instruments yet invented, and a syllabus for the education of novice and expert alike, the letterparts of which would later be worked into Pell's published An Idea of Mathematics (1638) - has come to be seen simultaneously as a Baconian attempt at the reform and advancement of mathematical study, and also as a 'peculiarly modest' attempt to secure patronage: one made all the more so as the author's name was omitted entirely from the Idea's original broadsheet publication, appearing only twelve years later when the work was reprinted and appended to John Dury's The Reformed Librarie-Keeper (1650). ${ }^{25}$

The reforms advocated for in the pages of the Idea were plans for little less than the restructuring and reorganization of all existing mathematical knowledge, with its author suggesting that this rearrangement was to be rolled out nationally, supported by the apparatus of the state. Designed with the understanding that the initial plans for this undertaking could be entrusted to an individual (i.e., Pell himself, bashfully angling for his keep), without the need for assistants likely to drain resources or create distractions, the mathematician's proposals also featured a

\footnotetext{
${ }^{24}$ John Pell, 'An Idea of Mathematics, written by John Pell to Samuel Hartlib', in John Dury, The Reformed Librarie-Keeper with a Supplement to the Reformed-School (London: William Du-Gard, 1650), p. 33. This text was translated from the original Latin letter of Pell to Hartlib, dated 23 July 1638, and published as a folio broadsheet without a title, author, or publication place in 1638.

${ }^{25}$ Noel Malcolm, 'The Publications of John Pell, F.R.S.: Some New Light and Some Old Conclusions', Notes and Records of the Royal Society, 54.3 (2000), pp. 275-292; particularly pp. 280281.
} 
series of new works: the Consiliarius Mathematicus, a general, historical compendium of mathematics, introducing the subject and encouraging its practice;

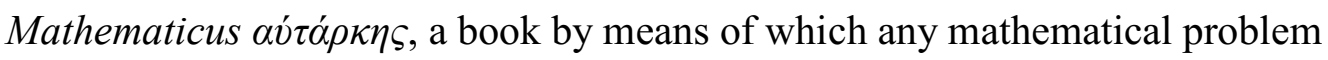
might be resolved from first principles; and Comes Mathematicus, a pocket-book of tables and their precepts, from which might be gleaned the ability to swiftly reference and resolve any number of practical problems. ${ }^{26}$

It might appear ironic that Pell sought to overcome the pestilent surfeit of books by producing more books, but the mathematician's ideal vade mecums were intended to release their users from the early modern multitude of texts. Pell's pedagogical goal in this enterprise was to ensure that the mathematical novice would no longer 'be tied to bookes', but might instead be able to consult a singular example 'exactly as if he had a complete Library by him'. ${ }^{27}$ In this manner the author should be viewed no differently to the many humanist reformers preaching educational overhauls in the period. In his reforms, Pell ultimately sought to enable his readers to internalise key mathematical principles: firstly, by condensing a storehouse of mathematical material into modes allowing for ready use; and, thereafter, by encouraging the reader to construct a kind of mathematical memory palace which was underpinned not by rote learning but rather by way of mental organisation. When fully internalised, this schema would enable the user to truly think mathematically, thus enabling them to solve any problem they might encounter via the methodological application of mathematical heuristics. ${ }^{28}$

Comes Mathematicus, John Pell's initial plan for this pocket book, was expressly tabular. It was intended to marry only the data considered most useful (by Pell) to its required theoretical precepts. As Noel Malcolm has convincingly shown, the work's initial form preceded its appearance as part of this group of mathematical texts. Malcolm reads the proposal as a 'self-sufficient' project, and one that we should decouple from Pell's future, all-encompassing interests in pedagogical

\footnotetext{
${ }^{26}$ Noel Malcolm and Jacqueline Stedall, John Pell (1611-1685) and his Correspondence with Sir Charles Cavendish: The Mental World of an Early Modern Mathematician, pp. 265-268.

${ }^{27}$ Pell, 'Idea of Mathematics', p. 40.

${ }^{28}$ Yeo, Notebooks, English Virtuosi, and Early Modern Science, p. 127. Yeo notes that Samuel Hartlib praised similar efforts for teaching reading designed by John Brook in 1635, as well as Nicolaus Mercator's 1655 advice on astronomical mnemonics for the recall of tables without texts.
} 
structures and systems. ${ }^{29}$ Predating the publication of Pell's Idea of Mathematics (1638) itself, Comes Mathematicus was first described to Hartlib in September 1635:

The Mathematicall booke which I wrote of I have for some reasons determined to make greater [...]The title thus Comes Mathematicus or the Mathematicians pocket booke Containing a briefe collection of all such tables as are requisite for ye exact $\&$ easy solution of any Mathematicall question in ordinary practise, With ye uses of [...] said Tables in Arithmetic, Geometry, Staticks; Optics Geodesy Geography. Astronomy. Navigation. Architecture. Fortification. $^{30}$

The mathematician's acknowledgement of the materials most applicable to 'ordinary practice' highlights the proposed use-value of this text. Consisting of tables for the calculation of problems across a number of inter-related fields, each underpinned by elements of mathematical theory, the Comes Mathematicus could have become an indispensable tool for thousands of workers in Stuart England: its tables and precepts a means by which the common English understanding of mathematics could be encouraged, and greatly improved.

As with so many attempted reforms of the seventeenth century, John Pell's dream ultimately went unfulfilled, his project for a Baconian mathematics unrealised. Comes Mathematicus, arguably the easiest element of the project to produce, remained unwritten: the rich merchants, due to a 'dulness' of mind, having refused to back it. ${ }^{31}$ But the failure to bring such an idealised text to market should not mask the fact that many iterations of the mathematical pocket book had already achieved a widespread popularity in seventeenth-century England. Nor should it go unrecognised that such texts were being used as objects containing immediately referenceable data, and, simultaneously, as the means by which some of the precepts behind such data might be auto-didactically internalised. As John Seller undoubtedly recognised in 1677, there remained space in the market for a compendium at first glance both occupational and scholarly - one combining useful as well as popular practices, incorporating mensuration, assize-weights, medico-astrological and calendrical data with dialing, navigational mathematics, and the study and use of the

\footnotetext{
${ }^{29}$ Malcolm and Stedall, John Pell, p. 266.

${ }^{30}$ London, British Library. John Pell, Pell Papers, $4^{\text {th }}$ Series. MS Add. 4425, f. 68 r.

${ }^{31}$ Taken from Pell's manuscript notes, London, British Library. John Pell, Pell Papers, ibid. MS Add. 4408, f. 30 r.; quoted in Malcolm and Stedall, John Pell, p. 266.
} 
terrestrial and celestial globes. As a proprietor stocking a wide range of mathematical and mathematically-adjacent materials, the practitioner could even supplant his rivals by offering customers bespoke compilations tailored to their needs.

If to use a book is to engage with it as a set of (material) forms and as a condition of thought, as Carla Mazzio and Bradin Cormack have postulated, ${ }^{32}$ then the use of such pocket books and their attendant instruments in early modern mathematical culture must be explored within the particular constraints of not only the early modern period's reading practices, but also the material and intellectual conditions particular to the producers and consumers of scientific and mathematical practices in that period. As the annotations present in the Science Museum's copy of John Seller's Pocket Book show (Figure 4.2), early modern active readers saw the empty spaces of mathematical books as opportunities to engage with a number of interpretative strategies. ${ }^{33}$

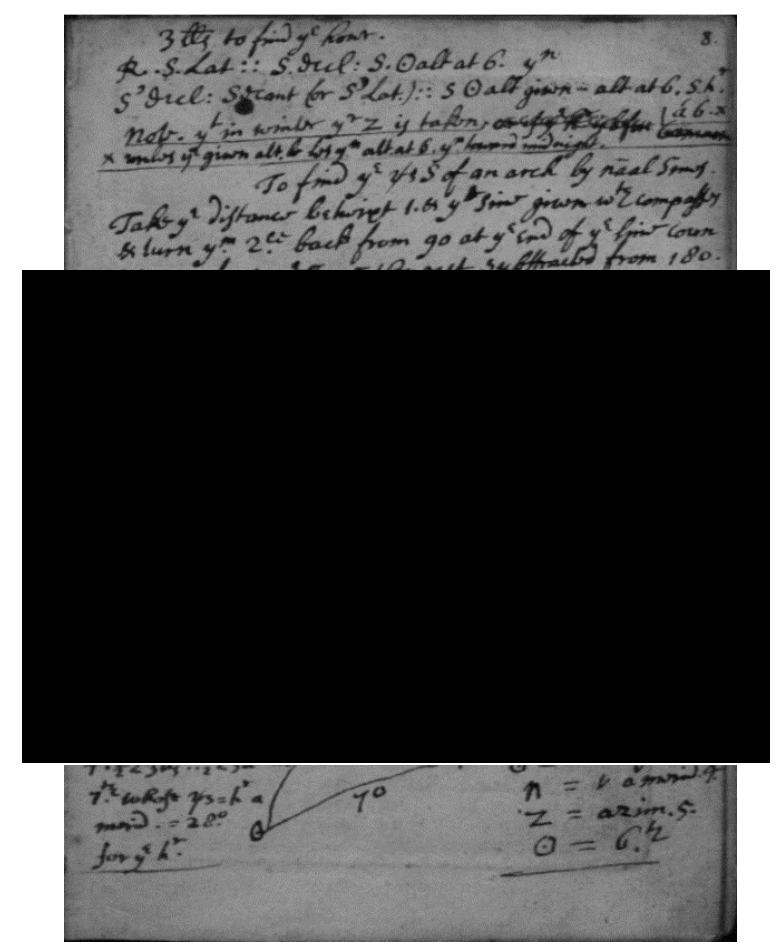

Figure 4.2. Excerpt of a user's trigonometric annotation from the Science Museum Library's copy of John Seller's Pocket Book (1685). Science Museum Library Shelfmark O. B. SEL SELLER 30209019360995.

\footnotetext{
${ }^{32}$ Carla Mazzio and Bradin Cormack, Book Use, Book Theory, 1500-1700 (Chicago: University of Chicago Press, 2005), p. 4.

${ }^{33}$ Seller, Pocket Book, unpaginated, manuscript annotation I: f. 8. Science Museum Library Shelfmark O. B. SEL SELLER 30209019360995.
} 
To fully explore the porous boundaries of print, manuscript, and mathematical practice, it is helpful to begin by first of all considering the career and products of the authors who served the mathematical market. Once we have gained a more thorough understanding of figures such as Seller, it will be possible to better explore the uses these materials were put to; as well as by whom, and what for.

\section{John Seller: The (in)Compleat Plattmaker}

Painted by some existing scholarship as not simply mathematically ignorant but malevolently dangerous in his poorly-hidden plagiarism, John Seller is often derided as an opportunistic hack: a merchant readily prepared, in one such famous argument, to endanger his consumers by selling incorrect and out-of-date navigational charts. ${ }^{34}$ More generous appraisals commend Seller for his perspicacity in helping to kickstart England's indigenous cartographic industry even as they demur on the finer points of his abilities. ${ }^{35}$ In his own time, opinions on Seller were equally divided. On the one hand, he was identified by Samuel Pepys as the first draughtsman of English maps, freeing the country and her mariners from their reliance on mainly Dutch materials and expertise; on the other, Pepys noted with equanimity the mutterings querying the exact nature of Seller's royal patronage. ${ }^{36}$ By the end of his career the practitioner's tendency toward plagiarism and his 'refreshing' of Dutch and English plates was common knowledge, and had long been a topic for discussion amongst peers such as Pepys, Jonas Moore, and the naval engineer Thomas Phillips:

[Phillips] at sea examined and showed me how Seller's book in 1668 was the very same Platts with the Dutch without a Dutch word so much as turned into English, much less anything in the maps altered. He says he knows it to be true and Seller will not deny it, that he bought the old Dutch coper plates, had them refreshed and has used them in his pretended new book. ${ }^{37}$

\footnotetext{
${ }^{34}$ Verner, 'Seller and the Chart Trade', p. 156.

${ }^{35}$ Phillip E. Steinberg, 'Calculating Similitude and Difference: John Seller and the 'Placing' of English Subjects in a Global Community of Nations', Social and Cultural Geography, 7.5 (2006), pp. 687-707, p. 689.

${ }^{36}$ Coolie Verner, 'Engraved Title Plates for the Folio Atlases of John Seller' in Helen Wallis and Sarah Tyacke, eds., My Head is a Map: Essays and Memoirs in honour of R. V. Tooley (London: Francis Edwards and Carta Press, 1973), pp. 21-52, p. 50. Verner, so often a harsh critic of Seller, diplomatically opines that such links 'cannot readily be explained'.

${ }^{37}$ Edwin Chappell, ed., The Tangier Papers of Samuel Pepys (London: Publications of the Navy Records Society, 1935), p. 107.
} 
Released after serving a brief sentence for his dubious participation in a treasonous gun-running conspiracy in 1663 , Seller had at first returned to his artisanal roots making and selling nautical compasses. It was in this guise that he corresponded with Robert Hooke, responding to two magnetical queries posed in the Philosophical Transactions of March $1667,{ }^{38}$ and his forays into compass-making and book-publishing garnered success soon after. As of 1672, the merchant was contracted to supply the Navy with instruments and glasses; meanwhile, his first forays into book-publishing met with notable success. His detailed tutor to the seaman, Practical Navigation, or an Introduction to that Whole Art (1669), proved extremely popular, and remained in print more than fifty years later. ${ }^{39}$ In keeping with John Seller's modus operandi, however, the text was almost entirely the product of another's labour, with significant portions taken from the expert Flemish practitioner Michiel Coignet's Instruction nouvelle des points plus excellents et necessaires, touchant l'art de naviguer (1581). Coignet's volume had already been repackaged (albeit with appropriate citation) for an English audience in Thomas Blundeville's Exercises in Sixe Treatises (1594). As the previous chapter of this thesis has shown, Blundeville's work was widely appreciated - particularly at the Inns of Court - and went through eight editions between 1594 and 1636, and was undoubtedly familiar to Seller and his contemporaries.

Despite (or perhaps because of) its clear similarities to the works of Coignet and Blundeville, it is easy to see why Practical Navigation sold well. The text offered a basic introduction to Euclidean geometry, defined essential trigonometric terms and their value to the doctrine of the sphere, and utilised the precepts of both in astronomical practice in plain language. Rudimentary in many places, the work still managed to impress upon readers the importance of its contents to nautical practice without an unnecessary didacticism. Often exhorting the reader to remember well mnemonic verses relevant to navigation, and drawing the attention to expeditious tables alongside gradually more complex geometrical and trigonometrical set-pieces, it is by no means difficult to imagine both the novice

\footnotetext{
${ }^{38}$ For the initial queries, see Robert Hooke, 'Some Observables about Lode-Stones and Compasses,' Philosophical Transactions, 23 (1667), pp. 423-424. For Seller's (erroneous) response, see John Seller, 'An Answer to some Magnetical Inquiries,' Philosophical Transactions, 26 (1667), pp. 478479.

${ }^{39}$ John Davis and Christopher Daniel, 'John Seller: Instrument Maker and Plagiarist,' Bulletin of the Scientific Instrument Society, 102 (2009), pp. 6-10, p. 6.
} 
sailor or gentlemanly scholar of the late-seventeenth century as grateful for its author's efforts. $^{40}$

Enjoying the patronage of Sir Nicholas Millet and, later, James, Duke of York, Seller was granted a royal privilege and the title of Hydrographer to the King in quick succession in March 1671. Succeeding Joseph Moxon in this role was no small task. Following his time in Holland in mid-century, Seller's illustrious predecessor had become a cornerstone of the English market for maps, charts, and terrestrial and celestial globes. Using this expertise to move into the publication of scientific and mathematical texts, Moxon's first offering not only reflected his cosmographical interests but was also something of an homage to Willem Janszoon Blaeu, being as it was a translation of the latter's Institutio astronomica (1634), published under the title of A Tutor to Astronomy and Geography (1654). Moxon was so enamoured of the title that he reused it twice more for later, if distinct, works. $^{41}$

Impressed by the technical and mechanical abilities of Blaeu and, even more so, Tycho Brahe, Moxon fashioned himself through his printed works as an authoritative manipulator of both theory and practice; his popular mathematical tracts including Mechanick Dialling (1668), Practical Perspective, or Perspective made Easie (1670), and a compendious Mathematics made Easie, or, A Mathematical Dictionary (1679). Previous endeavours in publishing the works of a variety of mathematicians ensured that his petition to be granted the role of Hydrographer, approved in 1662 by Charles II, was signed by two Professors of Gresham College: Lawrence Rooke, Professor of Geometry; and Walter Pope, by this time Rooke's successor to the astronomy professorship. Others with a professional interest in the mathematical sciences and their application, such as Jonas Moore, Henry Bond, and Euclid Speidell, also acted as signatories to the petition on Moxon's behalf. ${ }^{42}$

\footnotetext{
${ }^{40}$ Steinberg, 'Calculating Similitude and Difference', p. 689.

${ }^{41}$ Johns, Nature of the Book, pp. 84-85; Russell, 'Copernican System in Great Britain', p. 224.

${ }^{42}$ Graham Jagger, 'Joseph Moxon, F. R. S., and the Royal Society', Notes and Records of the Royal Society, 49.2 (1995), pp. 193-208; particularly pp. 195-197.
} 
Inhabiting a similar sociocultural sphere to Moxon, Jonas Moore, and Samuel Pepys, John Seller's enterprising nature led him to construct and sell the nautical instruments, maps and books upon which his business and fame grew following the Restoration. If the circumstances behind Seller's successful privilege remain murky, his subsequent map-making adventures have been used by historians more often than not to characterise him as an architect of excitable and incomplete grand schemes: one lacking the mathematical knowledge and the economic nous to see his plans through to completion. ${ }^{43}$

Ultimately, these judgements have served to mask his periods of success and popularity as an instrument maker and trader; furthermore, they obfuscate the financial cliff-edge many early modern merchants lived on. ${ }^{44}$ As Sarah Tyacke's study of the London map trade between 1650 and 1710 has amply shown, this field was particularly crowded between 1672 and 1685 . The popularity of maps and related instruments rose in direct correlation with periods of military activity; ${ }^{45}$ it is easy, therefore, to understand why the appellation of Royal Hydrographer might be profitable and sought-after. Whenever the characters or the outputs of Joseph Moxon and John Seller are juxtaposed, the latter suffers more often than not. Yet the two share many similarities; as an impressed correspondent, one 'observing person in the country', wrote in praise of the cultural impact of the Philosophical Transactions:

[N]ow Mr. Moxon, Mr. Seller, Mr. Green, Mr. Morden, and others are abundantly furnished with Sea-plots for all Navigations, Projections, Mathematical Books and Mathematical Instruments for all occasions of Travellers by Sea or Land. Neither Anarchasis, nor Democritus, Pythagoras, nor Apollonius Thyaneus could boast of such furniture for their Philosophical peregrinations. ${ }^{46}$

\footnotetext{
${ }^{43}$ Verner, 'Seller and the Chart Trade', pp. 102-103 and pp. 142-143.

${ }^{44}$ Sarah Tyacke, 'Map-Sellers and the London Map Trade, 1650-1710' in Helen Wallis and Sarah Tyacke, eds., My Head is a Map: Essays and Memoirs in honour of R. V. Tooley (London: Francis Edwards and Carta Press, 1973), pp.63-80, p. 77. Tyacke notes that, of the many mapmaking firms established in the late-seventeenth-century, precious few remained in business by the $1720 \mathrm{~s}$. Natural causes and financial insecurity can account for a number of these closures; alternative causes, however, remain obscure.

${ }^{45}$ Tyacke, ibid, p. 64. For additional information on map-selling and military activity, see also Jonathan Scott, When the Waves Ruled Britannia: Geography and Political Identities, 1500-1800 (Cambridge: Cambridge University Press, 2011), p. 5.

${ }^{46}$ Anon. 'Some Considerations of an Observing Person in the Country upon Numb. 133 of these Tracts, sent in a Letter to the Publisher of May 2, 1677,' Philosophical Transactions, 136 (1677), pp. 890-891.
} 
Perhaps framing Joseph Moxon as the archetype he himself so wished to be, John Seller cultivated peers in mathematical professions. At times, he worked to ingratiate himself with the nascent Royal Society, as Moxon had done to such great effect. The erstwhile merchant remained well-connected to mathematical networks at home and abroad, and can be seen acting as a steward of a London Mathematical Society in 1681, issuing dinner invitations to John Pell on behalf of the mathematical intelligencer John Collins; ${ }^{47}$ in 1699, perhaps unaware of Seller's passing two years before, the Paris-based mathematician Michael Butterfield (1634/5-1724) wrote to the physician, naturalist and fellow of the Royal Society Martin Lister (1639-1712) to request details of Seller so that he might provide profitable news of mathematical inventions from the continent. ${ }^{48}$

Coupled with his earlier successes in map-making, the popularity of Practical Navigation and other publications spurred John Seller's commercial expansion. Regrettably, this endeavour must be judged as one of the merchant's many attempts to reach beyond his grasp. By 1677, having significantly overestimated his ability to produce the grand nautical charts that would enshrine his primacy in the cartographic market, Seller was required to go into partnership with John Thornton, a chart maker, William Fisher, a publisher, and two teachers of mathematics in order to stay afloat: an endeavour ultimately not to his benefit. ${ }^{49}$ The early days of 1681 saw Seller once again reduced to the proprietor of a single shop in Wapping, separated from the aforementioned group and duly divested of the sole ownership of a number of nautical plates and stock. Rather than rolling out the impressive and imposing atlases he had imagined, Seller instead shrank his materials to fit a smaller purse, producing pocket-sized cartographical and mathematical texts to shore up his income. It was in this period that he began to produce various editions of miniaturised books compiled from larger materials previously utilised for the grand designs constituting Atlas Maritimus (1672) and Atlas Caelestis (1677).

\footnotetext{
${ }^{47}$ London, British Library. John Pell, Pell Papers, $3^{\text {rd }}$ Series. MS Add. 4398, f. 147 r. I am grateful to Philip Beeley for bringing this invitation to my attention.

${ }^{48}$ See Butterfield, Michael, to Lister, Martin, 28 December 1699, MS Lister 3, 066-068, Bodleian Library, University of Oxford. Image consulted on Early Modern Letters Online, Cultures of Knowledge, tinyurl.com/d4b373y, accessed 20 February 2017.

${ }^{49}$ Verner, 'Engraved Title Plates for the Folio Atlases of John Seller', p. 23.
} 
Examples of Seller's habitual plagiarism remain consistent throughout his career and dog historical analysis of his practices, and cannot be drawn into focus simply to explain away his behaviour in more testing economic periods. It is especially difficult to deny such charges when leafing through the Pocket Book, in which a number of plates are questionably presented as the author-compiler's own work. In one instance, the common trope of the zodiacal figure of man in the heavens placed at the centre of Seller's text bears notable similarity to the engraved images depicting man's micro- and macrocosmic relations to the universe as found in Robert Fludd's Utriusque Cosmi Historia (1617), published more than half a century earlier (Figure 4.3). ${ }^{50}$

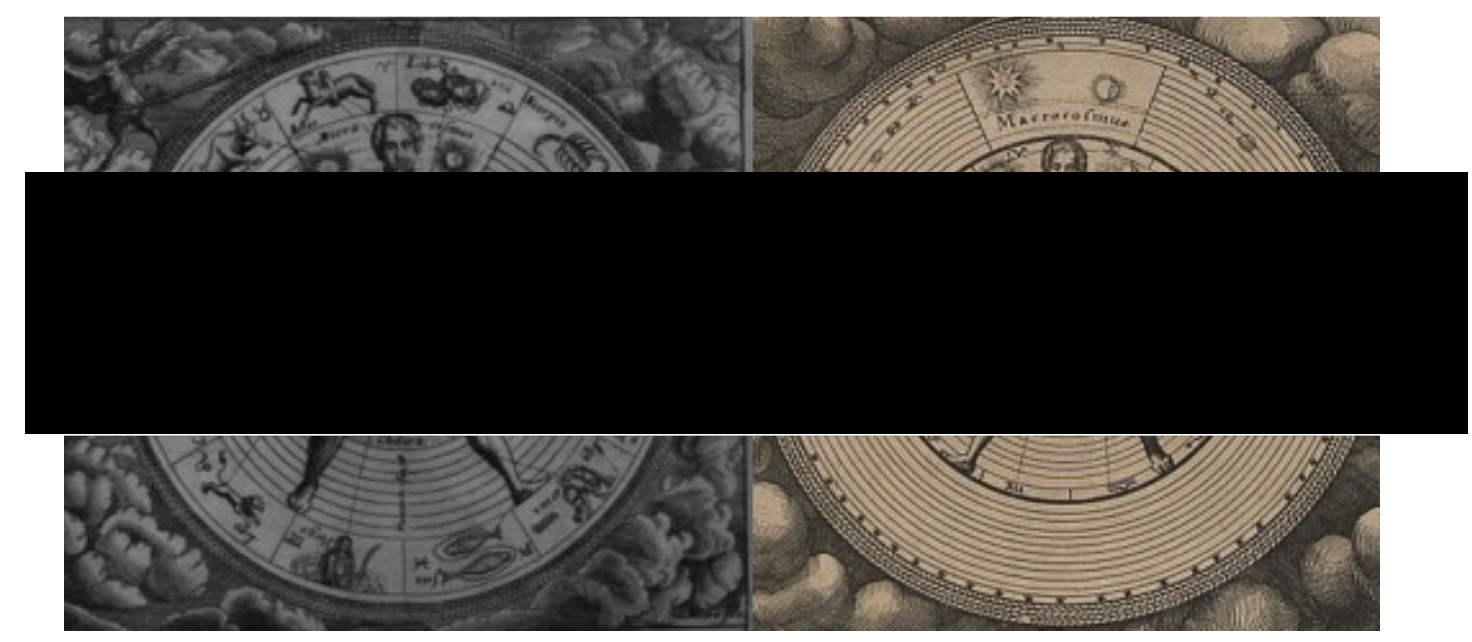

Figure 4.3. Composite image of John Seller's zodiacal man, left, and the title page of Fludd's Utriusque Cosmi Historia, right.

Seller had shown himself to be similarly unabashed when cannibalising his own works. The 1685 edition of the Pocket Book includes 'A Table shewing the Altitude of the Sun at every Hour of the Day', published in earlier editions of both the Pocket Book (1677) and the Atlas Coelestis (1680). Ostensibly created by Seller, the plate used bears evidence of a shadowy ' $G$ ' which the publisher has attempted to overwrite with his own initials (Figures 4.4 and 4.5) ${ }^{51}$ It has been theorised that this table was the work of either the astrologer John Gadbury (1627-1704) or the instrument maker Ralph Greatorex (ca. 1625-1675), and we may speculate as to

\footnotetext{
${ }^{50}$ Seller, Pocket Book, unpaginated, manuscript annotation I: ff. 33-34. Science Museum Library Shelfmark O. B. SEL SELLER 30209019360995. Robert Fludd, Utriusque cosmi maioris scilicet et minoris metaphysica physica atque technica historia (Oppenheim: Theodore de Bry, 1617), title page. ${ }^{51}$ Seller, Pocket Book, unpaginated, manuscript annotation I: f. 55. Science Museum Library Shelfmark O. B. SEL SELLER 30209019360995.
} 
whether Seller saw the popularity of Gadbury's printed materials as relevant to his own economic recovery. In their wider study of Seller's working practices, John Davis and Christopher Daniel's study leave little doubt that accusations of plagiarism are well-founded and applicable to books, maps, and at least one instrument, a double horizontal dial perhaps copied (at Seller's instruction) from the famed instrument maker Elias Allen (ca. 1588-1653). ${ }^{52}$

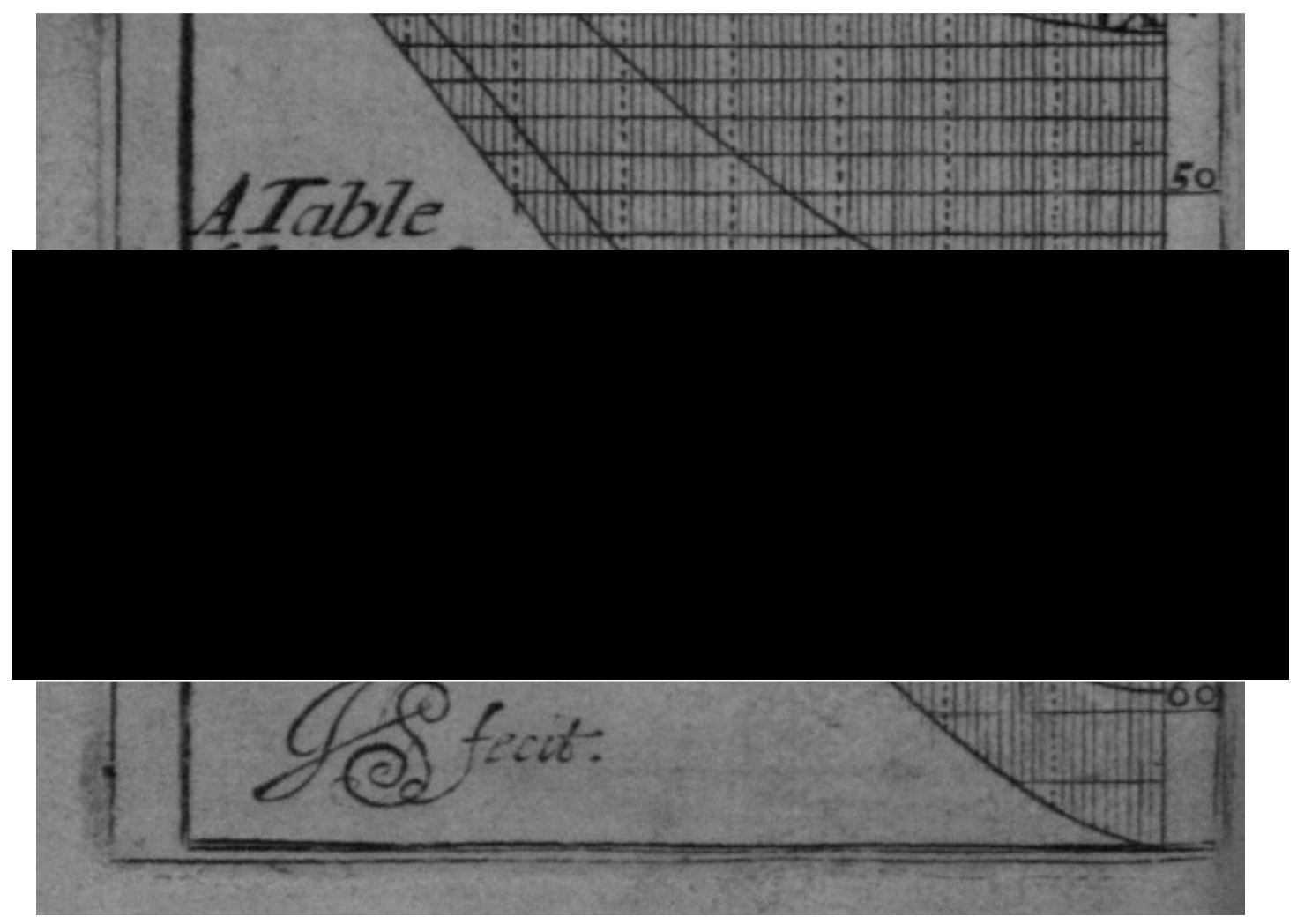

Figure 4.4. Image of John Seller's printed table for the sun's rising and setting for every hour of the day, with ' $J$. S. fecit' below the title. Science Museum Library Shelfmark O. B. SEL SELLER 30209019360995.

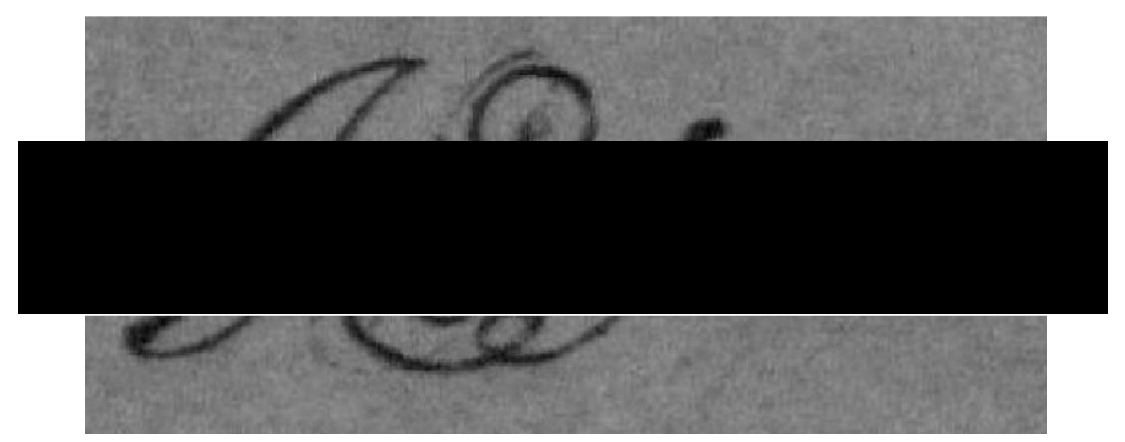

Figure 4.5. Expanded image of ' $J$. S. fecit' from the table above, in which the ghostly ' $G$ ' Seller had sought to overwrite is clearly visible. Science Museum Library Shelfmark O. B. SEL SELLER 30209019360995.

${ }^{52}$ Davis and Daniel, 'Instrument Maker and Plagiarist', particularly pp. 8-10. 
To what extent should Seller be damned for dabbling so frequently in plagiarism? It must be acknowledged that there is little evidence to suggest that he acted in a fashion alien to his peers in the early English maritime industry. 'Refreshing' maps was rife: prints were pulled multiple times from the same plates, were edited only minimally, and remained on sale for years if not decades thereafter. Across Europe, ‘(c)opying, re-engraving, and selling someone else's labour were lifeblood to the map trade throughout the eighteenth century', and the practices of seventeenth-century map and instrument makers were by no means unblemished in comparison. ${ }^{53}$ Manufacturers of similar products clustered together geographically, and an explosion in patents occurred only in tandem with the growth of the market and its practitioners' movement toward more industrial modes of manufacture. ${ }^{54}$

The market for bootleg printed texts experienced an equivalent boom, with references to piratical practices appearing increasingly throughout the Restoration. ${ }^{55}$ Earlier in the seventeenth century, registering works with the Stationers' Company ensured only printing and protection rights as conferred internally by the individual booksellers, printers, and publishers comprising the company itself. ${ }^{56}$ Though the Company and its Register were empowered under the auspices of statute by the Printing Act of 1662, a gradual erosion of the Stationers' propriety had begun long before. When the House of Commons chose not to renew the Act in 1695, it was noted that licensing efforts had become 'hopelessly inefficient, impossible to administer, and gravely subject to favouritism and abuse'. ${ }^{57}$

\footnotetext{
${ }^{53}$ Mary Sponberg Pedley, The Commerce of Cartography: Making and Marketing Maps in Eighteenth-Century France and England (Chicago and London: The University of Chicago Press, 2005), p. 96.

${ }^{54}$ Mario Biagioli, 'From Print to Patents: Living on Instruments in Early Modern Europe', History of Science, 44 (2006), pp. 138-186; particularly pp. 145-146. Biagioli notes that the proximity of like instrument manufacturers 'turned secrecy and confidentiality into highly perishable goods', and that the number of patents issued grew from seven prior to 1700 , to 100 by 1800 .

55 Adrian Johns, Piracy: The Intellectual Property Wars from Gutenberg to Gates (Chicago: The University of Chicago Press, 2009), pp. 23-24.

${ }^{56}$ Joseph F. Loewenstein, 'The Script in the Marketplace', Representations, 12 (1985), pp. 101-114; p. 105.

${ }^{57}$ Mark Rose, 'The Public Sphere and the Emergence of Copyright: Areopagitica, the Stationers' Company, and the Statue of Anne' in Ronan Deazley, Martin Kretschmer and Lionel Bently, Privilege and Property: Essays on the History of Copyright (Cambridge: Open Book Publishers, 2010), pp. 67- 88, particularly pp. 77-81. Ernest Sirluck, 'Areopagitica and a Forgotten Licensing Controversy’, The Review of English Studies, 11.43 (1960), pp. 260-274, p. 260.
} 
That Seller's competitors had their collective nose put out of joint by his access to privilege is clear; that they vocally disdained his unscrupulous practices (many of which they would likely have engaged in themselves), highly likely. More contentious is how relevant these issues were to his typical consumer. Seller's books sold well, their editions printed long after his death. Advertising himself as Hydrographer to the King no doubt aided Seller in convincing consumers of his mathematical skillset, thereby encouraging his clientele to place their confidence in his selection of 'severall Choice Collections' from a range of mathematical subjects. Though the appellation of Hydrographer is most frequently appended to his mapswhich predated the text, and were claimed by Seller as his own in somewhat questionable circumstances - the term was also prominently positioned on the Pocket Book's title page so as to garner sales in a competitive marketplace.

As their title indicated, the 'choice collections' collated by the author were intended to cover a broad sweep of applications, with excerpts promised from astronomy, surveying, dialling, navigation, geography, and gauging: in sum, a collection of activities which any number of interested parties might wish to become proficient in. In an age where intellectual virtuosity and practical application became intermingled, the hydrographer's late-career movement, away from grandiose seacharts and into the miniaturised compendia intended for a more diverse clientele, may reflect the changing character of his market.

The maritime trade of the seventeenth century was populated by significant numbers of largely illiterate practitioners, and the genre of navigational guides that existed is of more relevance to a study of their authors' mathematical ability and ambitions, rather than one seeking any serious evidence of uptake or use of these texts by the pilots of the period. ${ }^{58}$ Even as rates of literacy and numeracy improved steadily throughout the seventeenth century, sailors were still largely drawn from humble backgrounds, and the abilities of a crew were stratified by class and, subsequently, by role. Marcus Rediker's analysis of literacy amongst seafarers between 1700 and 1750 identifies that, while most, if not all, captains, mates, and surgeons aboard a ship were literate, only two thirds of common seamen could sign

${ }^{58}$ Eric H. Ash, 'Navigation Techniques and Practices in the Renaissance' in David Woodward, ed., The History of Cartography, Volume Three: Cartography in the European Renaissance (Chicago: University of Chicago Press, 2007), pp. 509-527, p. 524. 
their name. ${ }^{59}$ The growing necessity of signing a contract in order to guarantee employment should not, however, be seen as reflective of functional literacy across the board: many sailors' dalliance with reading and writing began and ended with their signature.

Earlier in the seventeenth century, the professionalization of maritime practice meant that merchant companies had begun to employ mathematicians to review the logbooks of captains, officers, and, eventually, navigators: by 1677 , would-be lieutenants of the Royal Navy and Royal Mathematical School apprentices alike were expected to submit their logs for examination. ${ }^{60}$ This professionalization brought with it a requirement of basic technical literacy, a factor which should not be overlooked when considering the development of mathematical and epistemic genres in and around the maritime trade in the late seventeenth and early eighteenth centuries. Whereas navigators in the early 1600s might work from memory, with only occasional reference to printed sources or their own handwritten logs, a growing number of maritime practitioners in the 1700 s were expected to make frequent use of printed and written materials to demonstrate their abilities at land and sea. Conversely, outside of these elevated roles, many rank-and-file sailors doubtless remained at best semi-literate, relying on work-arounds, rules of thumb, and a culture of orality and instruction aboard the ship itself to complete their tasks. ${ }^{61}$

John Seller's Pocket Book, inhabiting a practical space joining image, text, and table, could therefore have acted as perfect spur to a younger or inexperienced reader with dreams of ascending to the role of captain, officer, lieutenant or navigator; as a necessary handbook to the novice if semi-literate sailor; or, as a handy, partially pictorial guide to those in between. As a familiar presence in the maritime trade as a tutor, instrument maker, and merchant, John Seller was patronised by well-known luminaries such as Pepys and Hooke. Still in possession of his royal appellation at the time of the Pocket Book's first publication, Seller,

\footnotetext{
${ }^{59}$ Marcus Rediker, Between the Devil and the Deep Blue Sea: Merchant Seamen, Pirates, and the Anglo-American Maritime World, 1700-1750 (Cambridge: Cambridge University Press, 1987), p. 158.

${ }^{60}$ Margaret Schotte, 'Expert Records: Nautical Logbooks from Columbus to Cook', Information and Culture, 48.3 (2013), pp. 281-322, p. 294.

${ }^{61}$ Vincent V. Patarino Jr., 'The Religious Shipboard Culture of Sixteenth and Seventeenth-Century English Sailors' in Cheryl A. Fury, ed., The Social History of English Seamen, 1485-1649 (Woodbridge: The Boydell Press, 2012), pp. 141-192, particularly pp. 178-182.
} 
regardless of the dim view taken by some his contemporaries, was perfectly placed to target the gentleman in search of materials for his own leisure and edification, the student pursuing mathematical tuition, or the sailor seeking to learn and improve alike. The merchant's efforts to be all things to all people in his publishing and cartographic careers chime with his previous broad-brush advertisements of mathematical instruments, as well as with an ambitious, if irresponsible, character.

\section{The form and content of the Science Museum's Pocket Book (1685)}

Similarities in content between The English Pilot, Practical Navigation, and the Pocket Book demonstrate that Seller, as a publisher, saw the value of offering a range of materials that could be amended depending on buyers' abilities across the spectra of both literacy and numeracy. Given the one-time Hydrographer's importance to the map-trade of early modern England, it is no surprise that a number of valuable studies have focussed on this area of his life and work. Few, however, have offered much by way of judgement on his efforts in book-publishing. Though his earlier works demonstrate a level of expertise, care, and exactitude in their contents' selections and construction - something most clearly witnessed in Practical Navigation and The English Pilot (1671-1672) - Seller's haphazard approach to publication makes detailed analysis of his later oeuvre somewhat problematic. At least three editions of the Pocket Book were published between 1677 and 1685, and one edition was posthumously published by his son Jeremiah in 1700. Copies of the text were inconsistently composed, but we can perhaps attribute this in part to the norms of the map-selling business.

Customers would often request atlases and cartographic collections to be made up 'on demand', and it is uncommon to find extant copies of Seller's larger works with precisely the same contents. ${ }^{62}$ Composed largely from pre-existing copperplates and featuring many more graphical and tabular elements than printed text blocks, the involvement of early modern purchasers in the collation of their geographical materials allows consideration of how such instructions designed the form and order of works such as the Pocket Book. By selecting the content and order of their text, it is likely that the first owner of the Science Museum's copy of the text

${ }^{62}$ Verner, 'Engraved Title Plates for the Folio Atlases of John Seller', p. 24; also fn. 9. 
participated in its construction or reconstruction at some point. In this scenario, the order of the Pocket Book's contents is an example of the literal 'making' of mathematical practice. Moving beyond the point of sale, this personalised construction of the text, when allied to the later decanting of commonplace materials and excerpts from additional texts, points to individuated practices of reading, interpretation, collation, and use.

In this particular copy, owned by Jenkinson and written on by both Thomas and Edmund Withers, the book gives the impression of a loose compendium, its printed contents taken largely from other sources (amongst them, Seller's own works) and hurriedly bound together. Engraved copperplate prints dominate the volume, and were arranged at either side of a consistently-paginated section of letterpress instructions, commencing at page 1 yet placed at the middle of the volume. We can usefully divide the engraved plates into roughly three portions. The first contains a preponderance of information most commonly found in popular almanacs of the period; the second is concerned with mathematical problems, measurements, and custom duties; and the third presents materials pertaining to navigation and cartography.

So it is that the first of these group of plates presented information common to many early modern almanacs: that is, single-page prints of calendars of months and their feasts; tables to find Easter and the Golden Number; historical information on the reigns of kings; and larger, double-page, stylized illustrations such as that of the zodiacal man. Additional tables found in this section include ways to calculate the terms of the year (Michaelmas, Hilary, Easter, and Trinity) as well as a pair of combinatory volvelles - circular, moveable paper instruments designed, in this instance, to compute calendrical and zodiacal positions for astrological purposes. These were supplemented by larger, double-page copperplates on the use of the almanac, and a table showing the cycle of the Dominicall Letter from 1676 to 1731 . 


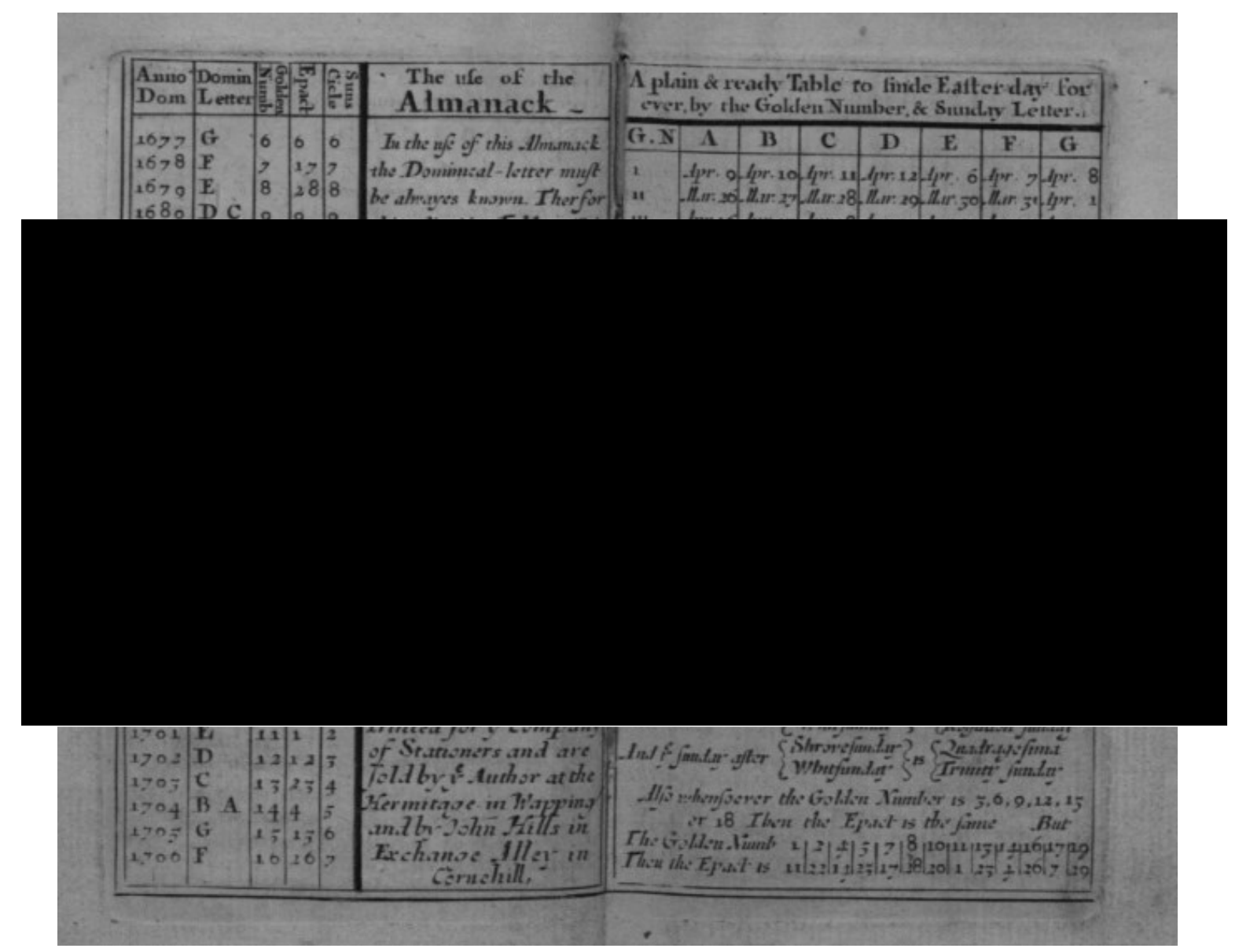

Figure 4.6. An example of John Seller's double-page copperplate printing - in this case, an engraved table on the use of the almanac. The indentation made by plate can clearly be seen around the outer edges of the table. The advertisement to the foot of the table suggests that Seller and his contemporary John Hills may also have sold this print separately as an individual sheet. Science Museum Library Shelfmark O. B. SEL SELLER 30209019360995.

Following the aforementioned 40 pages of consistently-paginated letterpress instruction, the Pocket Book's copperplate engravings then resumed with more specifically mercantile information, including tables of interest and of relationships between apothecaries' various weights and measures. In this second 'section' of the text we find a detailed table of arithmetic, and a calligraphic, engraved statement in a flowing hand describing its two parts: notation, or the value of numbers, and numeration, which teaches their 'composition and dissolution' by operative means of addition, subtraction, multiplication and division. The Pocket Book then presents tables of notation, a printed slide rule for trigonometric functions, three double-page analemmas, and several tables of latitude. Data on assize weights and the gauging of vessels, of use to the customs officer and importer alike, is succeeded by purchasing tables, tables of square and cubic roots, and synopses of trigonometry, before a plate 
concerning stereographic projection and two volvelles for calculating the circular parts of spherical triangles round off this tranche of the volume. The manipulable paper instruments bear a high degree of similarity to brass aide-memoires Seller is known to have fashioned. ${ }^{63}$

The third and final section of John Seller's work continues on from these materials with a brief illustration of basic geometrical rudiments, and begins with a bold engraving of a Pixis Nautica, or mariner's compass. This quasi-navigational section features an annotated figure of a ship's rig, a two-page set of geometrical 'Problems of Plain Sailing', and a brief dalliance with cryptography. In keeping with Seller's cartographical and navigational practice, the illustrative plates presented in this final section are often larger, double-page efforts. This portion of the volume ends with a series of maps of the world, the British Isles, and England, as well as a group of playing-card sized vignettes of the four continents known to early modern geography, namely Europe, Asia, Africa, and America, with North and South grouped together.

The appearance of both copperplate and letterpress printing in the Pocket Book draws together a number of meaningful elements of Seller's working practices, and helps to shed further light on the production and construction of the volume. Indeed, the practitioner presents a useful figure through which to explore in further detail, per Roger Gaskell's suggestion, the production processes behind the integration of copperplate and letterpress prints into the same text. ${ }^{64}$ As Arthur $\mathrm{H}$. Robinson has noted, the exchanges between map-makers and engravers encouraged stylistic meeting-points in which, for example, manuscript work-sheets were prepared in the style set by traditions developed thanks in part to the characteristics of the materials (in this case, copper) with which artisans worked. ${ }^{65}$ By producing and collating works featuring printed text and copperplate prints, John Seller worked

\footnotetext{
${ }^{63}$ Seller, Pocket Book, unpaginated, manuscript annotation II: f. 113. Science Museum Library Shelfmark O. B. SEL SELLER 30209019360995 An example of one of Seller's brass trigonometric medals is held in the Whipple Museum of the History of Science, Cambridge, Accession Number 2316. I am grateful to Josh Nall and to Glen van Brummelen for aiding my identification of this object.

${ }^{64}$ Roger Gaskell, 'Printing House and Engraving Shop. A Mysterious Collaboration', The Book Collector, 53 (2004), pp. 213-251.

${ }^{65}$ Arthur H. Robinson, 'Mapmaking and Map Printing: The Evolution of a Working Relationship' in David Woodward, ed., Five Centuries of Map Printing (Chicago and London: University of Chicago Press, 1975), pp. 1-23, p. 19.
} 
within both cartographic and typographic traditions specific to his time and to his choice of subjects.

At certain points in his career, Seller contracted out his letterpress requirements to John Darby, and the making of particular map-plates to Wenceslaus Hollar; ${ }^{66}$ he was at other points in time content to update, engrave, and sign (at times fraudulently) plates under his own steam. Issues of propriety notwithstanding, it is clear that copperplate map printing afforded to the producer a number of valuable qualities. Plates were relatively easy to alter should new (or problematic) information be found to be present, and they could be used over a longer period of time, reducing the cost per print. Furthermore, divorced from letterpress and presenting pictorial information, the appeal of printed maps was not restricted solely to literate consumers. ${ }^{67}$ As we have already seen, Seller - a refresher and producer of maps and charts, a merchant well-versed in London's nautical trade for a significant period of time, and, owing to these experiences, one keen to appeal to as many different consumers as possible - would likely have found each of these qualities essential.

The hand-engraved lettering seen in Seller's copperplate prints can meanwhile be placed within a longer tradition of the italic hand utilised in early modern European cartography. The cursive cancellaresca script which originated from the Papal Chancery was published in Ludovico Vincentino degli Arrighi's handwriting manual La Operina (1522); ${ }^{68}$ A. S. Osley has convincingly argued that Gerardus Mercator saw in the italic type of Aldus Manutius and the writing manuals of masters such as Arrighi a hand that would be particularly suited to technical inscription on maps, globes, and other products. ${ }^{69}$ Mercator adapted his style

\footnotetext{
${ }^{66}$ Coolie Verner, 'Copperplate Printing', in David Woodward, ed., Five Centuries of Map Printing (Chicago and London: University of Chicago Press, 1975), pp. 51-75, pp. 61-62.

${ }^{67}$ Verner, ibid, p. 71.

${ }^{68}$ Stanley Morrison, 'Notes on the Development of Latin Script' in Stanley Morrison and David McKitterick, ed., Selected Essays on the History of Letter Forms in Manuscript and Print, Volume 1 (Cambridge: Cambridge University Press, 1981; originally 1949, partly revised c. 1962), pp. 222-294, pp. 274-276. See also A. S. Osley, Scribes and Sources. Handbook of the Chancery Hand in the Sixteenth Century. Texts from the Writing-Masters selected, introduced and translated by A S. Osley with an account of John de Beauchesne by Berthold Wolpe (London: Faber and Faber, 1981).

${ }^{69}$ A. S. Osley, Mercator: A Monograph on the Lettering of Maps, etc. in the $16^{\text {th }}$ Century Netherlands, with a Facsimile and Translation of his Treatise on the Italic Hand and a Translation of Ghim's Vita Mercatoris (London: Faber and Faber, 1969), pp. 43-45. See also David Woodward, 'The Manuscript, Engraved, and Typographic Traditions of Map Lettering' in David Woodward, ed., Art and Cartography: Six Historical Essays (Chicago and London: The University of Chicago Press, 1987), pp. 174-212, p. 180 and pp. 186-189.
} 
gradually, and married it to the techniques of engravers following the rapid adoption of copperplate in the mid-sixteenth century. ${ }^{70}$ Charting the cartographer's influence up to 1600 , Osley identified Mercator's own writing manual, Literarum latinarum (1540), the network of his immediate circle of contemporaries (amongst them his teacher, Gemma Frisius) and the popularity of the techniques and products associated with the Louvain school to which he was affiliated as crucial to the style's spreading. $^{71}$

In this manner, a line of succession can be drawn to influential practitioners based in England - including the aforementioned Thomas Gemini, Humfray Cole (d. 1591), and Jodocus Hondius (1563-1612) - whose work continued this style (with personal and local variations) into the late sixteenth century and beyond. ${ }^{72}$ Influenced by the work of Mercator and by that of the Brussels-born schoolmaster Clemens Perret (b. 1551), Hondius himself produced from copper engravings a writing manual, Theatrum artis scribendi, in $1594 .{ }^{73}$ Hondius included examples from the works of a number of writing masters from Italy, the Low Countries, and England, and it has been argued that he was incentivized to publish his manual in part by the growing commercial and professional demands for well-written script present in early modern London. ${ }^{74}$ This demand would only grow as the seventeenth century progressed; to take but one popular example, the skilled engraver and teacher Edward Cocker (1631-1676), whose posthumously-published Arithmetick (1678) went through more than 100 editions over the next century, was first known

\footnotetext{
${ }^{70}$ Osley, Mercator, p. 47.

${ }^{71}$ Osley, ibid, pp. 77-91.

72 Osley, ibid, p. 99. Arthur M. Hind cites Cole, Richard Lyne, and Augustine Ryther as figures who followed Gemini, though he grouped each as 'little more than engravers of maps and topography', who lagged behind their foreign counterparts. Hind goes on to name Jodocus Hondius 'the greatest and last of the chart engravers of this early period', and the last of 'the foreigners who helped most to create the school of engraving in England in the sixteenth century'. Arthur M. Hind, A History of Engraving and Etching from the Fifteenth Century to the Year 1914, $3^{\text {rd }}$ edn (Boston and New York: Houghton Mifflin Company, 1923), pp. 135-136. For an exhaustive treatment of engravers, including many more involved in cartographic work, see Arthur M. Hind, Engraving in England in the Sixteenth and Seventeenth Centuries. A Descriptive Catalogue with Introductions, 3 vols. (Cambridge: Cambridge University Press, 1952-1964).

${ }^{73}$ Ton Croiset van Uchelen, 'Jodocus Hondius's Theatrum artis scribendi examined anew', Quaerendo, 34.1-2 (2004), pp. 53-86, pp. 57-58.

${ }^{74}$ van Uchelen, ibid, p. 60.
} 
for producing a series of manuals and copy-books presenting a number of European hands. $^{75}$

While Seller did not produce handwriting manuals or copy-books as Hondius, Cocker and others had, he did produce and engrave maps and charts using a form of italic hand comparable to fellow cartographic and nautical practitioners. Given Seller's familiarity with, and repurposing of, the Dutch publications which initially dominated the seventeenth-century nautical market, this commonality of style is unsurprising. Before moving on to the particular users of this copy of the Pocket Book, however, I wish to briefly explore how John Seller utilised both engraved and printed text to address and instruct his audience. As Keith Thomas's detailed survey of numeracy in early modern England has shown, many of the population lacked education in the mathematical principles behind many operations, their arithmetical abilities rarely going beyond basic addition and subtraction. Dexterity in mental arithmetic was rare, and not helped by inconsistent units of measurement; as a result of these factors, tradesmen remained almost wholly reliant on the vast numbers of reckoners and tables produced well into the late seventeenth century. ${ }^{76}$

To a certain extent, then, operators could have been trapped by such tables: skating by on quick rules of thumb and handy reference data, yet lacking the education or skill to build upon what little mathematical understanding they gleaned whilst on the job. Readers seeking assistance in calculating interest, for example, could refer to Seller's version of the ready-reckoners so familiar to the period; although Ann Blair has argued that early modern pedagogues considered tabulae 'self-explanatory' in their summation and depiction of complex material, a widespread view 'neither challenged nor defended in specific detail' by such educators, astronomical tabulae were commonly accompanied by canons explicating

\footnotetext{
${ }^{75}$ A sample of Edward Cocker's manuals include The Youth's Direction to Write Without a Teacher all the Useful Hands of England (London: sold by John Overton, 1652); The Pens Transcendencie, or faire writings labyrinth (London: sold by Samuel Ayre, 1657); Penna Volans, or the young mans accomplishment (London: printed for John Ruddiard, 1661), and The Compleat Writing Master (London: Printed for Thomas Basset and Robert Pawlet, 1670). The extended title of The Compleat Writing Master advertised that it was 'a copy book furnished with all the most usefull hands now practised by the best artists in London', and that the directions would provide readers with the capabilities for any employment whatsoever.

76 Thomas, 'Numeracy in Early Modern England', particularly pp. 106-117.
} 
their use. Most familiar with calendrical and navigational examples, Seller acted in a similar fashion by providing his readers with explanatory notes by which to understand and then utilise the data presented. ${ }^{77}$

In the textual letterpress rubric collated toward the middle of this particular copy (or, as in many other printed examples of the text, at the beginning) readers of 'The Use of the Table of Interest' were bluntly advised that 'this table is so plain it needs little example'. Despite this, the author continued,

Suppose I would know what the Interest of 1151 . comes to for 9 months (at 6 per Cent, for which the Table is made); first, look for 100 1., which I find at the bottom of the Table in the Second Column: and, under the title of 9 months, I find 4 1. 10s. 0d., in next I look for 15 1., but not finding it in the Table, I take it out at twice, first 101., and then 51: against 10 1. or 9 months, I find $9 \mathrm{~s}$. and against $5 \mathrm{l}$. under 9 months, I find $4 \mathrm{~s}$. $6 \mathrm{~d}$., which being added altogether makes 51. 12s. 6d., which is the Interest for 1151 for 9 months. ${ }^{78}$

These instructions help in part to highlight how little mathematical ability may reasonably be assumed on the part of many early modern creditors and debtors, even as late as 1685 . Although a useful degree of information was provided by interest tables, Seller went out of his way to unpack and express an example that might otherwise have vexed his audience: namely, making a relatively simple method of calculation available for figures not found therein.

It is reasonable to assume that Seller feared some of his audience would fail to grasp the rationale behind the data tabulated, and, as a consequence, would struggle to reckon the many unlisted figures hidden between those presented. Seller's table lists shillings in fives, from five to fifteen, moving on to single figures in pounds, from one to nine, and finally listing tens of pounds to a maximum of 100 ; subdividing the composite parts of 115 pounds into groups of 100 , ten, and five, calculating the interest due on each, and then recomposing them to find the total interest required would appear to be a series of operations the publisher perhaps considered as beyond the reach of his users. Although pedagogues may well have

\footnotetext{
${ }^{77}$ Ann Blair, Too Much to Know: Managing Scholarly Information before the Modern Age (New Haven and London: Yale University Press, 2010), p. 145.

${ }^{78}$ Seller, Pocket Book, printed pagination p. 5. Science Museum Library Shelfmark O. B. SEL SELLER 30209019360995. My emphasis.
} 
found numerical tables self-explanatory, Seller's examples demonstrate how publishers and authors were often less convinced of their consumers' mathematical capabilities.

Broadly speaking, the typography of the instructional, letterpress section of the Pocket Book was alternated in such a manner as to guide the reader's eye in the style common to English texts of the era. From his self-appointed role as the doyen of English printing, Joseph Moxon advised in the second volume of his Mechanick Exercises (1683) that the discerning compositor should 'have so much Sence and reason [...] when (to render the Sence of the Author more intelligent to the Reader) to Set some words or sentences in Italick or English Letters' ${ }^{79}$ As might be imagined, many of Moxon's rules of thumb were by this stage well-established working practices in England and further afield. ${ }^{80}$ In the letterpress section of the Pocket Book, titles and example headings were first of all set in italics so as to visually differentiate them from the accompanying, block roman 'how-to' text which explained the use of the various tables and illustrated contents found elsewhere in the text. In this instructional, letterpress section, the producer of the Pocket Book then capitalised and italicised the proper nouns - such as Easter, the Pleiades, London, and Thomas Bludworth - involved in the text's depiction of measuring time, tides, and the reigns of kings. Foreign terms, such as 'per cent', were also italicised, in keeping with the instructions Moxon would himself later put into print. ${ }^{81}$

Less frequently, Seller also utilised italic type to differentiate between discrete forms of address. In this manner, a number of the italic portions of the Pocket Book's printed text are a modulation of the authoritative voice common to earlier humanist works of the previous century: a voice wherein the reader was addressed dialogically in different typefaces. These italicised sections belong within a mathematical branch of this culture, pioneered in England by John Day's printing

\footnotetext{
79 Joseph Moxon, Mechanick Exercises, or, the Doctrine of Handy-Works. Applied to the Art of Printing. The Second Volumne (London: Joseph Moxon, 1683), p. 198. Moxon's emphasis.

${ }^{80}$ For a discussion on the appearance of italics and their importance in early modern English printed works, see Mark Bland, 'The Appearance of the Text in Early Modern England', Text, Vol 11 (1998), pp. 91-154, particularly pp. 93-96; also M. B. Parkes, Pause and Effect: An Introduction to the History of Punctuation in the West (Berkeley and Los Angeles: University of California Press, 1993), pp. 51-55. A wider discussion of the importance of typefaces to authority and authorship is found in Joseph F. Loewenstein, 'Idem: Italics and the Genetics of Authorship', Journal of Medieval and Renaissance Studies, 20.2 (1990), pp. 205-224.

${ }^{81}$ Moxon, ibid, p. 225.
} 
techniques. Day's editions of William Cunningham's The Cosmographical Glasse (1559) and of Henry Billingsley's translation of The Elements of Geometrie of the most auncient Philosopher Euclide of Megara (1570) featured contrasting typefaces, used in the former to express dialogue and in the latter to juxtapose original mathematical theories with the commentaries of later authors. ${ }^{82}$ In the Pocket Book's textual section, Seller appealed to a rather less erudite audience by printing his rhyming mnemonics in italic, using the typeface to address the reader in a sing-song format (common to early modern almanacs) by which they might internalise key information (Figure 4.7).

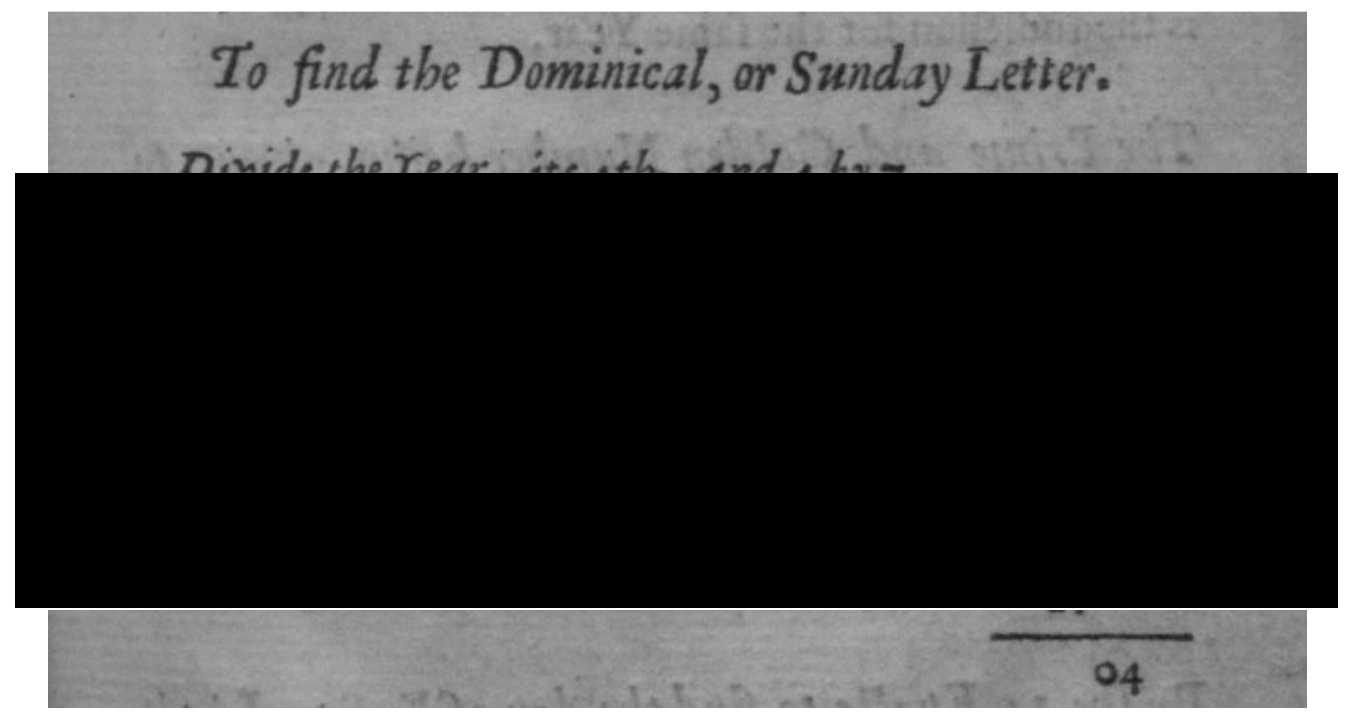

Figure 4.7. An example of John Seller's use of italic and roman types in the instructional, letterpress section of the Pocket Book; in this case, an italicised mnemonic to find the Dominical Letter, followed by a brief calendrical calculation by way of example. Science Museum Library Shelfmark O. B. SEL SELLER 30209019360995.

When placed together, the graphical and textual contents of the work are therefore to be seen in their entirety as contributory to a document intended for instruction, retention, and use. In collating the Pocket Book and its 'choice collections' using both copperplate engravings and letterpress print, John Seller utilised a number of the craft practices he had learned across a career servicing the mathematical, cartographical, and nautical needs of a wide range of consumers. Indeed, this was mirrored in the combination of materials found in Seller's text combinations which reflected the practical culture of his time.

\footnotetext{
${ }^{82}$ Bland, 'Appearance of the Text in Early Modern England', pp. 98-99.
} 
As Louise Hill Curth has demonstrated, sailors were one of several occupational groups targeted by almanac-makers from at least the mid-seventeenth century. ${ }^{83}$ Pseudonymous authors with names like John Waterman and Henry Seaman furnished their market with yearly works and collections. The latter's Kalendarium Nauticum (1676) assured customers that it presented not only 'what is generally contained in annual almanacks' but also 'such precepts, rules and tables, as are of daily use in the practice of navigation and traffick'. ${ }^{84}$ What this 'daily practice of navigation' involved can be seen in earlier works: Timothy Gadbury's The Young Seaman's Guide, or Mariner's Almanack (1659), for example, mapped out the winds, the weather, and on-board sickness as things predictable by astrological expertise; furthermore, it contained tables sailors could complete to document and reference the planetary positions prominent on the date a colleague fell ill and, we can assume, the success or failure of any treatment thereafter. ${ }^{85}$

Printed works combining astrological data and almanac tables continued to be popular into the second decade of the eighteenth century, as posthumous editions of John Gadbury's Nauticum Astrologicum, or the Astrological Seaman (1710), show. Merchants like Seller continued these traditions, to which they added more detailed workings on the mathematical rigours of seafaring, and the efforts of both Timothy and John Gadbury (amongst others) reveal the relationship between the mathematical and pseudo-mathematical nautical materials of the seventeenth century. The interrelation of astronomy and astrology had been discussed at length by the courtly mathematicians of the sixteenth century, and versions of these practices became attached to ever more practical settings. Attempting to show his reader something of the rationale behind his calculations, Timothy Gadbury referenced Ptolemy's astrological theory on planetary dignities and 'debilities' before producing an extensive table of ephemerides for the Julian and Gregorian calendars, mingling astrological and astronomical readings,.

${ }^{83}$ Louise Hill Curth, English Almanacs, Astrology and Popular Medicine: 1550-1700 (Manchester: Manchester University Press, 2007), pp. 49-50.

${ }^{84}$ Henry Seaman, Kalendarium Nauticum: The Seaman's Almanack for the Year of Christ, 1676 (London: T.N. for the Stationers' Company, 1676), title page.

${ }^{85}$ Elizabeth Lane Furdell, Fatal Thirst: Diabetes in Britain until Insulin (Leiden: Brill, 2009), pp. $72-$ 73. 
Whether interpreted for astrological or astronomical purposes, celestial observations could provide succour as well as essential empirical data. In adding brief tables 'shewing what Planets Rules every hour of the Day and Night' and prints such as that of the zodiac man, with horoscopic signs and their relevant body parts highlighted, Seller made sure that his works acquiesced to the astrological concerns enmeshed with the life of the mariner. By judging the planetary hours from sunrise onward, seamen regulated their day in accordance with celestial movements and influences alike. For the sailor wishing to anchor himself on faraway seas, tools that helped to combat medical crises, the ineffability of the immediate future, and the treachery of the skies above and of the seas below were all of significant value. Moreover, the influence of celestial bodies could be felt in other ways. Readers who relied on astronomical data to chart changes in their fortunes or health also made use of the firmament above to plot their positions in space and time.

Gathering at least some knowledge of astronomical navigation was a central part of early modern seafaring, and these concerns duly account for a number of pages of Seller's text. However, as the previous chapter has detailed, sailors were by no means alone in seeking knowledge of the 'doctrine of the sphere': it remained a central plank of astronomical study for those tackling the quadrivium. The addition of three analemmas - printed orthographic projections of the earth's sphere in plane-help to illustrate how astronomical theory was adjoined with navigational and horological practices, and each of these practices was reliant in its own way on lines projected onto the earth and the sky. Their projections belong to the lineage of spherical astronomy as received from antiquity, in which the form and the motion of the heavens, the planets, and the earth can all be explained with recourse to their sphericity.

As we have already seen, this cosmology placed the terrestrial earth at the centre of the universe, and circumscribed the concentric planetary and celestial spheres around the earth with a further series of circles. ${ }^{86}$ Five of these celestial lines are paralleled on the earth as 'zones'; divisions, in Peter Heylin's terms, of 'imaginary' parts that, despite 'not being at all in the Earth, must be supposed to be

${ }^{86}$ Elly Dekker, 'The Doctrine of the Sphere: A Forgotten Chapter in the History of Globes', Globe Studies, 49, (2002), pp. 25-44, p. 27. 
so, for the better teaching and learning of this Science; and are certain Circles going about the Earth, answerable to them in Heaven, in name'. Acting within this tradition, Seller's first analemma depicts the five temperate zones-'one over-hot, two over-cold, and two temperate', in Heylin's pithy estimation - that traverse the globe. ${ }^{87}$

Whilst classical theories concerning these zones and their inhabitants as handed down from authorities like Parmenides, Aristotle and Ptolemy had come under sustained attack from the geographical discoveries of the previous century, their mathematical certitude remained a tenet of sixteenth- and seventeenth-century geographical treatises even if questions of their inhabitation continued. ${ }^{88}$ Knowledge of the theory of the five zones was de facto useful cosmographical knowledge for the sailor, geographer, and the student, dividing as it did the world into hospitable and inhospitable sectors based upon the temperatures resulting from the sun's 'movement' along the line of the ecliptic and its declination as it travelled. ${ }^{89}$ Each could prepare themselves for inhospitable seas accordingly, even if some were then to find themselves surprised at what (or who) they met in those torrid waters.

Horological practices such as the early modern art of dialling, or time finding, relied equally on the doctrine of the sphere. Before instructing readers on how to make and use their dials mathematical authors would provide at least a basic introduction to spherical astronomy, situating the earth as encircled within this greater sphere. Indeed, the teachings of positional astronomy retained their value long beyond the early modern period precisely because they are equally useful regardless of whether their user subscribed to geocentric or heliocentric cosmologies: the observer remains at a central vantage point in each. This can be seen in John Blagrave's The Art of Dialling in Two Parts (1609), which introduced the Earth's

\footnotetext{
${ }^{87}$ Peter Heylin, Mikrokosmos: A Little Description of the Great World (Oxford: John Lichfield and William Turner, 1625), pp. 4-6.

${ }^{88}$ Sandra Young, The Early Modern Global South in Print: Textual Form and the Production of Human Difference as Knowledge (Farnham: Ashgate Publishing Ltd, 2015), pp. 69-71.

${ }^{89}$ Nicolas Wey Gomez, 'The Politics of Light: Al-Kindī's Optics and the Vindication of the American Tropics in Bartolomé de las Casas's Apologética historia sumaria (1527-1561)' in Walter S. Melion and Lee Palmer Wandel, eds., Early Modern Eyes (Leiden: Brill, 2010), pp. 11-54; particularly pp. 24-28.
} 
(and its observers') concentric position in relation to the celestial sphere in these essential terms:

Such is the great compass and immensity of the Heaven, that the whole earth in comparison to it, is but the centre point thereto: and therefore all Dyals are made as though we did dwell in the centre of the earth, and every plaine howsoever scituate is by reason thereof accompted all one with the plaine of that great circle of the Sphere unto which it is parallel..$^{90}$

For the mathematical authors and practitioners of the seventeenth century, in keeping with discoveries in medicine, anatomy, and astronomy, capturing solar time was another epistemic puzzle to be drawn from the book of nature. The Oxford mathematician Robert Hegge (1599-1629), in his unpublished manuscript on dials Heliotropium Sciotericum, wrote that the dial was the 'Visible map of Time', the 'anatomie of the day' and, poetically, 'the book of ye Sunn on which he writes the storie of the Day. ${ }^{91}$ From their inception, dialling texts were directed not only toward 'Students of the Arts Mathematicall, but also for divers Artificers, Architects, Surueyours of buildings, Free-masons, and others. ${ }^{92}$

By the publication of Seller's first edition of the Pocket Book, mathematicians and instrument makers as diverse as Thomas Fale (bap. 1561, d. after 1604), Edward Wright (1561-1615), Sylvanus Morgan (1620-1693), and William Leybourn (1626-1716) had successfully published works on the topic. Expounding on his methods of teaching dialling (along with arithmetic, geometry, trigonometry, and astronomy), Leybourn's advertisements to potential seafaring students promised that they would learn to dial three ways: arithmetically, through tables of sines, tangents and logarithms; geometrically, by scales and compasses; and instrumentally, by the use of sectors, quadrants, scales, and any other instrument used to draw lines. ${ }^{93}$

\footnotetext{
${ }^{90}$ Blagrave, Art of Dialling, p. 2.

${ }^{91}$ Robert Hegge, Heliotropium Sciothericum, Corpus Christi College, MS 430, fols. 16-34. Hegge's time at Oxford and his Heliotropium are mentioned in Feingold, Mathematician's Apprenticeship, pp. 71-72.

92 Thomas Fale, Horologiographia. The Art of Dialling (London: Thomas Orwin, 1593), title page.

${ }^{93}$ William Leybourn, Nine Geometrical Exercises for Young Sea-Men, and Others that are Studious in Mathematical Practices (London: James Flesher for George Sawbridge, 1669), advertisement, f. a $2 \mathrm{r}$.
} 
Pedagogical promises as made by Leybourn and other mathematically able teachers were found in the pages of books likely to have been beyond many early modern readers, and again the division between literate and illiterate consumers cannot be ignored. However, the mathematically able authors offering education and tuition remind us of the complementary methods of practice that demonstration and orality could add to textual understanding, and it is with this in mind that I wish to draw on one final example from Seller's text: in this case, a copperplate table on time-finding. By advocating the usefulness and portability of the skill of dialling, many seventeenth- and eighteenth-century authors encouraged their readers to see time-finding as something that could take place anywhere that a plane surface could be found. The lines circumscribing dials had an almost universal value if calculated correctly, requiring only the sun overhead, a plane surface below, and a fixed object suitable to cast a shadow.

Dials displayed the almost universal functionality of mathematics, their lines measuring and quantifying the passage of time. Their geometry could be read from texts and instruments aimed at both the novice and expert, with the lines and data of celestial cartography inscribed onto ornate instruments of gold and brass, or those of more quotidian paper and card. The application of its intermingled mathematical practice yoked heavenly spheres and their movements to the fixed, plane surface and a gnomon well below, returning for the diallist quantifiable data that was utilitarian yet impressive in its performance. While the technical proficiency advertised as acquirable by Leybourn and other mathematically able teachers was found in the pages of books likely to have been beyond both the literate and mathematical capabilities of many early modern users, finding the time nevertheless occupied a place in early modern culture some way beyond that of other mathematical endeavours, and its appeal cannot simply be ascribed to leisurely pursuits. ${ }^{94}$ Understanding the mathematical precepts underpinning time-finding —or simply possessing a table or instrument with which to mimic epistemic enquiry-

\footnotetext{
${ }^{94}$ On the misunderstanding of early modern dials and dialing practice, see Jim Bennett, 'Cosmography and the Meaning of Sundials,' in Mario Biagioli and Jessica Riskin, eds., Nature Engaged: Science in Practice from the Renaissance to the Present (New York and Houndmills: Palgrave Macmillan, 2012), pp. 249-262.
} 
consequently helped democratise the early modern empirical knowledge-making practices previously beyond the means of many.

In this manner, John Seller's brief examples of dialling, though simplistic, are entirely in keeping with the methods offered by his contemporaries. Seller's table of dialling is bookended with guidance on just how simply one can construct a limited form of the dial; with a staff of 'any length you please' divided by compasses,

(i)n some plain level place, where the Sun doth shine, set it up right, and mark where the end of the Shadow thereof falls, which done, measure with your Staff, the length of the shadow and note the parts it contains, which find out in this Table, against the day of the Month, and over head, you have the true hour of the day. ${ }^{95}$

As Seller (or his compositor) had done in the letterpress section of the Pocket Book, key referents in the instructional text - in this case, the table, and the data to be found therein - were differentiated by slanting the engraved text. Aligning instruments many surveyors, sailors and gaugers would be likely to have to hand-for example, a measuring staff, compasses, and a plane surface - with the expectation that the table (and, by extension, the Pocket Book) would always be on their person, this level of accessibility was again dependent on Seller convincing his reader that the tables provided would solve their problems both swiftly and adequately. The author's attempts to persuade his reader of just that are found beneath his table:

By this Example, you may see the ease, and excellent use of the Table which is as ready as any movable Sun-Dyal; so that whersoever you are, or travell, you may (having this Book about you) speedly know the true hour. ${ }^{96}$

Outlining the web of relationships between tables, texts, instruments, and their utility, this brief extract adumbrates a transmission of mathematical information that authors such as Seller relied upon. Having conjoined the staff, the compasses, the table, and his instructions to the empirical act of dialling, the merchant placed his Pocket Book at the centre of mathematical endeavour, even as more detailed

\footnotetext{
95 John Seller, Pocket Book, unpaginated, manuscript annotation I: f. 63. Science Museum Library Shelfmark O. B. SEL SELLER 30209019360995. Seller's emphasis.

${ }^{96}$ Seller, ibid. Seller's emphasis.
} 
instruction or explication of the theory of dialling is wanting. Having alternated the engraved text of his example in a similar style to the typefaces used in his letterpress section, Seller engraved his instructional example in an italic hand comparable to that commonly seen on cartographic works of the period. He then drew attention to the importance (and the comparability) of the table, the sundial, and the book by changing the style of his script. Though lacking a coherent understanding of the practice, owners of the Pocket Book could easily have demonstrated their timefinding abilities and, in the cultures of orality and practical manipulation of tools surrounding the ship-yard, field or seas, possessed a means to elevate themselves.

The breadth (if not the depth) of Seller's material means that the Pocket Book cannot be viewed as intended solely for consumption by a moderately-educated seafaring and occupational class. Our view should instead be broadened to include the many potential customers for whom mathematics could play its part: consumers for whom the correspondences between the micro- and macrocosms of the body, the globe of the world, and the wider celestial sphere still held sway. Increasingly reliant on the manipulation of mathematical methods and instruments, if not their understanding, these operators are nevertheless reflective of an idiosyncratic strand of early modern mathematical practice, and one to which Seller largely belongs - a culture moving slowly toward the more defined certitude of the mathematical sciences, yet respectful of existing cosmosophy, computational methods, and celestial correspondences.

It is by no means essential for us to place such consumers at sea. They can be located to a number of interlinked and porous spheres: spheres which intersected the university, the marketplace, and the ship-yard, and brought together the practitioner, the student, and the lay worker. What mattered to Seller was not how his readers intended to use mathematical texts and instruments, but simply that they valued having them: to their producer, the popularity of a pocket book which presented the many applications of mathematics was an opportunity to be exploited.

\section{Study, Use, and Collection: The Pocket Book and its Annotators}

If the printed materials of the Pocket Book evince the worth of broad mathematical compendia geared initially toward a sea-faring and occupational class familiar with 
the consultation of almanacs, zodiacs and tabulae upward, the annotations found in its blank spaces are instead evidence of individuals grappling with more in-depth understandings of mathematical theory. Nevertheless, a striking facet of the Pocket Book's inscriptions is that, even though the annotations appear to be operating at a much higher mathematical level than the printed text, their content is largely reflective of the interests John Seller assumed on the part of his market. The added comments demonstrate continuing levels of interest in many of the astronomical, geometrical and arithmetical elements initially provided by the author; where Seller's tables and examples proffer swift workarounds for interest calculation, positional astronomy and navigation, marginalia were instead used as a means to engage in much greater depth with many of the subjects at hand.

Manuscript evidence allows us to see the commonplacing of authoritative, intertextual tutors as part of a wider learning strategy, and so it is that an excerpt naming its source 'ex P. Herigoino', taken from the six-volume Cursus mathematicus, nova, brevi, et clara methodo demonstratus (published 1634-1637) of Pierre Herigone (Baron Clément Cyriaque de Mangin, 1580-1643) can be identified as being copied verbatim from Isaac Barrow's Latin edition of Euclid's Elements (Euclidis Elementorum, 1655) (Figure 4.8). Often copied out verbatim, these examples occasionally dutifully duplicated references: where Barrow references the work of the pseudonymic Herigone, one annotator followed suit. ${ }^{97}$

\footnotetext{
${ }^{97}$ Seller, Pocket Book, unpaginated, manuscript annotation II: ff. 122-123. Science Museum Library Shelfmark O. B. SEL SELLER 30209019360995. For the annotator's source material, see Isaac Barrow, Euclidis Elementorum Libri XV breviter demonstrati (Cambridge: ex celeberrimæ Academiæ typographeo. Impensis Guilielmi Nealand bibliopolæ, 1655), pp. 329-331.
} 


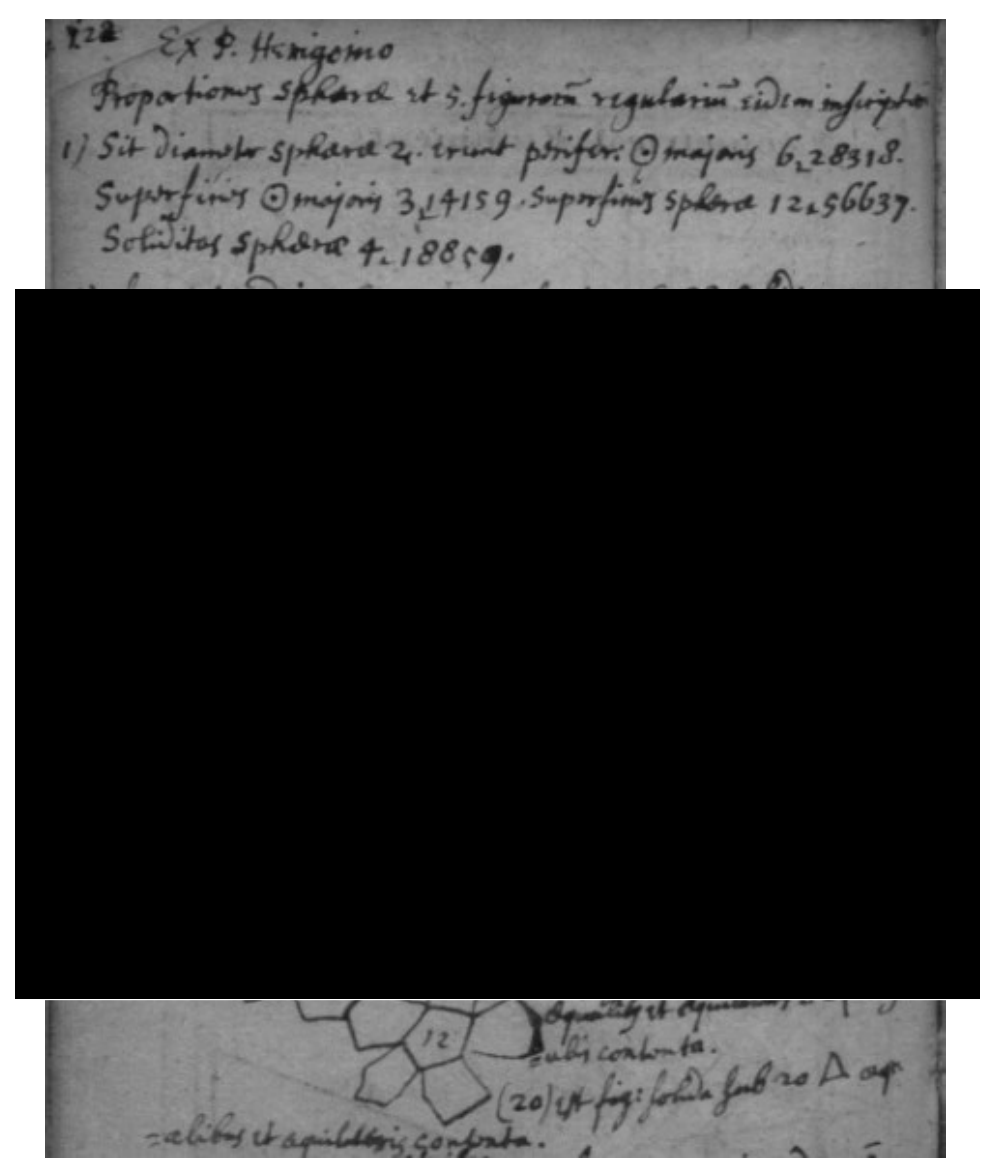

Figure 4.8. Mathematical annotation referencing ' $P$. Herigoino' as excerpted from Isaac Barrow's edition of Euclid, Euclidis Elementorum (1655). Science Museum Library Shelfmark O. B. SEL SELLER 30209019360995.

Pierre Herigone's ratios of proportion between the sphere and the five regular polyhedra (the tetrahedron, cube, octahedron, dodecahedron, and icosahedron) formed part of a grander mathematical encyclopaedia: one commencing with arithmetic, geometry, and analysis, and moving through fortification, gunnery, and navigation, before concluding with astronomy and music. ${ }^{98}$ The gradual ascent through these topics remained in keeping with the educational ideals of the quadrivium, and annotations elsewhere in this copy of the Pocket Book support the conclusion that this text was taken to university and beyond. As is evident from the provenance examples presented at the beginning of this chapter, signatures and bookplates found within the Science Museum copy show at least three clear owners

\footnotetext{
${ }^{98}$ Pierre Herigone, Cursus mathematicus, nova, brevi et clara methodo demonstratus, per notas reales \& universales, citra usum cuiuscunque idiomatis, intellectu faciles, 6 vols. (Paris: Henry Le Gras, 1634-1637). For a detailed treatment of Herigone's Cursus with particular reference to the author's treatment of algebra, see Ma. Rosa Massa Esteve, 'Symbolic Language in Early Modern Mathematics: The Algebra of Pierre Hérigone (1580-1643)', Historia Mathematica, 35.4 (2008), pp. 285-301.
} 
of the Pocket Book, two of whom have helpfully dated themselves: the book's first owner, S(imon) Jenkinson, bought the Pocket Book in its year of publication, and, by 1692, it was in the ownership of Edm(und) Withers.

These two clear hands are visible throughout the Pocket Book's annotation, and an example illustrating the breadth of interests to which a given owner (hereafter referred to as 'Simon Jenkinson') aspired is the reading list which appears in the blank leaves immediately following our title page. Beginning with the field 'Controv. Nat Ph.', and featuring further sections subtitled 'Moral', 'Geog.', and 'Chron.', this handlist is evidence of the reading habits (either actual or proposed) of an owner of Seller's text - likely a youthful undergraduate, seeking to acclimatise to their new surroundings. A number of works referenced, in both English and LatinRichard Hooker's On the Lawes of Ecclesiastical Politie (1594-1597), Hugo Grotius's De Jure Belli ac Pacis (1625), William Chillingworth's The Religion of Protestants: A Safe Way to Salvation (1637) and Henry Hammond's Practical Catechism (1644) - are suggestive of a reader engaged with weighty theological and civic deliberations. The contemporary nature of these concerns is further supported by the inclusion of two texts of Thomas Hobbes's - De Cive (1642), and Leviathan (1668) — alongside a possible reference to John Whitehall's The Leviathan Found Out, or, the answer to Mr Hobbes' Leviathan (1679). ${ }^{99}$

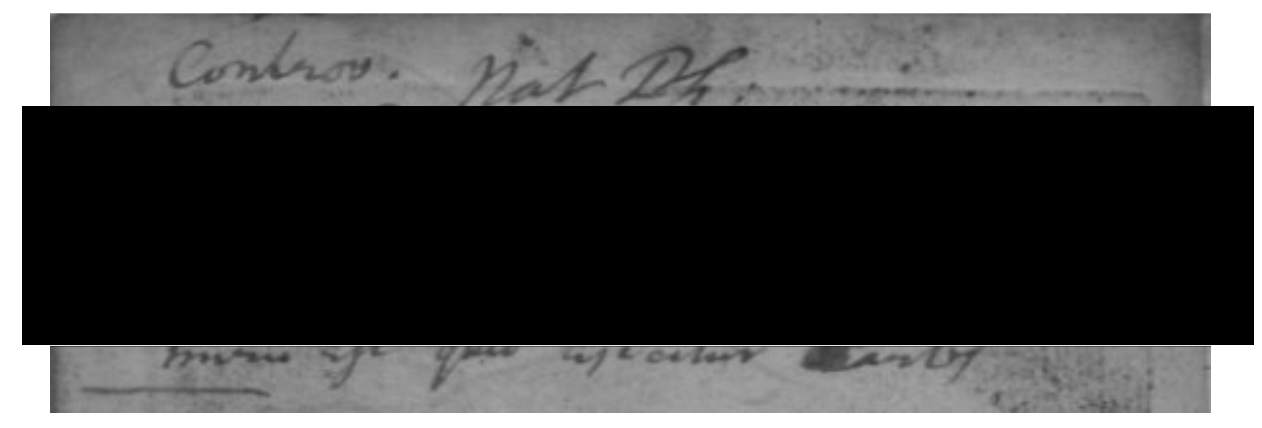

Figure 4.9. An excerpt from the reading list, titled 'Controv. Nat. Ph.'. Latin references to Hooker, Legrand, and Rohault are visible. Science Museum Library Shelfmark O. B. SEL SELLER 30209019360995.

Titles on natural history and the physical structure of the earth also populated the handwritten syllabus, with reference made to the descriptive geography of Peter

\footnotetext{
${ }^{99}$ Seller, Pocket Book, unpaginated, verso of title page and recto of following leaf. Science Museum Library Shelfmark O. B. SEL SELLER 30209019360995.
} 
Heylin, author of a number of geographical works and an enlarged Cosmographie, in Foure Bookes (1652), and to Carolus Clusius's Epitome: most likely his Aromatum, et simplicium aliquot medicamentorum apud Indos nascentium historia (1567), which consisted of revised translations of the journeys of Garcia de Orta, with later editions featuring Clusius' translations of the works of Nicolás Monardes and Cristóvão da Costa. ${ }^{100}$ Sir Walter Raleigh's History of the World, attributed to 'Rawleigh', also features, and is placed beneath an earlier addition of 'Burnetti Theoria Terre': that is, Thomas Burnet's Telluris Theoria Sacra, or, Sacred Theory of the Earth (1681, Latin; 1684, English).

Proto-scientific explorations of experimental knowledge-making were meanwhile accounted for in the works of Robert Boyle and Walter Charleton. Of this collection of texts, only a reference to 'Moxon - On the Globe', likely to be one version of Joseph Moxon's A Tutor to Astronomy \& Geography, or, the use of the Copernican Spheres (1654), can be can be said to evince an interest in practical mathematics, reflecting the initial bloom of this specific individual's burgeoning interest in geography and cosmography. When grouped together, works on natural history, natural philosophy, and the physical structure and contents of the earth demonstrate studies attuned to geographical endeavours. ${ }^{101}$

Beyond the list's title, suggestive as it is of controversies in natural philosophy and, perhaps, all aspects of civic and religious life thereafter, there exists evidence pointing toward ongoing and contemporaneous debates in the groupings of a number of texts. Perhaps the most notable educational development predating the Pocket Book's publication was Aristotle's loss of curricular ascendancy, his physics unseated earlier in the century by the emergence of mechanistic philosophy. The presence on the reading list of Jacques Rohault's popular textbook Traité de Physique (1671) - a text which expounded the mechanical philosophy and could be found at universities across Europe, including Oxford and Cambridge - points to this

\footnotetext{
${ }^{100}$ Brian W. Ogilvie, The Science of Describing: Natural History in Renaissance Europe (Chicago and London: The University of Chicago Press, 2006), pp. 244-238. For Clusius's printing endeavours and relations with the Plantin Press, see Dirk Imhof, Jan Moretus and the Continuation of the Plantin Press: A Bibliography of the Works Published and Printed by Jan Moretus I in Antwerp, Vol. 1: A-M, 2 vols (Leiden: Brill, Hes and De Graaf, 2014), pp. 195-199 and pp. 538-541.

${ }_{101}$ Seller, Pocket Book, unpaginated, verso of title page. Science Museum Library Shelfmark O. B. SEL SELLER 30209019360995.
} 
development as experienced by a contemporaneous reader. Attempts to syncretise biblical and scholastic teachings with Cartesian metaphysics were common particularly amongst Cambridge intellectual circles in the late seventeenth-century, and hybrid versions of this philosophy began to emerge thereafter. ${ }^{102} \mathrm{~A}$ degree of intellectual eclecticism accompanied these efforts, and the transmission of competing philosophical ideas (and their attempted syncretisation) are visible in the Pocket Book's reading list and annotations, in the inclusions of Pierre Gautruche's Philosophiae ac mathematicae totius clara, brevis et accurate institutio (1653) and Rohault's Traité de Physique respectively.

By 1686, the demand for Cartesian texts ensured that the university curriculum had felt the force of Cartesianism, with fellows recommending that students familiarise themselves with not only Descartes and Rohault, but also Henricus Regius (1598-1679) and Antoine Le Grand (1629-1699). ${ }^{103}$ Le Grand in particular was known to British audiences as an expositor and staunch defender of Cartesian principles and their application to natural philosophy, defending Descartes' works against detractors including the Bishop of Oxford Samuel Parker (1640-1688), John Sergeant (ca. 1623-ca. 1710), and Henry More (1614-1687). ${ }^{104}$ Furthermore, it is possible that Le Grand's translation of Rohault's work, and its subsequent popularity, may have motivated Samuel Clarke, a translator of Rohault, to compose the first of his ever-more voluminously annotated critical commentaries on Cartesianism from an avowedly proto-'Newtonian' standpoint. ${ }^{105}$

Some way from the structured, indexical listing of authorities identifiable to early modern humanist teaching, the syllabus appended to the verso of the Pocket

\footnotetext{
102 Stephen Gaukroger, The Collapse of Mechanism and the Rise of Sensibility: Science and the Shaping of Modernity, 1680-1760 (Oxford: Oxford University Press, 2010), p. 21. Gaukroger dubs Rohault's Traité de Physique the 'definitive textbook of Cartesian Natural Philosophy' of the period. See also Ann Blair, 'Natural Philosophy' in Katharine Park and Lorraine Daston, eds., The Cambridge History of Science, Volume 3: Early Modern Science (Cambridge: Cambridge University Press, 2006), pp. 365-405, p. 398.

${ }^{103}$ John Gascoigne, Cambridge in the Age of the Enlightenment: Science, Religion and Politics from the Restoration to the French Revolution (Cambridge: Cambridge University Press, 1988), p. 55. ${ }^{104}$ Sarah Hutton, British Philosophy in the Seventeenth Century (Oxford: Oxford University Press, 2015), pp. 67-68.

${ }^{105}$ Minhea Dobre, 'Rohault's Cartesian Physics' in Mihnea Dobre and Tammy Nyden, eds., Cartesian Empiricisms (Dordrecht: Springer Science + Business Media, 2013), pp. 203-226, particularly pp. 207-208. For Clarke's intermingling of theology and Newtonian physics, see Thomas C. Pfizenmaier, The Trinitarian Theology of Dr. Samuel Clarke (1675-1729): Context, Sources, and Controversy (Leiden, New York and Cologne: Brill, 1997), particularly pp. 76-85.
} 
Book's title page nonetheless helps to situate our annotators at Cambridge in the late seventeenth century, where a number of these texts were produced by local printers. Investigations into the activities and book-sellers of the University environs mark John Creed and Edward Story as willing proprietors of mathematical and scientific texts, even if the London trade naturally dominated. Creed sold editions of Walter Charleton's Oeconomica animalis (1669) printed in Cambridge, whilst Pierre Gautruche's works were printed by Edward Story in 1668, and again by Richard Green in $1683 .{ }^{106}$ The influence of Isaac Newton and, indeed, of Henry Jenks on Cambridge reading can be seen in the titles of Bernardhus Varenius (1622-1650) and Le Grand; their works intermingled with the established authors populating the Pocket Book's front flyleaves. ${ }^{107}$

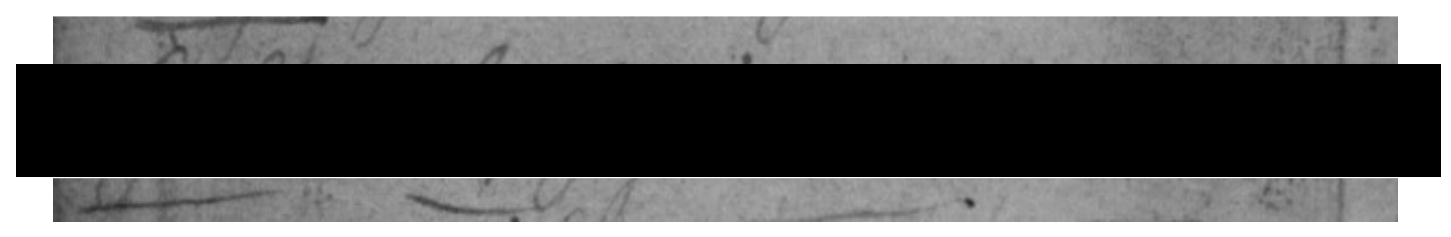

Figure 4.10. From the reading list, 'Galtruchii, Instit. Mathemat.', likely referring to Pierre Gautruche's Mathematicae totius institutio (1653). Science Museum Library Shelfmark O. B. SEL SELLER 30209019360995.

Evidently, the texts found in the reading list reflect the intellectual curiosity permeating university cloisters in the late seventeenth and early eighteenth centuries. Annotations found throughout the text bear witness to a vibrant early modern mathematical culture and its reading practices in this environment. A curious fact of the dual annotators at work in the pages of this precise Pocket Book is that where 'Jenkinson' appears to have put his pen down, 'Edmund Withers' will then pick his up: often, to write on a closely related topic. Of the book's 247 leaves, almost exactly one third (81) are annotated, with the contents often most focussed on practices interlinked by spherical trigonometry (Figure 4.11).

\footnotetext{
${ }^{106}$ David McKitterick, A History of Cambridge University Press, Volume One: Printing and the Book Trade in Cambridge, 1534-1698 (Cambridge: Cambridge University Press, 1992), pp. 370-371.

${ }^{107}$ McKitterick, ibid, pp. 365-366.
} 


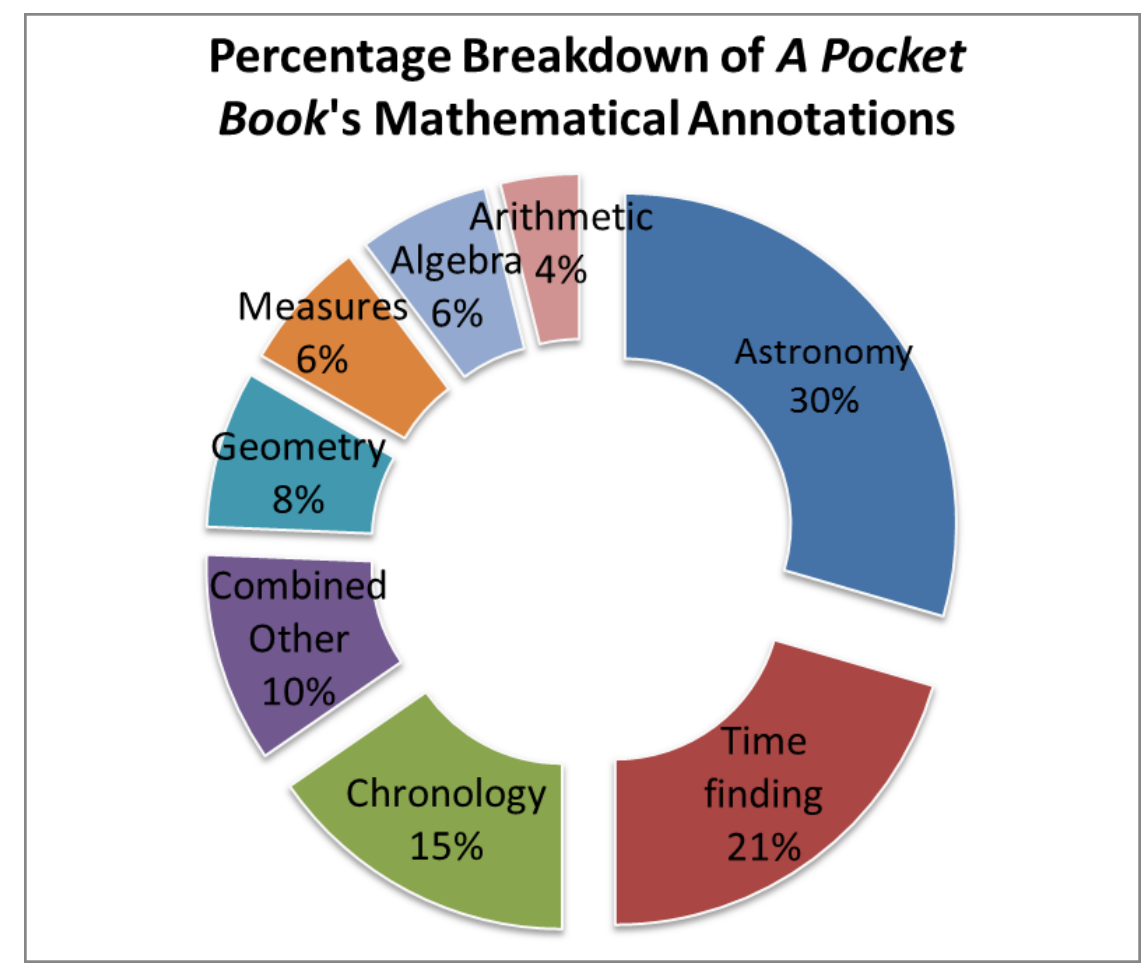

Figure 4.11. Exploded chart showing the percentage breakdown of the annotated leaves of the Science Museum's copy of John Seller's Pocket Book, as owned by Simon Jenkinson and Edmund Withers.

Although 'Simon Jenkinson' appears only occasionally in this copy of Pocket Book, the author who noted Joseph Moxon's text on the celestial and terrestrial globes also appeared to copy out a detailed excerpt reproduced from the 1626 commentary on Sacrobosco's De Sphaera of the Leiden professor Franciscus Burgersdicius (Franck Pieterszoon Burgersdijk, 1590-1635) (Figure 4.12). ${ }^{108}$

108 Seller, Pocket Book, unpaginated, manuscript annotation II: f. 92. Science Museum Library Shelfmark O. B. SEL SELLER 30209019360995. For Burgersdijk's source material, see Franciscus Burgersdicius, Sphaera Iohannis de Sacro Bosco, decreto in usum scholarum ejusdem provinciae recensita ut et latinitus et methodus emendata sit (Leiden: ex officina Bonaventurae et Abrahami Elzevier, 1626), pp. 97-98. 


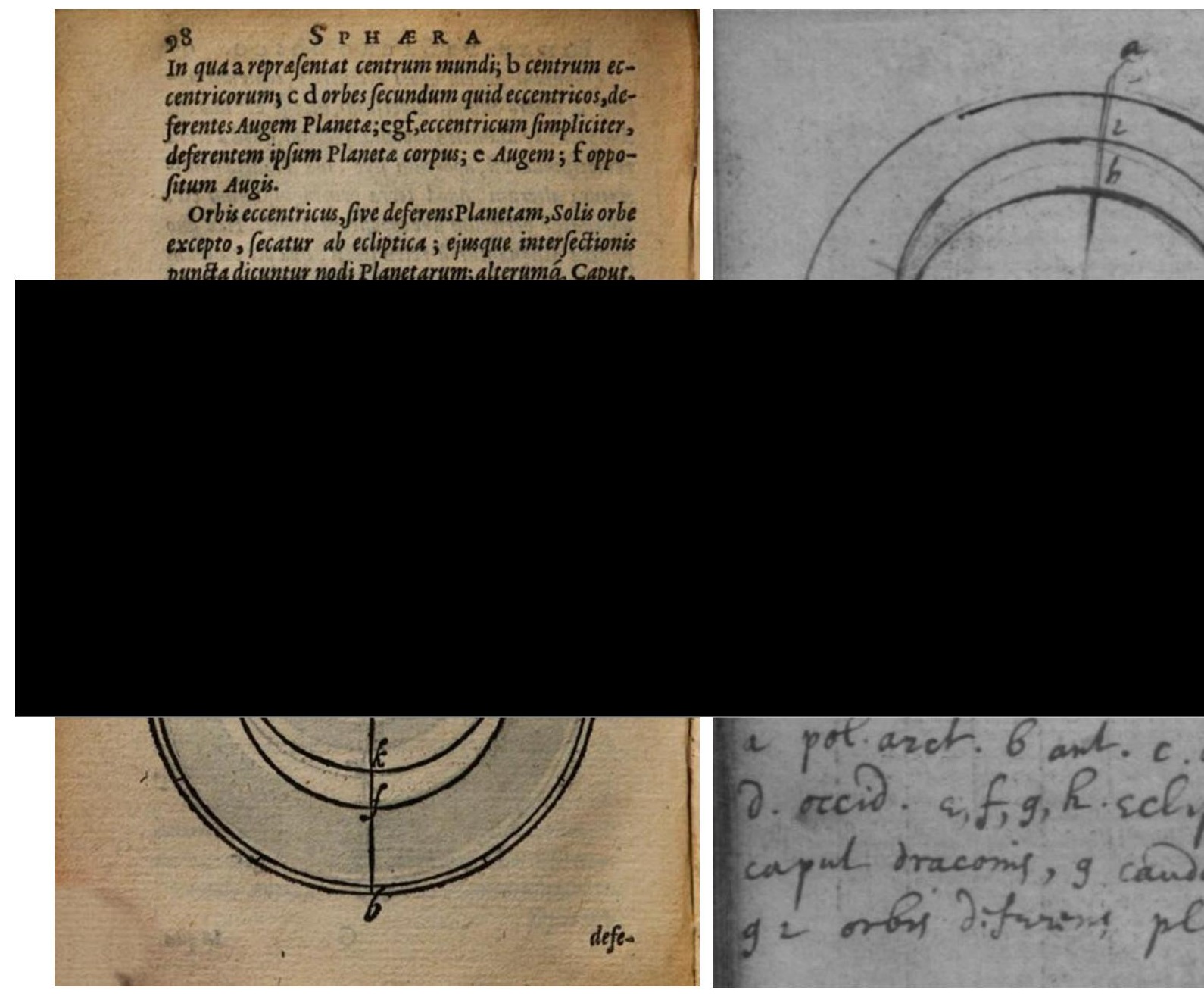

Figure 4.12. Comparison of Burgersdijk's commentary on De Sphaera (left) and annotated excerpt in the Museum Library Shelfmark O. B. SEL SELLER 30209019360995. 
Taken from Burgersdijk's commentary on the fourth chapter of De Sphaera Mundi, this excerpt details movements and circles - the equants, deferents, and epicycles - of each planet, and describes the causes of eclipses, with the diagram focused on lunar eclipses. The Sacroboscan text detailed the manner in which the lunar deferent (the eccentric circle carrying the body of the moon as 'planet') intersects the ecliptic in two distinct places. The line of this slant, drawn between the North and South lunar nodes (e and g) was from ancient times deemed akin to the shape of a great dragon. ${ }^{109}$ In Figure 4.12, then, A is the Arctic pole, B the Antarctic; points $\mathrm{C}$ and $\mathrm{D}$ are the orient and occidental respectively, namely, the Eastern and Western parts of the Horizon. The circle EFGH draws the ecliptic, with e the caput draconis, or dragon's head (the small e appears to be expressed variously as E and e in the notes below this diagram) and g its tail, or cauda. The circle EKGI, the 'orbis deferens planetam', is the eccentric which itself 'carries' the planet.

Burgersdijk's treatment of Sacrobosco was neither controversial nor revelatory. In fact, its elementary content was as in keeping with its author's broader commitment to conservative scholasticism as his style of pedagogic presentation, in which materials were presented in a straightforward manner. There was much to be said for this approach: Burgersdijk's works were popular in Leiden and beyond throughout the seventeenth century, each printed in multiple editions. ${ }^{110}$ In many ways, their structure and plain speaking were a boon to the undergraduate. As Mordechai Feingold has convincingly shown, the Leiden professor's textbooks performed a dual role in English universities in the period between circa 1620 and 1750. Initially, the pedagogue was lionized as part of the philosophical bulwark of the Leiden school, seen as part of an eclectic neo-Aristotelianism, and valued as part of the historical lineage central to the study of logic, ethics, and natural philosophy; having fulfilled this role, his works were then repurposed as an introductory precis

\footnotetext{
${ }^{109}$ Lynn Thorndike, The Sphere of Sacrobosco and its Commentators (Chicago: University of Chicago Press, 1949), pp. 141-142.

${ }^{110}$ M. J. Petry, 'Burgersdijk's Physics' in E.P. Bos and H. A. Krop, eds., Franco Burgersdijk (15901635): Neo-Aristotelianism in Leiden (Amsterdam and Atlanta, GA: Rodopi, 1993), pp. 83-118, p. 101. Petry remarks that the 'workmanlike' nature of Burgersdijk's Collegium Physicum (1632) was clearly no impediment to its success.
} 
for eighteenth-century students before they duelled with more up-to-date authorities. $^{111}$

Detailed annotation some twenty pages prior to the ecliptic manuscript diagram is proof of this second category. Theories on celestial mechanics were clearly of interest to one annotator: before a printed table of fixed stars, a lengthy excerpt, concerned with the correct description of the parts of the celestial sphere and written by the same hand as the book list - likely that of Simon Jenkinson - has clearly been copied from a number of chapters from the first book of Pierre Gassendi's astronomical textbook Institutio astronomica (1647) (Figure 4.13). ${ }^{112}$

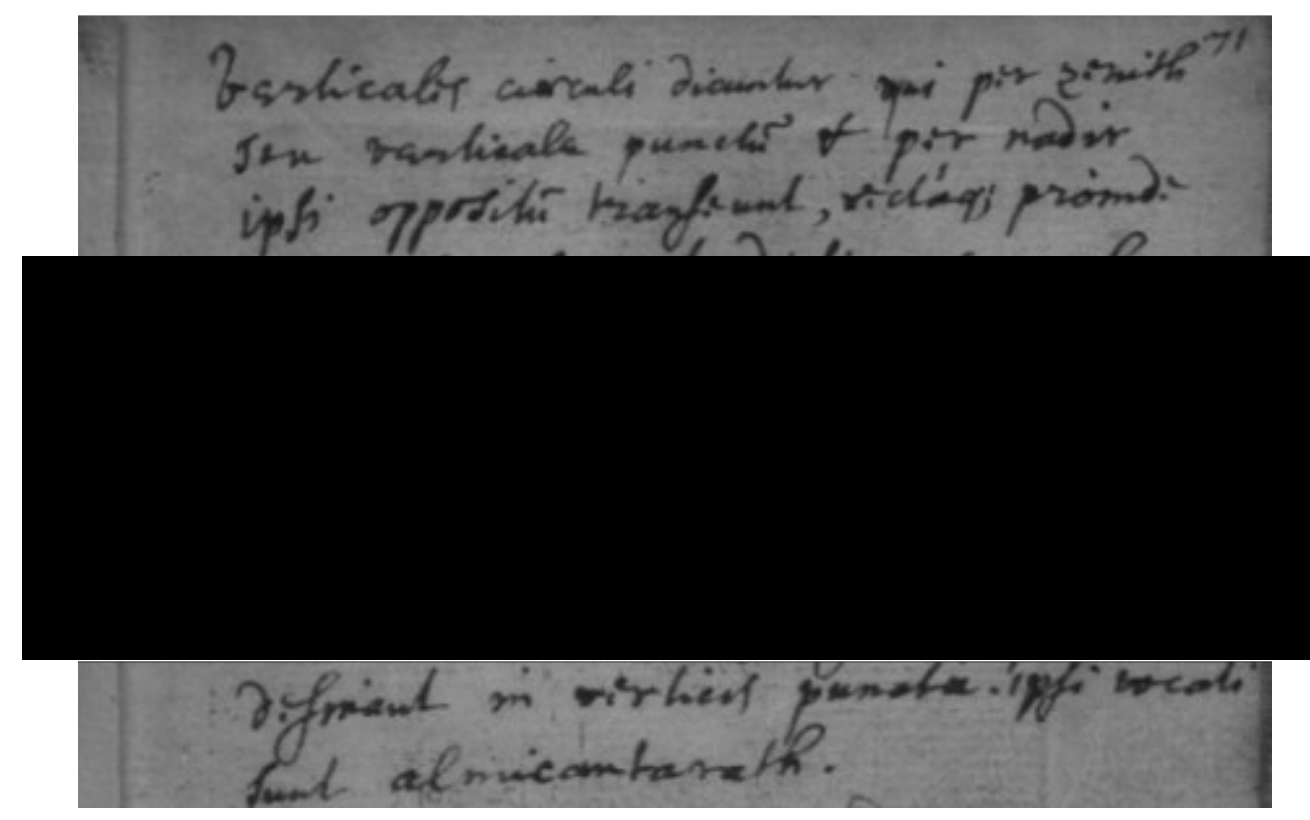

Figure 4.13. Image displaying annotations copied from Book 1, Chapter 13 of Pierre Gassendi's Institutio astronomica (1647). Science Museum Library Shelfmark O. B. SEL SELLER 30209019360995.

That the manuscript annotations resemble Gassendi's text is clear: the first four lines of the image above can be usefully compared with the original text, which reads:

\footnotetext{
${ }^{111}$ Mordechai Feingold, 'The Ultimate Pedagogue: Franco Petri Burgersdijk and the English Speaking Academic Learning' in E. P. Bos and H. A. Krop, eds., Franco Burgersdijk (1590-1635): Neo-Aristotelianism in Leiden (Amsterdam and Atlanta, GA: Rodopi, 1993), pp. 151- 166, p. 153. ${ }^{112}$ Seller, Pocket Book, unpaginated, manuscript annotation II: f. 71. Science Museum Library Shelfmark O. B. SEL SELLER 30209019360995. The materials excerpted from Gassendi's work run from II: ff. 71-87, and are unrelated to the printed materials of John Seller which appear in this section of the Pocket Book. See Pierre Gassendi, Institutio Astronomica, juxta Hypotheseis tam Veterum, quam Copernici, et Tychonis (Paris: Ludovic de Heuqueville, 1647), pp. 33-77.
} 
Verticales itaque circuli dicuntur, qui per Zenith, seu verticale punctum, et per Nadir ipsi oppositum transeunt; rectaque proinde horizontem secant. ${ }^{113}$

Although the marginalia veer slightly away from an exact transcription thereafter, a series of excerpts belonging identifiably to Institutio astronomica follow, culminating in a diagram copied from chapter 24, De Hebdomade, concerning the seven known planets (the Moon, Mercury, Venus, the Sun, Mars, Jupiter and Saturn), their positions in the heavens, and their dominion over the days of the week (Figure 4.14). ${ }^{114}$

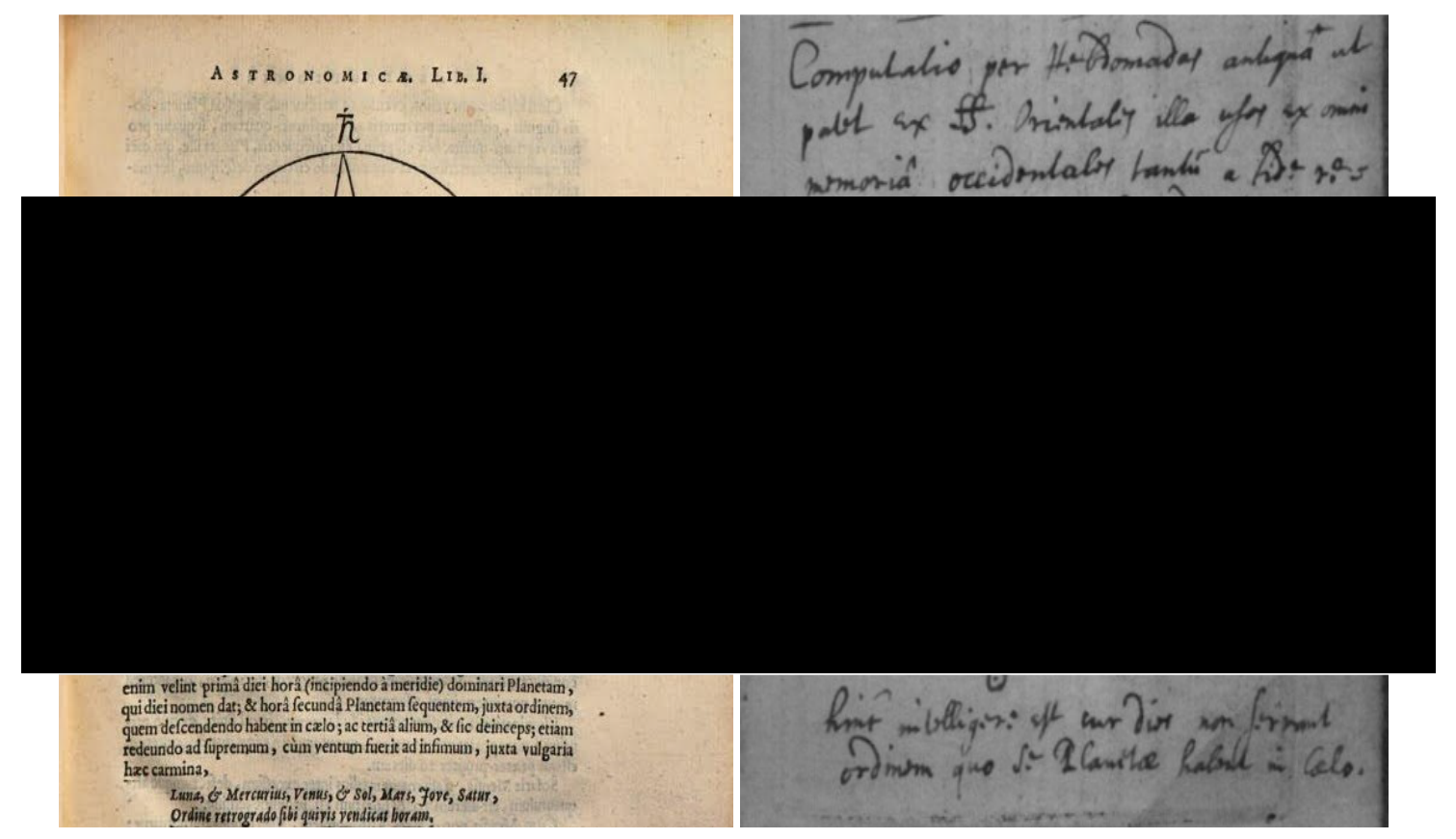

Figure 4.14. Comparison of Book 1, Chapter 24 of Gassendi's Institutio Astronomica, 'De Hebdomade' (left) and annotated excerpt from the Pocket Book (right). Science Museum Library Shelfmark O. B. SEL SELLER 30209019360995.

As might be expected, Gassendi's course on astronomical theory - as taught by its author at the Collège Royal, Paris - began by introducing the study of spherical kinematics and its precepts, operating within the familiar confines of the wider Sphaera tradition as initiated by Johannes de Sacrobosco (ca. 1195-ca. 1256), before moving on to presentations of theoricae and the relative merits of the Tychonic and Copernican world systems. Institutio astronomica was commonly

\footnotetext{
${ }^{113}$ Gassendi, Institutio Astronomica, p. 33.

${ }^{114}$ Seller, Pocket Book, unpaginated, manuscript annotation II: f. 79. Science Museum Library Shelfmark O. B. SEL SELLER 30209019360995.
} 
employed by university educators and their pupils from its publication onwards, featuring as it did on curricula on both sides of the Atlantic well into the eighteenth century. ${ }^{115}$ The close reworking of the text suggests that 'Jenkinson' was, in this instance, copying materials for swift retrieval at a later point, getting the gist of Gassendi's words for interpretation and later re-presentation.

By viewing the commonplace annotations of the Pocket Book as most consistently concerned with astronomy, time-finding, and technical chronology - that is, the calculation of historical, religious, and 'mythical' events, for scriptural exegesis and historical virtuosity - it is possible to reintroduce 'Edmund Withers', whose annotations allow the printed and manuscript materials comprising John Seller's volume to overlap once again. In keeping with the medieval computus tradition that underpinned the entirety of the continuous manuscript and print production of almanacs and Easter tables, ${ }^{116}$ John Seller had contented himself with printing a series of tables of arithmetical data for users to calculate the timing of religious feasts by cross-reference. While imperative annotations also advised the reader to return to data secreted elsewhere in the Pocket Book in manuscript, additions to the text supplemented its printed materials with hand-drawn circles of analogue computation. In one such example, 'Edmund Withers' outlined with technical specificity the moon's current cycle. 'Withers' concerned as he was with lunar and solar time, the Golden Number, and various religio-calendrical calculations, noted the importance of storing mathematically precise material amongst matters theological - marking that such data could be stored alongisde the calendrical information found in the Book of Common Prayer (Figure 4.15). ${ }^{117}$

\footnotetext{
${ }^{115}$ Owen Gingerich, 'Five Centuries of Astronomical Textbooks and their Role in Teaching', in Jay M. Pasachoff and John R Percy, eds., The Teaching of Astronomy: Proceedings of the 105th International Astronomical Union (IAU) Colloquium, held in Williamstown, Massachusetts, July 2630, 1988, (Cambridge: Cambridge University Press, 1990), pp. 192-195, p. 192. Lynn Sumida Joy, Gassendi the Atomist: Advocate of History in an Age of Science (Cambridge: Cambridge University Press, 1987), pp. 195-196. Antoni Malet, 'Kepler's Legacy: Telescopes and Geometrical Optics, 1611-1669' in Albert van Helden, Sven Dupré, Rob van Gent, and Huib Zuidevaart, eds., The Origins of the Telescope, (Amsterdam: Knaw Press, 2010) pp. 281-300; particularly pp. 287-288. Mel Gorman, 'Gassendi in America', Isis, 55, 4 (1964), pp. 409-417, particularly pp. 413-414. ${ }^{116}$ For the history of the calculation and use of Easter tables, see Stephen C. McCluskey, Astronomies and Cultures in Early Medieval Europe (Cambridge: Cambridge University Press, 1998), pp. 80-87. ${ }^{117}$ Seller, Pocket Book, unpaginated, manuscript annotation I: f. 19. Science Museum Library Shelfmark O. B. SEL SELLER 30209019360995. I am grateful to Stephen Johnston for providing additional clarification on this annotation.
} 


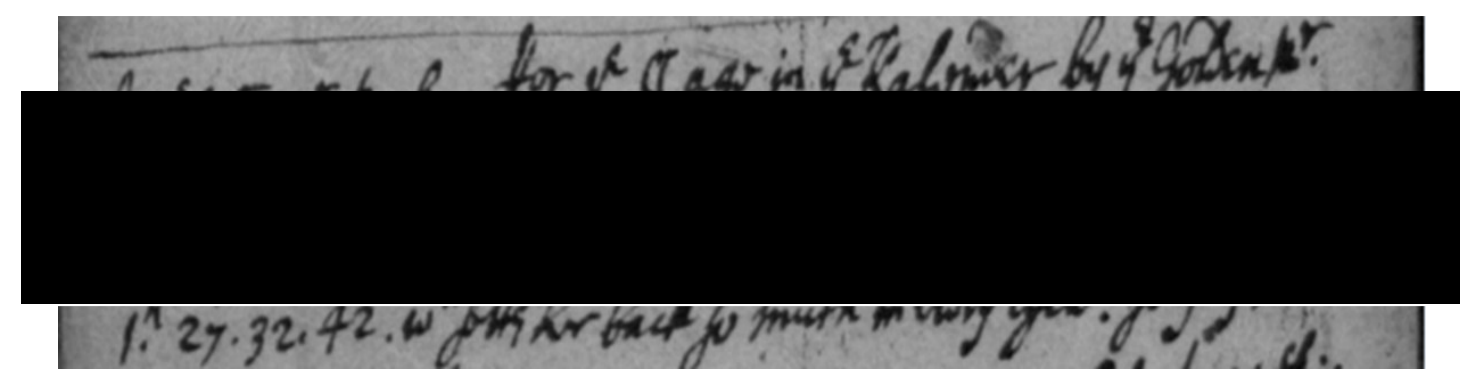

Figure 4.15. Edmund Withers's calendrical annotation. The text reads 'in ye Com[m]on Pr[ayer] Book, stor the moon's age in ye Kalender by ye Golden Number. The (moon's) cycle is not exactly 19 years, but falls short of that full space 1h. 27'. 32',. 42',' which setts h(e)r back so much in every cycle.' Science Museum Library Shelfmark O. B. SEL SELLER 30209019360995.

Hence 'Jenkinson's' copying of the hebdomade were not just a means to situate the majesty of the seven observable planets in the skies above, but were used by 'Edmund Withers' as part of a wider chronological study to link astronomical occurrences to the factuality of historical events by means of mathematical certainty. As Charles Leadbetter wrote in the second edition of $A$ Compleat System of Astronomy (1742), the seven days of the week were hebdomadal, and were made so that the planets above would be 'the lords thereof.' 118 Leadbetter, using a diagram almost identical to Gassendi's, explained how 'the seven Planets are placed in their Order round the Figure as they are in the Heavens' before listing each as a 'Governor' of their corresponding day. ${ }^{119}$ Ultimately, this chronology was put to hermeneutic work. Understanding the form and movement of the heavens meant that the entirety of human history could be chronicled, its events subjected to systematic analysis.

The Pocket Book's next owner, Edmund Withers, surpassed the materials provided by both John Seller and Simon Jenkinson by collating additional sources so as to apply incontrovertible mathematical data to the reading of calendrical, historical and scriptural information. In another densely annotated section, an annotator deposited portions from his reading of Joseph Scaliger's De Emendatione Temporum (1583) into his pocket-book without correction or commentary so as to learn the interpretative framework of the Julian period as proposed by the author for

\footnotetext{
${ }^{118}$ Charles Leadbetter, A Compleat System of Astronomy in Two Volumes (London: Printed for J. Wilcox, 1742), p. 64.

${ }^{119}$ Leadbetter, ibid.
} 
the orderly succession of historical epochs. ${ }^{120}$ The combination of historical reports, astronomical events, and horological calculations Scaliger used to systematize Babylonian, Chaldean, Persian, Greek and Roman eras formed for this user the bedrock of his chronological study. More broadly, the works of the Huguenot theorist held significant sway with scholars and neophytes throughout the seventeenth century.

Testing historical reports against quantitative celestial data allowed early modern chronologists to compute events down to their nearest second, and to test these events against historical reports and scriptural exegesis. As Anthony Grafton has suggested, the appeal of chronology was only strengthened by the idea that it 'offered perhaps more opportunities than any other field for the display of extravagant erudition and divinatory virtuosity. ${ }^{121}$ For those enamoured with learning, the recovery and correction of ancient authority, and the opportunity to advance all human knowledge, a method that unified astronomy, theology, mathematics, and historical inquiry was intoxicating.

Analysis of annotations belonging to both 'Simon Jenkinson' and 'Edmund Withers' clearly demonstrates that both possessed a pronounced interest in chronological computation, the ages of the moon, and ways and means of calculating Easter for eternity (Figure 4.16). ${ }^{122}$ The extensive nature of these annotations again draws us toward a view of the annotator as a student, and particularly one at Cambridge. Samuel Blythe, master of Clare College between 1678 and 1713, recommended both Burgersdijk's texts on logic and Gassendi's Institutio astronomica to his pupils, and Blythe's students also purchased copies of other texts found on the reading list: works such as Henry Hammond's Practical Catechism (1644) and William Cave's Primitive Christianity: or, the Religion of the ancient Christians in the first Ages of the Gospel (1672). ${ }^{123}$ The Cambridge professor and

\footnotetext{
${ }^{120}$ Seller, Pocket Book, unpaginated, manuscript annotation I: ff. 28-32. Science Museum Library Shelfmark O. B. SEL SELLER 30209019360995. Joseph Juste Scaliger, Opus novum de emendatione temporum in octos libros tributum (Paris: Sébastien Nivelle, 1583).

121 Anthony Grafton, 'Some Uses of Eclipses in Early Modern Chronology', Journal of the History of Ideas, 64.2 (2003), pp. 213-229, p. 220.

${ }^{122}$ Seller, Pocket Book, unpaginated, particularly manuscript annotation I: f. 19 and I: ff. 23-42. Science Museum Library Shelfmark O. B. SEL SELLER 30209019360995.

${ }^{123}$ David McKitterick, A History of Cambridge University Press, Volume One: Printing and the Book Trade in Cambridge, 1534-1698 (Cambridge, Cambridge University Press, 1992), pp. 363-365.
} 
tutor James Duport's (1606-1679) rules for his tutorial pupils commanded that students must 'carry (...) Chronology \& Geography along with you, or els you will miserably loose your self', and other pedagogues strongly advised undergraduates to familiarise themselves with chronology in their studies of both astronomy and history. ${ }^{124}$

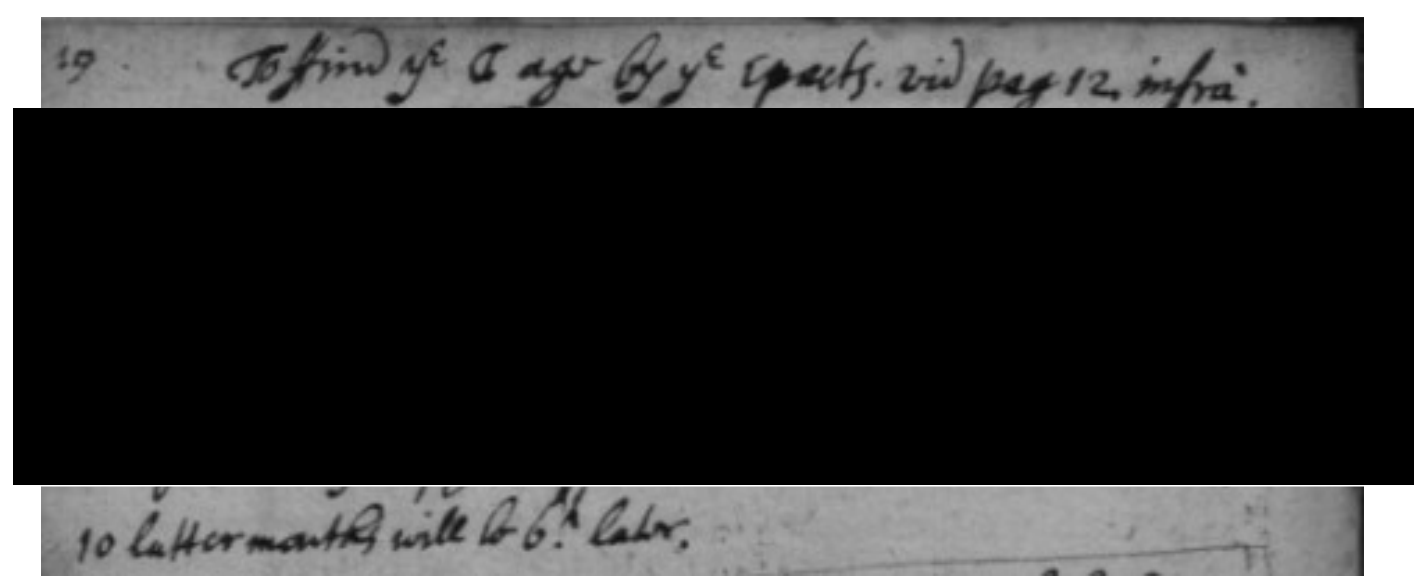

Figure 4.16. Annotation from John Seller's Pocket Book instructing a reader on how to find the moon's age by use of epacts: reference is also made to other pages of notes ('vid pag. 12 infra') in the volume. Science Museum Library Shelfmark O. B. SEL SELLER 30209019360995.

As with Cartesianism and mechanical philosophy, by 1700 disagreement dogged chronologist authors. Divisions and contested historiographies divided the field into warring factions: 'English versus French; Christian versus non-Christian; Catholic versus Protestant; classicist versus mediaevalist. ${ }^{125}$ If nothing else, the heatedness of these arguments demonstrates the vibrancy of the discipline in the decades preceding the turn of the eighteenth century. In England, the disciplinary promise of chronology, and its intersecting of mathematics, theology, and history, remained attractive: its acolytes included William Whitson, who in 1717 attempted to delineate the mathematical proofs of religion while simultaneously promoting a Newtonian world system.

\footnotetext{
${ }^{124}$ C. D. Preston and P. H. Oswald, 'James Duport's Rules for his Tutorial Pupils: A Comparison of Two Surviving Manuscripts', Transactions of the Cambridge Bibliographical Society, 14.4, (2011), pp. 317-362, p. 351. Scott Mandelbrote, 'The Doors Shall Fly Open’: Chronology and Biblical Intepretation in England, c. 1630-c.1730' in Kevin Killeen, Helen Smith, and Rachel Willie, eds., The Oxford Handbook of the Bible in Early Modern England, c. 1530-1700 (Oxford: Oxford University Press, 2015), pp. 176-195, p. 178.

125 James William Johnson, 'Chronological Writing: Its Concepts and Development', History and Theory, 2 (1962), pp. 124-145, p. 137.
} 
Whiston's efforts to popularise this mathematico-religious cosmology incorporated an extensive portrayal of Newton's theories on gravitation, matter, and motion, as well as measurements of celestial bodies and their movements; alongside these were placed scriptural exegesis, historical narratives, and population demographics, so that the 'ordinary Mathematicians' of his readership 'may easily apprehend the Force of each Argument, and see the Evidence for the several Conclusions all along. ${ }^{126}$ Newton himself offered mathematical means as part of a wider exploration to test the dating of historical, biblical, and mythic narratives. Calculating the travails of Jason and the Argonauts backward from 1689, he summarised that at a rate of 72 years to a degree, the measured movement of equinoctial colures indicated that the Argo's voyage took place 2627 years before, or 43 years after the death of Solomon. ${ }^{127}$

By the time of the posthumous publication of Newton's The Chronology of Ancient Kingdoms Amended (1728), biblical chronology had retained its academic and theological value in the minds of pedagogues and of divines. As the century progressed, though chronological calculations gradually gained traction amongst lay readers, the esoteric means of their finding perhaps adding to the mystique and grandeur of the discipline, its study simultaneously came to be disavowed in scholarly circles. ${ }^{128}$ For the annotators of this copy of Seller's Pocket Book, however, chronological concerns were clearly worth noting.

\section{Consistently excerpting materials of a chronological bent, 'Edmund} Withers's' manuscript measurements of time were further ballasted by annotation concerning the powers and physical properties of the seven planets and their relation

\footnotetext{
${ }^{126}$ William Whiston, Astronomical Principles of Religion, Natural and Reveal'd in Nine Parts (London: John Senex, 1717), p. 26.

${ }^{127}$ Isaac Newton, The Chronology of Ancient Kingdoms Amended (London: Printed for J. Tonson, J. Osborn, and T. Longman, 1728), p. 91. On the social, political and historical aspects of Newton's narrative attempts, particularly with reference to the Argonauts, see Kenneth J. Knoespel, 'Newton in the School of Time: The Chronology of Ancient Kingdoms Amended and the Crisis of SeventeethCentury Historiography', The Eighteenth Century, 30.3 (1989), pp. 19-41, pp. 32-33. For a detailed treatment of every aspect of Newtonian chronology and its roots in erudite study, see Jed Z. Buchwald and Mordechai Feingold, Newton and the Origin of Civilization (Princeton, NJ: Princeton University Press, 2013).

${ }^{128}$ Mandelbrote 'The Doors Shall Fly Open', pp. 191-192. On the fall of chronology into disrepute, see Johnson, Chronological Writing, p. 145. Earlier instances of chronology's fall from grace in Europe, though not England, can be found in Anthony Grafton, 'Joseph Scaliger and Historical Chronology: The Rise and Fall of a Discipline', History and Theory, 14.2 (1975), pp. 156-185.
} 
to calendrical historiography. Observations of celestial motion also appear to have been valued for their relevance to the introduction of the Gregorian calendar, and a significant portion of annotations concern, in Latin, the various calendrical efforts of a number of societies: beginning with the Hebrew horologists of antiquity, these notes include descriptions of the basic Hebrew unit of time, the helakim, 1080 of which were equivalent to the 60 minutes of an hour. Paragraphs on the civic and religious importance of earlier horologic efforts on the part of Babylonian, Chaldean, Jewish, Greek and Roman societies pre-empt a more detailed analysis of the work of the First Council of Nicaea (AD 325) and the history of the switch from the Julian calendar to the Gregorian. ${ }^{129}$

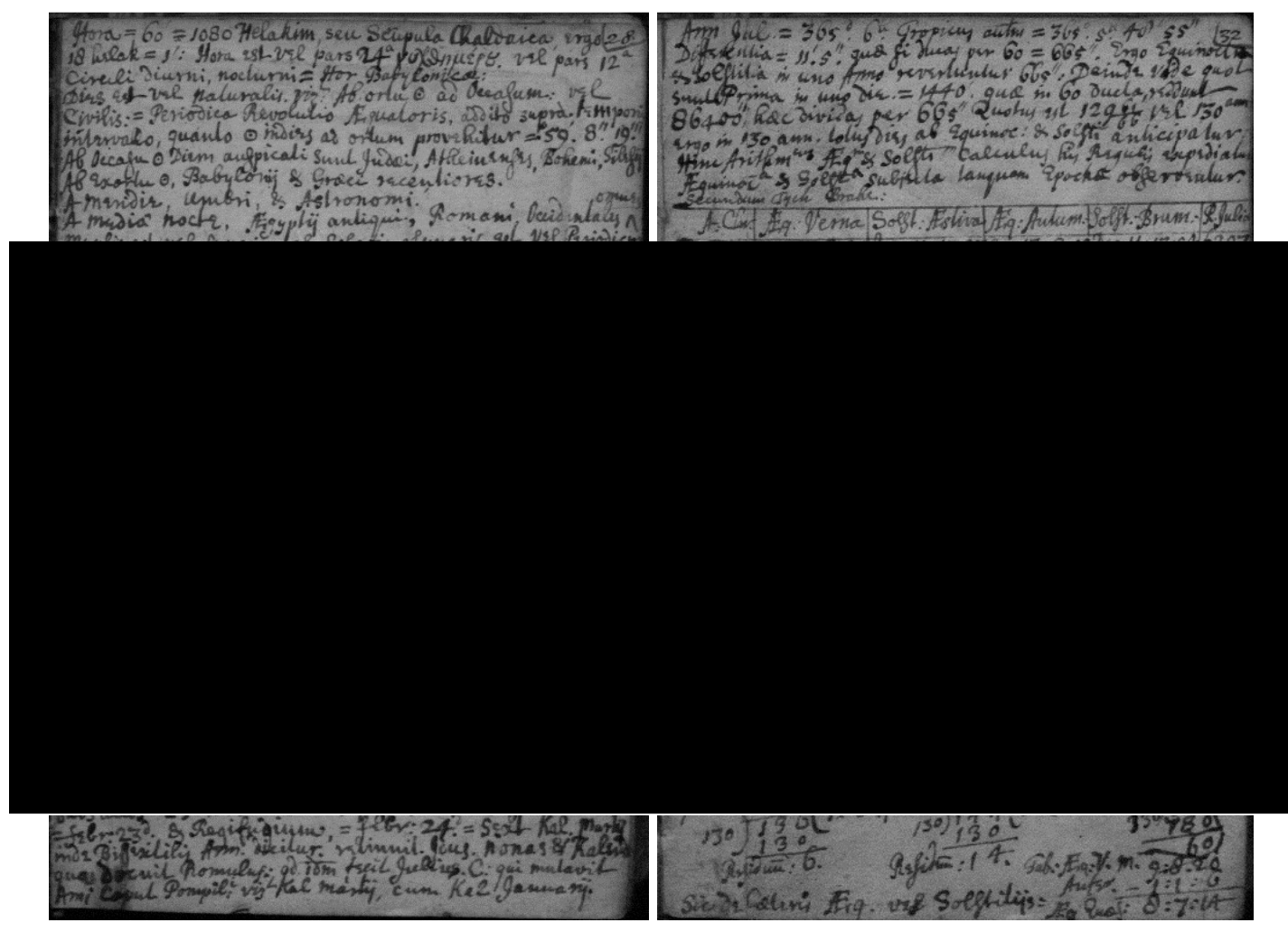

Figure 4.17. Examples of extensive chronological narrative and mathematical working by 'Edmund Withers'. Science Museum Library Shelfmark O. B. SEL SELLER 30209019360995.

The volume of these examples make readily apparent just how fixated Withers was on time, its calculation, and its wider theological and horological importance. Where Seller printed data on the Dominical Letter, and produced means

\footnotetext{
${ }^{129}$ Seller, Pocket Book, unpaginated, manuscript annotation I: ff. 31-32. Science Museum Library Shelfmark O. B. SEL SELLER 30209019360995.
} 
to identify days, weeks, months, and feasts, 'Withers's' annotations follow up with detailed manuscript notes sourced from elsewhere - perhaps the product of private tuition, or of additional, directed reading of other sources. That Edmund Withers's manuscript measurements of time followed on from his predecessor's commonplacing of the hebdomade therefore showcases the desires of a student to further ballast authoritative excerpts from Institutio astronomica with annotation concerning the powers and physical properties of the seven planets and their relation to calendrical historiography. Such operations can be delineated as commonplacing 'systematic' rather than 'humanistic' chronology, being as they were evidence of the use of technical methods to ascertain calendrical data ancient and modern, rather than for the benefit of textual recovery or editing. ${ }^{130}$

The overall effect is to produce a collation of text and manuscript demonstrating this owner's personal interest in the theory, practice, and narrative of time-finding in early modern England, and 'Withers' may have been taken with this interest at an earlier point. Additional notes describing the finding of the true meridian through the manual production of a dial with a 'wyre erected perpendicular' are in a looser, more juvenile hand, and are perhaps reflective of the annotator's introduction to mathematical dialling at a young age (Figure 4.18). ${ }^{131}$

\footnotetext{
${ }^{130}$ Anthony Grafton, Defenders of the Text: The Traditions of Scholarship in an Age of Science, 14501800 (Cambridge, MA: Harvard University Press, 1991), p. 120.

${ }^{131}$ Seller, Pocket Book, unpaginated, manuscript annotation I: f. 57. Science Museum Library Shelfmark O. B. SEL SELLER 30209019360995.
} 


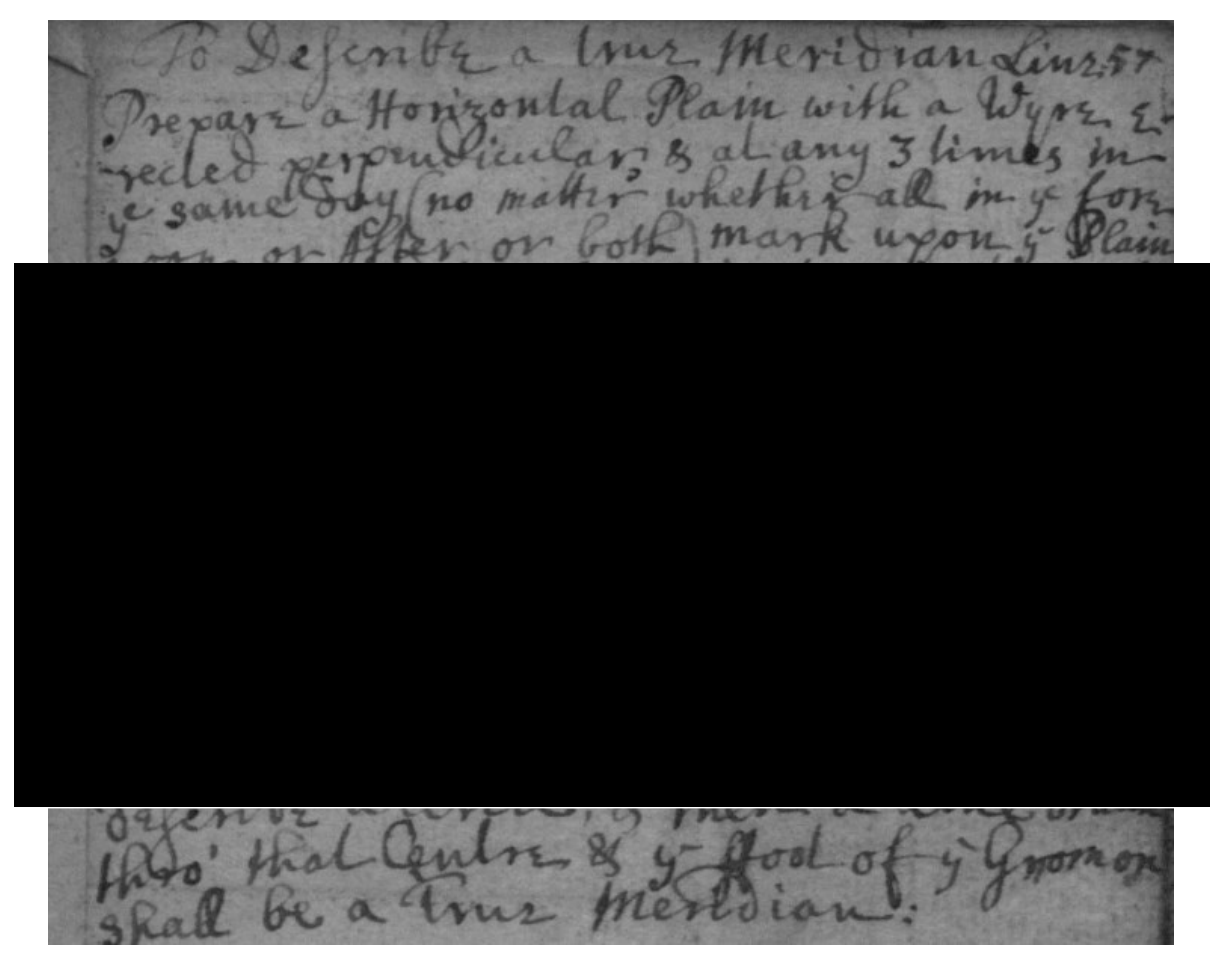

Figure 4.18. An example of a juvenile hand - possibly a later user than 'Edmund Withers', annotating on the finding of 'a true meridian line'. Science Museum Library Shelfmark O. B. SEL SELLER 30209019360995.

Evidence suggests that 'Jenksinon' and 'Withers' left and returned to the Pocket Book to deposit information as it was gleaned from other texts. The space surrounding printed data indicating the times of tides, the likely achievable height of iron, lead and stone shot, and the correct use of staff and compass was used as an aide-memoire, a testing ground for the working of problems, and, simply, as something to be filled with whichever commonplaces or excerpts a user might choose from other authors. ${ }^{132}$ The idea of the Pocket Book being used as a repository for studious commonplacing finds further support elsewhere within the volume, though it is at times challenging to say with certainty whether we are looking at the annotating hand of one student, or several. Where the hands that annotated this volume are often difficult to untangle, the contents of their marginalia can nevertheless be grouped.

\footnotetext{
${ }^{132}$ For Seller's tide tables, see Seller, A Pocket Book, unpaginated, manuscript annotation I: ff. 53-54; for his tables of gunnery, see manuscript annotation II: ff. 102-103. His thoughts on the use of compass and staff are found at manuscript annotation I: f. 63. Science Museum Library Shelfmark O. B. SEL SELLER 30209019360995.
} 
As we have seen, chronological interests account for a substantial amount of ink; nevertheless, as with the printed materials of the volume, the convergence of navigational and astronomical interests can be found in treatments of spherical trigonometry. Inscriptions complementary to studies of the doctrine of the sphere, chronology, and time-finding act as evidence of how 'Edmund Withers' engaged with the trigonometrical basis of astronomy. Elsewhere in the Pocket Book, annotations continued to address questions of positional astronomy in great detail. ${ }^{133}$ Through these notes, a practical handling of the discipline is witnessed, as well as attempts by a user to construct their own tables of celestial movements. ${ }^{134}$ The annotations demonstrate a form of 'live' working, and can perhaps be seen as attempts in using the space provided by the volume for performative trigonometry: one undertaken in private, before being shown to others, performed in educational or practical settings, and then being used assuredly elsewhere (Figure 4.19).

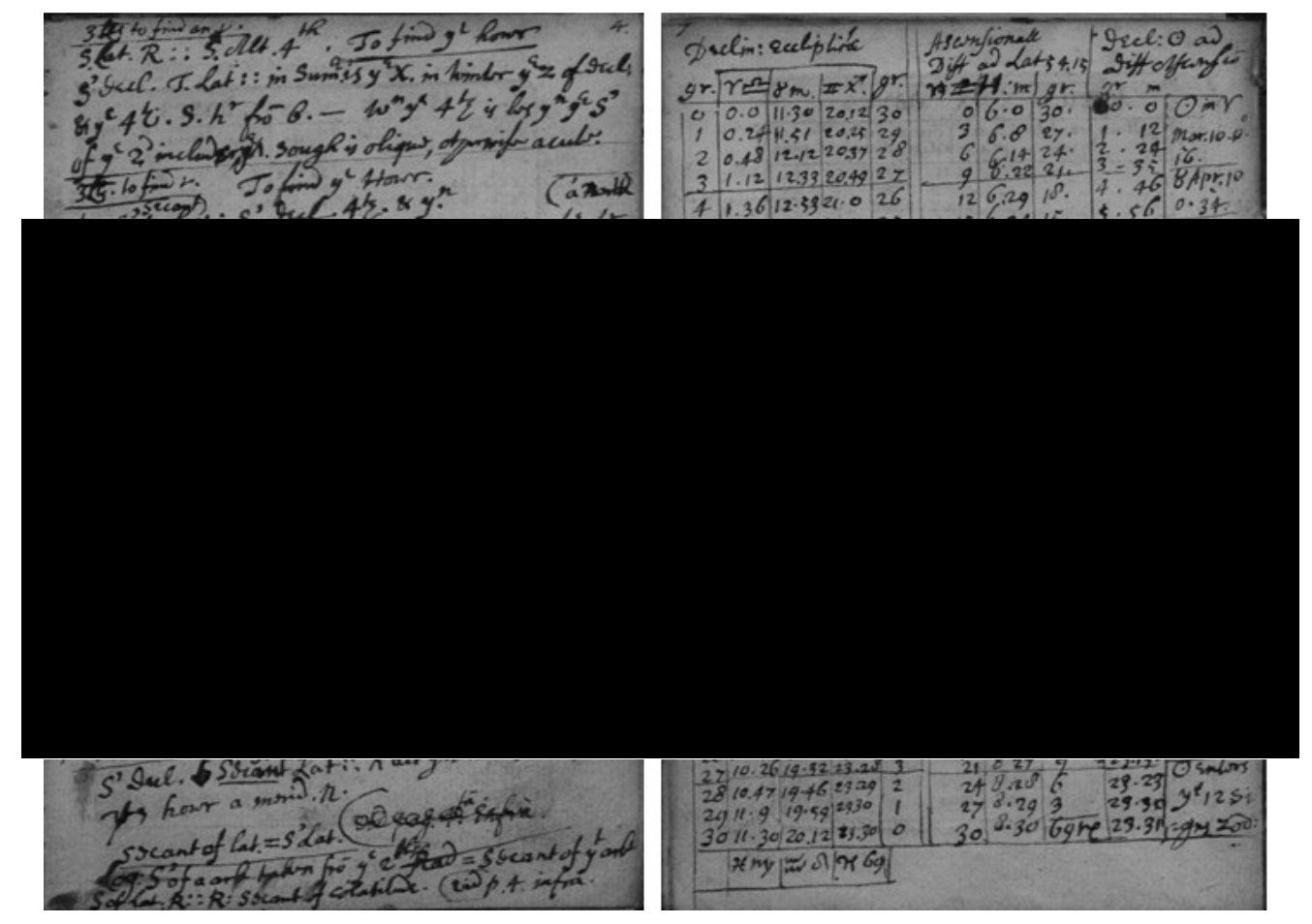

Figure 4.19. Images of manuscript annotation 'working out' of trigonometric questions (left) including ' 3 ways to find an angle', alongside a handwritten table of positional astronomy which includes data on the sun's ascensional difference for the latitude of $54.15^{\circ}$ (right). These annotations are interrupted in the volume by two pages of printed material. Science Museum Library Shelfmark O. B. SEL SELLER 30209019360995.

\footnotetext{
${ }^{133}$ Seller, Pocket Book, particularly unpaginated, manuscript annotation I: ff. 8 -13. Science Museum Library Shelfmark O. B. SEL SELLER 30209019360995.

${ }^{134}$ Seller, ibid, unpaginated, manuscript annotation I: f. 7.
} 
Importantly, 'Edmund Withers' followed both his instructors and John Seller by expressing the mathematical relationships behind his astronomical, trigonometrical and horological practice in descriptive prose and in algebraic shorthand. These actions represent the performance of mathematical exercise, whereby portions of copied text gradually give way to an operative rehearsal. Withers's models for symbolic notation can be seen in the rewriting and working through of examples from Mark Forster's Arithmetical Trigonometry (1690), John Ward's Compendium of Algebra (1695), and from Isaac Barrow's pocket-sized Latin edition of Euclid, Euclidis Elementorum (1655), previously seen in Figure 4.8.

Eschewing the order of Isaac Barrow's text if not its message, our reader followed this excerpt with another selection from Book XIII of the Euclidean summary. The eighteenth proposition of Book XIII related how the sides of the aforementioned regular polyhedra compared to one another and their circumscription within a sphere. The manuscript annotations visible at this point were not simply evidence of repetition, however. Their selection displays a user visualising, rewriting, and rehearsing their geometrical understanding in symbolic form, developing in the process a better understanding of the principles upon which many of their inter-related interests were predicated (Figure 4.20). 


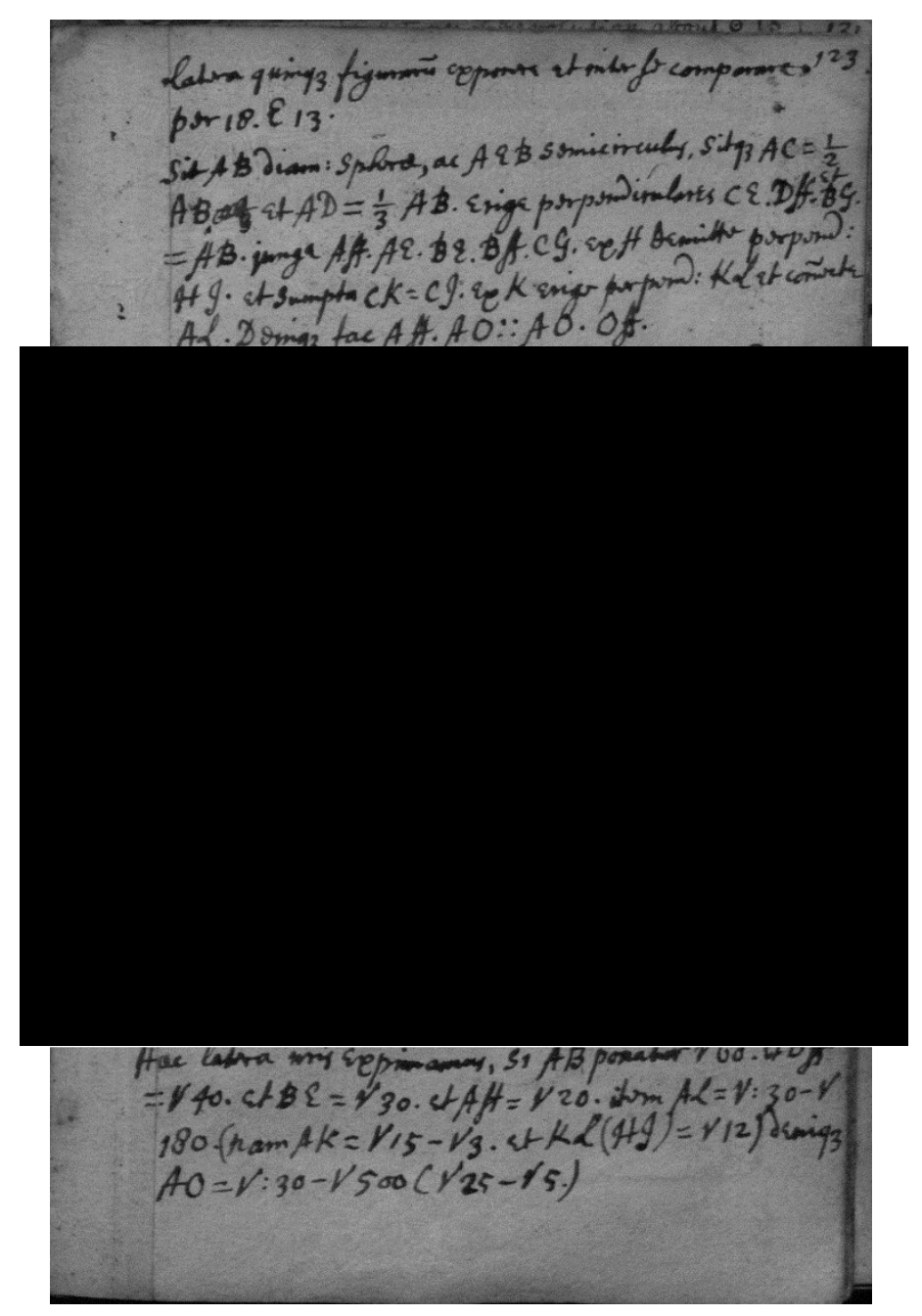

Figure 4.20. Annotation on the circumscription of regular polyhedra within a sphere, excerpted from Isaac Barrow's Euclidis Elementorum (1655). Science Museum Library Shelfmark O. B. SEL SELLER 30209019360995.

It would appear that this student read and copied Euclid's Proposition 18 in identical algebraic fashion to that of Barrow, albeit at a lower level of mathematical expertise. As its example made clear, the use of symbolic algebra lent itself particularly well to demonstrations of proportional relationships. When seen in this light, 'Edmund Withers's' testing out of different types of this writing style is lent interpretive significance by their working through a series of introductory astronomical questions delineating the mathematical relationships between the radii of spheres, celestial poles, and the sun's declination in like fashion (Figure 4.21). While the study of positional astronomy had for some time benefited from the widespread application of plane and spherical trigonometry - a fact readily witnessed in the navigational guides retailed by Seller and his peers - the notes littering the Pocket Book are nevertheless indicative of a reader's reception of 
changes to the mathematical lexicon as experienced in the late seventeenth century: changes that moved the reading of mathematics away from descriptive prose toward abbreviated symbolism, and from geometrical demonstration to algebraic.

Expressing the trigonometric proportions shared by the terrestrial and celestial spheres to calculate the declination, right ascension or azimuth of celestial bodies in such notation, this annotator rehearsed and demonstrated their ability to read mathematics within a new lexicographical tradition.

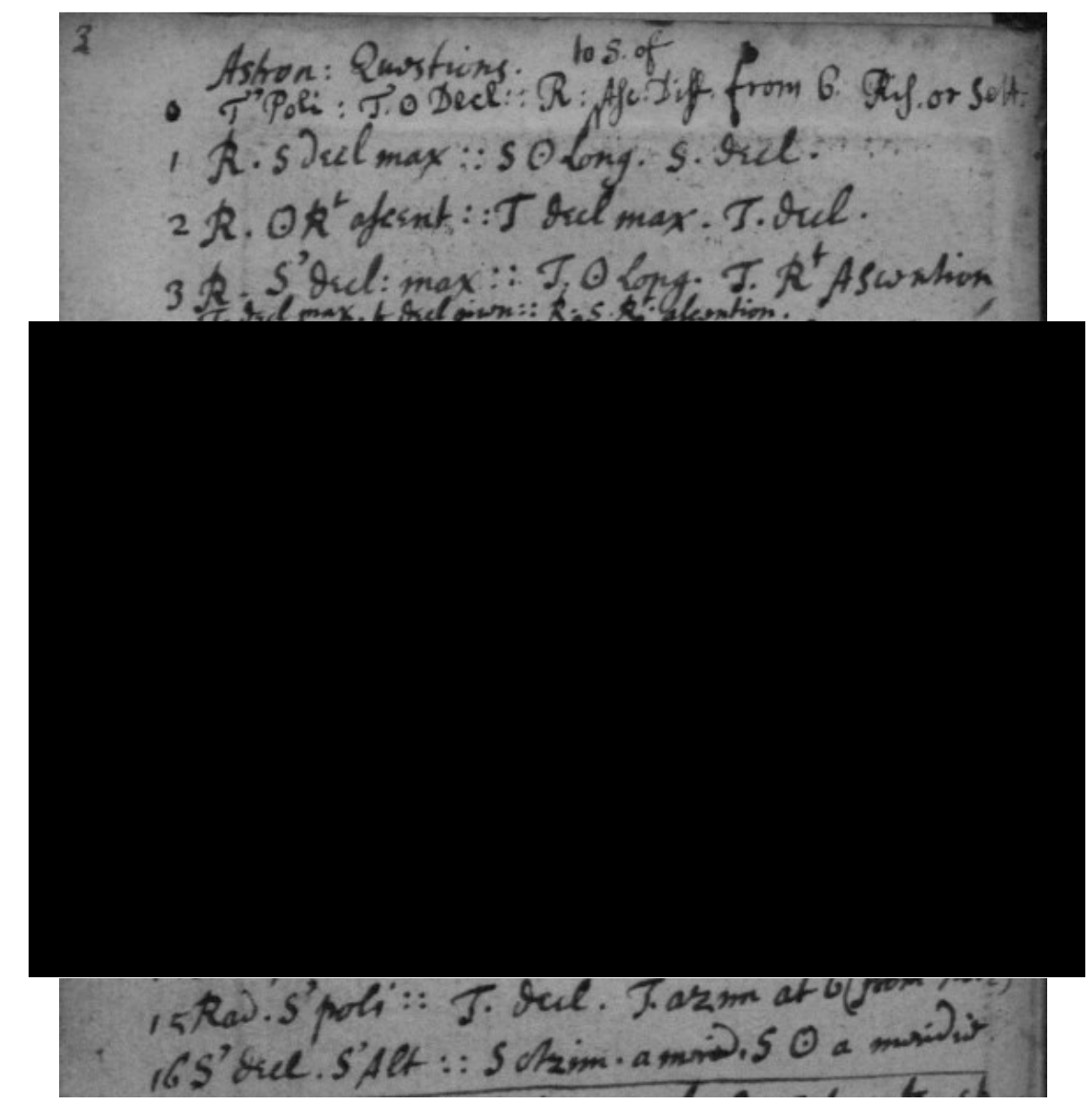

Figure 4.21. 'Edmund Withers's' list of 'Astron. Questions' expressing the relations shared by various parts of the celestial sphere. Science Museum Library Shelfmark O. B. SEL SELLER 30209019360995.

Elsewhere in the Pocket Book, owners and users utilised the symbolic notation provided by Seller (attached to a copperplate print of a trigonometric sliderule) to address questions of positional astronomy in greater detail. As the readerannotator who excerpted Barrow's Euclidean text and outlined the relationality of astronomical problems, 'Edmund Withers' also expanded upon the relationships defined in Seller's stereographic projection of the sphere to the latitude of $51^{\circ} 32^{\prime}$, or that of London, by annotating their text with additional (and contrary) information to 
that of the author on the extraneous conjuncts and disjuncts of the right-angled triangle RP and the quadrantal triangle $\odot \mathrm{PZ} .{ }^{135}$ This annotator then reformatted the example provided in Seller's text in the empty space to the beginning of the Pocket Book, reconstituting the author's projection along with a series of operations predicated on the relationships between complements and conjunctions of angles drawn within the greater sphere (Figure 4.22). ${ }^{136}$ Additional constructions were used to demonstrate a series of ways to find the time or take other planetary readings when only partial or fragmentary data was made available - for example, the sun's meridian altitude or declination, or the right ascension of a celestial body's semidiurnal arc. ${ }^{137}$ Previously occupied with astronomical questions of spherical trigonometry, 'Edmund Withers' dispersed complementary instructions and methods throughout their text.

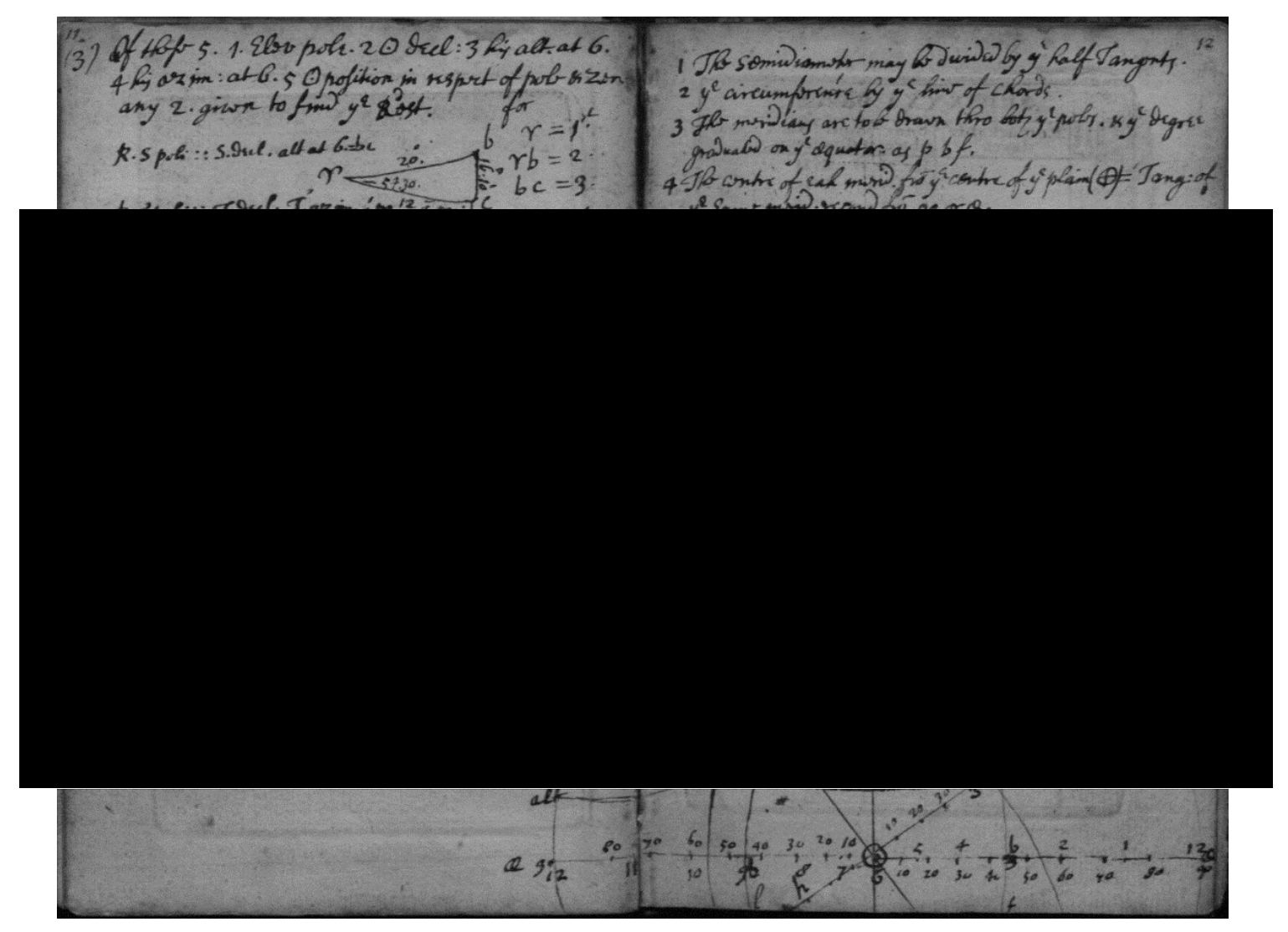

Figure 4.22. Annotations concerning multiple ways to find the time using spherical triangles, with a reconstitution of a sphere of latitude $51^{\circ} 32$ '. Science Museum Library Shelfmark O. B. SEL SELLER 30209019360995.

\footnotetext{
135 Seller, Pocket Book, unpaginated, manuscript annotation II: f. 113. Science Museum Library Shelfmark O. B. SEL SELLER 30209019360995.

${ }^{136}$ Seller, ibid, unpaginated, manuscript annotation I: ff. 8-13.

${ }^{137}$ Seller, ibid, unpaginated, manuscript annotation I: f. 12.
} 
These notes bear witness to the performative handling of mathematical information. Reference to these methods is not provided by this copy of Seller's text, and, indeed, the closest example is found in the Pocket Book's aforementioned stereographic projection of the sphere. Where comparisons with the earlier Practical Navigation (1669) appear to expose a gulf in content between the Pocket Book and its predecessors in Seller's canon, we should again consider the ways in which this particular volume was constructed and used. The scribal techniques found in this copy of the Pocket Book demonstrate mathematical practice in its literal sense: a repetition and reinterpretation of printed texts that saw the empty spaces of a users' commonplace volume as an area for rehearsal, undertaken in private, before being shown to others and performed in an educational setting or another site-specific environment. Such manuscript evidence demonstrates the attempts made by the latter to develop an understanding beyond that provided by the text with which they worked. ${ }^{138}$

At the same time, by emending John Seller's text with occasional contraries, replicating the author's use of symbolic notation, and depositing into their volumes fragmentary reinterpretations of the Hydrographer's 'choice collections' and works from more learned sources, the owners of the Pocket Book read in conversation with the printer-practitioner, using the skills and shorthand taught by the text and their tutors to rehearse and perform the technical skills essential to the practice of mathematical disciplines such as geometry, trigonometry, and astronomy. There can be little doubt that these users saw Seller's text as a repository in which to keep the mathematical elements of their chronological endeavours, or that the Pocket Book by necessity required improvement for them to do so. Making their volume into a setting in which to practice and demonstrate technical proficiency, these users transformed the Pocket Book into a store-house for the collection of mathematical material, a library for its reading, and a theatre for its rehearsal and demonstration.

Initially, John Seller's miniature work was created to service a market that was more attuned to tabulation than calculation. But in this particular instance, the Pocket Book was clearly owned by educated and mathematically capable individuals.

\footnotetext{
${ }^{138}$ Seller, Pocket Book, unpaginated, manuscript annotation I: ff. 11-12. Science Museum Library Shelfmark O. B. SEL SELLER 30209019360995.
} 
By utilising the empty spaces beyond printed texts and images for commonplacing and annotation, whether formal or informal, these owners ensured that the Science Museum's copy of the Pocket Book reflected their intentions to develop mathematical understanding over time, and to deposit that learning into a handy keepsake. As we have already seen, the versos of the copperplate prints which account for much of John Seller's text offered would-be users ample space in which to recast the practitioner's materials. By offering his prints as part of a foundational range of 'choice collections' to be built upon, Seller may well have encouraged buyers to construct and adapt his work as they saw fit.

Materials relating to astronomy and spherical trigonometry dominate the annotations dispersed through the Pocket Book, and the presentation of each helps to demonstrate the ways in which mathematical source texts were idiosyncratically manipulated by students interested in celestial, navigational and chronological matters. When placed together, the trigonometric 'Astronomical Questions', the excerpted portions of Gassendi's Institutio astronomica, and Burgersdijk's commentaries, and the detailed efforts to find the time all become evidence of the efforts of 'Jenkinson' and 'Withers' to think and work within interrelated mathematical disciplines toward both practical and theoretical applications.

If the owners of this edition were familiar with borrowing, excerpting, and repackaging mathematical materials for their own ends, then the very same is true of Seller as a practitioner. In cannibalising his own materials as well as those of others, however, the author's construction of his Pocket Book may well present us with another means of viewing the actual working practices of a mathematical practitioner: one who acted as a tutor, publisher, and cartographer. We have already witnessed how John Seller's modus operandi as a producer of goods was structured so as to afford him access to as wide a variety of consumers as possible. Throughout his many 'choice selections', ranging across a breadth of mathematical disciplines, Seller made of his text a useful cipher: interchangeable in a wide variety of scenarios, and containing enough lacunae to be improved upon by almost any owner.

Created in a contradictory fashion to many mathematical texts of the early modern period, the author professed no opinion as to who might avail themselves of his text; where they might put it to use; or even why they might come to need it. 
Instead, Seller presented himself only as the trusted maker of the volume of mathematical materials, and ultimately requested only that his collection be kept consistently about its owner. The malleability and the mutability of the Pocket Book may therefore lead us to consider the ways by which other such books travelled between the public, private, and intellectual spheres of mathematics in early modern England: as this individual copy demonstrates, significant and revealing forms of annotated practice may yet be found therein.

\section{Conclusion: Reading, Using, Collecting}

For two specific students, annotations of trigonometry, chronology, and astronomy appear to have been part of a broader effort toward the correct application of theory for practical usage. 'Edmund Withers', in particular, excerpted materials in a way that suggests he was commonplacing for useful endeavours, with abridged sections from a variety of mathematical texts on charging interest, finding time, and measuring areas all interspersed with the volume's printed contents. The interpolation of his father Thomas, himself a Cambridge graduate and theologian, may yet be part of this story as well. What relevant conclusions can be drawn from the mathematical practices of these users?

That the Pocket Book's largesse of chronological materials indicates ownership by a student is undeniable. When viewed in the round, selections from Gassendi, Burgersdijk, and Barrow portray consumers enveloped in the intellectual culture of English university life in the decades between 1685 and 1700, and it is in the records of these instructions that alumni matching the provenance data of the Pocket Book are found. One Simon Jenkinson matriculated as a sizar at Trinity College, Cambridge, in June 1689; in 1691, Edmund Withers, the son of the Cambridge graduate Thomas Withers, was admitted as a pensioner at the age of 16 , and graduated with his B.A. in 1694/5. ${ }^{139}$ Jenkinson, who may previously have attended Brasenose College, Oxford, graduated from Cambridge in 1692/3; meaning that, in 1685, he was a student in Oxford, and, at Edmund Withers's marking of the

\footnotetext{
139 John Venn and J. A.Venn, eds., Alumni Cantabrigienses: A Biographical List of all Known Students, Graduates and Holders of Office at the University of Cambridge, from the Earliest Times to 1900, Part I: From The Earliest Times to 1751, Volume IV: Sall - Zuinglius (Cambridge: Cambridge University Press, 1927), p. 444.
} 
Pocket Book in 1692, was finishing his studies in Cambridge. ${ }^{140}$ Did Thomas

Withers purchase Jenkinson's copy of the text as part of an academic book sale, and then gift it to his son? Passing the book on in this manner might help to explain the academic reading list, and the annotations of Gassendi in a different hand to those on chronology and later practical excerpts. Thomas Withers may have been attracted to Jenkinson's copy precisely because it bore evidence of scholarly engagement relating to topics relevant to Edmund's studies.

One further line of speculation suggests itself, and may help to highlight the unification of Seller's material with the printing environment of London later in the century, and with the materials pupils may have brought to university. The Pocket Book's manuscript excerpting of John Ward's A Compendium of Algebra of 1695 calls to mind the authors that were at that time advertising their services as tutors to a variety of audiences. ${ }^{141}$ Ward's textbook was intended as a complete course in algebra, either for commercial use or in preparation for university entry, with tuition offered at a variety of suitable locations, including the student's home, Ward's house, or at a local instrument-maker's. ${ }^{142}$ The Edmund Withers who matriculated at Cambridge went on to become a clergyman, reverend, and vicar in Yorkshire; however, he also spent thirty years as a schoolmaster in Doncaster Grammar School, between 1707 and 1737.

In such dual roles it is easy to imagine Edmund retaining his youthful interest in chronology and mathematics: and, indeed, to imagine that portions of a variety of textbooks might be found useful by his learners, as well as to his own pedagogical practice. Whether preparing his charges for university education or the rigours of working life with Ward's material, the combination of this individual Pocket Book's

\footnotetext{
${ }^{140}$ For Jenkinson's time at Cambridge, see John Venn and J. A. Venn, eds, Alumni Cantabrigienses: A Biographical List of all Known Students, Graduates and Holders of Office at the University of Cambridge, from the Earliest Times to 1900, Part I: From The Earliest Times to 1751, Volume II: Dabbs-Juxton (Cambridge: Cambridge University Press, 1927), p. 469. For his time at Oxford, see Joseph Foster, ed., Alumni Oxonienses; the Members of the University of Oxford, 1500-1714: Volume II: Early Series (Oxford: James Parker \& Company, 1891), p. 809. Jenkinson is here listed as 'Simeon' rather than 'Simon'.

${ }^{141}$ Seller, Pocket Book, unpaginated, manuscript annotation II: ff. 96-97. Science Museum Library Shelfmark O. B. SEL SELLER 30209019360995. For the materials excerpted from Ward, see John Ward, A Compendium of Algebra. Consisting of plain, easie and concise rules for the speedy attaining to that art (London: printed for the author, and sold by him at the Black-Boy Coffee-House in Goodmans-field, 1695), pp. 48-51.

${ }^{142}$ Ward, Compendium of Algebra, p. 113.
} 
practical and theoretical 'choice selections' appears to have remained close to hand. Withers's Cambridge interests in chronology, geography and Newtonianism certainly pertained. As the treasurer, keeper, and a lay member of the Doncaster parish library, Arthur Bedford's Scripture Chronology (1730), Christopher Cellarius's Notitia Orbis Antiqui, sive Geographia plenior (1701-1706), Sir Walter Raleigh's The History of the World (1614) and Henry Pemberton's A View of Sir I. Newton's Philosophy (1728) were numbered amongst his many loans. ${ }^{143}$

Whether further analysis allows for the precise identification of Tho(mas) Withers, Edm(und) Withers, or S(imon) Jenkinson is, to some extent, a moot point. The detailed sections of marginalia concerning spherical trigonometry, and the importance of that practice to a wide variety of disciplines, suggest that users of the Pocket Book were either being prepared or preparing themselves for action: a view further supported by lengthy marginalia on tables of annuity for the calculation of interest over a period of seven years, and by a user's frequent handling of a variety of measurements. These worked problems include the measuring of boards and cylinders, as well as lists of converted distances for Parisian, Scottish, Swedish and German miles. ${ }^{144}$ References in manuscript advised the self-directing reader to return to the printed text for depictions of troy, apothecary, and averdupois weights, and go on to list the various volumes and metric values of beer, spirits, wine, oil, and quicksilver. ${ }^{145}$ These metric volumes can be read both as relevant to an interest in the movement and transportation of goods, and as information relevant to the determination and consumption of imported and exported goods in the early modern period.

By the same token, the copied sections of weights and measures, interest tables, and methods to find cubes and squares join excerpts from Forster's Arithmetical Trigonometry (1690): it is through the conjunction of these works that the Pocket Book's position as a repository for mathematical techniques echoes the texts from which it draws. Forster advocated that a method which made the

\footnotetext{
${ }^{143}$ Graham Best, 'Books and Readers in Certain Eighteenth-Century Parish Libraries', unpublished PhD Dissertation, Loughborough University, 1985, particularly pp. 141-144.

${ }^{144}$ Seller, Pocket Book, unpaginated, manuscript annotation II: f. 90. Science Museum Library Shelfmark O. B. SEL SELLER 30209019360995.

${ }^{145}$ Seller, ibid, unpaginated, manuscript annotation II: f. 104.
} 
performance of plain trigonometry 'to any degree or minute (...) impossible without tables of those Numbers, (...) and impossible to commit to memory' was to be abandoned, and instead encouraged readers to learn the new techniques his book contained - with the intention of removing the reliance on books, as Pell once had almost a half-century prior. ${ }^{146}$ As Figure 4.23 shows, 'Edmund Withers', previously occupied with astronomical questions of spherical trigonometry, deposited Forster's method amongst these materials for inspection. As ever, questions concerning time finding and astronomical positions were rarely far away. ${ }^{147}$

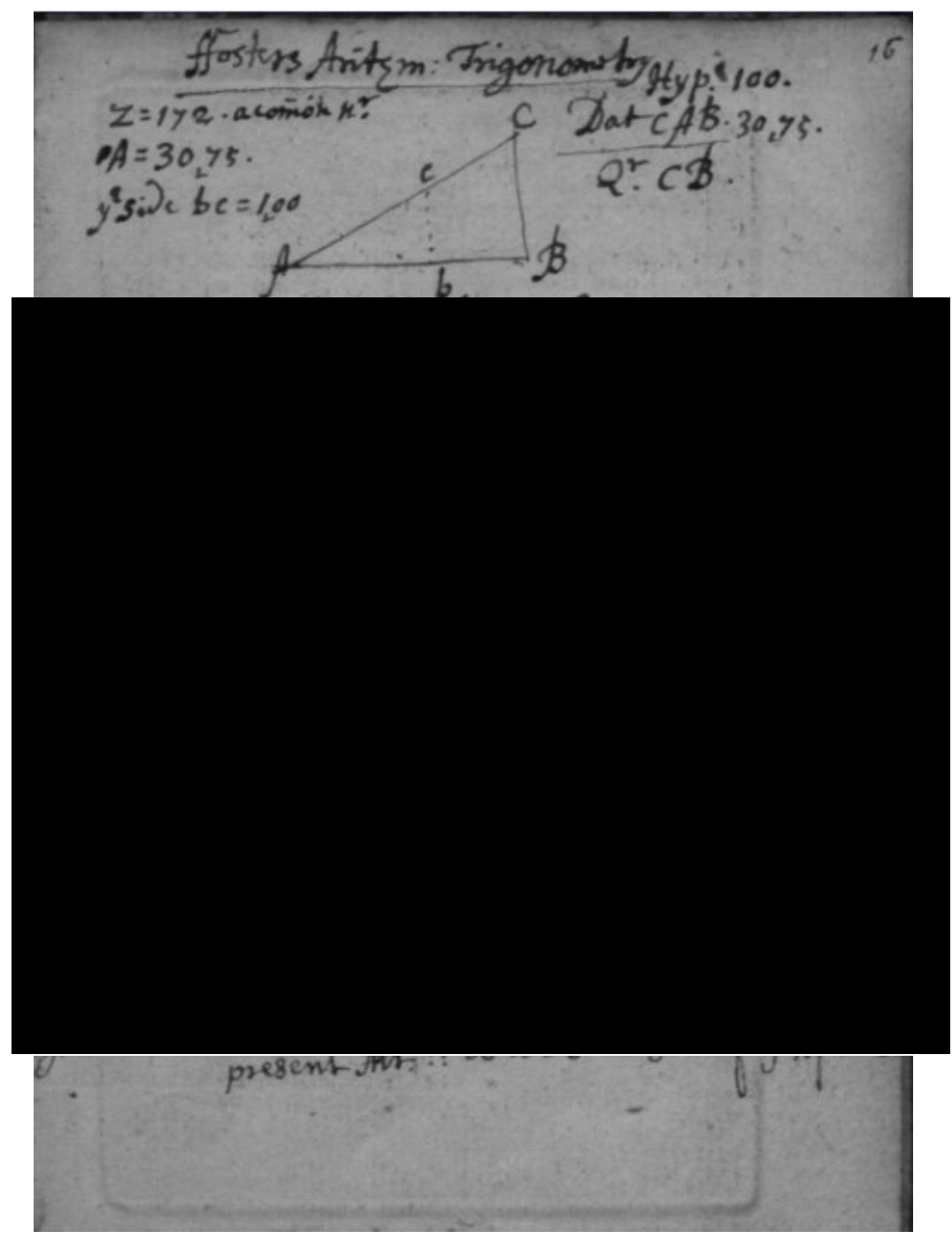

Figure 4.23. Manuscript excerpt taken from Mark Forster's Arithmetical Trigonometry (1690), with additional material on time-finding below. Science Museum Library Shelfmark O. B. SEL SELLER 30209019360995.

\footnotetext{
${ }^{146}$ Mark Forster, Arithmetical Trigonometry (London: Printed for R. Mount, 1690), ff. a 2 r - a 2 v.

${ }^{147}$ Seller, ibid, unpaginated, manuscript annotation I: f. 16.
} 
In much of this chapter I have sought to isolate, and then to elide, the apparent contradistinctions between the printed materials of John Seller's Pocket Book and the manuscript annotation of its later owners. Although a natural dichotomy exists in many texts between a publisher's intentions and their owners' actual application, in this instance the historical evidence of one copy of the Pocket Book illustrates the ways in which John Seller and the consumers of his work were engaged with revolutions of the same early modern mathematical sphere. What manuscript evidence can be gleaned points to the commonplacing of texts produced in this period, most specifically by a coterie of printers around Cambridge and London; neither texts in the reading lists nor manuscript excerpts from various sources appear to have originated beyond 1700. The disciplines users engaged with are of their time: positional astronomy and technical chronology exist hand in hand, each depending on the mathematical basis of spherical trigonometry for claims of disciplinary certitude. Our attention should therefore be drawn not towards the letterpress and copperplate materials of Seller's text, nor the pen and ink of 'Withers' et al, but rather to the idea of this copy of the Pocket Book as a unique though cohesive historical document: one defined by its evidence of methods of use and of collection.

Jenkinson's copy of the Pocket Book has led at least three lives. In its first iteration, the Pocket Book was designed as something that John Seller could sell to as broad a market as possible - somewhat literate, somewhat numerate, all interested in the utility mathematics could bring to their lives and careers. The text's second 'life', conjoined as it was to the university studies of 'Simon Jenkinson' and 'Edmund Withers', was an extension of sorts on this theme: the study and application of mathematics was a means to an occupational end for many ambitious students, but also an invigorating and intellectually elevating discipline for those adept to its demands. Finally, the Pocket Book's third term of use was as a commonplace book for the chronological, theological and pedagogic collections of Edmund Withers, kept as part of his career as a clergyman and schoolmaster. Each of these narratives is indicative of two key terms in practice: use, and collection. Each term endures in the volume's continued existence as a historical object in the Science Museum, and each helps to form a viable means for us to engage more completely with the history of mathematics. 
Seller's Pocket Book, then, apparently lacking in so many areas when compared to more mathematical guides of the late seventeenth century, could instead have been purchased as a serviceable introduction to astronomy, geography, or merchant sailing for the novice and the virtuoso alike, with the buyer understanding that its compendia were there not to teach, but to be exceeded. The combination of the printed and manuscript elements of this edition calls to mind John Pell's dream of an 'ideal' pocket book: one providing reference and theory when needed, and aiding the user in their search for genuine mathematical understanding. Rather than a strange chimera of contrasting cultures, this copy of the Pocket Book is a liminal object: printed to enable practical activities like gauging, navigating, and exchange, and annotated to engage more deeply with the theoretical precepts of mathematics. In its construction and subsequent use, the Science Museum's unique copy of the Pocket Book is bibliographical evidence of knowing, using, and, ultimately, collecting mathematics in early modern England. 
Chapter Five: The identities and institutional afterlives of early modern and modern $\underline{\text { libraries }}$

Having failed to provide his aristocratic patron Theophilius Hastings (1650-1701) with the latest news from home and abroad for quite some time, the mathematician and translator Thomas Salusbury was at pains to highlight the demands placed upon him by another nobleman. Begging pardon in a letter of June 1664, Salusbury confided in the teenaged Earl of Huntingdon and his advisors that the needs of Henry Pierrepont, $1^{\text {st }}$ Marquess of Dorchester (1606-1680) had kept him from writing, his silence 'necessitated by an unexpected business put upon one by my Lord of Dorchester viz the erecting of a Library for his Lordship [...] the sorting, placing, buying, perfecting of bookes, as also the titles and catalogue, hath tooke up very much of my time'. ${ }^{1}$ His task now complete, the author grasped the opportunity to demurely burnish his professional identity in front of Hastings. In his account, Pierrepont had entrusted him with this time-consuming task owing to "the pains I had taken in that particular way of knowing of books and libraries'. ${ }^{2}$ As Salusbury strove to fill the Marquess's library with the world's most famous works, Pierrepont's visitors, such as the Lord Chancellor, the Earl of Clarendon Sir Edward Hyde (16091674), cast an approving eye over his work, with their own grandiose projects in mind.

Employed to identify and procure books on the Marquess of Dorchester's behalf, Thomas Salusbury was merely one of several learned agents a wellconnected consumer could engage in the late seventeenth century. These gobetweens were called upon to provide social and political news from the court and the continent; to evaluate and report on the key philosophical and scientific issues of the day; and to identify, purchase and distribute texts and pamphlets, among other tasks. $^{3}$ As recent studies have shown, some intermediaries were able to move

\footnotetext{
${ }^{1}$ San Marino, CA. Huntington Library, Hastings MS 10660. Letter from Thomas Salusbury to Theophilius Hastings, Earl of Huntingdon, July 141664.

${ }^{2}$ San Marino, CA. Huntington Library, ibid.

${ }^{3}$ Sabrina A. Baron, 'The Guises of Dissemination in Early Seventeenth-Century England' in Brendan Dooley and Sabrina A. Baron, eds., The Politics of Information in Early Modern Europe (London and New York: Routledge, 2001), pp. 41-56, p. 42. Baron notes that the contents of such manuscripts exercised the Crown and its officials as much as those of printed materials. On the rhetoric of exchanges central to these coteries, see Claire Preston, The Poetics of Scientific Investigation in Seventeenth-Century England (Oxford: Oxford University Press, 2015), particularly pp. 158-195. On the process of exchanging letters as a form of testing ideas prior to their appearance in print, see
} 
between political, cultural, economic and confessional traditions, and were thus of significant importance to groups on either side of these divides. ${ }^{4}$ Valued for their connections as well as for their intellectual and linguistic capabilities, agents like Thomas Salusbury operated within a culture of epistolary correspondence, linking patrons and purchasers with authors, publishers, and fellow 'intelligencers'. The Anglo-Prussian Samuel Hartlib (ca. 1600-1662), the French priest Marin Mersenne (1588-1648), and the Moravian pedagogue Jan Amos Komenský (Comenius, 15921670) all pursued idiosyncratic but interlinked reformative and, in some cases, quasiBaconian utopian intellectual projects by gathering around themselves wide networks of individuals with expertise on diverse topics, ranging from husbandry to scientific experiments, from mathematics to state-craft, and from beekeeping to the governance of the Commonwealth. ${ }^{5}$

One such intelligencer and correspondent at work in seventeenth-century London was the ubiquitous John Collins (1625-1683), whose constant efforts to promote mathematics in England saw him dubbed 'Mersennus Anglus' by contemporaries including Isaac Barrow. ${ }^{6}$ Although the epithet flattered Collins, Barrow's comparison of his friend to the French friar was somewhat justified. Just as Mersenne had fostered an extensive web of continent-wide correspondence with

David A. Kronick, 'The Commerce of Letters: Networks and "Invisible Colleges" in Seventeenth- and Eighteenth-Century Europe', Library Quarterly, 71 (2001), pp. 28-43; for an exploration of the identities of agents in book-selling, see Marika Keblusek, 'Book Agents: Intermediaries in the Early Modern World of Books' in Hans Cools, Marika Keblusek, and Badeloch Noldus, eds., Your Humble Servant: Agents in Early Modern Europe (Hilversum: Uitgeverij Verloren, 2006), pp. 97-107. ${ }^{4}$ Peter Burke, "The Renaissance Translator as Go-Between", in Andreas Höfele \& Werner von Koppenfels, eds., Renaissance Go-Betweens: Cultural Exchange in Early Modern Europe (Berlin and New York: Walter de Gruyter, 2005), pp. 17-31. Burke identified two subgroups of translator, the professional and the leisurely, with the former often made up of itinerant merchants, teachers, diplomats, missionaries and displaced persons. Examples of scholarly works on the intermediaries moving between the borders listed above include Tijana Krstić, 'The Elusive Intermediaries: Moriscos in Ottoman and Western European Diplomatic Sources from Constantinople, 1560s-1630s, Journal of Early Modern History, 19.2 (2015), pp. 129-151; Noel Malcolm, Agents of Empire: Knights, Corsairs, Jesuits and Spies in the Sixteenth-Century Mediterranean World (Oxford: Oxford University Press, 2015); Nadine Akkerman, Invisible Agents: Women and Espionage in SeventeenthCentury Britain (Oxford: Oxford University Press, 2018).

${ }^{5}$ See, for example, Charles Webster, The Great Instauration: Science, Medicine, and Reform, 16261660, $2^{\text {nd }}$ edn (Oxford: Peter Lang, 2002); William Eamon, Science and the Secrets of Nature: Books of Secrets in Medieval and Early Modern Culture (Princeton, NJ: Princeton University Press, 1994), particularly pp. 323-326; Johns, Nature of the Book, pp. 266-323; on Mersenne, Robert Lenoble, Mersenne ou la Naissance du Mécanisme, $2^{\text {nd }}$ edn (Paris: J. Vrin, 1971), and James J. Bono, The Word of God and the Languages of Man. Interpreting Nature in Early Modern Science and Medicine. Volume 1: Ficino to Descartes (Madison, WI: University of Wisconsin Press, 1995).

${ }^{6}$ Philip Beeley and Christoph J. Scriba, eds., The Correspondence of John Wallis, Volume II (1660September 1668) (Oxford: Oxford University Press, 2005), p. 620. 
scholars including René Descartes (1596-1650), Constantin Huygens (1596-1687) and Evangelista Torricelli (1608-1647), ${ }^{7}$ Collins communicated frequently with his correspondents John Pell, Isaac Newton, Gottfried Leibniz and Henry Oldenburg between 1666 and 1677, often with a view to improving access to mathematical literature in either print or manuscript. ${ }^{8}$

In a letter to John Wallis of 12 August 1666, Collins sought to utilise this network to tie up several loose threads. Seeking information on the whereabouts of a particular set of mathematical texts as well as Thomas Salusbury's work as a translator, Collins asked Wallis whether he had in fact seen copies of 'Josephi Hebraei Bibliotheca mathematica 8(vo) Francofurti, Andraei Alexandri Mathemologium fo(lio), Saclari Apologia pro Archimede et Euclide' as previously intimated. Offering his correspondent a tidbit of information in the hope of receiving the same in return, the agent continued:

I never saw any of them, but the two latter are in the Marquese of Dorchesters Library. May I presume a little further I would likewise entreate your information concerning the Manuscript of Galileos in your Library, whether it be his Mechanic Problems which Mr Salusburie, whilst living, complained he could not obtain. ${ }^{9}$

The mathematical community to which John Collins and John Wallis belonged was well aware of Salusbury's many travails; indeed, Collins had himself endeavoured to see the translator's edition of Galileo's works into print, even as Salusbury railed against his publisher, the mathematician and stationer William Leybourn, and his continental correspondents for their many perceived

\footnotetext{
${ }^{7}$ Paul Tannery, Cornelis de Waard, Bernard Rochot, and René Pintard, eds., Correspondance du P. Marin Mersenne, religieux minime, 17 vols. (Paris: Éditions du Centre national de la Recherche Scientifique, 1933-1988); for his correspondence with Descartes, see John Cottingham, Robert Stoothoof, Dugald Murdoch and Anthony Kenny, trans., The Philosophical Writings of Descartes. Volume 3: The Correspondence (Cambridge: Cambridge University Press, 1991).

${ }^{8}$ Philip Beeley, ed., 'The Correspondence of John Collins', in Early Modern Letters Online, Cultures of Knowledge, http://emlo.bodleian.ox.ac.uk/forms/advanced?col cat $=$ Collins $\% 2 \mathrm{C}+\mathrm{John}$, accessed 27 February 2017. Additional information on Collins's correspondence is available in Philip Beeley and Christoph J. Scriba, eds., Correspondence of John Wallis, 4 vols. (Oxford: Oxford University Press, 2003-2014), and in Stephen Jordan Rigaud, Correspondence of Scientific Men of the Seventeenth Century, 2 vols. (Oxford: Oxford University Press, 1841).

${ }^{9}$ Letter from John Collins to John Wallis, [London], 2/[12] August [1666], 121, in Beeley and Scriba, eds., Correspondence of John Wallis, Volume II, p. 276.
} 
obstructions. ${ }^{10}$ Though sympathetic to the recently-deceased translator, Collins had had more than enough experience with the market for mathematical texts to be too down-hearted. His promotion of the knowledge and practice of mathematical disciplines in England had required him to scour book-stalls and printshops at home and abroad for mathematical literature: equally, as his letter to Wallis suggests, ensuring the transmission of mathematical material by circulating copies of works otherwise imprisoned in the private libraries of the gentility came with the territory.

As the previous chapter's treatment of John Pell's Idea of Mathematics has shown, the discipline of mathematics had featured prominently in some plans for the construction of the ideal library proposed earlier in the seventeenth century. Part of a series of moralistic and Baconian intellectual reforms, these efforts were promoted by the influential émigré intelligencer Samuel Hartlib as essential to the unification of Protestant and Puritan factions across Europe, with their by-product the betterment of all. In Hartlib's vision, this process would be kick-started only through education, with the opportunities offered to learning by the intersection of print technology and correspondence across the Republic of Letters the engine driving his reformative process. ${ }^{11}$ Samuel Hartlib's outlook was shared ardently by his English friend and co-reformer John Dury (1596-1680), who in The Reformed Librarie Keeper argued that the Baconian libraries and their keepers:

would bee of exceeding great use to all sorts of Scholars, and have an universal influence upon all the parts of Learning, to produce and propagate the same unto perfection. For if Librarie-keepers did understand themselvs in the nature of their work, and would make themselvs, as they ought to bee, useful in their places in a publick waie; they ought to becom Agents for the advancement of universal Learning. ${ }^{12}$

Such establishments were only one wing of a proposed educational overhaul, in which an all-encompassing, utopian Office of Address might oversee entirely the transmission of information to coordinate the advancement of learning across the

\footnotetext{
${ }^{10}$ Stillman Drake, 'Introduction', in Thomas Salusbury, Mathematical Collections and Translations, in Two Tomes, 2 vols. (Los Angeles: Zeitlin, 1968), p. iv.

${ }^{11}$ Charles Webster, ed., Samuel Hartlib and the Advancement of Learning (Cambridge: Cambridge University Press, 1970), p. 8.

12 Dury, Reformed Librarie-Keeper, p. 17. Dury went on to propose such agents as at the centre of a lattice-work of sub-agents, with each feeding back information gleaned from subordinate networks.
} 
entirety of the Commonwealth. ${ }^{13}$ Samuel Hartlib's efforts to fashion a totalising structure for the handling of knowledge reflect concerns over the free passage of information that were ubiquitous in the correspondence of a range of early modern scholars ${ }^{14}$ intelligencers such as John Collins fretted over their access to texts from the continent, and sought entry to private libraries on the recommendations of friends and colleagues so as to survey, copy, and benefit from the materials therein.

As the market for printed works expanded, highly literate, expert intermediaries naturally turned their skills in reading, writing, and informationhandling into advantageous economic and personal status in a society where text complemented orality as a key method of information exchange. ${ }^{15}$ In their roles as correspondents, intelligencers, producers and purchasers, these agents helped to construct and shape demand for occupational, intellectual and leisurely reading. Thomas Salusbury's communication with the teenage Earl of Huntingdon demonstrates how mathematically-literate agents were tasked with using their intellectual capabilities for the enrichment of their patrons' estates - for example, in collecting materials that would make for a prestigious library. Salusbury's selections were prudently chosen so as to offer a flattering depiction of Henry Pierrpont's erudition and scholarly judgement.

The requirement for a library stocked with the world's most important books voiced by the Marquess of Dorchester speaks, however, to the collection's equally important role as a form of presentation. This is further evinced by Salusbury's

\footnotetext{
${ }^{13}$ Webster, The Great Instauration, p. 70. On individuals and the establishment of Information Offices elsewhere in early modern Europe, see Catherine J. Minter, 'John Dury's Reformed LibrarieKeeper: Information and its Intellectual Contexts in Seventeenth-Century England', Library \& Information History, 31 (2015), pp. 18-34; Astrid Blome, 'Offices of Intelligence and Expanding Social Spaces', in Brendan Dooley, ed., The Dissemination of News and the Emergence of Contemporaneity in Early Modern Europe (Farnham: Ashgate, 2010), pp. 207-222.

${ }^{14}$ Michelle DiMeo has challenged the widely-accepted portrayal of the Hartlib circle as one which encouraged intellectual openness, arguing that cultures of discretion and secrecy remained important in discussions of certain topics (for example, alchemy), in discussions concerning the priority of ideas and inventions, and in those concerning commerce. Michelle DiMeo, 'Openness vs. Secrecy in the Hartlib Circle: Revisiting 'Democratic Baconianism' in Interregnum England' in Elaine Leong and Alisha Rankin, eds., Secrets and Knowledge in Science and Medicine (Farnham: Ashgate, 2011), pp. 105-124.

${ }^{15}$ Adam Fox, Oral and Literate Culture in England, 1500-1700 (Oxford: Clarendon Press, 2000) particularly pp. 170-172. Fox notes the change in scientific language in the later third of the seventeenth century, and contrasts this with existing proverbial wisdom transmitted primarily through speech. For the interplay of orality, print and manuscript in commercial, diplomatic, and other circles in early modern Italy, see Filipo de Vivo, Information and Communication in Venice: Rethinking Early Modern Politics (Oxford: Oxford University Press, 2007).
} 
report of the admiring glances of Lord Chancellor Hyde and others, and, indeed, by the cataloguing of the library's some 3,200 volumes (across classes such as 'Libri Mathematici', 'Libri Juris Civilis', 'Libri Medici' and 'Libri Philologici') in an ostentatious vellum-bound presentational entry-book, today held in the collections of the Royal College of Physicians in London. ${ }^{16}$ As Collins' report to Wallis demonstrates owners of such rich collections could limit or prohibit access by acting as gatekeepers to the circulation of rare or sought-after books amongst authors, printers, agents and readers.

The zeal for collection as defined and experienced by its early modern European adherents has been well-attested to in scholarly literature, with particular attention paid to the kunstkammern of princes, to the displays of natural wonder heralding the first modern museums, and to the professional holdings of physicians and apothecaries. ${ }^{17}$ Preceding these studies, Thomas DaCosta Kaufmann in a prescient article of 1978 called for a reinterpretation of the princely collection in particular, arguing that the imperial treasures amassed by Rudolf II formed an outward expression representing imperial power and glory and, simultaneously, a sanctuary, rather than a maddening trove of ever-more bizarre artefacts in which the Emperor lost his mind. ${ }^{18}$

While there is little doubt that princes and well-heeled noblemen (such as the Marquess of Dorchester) recognised the library's potential to impress upon visitors both the status and erudition of its owner, the collections of professionals - identified by Paula Findlen as predicated on utility - most closely echo the private English libraries of the late sixteenth and early-seventeenth century. ${ }^{19}$ Although T. A. Birrell's pithy summation that the book-buyers of the seventeenth century bought

\footnotetext{
${ }^{16}$ I am grateful to Katie Birkwood, Rare Books and Special Collections Librarian at the Royal College of Physicians, for drawing this to my attention. For the Marquess of Dorchester's catalogue, see Bibliotheca Marchionis Dorcestriae, Royal College of Physicians Library, RCP MS2000/81. ${ }^{17}$ Moran, 'German Prince-Practitioners', pp. 253-274; Eliska Fucíková, 'The Collection of Rudolf II at Prague: Cabinet of Curiosities or Scientific Museum?' in Oliver Impey and Arthur McGregor, eds., The Origins of Museums: The Cabinet of Curiosities in Sixteenth- and Seventeenth-century Europe (Oxford: Clarendon Press, 1985), pp. 51-61; Lorraine Daston and Katherine Park, Wonders and the Order of Nature (New York: Zone Books, 1998).

18 Thomas DaCosta Kaufmann, 'Remarks on the Collections of Rudolf II: The Kunstkammer as a Form of Representatio', Art Journal, 38 (1978), pp. 22-28.

${ }^{19}$ Findlen, Possessing Nature, p. 241
} 
only the books they needed still holds true, ${ }^{20}$ it is worth noting that the availability of books of every type rose considerably from the mid-1530s onwards. The dissolution of the monasteries, undertaken between 1536 and 1541 (and, by proxy, the dissolution of monastic libraries) saw thousands of previously-unavailable books enter the market, many of which would have been prized by the reader and collector alike. ${ }^{21}$ Aided by tumbling prices and access to new markets, readers and owners were presented with the opportunity to build appreciable domestic libraries for the first time. In these circumstances, reading slowly moved from an occupational to a leisurely or personal activity.

In many cases, these personal collections were the rock on which later institutional libraries came to be built. Although the religious institutions and colleges which remained less affected by political and religious upheaval were also well placed to benefit from cheap print and a growth in commerce, the university libraries of Oxford and Cambridge were both at one point or another reliant upon the charity of alumni and other associated individuals. ${ }^{22}$ As Robyn Adams and Louisiane Ferlier's case-studies of donors to the Bodleian Library amply demonstrates, the library's founder Thomas Bodley (1545-1613) sought to encourage further donations by advertising to visitors a 'visible core of philanthropy [...] proclaiming the library a public monument of benefaction'. ${ }^{23}$ The growth of borough and charitable libraries from the late-sixteenth century onward has similarly been used to chart the movement of private collections into the public sphere. ${ }^{24}$ One outcome of these

\footnotetext{
${ }^{20}$ T. A. Birrell, 'Reading as Pastime: The Place of Light Literature in some Gentleman's Libraries of the Seventeenth-Century' in Robin Myers and Michael Harris, eds., The Property of a Gentleman: The Formation, Organisation and Dispersal of the Private Library, 1620-1920 (Winchester: St Paul's Bibliographies, 1991), pp. 113-131, p. 114.

${ }^{21}$ Sears Jayne, Library Catalogues of the English Renaissance (Godalming: St Paul's Bibliographies, 1983), pp. 39-43.

22 On the dispersal of monastic libraries and their contents piecemeal reappearance in personal libraries, see R. H. Fritze, "'Truth Hath Lacked Witnesse, Tyme Wanted Light": The Dispersal of the English Monastic Libraries and Protestant Attempts at Preservation, ca. 1535-1625', Journal of Library History, 18 (1983), pp. 274-291.

${ }^{23}$ Robyn Adams and Louisiane Ferlier, 'Building a Library without Walls: The Early Years of the Bodleian Library', in Annika Bautz and James Gregory, eds., Libraries, Books, and Collectors of Texts, 1600-1900 (New York: Routledge, 2018), pp. 1-18, p. 8.

${ }^{24}$ William Poole, 'Analysing a Private Library, with a Shelflist Attributable to John Hales of Eton, c. 1624' in Edward Jones, ed., A Concise Companion to the Study of Manuscripts, Printed Books, and the Production of Early Modern Texts, $2^{\text {nd }}$ edn ( Oxford: Wiley Blackwell, 2015), pp. 41-65, p. 42. For examples of the foundation of institutional and public libraries, see Matthew Yeo, The Acquisition of Books by Chetham's Library, $1655-1700$ (Brill: Leiden and Boston, 2011); for the circulation of manuscripts and print in early modern libraries, see Jennifer Summit, Memory's Library: Medieval Books in Early Modern England (Chicago and London: University of Chicago, 2008).
} 
benefactions saw the book-owners and library-keepers of early modern England enter into a mutually beneficial relationship: one in which libraries expanded their holdings and warded off threats of loss or dispersal by simultaneously improving donors' social and religious credit. As both sets of participants might choose to see it, each thereby contributed to the good of the common weal in the process.

The records of educational and religious establishments are consequently rich storehouses of documents pertaining to the history of the book and the history of reading in early modern England. These institutions themselves functioned as largescale collectors of intellectual materials and instruments, and are by now wellstudied; nonetheless, opportunities for granular reconstructions of personal libraries and their evidence of intellectual and reading practices still reside unexploited within the holdings of larger institutional collections. The coalescences of these differentlyscaled libraries allow us to investigate the points at which the interests of the individual and the institution intersect - and, importantly, to investigate the points at which they diverge.

In previous chapters of this thesis, I have drawn attention to unique examples of texts found in the Rare Books Collection of the Science Museum to highlight discrete individuals' use and collection of mathematical materials. Though essential to our understanding of the scribal technologies of mathematics as practiced in the early modern period, specific readers are only one avenue of enquiry available to this study. To broaden the scope of my investigation and to more fully consider one site of mathematical practice, the construction, usage, and afterlife of the library in the early modern and modern periods form the penultimate chapter of the current thesis. Hitherto visualised as a locus in which to explore idiosyncratic responses to distinct texts and objects, the Science Museum collections also serve as storehouses of evidence relevant to histories of personal and institutional collection. Attending to the construction of this over-arching repository extends the temporal field of reference from the early modern to the present day.

This extension brings with it an essential change in methodological focus in two specific ways. First of all, the study must move from the singular reader or collector to a consideration of the multiplicity of actors responsible for the acquisitions of a given museum, library, or educational institution. Whereas previous 
chapters have offered synchronic case-studies of individual users and their texts as a means to investigate reading practices at a given historical point, the current chapter moves toward a diachronic presentation of three collections, charting instead the establishment, growth and subsequent diffusion of two libraries into one larger institution. Bridging the gap between the individual and the institutional collection, I then consider two twentieth-century sales in which the Science Museum acted as a purchaser: namely, the auction of Sion College library materials in 1938, some of which belonged to the early modern clergyman and mathematician Nathaniel Torporley (1564-1632); and the auction of the scientific library of the antiquarian and collector Robert Brodhead Honeyman (1897-1987) between 1978 and 1981.

Secondly, a diachronic reading of these materials requires that the identity of the wider collection be brought to the fore. Beginning with a reconstruction of Nathaniel Torporley's personal library and its relevance to his religious and mathematical careers, I explore how his 1633 bequest to the nascent Sion College was an integral and formative part of that institution's library. Though only briefly affiliated to the College in the final years of his life, the former vicar nonetheless saw the newfound establishment as a worthwhile home for his personal collection of texts on mathematics, astronomy, medicine, and theology. Most commonly thought of today with reference to either his friend the mathematician Thomas Harriot, or to the French analytical algebraist François Viète, for whom Torporley briefly acted as amanuensis, the clergyman's mathematical capabilities and intellectual interests have been dimmed by the light of his two more famed contemporaries. An overemphasis on these relationships has served to obscure the opportunity Torporley's bequest to the Anglican community provides. By reconstructing the scholarly library of this early modern mathematician and clergyman, it is possible to gain new insights into his reading and collecting habits, and to re-evaluate his intellectual practice thereafter.

Analysis of Nathaniel Torporley's bequest and its relevance to Sion College's institutional identity is then supplemented by an investigation into his library's dispersal at auction three centuries later, in 1938. Presenting evidence of the sales notes from this auction alongside acquisition materials from the Science Museum as an organisational collector, the current chapter then looks back to the 
creation of the Science Museum Library and the development of its identity before moving to its participation in a second auction: that of the American antiquarian, Robert Brodhead Honeyman, and his twentieth-century collection of texts and manuscripts belonging to the physical sciences, sold by Sotheby's in London between 1978 and 1981.

In similar fashion to Torporley, Robert Honeyman donated portions of his personal collection to his alma mater of Lehigh University, Pennsylvania throughout his life, and bequeathed a significant amount of material to the institution in his will. In contrast to the Anglican clergyman, whose texts functioned as a scholarly personal library, Honeyman perceived his collection as presenting an instructive and coherent narrative: one that displayed the development of the history of science. Having graduated with a degree in engineering in 1920, Honeyman soon began to collect rare and celebrated materials from various disciplines, lending treasured items to museums, libraries, and universities in California. As catalogues from Lehigh University Library illustrate, he contributed first editions and other rare texts and manuscripts to exhibitions on the centennial of Charles Darwin's On the Origin of Species; to displays on the history of mathematics; and, reflecting his personal interests in engineering, geology, and astronomy most clearly, to those on the form of the earth and the cosmos. ${ }^{25}$

By excavating evidence of the libraries of Torporley and Honeyman from the Rare Books Collection of the Science Museum, the goal of this chapter is thus to conclude the current thesis by exploring the Science Museum Library's formation and growth from the opening of the Science Library in 1883 to the Honeyman sale which commenced in 1978 . Within this reading will be placed a case study of Nathaniel Torporley's reading practices and library, as reflected in the synchronic moment of its entry to the Sion College Library in 1633. A second synchronic casestudy takes a snapshot of the Honeyman Collection at its point of sale, focussing on the value of various materials to the then-established Science Museum Library. By combining these studies in a diachronic history of the Science Museum Library, the current chapter seeks to avoid freezing the Science Museum's collection in time, and

${ }^{25}$ Lehigh University. Library and Honeyman, Robert B., "The History of Mathematics" (1961). Exhibition Catalogues. Paper 5; Lehigh University. Library and Honeyman, Robert B., 'The Size and Shape of the Earth' (1958), Exhibition Catalogues, Paper 3. 
to avoid obscuring the smaller collections it has to this point subsumed. ${ }^{26}$ It tackles the problematic effects of seeing the collection or the collector in singular or fixed terms, and instead highlights the multiplicity of libraries and collectors present within the library and the collection.

\section{The Foundation of Sion College and its Library}

Formally established by Royal Charter at the second attempt in July of 1630, Sion College was designed to serve two purposes. The first was the continuation and growth of the Anglican faith in London, via premises where the clergy of the city could meet, converse, and reside. The Reverend Dr Thomas White's (ca. 1550-1624) foundational bequest of $£ 3000$ was intended for the purchase and maintenance of such a property, with the accompanying intention that the college would also provide London with an alms-house comparable to his prior establishment of Temple Hospital in Bristol, in the parish of his birth. ${ }^{27}$ Governed by White from its foundation in 1613 to his death in 1624, Temple Hospital's patrons were to be unmarried individuals, over 50 years of age, with entry barred for at least a quarter of a year to those known to be drunkards, blasphemers or fornicators. ${ }^{28}$ Sion College was to function on similar grounds, providing shelter and sustenance to the disadvantaged as well as rented or pensioned lodgings for clergy, a handful of students, and their necessary ancillary staff consisting of porters, cleaners, and assorted help. The establishment and upkeep of both Temple Hospital and Sion College were paid for from moneys accrued from White's position as rector of St Dunstan in the West, in London's Fleet Street, and from the prebendaries of St Paul's and the Canonships of Christ Church, Oxford (1591 onwards) and St George's, Windsor (1593 onwards); when necessary, these funds were also supplemented by his personal estate.

Although Thomas White left no specific instructions for a library, his executor, kinsman, fellow cleric and the early College's first Librarian, John Simson,

\footnotetext{
${ }^{26}$ Oscar E. Vázquez, Inventing the Art Collection: Patrons, Markets, and the State in NineteenthCentury Spain (Pennsylvania: The Pennsylvania State University Press, 2001), p. 3.

${ }^{27}$ William Reading, The History of the Ancient and Present State of Sion-College, near Cripplegate, London; and of the London-Clergy's Library there (London: J Roberts, 1724), pp. 8-9. Reading's text provided close to the entirety of White's will.

${ }^{28}$ E. H. Pearce, Sion College and Library (Cambridge: Cambridge University Press, 1913), p. 149.
} 
saw fit to construct one for the benefit of the clergy. Apocryphally, this decision owed as much to the chance remark of a colleague on the architectural suitability of the alms-rooms atop which it would later be built as it did to any other grand design. ${ }^{29}$ Despite having failed to garner a Royal Charter at the first time of asking in 1626, Simson and his fellow would-be governors pressed ahead with White's plans for an alms-house capable of housing ten men and ten women. ${ }^{30}$ A site consisting of a priory, two main houses, several tenements and gardens at Elsing Spital, previously a hospital and before then a church, was identified and subsequently procured in April $1627 .^{31}$

In his formative role as architect and overseer of Sion's new library, John Simson acquired or helped to provide the funds for its furnishing, ensuring its yearly endowment of $£ 16 .{ }^{32} \mathrm{With}$ at least one eye toward posterity, the library’s founder established the Sion College Benefactor's Register in 1629; on the first page of the imposing Book of Benefactors, Simson left it in no doubt that he alone had borne the cost of the library's establishment. ${ }^{33}$ The College's first librarian was soon succeeded to this post by his son John in 1631, who was himself ably assisted (and then swiftly replaced, in 1633) by the stationer John Spencer. Spencer, a fractious and complicated character, appears to have made it a point of personal principle to ensure that the college accumulated a healthy collection of books and materials across his half-century of service in various positions.

\footnotetext{
${ }^{29}$ Pearce, Sion College and Library, p. 16.

${ }^{30}$ Elizabeth Edmondston, 'Unfamiliar Libraries IX: Sion College', The Book Collector, 14.2 (1965), pp. 165-177, p. 165.

${ }^{31}$ Pearce, Sion College and Library, p. 89. A detailed description of the history of the site, along with documents relating to its history as a hospital and priory in both Latin and English, is to be found in Reading, State of Sion-College, pp. 1-8.

32 Edmonston, 'Unfamiliar Libraries XI: Sion College', p. 166.

${ }^{33}$ London, Lambeth Palace Library. Book of Benefactors, Sion College Collection. L40.2/E64, unpaginated, f. $1 \mathrm{r}$.
} 


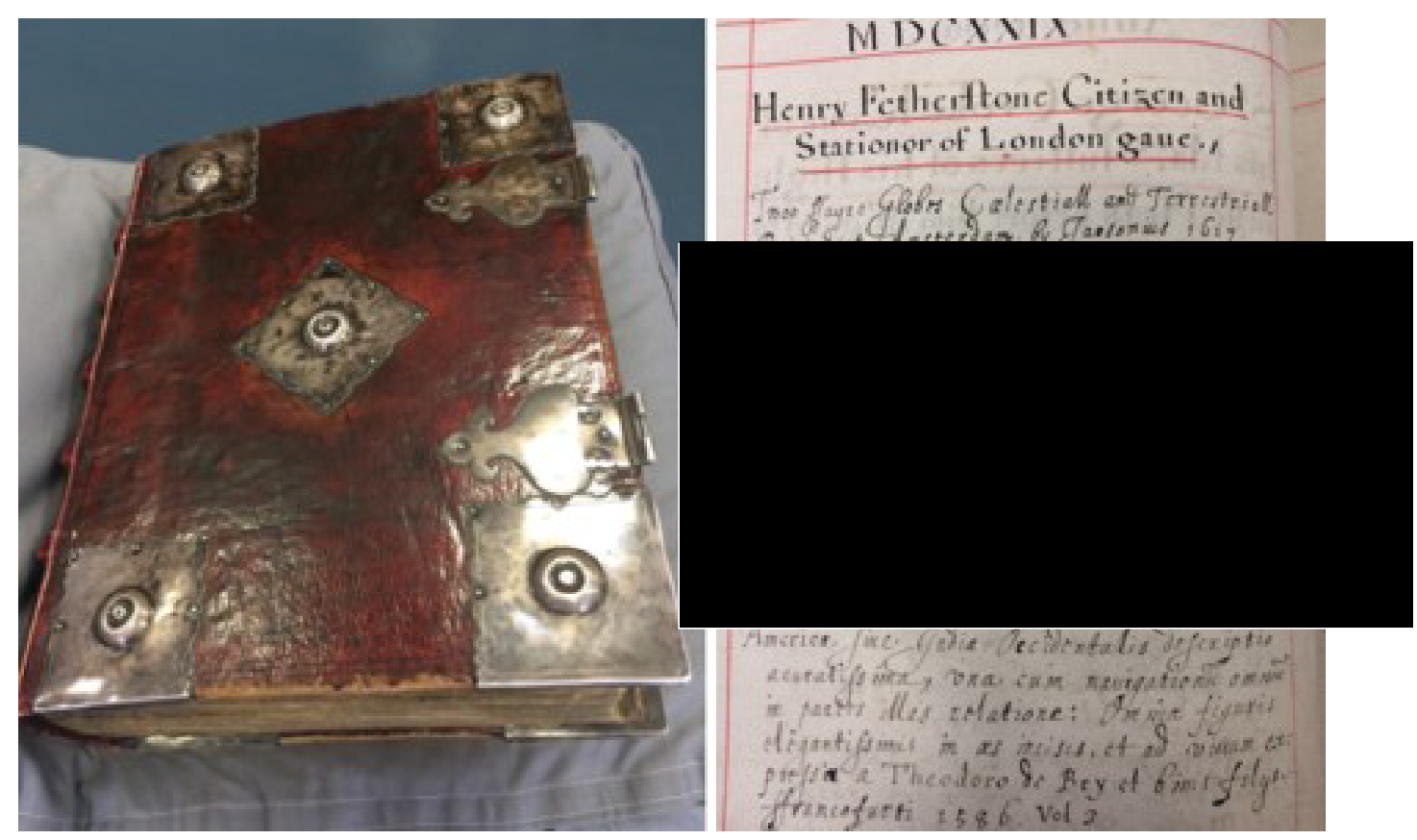

Figure 5.1. Composite image of the imposing Book of Benefactors (left) and a sample donation from Henry and Katharine Fetherstone, written by John Simson on vellum, 1629 (right). London, Lambeth Palace Library, Sion College Collection. L40.2/E64.

Though the College was not formally established until 1630 (by which time Nathaniel Torporley, the former rector of Salwarpe, was already sixty-six years old); the first general assembly of its President, Fellows and Governors was documented as taking place on May 3, 1631. ${ }^{34}$ With a keen eye for those who actually made the College tick, William Reading noted that the directors appointed in 1631 'LibraryKeepers, Clark, Porter, Cook of the College' and 'let Leases of three Tenements betwixt the Gate and the Church, and two in Philip-Lane: so that there is no Question but they were the first acting Governors. ${ }^{35}$ Nevertheless, there are indications that the College was, in some embryonic state, functional before being granted its Royal Charter. The library's founder John Simson began charting donations on vellum in 1628 , indicating that the soliciting of bequests and financial gifts had begun in earnest before the College was officially recognised. With little by way of funds demarcated specifically for the purchase of books, the first swathe of donations lodged in the Book of Benefactors reflect the founder's efforts to raise both capital and a collection. In 1629 Sir Paul Bayning, Baron of Horkesley, and his wife Lady Ann were among the first to offer substantive assistance, each giving $£ 50$ for the

\footnotetext{
${ }^{34}$ Reading, State of Sion-College, p. 14.

${ }^{35}$ Reading, ibid, p. 15.
} 
purchase of books; Simson entered his purchases in the Benefactors' register accordingly, with almost the entirety of the Baynings' donation spent on theological literature. ${ }^{36}$

Although the early donations secured by Simson consisted mainly of ecclesiastical, civic and historical works, astronomical and geographical materials occasionally appeared. The stationer Henry Fetherstone donated 'two fayre Globes Coelestiall and Terrestriall printed at Amsterdam by Jansonius, 1617', along with a number of atlases and maps; his wife Katharine supplemented these effects with her own donation of religio-geographical materials - Samuel Purchas's (ca. 1577?-1626) four-volume Hakluytus Posthumus, or Purchas his Pilgrimes, and the same author's Purchas His Pilgrimage of $1613 .{ }^{37}$ The College's third librarian, the long-serving John Spencer, did not content himself solely with charting the arrival of books, however. As an erstwhile clerk and historian of the nascent college, Spencer also noted donors' affiliations to the Sion residence, marking that one such contributor, Nathaniel Torporley, the mathematician and former rector, was 'sometime student of this Colledg'. ${ }^{38}$

Despite being sacked as Librarian after running into legal difficulties over his mishandling of Nathaniel Torporley's effects, ${ }^{39}$ John Spencer soon returned to a series of lesser posts, always attached to the library. In his rambunctious and occasionally hagiographic history of Sion College, E. H. Pearce notes that the Governors often cycled between periods of owing money to Spencer and being owed money by him $;{ }^{40}$ when not acting as either debtor or creditor, the librarian quietly added several hundred texts from his private collection to increase the library's stocks between 1631 and $1680 .{ }^{41}$ Spencer guided into publication the Library's first

\footnotetext{
${ }^{36}$ Sion College, Book of Benefactors, f. $1 \mathrm{r}$.

${ }^{37}$ Sion College, ibid, f. 4 v.

${ }^{38}$ Sion College, ibid, f. 23 r.

39 'Charles I - volume 344: January 15-26, 1637', in John Bruce, ed., Calendar of State Papers Domestic: Charles I, 1636-7 (London: Her Majesty's Stationery Office, 1867), pp. 363-393, p.364. Spencer was sued and compelled to pay the court $£ 4.00$ cash, eleven diamond rings, eight gold rings, and two bracelets. Archbishop Laud then removed Spencer from his position.

${ }^{40}$ Pearce, Sion College and Library, pp. 232-255. Pearce's brief relation of Spencer's mishandling of Torporley's effects and the fallout following appears on p. 234.

${ }^{41}$ Karen Attar, ed., Directory of Rare Book and Special Collections in the UK and Republic of Ireland, $3^{\text {rd }}$ edn (London: Facet Publishing and CILIP Rare Books and Special Collections Group, 2016), p. 192.
} 
printed catalogue in $1650,{ }^{42}$ and, following the example of the Simsons, personally oversaw the maintenance of the Book of Benefactors (Figure 5.1, above) to chart bequests and to inspire future gifts.

\section{Nathaniel Torporley's Entry into Sion College}

Nathaniel Torporley would seem to have crossed the threshold of the nascent institution by 1629, if not before, and there is evidence in the Benefactors' register to suggest that he donated materials to the library in the years before his death. As we shall soon see, one early donor of 1630 was marked down as 'N. T.', and offered the newly-struck library a number of alchemical and theological manuscripts - materials entirely in keeping with Torporley's wider collection. Whilst other manuscripts suggest that he could have been resident at Sion College from 1629 (or, perhaps, using its library as a day-visitor prior to this date), it is difficult to place Torporley at Sion College with any more exactitude prior to the institution's formal chartering in 1630, and the clergyman's death (a few months ahead of that of the Earl of Northumberland) in $1632 .{ }^{43}$

Having previously attained his B. A. from the University of Oxford in $1583 / 4,{ }^{44}$ Torporley may then have spent time soon after under the tutelage of François Viète. A letter to Thomas Harriot discussing his plans to meet with the French algebraist has been dated by J. V. Pepper to 1586, although more recent scholarship has challenged this by suggesting that the Torporley-Viète relationship might not have commenced until $1594 .{ }^{45}$ In an example of his dry humour,

\footnotetext{
$42 \mathrm{~J}(\mathrm{ohn}) \mathrm{S}$ (pencer), Catalogus Universalis Librorum omnium in bibliotheca Collegii Sionii apud Londinenses (London: Robert Leybourn, 1650).

${ }^{43}$ Given that grounds of the College were purchased in 1627, Wood's suggestion that Torporley resided at 'mostly at Sion Coll(ege), in London' from 1608 onwards seems impossible. Wood perhaps confused Sion College, in central London, with the Earl of Northumberland's Syon House, in Isleworth, West London. Wood, Athenae Oxonienses, p. 524.

${ }^{44}$ Andrew Clark, ed., Register of the University of Oxford, Volume 2 (1571-1622), Part 2: Matriculations and Subscriptions (Oxford: Printed for the Oxford Historical Society, 1887), p. 100. The subscription list notes that Torporley entered Christ Church College, Oxford as plebeian, on February 17, 1581, although somewhat confusingly a Roger Torpolé appears a mere two days later in the same list and at the same college.

45 J. V. Pepper, 'A Letter from Nathaniel Torporley to Thomas Harriot', The British Journal for the History of Science, 3.3 (1967), pp. 285-290, p. 289. Contradicting Pepper, Jacqueline A. Stedall has argued that religious tensions saw François Viète removed from the royal court in 1584; the mathematician would not return to Paris until 1594. Jacqueline A. Stedall, The Great Invention of Algebra: Thomas Harriot's Treatise on Equations (Oxford: Oxford University Press, 2003), p. 301, fn. 6. Anthony à Wood judiciously stated that Torporley's time with the French analyst was 'notoriously known, but the time when, whether before or after he was M. of A. we cannot tell'.
} 
Torporley self-deprecatingly referred to his first meeting with Viète in Paris by confiding in Harriot that he was 'gathering up my ruined wittes, the better to encounter that French Apollon', before comparing himself to the diminutive biblical tax-collector Zacchaeus 'to clime the tree, to gayne a view of that renoumned analist'. ${ }^{46}$

Torporley took his M. A. at Oxford in July 1591, and, his time with Viète notwithstanding, appears to have entered the clergy before the turn of the century. He published his sole work, Diclides coelometricae seu valvae astronomicae universales (London: Felix Kingston) in 1602, and was affiliated to Henry Percy, the 9th Earl of Northumberland (1564-1632) by this point. When Percy was arrested on trumped-up charges relating to treasonous foreknowledge of the failed Gunpowder Plot in November 1605, Torporley was interrogated by the Star Chamber; the clergyman immediately confessed to the nefarious activity of casting King James's nativity and drawing his horoscope at Harriot's (and, by implication, Henry Percy's) diabolical request. ${ }^{47}$ The Earl of Northumberland was thereafter committed to the Tower of London until 1621; Torporley and Harriot, meanwhile, seem to have avoided further sanction.

Whilst the movements of Nathaniel Torporley's final years are difficult to trace, we know that he resigned the vicarage of Salwarpe after 14 years in post in 1622, and that he retained a sinecure as rector of Liddington from 1608 until his death. ${ }^{48}$ His resignation from Salwarpe can be directly linked to Thomas Harriot's passing in 1621. Named 'Overseer of my Mathematical Writings' in Harriot's will, the clergyman was charged with the unenviable task of separating 'the chief of them from my waste papers, to the end that after he doth understand them he may make

\footnotetext{
Anthony à Wood, Athenae Oxonienses: An Exact History of All the Writers and Bishops who have had their Education in the University of Oxford, Volume 2, $3^{\text {rd }}$ edn, Phillip Bliss, ed., (London: Rivington et al., 1815), p.524.

${ }^{46}$ London, British Library. Add MS 6788, ff. $117 \mathrm{r}-117 \mathrm{v}$. Torporley's letter is reproduced in Pepper, 'A Letter from Nathaniel Torporley to Thomas Harriot'.

47 'Examination of Mr Nathaniel Torporley, about his casting of the King's nativity for Mr Heriot, who lived at Essex House, the Earl of Northumberlands', November 27, 1605. The Gunpowder Plot: a collection of correspondence, depositions and papers, in two parts. Public Records Office, SP 14/216, Part 2, p. 122.

48 'Torperley, Nathaniel (1608-1632)', Clergy of the Church of England Database, CCEd Person ID 83346. http://db.theclergydatabase.org.uk/jsp/persons/index.jsp . Accessed 22 July 2018.
} 
use in penning such doctrine that belongs unto them for public uses' ${ }^{49}$ To this end, one of Harriot's co-executors, John Protheroe, paid Torporley's pension from 1622, and left instructions to his wife to continue this arrangement after his death, which occurred in $1624 .^{50}$

Identifying the clergyman's precise movements between his resignation of the Salwarpe vicarage in 1622 and at least 1629 is difficult, but we can say with some certainty that he remained in the orbit of Henry Percy and his coterie. Kept afloat by John Protheroe, Torporley worked on the Harriot papers at the Earl of Northumberland's residences, either at Syon House, in Middlesex, or the library of Petworth House, in Sussex, between 1622 and 1627. As Jacqueline Stedall has noted, a manuscript written by Torporley on Harriot's method of interpolation by constant differences, entitled 'NA. TO. CONGESTOR $[\ldots]$ eodem se forte resolvit CONIECTOR', was dedicated to their shared patron, Henry Percy, and dated 5 October 1627; furthermore, Torporley went so far as to state that the work was completed in the Petworth House Library. ${ }^{51}$

By this date, Torporley had been granted a single year’s pension of $£ 40$ from the Earl of Northumberland, ${ }^{52}$ and, although he had been part of Percy's circle of mathematical practitioners for twenty years, this pension provides the first real evidence of his patronage. Thomas Harriot's will of 1621 commanded Torporley to return the former's manuscripts under lock and key to the Earl's library at Petworth House once their contents had been published. ${ }^{53}$ As one overseer of Harriot's posthumously published algebraical text Artis analyticae praxis (London: Robert Barker, 1631), Nathaniel Torporley may also have prepared some of his editorial work at Sion College.

\footnotetext{
${ }^{49}$ Gordon R. Batho, 'Thomas Harriot's manuscripts' in Robert Fox, ed., Thomas Harriot: An Elizabethan Man of Science (Aldershot: Ashgate, 2000), pp. 286-297, p. 288.

${ }^{50}$ Jacqueline A. Stedall, 'Rob'd of Glories: The Posthumous Misfortunes of Thomas Harriot and His Algebra', Archive for History of Exact Sciences, 54.6 (2000), pp. 455-497, p.460.

${ }^{51}$ Jacqueline Stedall, 'Reconstructing Thomas Harriot's Treatise on Equations', in Robert Fox, ed., Thomas Harriot and his World: Mathematics, Exploration and Natural Philosophy in Early Modern England (Farnham: Ashgate, 2012), pp. 53-64, p. 58.

${ }^{52}$ Gordon R. Batho, ed., The Household Papers of Henry Percy, Ninth Earl of Northumberland (1564-1632), (London: Royal Historical Society, 1962), p. 163.

${ }^{53}$ Batho, 'Thomas Harriot's manuscripts', p. 288.
} 
Against this relatively brief period of habitation can be set Nathaniel Torporley's activities in the final few years of his life. While his own oeuvre juddered to a halt in the first decade of the seventeenth century after the publication of Diclides coelometricae in 1602, the vicar continued to edit Harriot's papers for a decade after his friend's death in 1621. Harriot's will had advised that, if Torporley were to find himself unable to understand the manuscripts' mathematical notation, specialist help was to be sought from two other members of Percy's circle - Walter Warner (1563-1643), the keeper of Northumberland's library and mathematical instruments, and Robert Hues (1553-1632), the author of the popular work Tractatus de globis et eorum usu (London: Thomas Dawson, 1594) on terrestrial and celestial globes. ${ }^{54}$ If Walter Warner and Nathaniel Torporley appear to have worked in tandem for a period, their relationship soon soured. By 1631, Warner had seen Harriot's Artis Analyticae Praxis through the presses alone; Torporley's attempted edition, along with his plans for a summary and his scathing criticism of Warner's adaptation, remained in manuscripts bequeathed to Sion College.

It is useful, then, to envisage the clergyman as a working mathematician, whether at Petworth House or Sion College; one consulting his personal library of texts, manuscripts, and instruments, even in his final days. Two of the latest texts identified as belonging to Torporley in his 1633 bequest help us to visualise the clergyman's continued mathematical practice, even in later life: Claude Gaspard Bachet de Méziriac's 1621 edition of Diophantus's Arithmetica, translated from Greek to Latin, and Johannes Kepler's Tabulae Ruldophinae of 1627. Diophantus's work was later prized by the French theorist Pierre de Fermat (1607-1665), ${ }^{55}$ and would undoubtedly have been of use to Torporley in his attempts to edit Thomas Harriot's algebra. Kepler's astronomical tables, meanwhile, remind us of the vicar's personal intellectual interests, his lifelong interests in astronomy and prognostication, and the curious mixture of trigonometrical canons, judicial astrology, spherical astronomy, medicine, and theology witnessed in Diclides coelometricae.

\footnotetext{
${ }^{54}$ Rosalind C. H. Tanner, 'The Study of Thomas Harriot's Manuscripts. 1. Harriot's Will', History of Science, 6 (1967), pp. 1-16, p. 6.

${ }^{55}$ Harold M. Edwards, Fermat's Last Theorem: A Genetic Approach to Algebraic Number Theory (New York, Berlin, Heidelberg: Springer-Verlag, 1977), p. 2.
} 
Although the Sion College library would benefit from the donation of ca. 150 texts from the personal library of the Puritan minster Walter Travers (ca.1548-1635) in 1635 , as well as the much more substantial bequests of George Berkeley, ${ }^{\text {st }}$ Earl of Berkeley (1628-1698) (ca. 1900 volumes) and the mathematical printer Thomas Allen (d.1711) (ca. 2400 volumes) in 1698 and 1711 respectively, ${ }^{56}$ Torporley's 1633 bequest of more than 200 texts and at least eight manuscripts seems to have been the most notable non-monetary gift to the College in its first decade. The clergyman's donation to the emergent College is therefore an important example of how mathematical, philosophical and scientific texts and manuscripts filtered through institutional libraries in the early seventeenth century. In keeping with the university curricula of Oxford and Cambridge, the theologians and students passing through Sion College would have possessed much higher levels of literacy and numeracy than a clear majority of their contemporaries. ${ }^{57}$ Educated according to the scholastic quadrivium central to the university and familiar with arithmetic, geometry and astronomy as pertaining to the study of natural philosophy, these readers would at the very least have met with ideas and theory aimed at the more learned of early modern audiences.

As a consequence, what we might term such users' conceptual literacy - a toolkit of comprehensive reading practices honed during their education and spanning a range of scholarly topics - operated at an advanced level for the period. I suggest that the students and residents of the college were highly likely to explore the many intriguing mathematical, philosophical and theological texts left by benefactors such as Torporley. When seen in this light the purchasing decisions of

\footnotetext{
${ }^{56}$ Attar, ed., Directory of Rare Book and Special Collections, p. 193. I am also grateful to Ken Gibb, Rare Books Librarian at Lambeth Palace Library, for providing information on these donors and their bequests in personal correspondence.

${ }^{57}$ Hugh Kearney, Scholars and Gentlemen: Universities and Society in pre-Industrial Britain, 15001700 (London: Faber, 1970), p. 20. For a summary of the undergraduate experience of many seventeenth-century clerics in England, see Helen M. Jewell, Education in Early Modern England (Houndmills: Macmillan, 1998), pp. 62-65. For the extra-curricular reading requirements of the preeminent college for ministers, Emmanuel College, Cambridge, from the 1580s onwards, see Tom Webster, Godly Clergy in Early Stuart England: The Caroline Puritan Movement, c. 1620-1643 (Cambridge: Cambridge University Press, 1997), particularly pp. 15-19. For reference to the English universities and the changing role of natural theology, its debates, and its forms of evidentiary reading, see Scott Mandelbrote, 'Early modern Natural Theologies', in J. H. Brooke, F. Watts and R. R. Manning, eds., The Oxford Handbook of Natural Theology (Oxford: Oxford University Press, 2013), pp. 75-97, p. 79. For changes to clerical education later in the period, see W. M. Jacob, The Clerical Profession in the Long Eighteenth Century, 1680-1840 (Oxford: Oxford University Press, 2007), pp. 43-53.
} 
John Simson and, later, John Spencer are instructive. Whilst neither man could do much to influence the texts they were bequeathed from existing collections, both made a point of adding occasional mathematical, scientific, or practical texts where possible. In one notable example, Simson utilised part of Thomas Adison’s $£ 5$ benefaction of 1629 to secure editions of Thomas Fale's Horologiographia, or the Art of Dialling (London: Felix Kyngston, 1627; $3^{\text {rd }}$ edition), Thomas Hylles's The arte of vulgar arithmeticke (London: Gabriel Simson, 1600), Robert Recorde's The Castle of Knowledge (London: Valentin Sims, 1596; $2^{\text {nd }}$ edition) and, evidently a few years later, Henry Gellibrand's An institution trigonometricall (London: William Jones, 1635)..$^{58}$

Vastly outnumbered by the library's swelling collection of theological, ecclesiastical and civic volumes, the idiosyncratic materials found in Torporley's bequest would nonetheless have inspired the curiosity and piqued the interest of the library's users. Additionally, by occasionally supplementing their catalogue with new additions in practical mathematics, astronomy, and natural philosophy, the early librarians of the college demonstrated their acknowledgement of their clientele's intellectual appetites through the College's earliest acquisitions.

\section{Reconstructing Nathaniel Torporley's library}

The Sion College librarian charged with entering Torporley's bequest, John Spencer, entered the reverend-mathematician's 1633 donation in the Book of Benefactors as fully as he could, marking his margins with a small $(+)$ on the occasions when a book was deemed to be missing. Thus some 204 texts, between eight and eighteen manuscripts, and one clock, were intended to be of use to the nascent college as a working collection: one comprised of mathematics, philosophy, history, and theology (Figure 5.2, below) ${ }^{59}$ Torporley's effects were bequeathed in a nuncupatory will, and I have yet to find evidence of a personal inventory, meaning that a complete reconstruction of the collection is not currently possible. However, by examining the Book of Benefactors and Spencer's own parallel manuscript

\footnotetext{
58 Sion College, Book of Benefactors, f. $6 \mathrm{v}$.

${ }^{59}$ Sion College, ibid, ff. 23r - 25r. See also London, Lambeth Palace Library. John Spencer, Transcriptum Registri illius magni Benefactorum, 1629-1666. Sion College Collection. Shelfmark L40.2/E60, ff. 22v - 25v. Nathaniel Torporley's library as identified from the cross-referencing of various Sion College records and sales catalogues is detailed in Appendix 2.
} 
catalogue, Transcriptum registri magni benefactorum, we can see that a large majority of the rector of Salwarpe's bequests were added to the library. As the majority of missing texts are replicated across both catalogues, it is possible that titles known to belong to Torporley were missing at the time of Spencer's inventory. Additionally, some of these supposedly missing titles then reappeared in the printed catalogue of 1650, although it should be noted that it is by now impossible to trace their provenance. Given the fact that the Librarian is known to have purloined Torporley's goods, it is also possible that Spencer himself was responsible for the works being missing. ${ }^{60}$

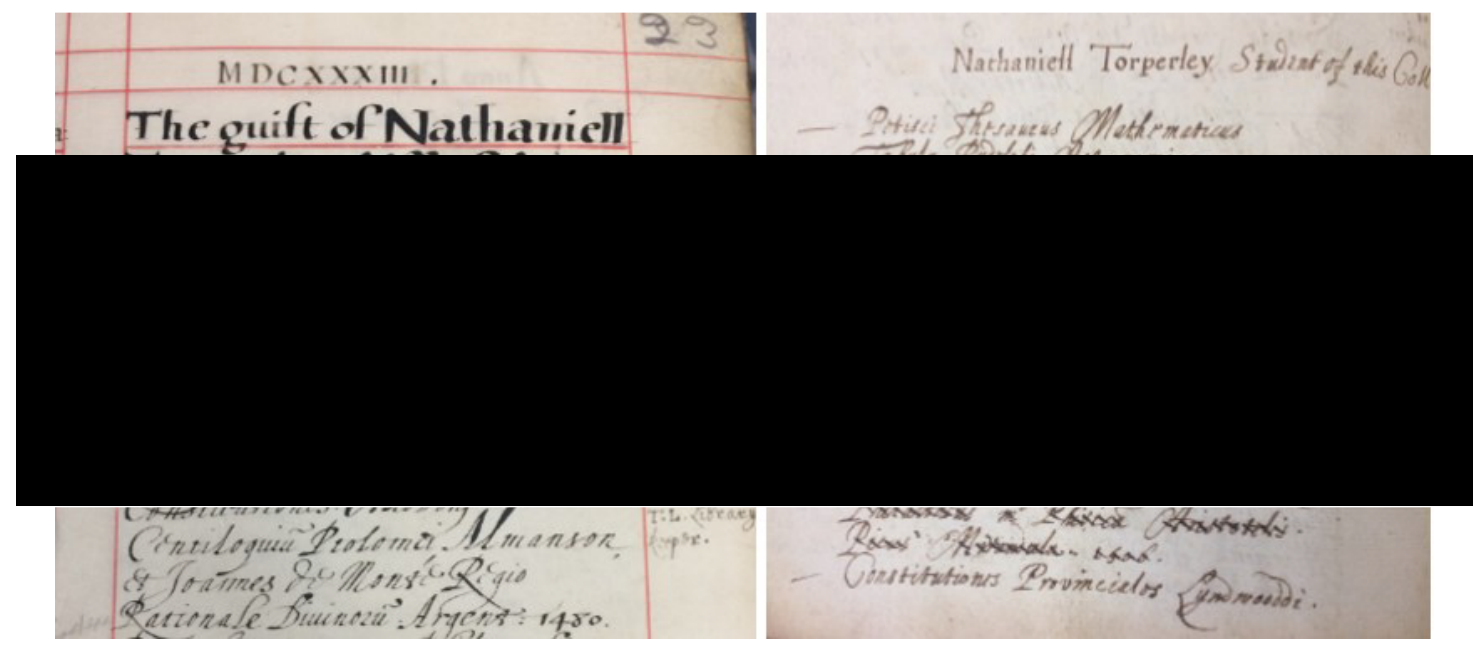

Figure 5.2. Composite image of John Spencer's entry for Nathaniel Torporley's 1633 bequest in the Book of Benefactors (left) and in Spencer's parallel manuscript catalogue (right).

Occasionally, Spencer's pen slipped into either the indiscernible or the unhelpful, as can be seen in his listing of materials authored by the famed Danish astronomer Tycho Brahe. These works were listed simply as 'Ticho Brahe' without additional detail in the Book of Benefactors, though in Spencer's parallel catalogue an entry of two volumes is marked as 'Ticho Brahe - Opera'. ${ }^{61}$ The printed catalogue of 1650, also compiled by Spencer, lists three entries under the heading 'tycho-braha'. The first is a quarto edition of Epistolarum Astronomicarum Libri; the

\footnotetext{
${ }^{60}$ Wood claims that Torporley also left Sion College 'all his astronomical instruments, notes, mapps, and his brass clock'. Whilst Spencer notes the acquisition of the clergyman's books, notes, and clock, Torporley's maps and instruments go unmentioned. Wood, Athenae Oxonienses, p. 525.

${ }^{61}$ Spencer, Transcriptum Registri illius magni Benefactorum, f. $23 \mathrm{v}$.
} 
next two Astronomiae instauratae Progymnasmata, and De mundi aetheri recentioribus Phaenomenis.

This latter pair were the first two volumes of Tycho's projected multi-series work on recent astronomical phenomena, begun in 1588, and it is highly likely that Torporley was the owner of both texts found in the Sion catalogues. Epistolae Astronomicae was branded with a Sion College shelfmark of T18.2 in the 1650 printed catalogue, with Astronomiae instauratae Progymnasmatia T18.3. In place of its own shelfmark, De mundi aetherei recentioribus Phaenomenis was marked 'ib(id)' in the catalogue, having been previously bound up with Epistolarum Astronomicarum. ${ }^{62}$ This is confirmed by the Hodgson and Co. auction catalogue of April 27, 1939, which lists Epistolarum Astronomicarum Libri as two volumes, Astronomiae Instauratae Progymnasmata as one, and De mundi aetherei not at all. ${ }^{63}$

Somewhat confusingly, the Book of Benefactors bears three separate donation lists that may have originated from Torporley, two of which date prior to his death. Sandwiched between more generous donors from 1629, a brief series of five manuscripts were listed under the heading 'Ex dono N. T.'. These manuscripts included theological, alchemical, and mathematical works from sources such as Thomas Aquinas and the contemporary Puritan divine Thomas Tymme, and sit comfortably alongside the remainder of Torporley's library. ${ }^{64}$ A second group of papers, donated in 1632, was entitled 'NA. TOR. chimicus donavit': comprised of five further manuscripts on alchemy, this bundle included Thomas Norton's (ca. 1433-1513) 1477 alchemical poem The Ordinal of Alchemy, George Ripley's Medulla Philosophicae (perhaps a corruption of Ripley's popular Medulla alchimiae

\footnotetext{
${ }^{62}$ Spencer, Catalogus Universalis Librorum, p. 145.

${ }^{63}$ London, Lambeth Palace Library. Lot numbers 127-128, Hodgson and Co., A Catalogue of Rare Early Scientific Books from the Library of Sion College London, Auction Catalogue Number 13 of 1938-1939 (London: Riddle, Smith, and Duffus, 1938), p. 11. Sion College Collection. Shelfmark Z999.S5

${ }^{64}$ Sion College, Book of Benefactors, f. 7 r. The manuscripts' titles include 'Tractatus de gratia Dei in Quaestionem logicam et sequentis Thomae Aquinatis'; 'Demonstration Theologicall, Philosophicall, and Mathematicall of a triple ternary setting out the perpetuall motion of the Universe and the cause thereof; together with a declaration of the immortality of Man's soules, by Tho. Tymme'; and 'Ephemeris Chirometrica. In qua continentur omnia quae ad Calendariu(m) vulgaru(m) spectant, citra Calendariu(m) memoriter, et per computationem manualem cognoscenda'.
} 
of 1476), and a possibly pseudographical work attributed to Ramond Llull, De Lapidum Philosophicum. ${ }^{65}$

Torporley does not appear to have signed his books, and I have yet to find evidence of manuscript annotation in the few materials I have viewed thus far. Nonetheless, several volumes belonging to the clergyman bear a contemporaneous manuscript donor label marking his benefaction, with the clergyman denoted as mathematicus. The panel, shown below in Figure 5.3, simply states that each volume was donated by Torporley to the Sion College Library, along with many others. ${ }^{66}$ The label was attached to the front paste-down or flyleaves of the text; similar handwritten and, later, printed slips were created for bequests such as those of William Haine, ${ }^{67}$ as well as to celebrate the benefactors who provided funds specifically intended for the purchase of books. ${ }^{68}$ Regrettably, the scattering of Torporley's library means that it has not yet been possible to conduct a thorough census of these texts, or know whether every constituent volume bore the College's benefaction label.

\footnotetext{
${ }^{65}$ Sion College, Book of Benefactors, f. 17 r. For a discussion of the Medulla alchimiae and its place in Ripley's corpus, see Jennifer M. Rampling, 'The Catalogue of the Ripley Corpus: Alchemical Writings Attributed to George Ripley (d. ca. 1490)', Ambix, 57.2 (2010), pp. 125-201, p. 129. 66 'Nathanael Torperley Mathematicus, volumen hoc cum multis aliis Bibliotheca huic Sionensi donavit. MDCXXXIII.' From Torporley's copy of Pierre Tartaret, Expositio magistri Petri Tatareti in Summulas Petri Hispani (Basel: Johannes Froben, 1514). London, Lambeth Palace Library. Sion College Collection. Shelfmark A51.2/D92T(1).

${ }^{67}$ Bonaventura Vulcanius, Thesaurus utriusque linguae (Leiden: Ioannis Patius, 1600). London, Lambeth Palace Library. Sion College Collection. Shelfmark H14.3/V97.

${ }^{68}$ Antonio Zara, Anatomia ingeniorum et scientiarum sectionibus quatuor comprehensa (Venice: Ambrosij Dei, \& fratrum, 1615). London, Lambeth Palace Library. Sion College Collection. Shelfmark C14.3/Z1. The accompanying bookplate states that the funds for the book's purchase were provided from the bequests of five separate donors.
} 


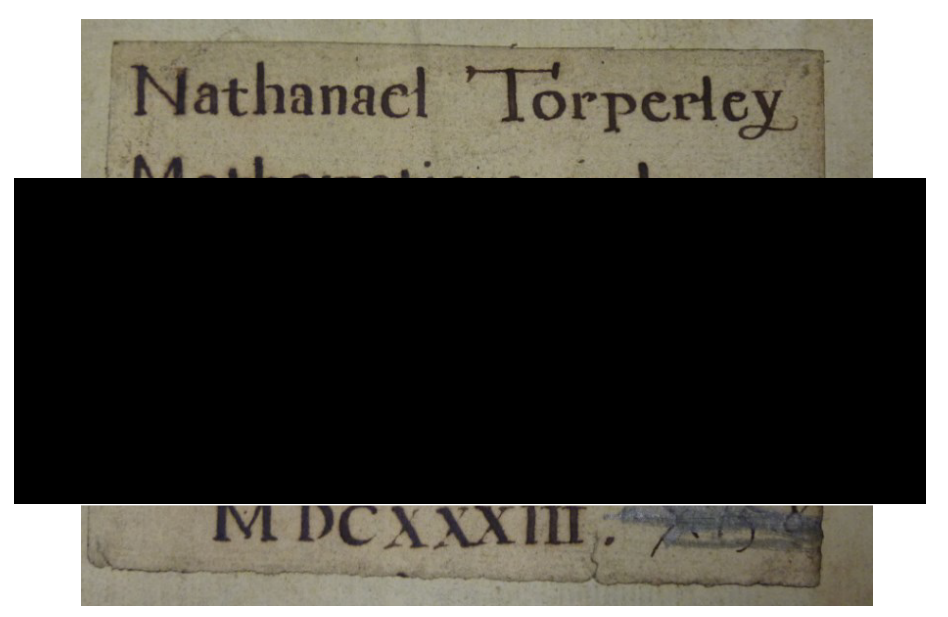

Figure 5.3. The donation label appended to the front pastedowns of a number of Nathaniel Torporley's texts. London, Lambeth Palace Library. Sion College Collection. Shelfmark A51.2/D92T(1).

By cross-referencing the Book of Benefactors, Spencer's parallel Transcriptum registri magni benefactorum, and the sales notes from the Hodgson auctions of 1938-1939, I have been able to successfully identify the broad subject groupings of 192 volumes, or 94\%, of Torporley's collection. As the graph in Figure 5.4 below illustrates, this subsection of 192 volumes is dominated by religious and ecclesiastical (77 of 192, or $40 \%$ ) and mathematical (43 of 192, or $22 \%$ ) texts, with the broad groupings of philosophy (including natural philosophy) (PHIL), history (HIST) and medicine (MEDI) accounting for a further 41 , or $21 \%$, of the remainder. Elsewhere in Torporley's collection, we find texts on alchemy, linguistics, and, occasionally, literature. 


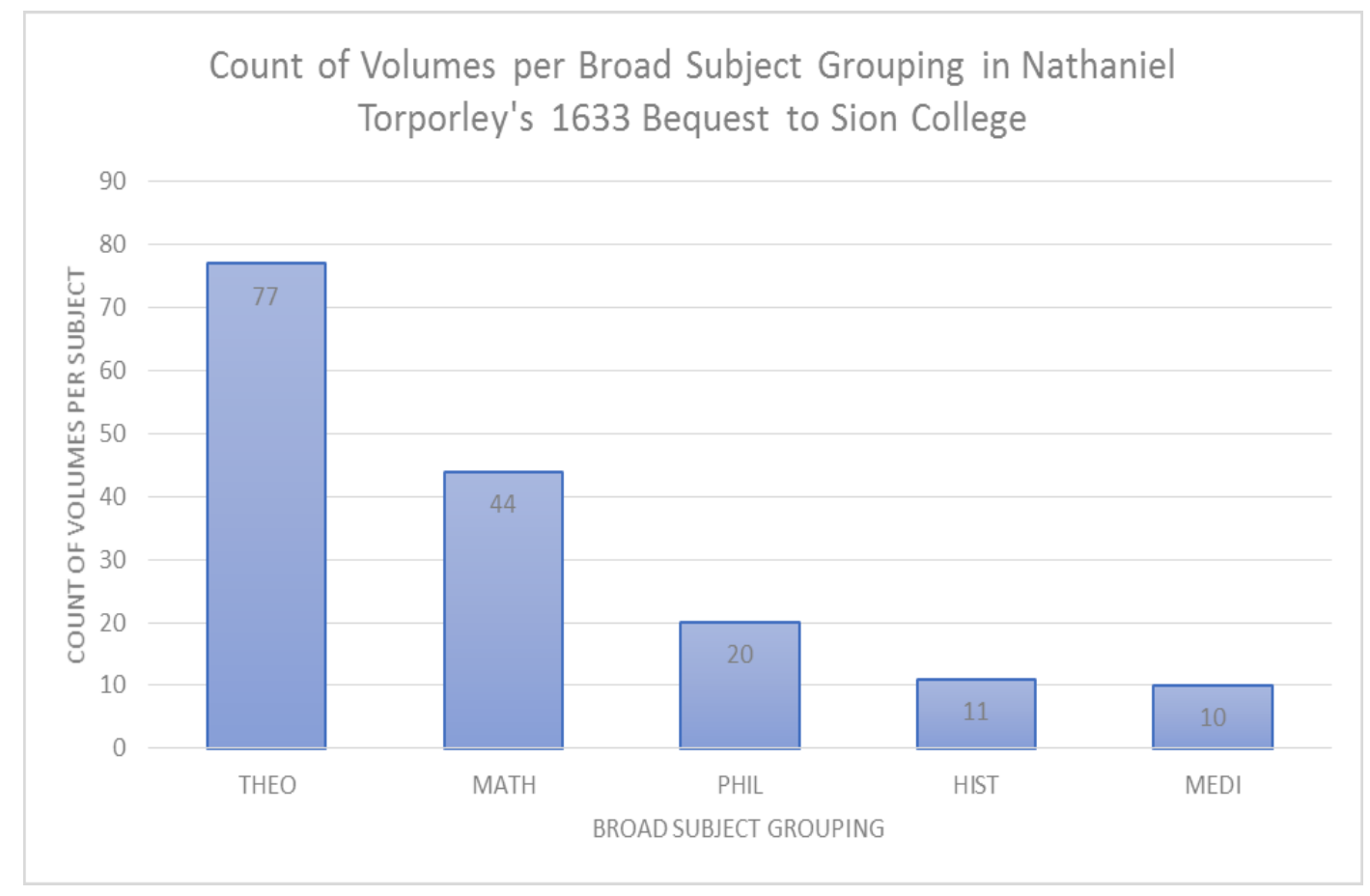

Figure 5.4. Graph detailing the top five broad subject groupings identified from an analysis of Nathaniel Torporley's donations to Sion College.

Of the 31 works marked by Spencer as absent, two belonged to mathematical disciplines: an undated edition of Diophantus's Arithmetica, and a copy of Willebrord Snel's Latin adaptation of, and commentary on, Ludolph van Ceulen's Fundamenta Arithmetica et Geometrica (Lyon, 1615). ${ }^{69}$ As copies of each of these texts appear elsewhere - again, in Spencer's own list in the Book of Benefactors, and in his printed catalogue of 1650 respectively - we should perhaps take their supposed absence with a grain of salt.

As we might expect, the vicar's introductory mathematical reading included the Elements; in fact, he was the owner of three separate Euclidean texts, two of which were glossed by commentaries from Christoph Clavius (Rome:

Bartholomaeum Grassium 1589), in a version intended for students at the Collegio Romano, and from Florimond Puteanus (Paris: I. de Heucqville, 1612) respectively. He kept abreast of mathematical developments throughout his life, owning, for example, a first edition of John Napier's work on logarithms, Mirifici logarithmorum canonis descriptio (Edinburgh: Andreae Hart, 1614). As a closer analysis of the

\footnotetext{
${ }^{69}$ For a discussion of Snel's adaptation of van Ceulen's work, see Liesbeth C. de Wreede, 'A dialogue on the use of arithmetic in geometry: Van Ceulen's and Snellius's Fundamenta Artihmetica et Geometrica', Historia Mathematica, 37 (2010), pp. 376-402.
} 
mathematical elements of Torporley's personal library demonstrates, the collection helps us to identify its owner's specific interests in astronomy, astrology, geometry, and trigonometry (Figure 5.5, below).

\section{PERCENTAGE OF DISCIPLINARY SUBGROUPINGS WITHIN \\ NATHANIEL TORPORLEY'S MATHEMATICAL TEXTS}
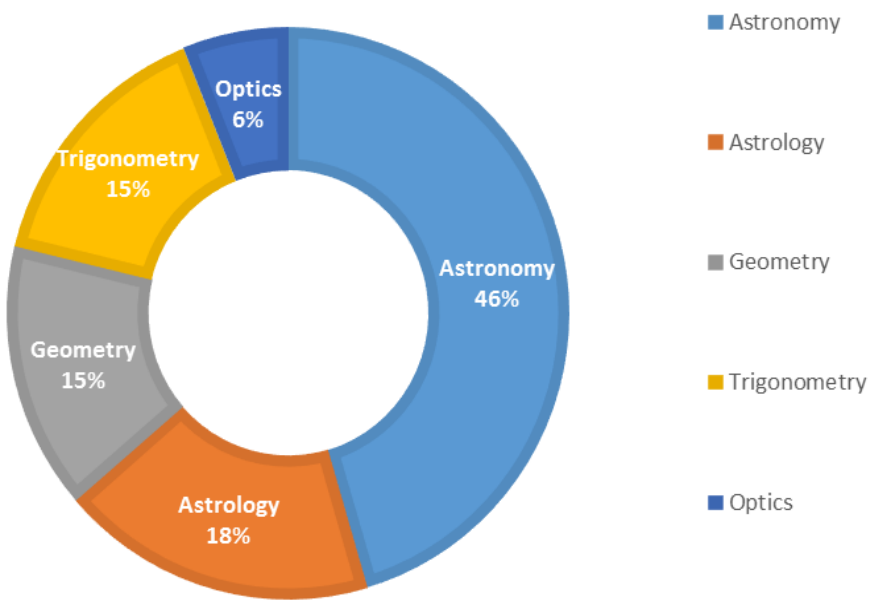

Figure 5.5. Specific mathematical disciplines as identified by texts found to be in Nathaniel Torporley's donations to Sion College.

The clergyman's astronomical texts ranged from introductory treatments of Ptolemaic astronomy, including Jacob Christmann's translation and commentary of the Elements of Chronology and Astronomy (Frankfurt: Andreas Wechel, 1590) of Alfraganus (Muhammad al-Farghān̄̄, ca. 800/805-870), to more advanced standard treatments of celestial mechanics, such as Georg Peurbach's Theoricae Novae Planetarum (Wittenberg: Iohannis Cratonis, 1580) as well as editions of several ephemerides and both the Alphonsine and Rudolphine tables. The vicar appears to have been intrigued by the competing astronomical theories of his day, comparing the received wisdom of Ptolemaic astronomy to the more recent systems proposed by Copernicus, Brahe, and Kepler. As well as Alfraganus's work, itself an introductory course on material from the Almagest, ${ }^{70}$ Torporley also owned Regiomontanus's summary, Epytoma Joannis de Monte Regio in Almagestum Ptolomei (Venice:

\footnotetext{
${ }^{70}$ Bahrom Abdukhalimov, 'Ahmad Al-Farghani and his Compendium of Astronomy', Journal of Islamic Studies 10, 2 (1999), pp. 142-158, p. 148. For Abdukhalimov's summary description of the contents of the thirty books of Alfraganus' work, see pp. 149-154.
} 
Johannes Hamman, 1496), and Erasmus Oswald Schreckenfuch's edited Claudii Ptolemcei Omnia quce extant opera, proter geographiam (Basel: Henrich Petri, 1551), the latter text supplemented in the library by the presence of a copy of Ptolemy's Geographia universalis (Basel: Henrich Petri, 1545).

Torporley's interest in heliocentric theory is reflected in his ownership of Nicolaus Copernicus's De revolutionibus and the more contemporary works of Johannes Kepler; Astronomiae pars optica and Epitome Astronomiae Copernicanae are numbered amongst his volumes. As we have seen, Tycho Brahe's proposals on a geo-heliocentric world system also featured, and I propose that Torporley read each of these texts (as did many others) with a view to evaluating the celestial mechanics they promulgated. In addition to these theoretical materials, a number of texts present in Torporley's library suggest that the English mathematician saw value in making instruments part of his astronomical practice. Works uniting theory, practice, and instrument as relating to spherical astronomy are further evident in the inclusions of Giovanni Paolo Gallucci's Speculum Uranicum (Venice: Damianus Zenarus, 1593), Gemma Frisius's De Astrolabio catholico (Antwerp: Joan. Seelsius, 1556), and Oronce Finé's De solaribus horologiis et quadrantibus (Paris: Guillaume Cavellat, 1560).

The trigonometric works listed as belonging to Torporley in the Book of Benefactors were authored primarily by Bartholomaeus Pitiscus, and were published in Frankfurt am Main by Nicolaus Hoffman between 1612 and 1613. These comprise a third edition of Pitiscus's Trigonometria (Frankfurt: Nicolaus Hoffman, 1612), bound up with the Canon triangulorum emendatissimus, and the Thesaurus Mathematicus, an adaptation of Georg Joachim Rheticus's tables of sines as completed by his student Valentin Otho, previously published in the latter's Opus palatinum de triangulis (Neustadt: Matthaeus Harnisius, 1596). ${ }^{71}$ The Rheticus-Otho tables were computed for every 10" to ten decimal places; Pitiscus improved upon these by computing the tangents and secants to fifteen decimal places, and later

\footnotetext{
${ }^{71}$ Nathaniel Torporley's copy of Bartholomaeus Pitiscus, Trigonometrice sive de dimensione Triangulorum Libri Quinque, item Problematum variorum : nempe geodceticorum, altimetricorum, geographicorum, gnomonicorum, astronomicorum libri decem, trigonometrice subjuncti ad usum ejus demonstrandum, Editio Tertia (Frankfurt: Nicolaus Hoffman, 1612) is today held in the Science Museum, London's Rare Books Collection. London, Science Museum Library Shelfmark O. B. PIT PITISCUS, 460871-2001.
} 
succeeded Otho as professor of mathematics at the University of Heidelberg in $1603 .^{72}$

As we have seen in the second chapter of the present work, a number of mathematical theorists (including, for example, Thomas Fincke) saw the study of triangles as both a means to re-present mathematical theory and as a tool to evaluate more precisely the canons of Ptolemy, Regiomontanus, and Georg Rheticus. Nathaniel Torporley's pronounced interest in trigonometric tables as linked to his astronomical practice is visible in his manuscripts, his Diclides coelometricae, and his collection of printed texts. Nevertheless, it is to be acknowledged that any division of these materials into various separate disciplines is to some extent a false partition. The career of Bartholomaeus Pitiscus is instructive in this regard, and parallels can usefully be drawn between the Calvinist mathematician and his Anglican counterpart.

Pitiscus began his studies in theology at the University of Heidelberg shortly after the Electoral Palatine of the Rhine, Frederick III of Simmern (1515-1576), had embraced the Protestant Reformation in $1559 .{ }^{73}$ Under Frederick's aegis, Zacharius Ursinus authored the Heidelberg Catechism and Ordinances (1563); Ursinus's Calvinist text, and the influence of his wider circle, helped the doctrine become entrenched as the Palatinate's new religious identity. ${ }^{74}$ This confessional position saw the prestigious University became a refuge for those seeking religious amnesty, attracting in the process high-calibre professors and an increasing number of students from throughout Central Europe. ${ }^{75}$

After completing his studies, Pitiscus acted as tutor to the youthful Frederick IV (1574-1610) from 1584, before rising to prominence as Court Preacher as his patron took on the role of Palatine Prince-Elector. As a committed Calvinist entrenched in the Heidelberg interpretation of reformed Protestantism, Pitiscus

\footnotetext{
72 Glen van Brummelen, The Mathematics of the Heavens and the Earth: The Early History of Trigonometry (Princeton and Oxford: Princeton University Press, 2009), pp. 273-282.

73 Tadataka Maruyama, The Ecclesiology of Theodore Beza: The Reform of the True Church (Geneva: Librarie Droz, 1978), p. 109.

${ }^{74}$ Manfred P. Fleischer, 'The Success of Ursinus: A Triumph of Intellectual Friendship', in Derek J. Visser, ed., Controversy and Conciliation: The Reformation and the Palatinate, 1559-1583, pp. 101116, pp. 101-102.

${ }^{75}$ Kenneth Austin, From Judaism to Calvinism. The Life and Writings of Immanuel Tremellius (Aldershot: Ashgate, 2007), p. 104
} 
authored both a continuation of Ursinus's conciliatory teachings and, in the same period, his influential Trigonometria, successfully juggling his intermingled clerical, courtly, and disciplinary identities in the service of the Palatine Electorate. ${ }^{76}$ Though it cannot be claimed that Torporley was anywhere near as successful (nor as wellconnected) as Pitiscus, so too was his mathematical practice entirely in keeping with the variegated intellectual culture common to his era. As a consequence, his identity as an Anglican rector meant that works on ecclesiastical and political history sat comfortably on his Sion College shelves beside those on calendrical computation, astronomy, and (perhaps less comfortably) judicial astrology.

Away from the pulpit, questions of atomism and alchemy whetted his appetite for investigations into the mutability of physical forms; whether marking astronomical observations with ephemerides or conducting alchemical experiments in the furnace bequeathed him in Harriot's will, ${ }^{77}$ the clergyman made practice and theory equal portions of his many arts. These interests perhaps elucidate why the librarians of Sion College marked the clericus first as chimicus and then later as mathematicus when listing his donations: perhaps unsure of how to fix Torporley's precise disciplinary identity, Spencer et al. made use of each option available. Thus we can evaluate Torporley's ownership of astronomical, astrological and mathematical texts as part of a wider intellectual worldview: one which incorporated the works of Macrobius, whose Commentary on the Dream of Scipio was central to a longer historical transmission of the philosophical contemplation of the heavenly spheres; one in which astrological authors such as Julius Firmicus Maternus, Guido Bonatti, and Girolamo Cardano complemented the neo-Platonic philosophy of Marsilio Ficino and Pico della Mirandola; and one in which ecclesiastical and political works met with each of these, and with Torporley's oft-mentioned interest in mathematical disciplines. Furthermore, the author's appreciation of this meltingpot of textual materials is clearly identifiable in his sole printed work.

In his Diclides coelometricae of 1602, Torporley promised to elucidate a doctrine of astrology according to a new method of computing and tabulating trigonometrical calculations. The clergyman introduced his work by advising the

\footnotetext{
${ }^{76}$ Fleischer, 'Success of Ursinus', p. 101.

${ }^{77}$ Rosalind C. H. Tanner, 'The Study of Thomas Harriot's Manuscripts. 1. Harriot's Will', p. 7.
} 
reader that he sought to look beyond the theories of Ptolemy, Copernicus, and Tycho and through the prism of Girolamo Fracastoro's Homocentrica (1538), using the world-system of the latter to propose a motionless earth at the centre of a series of homocentric spheres, moved by celestial levers. ${ }^{78}$ The text combined two books, Polyxestae and Pandectae Mitrosphaerica Memorabilisque, each subdivided into two further sections. Concerned with teaching the theory and method of Nathaniel Torporley's trigonometrical canons, Polyxestae's 146 pages led the reader through the construction of the author's own tables according to his distinctive application of spherical trigonometry, with directions then provided for the tables' use thereafter. ${ }^{79}$ Following on from this, Pandectae presented the most absolute and (simultaneously) simplest doctrine for the learning and memorization of the theory of spherical triangles, offering the reader the choice between Torporley's tables or the more perplexing efforts of other theorists. ${ }^{80}$

In practice, each book followed these guidelines only loosely. Polyxestae begins with a complex repositioning of the standard coordinates and circles of the celestial sphere, and builds its first three theorems from there; before outlining his theories with diagrams, Torporley takes care to recalibrate his reader's understanding of the celestial sphere conceptually and mathematically, arguing that the appropriate language to handle his theory is required so that demonstrations do not evade the reader. ${ }^{81}$ In his attempt to divine Torporley's goal in this section, Joel S. Silverberg suggests that the arc fip seen in Figure 5.6 below is that of a great circle passing through a celestial body at $i$, and that such an arc would appear to belong to a system following Regiomontanus's projection of the twelve astrological houses from the celestial equator onto the ecliptic. ${ }^{82}$

\footnotetext{
${ }^{78}$ Nathaniel Torporley, Diclides coelometricae seu valvae astronomicae universales (London: Felix Kingston, 1602), ff. a 3 r-v.

${ }^{79}$ Torporley, Diclides coelometricae, f. a 1 v: 'In primi enim Libri parte primae agitur de Tabularum fabrica, et earum ad Directionem deomonstratiua applicatione'.

80 Torporley, ibid: 'In secunda parte postremo agitur de absoluta et facillima Doctrina Triangulorum Sphaericorum [...] Unde totius pragmatis facultas comparator, et, sine perpelxa praeceptionium (aliorum) inculcatione conservatur; sive quis Authoris Tabulis, sive Canone Triangulorum uti maluerit.

${ }^{81}$ Torporley, ibid, f. $1 \mathrm{v}$.

${ }^{82}$ Joel S. Silverberg, 'Nathaniel Torporley and his Diclides Coelometricae (1602): A Preliminary Investigation', Proceedings of the Canadian Society for History and Philosophy of Mathematics, $34^{\text {th }}$ Annual Meeting (2009), pp. 143-154, pp. 152-153. Silverberg appears to be referring to Torporley, Diclides coelometricae, p 10: 'Cum autem aliquoties verba faciamus de arcu aequatoris posito inter
} 


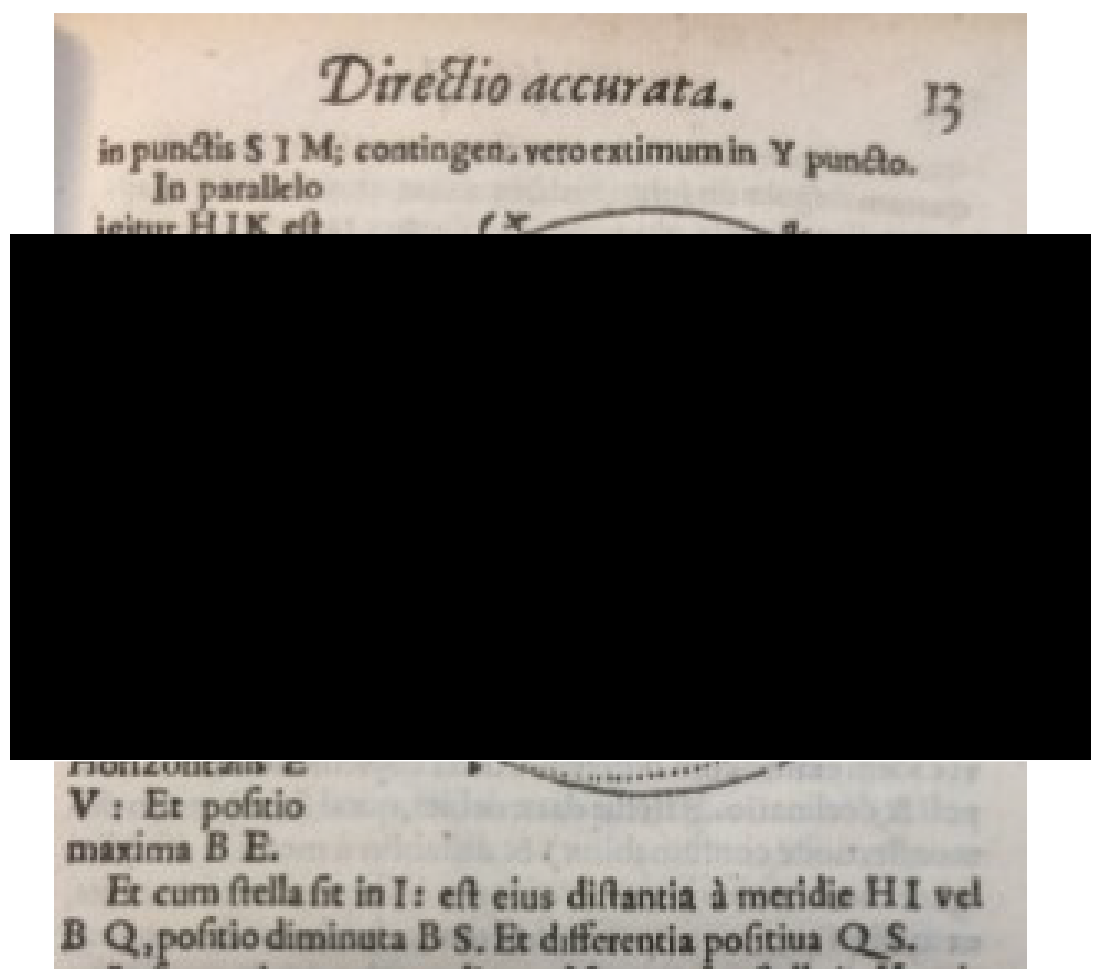

Figure 5.6. Nathaniel Torporley's proposed division of the celestial sphere in his Diclides coelometricae, with alternative circles drawn to those of the accepted great circles of ecliptic, zodiac, and so on. In this image, the arc fip has been constructed above the horizon $f p$.

horizontem vel circulum positionis et circulum transeuntem è polis mundi per locum stellae ad aequatorem (qui quidem arcus est differentia distantiae stellae à meridie et positionis stellae, et apud Regiomontanum nihil differt à differentia ascensionis, quam eius tabulae manifestam faciunt, cum cognita fuerit eleuatio poli supra eius circulum positionis, ubi meridianus supponitur alius, constituentis cum positionis circulo angulos rectos)'. 


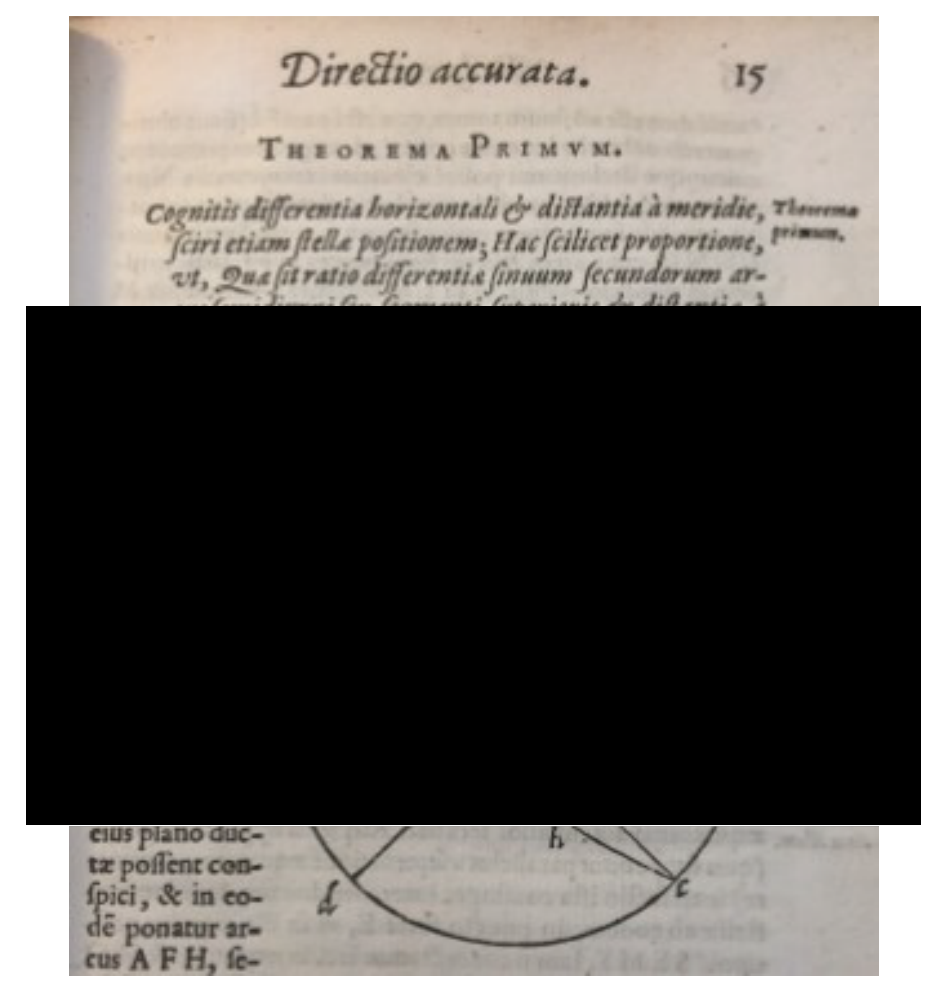

Figure 5.7. Diclides coelometricae's first theorem, drawn according to Torporley's alternative circles as mapped onto the celestial sphere.

Torporley's three theorems each use this reconfiguration of the celestial sphere to locate the positions of stars and celestial bodies according to alternative but complementary horizons, ${ }^{83}$ (Figure 5.7, above), before dwelling on astrological tables and the casting of zodiacal aspects at specific times. ${ }^{84}$ Polyxestae then concludes with a print of a semi-circular instrument, as seen in Figure 5.8, designed to aid the reader in their identification of these horizons and their attendant quincuncial aspects; the following book, Pandectae, takes Polyexstae's three key theorems so as to construct two sets of tables, entitled Quadrans vel Porta Dextra and Quincunx vel Porta Sinistra, which account for the remaining 150 or so pages of the work. These tables provide a means for the user to find any of the six parts of a spherical triangle by relation to a known side or angle. They follow a remarkably complex and, at times, inscrutable treatment of mnemonics entitled Mitrosphaerica Memorabilisque, in which spherical triangles are constructed within a bishop's mitre

${ }^{83}$ Torporley, Diclides coelometricae, p. 21.

${ }^{84}$ Torporley, ibid, p. 33. 
and the human body, accompanied by rhyming cantos to aid the reader's recollection (Figure 5.9, below).

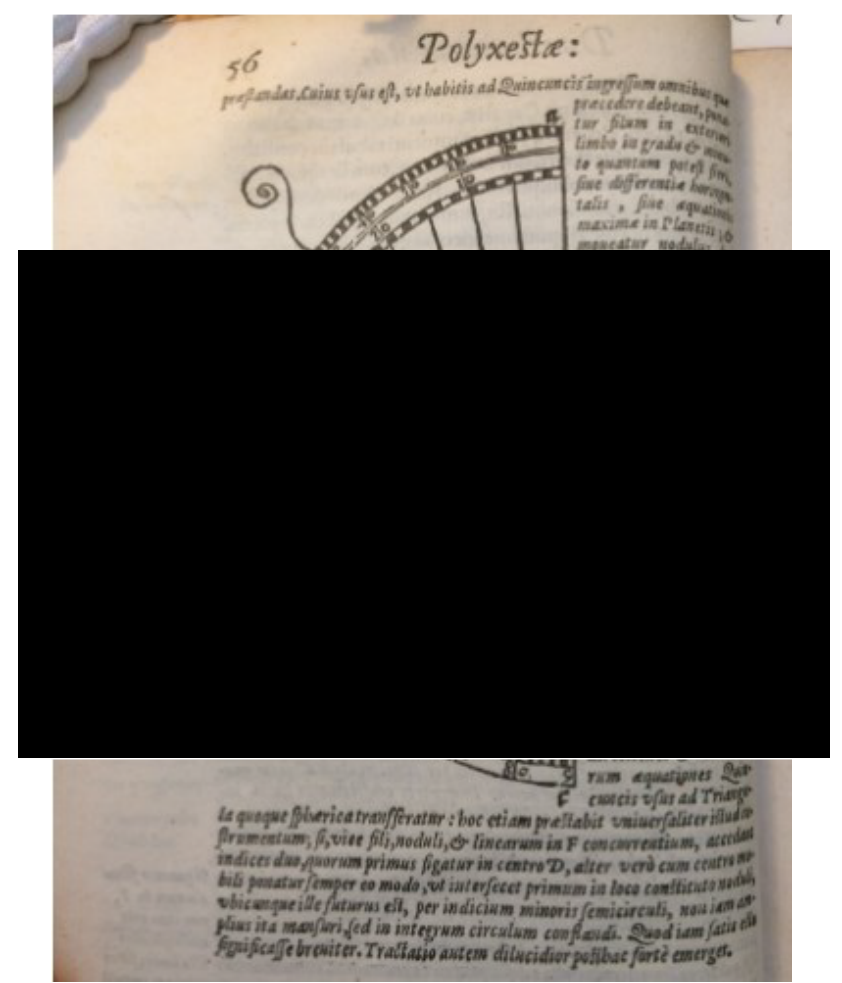

Figure 5.8. Torporley's semi-circular instrument, printed at the conclusion of Diclides coelometricae's first book, Polyxestae.

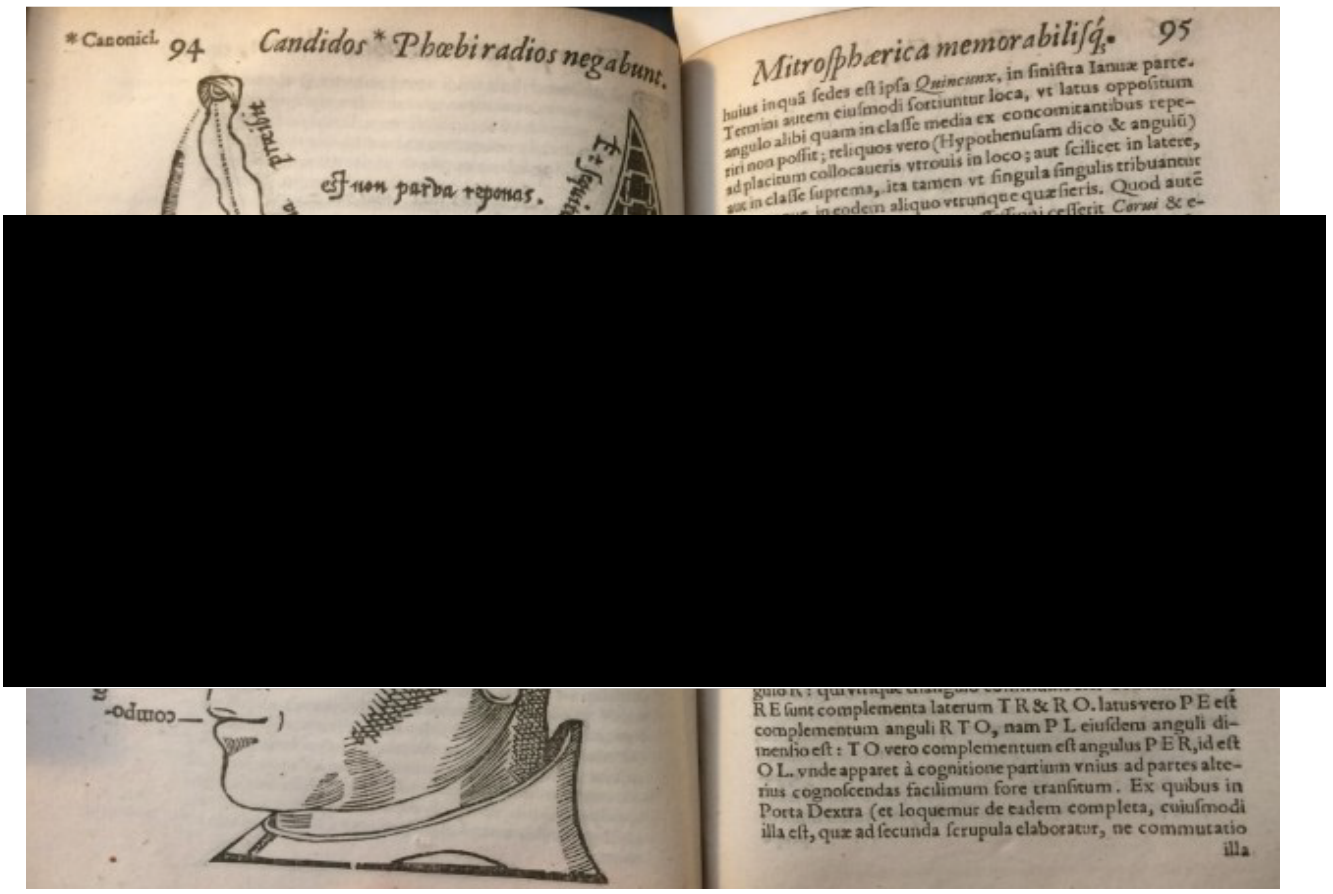

Figure 5.9. Torporley's redrawing of Menelaus's theorem as applied to spherical trigonometry via a bishop's mitre in Diclides coelometricae's second book, Pandectes. 
Torporley's six 'valves' — the prison, spear, shears, siphon, crow, and slingwere then split into two groups of three and positioned facing each other atop a bishop's mitre, with one identity termed a mother and the lesser two daughters. ${ }^{85}$ Silverberg has argued that the mathematician's illustrations were constructed so as to incorporate Ptolemy's use of Menelaus's theorem in spherical astronomy into Torporley's admixture of astronomy, judicial astrology, and mnemonics. ${ }^{86}$ Whilst this is likely correct, the vicar's attempts to construct a unique astronomical treatise containing a cohesive memory palace by way of trigonometry, bishop's mitres, the human form, and baroquely calculated canons seem certain to have proved impenetrable to all but his keenest reader. Even in an era in which the mnemonic techniques elaborated upon in Giulio Camillo's L'Idea del Teatro (Florence: Lorenzo Torrentino, 1550) and Giordano Bruno's De Umbris Idearum (Paris: Gilles Gourbin, 1582) found currency, Diclides coelometricae appears an arcane and byzantine text, and one that surely befuddled and frustrated in equal measure. ${ }^{87}$

Despite the clergyman's complicated Latin phrasing and his idiosyncratic application of spherical trigonometry, his friend Thomas Harriot chose Nathaniel Torporley as the editor of his unpublished algebra. The reasons underlying this choice have become muddied by our knowledge of the latter's subsequent struggles to arrange and publish Artis analyticae praxis; nevertheless, whether because of Torporley's companionship or his mathematical acumen, it is clear that Harriot deemed the clergyman the best candidate to whom to entrust his papers. To this we can also add the caveat — as Harriot did — that Walter Warner and Robert Hues might assist where required.

\footnotetext{
85 Torporley, Diclides coelometricae, pp. 85-89. See also Augustus de Morgan, 'On the Invention of the Circular Parts', in David Brewster, Richard Taylor, Richard Phillips, and Robert Kane, eds., The London, Edinburgh, and Dublin Philosophical Magazine and Journal of Science, Volume 22, January - June 1843 (London: Richard and John E. Taylor for the University of London, 1843), pp. 350-353, particularly pp. 351-352.

${ }^{86}$ Silverberg, 'Nathaniel Torporley's Diclides Coelometricae', p. 151. For a detailed treatment of Ptolemy's use of Menelaus' theorem in the Almagest, see Olaf Pedersen, A Survey of the Almagest with Annotation and New Commentary by Alex Jones (Springer: New York, 2010), pp. 69- 78.

${ }^{87}$ Arguing against Hilary Gatti's thesis that Giordano Bruno was an influence on Thomas Harriot's atomism, Stephen Clucas has pointed to a number of mathematical puzzles and conundrums present in Harriot's manuscripts. Whilst Torporley rejected atomism in some detail, it is of course possible that he and Harriot engaged one another with mathematical puzzles more generally at the time of Diclides coelometricae's writing. See Stephen Clucas, 'Thomas Harriot and the field of knowledge in the English Renaissance' in Robert Fox, ed., Thomas Harriot: An Elizabethan Man of Science (Aldershot: Ashgate, 2000), pp. 93-136, p. 100
} 
Ultimately, Harriot's judgement of his friends' capabilities to work together was to prove misguided; Torporley and Warner clearly came into dispute in their shared role as editors. Faced with more than 60 items collated by his friend before his death, Torporley nevertheless organised the contents of Harriot's analysis, moving from composite or prime numbers, to surds, to analytical arithmetic as inspired by François Viète. ${ }^{88}$ The clergyman would not see this plan to fruition. He was removed from his role by Thomas Harriot's co-executors, with Walter Warner publishing his version of Harriot's algebra in 1631. In a vituperative broadside launched prior to the Artis analyticae praxis's publication and directed at his fellow editors, Torporley in his Corrector analyticus artis posthumae Thomae Harrioti charged that Warner et al. had 'so utterly changed [Harriot's] method, that not only do they not retain his order but scarcely his words' ${ }^{89}$ In the vicar's reading, this was an assault on Thomas Harriot on a personal and professional level: one that made the departed mathematician's genius akin to 'the accidental findings of some illiterate'. ${ }^{90}$

Beyond the ten aforementioned theological and alchemical sets of papers he bequeathed to Sion College between 1629 and 1630, Torporley's Corrector analyticus is one of a further set of eight manuscripts which formed part of the clergyman's 1633 bequest. These include the clergyman's copy of Harriot's treatise on equations, titled Operationes logisticae in notis, ${ }^{91}$ as well as the aforementioned work on Congestor analyticus, Torporley's only coherent compilation of Harriot's material. ${ }^{92}$ Also present were a fair copy of John Bulkeley's work on squaring the circle in Torporley's hand, ${ }^{93}$ as well as Walter Warner's Certayne Definitions of the Planisphere, now lost. Bound up in a separate volume were a series of notes on 'the

\footnotetext{
${ }^{88}$ Nathaniel Torporley, Congestor analiticus cui accessit conjector ad tetragonisimi rimanda latibula fax rectrix. London, Lambeth Palace Library. Sion College Collection. MSS L40.2/L40, ff. 1r - 34v. See Jacqueline A. Stedall, The Greate Invention of Algebra: Thomas Harriot's Treatise on Equations (Oxford: Oxford University Press, 2003), pp. 18-19.

${ }^{89}$ Stedall, The Greate Invention of Algebra, p. 23. See also Nathaniel Torporley, Corrector analyticus artis posthumae Thomae Harrioti, Sion College MSS L40.2/E.10, ff. 7r -12v.

${ }^{90}$ Stedall, ibid.

${ }^{91}$ Nathaniel Torporley, Operationes logisticae in notis. London, Lambeth Palace Library. Sion College Collection. MSS L.40.2/L.40, ff. 35r -54v.

92 See Rosalind C. H. Tanner, 'Nathaniel Torporley's 'congestor analyticus' and Thomas Harriot's 'de triangulis laterum rationalium', Annals of Science, 34 (1977), pp. 393-428. For an exploration of the correct identification of Torporley's Sion College manuscripts as pertaining to Harriot, see Janet Beery and Jacqueline Stedall, eds., Thomas Harriot's Doctirne of Triangular Numbers: the 'Magisteria Magna' (Freiburg: European Mathematical Society Publishing House, 2009), pp. 20-21.

${ }^{93}$ Nathaniel Torporley, De quadratura circuli excogitatio per Joh. Bulkleium. London, Lambeth Palace Library. Sion College Collection. MSS L40.2/L40, ff. 215r - 234v.
} 
site and motion of the blasing starr' of 1618, taken at Oxford between November and December of that year. ${ }^{94}$ This final set of papers, relating to celestial observations made of the comet of 1618, may perhaps help to shed further light on the calculations of Diclides coelometricae. The latter's observations and tables can usefully be compared to a sheaf of notes featuring Nathaniel Torporley's astronomical calculations, in which two sets of tables of sines appear to have been computed according to the byzantine system mapped out in Torporley's printed text. $^{95}$

Emerging from this collection, then, is a reader who utilised his library as a means to construct an ordered (if enigmatic) system of relationships between man and the heavens. Although the particular idiosyncrasies of the non-religious texts found in Nathaniel Torporley's donation to Sion College recall their reader's previous affiliation with the so-called 'Wizard Earl', they more clearly point to a lifelong concern with the reformed relationship between God and man that we might expect from an early modern Anglican clergyman. Unlike many of his peers, Torporley appears to have held little interest in pious readings of botany or natural history: instead, his thoughts were attuned toward man's relationship with the Divine, to the movements in the heavens as representations of - and influences upon - the terrestrial sphere, and to the correct ordering of the Church and state according to theological decree. ${ }^{96}$ More playfully, Nathaniel Torporley's ludic appropriation of a bishop's mitre to illustrate Menelaus' Theorem suggests that these topics were often interwoven in the clergyman's thoughts. As the site of practice for his reading and the repository of his interests, Torporley's library formed the basis for various forms of astronomical, astrological, theological and alchemical practice, with both his manuscript materials and his own printed work bearing the evidence of influences contained therein.

\footnotetext{
${ }^{94}$ Nathaniel Torporley, Observationes [...] cometae nuper exorti, factae Oxoniae. London, Lambeth Palace Library. Sion College Collection. MSS L40.2/E10, ff. 1r - 4v.

${ }^{95}$ Nathaniel Torporley, Untitled. London, Lambeth Palace Library. Sion College Collection. MSS L40.2/L40, ff. 56r -166r.

${ }^{96}$ For Marin Mersenne's contemporaneous and more detailed search for order through language, mathematics and natural science in the early modern period, see James J. Bono, The Word of God and the Languages of Man. Interpreting Nature in Early Modern Science and Medicine. Volume 1: Ficino to Descartes (Madison, WI: University of Wisconsin Press, 1995), particularly pp. 262-265. Torporley's mathematical astrology and ludic mnemonics can perhaps be contrasted with Mersenne's more structured grammatological efforts in La Verité des Sciences (1625).
} 


\section{Torporley's library and the Sion College sales of 1938: The end of a collection}

By 1938, the last of Nathaniel Torporley's collection of mathematical and scientific holdings was deemed no longer relevant to the history and identity of the Sion College Library. By this point, a significant number of the texts listed as part of his bequest had already been dispersed, with the remainder sold as part of the Hodgson auction of rare early scientific books in 1938 and 1939. A more complete investigation into their whereabouts is beyond the scope of the current thesis. The catalogues pertaining to that sale did not mark out the clergyman's donation bookplate as evidence of provenance, nor is there reference to signatures or annotation. Regrettably, it has therefore proven difficult to trace the dispersal of Nathaniel Torporley's library much further. It may, however, be possible in future to complete a thorough census of the library, and for further evidence of the responses of this complex and erudite reader to his texts. Such research would doubtless shed more light on Torporley, independent of his more celebrated contemporaries, and thereby advance our understanding of the clergyman and his mathematical practices; such investigations might even aid the further decoding of the elaborate Diclides coelometricae.

Sion College auctioned the majority of its medical, mathematical and scientific books between the aforementioned Hodgson sales of 1938-39 and those of Sotheby's in April 1965 and June 1977. The institution's remaining collection today consisting of ca. 30,000 volumes printed before 1850, upwards of 30,000 pamphlets, and some 300 volumes of manuscripts - was subsequently transferred to its current location of Lambeth Palace Library upon the college's closure in $1996 .{ }^{97}$ Although the scientific, philosophical and medical volumes auctioned accounted for only a small proportion of the overall Library, they remain indicative of the protoscientific interests of the well-educated early modern readers attached to Sion College. Whilst it must be noted that the contents of the early Sion collection were skewed by the donations of Torporley and the mathematical printer Thomas Allen in

\footnotetext{
${ }^{97}$ Attar, ed., Directory of Rare Book and Special Collections, pp. 192-194. The post-1850 collections were moved to King's College Library, London.
} 
1711, it is clear that the Anglican community who used the library saw value in having access to such materials.

Throughout its history, the college was rarely able to spend significant amounts on the improvement of its library. As has been shown, when specificallyallocated funds allowed, John Simson and his successor John Spencer were happy to add mathematical and scientific texts to the Sion collection. Although the College Library was granted the right to claim a copy of any text registered at Stationers' Hall by the Copyright Act of 1710, and later received a grant from the Treasury to expand their collection in $1836,{ }^{98}$ the lion's share of materials was sourced from the bookshelves of donors belonging to a shared confessional and cultural identity. Sion College Library's catalogue prior to 1710 is subsequently a record of what its donors - themselves a broadly homogenous group of well-educated, male, ostensibly devout English Protestants - owned and read, supplemented with materials purchased thanks to the charity of others. ${ }^{99}$

The idea that Sion College's earliest residents and readers should be attracted to the mathematical disciplines is not in itself surprising. As we have already seen, the educational curricula of the period taught that the arts of geometry, astronomy, physics and natural philosophy belonged to one single intellectual continuum, and that the study of the natural world was to be undertaken as a means to better understand that of the divine. Those of a theological mindset (as the lives and works of Nathaniel Torporley and Bartholomaeus Pitiscus serve in part to demonstrate) were also inspired by the theory and practice of the mathematics underpinning calendrical computation and astronomical observation. With this in mind, further research into the holdings of institutional libraries established throughout the early modern period is likely to highlight hitherto undiscovered individuals and groups of shared communal identities reading, distributing and even discussing (in manuscript) mathematical or scientific material.

\footnotetext{
98 Attar, ed., Directory of Rare Book and Special Collections, p. 193.

${ }^{99}$ Although, in one notable exception of 1679, the College benefited from the confiscation of ca. 500 theological texts seized from a Jesuit library at Holbeck, near Leeds. Hannah Thomas, "“Books Which are Necessary For Them": Reconstructing a Jesuit Missionary Library in Wales and the English Borderlands, ca. 1600-1679' in Teresa Bela, Clarinda Calma, and Jolanta Rzegocka, eds., Publishing Subversive Texts in Elizabethan England and the Polish-Lithuanian Commonwealth (Leiden: Brill, 2016), pp. 100-128, p. 117.
} 
Before attending to the collecting practices of the Science Museum in light of the Sion College auction and later sales, one final point regarding the identity of the individual or institutional collector merits discussion. As the dispersal of Torporley's library, first into the wider catalogue of Sion College and then, centuries later, into gradually more diverse institutions demonstrates, it is important to mark the journeys made by discrete objects as they move through different types of collection wherever possible. To do so is to gain a much greater understanding of the individual or institutional collector at each stage, which in turn allows for a greater appreciation of the intellectual, social, historical, or antiquarian values ascribed to the material being collected.

Constructing the chronologies of collections and their constituent parts makes it possible to chart how these objects contributed to the personal and professional identities of their owners. As the previous chapters of this thesis have shown, the intentions of authors, stationers and instrument-makers were reinterpreted and recast in a variety of ways by the users of their products. Whilst it is crucial to identify distinct users and their responses to cultural ephemera, investigating communal sites of practice where feasible presents the opportunity to search for evidence of commonalities and contrasts in use. This process may in turn bring to light the ways in which intellectual materials and artefacts were transmitted within specific communities: a field of enquiry which will allow us to identify discrete teaching, reading or interpretative strategies in the history of science.

\section{Building an Institutional Library: The Science Museum Library, 1883-1938, and the Sion College Sale}

The analytic survey of the mathematical texts of the Science Museum's Rare Books collection has identified that Science Museum acquired at least 28 mathematical or mathematically-related volumes previously belonging to Sion College Library, 27 of which appear to have been sold by order in the Hodgson auction of rare early scientific books between April 1938 and April 1939 (Figure 5.10, below). 


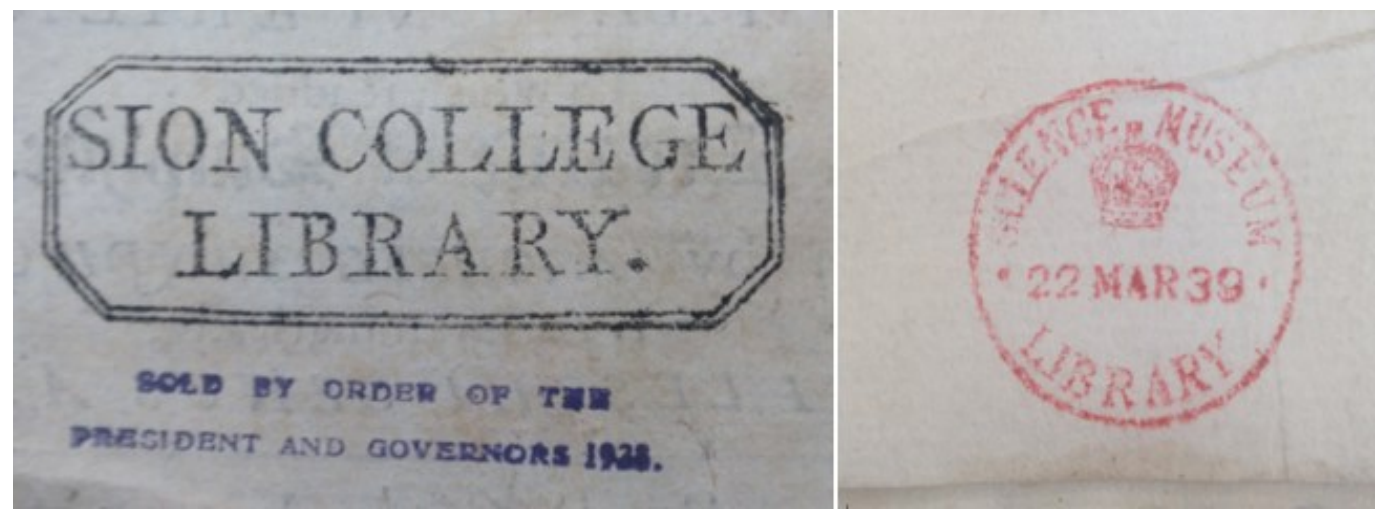

Figure 5.10. Composite image showing, to the left, the stamp of Sion College library, with the statement 'Sold by Order of the President and Governors 1938' added below; right, the red acquisition stamp of the Science Museum Library.

These new arrivals were added to the Science Museum Library's collection by May 1939, with each entry branded and dated with a red stamp denoting purchases, rather than its companion black stamp, used for donations, as seen above. One further text acquired from Sion College, The elements of clock and watch-work (London: J Hughs, 1766) of the mathematician, watchmaker and metal-worker Alexander Cumming, rejoined its former companions in their new home in February 1944. Comprising works printed between 1538 and ca. 1799, this subset of the Museum's collection incorporates editions of the classical theorists Archimedes, Euclid, and Ptolemy, along with the novel early modern astronomy of Nicolaus Copernicus and Johannes Kepler. Elsewhere, the celestial cartography of Johann Bayer is joined by philosophical texts such as Athanasius Kircher's Ars magna lucis et umbra (Rome: Hermanni Schues, 1646) and the popular English translation of Giambattista della Porta's Natural Magick, published in $1658 .{ }^{100}$

Only two of these lots - Bartholomaeus Pitiscus's Trigonometriae, bound up with Canon triangulorum emendatissimus, and the same author's Thesaurus Mathematicus - previously belonged to Nathaniel Torporley, and bear the donation label pasted in to mark his 1633 bequest. ${ }^{101}$ In an unintentional display of how

\footnotetext{
${ }^{100}$ A complete list of the mathematical and scientific texts acquired from Sion College and considered as part of the current study is detailed in Appendix 3.

101 Pitiscus, Trigonometriae, O. B. PIT PITISCUS, 460871-2001; bound up with Bartholomaeus Pitiscus, Canon triangulorum emendatissimus, et ad usum accomodatissimus (Frankfurt: Nicolas Hoffman, 1612), Science Museum Library Shelfmark O. B. PIT PITISCUS 460872-2001.

Bartholomaeus Pitiscus, Thesaurus mathematicus: sive canon sinuum ad radium
} 
collections themselves come to represent several layers of preservation, the Science Museum bookplate was pasted directly over Torporley's donation label, with only a slight edge of the latter remaining visible. Research into the Science Museum's participation in the Sion College sale of 1938 helps to highlight how the identity of one personal or institutional collection can be subsumed into (and, subsequently, allbut erased by) that of another. The shared religious identity which bound together Sion College and the effects of Nathaniel Torporley was, inevitably, stripped away during this transfer; in the process, the auction's formal act of dispersal, itself an entirely prosaic response to materials deemed expendable, atomised both a portion of the broader Sion College Library and the whole of Torporley's much smaller collection within it. In turn, this process served to dissolve the wider connection enjoyed between the clergyman as owner and user of a broad range of theological, philosophical, and mathematical texts, and the institution with which he was affiliated.

The most challenging by-product of this process of atomisation is found in the subsequent reappearance of fragments of libraries reconstituted in other collections: collections that share few meaningful points of contact with the identities of their original source. The difficulties this poses to our understanding of the early modern library and its owner is well-attested to in recent scholarship. Significant portions of smaller libraries may be hidden entirely in the bellies of large institutions; equally, materials belonging to a Regiomontanus or other such famed owners may simply have been used and discarded once no longer necessary, the simplicity of their bindings denying them entry to prized courtly collections. ${ }^{102}$ Attempts at reconstituting a personal identity through material objects are therefore liable to be partial, laborious, and, ultimately (if regrettably) incomplete. ${ }^{103}$

1.00000.00000.00000 (Frankfurt: Nicolas Hoffman, 1613), Science Museum Library Shelfmark F. O. B. PIT PITISCUS 462607-2001.

${ }^{102}$ Richard L. Kremer, 'Text to Trophy: Shifting Representations of Regiomontanus's Library' in James Raven, ed., Lost Libraries: The Destruction of Great Book Collections since Antiquity (Houndmills: Palgrave Macmillan, 2004), pp. 75-90.

${ }^{103}$ Pearson, Provenance Research in Book History, p. 8. Heidi Brayman Hackel. 'The Countess of Bridgewater's London Library' in Jennifer Andersen and Elizabeth Sauer, eds., Books and Readers in Early Modern England: Material Studies (Philadelphia, PA: University of Pennsylvania Press, 2002), pp. 138-159, p. 138. 
Individual owners naturally have little say over the multiple afterlives of their collections; if an initial bequest can at least be made to a favoured person or establishment, there is little scope to ensure that this transmission continues in the next generation. For the larger institution, a cyclical refashioning of identity through collected artefacts is necessary; in this process, the retention of the objects' previous histories can fall to chance. Sion College auctioned off its scientific, mathematical and medical texts by necessity; the sales served to prune the library, whilst preserving the ecclesiastical and theological materials that best reflected the institution's Anglican character. Likewise, in adding what fragments of the 1938 Sion College sale it could to its burgeoning holdings, the Science Museum took steps to secure its own institutional identity. However, whereas Sion College sought to promote the worship and learning of clergymen and students alongside its charitable aims, the initial shape of the Science Museum Library emerged from similarly educational roots, but with a different disciplinary orientation.

After an exhibition of educational texts and objects loaned from across the world in 1854, the Society of Arts was gifted many of the materials displayed. By 1857, this exhibition had made its home as the Educational Museum, with the ownership of these materials transferred to the British government's Science and Art Department. Within the next decade, the printed texts were to expand significantly through donations and purchases to form the Educational Library, one of two foundational precursors of today's collection (Figure 5.11, below). The need for a permanent science library was established by the 1882 Committee on Advice and Reference, with the new library opening in 1883; it would be close to a decade before the amalgamation of the South Kensington Museum's Educational Library and the library of the Museum of Practical Geology was confirmed by the printing of the first Science Library catalogue in $1891 .{ }^{104}$

${ }^{104}$ Wyatt, 'Waves of Change', pp. 136-137. 

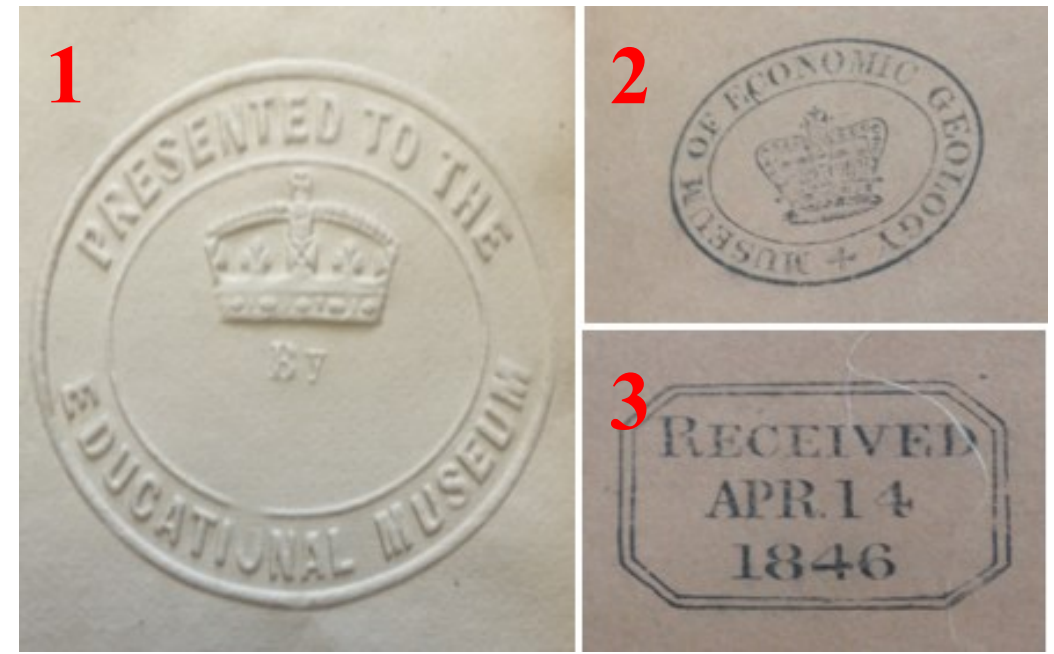

Figure 5.11. Composite image showing (1) the donation imprint of the Educational Museum; (2) the bookstamp of the Museum of Economic Geology, and (3) the Educational Museum's 1846 donation bookstamp, as found in books held by the Science Museum library today.

The dissolution of the collections of these two libraries into one overarching resource was intended to service the needs of the professors and students of the new Royal College of Science, with future purchases limited only to materials with a marked focus on pure science, mining, and metallurgy first, and applied sciences thereafter. ${ }^{105}$ In contrast to the private institutional libraries of the early modern period, Sion College amongst them, public readers were also welcomed. Books belonging to either the Educational Library or the Museum of Practical Geology that did not fit within these confines were distributed elsewhere; its remit now secure, between 1891 and 1918 the Library expanded its technical holdings, particularly its runs of scientific periodicals from across the globe. ${ }^{106}$

With the end of the First World War approaching, a national debate was to take place concerning the role and co-ordination of technical, industrial, and scientific literature for the use of the state. The newly-established Department of Scientific and Industrial Research (DSIR) was pressed by the Library Association,

\footnotetext{
${ }^{105}$ Wyatt, ibid, p. 137

${ }^{106}$ Materials from the Educational Library and the Museum of Practical Geology underwent slightly different selection processes prior to their entry or dispersal from the early Science Museum Library collections. Literature from the Museum of Practical Geology was identified prior to its entry to the Science Museum collection, with unsuitable material dispersed at this point. Literature from the Educational Library underwent a selection procedure after being acquisitioned by the Science Museum Library. I am grateful to Nicholas Wyatt, Head of Library and Archives at the Science Museum, for providing this clarification.
} 
by industry Heads of Research such as J. G. Pearce, and by professional groups such as the Faraday Society to design a blueprint for the sharing and distribution of technical literature between libraries and experts. ${ }^{107}$ The identity of the modern, postwar library was changing; as one of the leading holders of scientific and technical materials and periodicals, the Science Museum Library was to place itself at the forefront of these shifts.

Following a peak of close to 30,000 readers in the late 1880 s, the Library's numbers had steadily fallen in the opening decades of the twentieth century. In 1920, 12,000 users passed through the Library's reading room, served by a fourteen-strong staff including the Keeper Lionel Fulcher and his Assistant Keeper Samuel Clement Bradford (1878-1948). By the end of Henry Lyons's directorship of the Science Museum in 1933, the Library had doubled its volumes from around 125,000 to almost 250,000; sets of historical periodicals numbered around 3,000, with sets of current periodicals close to triple that figure. ${ }^{108}$ For the first time since the early 1890 s, visiting readers once again broke the 20,000 mark. ${ }^{109}$

Lyons's time as Director of the Museum overlapped with the tenure of Samuel Clement Bradford as Library Keeper. Bradford joined the Science Museum in 1899, and commenced working in the Library two years later; before retiring in 1938, he rose through the ranks, holding the positions of Assistant Keeper (1922), Deputy Keeper (1925), and finally Keeper, a post he retained from 1930 to $1937 .{ }^{110}$ For Lyons and Bradford, transforming the library into a national resource was crucial to its continued expansion and growth. Along with the scientists and engineers Henry Tizard, A. G. Church, and Magnus Mowatt, ${ }^{111}$ the pair lobbied the members of the Public Libraries Committee in order to position the collection as a centralised,

\footnotetext{
${ }^{107}$ Dave Muddiman, 'Science, Industry, and the State: Scientific and Technical Information in EarlyTwentieth-Century Britain' in Black, Alistair, Dave Muddiman, and Helen Plant, The Early Information Society: Information Management in Britain before the Computer (Farnham: Ashgate, 2006), pp. 55-78, p. 60.

${ }^{108}$ David Follett, The Rise of the Science Museum under Henry Lyons (London: Science Museum, 1978), p. 125.

${ }^{109}$ Wyatt, 'Waves of Change', p. 140.

${ }^{110}$ K. G. B. Bakewell, 'Bradford, S. C.', in Robert Wedgeworth, ed., World Encyclopedia of Library and Information Services, $3^{\text {rd }}$ edn (Chicago: American Library Association, 1993), p. 142.

${ }^{111}$ Muddiman, 'Science, Industry and the State', p. 61.
} 
comprehensive repository of use to scientists, researchers, and the public alike. ${ }^{112}$

These efforts caused notable friction, and the Library (and, by proxy, the Museum) was soon accused of grossly overstepping its bounds. Privately communicating his discomfort at Samuel Bradford's perceived overreach to his Private Secretary in May 1934, Robert S. Wood, Director of Establishments for the Board of Education, identified the librarian as 'pursuing a policy of aggrandisement with a view to becoming a comprehensive and all-embracing Science Library covering every field of scientific literature'; affright at the idea of such a ravenous policy remaining unfettered by control of any meaningful sort from the Board or Department responsible, Wood voiced his critique as part of wider endeavours to rein in the continued growth (and the perceived excesses) of the library. ${ }^{113}$

Nevertheless, Samuel Bradford was emboldened enough to continue his attempts to establish the Library as a national resource, at least in deed if not in name. Although he retired from the Science Museum in 1937, shortly before the Sion College auctions, the Keeper's efforts ensured that the Library was by this point a leading repository of contemporary texts and periodicals. Dissatisfied by the limits of contemporary documentation, Bradford's contribution to bibliometric research led to his observation that,

if journals carrying articles relevant to a given subject are ranked in decreasing order of productivity, and the number of papers contributed by each is computed, the result will be a core or nucleus of a few journals accounting for most of the articles on that subject, followed by other groups containing the same number of articles as the nucleus, but spread over an ever-increasing number of journals. ${ }^{114}$

In addition to these achievements, the unstinting Library Keeper remained committed to the collecting of important artefacts relevant to the history of science, and his combination of the contemporary and the historical shaped his immediate legacy. Just as Samuel Bradford had been enticed by the opportunity to acquire a

\footnotetext{
112 Wyatt, 'Waves of Change', p. 143.

113 Public Records Office Ed 24/1400, 10.5.34; originally cited in Follett, Rise of the Science Museum, p. 134.

${ }^{114}$ Nicola de Bellis, Bibliometrics and Citation Analysis. From the Science Citation Index to Cybermetrics (Lanham, MD, Toronto and Plymouth: The Scarecrow Press, 2009), p. 95. See also Samuel Clement Bradford, Documentation (London: Crosby Lockwood, 1948).
} 
first edition of Newton's Philosophiae Naturalis Principia Mathematica (1687) in 1937, so too would his successor Ernest Lancaster Jones secure works by Copernicus, Kepler, and Galileo as made available by Sion College soon afterwards.

\section{The Honeyman Collection and Sale}

The contrasting fortunes of the scientific collections of Sion College and the growth of the Science Museum Library in the early twentieth century demonstrates some of the ways in which the cyclical construction and reconstitution of the institutional library is a project decided in equal degrees by the interior interpretation of the identity of that institution, and by the institution's reaction to the effects of exterior forces in keeping with that constructed identity. These factors must, of necessity, be interpreted by individuals holding the roles of Keeper, Director, Librarian, and so forth, and by the committees on which they serve or to which they report. Equally, heritage institutions such as the Science Museum exist owing to their necessary reliance on the gifts of monarchical and governmental patronage - be they early modern Royal Charters and Copyright Acts, or the more recent exceptions granted by Her Majesty's Treasury or Stationery Office.

Evidence of the impact of such factors on the character of institutional collections is only seldom brought to light. In the notes and records of Sion College, the Science Museum Library, and in the Sales Catalogues of Sotheby's and Hodgson's, however, there exist rich seams of documents highlighting the individuals at work in constructing such libraries; furthermore, these documents serve to bring into focus the missing parts of a collection, as well as the almost-was, could-have-beens, and never-weres that were targeted for acquisition but made their way elsewhere.

An opportunity to acquire unique materials presented itself in Sotheby's sale of the scientific texts in Robert Brodhead Honeyman's collection, auctioned in London between 30 April 1978, and 20 May 1981. As its length alone indicates, the auction was a significant event, dominating many book collector's calendars, with a mammoth 3309 lots (detailed in seven printed catalogues) of scientific texts and 
manuscripts available for sale. ${ }^{115}$ In a notable departure from precedent, Sotheby's purchased the library outright at a cost of $£ 2,000,000$, before auctioning it as their own property immediately after - making only slight profit in the process. ${ }^{116}$ Notably, the scientific materials merely formed one tranche of the antiquarian's overall holdings: as has been shown, their owner's zeal for collecting is best described as eclectic, comprising as it did the acquisition of art, manuscripts, texts, stamps, and various other ephemera across a wide range of disciplines.

As the introduction to the current chapter has detailed, Robert Honeyman helped to arrange the exhibition of various portions of his remarkable personal collection at Lehigh University Library and elsewhere. When not on display, thousands of artefacts were housed in a private museum built on the grounds of Honeyman's property at Rancho Los Cerritos, Southern California, and the collection celebrated the depth of its curator's affiliation with his adopted home-state of California. Comprised of more than 2300 items in various media, including paintings, engravings, crockery, and cutlery, the Robert B. Honeyman Jr. Collection of Early Californian and Western American Pictorial Material acquisitioned by the Bancroft Library, University of California, Berkeley in 1963 details artistic interpretations of life in the American West from ca. 1790 to the early 1930s, with a significant focus on works produced immediately before and after the Gold Rush $(1848-1855) .{ }^{117}$

At the heart of his collection of textual materials was a lifelong interest in the mathematical basis of the physical sciences. As a result, the antiquarian's scientific texts and manuscripts included celebrated works of arithmetic, astronomy, geometry, physics, philosophy, metallurgy and medicine spanning the twelfth to the twentieth century. There is little doubt that these materials, marked by a concern with the quantification of physical change, and, in some instances, the machines invented to

\footnotetext{
115 The Honeyman Collection of Scientific Books and Manuscripts, Parts I-VII, sold in London by Sotheby Parke Bernet \& Co., 30 April 1978 - 20 May 1981. It should be noted that a number of lots were for more than one item, and that at times it is difficult to identify precisely how many items constitute a given lot. The number given is therefore intended to be read as illustrative, with the total items sold likely to be significantly higher.

${ }^{116}$ H. A. Feisenberger, 'The Honeyman Sales', The Book Collector, 4 (1981), pp. 491-496, p. 491.

${ }^{117}$ Mary W. Elings and Eva Garcelon, 'The Robert Honeyman Jr. Collection Digital Archive: EAD and the Use of Library and Museum Descriptive Standards', Archives and Museum Informatics, 12 (1998), pp. 205-219, p. 209.
} 
measure or influence such change, chimed with Robert Honeyman's disciplinary and professional identity as an engineer.

Even so, this identity can only account for a partial explanation of the collector's motivations and collecting practices. Influenced by the American book collector Adrian Joline, and by historians of science including Herbert McLean Evans, Rupert Hall, and Stillman Drake, Honeyman intended his library to showcase the development of scientific thought in its entirety. ${ }^{118}$ His collection therefore travelled well beyond professional identity and into the narrative presentation of a discipline more commonly associated with museum exhibition.

The Science Museum acquired at least 115 volumes in the Sotheby's Honeyman sale, 26 of which bear the red and gold ex libris bookplate seen in Figure 5.12 below. 75 of these volumes are considered as part of the mathematical subset currently under study. ${ }^{119}$ In addition to his bookplates, the exterior of these volumes is often recognisable: in several instances, Honeyman took care to rehouse his rare books in red half morocco slip-cases. The items purchased date from a fifteenthcentury edition of Nicole Oresme's geometrical work Incipit p[er]utilis tractatus de latitudinibus forma[rum] (Padua: Matthaeus Cerdonis, 1486) to a signed copy of Albert Einstein's Über die spezielle und die allgemeine Relativitätstheorie (Braunschweig: F. Vieweg, 1917).

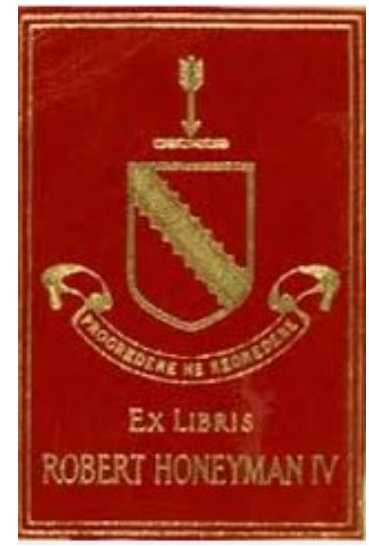

Figure 5.12. Robert Brodhead Honeyman's ex libris bookplate, as found in $22 \%$ of the texts surveyed as part of the current study as purchased from the Honeyman sale. Science Museum Library Shelfmark O.B. RAM RAMUS 460390-2001.

\footnotetext{
${ }^{118}$ Feisenberger, 'The Honeyman Sales', p. 492.

119 The materials acquired by the Science Museum in this auction and reviewed as part of the current study are detailed in Appendix 4.
} 
Notable acquisitions from the sale include a rare editio princeps of Petrus Peregrinus de Maricourt's late thirteenth-century treatise on magnetism, Epistola de Magnete (Augsburg: Achilles Gasser, 1558), purchased for a hammer price of $£ 11,000$; Galileo Galilei's Le operazioni del compasso geometrico et militare (Padova: P. Marinelli, 1606), purchased for a hammer price of $£ 9,000$, and Dmitri Mendeleev's On the Relation of the Properties to the Atomic Weights of the Elements (Sootnoshenie svoistv s atomnym vesom elementov, 1869), in which the author proposed the first periodic table, purchased for a hammer price of $£ 3500$.

It is apparent that, in keeping with its raison d'etre of a nationally-important repository of historical and contemporary scientific literature, Lance Day-Keeper of the Science Museum Library from 1976 to 1987—saw inestimable value in adding these materials to the Museum's holdings. The titles purchased span a broad range of materials, treating works on theory and instrument with the same respect, and the Library's prioritisation of the famed works of scientists and theoreticians in this period is undeniable. This should not, however, serve to overshadow the secondary provenance evidence of previous users and owners, collected almost by proxy. As we have seen in the second chapter of the current thesis, artefacts such as the Wittenberg Sammelband bear the marginalia of mathematical readers several levels below the genius of Kepler, Galileo, or Newton; as the current thesis has shown, understanding the responses of readers to such texts is vital to both the history of science and the history of the book. Even today, many collectors show little interest in copies marked as anything other than 'clean'. Whether the assembled purchasers were put off by the significant annotation, or perhaps by the pugnacious Ramus or the less-heralded Fincke, is impossible to know: nonetheless, the Sammelband was acquired at this sale for the less-than-princely sum of $£ 160 .^{120}$

As in the album amicorum left by Johannes Lobhartzberger, David Klynaeus and Nicolaus Hommer, evidence of provenance such as armorials, signatures, and bookplates pepper the mathematical texts from Robert Honeyman's library considered in the current study. Unique provenance markings mean that in specific cases it is possible to trace unique copies through multiple auctions: for example, a

\footnotetext{
${ }^{120}$ According to the Bank of England's online Inflation Calculator, the equivalent price in 2017 would be $£ 872.65$, with inflation averaged to $4.4 \%$. https://www.bankofengland.co.uk/monetarypolicy/inflation/inflation-calculator, accessed 25.9.2018.
} 
copy of Thomas Everard's Stereometry made easie, or, The description and use of a new gauging-rod or sliding-rule (London: J Playford for R Clavel and C Hussey, 1684), previously part of the library of Sir Isaac Newton, is recognisable thanks to the armorial of the Reverend Dr James Musgrave (d.1778), Rector of Chinnor in South Oxfordshire. ${ }^{121}$ Following Newton's passing, intestate, in 1727, his neighbour, the Fleet Street prison warden John Huggins, bought the majority of his library for $£ 300$ for his son, the Reverend Charles Huggins (d.1750).

After the latter's death in 1750, Huggins's successor as Rector of Chinnor purchased the books at auction for $£ 400$ in 1750 , immediately pasting over Huggins's bookplates with his own, identifiable via the marriage of the Musgrave arms, dexter, and the Huggins arms, sinister, above the Musgrave motto 'Philosophemur'; 122 the combination of the two sets of arms reflect the fact that James Musgrave had, by this point, wed Charles Huggins' niece. ${ }^{123}$. In 1778 the library was then transported to Musgrave's son's collection in Barnsley Park, Gloucestershire, as can be witnessed in the shelfmark 'Case G C.16 Barnesley' in Figure 5.13 below; the underlying Huggins bookplate can be seen beneath, albeit scarcely.

\footnotetext{
${ }^{121}$ Thomas Everard, Stereometry made easie, or, The description and use of a new gauging-rod or sliding-rule (London: J Playford for R Clavel and C Hussey, 1684). Science Museum Library Shelfmark O.B. EVE EVERARD 459930-2001.

${ }^{122}$ H. A. Feisenberger, 'The Libraries of Newton, Hooke and Boyle', Notes and Records of the Royal Society of London, 21.1 (1966), pp. 42-55, p. 42 and p. 44.

${ }^{123}$ James Stokeley, 'Sir Isaac Newton's Library Offered for Sale in England', Journal of the Royal Astronomical Society of Canada, 23 (1929), pp. 397-398, p. 397.
} 


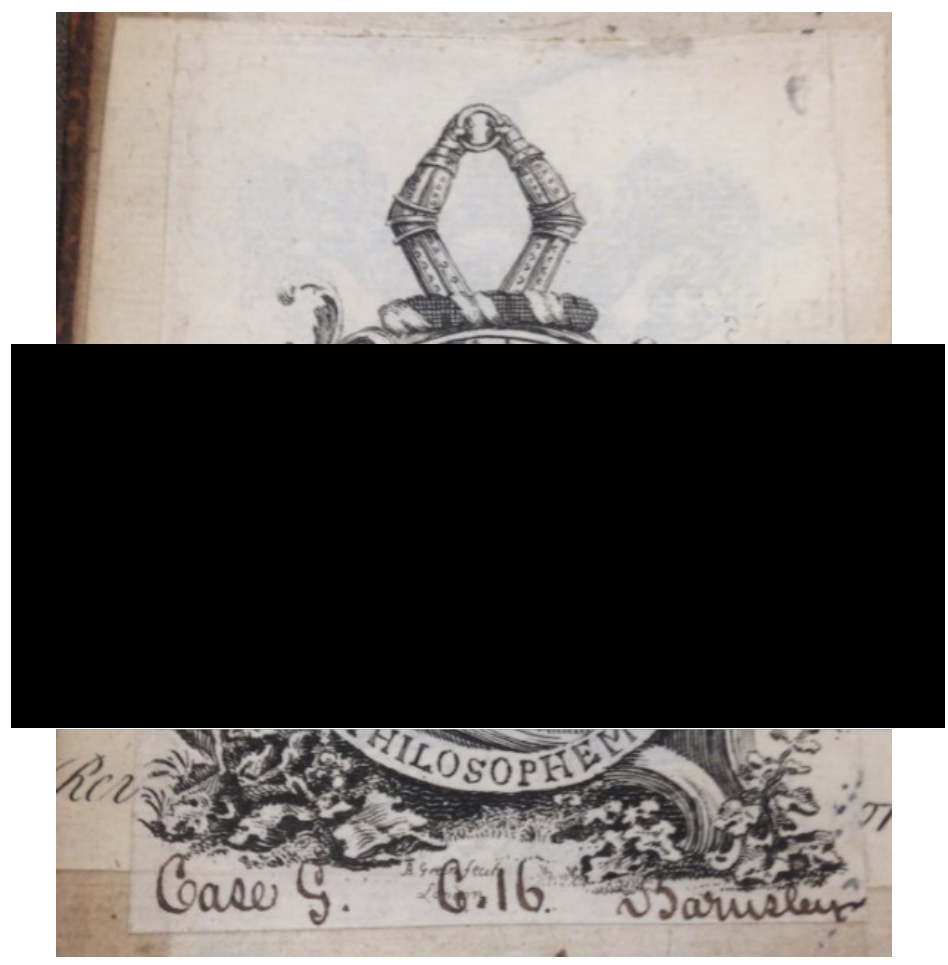

Figure 5.13. James Musgrave's bookplate, bearing the motto 'Philosophemur' and the Barnesley Park Shelfmark. Huggins's bookplate can just be seen beneath. Thomas Everard, Stereometry made easie, Science Museum Library Shelfmark O. B. EVE EVERARD 459930-2001.

Although it is not possible today to complete a full analysis of the Honeyman library to uncover examples of provenance and annotation in its constituent texts, the small number of texts acquired by the Science Museum and considered as part of the current study can at least be reviewed to draw conclusions on those texts that have made their way into the Rare Books collection. Of the circa 115 volumes purchased, 75 are directly relevant to the current study of mathematical texts as printed in the early modern period, including two incunabula: Nicole Oresme's aforementioned Incipit p[er] utilis tractatus, and Leopoldus of Austria's thirteenth-century astrological treatise, Compilatio de astrorum scientia (Augsburg: Ernest Ratdolt, 1489). 


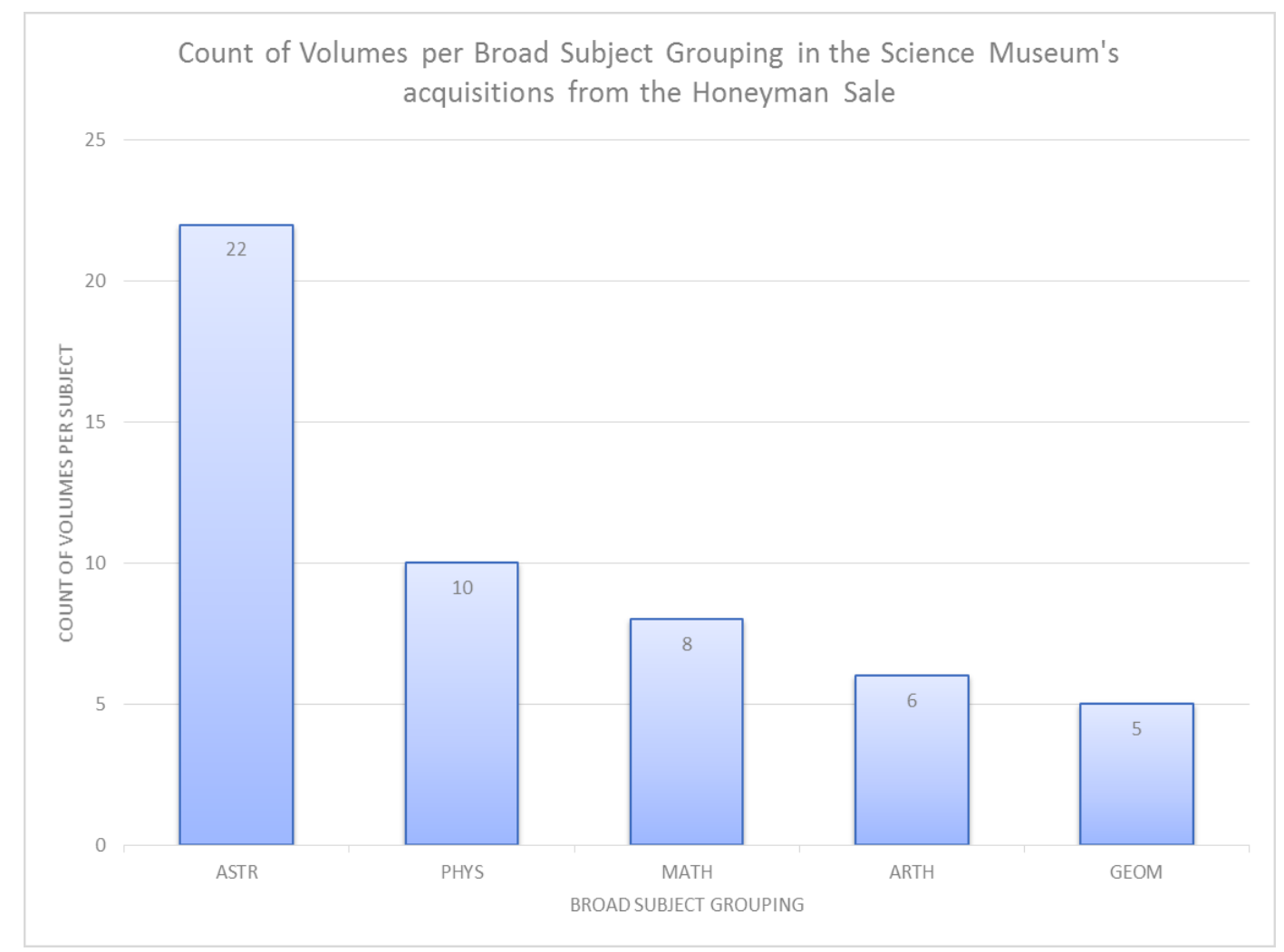

Figure 5.14. Graph showing texts purchased from the Honeyman sale by the Science Museum, classified in broad mathematical subject groupings.

Materials pertaining to astronomy ( 22 of 75 , or $29 \%$ of those surveyed) dominate this subset, with the disciplines of physics, mathematics (in this case, grouped compendia or volumes of more than one mathematical discipline), arithmetic and geometry accounting for 29 of 75 texts (39\%). The remaining $32 \%$ of texts are widely spread in groups of 3 or less, but include works on surveying, cosmography, hydrostatics and mathematical instruments. 70\% (53 of 75) texts show no evidence of annotation: although this might suggest a preference for clean copies, the presence of heavily annotated editions such as the Wittenberg Sammelband, along with more moderate marginalia in 19 further texts including works from Robert Recorde, Thomas Digges, and Gaspar Schott, demonstrate that the collector was happy to acquire marked texts.

Given that Honeyman sought to construct a progressivist collection which told of the triumph of scientific thought, the presence of readers responding to such important texts seems unlikely to have put him off their purchase. That close to $30 \%$ of Honeyman's mathematical texts present some annotation - a higher percentage than that seen across the entirety of the subset under study - there is reason to 
believe that the remainder of the antiquarian's library may possess similarly high numbers of readers' responses. Clearly, a fuller reconstruction of the entire collection is needed to gauge both the depth of annotated materials in Honeyman's library, and the contents of these materials as valuable to the history of science and the history of the book.

As we have already seen, previous owners of these materials include Isaac Newton, and the clergymen Charles Huggins and James Musgrave. Whilst the signatures which appear within the Honeyman materials are often more difficult to identify, it is nonetheless possible to identify gifts from one reader to another, as in James Gill's present of Robert Recorde's The Whetstone of Witte (London: John Kyngstone, 1557) to John Thomas, with calculations subtracting 1557, the year of the book's publication, from 1649; as well as markings ranging from one George Cooper's juvenile notes on astronomy, seen in a 1600 copy of Pitiscus's Trigonometria, to the signatures of statesmen such as Christian Ernest, Count of Stolberg-Wernigerode (1691-1771). ${ }^{124}$

Occasionally, it is possible to trace the reading of would-be and well-known theoreticians. The French astronomer and clockmaker, Joseph Lepaute Dagelet (1751-1788), whose work on astronomical calculations and observations led to his untimely death aboard the Comte de Lapérouse's expedition of 1788 to circumnavigate the globe, appears in 1770 to have signed and dated his copy of Galileo's Les mechaniques de Galilee mathematicien \& ingenieur du Duc de Florence (Paris: Henri Guenon, 1634); elsewhere (and more happily) the stamp of the English physicist, chemist and discoverer of hydrogen, Henry Cavendish (17311810) is to be seen, ${ }^{125}$ as well as the bookplate of the influential French chemist Antoine-Laurent de Lavoisier (1743-1794). ${ }^{126}$ In acquiring these materials, Lance

\footnotetext{
${ }^{124}$ Robert Recorde, The whetstone of witte (London: John Kyngstone, 1557), Science Museum Library Shelfmark O. B. REC RECORDE 460946-2001; Bartholomaeus Pitiscus, Trigonometrice: sive de dimensione triangulos libri quinque (Augsburg: S. N., 1600), Science Museum Library Shelfmark O. B. PIT PITISCUS 460870-2001. Christian Ernest's signature appears in the Honeyman copy of Nicolaus Rensberger's Astronomia teutsch (Augsburg: Mattheum Francken, 1569), Science Museum Library Shelfmark O.B. REN RENSBERGER 460957-2001.

${ }^{125}$ Gabriel Mouton, Observationes diametrorum solis et lunce apparentium (Lyon: Matthaei Liberal, 1670), Science Museum Library Shelfmark O.B. MOU MOUTON 460709-2001.

${ }^{126}$ Lavoisier's bookplate is found in the Honeyman copy of Nicolas Louis de la Caille, Astronomiae fundamenta (Paris: J. J. Stephani Collombat, 1757), Science Museum Library Shelfmark Q.O.B. LAC LACAILLE 461647-2001.
} 
Day and his Assistant Keeper Hyman Woolfe provided an invaluable source of materials to present and future researchers: as a result, they continued the efforts of Lyons, Bradford, and Sherwood Taylor by adding to the growth of the Library's collections, and by maintaining the identity of the Library as both a resource of technical literature and a repository for the history of science. ${ }^{127}$

As the internal communication of Day, Woolfe, and others illustrates, however, individuals' efforts to assure the continuation of this identity depended on a mixture of business acumen, tact, and opportunity. To review the notes, memos, invoices and files collated by a team of employees on the behalf of a large institutional purchaser is to find oneself in the competing intra-departmental worlds of bureaucratic power structures and personal and professional exchanges, and amidst negotiations between governments, heritage institutions, and private sellers. A flurry of memos mark the counter-signed exchanges between Day, Woolfe, and the then-Director of the Museum, Margaret Weston, who was called upon to authorise specific purchases. One example of this kind of approval can be seen in a note from Day to Weston, dated November 1, 1979. With the next phase of the Sotheby's auction due to commence a few days later, Day thanked the Director for interceding on the Library's behalf with Her Majesty's Treasury: Weston's timely intervention resulted in the Treasury advising Her Majesty's Stationery Office to release additional funds that subsequently proved crucial to the purchase of Honeyman's fine copy of William Harvey's De Motu Cordis (Frankfurt: William Fitzer, 1628) for a hammer price of $£ 90,000 .{ }^{128}$

\footnotetext{
${ }^{127}$ Robert Bud, 'History of Science and the Science Museum', British Journal for the History of Science, 30 (1997), pp. 47-50, p. 47. Bud notes that, upon its formal opening in 1928, the wider Science Museum was not intended to be primarily historical; it was instead to follow the footsteps of its predecessors to 'inspire the visitor with interesting glimpses of current or near current technology'. The Library can perhaps be said to have communicated, in equal measure, the Museum's need to provide insight into contemporary as well as historical 'scientific' culture.

${ }^{128}$ Memo A/18674, Lance Day to Director, 1.11.79, 'The Honeyman Collection', Science Museum File 2009/00/02. Her Majesty's Stationery Office (HMSO) acted as the Library's purchasing agent for all its books and journals from 1919 until 1968. HMSO bought books for government departments as an allied service, and was endorsed by the Treasury. After 1968, the library was given permission to purchase lower-value material from the Department of Education and Science (DES) vote instead. The HMSO vote was closely monitored by the Treasury especially as Library had a continuing tendency to overspend its HMSO limits. When the Library was bidding for books at the Sotheby's Honeyman auctions, it received special allocations of funding from the HMSO, authorised by the Treasury. I am very grateful to Nick Wyatt, Head of Library and Archives at the Science Museum, for providing this clarification.
} 
Evidence of the often collegial relationships shared by institutions operating within similar markets (and, in this case, based in the same city) also comes into focus. In a memo again dated to the first of November, an unnamed author (likely Hyman Woolfe, who appears to have been collating the list of books to be purchased) communicated to Day that the British Library, anxious to acquire Lot 1770 - the anonymously-authored astrological incunabulum Judicium cum tractatibus planetariis, printed in Milan in 1496- had requested that the Science Museum withdraw their bid. ${ }^{129}$ Recognising an opportunity to maximise their own haul, Day and Woolfe gracefully stepped aside - but not before substituting their bid for Judicium with bids on works by Oronce Finé and Carl Friedrich Gauss. ${ }^{130}$

Such written records showcase both the prior authorisation required for institutional acquisition and, by contrast, the fast-moving and changeable nature of an auction - even outside the doors of the auction-house itself. The notes simultaneously display the ideal collection as imagined by the Library Keeper and his assistant; in some cases, the second, third or fourth choices, recalculated as bids moved forward, and, finally, the actual acquisitions secured, complete with agents fees, postage, commission, and all other required sundries. The correspondence between interested parties holds up a mirror to the collection in which can be seen the alternative texts that might have taken their place on the library's shelves.

One final example of the dynamics of the modern book auction that might otherwise go unrecorded without the memos of Day and Woolfe is the role of booksellers acting as agents as part of the auction process. In a note dated 30 May, 1980, Lance Day informed the Director that the Honeyman copy of Johannes Kepler's De Cometis (Augsburg: Andreas Asperger, 1619) was found, after inspection, to be imperfect: the Science Museum's agent, the book-dealer Quaritch and Sons, was therefore not authorised to bid on the lot. ${ }^{131}$ With an allowance of up

\footnotetext{
${ }^{129}$ Memo 17/759, Hyman Woolfe to Director, 1.11.79, ‘The Honeyman Collection', Science Museum File 2009/00/02.

${ }^{130}$ Ibid, Science Museum File 2009/00/02. Replacement bids were instead placed on Oronce Finé, Canonum Astronomicorum libri II (Paris: Michel de Vascosan, 1553), Lot 1316; Karl Friedrich Gauss, Theoria Motus Corporum Coelestium, in sectionibus conicis solem ambientium (Hamburg: Friedrich Perthes and I.H. Besser, 1809), Lot 1451; and Karl Friedrich Gauss, Dioptrische Untersuchungen (Göttingen: Dieterichschen Buchhandlung, 1841), Lot 1457. Each of these bids was ultimately unsuccessful.

${ }^{131}$ Memo 894/80, Lance Day to Director, 30.5.80, 'The Honeyman Collection', Science Museum File 2009/00/02.
} 
to $£ 3,300$ afforded for this particular artefact, Roger Gaskell of Quaritch’s soon contacted the Science Museum early in the following year to offer a similar, though perfect, copy, bound in contemporary limp vellum. As Quaritch's likely surmised, the Museum had retained its interest. Following negotiations held between Hyman Woolfe and Roger Gaskell, a deal was struck for £2,750. After praising Woolfe’s business acumen, Day drily indicated in a memo to the Director that the opportunity presented a good deal all round:

The book is desirable, having an important place in the history of comets, and being a basis for Halley's work on comets. The price seems fair and reasonable (a copy went for $£ 20004$ years ago). ${ }^{132}$

\section{Conclusion}

Acting as an intermediary agent for a larger book seller, Gaskell sourced and delivered a rare Latin text on comets by a famed court mathematicus from the continent to his English purchaser. That selfsame purchaser was a keen Library Keeper, charged by a state-backed employer with stocking the shelves of their collection with a range of materials beneficial to the education and development of a national programme for improvements in the sciences. Gaskell's role in the process returns us to the actions of seventeenth-century intelligencers and agents such as Thomas Salusbury and John Collins, commissioned by noble or institutional patrons to scour the markets for the finest mathematical, scientific, and philosophical works to add to their burgeoning collections.

The agent's mediation after Sotheby's auction of the Honeyman collection calls to mind a number of parallels from the early seventeenth century. A halfcentury before the first English auction catalogue marking the sale of a library was printed in 1677, the Stationers' Company had in 1628 produced a list of close to forty booksellers dealing in old libraries and second-hand books imported from the continent; this number would expand well beyond the oversight of the Company as the century advanced. ${ }^{133}$ These figures highlight the growing demand for Latin and

\footnotetext{
132 Science Museum File 2009/00/02, ibid. I am grateful to Roger Gaskell for granting in personal correspondence his permission to be named in this thesis.

133 John Bruce, ed., Calendar of State Papers Domestic, Charles 1, 1629-31 (London: Her Majesty's Stationery Office, 1860), p. 306; cited in Yeo, Acquisition of Books by Chetham's Library, p. 84.
} 
vernacular works from the continent, with availability as much a driving force as rarity or condition. Institutions such as Chetham's Library in Manchester, founded on the bequest of Humphrey Chetham in 1655, chose to rely upon booksellers like Robert Littlebury to furnish their collections and, to some extent, to represent them at market. ${ }^{134}$

Alongside these agents are the donors and benefactors without whom the institutional library would rarely exist. Although the Sion College and Science Museum libraries were established for different professional communities (and, in the case of the Science Museum, for another public community of readers), each library benefited immensely from foundational bequests, whether in the form of capital investment or, more simply, the books that commenced their collections. As the current chapter has demonstrated, investigating the foundational elements of a collection necessitates investigating the archives of the overarching institution, as well as - in the cases of Torporley and Honeyman - the individual texts of notable libraries the institution has subsumed.

The differing uses of these three collections returns us to a question shared by studies of libraries, collections, and museums alike: what were they actually for? In the case of Nathaniel Torporley's books, I have argued that these were first and foremost a working collection, materials that accompanied their owner in his authorial, ecumenical, and editorial roles, travelling from Henry Percy's library at Petworth House, to Salwarpe, and lastly to Sion College. In Robert Honeyman's case, the rare and famous texts were both a narrative display of scientific progress, and a form of intellectual representatio, simultaneously showcasing both their owner's disciplinary expertise background and his antiquarian sensibilities. For the Library Keepers of the Science Museum, the collection was to reflect its initial users' technical requirements, and to celebrate intellectual ingenuity and development throughout history. These guidelines find an echo in the broader collecting policies of the present day, which recommend a 5-part process of identification, encompassing historically relevant association, evidence of scientific practice,

\footnotetext{
${ }^{134}$ Yeo, Acquisition of Books by Chetham's Library, p. 87. For a complete examination of Littlebury
} and his importance to Chetham's Library, see Yeo, ibid, pp. 81-121. 
processes of disciplinary change, the role of science in the public eye, and a focus on non-Western science and technology. ${ }^{135}$

Each of these examples serves to highlight the view of the library expounded by John Willis Clark in his Rede Lecture of 1894. Clark asserted that the construct was best seen from two conflicting points of view: either as a workshop, or as a museum. The former was characterised by Clark's modernist, fin-de-siècle marriage of practical application and mechanical ingenuity, a combination which would accelerate the acquisition of knowledge akin to steam-powered travel, 'a gigantic mincing-machine, into which the labours of the past are flung, to be turned out again in a slightly altered form as the literature of the present'. ${ }^{136}$ The latter was evoked by the speaker in its classical sense as a temple of the Muses: every intellectual discipline was provided for (as it was in the mincing-machine), but a more personal and romantic material history was brought to the fore. Visitors to the second place, however, might also content themselves with

the development of printing, as a result of individual effort; the art of bookbinding, as practised by different persons in different countries; the histories of the books themselves, the libraries in which they have found a home, the hands that have turned their pages, are there taken care of. ${ }^{137}$

Clark's elegy for the library as a classical haunt of muses rather than a satanic information mill recalls the fact that, from its establishment, the library has often been seen in such terms. Redesigned in every day and age for the betterment of its users and for wider societal goals, the library collection, whether personal or institutional, has remained a mirror in which the user sees reflected their intellectual goals as well as that of the image they wish to portray. This is as true now as it was in the seventeenth century: in an encomium of famed astronomers, appended to his translation of Marcus Manilius's didactic poem Astronomica (ca. AD 10-20),

\footnotetext{
${ }^{135}$ Robert Bud, 'Collecting for the Science Museum: Constructing the Collections, the Culture and the Institution' in Peter J. T. Morris, ed., Science for the Nation: Perspectives on the History of the Science Museum (Houndmills: Palgrave MacMillan, 2010), pp. 250-272, p. 268.

${ }^{136}$ J. W. Clark, Libraries in the Medieval and Renaissance Periods (Cambridge: Macmillan and Bowes, 1894), p. 6.

${ }^{137}$ Clark, ibid.
} 
Edward Sherburne lauded Nathaniel Torporley's library and Diclides coelometricae in equal measure:

NATHANIEL TORPORLEY [...] set forth a Treatise, entitled Diclides Coelo-Metricae, seu Valvae Astronomicae Universales, in two books. The first shewing the Composition of Astronomical Tables, with their Application, as to Directions; comprized in a new Universal and most easie Method. The second teaching to calculate the Prostaphaereses of the Planets Motions, without the Subdititious Aid of Proportional Scruples; and setting forth the Doctrine of Spherical Triangles most fully and easily; the whole Artifice being reduced to Six Words in a Tractable Order, represented in the Form or Figure of a Mitre. [...] He was sometime Amanuensis to the famous Vieta, and merits commendation for the Legacy he bequeathed of many choice Books toward furnishing the Library at Sion Colledge, London. ${ }^{138}$

Whilst primarily a repository of materials for practical reference or guidance, intellectual development, or leisurely reading, libraries also performed an outwardfacing role, projecting the identity constructed by their curator, keeper, or overseeing institution to the watching world. The self-fashioning renewal of this identity may bring with it changes over the longue durée. As James Raven has noted, one element of the enduring fascination with the library of Alexandria and its destruction is the story's capability to act as a leitmotif for the continuous dispersal, exchange, and reconstitution of book collections everywhere; the making of a library is itself suggested as 'not just the evolution but the sudden metamorphosis of a collection [...] one that might be reformed many times within a physical library building'. ${ }^{139}$ By charting the presence of the smaller, personal collection within that of today's large institution, it remains possible to track these sudden and multiple metamorphoses, and to keep sight of the individual owners, users, and collectors who remain present in the library, awaiting their rediscovery.

\footnotetext{
${ }^{138}$ Edward Sherburne, The Sphere of Marcus Manilius, made an English poem with annotations and an astronomical appendix (London: Printed for Nathanael Brooke, 1675), p. 78. Sherburne's emphasis.

139 James Raven, 'The Resonances of Loss' in James Raven, ed., Lost Libraries: The Destruction of the Great Book Collections since Antiquity (New York: Palgrave Macmillan, 2004), pp. 1-40, p. 29.
} 
Writing in his youthful diaries to 1667, the future first Astronomer Royal John Flamsteed (1646-1719) told of a year of reading during a period of chronic illness during his university days:

Being withdrawn from school, I, within a month or two after, had Sacrobosco's Sphere in Latin, lent me, which I had set myself to read without any director in it, but not unsuccessfully. For here I laid the ground of my mathematical knowledge (...) This winter I was weak, and my disease held on with me til the summer, when it mended a little. This summer (1663) I prosecuted my studies; for, returning home, I was brought into company with Elias Grice, who told me of the artificial tables, and showed me (as I remember) Wingate's Canon. I likewise now got Mr. Stirrup's Art of Dialling, which I read this summer, and some other authors on mathematical subjects as Mr. Gunther's Sector and Canon; and soon after I acquired Oughtred's Canon of mine own. ${ }^{2}$

This reading list is instructive for several reasons. Showcasing the appetite for both theory and practice that he would later bring to the observation of the heavens, the youthful student's reading list includes a Sacroboscan grounding in the theory common to the era, as well as the mass produced tables made available by print. Variations on the figure of the 'mathematical practitioner', providing texts and instruments for every kind of purchaser, are embodied in Flamsteed's acquisition of the works of the author, instrument-maker, and publisher William Oughtred, by the clergyman, inventor, author and Gresham Professor of Astronomy Edmund Gunter (1581-1626), and by the mathematical expositor Edmund Wingate (1596-1656). ${ }^{3}$ The art of dialling, both a leisurely and an academic pursuit, was referenced by the juvenile Flamsteed as a foundational part of his mathematical knowledge.

\footnotetext{
${ }^{1}$ This title is borrowed from Anthony V. Simcock, 'Elucidatio fabricae ususque: Rambling Among the Beginnings of the Scientific Instrument Bookshelf', in W. D. Hackmann and A. J. Turner, eds., Learning, Language and Invention: Essays Presented to Francis Maddison (Aldershot and Paris: Variorum, 1994), pp. 273-296.

2 John Flamsteed and Francis Baily, ed., An Account of the Revd. John Flamsteed, the First Astronomer-Royal: To Which Is Added, his British Catalogue of Stars, Corrected and Enlarged (London: Printed by order of the Lord's Commissioner of the Admiralty, 1835), p. 10.

${ }^{3}$ These examples again serve to partially highlight the problematic nature of the term 'mathematical practitioner'. The identities of such figures are often characterised through their publishing or commercial careers, with an over-emphasis on authorship and instrument-making, rather than through the actual details of their personal disciplinary understanding and practice.
} 
John Flamsteed's report reminds us of the various ways users could come into contact with mathematical texts in different locations. Although reading throughout his illness and as such perhaps not entirely 'active', the diarist made frequent reference to his father's guidance in mathematical materials, and to the astronomical tasks he was subsequently able to put his learning toward. His crossreferencing of authors writing on similar topics across the period demonstrates the presence of a mathematical market for books in the early modern period, and highlights how users often combined instruments - such as globes, quadrants, and dials - with texts, thus mediating their experience of the physical world through different types of printed or inscribed instruments. Disciplines old and new were combined, the spherical astronomy of Sacrobosco's Sphere studied together with Oughtred's trigonometric Canon. Flamsteed spoke of his familiarity with authors in the same tone we might expect from a reader of novels, the piece serving to suggest that this particular summer - despite the infirmity the young reader experienced lived long in the memory.

Clearly, John Flamsteed attached no little value to the mathematical texts that accompanied his confinement in the summer of 1663. It is easy to imagine the astronomer returning to particular works throughout his life, seeking answers, guidance and inspiration from the titles that proved foundational at an early age. Fundamental to mathematical practice in the early modern period, books and instruments so often accompanied one another, with print and manuscript establishing the theory, use and construction of instruments, and instruments returning the data that users often recorded to validate and then improve their practice - and, thereafter, their understanding.

Every aspect of this material culture, whether manuscript, map, compass, astrolabe, text or globe, could take a quotidian or a prestigious form. Objects represented the image their owner wished to present; status, power, and mastery; the necessary elements of a working identity; evidence of erudition and expertise; tools for self-improvement, both economically and intellectually; or, as was often the case, some combination of each of these. The value individual owners ascribed to their objects may not have been proportional to the value we perceive it as holding in the modern era. Without insight into the personal motivations for owning and using such 
materials, their true worth may continue to escape historical study. As the introduction to this thesis has demonstrated, there by now exists a vast amount of literature on early modern knowledge-making, the role of mathematics in that process, its practitioners, and the commodification and commercialization of mathematical culture. The social relations of these exchanges, however, require further attention - most particularly from their user's perspective. ${ }^{4}$

The larger collections of today demonstrate both the consistencies and lacunae which exist between copies and instruments; a situation which, almost twenty years ago, provoked Silvia De Renzi's demand for the decoding of the material features of books - their language, quality of paper and of illustrations, and format - and the application of this information in the history of science. ${ }^{5}$ After all, thanks to their sacralised cultural position as carriers and protectors of knowledge, books remain among the hardiest and most well-preserved cultural objects we possess. So often spoken of in terms of their ephemerality, vast amounts of paper and vellum continue to be collected by individuals and institutions across the globe, with manuscripts, incunabula, news-sheets, broadsides, and old books continually offering researchers new findings. The textual 'ideal copy' fetishized in much of the language of fixity accompanying discussions of the cultural revolutions inspired by print has instead begun to be replaced by discussions of books as defined by singularities, with their missing quires, sophisticated title pages, and printing errors as of much interest to today's historian as the idealized versions dreamt up by early modern stationers and authors. ${ }^{6}$

Such a taxonomy would undoubtedly be of specific use to our appreciation of the value ascribed to mathematics and its materials in the early modern period, and it was with this process of analysis and classification in mind that the analytical survey, detailed in Chapter One of this thesis, commenced. Less influenced by personal taste and proclivity than that of the individual collector, The Rare Books

\footnotetext{
${ }^{4}$ Susan Stewart, On Longing: Narratives of the Miniature, the Gigantic, the Souvenir, the Collection (Durham and London: Duke University Press, 1993), p. 164. Stewart argues that, just as 'the collection can serve as a metaphor for the individual personality, so the collection can serve as metaphor for the social relations of an exchange economy'. I suggest that in this instance the metaphorical qualities of the collection are better served momentarily set down in favour of the empirical evidence it presents.

${ }^{5}$ de Renzi, Instruments in Print, p. 25.

${ }^{6}$ Joseph A. Dane, The Myth of Print Culture (Toronto: University of Toronto Press, 2007), p. 87.
} 
Collection of the Science Museum has been situated as an invaluable locus for the exploration of the contents of books, of their internal marginalia, annotations, and inscriptions, and their bookplates and stamps; of their external bindings, toolings, armorials and bookplates; and, finally, of the wider relationships and uses such evidence points toward.

In its accumulation and classification of as much of this data as possible, the first chapter of this thesis presented detailed evidence proving that the Rare Books Collection may be seen as representative of the culture which produced such material. Although such an intensive analytical survey is necessarily laborious, I believe that the example set by this chapter may be of use to future studies of similarly thematic collections or subsets of collections. Studies of large-scale, institutional accumulations of books, manuscripts, instruments or other material goods and studies focussing on individual figures and their collections are complementary: only by bringing to light the material evidence kept in a variety of collections will it be possible to reconstitute fully practices of use, collection, and valuation in periods of growing consumption such as the early modern. Future studies may consider the use of digital humanities tools to link individual collectors across multiple collections or institutions, or, for example, to utilise visual presentations of provenance evidence via image-hosting websites. Similarly, metadata may be shared or made available through XML or SQL databases and micro-sites to encourage researchers in various fields and locations to pool their resources and, by proxy, deepen their findings.

Of course, early modern readers and users of texts had their own communication networks and tools of information handling. As Chapter Two's case study of the Wittenberg Sammelband demonstrates, sixteenth-century German readers replicated in manuscript the visio-spatial method taught by Ramism to best unify mathematical pedagogy with dialectic. Despite its popularity in the period, onthe-ground studies of the transmission of Ramist philosophy in almost any discipline are lacking. This is almost in inverse correlation to the methodology itself, which made significant progress in the schools and educational institutions of Europe in the late sixteenth and early seventeenth centuries, and may have had a lasting impact on the structure of teaching materials thereafter. Of the many ways in which it would be 
possible to extend the current study of the early modern use of mathematics presented in this thesis, one would be a more in-depth and complete study of the use of Ramist textbooks across a range of European locations, with a view to more completely detailing the spread of this method and its possible impact upon mathematical reading, teaching, and practice, both in theory and in application.

Questions of education, audience, and use are integral to Chapter Three, and its treatment of the unification of text, instrument, and use in Thomas Blundeville's Exercises. Highlighting the introduction of continental tools and practices to the English market, this chapter helps to demonstrate how textual compendia acted as a stage to present mathematics, affording their users the opportunity to learn to manipulate, test and apply paper iterations of instruments in theory and in practice. The construction and use of these paper tools encouraged users to develop the intellectual visualisation required for mathematical thinking, making their texts hybrid instruments in the process. Blundeville's hand in the transmission and reception of continental material, ostensibly for the gentry and in service of the state, can be linked to the growth of mathematical coteries in the late sixteenth century.

At the same time, by presenting users with affordable compendia moving from first principles to more detailed treatments, the author secured a wide audience for his materials: so much so that his text remained popular well beyond his death. As the examples of both paper tools and annotations demonstrate, readers utilised Blundeville's texts in order to participate in celestial observation, honing their mathematical abilities and engaging with instruments linked to culturally-valued endeavours, including dialling or time-finding. Often under-appreciated even in more recent studies of mathematical culture, dialling and other horological practices are here presented as a form of training for amateurs, and as a gateway to more expert types of mathematical and astronomical practice.

The growth and development of the English market for practical mathematics in London and beyond is detailed in Chapter Four, on John Seller's Pocket Book of 1685. Highlighting the apparent dichotomy existing between its maker, its intended audience, and its actual users, this chapter encourages greater study of the intentions of the figure of the printer-practitioner and the actual use of their products. Beginning by attending to Seller's position as an expert producer of printed 
mathematical goods such as instruments, globes, maps and atlases, before moving into his possible plagiarism and economic downturn, Chapter Four draws attention to a fascinating figure at the heart of late seventeenth-century London's maritime trade. As the Science Museum's unique copy of Seller's Pocket Book shows, however, Seller's products travelled well beyond their intended clientele, and were repurposed as a university commonplace book. By linking together the scribal technologies at work in previous chapters, analysis of the annotations found in the Pocket Book showcase the erudite pursuit of chronology undertaken at university, and the ways in which the study of history, mathematics, astronomy and religion were all co-opted as part of a single intellectual continuum at the University of Cambridge in the late seventeenth century.

When placed side-by-side, Chapters 3 and 4 help to draw our attention to the reception of developments in trigonometry, and the application of these developments at various scenes of inquiry. These chapters also serve to establish the continuation of the use and reading of Sacrobosco's Sphere, and of the importance of spherical astronomy in mathematical teaching and learning more generally. The common scribal technologies put to use by a variety of readers meanwhile suggest that future research into the taxonomies of mathematical reading - types witnessed for repetition, rehearsal, and performance, for example - may further shape our understanding of users reading practices according to specific genres in the early modern period. Central to these issues is the malleability of the codex itself, with the text a vehicle for information transfer, a repository for information, and a spur to action, consistently remade, repackaged, and reconstituted depending on its terms of use. In future, it may be possible to subject specific subsets of this marginalia to wider study: for example, through crowd-sourced analysis via citizen science web portals. In doing so, it may be possible to classify ever-greater amounts of scribal information, and to chart its changing over time.

The final chapter of the thesis, concerning the collections of the astrologer and Anglican divine Nathaniel Torporley and the twentieth-century antiquarian Robert Brodhead Honeyman, seeks to bring together several strands outlined throughout this study. By attending to processes of acquisition in both individual and institutional contexts, this chapter highlights the construction of identity at play in 
each, excavating in the process the creation and recreation of an external place: one which, in Derrida's terms, 'assures the possibility of memorization, of repetition, of reproduction, or of reimpression'. ${ }^{7}$ After reconstructing these libraries - whether those of Torporley, Sion College, Honeyman, or the Science Museum, or even the ideal library envisioned by Day, Woolfe and others whilst at auction - Walter Benjamin's idea of collection-as-renewal, and its commingling of romantic and pragmatic approaches may perhaps be reintroduced.

The collection, a place where property and possession were often clashing spheres, acted for Benjamin as an opportunity to see dates, place names, formats, provenance evidence, and bindings not as 'dry, isolated facts, but as a harmonious whole'. ${ }^{8}$ Robert Honeyman's desire to construct a progressivist narrative of the history of science, marked by evidence of its great leaps forward, evinces one type of acquisition predicated on the formulation of harmony. By the same token, Honeyman's style of collection helped to continue what Lucien Karpik, in his adaptation of Igor Koptyoff, ${ }^{9}$ has identified as the further layering of value added to certain items by their status as "incommensurable” goods. In Karpik's view, the unique irreplaceable or singular qualities of such materials demand that they can be preserved only by safeguarding in protected enclaves. In each circuit, the same teleology is in play: though an acquisition may be targeted precisely for its novel or inspiring stimulus, the aim of the collector becomes to safeguard it from a wider market and thereby commit it to the intransigence of an archive, effectively limiting the acquisition's capacity to communicate its use-value, if at the same time protecting its commodity-value. ${ }^{10}$

In its testing of the continuing value of the collection beyond its possible era of practical utility, this study rejects the ossification implied in Karpik's enclave by celebrating the value of use. Thus the Science Museum Library's Rare Books

\footnotetext{
7 Jacques Derrida, ‘Archive Fever: A Freudian Impression', trans. Eric Prenowitz, Diacritics, 25.2 (1995), pp. 9-63, p. 14.

${ }^{8}$ Walter Benjamin, 'Unpacking my Library: A Talk about Book Collecting', in Walter Benjamin and Hannah Arendt, ed., Illuminations (London: Pimlico, 1999), pp. 61-69, pp. 63-64.

${ }^{9}$ Igor Koptyoff, 'The Cultural Biography of Things: Commoditization as Process' in Arjan Appadurai, ed., The Social Life of Things. Commodities in Cultural Perspective, Second Edition (Cambridge: Cambridge University Press, 1997), pp. 64-91.

${ }^{10}$ Lucien Karpik, Valuing the Unique: The Economics of Singularities (Princeton: Princeton University Press, 2010), p. 5.
} 
Collection turns toward Lisa Jardine's conception of the Renaissance personal library: one functioning 'at two levels, that of the status symbol or ostentatious display or art collections, and that of a serious text-bank, a systematically organized repository for recovered and original compositions'. ${ }^{11}$ Belonging to a public collection, these objects (once identified and excavated) are free to communicate both their uniqueness and their use-value to new generations of users - users for whom the commodity-value of the object need not be a concern.

By doing so, the goals of today's Library may be seen as very much a product of the era in which it was first established: central to the recurring efforts of the nineteenth-century to incorporate libraries in support and service of the burgeoning knowledge economy of which they were a part. In this regard, the collection protects itself from the tendency of collections identified by James Clifford to move toward a form of self-sufficiency which supresses the historical, economic and political processes of their production. ${ }^{12}$ Attesting to the multi-faceted use of mathematics in the early modern period and beyond by attending to processes of reading, acquisition, collection and preservation, the current study is therefore an important step toward understanding the making, practice and maintenance of mathematical culture in the early modern and modern eras in much greater detail.

With this in mind, the limitations of the current study may also prove beneficial to future research. It must be recognised that the evidence that the current study has presented is of users of relatively high mathematical competence, and that evidence of mathematical tyros moving from basic to intermediary forms of understanding is seen only fleetingly. Yet, as I have already argued in Chapter One, a repository such as the Science Museum Library's Rare Books Collection can be determined as representative of the mathematical culture of the early modern period. Thanks in no small part to the successful integration of the histories of the book and of reading into the history of science, it may now be argued that we are no longer fixated on anachronistic conceptions of the 'ideal' scientific text as produced in the early modern period. As a next step, this study suggests that we diverge from notions

\footnotetext{
${ }^{11}$ Jardine, Worldly Goods, p. 191.

12 James Clifford, 'On Collecting Art and Culture', in Nicholas Mirzoeff, ed., The Visual Culture Reader (New York: Routledge 1998), pp. 94-107, p. 103.
} 
of the 'ideal reader' of the mathematical text, and attend instead to the actual readers in all their varieties.

How might this be done? As we have seen, readers of texts such as John Seller's Pocket Book did not necessarily match the kinds of individual the text claimed to be directed at. Finding absolute mathematical novices is likely to be further complicated by two factors: first of all, their texts may not have been deemed worthy of preservation or collection; secondly, their reading practices may not have extended to the note-taking, commonplacing, and storing frequently seen at institutions of higher education. Even if such readers may therefore remain at the fringes of our understanding, illuminating mathematical culture as far as these fringes is undoubtedly valuable to our mapping of the contours of mathematical practice in all its forms.

As we have already seen, the past four decades have witnessed scholars pay significant attention to mathematical practitioners, gifting these figures in the process a central role in the transformation of early modern mathematical culture, and, indeed, a central role in the mathematization of nature more generally. A general audience of users has, for a variety of reasons, remained somewhat in the shadows. Yet both practitioners and users should be seen as reciprocal actors in these developments; if users remain neglected, our understanding of the making of this culture can only be partial. Writing in 2000, Nick Jardine suggested that historians of science might usefully draw upon the work of Gérard Genette by attending to the role of intertextuality in the production and authorship of early modern texts. ${ }^{13}$ Jardine's suggestion can be widened to include Genette's work on paratextuality. As I have sought to show in Chapter Two, readers and authors alike operated at the thresholds of mathematical interpretation, bringing what Genette defined as the peritextual and epitextual qualities of their volumes to bear on their engagement with existing and novel presentations of mathematical theory and practice at educational, occupational, and recreational sites of practice.

\footnotetext{
${ }^{13}$ Nicholas Jardine, 'Books, Texts and the Making of Knowledge' in Marina Frasca-Spada and Nicholas Jardine, eds., Books and the Sciences in History (Cambridge: Cambridge University Press, 2000), pp. 393-407, p. 401.
} 
To this end, widening our sense of what constitutes mathematical practice is likely to be of significant value to historians' appreciation of early modern mathematical culture. Arguing that the term 'practice' has become so extendable as to almost defy concrete explanation, Sophie Roux has recently proposed that we ask ourselves what speaking of mathematical practices commits us to. ${ }^{14}$ Roux suggested three forms of mathematical practice, none of which need be mutually exclusive. Firstly, (citing Paolo Mancosu), practice may in Roux's argument resemble 'mathematics as it is done, not as it should be done according to some preconceived philosophical viewpoint'; secondly, it may refer to 'the non-verbal commitments shared by mathematicians' that help them to define a scientific style and form an intellectual community; finally, mathematical practice may be associated with practical mathematics (in contrast to pure mathematics) and their application in the real world, 'with its economic interests, practical concerns, material instrumentation, local settings and complex social networks'. ${ }^{15}$ The practice of users of all stripes can be usefully grafted onto each of these categories: doing so, I argue, will advance not only our understanding of both consumers and practitioners, but also of the wider historical culture in which they operated.

\footnotetext{
${ }^{14}$ Sophie Roux, 'Forms of Mathematization (14th-17th Centuries)', Early Science and Medicine, 15 (2010), pp. 319-337, p. 327

${ }^{15}$ Roux, ibid, pp. 327-328; Mancosu, Philosophy of Mathematics and Mathematical Practice, p. 4.
} 


\section{Bibliography}

\section{Manuscript Primary Sources Cited, by Author}

London. British Library.

Harriot, Thomas. Untitled. MS Ad 6788, ff. 117 r - 117 v.

Pell, John. Pell Papers ( $3^{\text {rd }}$ Series). Mathematical collections of John Pell, consisting of treatises, calculations, and extracts from printed works, with other miscellaneous matter, chiefly in Pell's autograph. MS Add. 4398.

Pell, John. Pell Papers, (4 $4^{\text {th }}$ Series). Mathematical collections of John Pell, consisting of treatises, geometrical and other problems and their solutions, tables and calculations of logarithms, etc. MS Add. 4408.

Pell, John. Pell Papers (4 ${ }^{\text {th }}$ Series). Mathematical collections of John Pell, consisting of treatises, geometrical and other problems and their solutions, tables and calculations of logarithms, etc. MS Add. 4425.

London. Lambeth Palace Library.

Spencer, John, and Various. Sion College Book of Benefactors, 1629-1688. Sion College Collection. L40.2/E64.

Spencer, John. Transcriptum Registri illius magni Benefactorum, 1629-1666. Sion College Collection. L40.2/E60.

Torporley Nathaniel. Corrector analyticus artis posthumae Thomae Harrioti, Sion College Collection. MSS L40.2/E.10, ff. 7 r -12 v.

Torporley, Nathaniel. Congestor analiticus cui accessit conjector ad tetragonisimi rimanda latibula fax rectrix, Sion College Collection. MSS L40.2/L40, ff. $1 \mathrm{r}-34 \mathrm{v}$.

Torporley, Nathaniel. De quadratura circuli excogitatio per Joh. Bulkleium. Sion College Collection. MSS L40.2/L40, ff. 215 r - 234 v.

Torporley, Nathaniel. Observationes [...] cometae nuper exorti, factae Oxoniae. Sion College Collection. MSS L40.2/E10, ff. $1 \mathrm{r}-4 \mathrm{v}$.

Torporley, Nathaniel. Operationes logisticae in notis. Sion College Collection. MSS L.40.2/L.40, ff. 35 r -54 v.

Torporley, Nathaniel. Untitled. Sion College Collection. MSS L40.2/L40, ff. $56 \mathrm{r}-166 \mathrm{r}$. 
London. Royal College of Physicians.

Bibliotheca Marchionis Dorcestriae, Royal College of Physicians Library, MS 2000/81.

London. Science Museum Library and Archive.

Bayly, William. Manuscripts related to navigational and astronomical problems. MS 424.

Various. The Honeyman Collection. Science Museum File 2009/00/02.

Oxford. Corpus Christi College.

Hegge, Robert. Heliotropium Sciothericum, Corpus Christi College, MS 430, ff. 16-34.

San Marino, California. Huntington Library, Art Collections and Gardens.

Salusbury, Thomas. Letter to Theophilius Hastings, Earl of Huntingdon, July 14 1664. Hastings MS 10660.

\section{Printed Primary Sources bearing Annotation or Provenance Markers, or otherwise cited, by Author}

London. British Library.

Blagrave, John. The Mathematical Jewel, shewing the Making, amd Most Excellent Use of a Singular Instrument so called (London: Walter Venge, 1585). 60.07.

Blagrave, John. The Mathematical Jewel, shewing the Making, amd Most Excellent Use of a Singular Instrument so called (London: Walter Venge, 1585). 528 n.20. (1).

Blundeville, Thomas. M. Blundeuile his Exercises containing Sixe Treatises (London: John Windet, 1594). C.145.C.16.

Blundeville, Thomas. M. Blundeuile his Exercises, containing Eight Treatises $4^{\text {th }}$ edn (London: Imprinted by William Stansby, 1613). C.145.C.17.

Blundeville, Thomas. The Theoriques of the Seven Planets (London: Adam Islip, 1602). C.184.d.2. 
London. Science Museum Library and Archives.

Apian, Peter. Cosmographia Petri Apiani (Paris: apud Vivantium Gaultherot, 1551). Q. O. B. GEM GEMMA 461575-2001.

Apian, Peter. Quadrans Apiani astronomicus et iam recens inventus et nunc primum editus. (Ingolstadt: Peter Apian, 1532). Q. O. B. API APIANUS 461587-2001.

Blundeville, Thomas. Mr Blundevil his Exercises, contayning Eight Treatises, 7th edn (London: Richard Bishop, 1636). O. B. BLU BLUNDEVILLE 459578-2001.

Cardano, Girolamo. De subtilitate libri XXI (Lyon: Apud Gulielmum Rovillium, 1559). O. B. CAR CARDANO 459700-2001.

de la Caille, Nicolas Louis. Astronomiae fundamenta (Paris: J. J. Stephani Collombat, 1757). Q. O. B. LAC LACAILLE 461647-2001.

Everard, Thomas. Stereometry made easie, or, The description and use of a new gauging-rod or sliding-rule (London: J Playford for R Clavel and C Hussey, 1684). O. B. EVE EVERARD 459930-2001.

John Peckham, Joannis Archiepiscopi Cantuariensis, Perspectivae communis libri tres. Iam postremo correcti ac figuris illustrati. (Cologne: Arnold Birckmann, 1580). O. B. RAM RAMUS 30209019362791.

Mouton, Gabriel. Observationes diametrorum solis et lunce apparentium (Lyon: Matthaei Liberal, 1670). O. B. MOU MOUTON 460709-2001.

Newton, Isaac. Philosophice Naturalis Principia Mathematica (London: J. Streater for the Royal Society, 1687). Q. O. B. NEW NEWTON 30209019359067.

Norwood, Matthew. Norwood's System of Navigation: teaching the whole art, in a way more familiar, easie, and practical, than hath been hitherto done (London: Printed for H. Sawbridge and T. Wall, 1685). O. B. NORWOOD 460784-2001.

Oresme, Nicole. Incipit p [er] utilis tractatus de latitudinibus forma[rum] (Padova: Mathieu Cerdonis, 1486). O. B. ORE ORESME 460790-2001.

Pitiscus, Bartholomaeus. Canon triangulorum emendatissimus, et ad usum accomodatissimus (Frankfurt: Nicolas Hoffman, 1612). O. B. PIT PITISCUS 460872-2001.

Pitiscus, Bartholomaeus. Thesaurus mathematicus:sive canon sinuum ad radium 1.00000.00000.00000 (Frankfurt: Nicolas Hoffman, 1613). F. O. B. PIT PITISCUS 462607-2001. 
Pitiscus, Bartholomaeus. Trigonometrice sive de dimensione Triangulorum Libri Quinque, item Problematum variorum : nempe geodoeticorum, altimetricorum, geographicorum, gnomonicorum, astronomicorum libri decem, trigonometrice subjuncti ad usum ejus demonstrandum, Editio Tertia (Frankfurt: Nicolaus Hoffman, 1612). O. B. PIT PITISCUS, 460871-2001.

Pitiscus, Bartholomaeus. Trigonometrice: sive de dimensione triangulos libri quinque (Augsburg: S. N., 1600). O. B. PIT PITISCUS 460870-2001.

Ramus, Petrus. P Rami Arithmeticae libri duo: Geometriae septem et viginti (Basel: haer. Nikolaus II Episcopius, 1580). O. B. RAM RAMUS 30209019362784.

Recorde, Robert. The whetstone of witte, whiche is the seconde parte of Arithmetike: containyng thextraction of rootes: the cossike practise, with the rule of equation: and the woorkes of surde nombers (London: John Kyngstone, 1557). O. B. REC RECORDE 460946-2001.

Rensberger, Nicolaus. Astronomia teutsch (Augsburg: Mattheum Francken, 1569). O. B. REN RENSBERGER 460957-2001.

Sacro Bosco, Joannes de. Opus sphericum magistri Ioamnis de Sacro Busco natione angli figuris verissime exculptis et interpretatione familiari ad commoditatem desiderantium iucundissima Artis Astronomice callere principia pulcherrime et iterate recognitione illustratum (Cologne: Henrici Quentel, 1505). O. B. SAC SACRO 461008-2001.

Seller, John. A Pocket Book, containing several choice collections: in Arithmetick, Astronomy, Geometry, Surveying, Dialling, Navigation, Astrology, Geography, Measuring, Gageing, etc (London: John Seller, 1685). O. B. SEL SELLER 30209019360995.

Stöffler, Johannes. Elucidatio fabricae ususque astrolabii (Oppenheim: J. Koebel, 1513). Q. O. B. STO STOEFFLER 461834-2001.

Thomas Fincke, Thomae Finkii Flenspurgensis Geometriae rotundi libri XIIII (Basel: Sebastian Henric-Petri, 1583), O. B. RAM RAMUS 30209019362777.

London. Lambeth Palace Library.

Tartaret, Pierre. Expositio magistri Petri Tatareti in Summulas Petri Hispani (Basel: Johannes Froben, 1514). Sion College Collection. A51.2/D92T(1).

Vulcanius, Bonaventura. Thesaurus utriusque linguae (Leiden: Ioannis Patius, 1600). Sion College Collection. H14.3/V97. 
Zara, Antonio. Anatomia ingeniorum et scientiarum sectionibus quatuor comprehensa (Venice: Ambrosij Dei, \& fratrum, 1615). Sion College Collection. C14.3/Z1.

\section{Contemporaneously Printed Primary Sources Cited, by Author}

Anon. 'Some Considerations of an Observing Person in the Country upon Numb. 133 of these Tracts, sent in a Letter to the Publisher of May 2, 1677,' Philosophical Transactions, 136 (1677), pp. 890-891.

Apian, Peter. Cosmographicus Liber Petri Apiani Mathematici Studiose Collectus (Landshut: Peter Apian, 1524).

Apian, Peter. Folium Populi. Instrumentum hoc a Pietro Apiano (Ingolstadt: Peter Apian, 1533).

Ballard, Thomas. A catalogue of the libraries of the learned Sir Thomas Brown, and Dr. Edward Brown, his son (London: Thomas Ballard, 1711).

Barrow, Isaac. Euclidis Elementorum Libri XV breviter demonstrati (Cambridge: ex celeberrimæ Academiæ typographeo. Impensis Guilielmi Nealand bibliopolæ, 1655).

Blagrave, John. The Art of Dialling in Two Parts (London: Nicholas Okes for Simon Waterson, 1609).

Blundeville, Thomas. A New Booke containing the Arte of Ryding (London: William Seres, c. 1561).

Blundeville, Thomas. M. Blundeuile his Exercises in Sixe Treatises (London: John Windet, 1594).

Blundeville, Thomas. The Art of Logick (London: William Stansby, 1617; first published 1599).

Blundeville, Thomas. The Fowre Chiefyst Offices belonging to Horsemanshippe (London: William Seres, 1565).

Burgersdicius, Franciscus. Sphaera Iohannis de Sacro Bosco, decreto in usum scholarum ejusdem provinciae recensita ut et latinitus et methodus emendata sit (Leiden: ex officina Bonaventurae et Abrahami Elzevier, 1626).

Cocker, Edward. Penna Volans, or the young mans accomplishment (London: printed for John Ruddiard, 1661).

Cocker, Edward. The Compleat Writing Master (London: Printed for Thomas Basset and Robert Pawlet, 1670).

Cocker, Edward. The Pens Transcendencie, or faire writings labyrinth (London: sold by Samuel Ayre, 1657). 
Cocker, Edward. The Youth's Direction to Write Without a Teacher all the Useful Hands of England (London: sold by John Overton, 1652).

Coignet, Michel. Nieuwe Onderwijsinghe op de Principaelste Puncten der Zeevaert (Antwerp: Hendrik Hendriksen, 1580).

Coignet, Michiel. Instruction Nouvelle des Points plus Excellents et Nécessaires, touchant l'art de Navigeur (Anvers: Hendrick Hendersen, 1581).

Dasypodius, Conrad. Volumen primum mathematicum. Prima, et simplicissima mathematicarum disciplinarum principia complectens: Geometriae. Logisticae. Astronomiae. Geographiae. Per Cunradum Dasypodium in utilitatem academiae Argentinensis collectum (Strasbourg: Josias Rihel, 1567).

Davis, John. The Seamans Secrets (London: Thomas Dawson, 1595).

Dibdin, Thomas Frognall. Bibliomania: Or Book-madness, $2^{\text {nd }}$ edn (London: Henry G. Bohn, 1832).

Digges, Leonard. A Boke Named Tectonicon (London: John Day for Thomas Gemini, 1556).

Donne, John. An Anatomy of the World, Wherein, by Occasion of the Untimely Death of Mistress Elizabeth Drury, the Frailty and the Decay of this Whole World is Represented. The First Anniversary (London: Printed for Samuel Macham, 1611).

Dury, John. The Reformed Librarie-Keeper, with a Supplement to the ReformedSchool (London: William du-Gard, 1650).

Euclid. The Elements of Geometrie of the Most Auncient Philosopher Euclide of Megara, trans. Henry Billingsley, (London: John Daye, 1570).

Fale, Thomas. Horologiographia. The Art of Dialling (London: Thomas Orwin, 1593.

Fludd, Robert. Utriusque cosmi maioris scilicet et minoris metaphysica, physica atque technica historia (Oppenheim: Theodore de Bry, 1617).

Forster, Mark. Arithmetical Trigonometry (London: Printed for R. Mount, 1690).

Gassendi, Pierre. Institutio Astronomica, juxta Hypotheseis tam Veterum, quam Copernici, et Tychonis (Paris: Ludovic de Heuqueville, 1647).

Hayes, Walter. Trade card (London: Walter Hayes, at the Crosse Daggers in Moore Fields, next door to the Popes-head Tavern, Bethlem Gate, 1680). Science Museum Collection, Object 1934-121/55.

Herigone, Pierre. Cursus mathematicus, nova, brevi et clara methodo demonstratus, per notas reales \& universales, citra usum cuiuscunque idiomatis, intellectu faciles. 5 vols. (Paris: Henry Le Gras, 1634-1637). 
Heylin, Peter. Mikrokosmos: A Little Description of the Great World (Oxford: John Lichfield and William Turner, 1625).

Hodder, James. Hodder's Decimal Arithmetick: or, a plain and more methodical way of teaching the said art (London: Thomas Rooks, 1668).

Hodgson and Co., A Catalogue of Rare Early Scientific Books from the Library of Sion College London, Auction Catalogue Number 13 of 1938-1939 (London: Riddle, Smith, and Duffus, 1938).

Holwell, John. Clavis Horologiae; or, A Key to the Whole Art of Arithmetical Dyalling, in two parts (London: William Bonny for Thomas Hawkins, 1686).

Hood, Thomas. The Use of both the Globes, Celestial and Terrestrial (London: Thomas Dawson, 1592).

Hooke, Robert. 'Some Observables about Lode-Stones and Compasses,' Philosophical Transactions, 23 (1667), pp. 423-424.

Hopton, Arthur. Speculum Topographicum, or the Topographicall Glasse (London: Simon Waterson, 1611).

Hues, Robert. Tractatus de Globis et Eorum Usu (London, Thomas Dawson, 1594).

Johnson, John. Iohnson's Arithmatick in Two Bookes (London: Augustine Matthews, 1623).

Leadbetter, Charles. A Compleat System of Astronomy in Two Volumes (London: Printed for J. Wilcox, 1742).

Leybourn, William. Nine Geometrical Exercises for Young Sea-Men, and Others that are Studious in Mathematical Practices (London: James Flesher for George Sawbridge, 1669).

Martyn, John. Mensuration made Easie: or, The way of measuring all solid and regular bodies, as of timber, stone, glass, \&c. (London: James Cottrell, 1661).

Melanchthon, Philip. Compendiaria dialectica ratio, Libri XX (Wittenberg: Melchior Lotther Junior, 1520).

Moore, Jonas. A Mathematical Compendium; or, useful practices in arithmetick, geometry, and astronomy, geography and navigation, embattelling, and quartering of armies, fortification and gunnery, gauging and dialling (London: Printed for Robert Hardford, 1681)

Moxon, Joseph. A Tutor to Astronomy and Geography, or, The Use of The Copernican Spheres (London: Joseph Moxon, 1665). 
Moxon, Joseph. A Tutor to Astronomy and Geography: Or, an Easie and Speedy Way to Know the Use of Both the Globes, Celestial and Terrestrial (London: Joseph Moxon, 1659).

Moxon, Joseph. Mechanick Exercises, or, the Doctrine of Handy-Works. Applied to the Art of Printing. The Second Volumne (London: Joseph Moxon, 1683).

Napier, John. Mirifici logarithmorum canonis descriptio (Edinburgh: Andreae Hart, 1614).

Newton, Isaac. The Chronology of Ancient Kingdoms Amended (London: Printed for J. Tonson, J. Osborn, and T. Longman, 1728).

Norwood, Richard. The Seaman's Practice (London: printed for George Hurlock, 1637).

Oldcastle, Hugh. A Briefe Instruction and Manner how to keepe Books of Accompts (London: John Windet, 1588).

Pell, John. 'An Idea of Mathematics, written by John Pell to Samuel Hartlib', in John Dury, The Reformed Librarie-Keeper, with a Supplement to the Reformed-School (London: William Du-Gard, 1650).

Peurbach, Georg. Theoricae Novae Planetarum (Wittenberg: Joseph Klug, 1535).

Ramus, Peter, Via Regia ad Geometriam, or The Way to Geometry, trans. William Bedwell (London: Printed for Thomas Cotes, 1636).

Ramus, Petrus, ed. Euclides (Paris: Lud. Grandinum, 1545).

Ramus, Petrus. Dialecticae institutiones (Paris: Jacobus Bogardus, 1543).

Ramus, Petrus. The Art of Arithmeticke in Whole Numbers and Fractions, trans. William Kempe (London: Richard Field for Robert Dexter, 1592).

Reading, William. The History of the Ancient and Present State of Sion-College, near Cripplegate, London; and of the London-Clergy's Library there (London: J Roberts, 1724).

Recorde, Robert. The ground of artes teachyng the worke and practise of arithmetike (London: Reynold Wolff, 1552).

Recorde, Robert. The Pathway to Knowledg (London: Reynold Wolfe, 1551).

S(pencer), J(ohn). Catalogus Universalis Librorum omnium in bibliotheca Collegii Sionii apud Londinenses (London: Robert Leybourn, 1650).

Scaliger, Joseph Juste. Opus novum de emendatione temporum in octos libros tributum (Paris: Sébastien Nivelle, 1583). 
Schöner, Lazarus. De Logistice sexagenaria liber, in Ramus, Petrus, Petri Rami Arithmetices Libri duo, et Algebrae totidem (Frankfurt: Andreae Wechelus, 1586).

Seaman, Henry. Kalendarium Nauticum: The Seaman's Almanack for the Year of Christ, 1676 (London: T. N. for the Stationers' Company, 1676).

Seller, John. 'An Answer to some Magnetical Inquiries,' Philosophical Transactions, 26 (1667), pp. 478-479.

Seller, John. The English Pilot (London: John Seller, 1671).

Sennert, Daniel. Templum Mnemosynes (Wittenberg: M. Henkel, 1599).

Sherburne, Edward. The Sphere of Marcus Manilius, made an English poem with annotations and an astronomical appendix (London: Printed for Nathanael Brooke, 1675).

Stadius, Johannes. Ephemerides Joannis stadii leonnouthensis mathematici, secundum antvverpiae longitudinem, ab anno 1554. Usque ad annum 1606. Iam recèns ab auctore auctae: adiecto quoque canone sinuum, vel semissium rectarum, in circulo, subtensarum, eodem auctore (Cologne: haer. Arnold I Birckmann, 1570).

Taubmann, Friedrich, Melodaesia sive Epulum Musaeum (Leipzig: Thomas Schurer, 1597).

The Gunpowder Plot: a collection of correspondence, depositions and papers, in two parts. Public Records Office, SP 14/216.

The Honeyman Collection of Scientific Books and Manuscripts, Parts I-VII, sold in London by Sotheby Parke Bernet \& Co., 30 April 1978 - 20 May 1981.

Torporley, Nathaniel. Diclides Coelometricae seu valvae astronomicae universales (London: Felix Kingston, 1602).

Ward, John. A Compendium of Algebra. Consisting of plain, easie and concise rules for the speedy attaining to that art. Exemplified by various problems, with the solution of their cequations in numbers (London: printed for the author, and sold by him at the Black-Boy Coffee-House in Goodmans-field, 1695).

Whiston, William. Astronomical Principles of Religion, Natural and Reveal'd in Nine Parts (London: John Senex, 1717).

\section{Retrospectively Printed Primary Sources Cited, by Author}

Batho, Gordon R., ed. The Household Papers of Henry Percy, Ninth Earl of Northumberland (1564-1632) (London: Royal Historical Society, 1962).

Beeley, Philip, and Christoph J. Scriba, eds. The Correspondence of John Wallis, 4 vols (Oxford: Oxford University Press, 2003-2014). 
Beeley, Philip, and Christoph J. Scriba, eds. The Correspondence of John Wallis, Volume II (1660-September 1668) (Oxford: Oxford University Press, 2005).

Beeley, Philip, ed., 'The Correspondence of John Collins', in Early Modern Letters Online, Cultures of Knowledge, http://emlo.bodleian.ox.ac.uk/forms/advanced?col cat=Collins $\% 2 \mathrm{C}+\mathrm{John}$

Beery, Janet, and Jacqueline Stedall, eds. Thomas Harriot's Doctrine of Triangular Numbers: the 'Magisteria Magna' (Freiburg: European Mathematical Society Publishing House, 2009).

Bruce, John, ed. Calendar of State Papers Domestic, Charles 1, 1629-31 (London: Her Majesty's Stationery Office, 1860).

Bruce, John, ed. Calendar of State Papers Domestic: Charles I, 1636-7 (London: Her Majesty's Stationery Office, 1867).

Butterfield, Michael. Letter to Martin Lister, 28 December 1699. MS Lister 3, 066068, Bodleian Library, University of Oxford. Image consulted on Early Modern Letters Online, Cultures of Knowledge, tinyurl.com/d4b373y.

Chappell, Edwin, ed. The Tangier Papers of Samuel Pepys (Colchester: Ballantyne Press for the Navy Records Society, 1935).

Cicero, Rhetorica ad Herennium, trans. Harry Caplan (Cambridge, MA: Loeb Classical Library and Harvard University Press, 1954).

Cottingham, John, Robert Stoothoof, Dugald Murdoch and Anthony Kenny, trans., The Philsophical Writings of Descartes, Volume 3: The Correspondence (Cambridge: Cambridge University Press, 1991).

Flamsteed, John and Francis Baily, ed. An Account of the Revd. John Flamsteed, the First Astronomer-Royal: To Which Is Added, his British Catalogue of Stars, Corrected and Enlarged (London: Printed by order of the Lord's Commissioner of the Admiralty, 1835).

Halporn, Barbara C., trans. and ed. The Correspondence of Johann Amerbach: Early Printing in Its Social Context (Ann Arbor: University of Michigan Press, 2000).

Heath, Thomas L., trans. and ed. The Thirteen Books of Euclid's Elements, Volume III, 2nd edn (Cambridge: Cambridge University Press, 1926; reissued in paperback 2014).

Malcolm, Noel, and Jacqueline Stedall. John Pell (1611-1685) and his Correspondence with Sir Charles Cavendish: The Mental World of an Early Modern Mathematician (Oxford: Oxford University Press, 2005).

Melanchthon, Philip, and Kusukawa, Sachiko, ed., Christine F. Salazar, trans. Orations on Philosophy and Education (Cambridge: Cambridge University Press, 1999). 
Regiomontanus and Felix Schmeidler, ed., Opera collectanea (O. Zeller: Osnabruk, 1972).

Rigaud, Stephen Jordan. Correspondence of Scientific Men of the Seventeenth Century, 2 vols (Oxford: Oxford University Press, 1841).

Salusbury, Thomas, and Stillman Drake, ed. Mathematical Collections and Translations, in Two Tomes, 2 vols (Los Angeles: Zeitlin, 1968).

Tannery, Paul, Cornelis de Waard, Bernard Rochot, and René Pintard, eds. Correspondance du P. Marin Mersenne, religieux minime, 17 vols (Paris: Éditions du Centre national de la Recherche Scientifique, 1933-1988).

Thorndike, Lynn. The Sphere of Sacrobosco and its Commentators (Chicago: University of Chicago Press, 1949).

Toomer, G. J., trans. and ed., Ptolemy's Almagest (Princeton, NJ: Princeton University Press, 1998; originally London: Duckworth Press, 1984).

\section{Secondary Works Cited, by Author}

'Torperley, Nathaniel (1608-1632)', Clergy of the Church of England Database, CCEd Person ID 83346, http://db.theclergydatabase.org.uk/jsp/persons/index.jsp . Accessed 22/07/2018.

Abdukhalimov, Bahrom. 'Ahmad Al-Farghani and his Compendium of Astronomy', Journal of Islamic Studies, 10.2 (1999), pp. 142-158.

Adams, Robyn, and Louisiane Ferlier. 'Building a Library Without Walls: The Early Years of the Bodleian Library', in Bautz, Annika, and James Gregory, eds., Libraries, Books, and Collectors of Texts, 1600-1900 (New York: Routledge, 2018), pp. 1-18.

Akkerman, Nadine. Invisible Agents: Women and Espionage in Seventeenth-Century Britain (Oxford: Oxford University Press, 2018).

Alexander, Amir. 'The Skeleton in the Closet: Should Historians of Science Care about the History of Mathematics?', Isis, 102.3 (2011), pp. 475-480.

Allen, Robert C. 'Progress and Poverty in Early Modern Europe', Economic History Review, 56.3 (2003), pp. 403-443.

Alpers, Svetlana. The Art of Describing: Dutch Art in the Seventeenth Century (Chicago: University of Chicago Press, 1983).

Ariew, Roger, and Peter Barker. 'Duhem and Continuity in the History of Science', Revue internationalle de philosophie, 46.182 (1992), pp. 323-343. 
Armstrong, Gudya. 'Print, Paratext and a Seventeenth Century Sammelband: Boccaccio's Ninfale Fiesolano in English Translation', in Barker, Sara K. and Brenda M. Hosington, eds., Renaissance Cultural Crossroads: Translation, Print and Culture in Britain, 1473-1640 (Leiden and Boston: Brill, 2013), pp. 79-99.

Arnold, Ken, and Thomas Söderqvist. 'Medical Instruments in Museums: Immediate Impressions and Historical Meanings', Isis, 102.4 (2011), pp. 718-729.

Ash, Eric H. 'Navigation Techniques and Practices in the Renaissance', in Woodward, David, ed., The History of Cartography, Volume Three: Cartography in the European Renaissance, Part 1 (Chicago: University of Chicago Press, 2007), pp. 509-527.

Ash, Eric H. Knowledge, Power and Expertise in Elizabethan England (Baltimore and London: The Johns Hopkins University Press, 2004).

Attar, Karen, ed., Directory of Rare Book and Special Collections in the UK and Republic of Ireland, $3^{\text {rd }}$ edn (London: Facet Publishing and CILIP Rare Books and Special Collections Group, 2016).

Austin, Kenneth. From Judaism to Calvinism. The Life and Writings of Immanuel Tremellius (Aldershot: Ashgate, 2007).

Axtell, James. Wisdom's Workshop: The Rise of the Modern University (Princeton: Princeton University Press, 2016).

Baigrie, Brian S., ed., Picturing Knowledge: Historical and Philosophical Problems Concerning the Use of Art in Science (Toronto: University of Toronto Press, 1996).

Bakewell, K. G. B. 'Bradford, S. C.', in Wedgeworth, Robert, ed. World Encyclopedia of Library and Information Services, $3^{\text {rd }}$ edn (Chicago: American Library Association, 1993), p. 142.

Baldasso, Renzo. 'The Role of Visual Representation in the Scientific Revolution: A Historiographic Inquiry', Centaurus, 48 (2006), pp. 69-88.

Banks, David. 'Starting Science in the Vernacular. Notes on Some Early Issues of the Philosophical Transactions and the Journal des Scavans, 1665-1700', ASp, la revue du GERAS, 55 (2009), pp. 5-22.

Baron, Sabrina Alcorn. 'The Guises of Dissemination in Early Seventeenth-Century England', in Dooley, Brendan and Sabrina A. Baron, eds., The Politics of Information in Early Modern Europe (London and New York: Routledge, 2001), pp. 41-56.

Baten, Joerg, and Jan Luiten van Zanden. 'Book Production and the Onset of Modern Economic Growth', Journal of Economic Growth, 13.3 (2008), pp. 217-235.

Batho, Gordon R. 'Thomas Harriot's Manuscripts', in Fox, Robert, ed., Thomas Harriot: An Elizabethan Man of Science (Aldershot: Ashgate, 2000) pp. 286-297. 
Beal, Peter. A Dictionary of English Manuscript Terminology, 1450-2000 (Oxford: Oxford University Press, 2008).

Becker, Howard Saul. Art Worlds (Berkeley, Los Angeles, and London: University of California Press, 1982).

Bell, E. T. Men of Mathematics: The Lives and Achievements of the Great Mathematicians from Zeno to Poincaré, 2 vols. (London: Penguin, 1953; first published 1937)

Benjamin, Walter. 'Unpacking my Library: A Talk about Book Collecting', in Arendt, Hannah, ed., Illuminations (London: Pimlico, 1999), pp. 61-69.

Bennett, J. A. 'Cosmography and the Meaning of Sundials', in Biagioli, Mario, and Jessica Riskin, eds., Nature Engaged: Science in Practice from the Renaissance to the Present (New York: Palgrave Macmillan, 2012), pp. 249-262.

Bennett, J. A. 'Early Modern Mathematical Instruments', Isis, 102.4 (2011), pp. $697-$ 705 .

Bennett, J. A. 'Geometry in Context in the Sixteenth Century: The View from the Museum', Early Science and Medicine, 7 (2002), pp. 214-230.

Bennett, J. A. 'Knowing and Doing in the Sixteenth Century: What were Instruments for?', British Journal for the History of Science, 36.2 (2003), pp. 129-150.

Bennett, J. A. 'Museums and the Establishment of the History of Science at Oxford and Cambridge', British Journal for the History of Science, 30.1 (1997), pp. 29-46.

Bennett, J. A. 'The Challenge of Practical Mathematics', in Pumfrey, Stephen, Paolo L. Rossi, and Maurice Slawinski, eds., Science, Culture and Popular Belief in Renaissance Europe (Manchester and New York: Manchester University Press, 1991), pp. 176-190

Bennett, J. A. 'The Mechanics' Philosophy and the Mechanical Philosophy', History of Science, 24.1 (1986), pp. 1-28.

Bennett, J. A. The Divided Circle: A History of Instruments for Astronomy, Navigation and Surveying (Oxford: Phaidon and Christie's, 1987).

Berland, Kevin Joel, Jan Kirsten Gillam, and Kenneth A. Lockridge, eds., The Commonplace Book of William Byrd II of Westover (Chapel Hill: Omohundro Institute of Early American History and Culture by the University of North Carolina Press, 2001).

Biagioli, Mario. 'From Print to Patents: Living on Instruments in Early Modern Europe', History of Science, 44 (2006), pp. 138-186.

Biagioli, Mario. 'The Social Status of Italian Mathematicians, 1450-1600', History of Science, 27 (1989), pp. 41-95. 
Biagioli, Mario. Galileo, Courtier: The Practice of Science in the Culture of Absolutism (Chicago: University of Chicago Press, 1993).

Biagioli, Mario. Galileo's Instruments of Credit: Telescopes, Images, Secrecy (Chicago: University of Chicago Press, 2006).

Bird, Alexander. 'Kuhn, Naturalism, and the Social Study of Science', in Kindi, Vasso, and Theodore Arabatzis, eds., Kuhn's The Structure of Scientific Revolutions Revisited (New York: Routledge, 2012), pp. 205-230.

Birrell, T. A. 'Reading as Pastime: The Place of Light Literature in some Gentleman's Libraries of the Seventeenth-Century', in Myers, Robin, and Michael Harris, eds., The Property of a Gentleman: The Formation, Organisation and Dispersal of the Private Library, 1620-1920 (Winchester: St Paul's Bibliographies, 1991), pp. 113-131.

Blair, Ann. 'Errata Lists and the Reader as Corrector', in Baron, Sabrina Alcorn, Eric N. Lindquist, and Eleanor F. Shevlin, eds., Agent of Change: Print Culture Studies after Elizabeth L. Eisenstein (Amherst and Boston: University of Massachusetts Press, 2007), pp. 21-41.

Blair, Ann. 'Humanist Methods in Natural Philosophy: The Commonplace Book', Journal of the History of Ideas, 53.4 (1992), pp. 541-551.

Blair, Ann. 'Natural Philosophy', in Park, Katharine, and Lorraine Daston, eds., The Cambridge History of Science, Volume 3: Early Modern Science (Cambridge: Cambridge University Press, 2006) pp. 365-405.

Blair, Ann. 'Reading Strategies for Coping with Information Overload, ca. 15501700', Journal of the History of Ideas, 64.1 (2003), pp. 11-28.

Blair, Ann. 'The Rise of Note-Taking in Early Modern Europe', Intellectual History Review, 20.3 (2010), pp. 303-16.

Blair, Ann. Too Much to Know: Managing Scholarly Information before the Modern Age (New Haven and London: Yale University Press, 2010).

Bland, Mark B. 'John Windet and the Transformation of the Book Trade, 15841610', Papers of the Bibliographical Society of America, 102.2 (2013), pp. 151-192.

Bland, Mark B. 'The Appearance of the Text in Early Modern England', Text, 11 (1998), pp. 91-154.

Bland, Mark B. 'The London Book Trade in 1600', in Kastan, David Scott, ed., $A$ Companion to Shakespeare (Oxford; Blackwell, 1999), pp. 450-463.

Blome, Astrid. 'Offices of Intelligence and Expanding Social Spaces', in Dooley, Brendan, ed., The Dissemination of News and the Emergence of Contemporaneity in Early Modern Europe (Farnham: Ashgate, 2010), pp. 207-222. 
Boffey, Julia. Manuscript and Print in London c. 1475-1530 (London: British Library, 2012).

Bono, James J. The Word of God and the Languages of Man. Interpreting Nature in Early Modern Science and Medicine. Volume 1: Ficino to Descartes (Madison, WI: University of Wisconsin Press, 1995).

Borkenau, Franz. Der Übergang vom feudalen zum bürgerlichen Weltbild: Studien zur Geschichte der Philosophie der Manufakturperiode (Paris: F. Alcan, 1934).

Boucekkine, Raouf, David de la Croix and Dominique Peeters. 'Early Literacy Achievements, Population Density, and the Transition to Modern Growth', Journal of the European Economic Association, 5.1 (2007), pp. 183-226.

Boucekkine, Raouf, David de la Croix and Omar Licandro. 'Early Mortality Rates at the Dawn of Modern Growth', The Scandinavian Journal of Economics, 105.3 (2003), pp. 401-418.

Bradford, Samuel Clement. Documentation (London: Crosby Lockwood, 1948).

Braswell-Means, Laurel. 'The Vulnerability of Volvelles in Manuscript Codices', Manuscripta, 35 (1991), pp. 43-54.

Bregman, Alvan. 'Alligation Alternate and the Composition of Medicines: Arithmetic and Medicine in Early Modern England', Medical History, 49.3 (2005), pp. 299-320.

Brewer, John, and Roy Porter, eds., Consumption and the World of Goods (London: Routledge, 1993).

Brockliss, Laurence. 'Curricula', in de Ridder-Symoens, Hilde, ed., A History of the University in Europe, Volume 2: Universities in Early Modern Europe (1500-1800) (Cambridge: Cambridge University Press, 1996), pp. 563-620

Brown, Gary I. 'The Evolution of the Term 'Mixed Mathematics', Journal of the History of Ideas, 52 (1991), pp. 81-102.

Brown, Michelle P. A Guide to Western Historical Scripts from Antiquity to 1600 (London: The British Library, 1990).

Bryden, D. J. 'Evidence from Advertising for Mathematical Instrument Making in London, 1556-1714', Annals of Science, 49 (1992), pp. 301-336.

Bryden, D. J. Scottish Scientific Instrument Makers (Edinburgh: Royal Scottish Museum, 1972).

Buchwald, Jed Z., and Mordechai Feingold, Newton and the Origin of Civilization (Princeton, NJ: Princeton University Press, 2013). 
Bud, Robert. 'Collecting for the Science Museum: Constructing the Collections, the Culture and the Institution', in Morris, Peter J. T., ed., Science for the Nation: Perspectives on the History of the Science Museum. Houndmills: Palgrave MacMillan, 2010), pp. 250-272.

Bud, Robert. 'History of Science and the Science Museum', British Journal for the History of Science, 30 (1997), pp. 47-50.

Buonanno, Roberto. The Stars of Galileo Galilei and the Universal Knowledge of Athanasius Kircher, trans. Roberto Buonnano, and Giuliana Giobbi (Cham: Springer, 2014).

Buringh, Eltjo, and Jan Luiten van Zanden. 'Charting the "Rise of the West". Manuscripts and Printed Books in Europe, A Long-Term Perspective from the Sixth through Eighteenth Centuries', Journal of Economic History, 69.2 (2009), pp. 409445 .

Burke, Peter. 'The Renaissance Translator as Go-Between', in Höfele, Andreas, and Werner von Koppenfels, eds., Renaissance Go-Betweens: Cultural Exchange in Early Modern Europe (Berlin and New York: Walter de Gruyter, 2005), pp. 17-31.

Burke, Peter. Languages and Communities in Early Modern Europe (Cambridge: Cambridge University Press, 2004).

Burke, Peter. The Historical Anthropology of Early Modern Italy: Essays on Perception and Communication (Cambridge: Cambridge University Press, 1987).

Butterfield, Herbert. The Origins of Modern Science 1300-1800, revised edn (New York: The Free Press, 1997; first published London: Bell, 1950; new edition first published London, G. Bell and Sons, 1957).

Büttner, Jochen, Peter Damerow, Jürgen Renn and Matthias Schemmel. 'The Challenging Images of Artillery: Practical Knowledge and the Roots of the Scientific Revolution', in Lefèvre, Wolfgang, Jürgen Renn, and Urs Schoepflin, The Power of Images in Early Modern Science (Basel: Birkhäuser, 2003), pp. 3-27.

Byrne, James Steven. 'A Humanist History of Mathematics? Regiomontanus's Padua Oration in Context', Journal of the History of Ideas, 67 (2006), pp. 41-61.

Cajori, Florian. A History of Mathematical Notations, Two Volumes Bound as One (New York: Dover Publications, 1993; originally Chicago: Open Court, 1928-1929).

Cantor, Moritz. Vorlesungen über Geschichte der Mathematik, 4 vols. (Leipzig: B. G. Teubner, 1894-1908).

Capozzi, Mirella, and Gino Roncaglia. 'Logic and Philosophy of Logic from Humanism to Kant', in Haaparanta, Leila, ed., The Development of Modern Logic (Oxford: Oxford University Press, 2009), pp. 78-158. 
Capp, Bernard. Astrology and the Popular Press: English Almanacs 1500-1800 (London: Faber, 1979).

Carter, Harry, and H. D. L. Vervliet. Civilité Types (Oxford: Oxford University Press, 1966).

Cartwright, Kent. Theatre and Humanism: English Drama in the Sixteenth Century (Cambridge: Cambridge University Press, 2004).

Caspar, Max. Kepler, trans. and ed. C. Doris Hellman, (New York: Dover Publications, 1993; originally London and New York: Abelard-Schulman, 1959).

Chabás, José, and Bernard R. Goldstein. A Survey of European Astronomical Tables in the Late Middle Ages (Leiden and Boston: Brill, 2012).

Chartier, Roger and Guglielmo Cavallo, eds., History of Reading in the West (Amherst: University of Massachusetts Press, 1999).

Childs, David. The Warship Mary Rose: The Life and Times of King Henry VII's Flagship (London: Chatham Publishing, 2007).

Cifoletti, Giovanna C. 'From Valla to Viète: The Rhetorical Reform of Logic and its Use in Early Modern Algebra', Early Science and Medicine, 11.4 (2006), pp. 390423.

Cifoletti. Giovanna C. 'Mathematics and Rhetoric: Introduction', Early Science and Medicine, 11.4 (2006), pp. 369-389.

Clark, Andrew, ed., Register of the University of Oxford, Volume 2 (1571-1622), Part 2: Matriculations and Subscriptions (Oxford: Printed for the Oxford Historical Society, 1887).

Clark, J. W. Libraries in the Medieval and Renaissance Periods (Cambridge: Macmillan and Bowes, 1894).

Clark, John F. M. 'Intellectual History and the History of Science' in Whatmore, Richard, and Brian Young, eds., A Companion to Intellectual History (Chichester: John Wiley and Sons, 2016), pp. 155-169.

Clegg, Arthur. 'Craftsmen and the Origin of Science', Science and Society, 43 (1979), pp. 186-201.

Clifford, James. 'On Collecting Art and Culture', in Mirzoeff, Nicholas, ed., The Visual Culture Reader (New York: Routledge 1998), pp. 94-107.

Clifton, Gloria C. Directory of British Scientific Instrument Makers, 1550-1851 (London: Zwemmer in association with the National Maritime Museum, 1995). 
Clucas, Stephen. 'Thomas Harriot and the Field of Knowledge in the English Renaissance', in Fox, Robert, ed., Thomas Harriot: An Elizabethan Man of Science (Aldershot: Ashgate, 2000), pp. 93-136

Cobb, Harold M., ed., Dictionary of Metals (Ohio: ASM International, 2012).

Cohen, H. Floris. 'The Mathematization of Nature': The Making of a Concept, and How it has Fared in Later Years', in Remmert, Volker R., Martina R. Schneider, and Henrik Kragh Sørensen, eds., Historiography of Mathematics in the 19th and 20th Centuries (Cham: Birkhäuser, Springer International Publishing, 2016), pp. 143-160.

Cohen, H. Floris. The Scientific Revolution: A Historiographical Inquiry (Chicago and London: University of Chicago Press, 1994).

Cohen, I. Bernard. Revolution in Science (Cambridge, MA, and London: The Belknap Press of Harvard University Press, 1985).

Cohen, I. Bernard. The Newtonian Revolution: With Illustrations of the Transformation of Scientific Ideas (Cambridge: Cambridge University Press, 1980).

Comte, Auguste. The Positive Philosophy of Auguste Comte, trans. and ed. Harriet Martineau, (Kitchener: Batoche Books, 2000; originally New York: Calvin Blanchard, 1855; originally published in French as Auguste Comte, Cours de philosophie positive, 6 vols. Paris: Bachelier, 1830-1842).

Conley, Thomas M. Rhetoric in the European Tradition, $2^{\text {nd }}$ edn (Chicago and London: University of Chicago Press, 1994).

Cook, H. J. Matters of Exchange: Commerce, Medicine, and Science in the Dutch Golden Age (New Haven and London: Yale University Press, 2008).

Copenhaver, Brian P. 'Did Science have a Renaissance?', Isis, 83.3 (1992), pp. 387407.

Cormack, Lesley B. 'Glob(al) Visions', in Wilson, Bronwen, and Paul Yachnin, eds., Making Publics in Early Modern Europe: People, Things, Forms of Knowledge (Abingdon and New York: Routledge, 2010), pp. 138-156.

Cormack, Lesley B. 'Handiwork and Brainwork: Beyond the Zilsel Thesis', in Cormack, Lesley B., Stephen A. Walton, and John A. Schuster, eds., Mathematical Practitioners and the Transformation of Natural Knowledge in Early Modern Europe (Cham: Springer, 2017), pp. 11-37

Cormack, Lesley B. 'Introduction: Practical Mathematics, Practical Mathematicians, and the Case for Transforming the Study of Nature', in Cormack, Lesley B., Steven A. Walton and John A. Schuster, eds., Mathematical Practitioners and the Transformation of Natural Knowledge in Early Modern Europe (Cham: Springer, 2017), pp. 1-8. 
Cormack, Lesley B. Charting an Empire: Geography at the English Universities 1580-1620. (Chicago: University of Chicago Press, 1997).

Cowen Orlin, Lena. 'Fictions of the Early Modern Probate Inventory', in Turner, Henry S., ed., The Culture of Capital: Property, Cities, and Knowledge in Early Modern England (New York and London: Routledge, 2002), pp. 51-84

Crane, Mary Thomas. Framing Authority: Sayings, Self, and Society in SixteenthCentury England (Princeton, NJ: Princeton University Press, 1993).

Cressy, David. Literacy and the Social Order: Reading and Writing in Tudor and Stuart England (Cambridge: Cambridge University Press, 1980).

Crombie, A. C. 'Science and the Arts in the Renaissance: The Search for Truth and Certainty, Old and New', History of Science, 18 (1980), pp. 233-46.

Crombie, A. C. Augustine to Galileo: The History of Science, A.D. 400-1650 (London: Falcon Press, 1952).

Crombie, A. C. Medieval and Early Modern Science, 2 vols, revised 2nd edn (Garden City, New York: Doubelday, 1959).

Crosby, Alfred W. The Measure of Reality: Quantification and Western Society, 1250-1600 (Cambridge: Cambridge University Press, 1997).

Crowther, Kathleen M., and Peter Barker. 'Training the Intelligent Eye: Understanding Illustrations in Early Modern Astronomy Texts, Isis, 104.3 (2013), pp. 429-470.

Crowther, Kathleen, Ashley Nicole McCray, Leila McNeill, Amy Rodgers, and Blair Stein. 'The Book Everybody Read: Vernacular Translations of Sacrobosco's Sphere in the Sixteenth Century', Journal for the History of Astronomy, 46 (2015), pp. 4-28.

Cummings, Robert. 'Versifying Philosophy: Thomas Blundeville's Plutarch', in Barker, S. K., and Brenda M. Hosington, Renaissance Cultural Crossroads: Translation, Print and Culture in Britain, 1473-1650 (Leiden and Boston: Brill, 2013), pp. 101-120.

Cunningham, Andrew and Perry Williams. 'De-Centring the 'Big Picture': "The Origins of Science" and the Modern Origins of Science', The British Journal for the History of Science, 26.4 (1993), pp. 407-432.

Dackerman, Susan. Prints and the Pursuit of Knowledge in Early Modern Europe (Cambridge MA: Harvard University Art Museums, 2011).

DaCosta Kaufmann, Thomas. 'Remarks on the Collections of Rudolf II: The Kunstkammer as a Form of Representatio', Art Journal, 38 (1978), pp. 22-28.

Dane, Joseph A. The Myth of Print Culture (Toronto: University of Toronto Press, 2007). 
Daston, Lorraine, and Katherine Park. Wonders and the Order of Nature (New York: Zone Books, 1998).

Davis, John, and Christopher Daniel. 'John Seller: Instrument Maker and Plagiarist', Bulletin of the Scientific Instrument Society, 102 (2009), pp. 6-10.

de Bellis, Nicola. Bibliometrics and Citation Analysis. From the Science Citation Index to Cybermetrics (Lanham, MD, Toronto, and Plymouth: The Scarecrow Press, 2009).

de Ceglia, Francesco Paolo. 'Additio illa non videtur edenda: Giuseppe Biancani, Reader of Galileo in an Unedited Censored Text', in Feingold, Mordechai, ed., The New Science and Jesuit Science: Seventeenth Century Perspectives (Dordrecht: Kluwer Academic Publications, 2003), pp. 159-186.

de Morgan, Augustus. 'On the First Introduction of the Words Tangent and Secant', in Brewster, David, Richard Taylor, Richard Phillips, and Robert Kane, eds., The London, Edinburgh, and Dublin Philosophical Magazine and Journal of Science, Volume 28, January - June 1846 (London: Richard and John E. Taylor for the University of London, 1846), pp. 382-387

de Morgan, Augustus. 'On the Invention of the Circular Parts', in Brewster, David, Richard Taylor, Richard Phillips, and Robert Kane, eds., The London, Edinburgh, and Dublin Philosophical Magazine and Journal of Science, Volume 22, January June 1843 (London: Richard and John E. Taylor for the University of London, 1843), pp. 350-353.

de Morgan, Augustus. Arithmetical Books from the Invention of Printing to the Present Time (London: Taylor and Walton, 1847).

de Renzi, Silvia. Instruments in Print: Books from the Whipple Collection (Cambridge: Whipple Museum for the History of Science, 2000).

de Risi, Vincenzo. 'The development of Euclidean axiomatics. The systems of principles and the foundations of mathematics in editions of the Elements in the Early Modern Age', Archive for History of Exact Sciences, 70.6 (2016), pp. 591676.

de Solla Price, Derek J. 'Book Review: Astronomicum Caesarum, The Book as a Scientific Instrument', Science, 158.3797 (1967), pp. 102-104.

de Solla Price, Derek J. The Equatorie of the Planetis (Cambridge: Cambridge University Press, 1955).

de Vivo, Filipo. Information and Communication in Venice: Rethinking Early Modern Politics (Oxford: Oxford University Press, 2007).

de Vries, Jan. The First Modern Economy: Success, Failure, and Perseverance of the Dutch Economy, 1500-1815 (Cambridge: Cambridge University Press, 1997). 
de Wreede, Liesbeth C. 'A dialogue on the use of arithmetic in geometry: Van Ceulen's and Snellius's Fundamenta Artihmetica et Geometrica', Historia Mathematica, 37 (2010), pp. 376-402.

Dear, Peter. 'The Church and the New Philosophy', in Pumfrey, Stephen, Paolo L. Rossi and Maurice Slawinski, eds., Science, Culture and Popular Belief in Renaissance Europe (Manchester and New York: Manchester University Press, 1991), pp. 119-139.

Dear, Peter. 'The History of Science and the History of the Sciences: George Sarton, Isis, and the Two Cultures', Isis, 100.1 (2009), pp. 89-93.

Dear, Peter. Discipline and Experience: The Mathematical Way in the Scientific Revolution (Chicago: University of Chicago Press, 1995).

Dear, Peter. Revolutionizing the Sciences: European Knowledge and its Ambitions, 1500-1700 (Houndmills: Palgrave Macmillan, 2001).

Dekker, Elly. 'The Doctrine of the Sphere: A Forgotten Chapter in the History of Globes', Globe Studies, 49 (2002), pp. 25-44.

Dekker, Elly. Illustrating the Phaenomena: Celestial Cartography in Antiquity and the Middle Ages (Oxford: Oxford University Press, 2013).

Derrida, Jacques. 'Archive Fever: A Freudian Impression', trans. Eric Prenowitz, Diacritics, 25.2 (1995), pp. 9-63.

Dew, Nicholas. 'A Gymnosophist at Versailles: The Geography of Knowledge in the Iconography of Louis XIV', in Rubiés, Joan Pau, Melissa Calaresu, and Filippo de Vivo, eds., Exploring Cultural History: Essays in Honour of Peter Burke (Farnham: Ashgate, 2010), pp. 249-264.

Dick, Hugh G. 'Thomas Blundeville's The True Order and Methode of Writing and Reading Hystories (1574)', Huntington Library Quarterly, 3.2 (1940), pp. 149-170.

Diehl, Edith. Bookbinding: Its Background and Technique, Volume 1 (New York: Dover, 1980; originally New York: Rinehart and Co., 1946).

DiMeo, Michelle. 'Openness vs. Secrecy in the Hartlib Circle: Revisiting 'Democratic Baconianism' in Interregnum England', in Leong, Elaine, and Alisha Rankin, eds., Secrets and Knowledge in Science and Medicine (Farnham: Ashgate, 2011), pp. 105-124.

Dobre, Minhea. 'Rohault's Cartesian Physics', in Dobre, Mihnea, and Tammy Nyden, eds., Cartesian Empiricisms (Dordrecht: Springer Science + Business Media, 2013), pp. 203-226.

Doppelmayr, Johann Gabriel. Historische Nachricht von den Nurnbergischen Mathematicis und Künstlern (Nuremberg: Peter Conrad Monaths, 1730). 
Duhamel, Pierre Albert. 'The Logic and Rhetoric of Peter Ramus', Modern Philology, 46.3 (1949), pp. 163-171.

Duhem, Pierre. 'Research on the History of Physical Theories', in Ariew, Roger, and Peter Barker, trans. and eds. Essays in the History and Philosophy of Science (Indianapolis : Hackett Publishing Company, 1996; originally published in French as part of Duhem, Pierre, Le système du monde, histoire des doctrines cosmologiques de Platon à Copernic, 10 vols (Paris: Hermann, 1913-1959).

Duhem, Pierre. To Save the Phenomena: An Essay on the Idea of Physical Theory from Plato to Galileo, trans. Edmund Dolan and Chaninah Masler (Chicago: University of Chicago Press, 1969).

Duncan, Carol. Civilizing Rituals: Inside Public Art Museums (London: Routledge, 1995).

Dupré, Sven. 'Trading Luxury Glass, Picturing Collections and Consuming Knowledge in Early Seventeenth-Century Antwerp', in Dupré, Sven, and Christoph Lüthy, eds., Silent Messengers: The Circulation of Material Objects of Knowledge in the Early Modern Low Countries (Berlin: Lit Verlag, 2011), pp. 261-292.

Eagleton, Catherine. 'Oronce Fine's Sundials: The Sources and Influences of De solaribus horologiis', in Marr, Alexander, ed., The Worlds of Oronce Fine: Mathematics, Instruments and Print in Renaissance France (Donnington: Shaun Tyas, 2009), pp. 83-99.

Eagleton, Catherine. Monks, Manuscripts and Sundials: The Navicula in Medieval England (Leiden and Boston: Brill, 2010).

Eamon, William. Science and the Secrets of Nature: Books of Secrets in Medieval and Early Modern Culture (Princeton, NJ: Princeton University Press, 1994).

Edgerton, Samuel Y. The Renaissance Rediscovery of Linear Perspective (New York: Basic, 1975).

Edmondston, Elizabeth. 'Unfamiliar Libraries IX: Sion College', The Book Collector, 14.2 (1965), pp. 165-177.

Edwards, Harold M. Fermat's Last Theorem: A Genetic Approach to Algebraic Number Theory (New York, Berlin, Heidelberg: Springer-Verlag, 1977).

Eisenstein, Elizabeth L. The Printing Press as Agent of Change: Communications and Cultural Transformations in Early Modern Europe, 2 vols (Cambridge: Cambridge University Press, 1979).

Elings, Mary W., and Eva Garcelon, 'The Robert Honeyman Jr. Collection Digital Archive: EAD and the Use of Library and Museum Descriptive Standards', Archives and Museum Informatics, 12 (1998), pp. 205-219. 
Evans, R. J. W. Rudolf II and his World: A Study in Intellectual History, 1576-1612 (Oxford: Oxford University Press, 1973);

Evenden, Elizabeth. 'The Fleeing Dutchmen? The Influence of Dutch Immigrants upon the Print Shop of John Day', in Loades, David Michael, ed., John Foxe at Home and Abroad (Bodmin: MPG Books, 2004), pp. 63-78.

Evenden, Elizabeth. Patents, Pictures and Patronage: John Day and the Tudor Book Trade (Aldershot: Ashgate, 2008).

Falk, Seb. 'The Scholar as Craftsman: Derek DeSolla Price and the Reconstruction of a Medieval Instrument', Notes and Records of the Royal Society, 68 (2014), pp. 111-134.

Febvre, Lucien and Henri-Jean Martin. The Coming of the Book: The Impact of Printing, 1450-1800 (London: Verso, 1976; first published as L'Apparition du Livre, Paris: Editions Albin Michel, 1958).

Feingold, Mordechai. 'The Ultimate Pedagogue: Franco Petri Burgersdijk and the English Speaking Academic Learning', in Bos, E. P., and H. A. Krop, eds., Franco Burgersdijk (1590-1635): Neo-Aristotelianism in Leiden (Amsterdam and Atlanta, GA: Rodopi, 1993), 151- 166.

Feingold, Mordechai. The Mathematician's Apprenticeship: Science, Universities and Society in England, 1560-1640 (Cambridge: Cambridge University Press, 1984).

Feisenberger, H. A. 'The Honeyman Sales', The Book Collector, 4 (1981), pp. 491496.

Feisenberger, H. A. 'The Libraries of Newton, Hooke and Boyle', Notes and Records of the Royal Society of London, 21.1 (1966), pp. 42-55.

Field, J. V. 'What is Scientific about a Scientific Instrument?', Nuncius, 3.2 (1988), pp. 3-26.

Findlen, Paula. Possessing Nature: Museums, Collecting, and Scientific Culture in Early Modern Italy (Berkeley, Los Angeles, and London: University of California Press, 1994).

Fleischer, Manfred P. 'The Success of Ursinus: A Triumph of Intellectual Friendship', in Visser, Derek J., ed., Controversy and Conciliation: The Reformation and the Palatinate, 1559-1583 (Allison Park, PA: Pickwick Publications, 1986), pp. 101-116.

Folkerts, Menso, Christoph J. Scriba, and Hans Wussing. 'Germany' in Dauben, Joseph W., and Christoph J. Scriba, eds., Writing the History of Mathematics: Its Historical Development (Basel, Boston and Berlin: Birkhäuser Verlag, 2002), pp. 109-150. 
Follett, David. The Rise of the Science Museum under Henry Lyons (London: Science Museum, 1978).

Foster, Joseph, ed., Alumni Oxonienses; the Members of the University of Oxford, 1500-1714. Volume II: Early Series (Oxford: James Parker \& Company, 1891).

Fox, Adam. Oral and Literate Culture in England, 1500-1700 (Oxford: Clarendon Press, 2000).

Frängsmyr, Tore. 'Sarton and Nordstrom', Isis, 75.1 (1984), pp. 49-55.

Fransen, Sietske. 'Latin in a Time of Change: The Choice of Language as Signifier of a New Science?', Isis, 108.3 (2017), pp. 629-635.

Freedman, Joseph S. 'Philosophy Instruction within the Institutional Framework of Central European Schools and Universities during the Reformation Era', History of Universities, 5 (1985), pp. 117-166.

Freedman, Joseph S. 'The Diffusion of the Writings of Petrus Ramus in Central Europe, c.1570 - c.1630', Renaissance Quarterly, 46.1 (1993), pp. 98-152.

Fried, Michael N. 'The Discipline of History and the "Modern Consensus in the Historiography of Mathematics", Journal of Humanistic Mathematics, 4.2 (2014), pp. 124-136.

Fritze, R. H. “"Truth Hath Lacked Wtinesse, Tyme Wanted Light”: The Dispersal of the English Monastic Libraries and Protestant Attempts at Preservation, ca. 15351625', Journal of Library History, 18 (1983), pp. 274-291.

Fucíková, Eliska. 'The Collection of Rudolf II at Prague: Cabinet of Curiosities or Scientific Museum?', in Impey, Oliver, and Arthur McGregor, eds., The Origins of Museums: The Cabinet of Curiosities in Sixteenth-and Seventeenth-century Europe (Oxford: Clarendon Press, 1985), pp. 51-61.

Gaida, Margaret. 'Reading Cosmographia: Peter Apian's Book-Instrument Hybrid and the Rise of the Mathematical Amateur in the Sixteenth Century', Early Science and Medicine, 21 (2016), pp. 277-302.

Galison, Peter. 'Trading with the Enemy', in Gorman, Michelle E., ed., Trading Zones and Interactional Expertise: Creating New Kinds of Collaboration (Cambridge, MA: Massachusetts Institute of Technology Press, 2010).

Galison, Peter. Image and Logic: A Material Culture of Microphysics (Chicago: University of Chicago Press, 1997).

Gascoigne, John. Cambridge in the Age of the Enlightenment: Science, Religion and Politics from the Restoration to the French Revolution (Cambridge: Cambridge University Press, 1988). 
Gaskell, Roger. 'Printing House and Engraving Shop. A Mysterious Collaboration', The Book Collector, 53 (2004), pp. 213-251.

Gaukroger, Stephen. The Collapse of Mechanism and the Rise of Sensibility: Science and the Shaping of Modernity, 1680-1760 (Oxford: Oxford University Press, 2010).

Genette, Gérard. Paratexts: Thresholds of Interpretation, trans. Jane E. Lewin (Cambridge: Cambridge University Press, 1997; originally published in French as Seuils, Paris: Editions de Seuils, 1987).

Gingerich, Owen. 'A Tusi Couple from Schoener's De Revolutionibus?', Journal for the History of Astronomy, 15 (1984), pp. 128-133.

Gingerich, Owen. 'Astronomical Paper Instruments with Moving Parts', in Anderson, R. G. W., J. A. Bennett, and W. F. Ryan, eds., Making Instruments Count. Essays on Historical Scientific Instruments presented to Gerard L'Estrange Turner (Aldershot: Variorum, Ashgate Publishing Ltd, 1993), pp. 63-74.

Gingerich, Owen. 'Five Centuries of Astronomical Textbooks and their Role in Teaching', in Pasachoff, Jay M., and John R. Percy, eds., The Teaching of Astronomy: Proceedings of the 105th International Astronomical Union (IAU) Colloquium, held in Williamstown, Massachusetts, July 26-30, 1988 (Cambridge: Cambridge University Press, 1990), pp. 192-195.

Gingerich, Owen. 'From Copernicus to Kepler: Heliocentrism as Model and as Reality', Proceedings of the American Philosophical Society, Symposium on Copernicus, 117.6 (1973), pp. 513-522.

Gingerich, Owen. The Book Nobody Read (New York: Walker, 2004).

Gispert, Hélène. 'The German and French Editions of the Klein-Molk Encyclopedia: Contrasted Images' in Bottazzini, Umberto, and Amy Dahan Dalmedico, eds., Changing Images in Mathematics: From the French Revolution to the New Millennium (London: Routledge, 2001), pp. 93-112.

Glaisyer, Natasha. 'Calculating Credibility: Print Culture, Trust and Economic Figures in Early Eighteenth-Century England', The Economic History Review, New Series, 60. 4 (2007), pp. 685-711.

Glaisyer, Natasha. The Culture of Commerce in England, 1660-1720 (Woodbridge: The Royal Historical Society and The Boydell Press, 2006).

Goeing, Anja-Silvia. Storing, Archiving, Organizing: The Changing Dynamics of Scholarly Information Management in Post-Reformation Zurich (Leiden: Brill, 2017).

Goldgar, Anne. Impolite Learning: Conduct and Community in the Republic of Letters, 1680-1750 (New Haven, CT: Yale University Press, 1995). 
Goldthwaite, Richard A. 'The Empire of Things: Consumer Demand in Renaissance Italy', in Kent, F. W., and Patricia Simons, eds., with J. C. Eade, Patronage, Art, and Society in Renaissance Italy (Oxford: Clarendon Press, 1987), pp. 153-175.

Goldthwaite, Richard A. Wealth and the Demand for Art in Italy, 1300-1600 (Baltimore: The Johns Hopkins University Press, 1993).

Golinski, Jan. Making Natural Knowledge: Constructivism and the History of Science, 2nd edn (Chicago and London: University of Chicago Press, 2005; first published Cambridge: Cambridge Univeristy Press, 1998).

Gonzalez-Velasco, Enrique A. Journey through Mathematics: Creative Episodes in Its History (New York: Springer Science + Business Media, 2011).

Goodman, David C. Power and Penury: Government, Technology and Science in Philip II's Spain (Cambridge: Cambridge University Press, 1988).

Gorham, Geoffrey, Benjamin Hill, and Edward Slowik. 'Introduction', in Gorham, Geoffrey, Benjamin Hill, Edward Slowik, and C. Kenneth Waters, eds., The Language of Nature: Reassessing the Mathematization of Natural Philosophy in the Seventeenth Century (Minneapolis: University of Minnesota Press, 2016), pp. 1-28.

Gorham, Geoffrey, Benjamin Hill, Edward Slowik, and C. Kenneth Waters, eds. The Language of Nature: Reassessing the Mathematization of Natural Philosophy in the Seventeenth Century (Minneapolis: University of Minnesota Press, 2016).

Gorman, Mel. 'Gassendi in America', Isis, 55.4 (1964), pp. 409-417.

Gouk, Penelope. The Ivory Sundials of Nuremberg, 1500-1700 (Cambridge: The Whipple Museum of the History of Science, 1988).

Goulding, Robert. 'Method and Mathematics: Peter Ramus's Histories of the Sciences', Journal of the History of Ideas, 67.1 (2006), pp. 63-85.

Goulding, Robert. Defending Hypatia: Ramus, Savile and the Renaissance Rediscovery of Mathematical History (Berlin and New York: Springer, 2010).

Grafton, Anthony, and Lisa Jardine. From Humanism to the Humanities: Education and the Liberal Arts in Fifteenth-and Sixteenth-Century Europe (London: Duckworth, 1986).

Grafton, Anthony, and Nancy Siraisi, 'Between the Election and My Hopes: Girolamo Cardano and Medical Astrology', in Newman, William R., and Anthony Grafton, eds., Secrets of Nature: Astrology and Alchemy in Early Modern Europe (Cambridge, MA., and London: The MIT Press, 2001), pp. 69-132.

Grafton, Anthony. 'Joseph Scaliger and Historical Chronology: The Rise and Fall of a Discipline', History and Theory, 14.2 (1975), pp. 156-185. 
Grafton, Anthony. 'Some Uses of Eclipses in Early Modern Chronology', Journal of the History of Ideas, 64.2 (2003), pp. 213- 229.

Grafton, Anthony. 'The Importance of Being Printed', Journal of Interdisciplinary History, 11 (1980), pp. 265-86.

Grafton, Anthony. Cardano's Cosmos: The Worlds and Works of a Renaissance Astrologer (Cambridge, MA, and London: Harvard University Press, 1999).

Grafton, Anthony. Defenders of the Text: The Traditions of Scholarship in an Age of Science, 1450-1800 (Cambridge, MA: Harvard University Press, 1991).

Grant, Edward. The Nature of Natural Philosophy in the Late Middle Ages (Washington, DC: The Catholic University Press, 2010).

Grant, Roger Matthew. Beating Time and Measuring Music in the Early Modern Era (Oxford: Oxford University Press, 2014).

Graßhoff, Gerd. The History of Ptolemy's Star Catalogue (New York: SpringerVerlag, 1990).

Grattan-Guiness, Ivor. The Rainbow of Mathematics: The Fontana History of the Mathematical Sciences (London: Fontana, 1997).

Grattan-Guinness, Ivor. 'On Certain Somewhat Neglected Features of the History of Mathematics', in Grattan-Guinness, Ivor, Routes of Learning: Highways, Pathways and Byways in the History of Mathematics (Baltimore: The Johns Hopkins University Press, 2009), pp. 83-103.

Grattan-Guinness, Ivor. 'Talepiece: The History of Mathematics and its own History' in Grattan-Guinness, Ivor, ed., Companion Encyclopedia of the History and Philosophy of the Mathematical Sciences, Vol. 2 (London and New York: Routledge, 1994), pp. 1665-1675.

Gray, Jeremy. 'Histories of Modern Mathematics in English in the 1940s, 50s and 60s', in Remmert, Volker R., Martina R. Schneider, and Henrik Kragh Sørensen, eds., Historiography of Mathematics in the 19th and 20th Centuries (Cham: Birkhäuser, Springer International Publishing, 2016), pp. 161-183.

Green, Robin M. Spherical Astronomy (Cambridge: Cambridge University Press, 1985).

Grell, Ole Peter. 'Caspar Bartholin and the Education of the Pious Physician', in Grell, Ole Peter, and Peter Cunningham, eds., Medicine and the Reformation (London: Routledge, 1993), pp. 78-100.

Grendler, Paul F. Schooling in Renaissance Italy: Literacy and Learning, 1300-1600 (Baltimore and London: The Johns Hopkins University Press, 1989). 
Grossman, Henryk. 'The Social Foundations of the Mechanistic Philosophy and Manufacture' in Freudenthal, Gideon and Peter McLaughlin, eds., The Social and Economic Roots of the Scientific Revolution. Texts by Boris Hessen and Henryk Grossman (Dordrecht: Springer, 2009), pp. 103-156. Originally published in German as 'Die Gesellschaftlichen Grundlagen der Mechanistischen Philosophie und die Manufaktur', Zeitschrift fur Sozialforschung, 4 (1935), pp. 161-231.

Guicciardini, Niccolò. Isaac Newton on Mathematical Certainty and Method (Cambridge, MA: Massachusetts Institute of Technology Press, 2009).

Hackel, Heidi Brayman. 'The Countess of Bridgewater's London Library', in Andersen, Jennifer, and Elizabeth Sauer, eds., Books and Readers in Early Modern England: Material Studies (Philadelphia, PA: University of Pennsylvania Press, 2002), pp. 138-159.

Hackel, Heidi Brayman. Reading Material in Early Modern England: Print, Gender, and Literacy (Cambridge: Cambridge University Press, 2005).

Hackett, Jeremiah. 'Roger Bacon on the Classification of the Sciences', in Hackett, Jeremiah, ed., Roger Bacon and the Sciences: Commemorative Essays (Leiden, New York, and Cologne: Brill, 1997), pp. 49-66.

Hadden, Richard W. On the Shoulders of Merchants: Exchange and the Mathematical Conception of Nature in Early Modern Europe (Albany: State University of New York Press, 1994).

Hall, A. Rupert. 'Merton Revisited, or Science and Society in the Seventeenth Century’, History of Science, 2.1 (1963), pp. 1-16.

Hall, A. Rupert. 'The Scholar and the Craftsman in the Scientific Revolution' in Clagett, Marshall, ed., Critical Problems in the History of Science (Madison, Milwaukee, and London: University of Wisconsin Press, 1969), pp. 3-23.

Hall, A. Rupert. Ballistics in the Seventeenth Century. A Study in the Relations of Science and War with reference particularly to England (Cambridge: Cambridge University Press, 1952).

Hall, A. Rupert. From Galileo to Newton (London: Collins, 1963).

Hall, A. Rupert. The Scientific Revolution, 1500-1800: The Formation of the Modern Scientific Attitude (London: Longmans, Green and Co, 1954).

Hamilton, Alastair. William Bedwell the Arabist, 1563-1632 (Leiden: Published for the Sir Thomas Browne Institute by E. J. Brill and The University of Leiden Press, 1985).

Harris, Jason. 'The Practice of Community: Humanist Friendship during the Dutch Revolt', Texas Studies in Literature and Language, 47.4 (2005), pp. 299-325. 
Heilbron, J. L. Electricity in the 17th and 18th Centuries: A Study of Early Modern Physics (Berkeley, Los Angeles, and London: University of California Press, 1979).

Hellman, C. Doris. The Comet of 1577: Its Place in the History of Astronomy (New York: Columbia University Press, 1944).

Henninger-Voss, Mary. 'How the New Science of Cannons Shook up the Aristotelian Cosmos', Journal of the History of Ideas, 63.3 (2002), pp. 371-397.

Hersey, George. Architecture and Geometry in the Age of the Baroque (Chicago: University of Chicago Press, 2000).

Hessen, Boris. 'The Social and Economic Roots of Newton's "Principia", reproduced in Freudenthal, Gideon and Peter McLaughlin, eds., The Social and Economic Roots of the Scientific Revolution: Texts by Boris Hessen and Henryk Grossman (Dordrecht: Springer, 2009), pp. 41-102.

Higton, Hester. Sundials at Greenwich: a catalogue of the sundials, nocturnals, and horary quadrants in the National Maritime Museum, Greenwich (Oxford, New York, and Greenwich: Oxford University Press and National Maritime Museum, 2002).

Hilgert, Earle. 'Johann Froben and the Basel University Scholars, 1513-1523', The Library Quarterly: Information, Community, Policy, 41.2 (1971), pp. 141-169.

Hill Curth, Louise. English Almanacs, Astrology and Popular Medicine: 1550-1700 (Manchester: Manchester University Press, 2007).

Hill, H. O., and E. W. Paget-Tomlinson. Instruments of Navigation: a catalogue of instruments at the National Maritime Museum with notes upon their use (London: National Maritime Museum and Her Majesty's Stationery Office, 1958).

Hill, Katherine. "“Juglers or Schollers?” Negotiating the Role of a Mathematical Practitioner', British Journal for the History of Science, 31.3 (1998), pp. 253-274.

Hind, Arthur M. A History of Engraving and Etching from the Fifteenth Century to the Year 1914, $3^{\text {rd }}$ edn (Boston and New York: Houghton Mifflin Company, 1923).

Hind, Arthur M. Engraving in England in the Sixteenth and Seventeenth Centuries. A Descriptive Catalogue with Introductions, 3 vols. (Cambridge: Cambridge University Press, 1952-1964).

Holton, Gerald. 'George Sarton, His Isis, and the Aftermath', Isis, 100.1 (2009), pp. 79-88.

Hookyaas, Reijer. Fact, Faith and Fiction in the Development of Science: The Gifford Lectures given in the University of St Andrews 1976 (Dordrecht: Springer Science + Business Media, 1999; $1^{\text {st }}$ edn Kluwer Academic Publishers, 1999). 
Hookyaas, Rejier. 'Humanities, Mechanics and Painting (Petrus Ramus; Francisco de Holanda)', Revista da Universidade de Coimbra, 36 (1991), pp. 1-31.

Hoppen, K. Theodore. The Common Scientist in the Seventeenth Century: A Study of the Dublin Philosophical Society, 1683-1708 (London: Routledge and Kegan Paul, 1970).

Hotchkiss, Valerie, and Fred C. Robinson. English in Print from Caxton to Shakespeare to Milton (Urbana and Chicago: University of Illinois Press, 2008).

Hotson, Howard. Commonplace Learning: Ramism and its German Ramifications, 1543-1630 (Oxford: Oxford University Press, 2007).

Houston, R. A. Literacy in Early Modern Europe: Culture and Education 1500$1800,2^{\text {nd }}$ edn (Abingdon and New York: Routledge, 2013).

Hulvey, Monique. 'Not so Marginal: Manuscript Annotations in the Folger Incunabula', The Papers of the Bibliographical Society of America, 92.2 (1998), pp. 159-176.

Husserl, Edmund. The Crisis of European Sciences and Transcendental Phenomenology: An Introduction to Phenomenological Philosophy, trans. David Carr (Evanston: Northwestern University Press, 1970; originally published as 'Die Krisis der europäischen Wissenschaften und die transzendentale Phänomenologie: Eine Einleitung in die phänomenologische Philosophie', Philosophia. 1 (1936), pp 77-176).

Hutton, Sarah. British Philosophy in the Seventeenth Century (Oxford: Oxford University Press, 2015).

Imhof, Dirk. Jan Moretus and the Continuation of the Plantin Press: A Bibliography of the Works Published and Printed by Jan Moretus I in Antwerp, Vol. 1: A-M, 2 vols (Leiden: Brill, Hes and De Graaf, 2014).

International Astronomical Union and Sky and Telescope Magazine, https://www.iau.org/static/public/constellations/pdf/AUR.pdf, accessed 14 February 2018 .

Jackson, H. J. Marginalia: Readers Writing in Books (New Haven and London: Yale University Press, 2001).

Jacob, W. M. The Clerical Profession in the Long Eighteenth Century, 1680-1840 (Oxford: Oxford University Press, 2007).

Jagger, Graham. 'Joseph Moxon, F. R. S., and the Royal Society', Notes and Records of the Royal Society, 49.2 (1995), pp. 193-208.

Jardine, Boris S. 'State of the Field: Paper Tools', Studies in History and Philosophy of Science, Part A, 64 (2017), pp. 53-63. 
Jardine, Lisa, and Anthony Grafton. "'Studied For Action": How Gabriel Harvey Read his Livy', Past and Present, 129 (1990), pp. 30-78.

Jardine, Lisa. Worldly Goods: A New History of the Renaissance (London: Macmillan, 1996).

Jardine, Nicholas, and Isla Fay, eds., Observing the World through Images: Diagrams and Figures in the Early-Modern Arts and Sciences (Leiden and Boston: Brill, 2014).

Jardine, Nicholas. 'Books, Texts, and the Making of Knowledge', in Frasca-Spada, Marina and Nicholas Jardine, eds., Books and the Sciences in History (Cambridge: Cambridge University Press, 2000), pp. 393-407.

Jardine, Nicholas. 'The Places of Astronomy in Early Modern Culture', Journal for the History of Astronomy, 29 (1998), pp. 49-62.

Jardine, Nicholas. The Birth of History and Philosophy of Science: Kepler's A Defence of Tycho against Ursus with Essays on its Provenance and Significance, corrected edition (Cambridge: Cambridge University Press, 1988).

Jayne, Sears. Library Catalogues of the English Renaissance (Godalming: St Paul's Bibliographies, 1983).

Jewell, Helen M. Education in Early Modern England (Houndmills: Macmillan, 1998).

Johns, Adrian. Piracy: The Intellectual Property Wars from Gutenberg to Gates (Chicago: The University of Chicago Press, 2009).

Johns, Adrian. The Nature of the Book: Print and Knowledge in the Making (Chicago and London: University of Chicago Press, 1998).

Johnson, Francis R. 'Notes on English Retail Book-Prices, 1550-1640', The Library, Fifth Series, 5.2 (1950), pp. 83-112.

Johnson, Francis R. Astronomical Thought in Renaissance England. A Study of the English Scientific Writings from 1500 to 1645 (Baltimore: The Johns Hopkins University Press, 1937).

Johnson, James William. 'Chronological Writing: Its Concepts and Development', History and Theory, 2 (1962), pp. 124-145.

Johnston, Stephen. 'John Dee on Geometry: Texts, Teaching and the Euclidean Tradition', Studies in History and Philosophy of Science, 43 (2012), pp. 470-479.

Johnston, Stephen. 'Like Father, Like Son? John Dee, Thomas Digges and the Identity of the Mathematician', in Clucas, Stephen, ed., John Dee: Interdisciplinary Studies in English Renaissance Thought (Dordrecht: Springer, 2006), pp. 65-84. 
Johnston, Stephen. 'Mathematical Practitioners and Instruments in Elizabethan England', Annals of Science, 48.4 (1991), pp. 319-344.

Johnston, Stephen. 'Review of Eric H. Ash, Power, Knowledge and Expertise in Elizabethan England', Isis, 97.2 (2007), pp. 348-349.

Johnston, Stephen. 'The Identity of the Mathematical Practitioner in 16th-Century England', in Hantsche, Irmgarde, ed., Der "mathematicus": Zur Entwicklung und Bedeutung einer neuen Berufsgruppe in der Zeit Gerhard Mercators, Duisburger Mercator-Studien, vol. 4. (Bochum: Universitätsverlag Dr. N. Brockmeyer, 1996), pp. 93-120.

Joy, Lynn Sumida. Gassendi the Atomist: Advocate of History in an Age of Science (Cambridge: Cambridge University Press, 1987).

Kanas, Nick. Star Maps: History, Artistry, Cartography, $2^{\text {nd }}$ edn (Berlin, New York, and Chichester: Springer Science + Business Media, in association with Praxis Publishing, 2009).

Karpik, Lucien. Valuing the Unique: The Economics of Singularities (Princeton: Princeton University Press, 2010).

Karr Schmidt, Suzanne, with Kimberley Nichols, Altered and Adorned: Using Renaissance Prints in Daily Life (Chicago and New Haven: Art Institute of Chicago, distributed by Yale University Press, 2011).

Karr Schmidt, Suzanne. 'Making Time and Space: Collecting Early Modern Printed Instruments', in Karr Schmidt, Suzanne, and Edward H. Wouk, eds., Prints in Translation, 1450-1750. Image, Materiality, Space (Abingdon: Routledge, 2017), pp. 114-135.

Kassell, Lauren. Medicine and Magic in Elizabethan England: Simon Forman: Astrologer, Alchemist, Physician (Oxford: Clarendon Press, 2005).

Kearney, Hugh. Scholars and Gentlemen: Universities and Society in pre-Industrial Britain, 1500-1700 (London: Faber, 1970).

Keblusek, Marika. 'Book Agents: Intermediaries in the Early Modern World of Books', in Cools, Hans, Marika Keblusek, and Badeloch Noldus, eds., Your Humble Servant: Agents in Early Modern Europe (Hilversum: Uitgeverij Verloren, 2006), pp. 97-107.

Kemp, Martin. The Science of Art: Optical Themes in Western Art from Brunelleschi to Seurat (New Haven, CT: Yale University Press, 1990).

Kettering, Sharon. Patrons, Brokers and Clients in Seventeenth Century France (Oxford and New York: Oxford University Press, 1986).

Kieckhefer, Richard. 'The Specific Rationality of Medieval Magic' in Levack, Brian P., ed., New Perspectives on Witchcraft, Magic and Demonology, Volume 1: 
Demonology, Religion, and Witchcraft (New York and London: Routledge, 2001), pp. 59-82.

King, David A. 'Astrolabe' in Bud, Robert, and Deborah Jean Warner, eds., Instruments of Science: An Historical Encyclopedia (New York and London: The Science Museum, London and The National Museum of American History, Smithsonian Institution in association with Garland Publishing, 1998), pp. 33-34.

Kirschner, Stefan, and Andreas Kühne. 'The Decline of Medieval Disputation Culture and the 'Wittenberg Interpretation' of the Copernican Theory', in Neuber, Wolfgang, Thomas Rahn and Claude Zittel, eds., The Making of Copernicus: Early Transformations of the Scientist and his Science (Leiden and Boston: Brill, 2015), pp. 13-41.

Kline, Morris. Mathematics in Western Culture (Oxford: Oxford University Press, 1953).

Kline, Morris. Mathematics: The Loss of Certainty (Oxford and New York: Oxford University Press, 1980).

Klose, Wolfgang. Wittenberger Gelehrtenstammbuch (Halle: Mitteldeutscher Verlag, 1999).

Knoespel, Kenneth J. 'Newton in the School of Time: The Chronology of Ancient Kingdoms Amended and the Crisis of Seventeenth-Century Historiography', The Eighteenth Century, 30.3 (1989), pp. 19-41.

Knorr, Wilbur R. 'Sacrobosco's Quadrans: Date and Sources', Journal for the History of Astronomy, 28 (1997), pp. 187-222.

Knorr, Wilbur R. 'The Latin Sources of Quadrans Vetus, and What They Imply for Its Authorship and Date', in Sylla, Edith, and Michael McVaugh, eds., Texts and Contexts in Ancient and Medieval Science. Studies on the Occasion of John E. Murdoch's Seventieth Birthday (Leiden: Brill, 1997), pp. 23-67.

Koptyoff, Igor, 'The Cultural Biography of Things: Commoditization as Process', in Appadurai, Arjan, ed., The Social Life of Things. Commodities in Cultural Perspective, $2^{\text {nd }}$ edn (Cambridge: Cambridge University Press, 1997), pp. 64-91.

Koyré, Alexandre. 'Galileo and the Scientific Revolution of the Seventeenth Century’, Philosophical Review. 52.4 (1943), pp. 333-348.

Koyré, Alexandre. 'The Significance of the Newtonian Synthesis' in Koyré, Alexandre, Newtonian Studies (Cambridge, MA: Harvard University Press, 1965), pp. 3-24.

Koyré, Alexandre. Galileo Studies, trans. John Mepham (Hassocks: The Harvest Press, 1978). 
Kremer, Richard L. 'Experimenting with Paper Instruments in Fifteenth- and Sixteenth-Century Astronomy: Computing Syzygies with Isotemporal Lines and Salt Dishes', Journal for the History of Astronomy, 42 (2011), pp. 223-258.

Kremer, Richard L. 'Playing with Geometrical Tools: Johannes Stabius's Astrolabium imperatorium (1515) and its Successors', Centaurus, 58 (2016), pp. 104-134.

Kremer, Richard L. 'Text to Trophy: Shifting Representations of Regiomontanus's Library', in Raven, James, ed. Lost Libraries: The Destruction of Great Book Collections since Antiquity (Houndmills: Palgrave Macmillan, 2004), pp. 75-90.

Kronick, David A. 'The Commerce of Letters: Networks and "Invisible Colleges" in Seventeenth- and Eighteenth-Century Europe', Library Quarterly, 71 (2001), pp. 2843.

Krstić, Tijana. 'The Elusive Intermediaries: Moriscos in Ottoman and Western European Diplomatic Sources from Constantinople, 1560s-1630s', Journal of Early Modern History, 19.2 (2015), pp. 129-151.

Kuhn, Thomas S. 'Mathematical Versus Experimental Traditions in the Development of Physical Science', Journal of Interdisciplinary History, 7 (1976), pp. 1-31.

Kuhn, Thomas S. 'The Trouble with the Historical Philosophy of Science', Robert and Maurine Rothschild Distinguished Lecture 19 November 1991. An Occasional Publication of the Department of the History of Science (Cambridge, MA. Harvard University Press, 1992).

Kuhn, Thomas S. The Structure of Scientific Revolutions, $2^{\text {nd }}$ edn, enlarged (Chicago: University of Chicago Press, 1970; originally published 1962).

Kusukawa, Sachiko. The Transformation of Natural Philosophy: The Case of Phillip Melanchthon (Cambridge: Cambridge University Press, 1995).

Kyriss, Ernst. 'Parisian Panel Stamps between 1480 and 1530', Studies in Bibliography, 7 (1955), pp. 113-124.

L'Estrange Turner, Gerard. Elizabethan Instrument Makers. The Origins of the London Trade in Precision Instrument Making (Oxford: Oxford University Press, 2000).

L'Estrange Turner, Gerard. Scientific Instruments, 1500-1900: An Introduction (Berkeley, Los Angeles, London: University of California Press, 1998).

Lane Furdell, Elizabeth. Fatal Thirst: Diabetes in Britain until Insulin (Leiden: Brill, 2009). 
Lattis, James M. Between Copernicus and Galileo: Christoph Clavius and the Collapse of Ptolemaic Cosmology (Chicago and London: University of Chicago Press, 1994).

Lee, H. D. P. 'Geometrical Method and Aristotle's Account of First Principles', Classical Quarterly, 29.2 (1935), pp. 113-124.

Lehigh University Library and Honeyman, Robert B., "The History of Mathematics" (1961). Exhibition Catalogues. Paper 5.

Lehigh University Library and Honeyman, Robert B., 'The Size and Shape of the Earth' (1958), Exhibition Catalogues, Paper 3.

Lenoble, Robert. Mersenne ou la Naissance du Mécanisme, $2^{\text {nd }}$ edn (Paris: J. Vrin, 1971).

Lerer, Seth. 'Medieval Literature and Early Modern Readers: Cambridge University Library Sel.5.51-5.63', Papers of the Bibliographical Society of America, 97.3 (2003), pp. 311-332.

Leu, Urs B., Raffael Keller, and Sandra Weidman. Conrad Gesner's Private Library (Leiden: Brill, 2008).

Lindberg, Sten G. 'Mobiles in Books: Volvelles, Inserts, Pyramids, Divinations, and Children's Games', trans. William S. Mitchell, Private Library, $3^{\text {rd }}$ series, 2 (1979) pp. 49-82.

Lloyd, Steven A. 'Lunar Volvelles and Moondials in Baroque Germany', Journal for the History of Astronomy, 20 (1989), pp. 121-127.

Lloyd, Steven A. Ivory Diptych Sundials, 1570-1750 (Cambridge, MA: Collection of Historical Scientific Instruments, Harvard University; Harvard University Press, 1992).

Loewenstein, Joseph F. 'Idem: Italics and the Genetics of Authorship', Journal of Medieval and Renaissance Studies, 20.2 (1990), pp. 205-224.

Loewenstein, Joseph F. 'The Script in the Marketplace', Representations, 12 (1985), pp. 101-114.

Long, Pamela O. 'Multi-Tasking "Pre-Professional" Architect / Engineers and Other Bricolagic Practitioners as Key Figures in the Elision of Boundaries between Practice and Learning in Sixteenth-Century Europe: Some Roman Examples', in Valleriani, Matteo, ed., The Structures of Practical Knowledge (Cham: Springer International Publishing, 2017), pp. 223-246.

Long, Pamela O. 'Trading Zones in Early Modern Europe', Isis, 106.4 (2015), pp. 840-847. 
Loveman, Kate. Samuel Pepys and his Books: Reading, Newsgathering, and Sociability, 1660-1703 (Oxford: Oxford University Press, 2015).

Lowood, Henry E., and Robin E. Rider. 'The Scientific Book as a Cultural and Bibliographical Object', in Hunter, Andrew, ed., Thornton and Tully's Scientific Books, Libraries, and Collectors: A Study of Bibliography and the Book Trade in Relation to the History of Science, $4^{\text {th }}$ edn (Aldershot: Ashgate, 2000), pp. 1-25.

Lüthy, Christoph H., and William R. Newman, 'Daniel Sennert's Earliest Writings (1599-1600) and Their Debt to Giordano Bruno', Bruniana and Campaneliana, 6 (2000), pp. 261-279.

Lüthy, Christoph, and Alexis Smets, 'Words, Lines, Diagrams, Images: Towards a History of Scientific Imagery', Early Science and Medicine, 14 (2009), pp. 398-439.

Lynch, Kathleen. 'Devotion Bound: A Social History of The Temple', in Andersen, Jennifer, and Elizabeth Sauer, eds., Books and Readers in Early Modern England: Material Studies (Philadelphia: University of Pennsylvania Press, 2002), pp. 177198.

Lytle, Guy Fitch, and Stephen Orgel, eds., Patronage in the Renaissance (Princeton, N.J., Princeton University Press, 1981).

Mack, Peter. A History of Renaissance Rhetoric, 1380-1620 (Oxford: Oxford University Press, 2011).

Maclean, Ian. Learning in the Marketplace: Essays in the History of the Early Modern Book. (Leiden: Brill, 2009).

Maclean, Ian. Logic, Signs and Nature in the Renaissance: The Case of Learned Medicine (Cambridge: Cambridge University Press, 2002).

Mahoney, Michael Sean. The Mathematical Career of Pierre de Fermat, 2nd edn (Princeton, NJ: Princeton University Press, 1994).

Mahoney, Michael Sean. 'Diagrams and Dynamics: Mathematical Perspectives on Edgerton's Thesis', in Shirley, John W., and F. David Hoeniger, eds., Science and the Arts in the Renaissance (Washington, DC: Folger Shakespeare Library, 1985), pp. 198-220.

Malcolm, Noel. 'The Publications of John Pell, F.R.S.: Some New Light and Some Old Conclusions', Notes and Records of the Royal Society, 54.3 (2000), pp. 275-292.

Malcolm, Noel. Agents of Empire: Knights, Corsairs, Jesuits and Spies in the Sixteenth-Century Mediterranean World (Oxford: Oxford University Press, 2015).

Malet, Antoni. 'Kepler's Legacy: Telescopes and Geometrical Optics, 1611-1669', in van Helden, Albert, Sven Dupré, Rob van Gent, and Huib Zuidevaart, eds., The Origins of the Telescope (Amsterdam: Knaw Press, 2010), pp. 281-300. 
Mancosu, Paolo. Philosophy of Mathematics and Mathematical Practice in the Seventeenth Century (Oxford: Oxford University Press, 1996).

Mandelbrote, Giles. 'Scientific Books and Their Owners: A Survey to c. 1720', in Hunter, Andrew, ed., Thornton and Tully's Scientific Books, Libraries, and Collectors: A Study of Bibliography and the Book Trade in Relation to the History of Science, $4^{\text {th }}$ edn (Aldershot: Ashgate, 2000), pp. 333-366.

Mandelbrote, Scott. 'Early modern Natural Theologies', in Brooke, J. H., F. Watts and R. R. Manning, eds., The Oxford Handbook of Natural Theology (Oxford: Oxford University Press, 2013), pp. 75-97.

Mandelbrote, Scott. 'The Doors Shall Fly Open': Chronology and Biblical Intepretation in England, c. 1630-c.1730', in Killeen, Kevin, Helen Smith, and Rachel Willie, eds., The Oxford Handbook of the Bible in Early Modern England, $c$. 1530-1700 (Oxford: Oxford University Press, 2015), pp. 176-195.

Mann, Tony. 'History of Mathematics and History of Science', Isis, 102.3 (2011), pp. 518-526.

Marr, Alexander. 'The Production and Distribution of Mutio Oddi's Dello Squadro (1625)', in Kusukawa, Sachiko and Ian Maclean, eds., Transmitting Knowledge: Words, Images and Instruments in Early Modern Europe (Oxford: Oxford University Press, 2006), pp. 165-192.

Marr, Alexander. Between Raphael and Galileo: Mutio Oddi and the Mathematical Culture of Late Renaissance Italy (Chicago and London: University of Chicago Press, 2011).

Maruyama, Tadataka. The Ecclesiology of Theodore Beza: The Reform of the True Church (Geneva: Librarie Droz, 1978).

Massa Esteve, Ma. Rosa. 'Symbolic Language in Early Modern Mathematics: The Algebra of Pierre Hérigone (1580-1643)', Historia Mathematica, 35.4 (2008), pp. 285-301.

Maxted Ian. 'Impressorie Arte: The Impact of Printing in Exeter and Devon', in Costas, Benito Rial, ed., Print Culture and Peripheries in Early Modern Europe: A Contribution to the History of Printing and the Book Trade in Small European and Spanish Cities (Leiden: Brill, 2013), pp. 127-146.

Maxwell, Robert L. RBMS/BSC Latin Place Names File, http://rbms.info/lpn/.

Mayer, Anna K. 'Setting up a discipline, II: British history of science and "the end of ideology”, 1931-1948', Studies in History and Philosophy of Science, 35 (2004), pp. 41-72.

Mazzio, Carla, and Bradin Cormack. Book Use, Book Theory, 1500-1700 (Chicago: University of Chicago Press, 2005). 
McClain, E. G. The Myth of Invariance: The Origins of the Gods, Mathematics and Music from the Rig Veda to Plato (York Beach, ME: Nicolas-Hays, Inc, 1976).

McCluskey, Stephen C. Astronomies and Cultures in Early Medieval Europe (Cambridge: Cambridge University Press, 1998).

McKitterick, David. A History of Cambridge University Press, Volume One: Printing and the Book Trade in Cambridge, 1534-1698 (Cambridge: Cambridge University Press, 1992).

McKitterick, David. Print, Manuscript and the Search for Order, 1450-1830 (Cambridge: Cambridge University Press, 2003).

McKitterick, Rosamond. 'Books and Sciences before Print', in Frasca-Spada, Marina and Nicholas Jardine, Books and the Sciences in History (Cambridge: Cambridge University Press, 2000), pp. 13-34.

McLean, Matthew. 'Between Basel and Zurich: Humanist Rivalries and the Works of Sebastian Münster', in Walsby, Malcolm, and Graeme Kemp, eds., The Book Triumphant: Print in Transition in the Sixteenth and Seventeenth Centuries (Leiden and Boston: Brill, 2011), pp. 270-294.

McNeil, William H. The Pursuit of Power: Technology, Armed Force, and Society since A.D. 1000 (Chicago: University of Chicago Press, 1982).

Meadow, Mark A. 'Merchants and Marvels: Hans Jacob Fugger and the Origins of the Wunderkammer', in Smith, Pamela, and Paula Findlen, eds., Merchants and Marvels: Commerce, Science, and Art in Early Modern Europe (New York: Routledge, 2002), pp. 182-200.

Means, Laurel. 'The Vulnerability of Volvelles in Medieval Manuscripts', Manuscripta, 25 (1991), pp. 43-54.

Meerhoff, Kees. 'International Humanism', in Horner, Winifred Bryan, and Michael Leff, eds., Rhetoric and Pedagogy: its History, Philosophy and Practice: Essays in Honour of James J. Murphy (New York: Routledge, 1995), pp. 213-226.

Menghini, Marta. 'From Practical Geometry to the Laboratory Method: The Search for an Alternative to Euclid in the History of Teaching Geometry', in Cho, Sung Je, ed., Selected Regular Lectures from the 12th International Congress on Mathematical Education (Heidelberg, New York, Dordrecht, and London: Springer International Publishing, 2015), pp. 561-587.

Merton, Robert King. 'Science, Technology and Society in Seventeenth Century England', originally published in Osiris: Studies on the History and Philosophy of Science, and on the History of Learning and Culture (Burges: St. Catherine Press, 1938), 4.2, pp. 360-632. 
Meskens, Ad. Practical Mathematics in a Commercial Metropolis: Mathematical Life in Late 16th Century Antwerp (Dordrecht: Springer Science \& Business Media, 2013).

Mesnard, Pierre. 'The Pedagogy of Johann Sturm (1507-1589) and its Evangelical Inspiration', Studies in the Renaissance, 13 (1966), pp. 200-219.

Methuen, Charlotte. 'Interpreting the Books of Nature and Scripture in Medieval and Early Modern Thought: An Introductory Essay', in van der Meer, Jitse M., and Scott Mandelbrote, eds., Nature and Scripture in the Abrahamic Religions: Up to 1700, Volume 1. (Brill: Leiden and Boston, 2008), pp. 179-218.

Midelfort, H. C. Erik. A History of Madness in Sixteenth-Century Germany (Stanford, CA: Stanford University Press, 1999).

Minns, Chris, and Patrick Wallis. 'Rules and Reality: Quantifying the Practice of Apprenticeship in Early Modern England', Economic History Review, 65.2 (2012), pp. 556-579.

Minter, Catherine J. 'John Dury's Reformed Librarie-Keeper: Information and its Intellectual Contexts in Seventeenth-Century England', Library \& Information History, 31 (2015), pp. 18-34.

Moesgaard, Kristian Peder. 'How Copernicanism Took Root in Denmark and Norway', in Jerzy Dobrzycki, ed., The Reception of Copernicus' Heliocentric Theory: proceedings of a symposium organized by the Nicolas Copernicus Committee of the International Union of the History and Philosophy of Science, Toruń, Poland, 1973 (Dordrecht: Springer Science + Business Media BV, 1972), pp. 117-152.

Molland, George A. 'Mathematics', in Lindberg, David C., and Michael H. Shank, eds., The Cambridge History of Science, Volume 2: Medieval Science (Cambridge: Cambridge University Press, 2013), pp. 512-531.

Monfasani, John. George of Trebizond: A Biography and Study of his Rhetoric and Logic. (Brill: Leiden, 1976).

Moran, Bruce T. 'German Prince-Practitioners: Aspects in the Development of Courtly Science, Technology, and Procedures in the Renaissance", Technology and Culture, 22.2 (1981), pp. 253-274.

Moran, Bruce T., ed., Patronage and Institutions: Science, Technology and Medicine at the European Court, 1500-1750 (Rochester, N.Y.: The Boydell Press, 1991).

Moran, Dermot. Husserl's Crisis of the European Sciences and Transcendental Philosophy: An Introduction (Cambridge: Cambridge University Press, 2012).

Mori, Giuliano. 'Mathematical Subtleties and Scientific Knowledge: Francis Bacon and Mathematics, at the Crossing of Two Traditions', British Journal for the History of Science, 50.1 (2017), pp. 1-21. 
Morrison, Stanley. 'Notes on the Development of Latin Script' in Morrison, Stanley, and David McKitterick, ed., Selected Essays on the History of Letter Forms in Manuscript and Print, Volume 1 (Cambridge: Cambridge University Press, 1981; originally 1949, partly revised c. 1962), pp. 222-294.

Morrison-Low, A. D. Making Scientific Instruments in the Industrial Revolution (Aldershot: Ashgate, 2007).

Mörzer Bruyns, W. F. J. Sextants at Greenwich: a catalogue of the mariner's quadrants, mariner's astrolabes, cross-staffs, backstaffs, octants, sextants, quintants, reflecting circles and artificial horizons in the National Maritime Museum, Greenwich (Oxford: Oxford University Press, 2009).

Mosley, Adam, 'Early Modern Cosmography: Fine's Sphaera Mundi in Content and Context', in Marr, Alexander, ed., The Worlds of Oronce Fine: Mathematics, Instruments and Print in Renaissance France (Donnington: Shaun Tyas, 2009), pp. 114-136.

Mosley, Adam. 'Objects of Knowledge: Mathematics and Models in SixteenthCentury Cosmology and Astronomy' in Kusukawa, Sachiko, and Ian Maclean, eds., Transmitting Knowledge: Words, Images, and Instruments in Early Modern Europe (Oxford: Oxford University Press, 2006), pp. 193-216.

Mosley, Adam. 'Objects, Texts and Images in the History of Science', Studies in History and Philosophy of Science, 38.2 (2007), pp. 289-302.

Mosley, Adam. 'Spheres and texts on spheres: the book-instrument relationship and an armillary sphere in the Whipple Museum of the History of Science', in Taub, Liba, and Frances Willmoth, eds., The Whipple Museum of the History of Science: Instruments and Interpretations, to Celebrate the Sixtieth Anniversary of R. S. Whipple's Gift to the University of Cambridge (Cambridge: The Whipple Museum of the History of Science, 2006), pp. 301-318.

Mosley, Adam. 'The Cosmographer's Role in the Sixteenth Century: A Preliminary Study', Archives Internationales d'Histoire des Sciences, 59 (2009), pp. 423-439.

Moyer, Ann E. The Philosopher's Game: Rithmomachia in Medieval and Renaissance Europe (Ann Arbor: University of Michigan Press, 2001).

Muddiman, Dave. 'Science, Industry, and the State: Scientific and Technical Information in Early-Twentieth-Century Britain', in Black, Alistair, Dave Muddiman, and Helen Plant, eds., The Early Information Society: Information Management in Britain before the Computer (Farnham: Ashgate, 2006), pp. 55-78.

Neal, Katherine. 'The Rhetoric of Utility: Avoiding Occult Associations for Mathematics through Profitability and Pleasure', History of Science, 37.2 (1999), pp. $151-178$.

Netz, Reviel. 'Proclus' Division of the Mathematical Proposition into Parts: How and Why Was It Formulated?', The Classical Quarterly, 49.1 (1999), pp. 282-303. 
Neugebauer, Otto. 'The Early History of the Astrolabe. Studies in Ancient Astronomy IX', Isis, 40.3 (1949), pp. 240-256.

Neugebauer, Otto. The Exact Sciences in Antiquity, $2^{\text {nd }}$ edn (Providence R.I: Brown University Press: 1957; first published Copenhagen: Ejnar Munksgaard, 1951).

Nnaji, John, and José Luis Luján, 'The Content of Science Debate in the Historiography of the Scientific Revolution', International Studies in the Philosophy of Science, 30.2 (2017), pp. 99-109.

North, J. D. The Universal Frame. Historical Essays in Astronomy, Natural Philosophy and Scientific Method (London and Ronceverte: The Hambledon Press, 1989).

Oestmann, Günther. 'On the History of the Nocturnal', Bulletin of the Scientific Instrument Society, 69 (2001), pp. 5-9.

Ogilvie, Brian W. The Science of Describing: Natural History in Renaissance Europe (Chicago and London: The University of Chicago Press, 2006).

Ohly, Friedrich. 'Deus Geometra: Skizzen zur Geschichte einer vorstellung von Gott', in Kamp, Norbert, and Joachim Wollasch, eds., Tradition als Historische Kraft: Interdiziplinare zur Geschichte des Fruheren Mittelalters (Berlin: Walter de Gruyter, 1982), pp. 1-41.

Oldham, J. Basil. English Blind-Stamped Bindings (Cambridge: Cambridge University Press, 1952).

Omodeo, Pietro Daniel. 'Hoffmanstreit', in Omodeo, Pietro Daniel, and Karin Friedrich, eds., Networks of Polymathy and the Northern European Renaissance (Leiden and Boston: Brill, 2016), pp. 82-85.

Omodeo, Pietro Daniel. Copernicus in the Cultural Debates of the Renaissance: Reception, Legacy, Transformation (Leiden and Boston: Brill, 2014).

Ong, Walter J. 'Christianus Ursitius and Ramus's New Mathematics', Bibliothèque d'Humanisme et Renaissance, 36.3 (1974), pp. 603-610.

Ong, Walter J. Ramus and Talon Inventory: A Short-Title Inventory of the Published Works of Peter Ramus (1515-1572) and Omer Talon (Ca. 1510-1562) in their Original and Variously Altered Forms (Cambridge, MA: Harvard University Press, 1958).

Ong, Walter J. Ramus, Method, and the Decay of Dialogue: From the Art of Discourse to the Art of Reason, $2^{\text {nd }}$ edn (Chicago and London: University of Chicago, 2004; originally Cambridge, MA: Harvard University Press, 1958).

Oosterhoff, Richard J. 'A Pen, a Book, and the Sphere: Reading Sacrobosco in the Renaissance', History of Universities, 28.2 (2015), pp. 1-54. 
Oosterhoff, Richard J. 'The Fabrist Origins of Erasmian Science: Mathematical Erudition in Erasmus' Basle', Journal of Interdisciplinary History of Ideas, 3.6, Item 3 (2014), pp. 1-37.

Oosterhoff, Richard J. Making Mathematical Culture: University and Print in the Circle of Lefèvre D'Étaples (Oxford: Oxford University Press, 2018).

Osler, Margaret J. 'The Canonical Imperative: Rethinking the Scientific Revolution' in Osler, Margaret J., ed., Rethinking the Scientific Revolution (Cambridge:

Cambridge University Press, 2000), pp. 3-24.

Osley, A. S. Mercator: A Monograph on the Lettering of Maps, etc. in the $16^{\text {th }}$ Century Netherlands, with a Facsimile and Translation of his Treatise on the Italic Hand and a Translation of Ghim's Vita Mercatoris (London: Faber and Faber, 1969).

Osley, A. S. Scribes and Sources. Handbook of the Chancery Hand in the Sixteenth Century. Texts from the Writing-Masters selected, introduced and translated by A S. Osley with an account of John de Beauchesne by Berthold Wolpe (London: Faber and Faber, 1981).

Panofsky, Erwin. Idea: A Concept in Art Theory, trans. Joseph J. S. Peak (New York: Harper and Row, 1968).

Park, Katharine, and Lorraine Daston. 'Introduction: The Age of the New', in Park, Katharine, and Lorraine Daston, eds., The Cambridge History of Science. Volume 3: Early Modern Science (Cambridge: Cambridge University Press, 2006), pp. 1-17.

Parkes, M. B. Pause and Effect: An Introduction to the History of Punctuation in the West (Berkeley and Los Angeles: University of California Press, 1993).

Parsons, Ben. 'Dutch influences on English literary culture in the early Renaissance, 1470-1650', Literature Compass, 4 (2007), pp. 1577-1596.

Patapievici, Horia-Roman. 'The 'Pierre Duhem Thesis'.A Reappraisal of Duhem's Discovery of the Physics of the Middle Ages', Logos \& Episteme, 6.2 (2015), pp. 201-218.

Patarino Jr., Vincent V. 'The Religious Shipboard Culture of Sixteenth and Seventeenth-Century English Sailors', in Fury, Cheryl A., ed., The Social History of English Seamen, 1485-1649 (Woodbridge: The Boydell Press, 2012), pp. 141-192.

Pearce, E. H. Sion College and Library (Cambridge: Cambridge University Press, 1913).

Pearson, David. Provenance Research in Book History: A Handbook. (London: The British Library, 1998).

Pedersen, Olaf J. 'In Quest of Sacrobosco', Journal of the History of Astronomy, 12 (1981), pp. 113-123. 
Pedersen, Olaf, and Alex Jones. A Survey of the Almagest (Springer: New York, 2010).

Pedersen, Olaf. 'The Decline and Fall of the Theorica Planetarum: Renaissance Astronomy and the Art of Printing', Studia Copernicana, 16 (1978), pp. 157-185.

Pennell, Sara. 'Consumption and Consumerism in Early Modern England', Historical Journal, 42.2 (1999), pp. 549-564.

Pepper, J. V. 'A Letter from Nathaniel Torporley to Thomas Harriot', British Journal for the History of Science, 3.3 (1967), pp. 285-290.

Petry, M. J. 'Burgersdijk's Physics', in Bos, E. P., and H. A. Krop, eds., Franco Burgersdijk (1590-1635): Neo-Aristotelianism in Leiden (Amsterdam and Atlanta, GA: Rodopi, 1993), pp. 83-118.

Pettegree, Andrew. 'Centre and Periphery in the European Book World', Transactions of the Royal Historical Society, 6.18 (2008), pp. 101-128.

Pettegree, Andrew. The Book in the Renaissance (New Haven: Yale University Press, 2010).

Petto, Christine Marie. Mapping and Charting in Early Modern England and France: Power, Patronage and Production (Lanham, MD: Lexington Books, 2015).

Pfizenmaier, Thomas C. The Trinitarian Theology of Dr Samuel Clarke (16751729): Context, Sources, and Controversy (Leiden, New York, and Cologne: Brill, 1997).

Pickwoad, Nicholas. 'Onward and Downward: How Binders Coped with the Printing Press Before 1800', in Myers, Robin, and Michael Harris, eds., A Millennium of the Book: Production, Design \& Illustration in Manuscript \& Print 900-1900 (Winchester and Delaware: St. Paul's Bibliographies and Oak Knoll Press, 1994), pp. 61-106.

Pollard, Graham. 'Changes in the Style of Bookbinding, 1550-1830', The Library, $5^{\text {th }}$ series, 11 (1956), pp. 71-94.

Pomata, Gianna. 'Observation Rising: Birth of an Epistemic Genre, 1500-1650', in Daston, Lorraine, and Elizabeth Lunbeck, eds., Histories of Scientific Observation (Chicago: University of Chicago Press, 2011), pp. 45-80.

Poole, William. 'Analysing a Private Library, with a Shelflist Attributable to John Hales of Eton, c. 1624', in Jones, Edward, ed., A Concise Companion to the Study of Manuscripts, Printed Books, and the Production of Early Modern Texts, $2^{\text {nd }}$ edn (Oxford: Wiley Blackwell, 2015), pp. 41-65.

Poovey, Mary. Making a Social Body: British Cultural Formation, 1830-1864 (Chicago: University of Chicago Press, 1995). 
Portuondo, María M. Secret Science: Spanish Cosmography and the New World (Chicago and London: University of Chicago Press, 2009).

Potten, Edward. 'Beyond Bibliophilia: Contextualizing Private Libraries in the Nineteenth Century’, Library \& Information History, 31.2 (2015), pp. 73-94.

Preston, C. D., and P. H. Oswald. 'James Duport's Rules for his Tutorial Pupils: A Comparison of Two Surviving Manuscripts', Transactions of the Cambridge Bibliographical Society, 14.4 (2011), pp. 317-362.

Preston, Claire. The Poetics of Scientific Investigation in Seventeenth-Century England (Oxford: Oxford University Press, 2015).

Pumfrey, Stephen, and Frances Dawbarn, 'Science and Patronage in England, 15701625: A Preliminary Study’, History of Science, 42.2 (2004), pp. 137-188.

Rampling, Jennifer M. 'The Catalogue of the Ripley Corpus: Alchemical Writings Attributed to George Ripley (d. ca. 1490)', Ambix, 57.2 (2010), pp. 125-201.

Raphael, Renée. Reading Galileo: Scribal Technologies and the Two New Sciences (Baltimore: The Johns Hopkins University Press, 2017).

Raven, James. 'Debating Bibliomania and the Collection of Books in the Eighteenth Century’, Library \& Information History, 29.3 (2013), pp. 196-209.

Raven, James. 'The Resonances of Loss', in Raven, James, ed., Lost Libraries: The Destruction of the Great Book Collections since Antiquity (New York: Palgrave Macmillan, 2004), pp. 1-40

Raven, James. Publishing Business in Eighteenth-Century England (Woodbridge: Boydell and Brewer, 2014).

Raven, James. The Business of Books: Booksellers and the English Book Trade 1450-1850 (New York and London: Yale University Press, 2007).

Rediker, Marcus. Between the Devil and the Deep Blue Sea: Merchant Seamen, Pirates, and the Anglo-American Maritime World, 1700-1750 (Cambridge:

Cambridge University Press, 1987).

Reingold, Nathan. 'History of Science Today, 1. Uniformity as Hidden Diversity: History of Science in the United States, 1920-1940', British Journal for the History of Science, 19.3 (1986), pp. 243-262.

Reiss, Timothy J. 'From Trivium to Quadrivium: Ramus, Method and Mathematical Technology', in Reis, Timothy J., and Jonathan Sawday, eds., The Renaissance Computer: Knowledge Technology in the First Age of Print (London: Routledge, 2000), pp. 43-56.

Reiss, Timothy J. Knowledge, Discovery and Imagination in Early Modern Europe: The Rise of Aesthetic Rationalism (Cambridge: Cambridge University Press, 1997). 
Remmert, Volker R. "“Docet parva pictura, quod multae scripturae non dicunt." Frontispieces, their Functions, and their Audiences in Seventeenth-Century Mathematical Sciences', in Kusukawa, Sachiko, and Ian Maclean, eds., Transmitting Knowledge: Words, Images, and Instruments in Early Modern Europe (Oxford: Oxford University Press, 2006), pp. 239-270.

Richardson, Brian. Printing, Writers and Readers in Renaissance Italy (Cambridge: Cambridge University Press, 1999).

Robinson, Arthur H. 'Mapmaking and Map Printing: The Evolution of a Working Relationship' in Woodward, David, ed., Five Centuries of Map Printing (Chicago and London: University of Chicago Press, 1975), pp. 1-23.

Roche, John J. 'Harriot's 'Regiment of the Sun' and its Background in SixteenthCentury Navigation', British Journal for the History of Science, 14.3 (1981), pp. 245-262.

Rose, Mark. 'The Public Sphere and the Emergence of Copyright: Areopagitica, the Stationers' Company, and the Statue of Anne', in Deazley, Ronan, Martin Kretschmer and Lionel Bently, eds., Privilege and Property: Essays on the History of Copyright (Cambridge: Open Book Publishers, 2010), pp. 67-88.

Rose, Paul Lawrence, and Stillman Drake, 'The Pseudo-Aristotelian Questions of Mechanics in Renaissance Culture,' Studies in the Renaissance, 18 (1974), pp. 65104.

Rose, Paul Lawrence. 'Humanist Libraries and Renaissance Mathematics: The Italian Libraries of the Quattrocento', Studies in the Renaissance, 20 (1973), pp. 46105.

Rose, Paul Lawrence. The Italian Renaissance of Mathematics: Studies on Humanists and Mathematicians from Petrarch to Galileo (Geneva: Librarie Droz, 1975).

Rosen, Edward. Copernicus and his Successors (London: The Hambledon Press, 1995).

Rosenberg, Eleanor. Leicester, Patron of Letters (New York: Columbia University Press, 1955).

Rosenthal, Margaret F. 'Fashions of Friendship in an Early Modern Illustrated Album Amicorum: British Library, MS Egerton 1191', Journal of Medieval and Early Modern Studies, 39.3 (2009), pp. 619-641.

Rosińska, Grazya. "Mathematics for Astronomy” at Universities in Copernicus' Time: Modern Attitudes toward Ancient Problems', in Feingold, Mordechai, and Victor Navarro-Brotons, eds., Universities and Science in the Early Modern Period (Dordrecht: Springer, 2006), pp. 9-28. 
Ross, James Bruce. 'Venetian Schools and Teachers Fourteenth to Early Sixteenth Century: A Survey and Study of Giovanni Battista Egnazio', Renaissance Quarterly, 39 (1976), pp. 521-566.

Ross, Richard P. 'Oronce Fine's De Speculo Ustorio: A Heretofore Ignored Early French Renaissance Printed Treatise on Mathematical Optics', Historia Mathematica, 3 (1976), pp. 63-70.

Rossi, Paolo. 'Hermeticism, Rationality, and the Scientific Revolution' in Righini Bonelli, M. L and William R. Shea, eds., Reason, Experiment and Mysticism in the Scientific Revolution (New York: Science History Publications, 1975), pp. 247-273.

Rossi, Paolo. Philosophy, Technology, and the Arts in the Early Modern Era, trans. Salvator Attanasio, ed. Benamin Nelson (New York: Harper and Row 1970; originally published as I filosofi e le macchine: 1400-1700, Milan: Feltrinelli, 1962).

Rouse Ball, W. W. A History of the Study of Mathematics at Cambridge (Cambridge: Cambridge University Press, 1889).

Roux, Sophie. 'Forms of Mathematization (14th-17th Centuries)', Early Science and Medicine, 15 (2010), pp. 319-337.

Russell, John L. 'The Copernican System in Great Britain', in Dobrzycki, Jerzy ed., The Reception of Copernicus' Heliocentric Theory: Proceedings of a Symposium Organized by the Nicolas Copernicus Committee of the International Union of the History and Philosophy of Science Toruń, Poland, 1973 (Dordrecht: Springer Science + Business Media, 1972), pp. 189-239.

Rutkin, H. Darrel. 'Various Uses of Horoscopes: Astrological Practices in Early Modern Europe', in Oestmann, Günther, H. Darrel Rutkin, and Kocku von Stuckrad, eds., Horoscopes and Public Spheres: Essays on the History of Astrology (Berlin: Walter De Gruyter GmbH, 2005), pp. 167-178.

Sarton, George. 'L'histoire de la science', Isis, 1.1 (1913), pp. 3- 46.

Sarton, George. The Study of the History of Mathematics (New York: Dover, 1957; originally Cambridge, MA.: Harvard University Press, 1937).

Sasaki, Chikara. Descartes's Mathematical Thought (Dordrecht, Boston, and London: Kluwer Academic Publishers, 2003).

Scaglione, Aldo. The Liberal Arts and the Jesuit College System (Amsterdam and Philadelphia: The John Benjamins Publishing Company, 1986).

Schaffer, Simon. 'Newton at the Crossroads', Radical Philosophy, 37 (1984), pp. 2328.

Schechner Genuth, Sara. 'Armillary Sphere', in Bud, Robert, and Deborah Jean Warner, eds., Instruments of Science: An Historical Encyclopedia (New York and London: The Science Museum, London and The National Museum of American 
History, Smithsonian Institution in association with Garland Publishing, 1998), pp. 28-31.

Schindling, Anton. Humanistische Hochschule und freie Reichsstadt: Gymnasium und Akademie in Strassburg 1538-1621 (Wiesbaden: Steiner, 1977).

Schmitt, Charles B. 'Reappraisals in Renaissance Science', History of Science, 16 (1978), pp. 200-214.

Schmitt, Charles B. 'Towards a Reassessment of Renaissance Aristotelianism', History of Science, 11 (1973), pp. 159-193.

Schmitt, Charles B. Aristotle and the Renaissance (Cambridge, MA: and London: Harvard University Press for Oberlin College, 1983).

Schmitt, Charles B. John Case and Aristotelianism in Renaissance England (Kingston and Montreal: McGill Queen's University Press, 1983).

Schönbeck, Jürgen. 'Thomas Fincke und die Geometriae rotundi', NTM Zeitschrift für Geschichte der Wissenschaften, Technik und Medizin, 12.2 (2004), pp. 80-89.

Schotte, Margaret. 'Expert Records: Nautical Logbooks from Columbus to Cook', Information and Culture, 48.3 (2013), pp. 281-322.

Schuster, John. 'Internalist and Externalist Historiographies of the Scientific Revolution', in Applebaum, Wilbur, ed., The Encyclopedia of the Scientific Revolution: From Copernicus to Newton (New York: Routledge, 2008) pp. 334-336.

Scinto, Janet E. 'The Panel Stamp in Early and Modern Bindings', Library Quarterly: Information, Community, Policy, 85 (2015), pp. 106-111.

Scott, Jonathan. When the Waves Ruled Britannia: Geography and Political Identities, 1500-1800 (Cambridge: Cambridge University Press, 2011).

Sebastiani, Valentina. Johann Froben, Printer of Basel: A Biographical Profile and Catalogue of his Editions (Leiden and Boston: Brill, 2018).

Sgarbi, Marco. The Aristotelian Tradition and the Rise of British Empiricism: Logic and Epistemology in the British Isles (Dordrecht: Springer, 2013).

Shank, Michael H. 'The Geometrical Diagrams in Regiomontanus's Edition of his own Disputationes (c. 1475): Background, Production, and Diffusion', Journal for the History of Astronomy, 43.1 (2012), pp. 27-55.

Shapin, Steven. 'Discipline and Bounding: The History and Sociology of Science as seen through the Externalism-Internalism Debate', History of Science, 30.4 (1992), pp. 333-369.

Shapin, Steven. 'Here and Everywhere - Sociology of Scientific Knowledge', Annual Review of Sociology, 21 (1995), pp. 289-321. 
Shapin, Steven. The Scientific Revolution (Chicago and London: University of Chicago Press, 1996).

Sharpe, Kevin. Reading Authority and Representing Rule in Early Modern England (London: Bloomsbury Academic, 2013).

Sharratt, Peter. 'La Ramée's Early Mathematical Teaching', Bibliothèque d'Humanisme et Renaissance, 28.3 (1966), pp. 605-614.

Shea, William, ed., Nature Mathematized. Historical and Philosophical Case Studies in Classical Modern Natural Philosophy, 2 vols (Dordrecht, Boston and London: D. Reidel, 1983).

Sherman, William H. ' Soiled by use' or 'enlivened by association'? Attitudes toward marginalia', in Edwards, Rosalind, John Goodwin, Henrietta O'Connor, and Ann Phoenix, eds., Working with Paradata, Marginalia, and Field Notes: The Centrality of By-Products of Social Research (Cheltenham and Northampton, MA: Edward Elgar Publishing, 2017), pp. 134-153.

Sherman, William H. 'The Place of Reading in the English Renaissance', in Raven, James, Helen Small \& Naomi Tadmor, eds., The Practice and Representation of Reading in England (Cambridge: Cambridge University Press, 1996) pp. 42-76.

Sherman, William H. John Dee: The Politics of Reading and Writing in the Renaissance (Amherst: University of Massachusetts Press, 1995).

Sherman, William H. Used Books: Marking Readers in Renaissance England (Philadelphia: University of Pennsylvania Press, 2008).

Silverberg, Joel S. 'Nathaniel Torporley and his Diclides Coelometricae (1602): A Preliminary Investigation', Proceedings of the Canadian Society for History and Philosophy of Mathematics, 34th Annual Meeting (2009), pp. 143-154.

Simcock, Anthony V. 'Elucidatio fabricae ususque: Rambling among the Beginnings of the Scientific Instrument Bookshelf', in Hackmann, W. D., and A. J. Turner, eds., Learning, Language and Invention: Essays Presented to Francis Maddison (Aldershot \& Paris: Variorum, 1994), pp. 273-296.

Sirluck, Ernest. 'Areopagitica and a Forgotten Licensing Controversy', The Review of English Studies, 11.43 (1960), pp. 260-274.

Smith, David Eugene. A Source Book in Mathematics (New York: Dover Publications, 1959; originally poublished 1929).

Smith, David Eugene. Rara Arithmetica: A Catalogue of the Arithmetics Written Before the Year MDCI, with a Description of Those in the Library of George Arthur Plimpton of New York, $4^{\text {th }}$ edn, including Augustus De Morgan's Arithmetical Books (New York: Chelsea, 1970). 
Smith, Helen and Louise Wilson, eds., Renaissance Paratexts (Cambridge:

Cambridge University Press, 2011).

Smith, Pamela H. The Body of the Artisan: Art and Experience in the Scientific Revolution (Chicago: University of Chicago Press, 2004).

Sonar, Thomas. 'The 'Regiments' of Sun and Pole Star: On Declination Tables in early modern England', GEM International Journal on Geomathematics, 1 (2010), pp. 5-21.

Spitz, Lewis W., and Barbara Sher Tinsley. Johann Sturm on Education (St Louis, MO: Concordia Publishing House, 1995).

Sponberg Pedley, Mary. The Commerce of Cartography: Making and Marketing Maps in Eighteenth-Century France and England (Chicago and London: The University of Chicago Press, 2005).

Spufford, Margaret. 'First Steps in Literacy: The Reading and Writing Experiences of the Humblest Seventeenth-Century Spiritual Autobiographers', Social History, 4 (1979), pp. 407-435.

Stallybrass, Peter. 'Books and Scrolls: Navigating the Bible' in Andersen, Jennifer, and Elizabeth Sauer, eds., Books and Readers in Early Modern England: Material Studies (Philadelphia: University of Pennsylvania Press, 2002), pp. 42-79.

Stedall, Jacqueline A. 'Reconstructing Thomas Harriot's Treatise on Equations', in Fox, Robert, ed., Thomas Harriot and his World: Mathematics, Exploration and Natural Philosophy in Early Modern England (Farnham: Ashgate, 2012), pp. 53-64.

Stedall, Jacqueline A. 'Rob'd of Glories: The Posthumous Misfortunes of Thomas Harriot and His Algebra', Archive for History of Exact Sciences, 54.6 (2000), pp. 455-497.

Stedall, Jacqueline A. The Great Invention of Algebra: Thomas Harriot's Treatise on Equations (Oxford: Oxford University Press, 2003).

Stedall, Jacqueline. Mathematics Emerging: A Sourcebook, 1540-1900 (Oxford: Oxford University Press, 2008).

Steel, J. M. 'Dunthorne, Mayer and Lalande on the Secular Acceleration of the Moon', in Jones, Alexander, ed., Ptolemy in Perspective: Use and Criticism of his Work from Antiquity to the Nineteenth Century (Dordrecht: Springer, 2010), pp. 203215.

Steinberg, Phillip E. 'Calculating Similitude and Difference: John Seller and the 'Placing' of English Subjects in a Global Community of Nations', Social and Cultural Geography, 7.5 (2006), pp. 687-707.

Stewart, Susan. On Longing: Narratives of the Miniature, the Gigantic, the Souvenir, the Collection (Durham and London: Duke University Press, 1993). 
Stoddard, Roger. Marks in Books, Illustrated and Explained (Cambridge, MA: Houghton Library, Harvard University, 1985).

Stokeley, James. 'Sir Isaac Newton's Library Offered for Sale in England', Journal of the Royal Astronomical Society of Canada, 23 (1929), pp. 397-398.

Summit, Jennifer. Memory's Library: Medieval Books in Early Modern England (Chicago and London: University of Chicago, 2008).

Swann, Marjorie. Curiosities and Texts: The Culture of Collecting in Early Modern England (Philadelphia: The University of Pennsylvania Press, 2001).

Swerdlow, N. M. 'Tycho, Longomontanus, and Kepler on Ptolemy's Solar Observations and Theory, Precession of the Equinoxes, and Obliquity of the Ecliptic', in Jones, Alexander, ed., Ptolemy in Perspective: Use and Criticism of his Work from Antiquity to the Nineteenth Century (Dordrecht: Springer, 2010), pp. 151202.

Tanner, Rosalind C. H. 'Nathaniel Torporley's 'congestor analyticus' and Thomas Harriot's 'de triangulis laterum rationalium', Annals of Science, 34 (1977), pp. 393428.

Tanner, Rosalind C. H. 'The Study of Thomas Harriot's Manuscripts. 1. Harriot's Will', History of Science, 6 (1967), pp. 1-16.

Taub, Liba. 'Introduction: Re-engaging with Instruments', Isis, 102.4 (2011), pp. 689-696.

Taylor, E. G. R. The Mathematical Practitioners of Hanoverian England, 1714-1840 (Cambridge: Institute of Navigation at the University Press, 1966).

Taylor, E. G. R. The Mathematical Practitioners of Tudor and Stuart England (Cambridge: Institute of Navigation at the University Press, 1954).

Taylor, E. G. R., and M. W. Richley, ed., The Geometrical Seaman: A Book of Early Nautical Instruments (London: Hollis \& Carter for the Institute of Navigation, 1962).

Taylor, Katie. 'A "Practique Discipline"? Mathematical Arts in John Blagrave's The Mathematical Jewel (1585)', Journal for the History of Astronomy, 41.3 (2010), pp. 329-353.

Theunissen, Bert. 'Unifying Science and Human Culture: The Promotion of the History of Science by George Sarton and Frans Verdoorn', in Kamminga, Harmke and Geert Somsen, eds., Pursuing the Unity of Science: Ideology and Scientific Practice from the Great War to the Cold War (London and New York: Routledge, 2016), pp. 182-206.

Thomas, Hannah. “"Books Which are Necessary For Them”: Reconstructing a Jesuit Missionary Library in Wales and the English Borderlands, ca. 1600-1679', in Bela, Teresa, Clarinda Calma, and Jolanta Rzegocka, eds., Publishing Subversive Texts in 
Elizabethan England and the Polish-Lithuanian Commonwealth (Leiden: Brill, 2016), pp. 100-128.

Thomas, Keith. 'Numeracy in Early Modern England: The Prothero Lecture', Transactions of the Royal Historical Society, 37 (1987), pp. 103-132.

Thomas, Keith. Religion and the Decline of Magic: Studies in Popular Beliefs in Sixteenth and Seventeenth Century England (Oxford: Oxford University Press, 1971).

Thompson, Grahame. 'Early Double-Entry Bookkeeping and the Rhetoric of Accounting Calculation', in Hopwood, Anthony G., and Peter Miller, eds., Accounting as Social and Institutional Practice (Cambridge: Cambridge University Press, 1994), pp. 40-66.

Thoren, Victor E. 'Prosthaphaeresis Revisited', Historia Mathematica, 15 (1988), pp. 32-39.

Thorndike, Lynn. A History of Magic and Experimental Science, 8 vols (New York: Columbia University Press, 1923-1958).

Thorndike, Lynn. The Sphere of Sacrobosco and its Commentators (Chicago: University of Chicago Press, 1949),

Todd Knight, Jeffrey. 'Fast Bind, Fast Find: The History of the Book and the Modern Collection', Criticism, 51.1 (2009), pp. 79-104.

Turner, A. J. 'From Mathematical Practice to the History of Science', Journal of the History of Collections, 7.2 (1995), pp. 135-150.

Turner, A. J. 'Interpreting the History of Scientific Instruments', in Anderson, R. G. W., J. A. Bennett, and W. F. Ryan, eds., Making Instruments Count. Essays on Historical Scientific Instruments presented to Gerard L'Estrange Turner (Aldershot: Variorum, Ashgate Publishing Ltd, 1993), pp. 17-26.

Turner, A. J. 'Mathematical Instruments and the Education of Gentlemen', Annals of Science, 30.1 (1973), pp. 51-88.

Turner, A. J. Early Scientific Instruments, Europe 1400-1800 (London: Sotheby's, 1987).

Tyacke, Sarah. 'Map-Sellers and the London Map Trade, 1650-1710', in Wallis, Helen, and Sarah Tyacke, eds., My Head is a Map: Essays and Memoirs in Honour of R. V. Tooley (London: Francis Edwards and Carta Press, 1973), pp. 63-80.

Uhlig, Claus. 'National Historiography and Cultural Identity: The Example of the English Renaissance', in Grabes, Herbert, ed., Writing the Early Modern English Nation: The Transformation of National Identity in Sixteenth-and SeventeenthCentury England. (Amsterdam and Atlanta, GA: Rodopi B. V., 2001), pp. 89-108. 
Unwin, George. The Guilds and Companies of London, $4^{\text {th }}$ edn (London: Frank Cass, 1963).

Valleriani, Matteo. 'The Epistemology of Practical Knowledge', in Valleriani, Matteo, ed., The Structures of Practical Knowledge (Cham: Springer International Publishing AG, 2017), pp. 1-21.

Valleriani, Matteo. 'The Tracts on the Sphere: Knowledge Restructured Over a Network', in Valleriani, Matteo, ed., The Structures of Practical Knowledge (Cham: Springer International Publishing, 2017), pp. 421-473.

Valleriani, Matteo. Galileo Engineer (Dordrecht: Springer, 2010).

van Brummelen, Glen. The Mathematics of the Heavens and the Earth: The Early History of Trigonometry (Princeton and Oxford: Princeton University Press, 2009).

van Helden, Albert, and Thomas L. Hankins. 'Introduction: Instruments in the History of Science', Osiris, 9 (1994), pp. 1-6.

van Uchelen, Ton Croiset. 'Jodocus Hondius's Theatrum artis scribendi examined anew', Quaerendo, 34.1-2 (2004), pp. 53-86.

Vanden Broecke, Steven. 'The Use of Visual Media in Renaissance Cosmography: The Cosmography of Peter Apian and Gemma Frisius', Pedagogica Historica, 36 (2000), pp. 130-150.

Vázquez, Oscar E. Inventing the Art Collection: Patrons, Markets, and the State in Nineteenth-Century Spain (Pennsylvania: The Pennsylvania State University Press, 2001).

Veazie Skalnik, James. Ramus and Reform: University and Church at the End of the Renaissance (Kirksville, MO: Truman State University, 2002).

Venn, John, and J. A. Venn, eds., Alumni Cantabrigienses: A Biographical List of all Known Students, Graduates and Holders of Office at the University of Cambridge, from the Earliest Times to 1900. Part I: From The Earliest Times to 1751. Volume IV: Sall - Zuinglius (Cambridge: Cambridge University Press, 1927).

Venn, John, and J. A. Venn, eds., Alumni Cantabrigienses: A Biographical List of all Known Students, Graduates and Holders of Office at the University of Cambridge, from the Earliest Times to 1900. Part I: From The Earliest Times to 1751. Volume II: Dabbs-Juxton (Cambridge: Cambridge University Press, 1927).

Vermeir, Koen. “'Bent and Directed Towards Him': A Stylistic Analysis of Kircher's Sunflower Clock', in Gal, Ofer, and Raz Chen-Morris, eds., Science in the Age of the Baroque (Dordrecht: Springer, 2013), pp. 47-76.

Verner, Coolie. 'Copperplate Printing', in Woodward, David, ed., Five Centuries of Map Printing (Chicago and London: University of Chicago Press, 1975), pp. 51-75. 
Verner, Coolie. 'Engraved Title Plates for the Folio Atlases of John Seller', in Wallis, Helen, and Sarah Tyacke, eds., My Head is a Map: Essays and Memoirs in Honour of R. V. Tooley (London: Francis Edwards and Carta Press, 1973), pp. 21-52.

Verner, Coolie. 'John Seller and the Chart Trade in Seventeenth-Century England', in Thrower, N. J. W., ed., The Compleat Plattmaker: Essays on Chart, Map, and Globe Making in England in the Seventeenth and Eighteenth Centuries (Berkeley, Los Angeles, and London: University of California Press, 1978), pp. 127-158.

Vickers, Brian. 'Epideictic and Epic in the Renaissance', New Literary History, 14.3 (1983), pp. 497-537.

von Braumühl, Anton Elder. Vorlesungen über Geschichte der Trigonometrie, Erster Teil. (Leipzig: B. G. Teubner, 1900-1903).

Wallis, H. M. 'The Molyneux Globes', British Museum Quarterly, 16.4 (1952), pp. 89-90.

Wallis, Helen. 'Navigators and Mathematical Practitioners in Samuel Pepys' Day: The Eva G. R. Taylor Lecture', Journal of Navigation, 47.1 (1994), pp. 1-19.

Ward Gilbert, Neal. Renaissance Concepts of Method (New York: Columbia University Press, 1960).

Wardhaugh, Benjamin. 'Consuming Mathematics: John Ward's Young Mathematician's Guide (1707) and Its Owners', Journal for Eighteenth-Century Studies, 38 (2015), pp. 65-82.

Wardhaugh, Benjamin. 'Mathematics in English Printed Books, 1473-1800: A Bibliometric Analysis', Notes and Records of the Royal Society, 63 (2009), pp. 325338.

Wardhaugh, Benjamin. How to Read Historical Mathematics (Princeton and Oxford: Princeton University Press, 2010).

Wardhaugh, Benjamin. Music, Experiment and Mathematics in England, 1653-1705 (Aldershot: Ashgate, 2008).

Warner, Deborah Jean. 'What is a scientific instrument, when did it become one, and why?', British Journal of the History of Science, 23 (1990), pp. 83-93.

Waters, David W. The Art of Navigation in England in Elizabethan and Early Stuart Times, 3 vols, $2^{\text {nd }}$ edn (London: National Maritime Museum, 1978; originally London: Hollis and Carter, 1958).

Webster, Charles, ed., Samuel Hartlib and the Advancement of Learning (Cambridge: Cambridge University Press, 1970).

Webster, Charles. The Great Instauration: Science, Medicine, and Reform, 16261660, $2^{\text {nd }}$ edn (Oxford: Peter Lang, 2002). 
Webster, Tom. Godly Clergy in Early Stuart England: The Caroline Puritan Movement, c. 1620-1643 (Cambridge: Cambridge University Press, 1997).

Westfall, Richard S. The Construction of Modern Science: Mechanisms and Mechanics (New York: John Wiley \& Sons, 1971).

Westman, Robert S. 'Magical Reform and Astronomical Reform: The Yates Thesis Reconsidered', in Westman, Robert S., and J. E. McGuire, eds., Hermeticism and the Scientific Revolution (Los Angeles: William Andrews Clark Memorial Library, 1977), pp. 1-91.

Westman, Robert S. 'The Astronomer's Role in the Sixteenth Century: A Preliminary Study', History of Science, 18.2 (1980), pp. 105-147.

Westman, Robert S. 'The Melanchthon Circle, Rheticus, and the Wittenberg Interpretation of the Copernican Theory', Isis, 66.2 (1975), pp. 164-193.

Westmann, Robert S. The Copernican Question: Prognostication, Skepticism, and Celestial Order (Berkeley, Los Angeles and London: The University of California Press, 2011).

Wey Gomez, Nicolas. 'The Politics of Light: Al-Kindī's Optics and the Vindication of the American Tropics in Bartolomé de las Casas's Apologética historia sumaria (1527-1561)', in Melion, Walter S., and Lee Palmer Wandel, eds., Early Modern Eyes (Leiden: Brill, 2010), pp. 11-54.

Willmoth, Frances. Sir Jonas Moore: Practical Mathematics and Restoration Science (Woodbridge: The Boydell Press, 1993).

Wilson, Bronwen. The World in Venice: Print, the City, and Early Modern Identity (Toronto: University of Toronto Press, 2005).

Wittkower, Rudolf. Architectural Principles in the Age of Humanism (London: Studies of the Warburg Institute, 1949).

Wolfe, Jessica. Humanism, Machinery, and Renaissance Literature (Cambridge: Cambridge University Press, 2004).

Wood, Anthony à, and Phillip Bliss, ed., Athenae Oxonienses: An Exact History of All the Writers and Bishops who have had their Education in the University of Oxford, Volume 2, $3^{\text {rd }}$ edn (London: Rivington, 1815).

Woodward, David. 'Techniques of Map Engraving, Printing, and Coloring in the European Renaissance', in Woodward, David, ed., The History of Cartography, Volume Three: Cartography in the European Renaissance, Part 1 (Chicago: University of Chicago Press, 2007), pp. 591-610.

Woodward, David. 'The Manuscript, Engraved, and Typographic Traditions of Map Lettering' in Woodward, David, ed., Art and Cartography: Six Historical Essays (Chicago and London: The University of Chicago Press, 1987), pp. 174-212. 
Wyatt, Nicholas. 'Waves of Change: How the Science Museum's Library Rose, Fell and Rose Again', in Morris, Peter J. T., ed., Science for the Nation: Perspectives on the History of the Science Museum (Houndmills: Palgrave Macmillan, 2010), pp. 136-156.

Yates, Frances A. 'The Hermetic Tradition in Renaissance Science' in Singleton, Charles S., ed., Art, Science and History in the Renaissance (Baltimore: The Johns Hopkins University Press, 1967), pp. 255-274.

Yates, Frances A. Giordano Bruno and the Hermetic Tradition (London: Routledge and Kegan Paul, 1964).

Yeo, Matthew. The Acquisition of Books by Chetham's Library, 1655-1700 (Leiden and Boston: Brill, 2011).

Yeo, Richard. Notebooks, English Virtuosi, and Early Modern Science (Chicago: University of Chicago Press, 2014).

Yoder, Joella G. Unrolling Time: Christiaan Huygens and the Mathematization of Nature (Cambridge: Cambridge University Press, 1989).

Young, Sandra. The Early Modern Global South in Print: Textual Form and the Production of Human Difference as Knowledge (Farnham: Ashgate Publishing Ltd, 2015).

Zemon Davis, Natalie. 'Beyond the Market: Books as Gifts in Sixteenth-Century France: The Prothero Lecture', Transactions of the Royal Historical Society, 33 (1983), pp. 69-88.

Zemon Davis, Natalie. 'Sixteenth-Century French Arithmetics on the Business Life', Journal of the History of Ideas, 21.1 (1960), pp. 18-48.

Zilsel, Edgar. 'The Methods of Humanism', in Raven, Diedrick, Wolfgang Krohn, and Robert S. Cohen, eds., The Social Origins of Modern Science (Dordrecht: Springer Science + Business Media, 2003), pp. 50-65.

Zilsel, Edgar. 'The Sociological Roots of Science', in Raven, Diedrick, Wolfgang Krohn, and Robert S. Cohen, eds., The Social Origins of Modern Science (Dordrecht: Springer Science + Business Media, 2003), pp. 7-21.

Zinner, Ernst, Regiomontanus: His Life and Work, trans. E. Brown (Amsterdam: Elsevier Science Publishers, 1990).

Zinner, Ernst. Deutsche und Niederländische Astronomische Instrumente des 11.-18. Jahrhunderts (Munich: C. H. Beck, 1956).

Zinner, Ernst. Deutsche und Niederländische Astronomische Instrumente des 11. bis 18. Jahrhunderts, $2^{\text {nd }}$ edn (Munich: C. H. Beck, 1979). 
Zinner, Ernst. Leben und Wirken des Johannes Müller von Königsberg gennant Regiomontanus (Munich: C. H. Beck, 1938).

\section{Unpublished Secondary Sources Cited, by Author}

Best, Graham. 'Books and Readers in Certain Eighteenth-Century Parish Libraries', unpublished PhD Dissertation, Loughborough University, 1985.

(Henninger-) Voss, Mary. 'Between the Cannon and the Book: Mathematics and Military Culture in Cinquecento Italy', Unpublished Ph.D. Dissertation, The Johns Hopkins University, 1995.

Johnston, Stephen. 'Making Mathematical Practice: Gentlemen, Practitioners and Artisans in Early Modern England', unpublished PhD Dissertation, University of Cambridge, 1994. 
Calculating Value: Using and Collecting the Tools of Early Modern Mathematics

Appendices 

Appendix 1: Science Museum Rare Books Collection: Data on Subject Groupings and Unseen Texts

\begin{tabular}{|c|c|c|c|c|}
\hline Existing Broad Subject Grouping & $\begin{array}{c}\text { Abbreviated } \\
\text { Subject Grouping }\end{array}$ & $\begin{array}{c}\text { Total } \\
\text { Number of } \\
\text { Titles } \\
\text { Reviewed }\end{array}$ & $\begin{array}{c}\text { Total } \\
\text { Number of } \\
\text { Titles in } \\
\text { Collection }\end{array}$ & $\begin{array}{c}\text { Percentage } \\
\text { of Total Titles } \\
\text { reviewed per } \\
\text { grouping }\end{array}$ \\
\hline Astronomy & ASTR & 178 & 184 & 96.7 \\
\hline Physics and Natural Philosophy & PHYS & 174 & 175 & 99.4 \\
\hline Mathematics & MATH & 139 & 142 & 97.9 \\
\hline Mathematics - Arithmetic & ARTH & 71 & 74 & 95.9 \\
\hline Science - General and Societies & SCIE & 71 & 73 & 97.3 \\
\hline Astronomical Instruments and Globes & ASTI & 63 & 64 & 98.4 \\
\hline Physics - Optics & OPTC & 56 & 57 & 98.2 \\
\hline Mathematics - Geometry & GEOM & 52 & 53 & 98.1 \\
\hline Weights and Measures & WGMS & 48 & 49 & 98.0 \\
\hline Transport - Ships, Shipbuilding and Naval History & SHIP & 47 & 48 & 97.9 \\
\hline Scientific Instruments - Surveying and Geodesy & SURV & 47 & 47 & 100.0 \\
\hline Scientific Instruments & SCIN & 46 & 46 & 100.0 \\
\hline Mathematical Instruments & MTHI & 45 & 45 & 100.0 \\
\hline Engineering - Machines and Mechanical Engineering & $\mathrm{MECH}$ & 39 & 40 & 97.5 \\
\hline Scientific Instruments - Sundials & SUND & 38 & 38 & 100.0 \\
\hline Microscopes and Microscopy & MICR & 36 & 36 & 100.0 \\
\hline Geography, Atlases, Maps \& Charts & GEOG & 35 & 88 & 39.8 \\
\hline Physics - Hydrodynamics, Hydrostatics & HyDS & 32 & 32 & 100.0 \\
\hline Chemistry - Alchemy & $\mathrm{ALCH}$ & 29 & 62 & 46.8 \\
\hline Engineering - Civil Engineering & CVLE & 28 & 31 & 90.3 \\
\hline Science - Navigation & NAVG & 24 & 24 & 100.0 \\
\hline Scientific Instruments - Horology & HORL & 23 & 23 & 100.0 \\
\hline Encyclopaedias & ENCY & 21 & 25 & 84.0 \\
\hline Engineering - Metallurgy & METL & 21 & 96 & 21.9 \\
\hline Chemistry & CHEM & 21 & 115 & 18.3 \\
\hline Engineering - Hydraulic Engineering & HYDR & 20 & 32 & 62.5 \\
\hline Engineering - Military Arts and Engineering & MLTY & 19 & 19 & 100.0 \\
\hline Mathematics - Perspective & PERS & 18 & 18 & 100.0 \\
\hline Astronomy - Cosmology and Cosmography & CSMO & 18 & 18 & 100.0 \\
\hline Science - Philosophy, Philosophy Of Science, Logic & PHIL & 16 & 35 & 45.7 \\
\hline Earth Sciences - Weather, Meteorology & MTEO & 12 & 34 & 35.3 \\
\hline Mathematics - Business, Taxes and Duties & BSNM & 12 & 12 & 100.0 \\
\hline Mathematics - Trigonometry & TRIG & 12 & 12 & 100.0 \\
\hline Medicine & MEDI & 12 & 77 & 15.6 \\
\hline Mathematics - Calculus & CALC & 11 & 12 & 91.7 \\
\hline Scientific Instruments - Navigation & NAVI & 11 & 11 & 100.0 \\
\hline Chemistry - Mineralogy & MNRL & 11 & 117 & 9.4 \\
\hline Mathematics - Logarithms & LOGS & 10 & 11 & 90.9 \\
\hline Mathematics - Algebra & ALGB & 10 & 10 & 100.0 \\
\hline Natural History & NATH & 8 & 84 & 9.5 \\
\hline Physics - Electricity and Magnetism & ELCT & 8 & 62 & 12.9 \\
\hline Biography and History & HIST & 8 & 62 & 12.9 \\
\hline Earth Sciences - Earth - Shape, Figure, Size, Age & ERTH & 6 & 9 & 66.7 \\
\hline Arts \& Literature - Architecture and Building & $\mathrm{ARCH}$ & 5 & 14 & 35.7 \\
\hline Food \& Farming - Agriculture & AGRC & 5 & 31 & 16.1 \\
\hline Astronomy - Astrology and The Occult & ASTL & 5 & 6 & 83.3 \\
\hline Museums & MUSM & 5 & 17 & 29.4 \\
\hline Engineering - Inventions & $\mathbb{N} V N$ & 5 & 11 & 45.5 \\
\hline Industries, Trades \& Commerce & INDU & 4 & 56 & 7.1 \\
\hline Medicine - Pharmacopaeia and Materia Medica & PHRM & 4 & 38 & 10.5 \\
\hline Geology - Palaeontology & PALN & 3 & 22 & 13.6 \\
\hline Earth Sciences - Geophysics, Seismology and Volcanology & GEOP & 3 & 36 & 8.3 \\
\hline \multirow[t]{2}{*}{ Languages and Literature } & LANG & 3 & 24 & 12.5 \\
\hline & Grand Total & 1648 & 2557 & 64.5 \\
\hline
\end{tabular}




\section{Appendix 1: Science Museum Library Rare Books Collection - Unseen texts}

Owing to display, conservation concerns, or other issues, the following texts were unable for review as part 0 taken from the existing Science Museum Library catalogue data as provided at the beginning of the current $p$ online via https://smg.koha-ptfs.co.uk/.

\section{BROAD AUTHOR ENTRY ON TITLE SUBJECT CATALOGUE}

\begin{tabular}{|c|c|c|}
\hline ASTR & Ptolemy, 2nd cent. & Epytoma Joãnis De mõte regio Jn almagestu ptolomei. \\
\hline МАТН & Ptolemy, 2nd cent. & [Syntaxis. Greek] KL. Ptolemaiou Megales suntáxeos \\
\hline ARCH & Vitruvius Pollio. & De architectura libri decem ... \\
\hline ASTL & Ptolemy, 2nd cent. & Eis $t^{-}$en Tetrabiblon tou Ptolemaiou ex egetes an onymos \\
\hline GEOM & Euclid. & $\begin{array}{l}\text { [Elements. English 1570] The Elements of geometrie of the most } \\
\text { philosopher Evclide of Megara / Faithfully (now first) translated } \\
\text { toung bv H. Billingslev }\end{array}$ \\
\hline ASTR & $\begin{array}{l}\text { Kepler, Johannes, 1571- } \\
1630 .\end{array}$ & Astronomia nova \\
\hline ASTR & $\begin{array}{l}\text { Galilei, Galileo, } 1564- \\
1642\end{array}$ & Sidereus nuncius \\
\hline ASTR & $\begin{array}{l}\text { Kepler, Johannes, } 1571- \\
1630 .\end{array}$ & Dissertatio cum Nuncio sidereo nuper ad mortales misso a Galil \\
\hline SHIP & $\begin{array}{l}\text { Furttenbach, Joseph, 1591- } \\
1667 .\end{array}$ & $\begin{array}{l}\text { Architectura navalis : das ist, von dem Schiffgebäw, auff dem Me } \\
\text { zugebrauchen ... }\end{array}$ \\
\hline ASTR & $\begin{array}{l}\text { Galilei, Galileo, 1564- } \\
1642\end{array}$ & Dialogo \\
\hline
\end{tabular}




\begin{tabular}{|c|c|c|}
\hline ARTH & $\begin{array}{l}\text { Wingate, Edmund, 1596- } \\
1656 .\end{array}$ & $\begin{array}{l}\text { Mr. Wingate's arithmetick: containing a plain and familiar meth } \\
\text { knowledge and practice of common arithmetick. The fifth edition, }\end{array}$ \\
\hline ARTH & $\begin{array}{l}\text { Morland, Samuel, Sir, } \\
1625-1695 .\end{array}$ & $\begin{array}{l}\text { The description and use of two arithmetick instruments : togeth } \\
\text { treatise, explaining and demonstrating the ordinary operations } \\
\text { likewise, a perpetual almanack, and several useful tables ... }\end{array}$ \\
\hline PHYS & $\begin{array}{l}\text { Newton, Isaac, Sir, 1642- } \\
1727\end{array}$ & Principia mathematica \\
\hline MATH & $\begin{array}{l}\text { Torricelli, Evangelista, } \\
1608-1647 .\end{array}$ & $\begin{array}{l}\text { Lezioni accademiche d'Evangelista Torricelli, mattematico e fil } \\
\text { Ferdinando II, granduca di Toscana, lettore delle mattematich } \\
\text { Firenze e accademico della Crusca. }\end{array}$ \\
\hline CALC & $\begin{array}{l}\text { Newton, Isaac, Sir, 1642- } \\
1727\end{array}$ & The method of fluxions and infinite series \\
\hline INDU & Smith, George, 18th cent. & The laboratory, or School of arts. The 2nd ed. \\
\hline NAVI & Wakely, Andrew. & $\begin{array}{l}\text { The mariner's compass rectified: containing tables, shewing th } \\
\text { the sun being upon any point of the compass ... }\end{array}$ \\
\hline OPTC & $\begin{array}{l}\text { Priestley, Joseph, 1733- } \\
1804 .\end{array}$ & The history and present state of discoveries relating to vision, lig \\
\hline ASTR & $\begin{array}{l}\text { Kaestner, Abraham } \\
\text { Gotthelf, 1719-1800. }\end{array}$ & Formulae disco lunari dato tempore describendo \\
\hline ASTI & $\begin{array}{l}\text { Ludlam, William, 1717- } \\
1788 .\end{array}$ & $\begin{array}{l}\text { An introduction and notes, on Mr. Bird's Method of dividing as } \\
\text { instruments. }\end{array}$ \\
\hline SCIE & $\begin{array}{l}\text { Wilckens, Heinrich David, } \\
\text { 1763-1832. }\end{array}$ & Aufsätze mathematischen, physikalischen, chemischen Inhalts. Er \\
\hline
\end{tabular}




\begin{tabular}{|c|c|c|}
\hline MATH & Archimedes. & $\begin{array}{l}\text { [Works. Latin \& Greek. 1792] Archimedous ta sozomena meta to } \\
\text { Askalonitou hypomnematon: Archimedis qua supersunt omnia c } \\
\text { Ascalonitae commentariis }\end{array}$ \\
\hline CVLE & Phillips, J. (John), fl.1792. & $\begin{array}{l}\text { A general history of inland navigation, foreign and domestic: } \\
\text { account of the canals already executed in England, ... }\end{array}$ \\
\hline CVLE & Smeaton, John, 1724-1792 & Eddystone Lighthouse. 2nd ed. \\
\hline МЕСН & $\begin{array}{l}\text { Smeaton, John, 1724- } \\
1792 .\end{array}$ & $\begin{array}{l}\text { Experimental enquiry concerning the natural powers of wind a } \\
\text { and other machines depending on a circular motion. }\end{array}$ \\
\hline CVLE & Great Britain. & $\begin{array}{l}\text { An act to enable the Most Noble Francis Duke of Bridgewater } \\
\text { cut from his present navigation in the township of Worsley, .. }\end{array}$ \\
\hline BSNM & & $\begin{array}{l}\text { Useful suggestions favourable to the comfort of the labouring pe } \\
\text { housekeepers, explaining how a small income may be made to go } \\
\text { as to occasion a considerable saving in the article of bread, a cir } \\
\text { importance to be known at the present juncture. }\end{array}$ \\
\hline ENCY & ENCYCLOPAEDIA & Encyclopaedia Britannica: or, A dictionary of arts and scienc \\
\hline WGMS & $\begin{array}{l}\text { Institut de France. Classe } \\
\text { des sciences } \\
\text { mathématiques et } \\
\text { physiques. }\end{array}$ & $\begin{array}{l}\text { Discours prononcé a la barre des deux conseils du Corps législa } \\
\text { l'Institut national des sciences et des arts, lors de la présentation } \\
\text { prototypes du mètre et du kilogramme, et du rapport sur le trava } \\
\text { des poids et des mesures. }\end{array}$ \\
\hline ARTH & Vyse, Charles. & $\begin{array}{l}\text { The tutor's guide: being a complete system of arithmetic; with va } \\
\text { mathematics ... The fourth edition, corrected and improved, with }\end{array}$ \\
\hline
\end{tabular}




\begin{tabular}{l|ll} 
SCIE & $\begin{array}{l}\text { Hooke, Robert, 1635- } \\
1703 .\end{array}$ & $\begin{array}{l}\text { Philosophical collections, containing an account of ... physical, a a } \\
\text { chymical, astronomical, optical or other mathematical and philo } \\
\text { observations ... }\end{array}$ \\
ENCY & Harris, John, 1667?-1719. $\begin{array}{l}\text { Lexicon technicum: or, An universal English dictionary of arts ar } \\
\text { explaining not only terms of art, but the arts themselves. }\end{array}$ \\
MATH & $\begin{array}{l}\text { [Encyclopédie méthodique]. Dictionnaire des jeux familiers, ou, } \\
\text { société : faisant suite au Dictionnaire des jeux, annexé au tome I } \\
\text { Mathématiques. }\end{array}$
\end{tabular}


Appendix 2: A Reconstruction of Nathaniel Torporley's Library via his Bequest to Sion College

As detailed in Chapter 5 of the current thesis, titles of works owned by Nathaniel Torporley and bequeathed to Si with reference to the manuscript entries in the Sion College Book of Benefactors, Sion College shelfmark L40.2/E manuscript catalogue, Transcriptum Registri illius magni Benefactorum, 1629-1666, Sion College shelfmark L4C catalogue of 1650, Catalogus Universalis Librorum omnium in bibliotheca Collegii Sionii apud Londinenses (Lo1 such, the below is offered as a partial reconstruction of Torporley's collection.

\begin{tabular}{|c|c|c|c|}
\hline $\begin{array}{l}\text { Broad } \\
\text { Subject }\end{array}$ & $\begin{array}{l}\text { Manuscript Entry in Sion } \\
\text { College Book of } \\
\text { Benefactors / Spencer's } \\
\text { Transcriptum }\end{array}$ & Proposed Author & Proposed Title \\
\hline TRIG & $\begin{array}{l}\text { Petisci Thesaurus } \\
\text { Mathematicus }\end{array}$ & Pitiscus, Bartholomaeus & Thesaurus Mathematicus \\
\hline ASTRN & $\begin{array}{l}\text { Tabulae Rudolphi } \\
\text { Astronomiae }\end{array}$ & Kepler, Johannes & Tabulae Rudolphinae Astronomicae \\
\hline ARITH & $\begin{array}{l}\text { Diophanti Arithmeticae grae } \\
\text { Lat }\end{array}$ & $\begin{array}{l}\text { Diophantus of } \\
\text { Alexandra }\end{array}$ & $\begin{array}{l}\text { Liber Arithmeticus et de numerisu Po } \\
\text { seu multi-anulis cum Com. Gr Lat }\end{array}$ \\
\hline ASTRN & Gallucii Speculu $\sim$ Uranicu $\sim$ & $\begin{array}{l}\text { Gallucci, Giovanni } \\
\text { Paolo }\end{array}$ & $\begin{array}{l}\text { Speculum uranicum in quo vera loca } \\
\text { octavae sphaerae }\end{array}$ \\
\hline THEO & Hookr's Polity & Hooker, Richard & On the Laws of Ecclesiastical Polity \\
\hline ASTRN & Provitii Ephermerides & & \\
\hline
\end{tabular}




\begin{tabular}{|c|c|c|c|}
\hline & Constitutiones Oshoboni & & \\
\hline \multirow[t]{2}{*}{ ASTL } & $\begin{array}{l}\text { Centiloqueu Ptolomaei, } \\
\text { Almansor et Joannes de } \\
\text { Monte Regio }\end{array}$ & Ptolemy & $\begin{array}{l}\text { Epytoma Joannis de Monte Regio in } \\
\text { Almagestum Ptolomei }\end{array}$ \\
\hline & $\begin{array}{l}\text { Rationale Divionru Argent. } \\
1480\end{array}$ & & \\
\hline PHIL & $\begin{array}{l}\text { Paraphrasis totius } \\
\text { Philosophiae naturalis }\end{array}$ & $\begin{array}{l}\text { Aristotle; d'Etaples, } \\
\text { Jacques Lefevre }\end{array}$ & $\begin{array}{l}\text { Totius philosophiae naturalis } \\
\text { Paraphrasis: adjecto ad Litteram fam } \\
\text { Commentario }\end{array}$ \\
\hline ARCH & Architecture de Jean Martin & Martin, Jean; Vitriuvius & Architecture, ou art de bien bastir... \\
\hline OPTC & Vitellionis Perspectivae & Vitello & Perspectiva \\
\hline PHIL & $\begin{array}{l}\text { Philaltheus in Phisic } \\
\text { Aristotelis }\end{array}$ & $\begin{array}{l}\text { Lucillus Philaltheus } \\
\text { (Maggi, Lucilio) }\end{array}$ & $\begin{array}{l}\text { In IIII. libros Aristotelis de Caelo et } \\
\text { Commentarii }\end{array}$ \\
\hline PHIL & Picus Mirandola 1506 & Della Mirandola, Pico & Opera Omnia \\
\hline THEO & $\begin{array}{l}\text { Provinciales Constitut: } \\
\text { Linwooddi }\end{array}$ & Lyndwood, William & $\begin{array}{l}\text { Constitutiones provinciales ecclesie } \\
\text { anglica[n]e }\end{array}$ \\
\hline PHIL & Tartareti in Philosoph: & Tartaret, Pierre & $\begin{array}{l}\text { Possibly Com. in Sentent; or Expositic } \\
\text { summulas Hispani }\end{array}$ \\
\hline MEDI & Wecker Antedotariu & $\begin{array}{l}\text { Wecker, Johannes } \\
\text { Jacob }\end{array}$ & Antidotarium Speciale \\
\hline ASTRN & Alphonsi Tab Astronom: & Anonymous & Tabulae Astronomicae Alphonsinae \\
\hline ASTL & $\begin{array}{l}\text { Cardanus in Ptolomeu: de } \\
\text { Astris }\end{array}$ & $\begin{array}{l}\text { Cardano, Girolamo; } \\
\text { Ptolemy }\end{array}$ & $\begin{array}{l}\text { In Claudi Ptolemaei Pelusiensis IIII d } \\
\text { astrorum judiciis aut ut vulgo vocant, } \\
\text { quadripartite constructionis libros } \\
\text { commentaria, quae non solum astronc }\end{array}$ \\
\hline
\end{tabular}




\begin{tabular}{|c|c|c|c|}
\hline & & & $\begin{array}{l}\text { astrologis, sed etiam omnibus philoso } \\
\text { studiosis plurimum adiumenti adsere } \\
\text { poterunt }\end{array}$ \\
\hline MEDI & Imagines partium Corporis & $\begin{array}{l}\text { De Amusco, Juan } \\
\text { Valverde }\end{array}$ & $\begin{array}{l}\text { Vivae imagines partium corporis hum } \\
\text { aereis formis expressae }\end{array}$ \\
\hline PHIL & Sextus Empiricus & Sextus Empiricus & $\begin{array}{l}3 \text { works listed - Sentent., De Vita - B } \\
\text { Martini, and Dialogi }\end{array}$ \\
\hline MEDI & Weckeri Syntaxis Medicinae & $\begin{array}{l}\text { Wecker, Johannes } \\
\text { Jacob }\end{array}$ & Praxis Medicinae utriusq. \\
\hline GEOM & $\begin{array}{l}\text { Puteanus in } 10 \text { Libru } \\
\text { Euclidis }\end{array}$ & $\begin{array}{l}\text { Euclid; Puteanum, } \\
\text { Florimond }\end{array}$ & $\begin{array}{l}\text { Elementum } 10 \text { Lat Expressum per Flo } \\
\text { Puteanum }\end{array}$ \\
\hline HIST & $\begin{array}{l}\text { La vida del Emperadror } \\
\text { Izajano Span. }\end{array}$ & & \\
\hline MATH & Ptolomei Opera & Ptolemy & $\begin{array}{l}\text { Opera prae ter Geographiam Lat per } \\
\text { Schrekenfuchsium }\end{array}$ \\
\hline NATP & Macrobius & Macrobius & Opera \\
\hline GEOG & $\begin{array}{l}\text { Ptolomei Geographi Origines } \\
\text { Bas: } 1545\end{array}$ & Ptolemy & Geographia Lat \\
\hline THEO & Damasceni Theologicae & $\begin{array}{l}\text { Johannes Damascenus; } \\
\text { D'Etaples, Jacques } \\
\text { Lefevre }\end{array}$ & Contenta Theologia Damasceni \\
\hline ASTL & Julis Firmii Astroma & $\begin{array}{l}\text { Maternus, Julius } \\
\text { Firmicus }\end{array}$ & Astronomiae Libri VIII \\
\hline THEO & Fulk on Rhem: Just & Fulk, Willam & Annotations on the Rhemists Text \\
\hline
\end{tabular}




\begin{tabular}{|c|c|c|c|}
\hline LING & $\begin{array}{l}\text { Calcpini Dictionariu } 5 \\
\text { Linguis }\end{array}$ & & \\
\hline ARTH & Diophanti Arithmetica Lat & $\begin{array}{l}\text { Diophantus of } \\
\text { Alexandra }\end{array}$ & Arithmetica \\
\hline GEOM & Archimedis Opera & Archimedes & Opera Grae Lat \\
\hline \multirow[t]{2}{*}{ ASTRN } & $\begin{array}{l}\text { Copernicus de Revolutionib } \\
\text { Orbiu } \sim \text {; Descriptio orbiu } \\
\text { aliquot tab. colurat: }\end{array}$ & Copernicus, Nicolaus & De revolutionibus Orbium \\
\hline & $\begin{array}{l}\text { Pardonis (Buridanis?) } \\
\text { Dialectica }\end{array}$ & Possibly Buridan, Jean & Possibly Summa de Dialectica \\
\hline ASTL & Bonati Astronomia & Bonatti, Guido & De Astronomia tract. 10 \\
\hline PHIL & Seneca Opera ven 1503 & Seneca & Opera \\
\hline THEO & Postilae totius ami & Anonymous & Postillae Anni \\
\hline PHIL & $\begin{array}{l}\text { Plotinus de Rebus } \\
\text { Philosophicus }\end{array}$ & Plotinus & $\begin{array}{l}\text { De Rebus Philosophicus cum com. Mc } \\
\text { Ficini }\end{array}$ \\
\hline & $\begin{array}{l}\text { Liber de principis reru } \\
\text { naturalium }\end{array}$ & & \\
\hline TRIG & Canon Mathematicus & $\begin{array}{l}\text { Pitiscus, } \\
\text { Bartholomaeus; Otho, } \\
\text { Valentin }\end{array}$ & $\begin{array}{l}\text { Possibly Thesaurus Mathematicus siv } \\
\text { Canon Sinuum }\end{array}$ \\
\hline PHIL & Aquinatis Metyphysica & Aquinas, Thomas & Metaphysica et de Anima (MSS) \\
\hline THEO & Concordantiae Biblioru & $\begin{array}{l}\text { Conradus of } \\
\text { Halberstadt }\end{array}$ & Concordantiae Bibliorum \\
\hline
\end{tabular}




\begin{tabular}{|c|c|c|c|}
\hline ASTRN & $\begin{array}{l}\text { Kepleri Harmonices Mundi } \\
\text { (libri v) }\end{array}$ & Kepler, Johannes & Harmonices Mundi \\
\hline THEO & $\begin{array}{l}\text { Concilia Generalia de Pet } \\
\text { Crabb ( } 2 \text { vols } 1530)\end{array}$ & Crabbe, Petrus & Concilia Generalia et Provincilia \\
\hline ALGB & Vietae Isagoge & Viete, Francois & $\begin{array}{l}\text { No title matching - Viete's listed work } \\
\text { Opera Mathematica and } 4 \text { others }\end{array}$ \\
\hline \multirow[t]{2}{*}{ TRIG } & $\begin{array}{l}\text { Canon Trianguloru (vida } \\
\text { Canon Mathemat.) }\end{array}$ & Pitiscus, Bartholomaeus & Canon Triangulorum \\
\hline & $\begin{array}{l}\text { Biblia Junis est Trinitiis - } \\
\text { eadem Hi eo, cu Hist Grae et }\end{array}$ & & \\
\hline THEO & $\begin{array}{l}\text { Idem Heb Octavo cum } \\
\text { Psalmis Anglice }\end{array}$ & & \\
\hline PHIL & Campanellus de sensu rerum & Campanella, Tomasso & De Sensu rerum et magia \\
\hline ASTRN & Ticho Brahe & Brahe, Tycho & Opera Vol. 2 \\
\hline МАТН & Ceuleriij Aritmet et Geomet & van Ceulen, Ludolph & Fundamenta Arithmetica et Geometri \\
\hline NATP & Metochita in Astit Phys & Metochites, Theodore & \\
\hline THEO & Manuale ad usu $\sim$ Saru & & \\
\hline TRIG & Petisici Trigonometria & Pitiscus, Batholomaeus & Trigonometria \\
\hline POLT & Brevarium Jo de Vanguel & $\begin{array}{l}\text { Kölner, Johannes } \\
\text { (Johanne de Vanckel) }\end{array}$ & Breviarium Sexti et Clementinarum in \\
\hline ASTRN & $\begin{array}{l}\text { Kepleri. Astronomiae pars } \\
\text { optica }\end{array}$ & Kepler, Johannes & Astronomiae Par Optica \\
\hline
\end{tabular}




\begin{tabular}{|c|c|c|c|}
\hline ASTRN & Cardanii Astronomia & Cardano, Girolamo & $\begin{array}{l}\text { Possibly Aphorismorum Astronomico } \\
\text { Segmenta }\end{array}$ \\
\hline THEO & $\begin{array}{l}\text { Dr James Corruption of } \\
\text { Fathers }\end{array}$ & James, Thomas & $\begin{array}{l}\text { The Corruption of Scriptures, Fathers } \\
\text { Councell }\end{array}$ \\
\hline LIT & Aristophanes Comediae & Aristophanes & Comoedia 9 Grae ex Aldana edit \\
\hline ARITH & Nepiri Logarithma & Napier, John & Logarithmorum Canonis Descriptio \\
\hline ASTL & Schoneri Astrologia & Schoener, Johannes & Opusculum Astrologicum \\
\hline GEOM & $\begin{array}{l}\text { Orontius de Solaribus } \\
\text { Horolgiis }\end{array}$ & Finé, Oronce & De solaribus horologiis et quadrantib \\
\hline ASTRN & Liber astronomicus Hassice & & \\
\hline ASTL & Hispani Astrologia & Nabod, Valentin & Hispalensis Epitome Totitus Astrolgia \\
\hline THEO & P Comestoris historia biblica & Comestor, Petrus & Historia Scholastica \\
\hline HIST & Voscii Historia Pelagcina & Vossius, Gerardus & Historia Pelagiana \\
\hline ASTRN & $\begin{array}{l}\text { Liber judicum in Judiciis } \\
\text { Astronom. }\end{array}$ & $\begin{array}{l}\text { Māshā'allāh; } \\
\text { Liechtenstein, Peter }\end{array}$ & Liber novem judicum in judicijs astro \\
\hline ASTRN & $\begin{array}{l}\text { Torporley valuae } \\
\text { Astronomicae }\end{array}$ & Torporley, Nathaniel & $\begin{array}{l}\text { Diclides Coelometricae; seu Valuae } \\
\text { Astronomicae universales }\end{array}$ \\
\hline MUSC & $\begin{array}{l}\text { Aristoxeni Harmonica } \\
\text { Elementa }\end{array}$ & Aristoxenus & Elementa harmonica \\
\hline THEO & Acinae Sylvis Opera & $\begin{array}{l}\text { Piccolomini, Aeneas } \\
\text { Silvius (Pope Pius II) }\end{array}$ & Opera \\
\hline MEDI & $\begin{array}{l}\text { Severinis Iacta Mediciane } \\
\text { Philosophicae }\end{array}$ & Severinus, Peter & Idea medicinae philosophicae \\
\hline HIST & Orosii Histor Rom & Orosius, Paulus & Historiae Adversus Paganos \\
\hline
\end{tabular}




\begin{tabular}{|c|c|c|c|}
\hline THEO & $\begin{array}{l}\text { Expositio Hymnoru } \sim \text { ad usu } \sim \\
\text { saru } \sim\end{array}$ & & \\
\hline THEO & $\begin{array}{l}\text { Jo de Burgo: Casus } \\
\text { Conscientiae }\end{array}$ & & \\
\hline LING & Alphabectu Arabicu & & \\
\hline LING & Grammatica Arabicu & & \\
\hline THEO & $\begin{array}{l}\text { Schigkius de } 2 \text { bus natrius } \\
\text { Christi }\end{array}$ & Schegkius, Jacob & $\begin{array}{l}\text { Responsiones ad Anonymi librum de } \\
\text { persona et duabus Christi naturis }\end{array}$ \\
\hline THEO & $\begin{array}{l}\text { Trithem de Scriptoribus } \\
\text { Ecclesiasticus }\end{array}$ & Trithemius, Johannes & Liber de scriptoribus ecclesiasticis \\
\hline THEO & $\begin{array}{l}\text { Olimpiodorus in } \\
\text { ecclesiastic }(. . .)\end{array}$ & $\begin{array}{l}\text { Olympiodorus the } \\
\text { Younger }\end{array}$ & In Ecclesiastes \\
\hline HORL & Clavii Calendariu & Clavius, Christopher & $\begin{array}{l}\text { Apologia Calendarii Rom. Contra Mi } \\
\text { Maestlinum }\end{array}$ \\
\hline ALCH & $\begin{array}{l}\text { Lombardus in artem } \\
\text { Chemiae }\end{array}$ & $\begin{array}{l}\text { Bonus (Lombardus), } \\
\text { Petrus }\end{array}$ & Introductio in Divinam Chemicae Arte \\
\hline THEO & $\begin{array}{l}\text { Hug. Cardinalis Postillae ps } \\
2 \mathrm{da}\end{array}$ & & \\
\hline THEO & Darrells Fradulens Practises & Darrell, John & $\begin{array}{l}\text { His Fradulent Practises Discovered } \\
\text { concerning dispossession of Devils }\end{array}$ \\
\hline HIST & $\begin{array}{l}\text { Hist Brittanica defensio pe } \\
\text { Pricae }\end{array}$ & Price, Sir John & Historia Britannicae Defensio \\
\hline THEO & $\begin{array}{l}\text { Prestoni est Praenis } \\
\text { appellatio a Papa }\end{array}$ & $\begin{array}{l}\text { Preston, Thomas, and } \\
\text { Grenveus }\end{array}$ & Appellatio ad Papam \\
\hline GEOG & Fabrica del Mondo Ital & Aluno, Francesco & Della Fabrica del Mondo \\
\hline
\end{tabular}




\begin{tabular}{|c|c|c|c|}
\hline MEDI & $\begin{array}{l}\text { Fasciculus Mediciane } \\
\text { Paracelsicae }\end{array}$ & $\begin{array}{l}\text { Paracelsus, } \\
\text { Theophrastus von }\end{array}$ & Fasciculus Paracelsicae Medicinae \\
\hline MEDI & Bertachius de Spiritibus & Bertacchio, Domenico & De Spiritibus 4 et facultate vitali \\
\hline \multirow[t]{2}{*}{ LIT } & Bartas, Francois & $\begin{array}{l}\text { Du Bartas, Guillaume } \\
\text { de Salluste }\end{array}$ & La Sepmaine \\
\hline & $\begin{array}{l}\text { Aequiniti: Methodus } \\
\text { medendi }\end{array}$ & & \\
\hline THEO & Calvini Institutiones & Calvin, John & Institutiones Theologicae \\
\hline OCC & $\begin{array}{l}\text { Agrippa de Occulta } \\
\text { Philosoph }\end{array}$ & $\begin{array}{l}\text { Agrippa, Heinrich } \\
\text { Cornelius }\end{array}$ & De Occulta Philosophia Libri III \\
\hline THEO & Peucerus de Diviniationibus & Peucer, Caspar & De praecipus Divinationum generibu \\
\hline PHIL & Pomponatii Opera & Pomponazzi, Pietro & Opera \\
\hline THEO & Sculteti Dommcalia & Scultetus, Abraham & Idea Concionum Dominicalium \\
\hline THEO & Cyrilli Catechesis & Cyril of Jerusalem & Catecheses \\
\hline ASTRN & $\begin{array}{l}\text { Kepleri Epitome Astronom. } \\
\text { Copernicanae }\end{array}$ & Kepler, Johannes & Epitome Astronomiae Copernicanae \\
\hline PHIL & $\begin{array}{l}\text { Taurelli Triumphus } \\
\text { Philosophiae }\end{array}$ & Taurellus, Nicolaus & Philosophiae Triumphus \\
\hline THEO & Bible Dutch & & \\
\hline ASTRN & $\begin{array}{l}\text { Purbachiij Theoria } \\
\text { Planetaru }\end{array}$ & Peurbach, Georg & Theoricae Novae Planetarum \\
\hline MEDI & Varollii Anatomia & Varolius, Constantius & Anatomiae de corporis humani \\
\hline ALCH & Rubeus de Distillatione & Rubeus, Hieronymous & De Distillatione \\
\hline POLT & $\begin{array}{l}\text { Branti Expositio Tituloru } \\
\text { iuris Civilis }\end{array}$ & Brant, Seb. & Titulorum Juris utriusque \\
\hline
\end{tabular}




\begin{tabular}{|c|c|c|c|}
\hline PHIL & Zenophon Grae 3 Vol & Xenophon of Athens & Opera, Vol 2, Gr \\
\hline & Natalis Comes & & \\
\hline THEO & $\begin{array}{l}\text { Julii Africani historia } \\
\text { certaminis Apostoloru }\end{array}$ & & \\
\hline PHIL & Philo Judaeis Lat 2 vol & Philo of Alexandria & Opera Gr Lat \\
\hline THEO & Beza in No Just 2 vols & Beza, Theodore & $\begin{array}{l}\text { Potentially one of several referenced } \\
\text { catalogue }\end{array}$ \\
\hline THEO & Dadraej Lo Com & Dadreus, Johannes & Loci Com Theologiae \\
\hline LING & Paginii Thesaurus Lin Hib. & Paganinus, Sainct. & Epitome Thesauri ling. Sanctae \\
\hline THEO & Rupertus de divinis Officius & Rupert of Deutz & De divinis officiis \\
\hline THEO & $\begin{array}{l}\text { Voragini sermones de Maria } \\
1503\end{array}$ & $\begin{array}{l}\text { da Varagine, Jacobus } \\
\text { (Jacopo de Fazio) }\end{array}$ & $\begin{array}{l}\text { Liber marialis, Sermones aurei de } M \\
\text { Virgine }\end{array}$ \\
\hline & Pinotti Apologia & & \\
\hline ALCH & Turba Philosophoru & Various & $\begin{array}{l}\text { Turba Philosophorum (Alternatively: } \\
\text { Auriferae artis, quam chemiam vocan } \\
\text { antiquissimi authores, sive Turba } \\
\text { philosophorum) }\end{array}$ \\
\hline MILT & Vigetius de re militarii & $\begin{array}{l}\text { Publius Flvaius } \\
\text { Vegetius Renatus }\end{array}$ & De re Militari cum notis Fr Modii \\
\hline ASTL & $\begin{array}{l}\text { Ptolomei Cent, dicta ad } \\
\text { Syru }\end{array}$ & Pseudo-Ptolemy & Centiloquium \\
\hline THEO & $\begin{array}{l}\text { Nimesius de Natura hominis } \\
\text { grae }\end{array}$ & Nemesius & De Natura Hominis \\
\hline ALCH & De Alchimia Dialog: duo: & & \\
\hline NATP & Cardanus De Subtilitate & Cardano, Girolamo & De Subtilitate \\
\hline
\end{tabular}




\begin{tabular}{|c|c|c|c|}
\hline THEO & Lutherus in Palatas(?) & Luther, Martin & $\begin{array}{l}\text { Possibly Commentary on the Epistle t } \\
\text { Galatians }\end{array}$ \\
\hline ASTL & Casmami Astrolog; & $\begin{array}{l}\text { Possibly Casmann, } \\
\text { Otto? }\end{array}$ & Possibly Astronomia et Chronographi \\
\hline NUMR & Lulli vade mecu & Lull, Ramon & Vade Mecum \\
\hline THEO & Malleus Maleficarum & Kramer, Heinrich & Malleus Maleficarum \\
\hline THEO & Cassandii Consultatio & & \\
\hline THEO & Freneus contra Hiereses & & \\
\hline HIST & Hagesippus de bello Judaeio & Hegesippus & $\begin{array}{l}\text { De Excidio Urbis Hierosolymita cum } \\
\text { Corn Gualtheri }\end{array}$ \\
\hline THEO & Concilium de Eucharistia & & \\
\hline THEO & $\begin{array}{l}\text { Onomasticon Theologicum } \\
\text { per Theophil Libeum }\end{array}$ & Lebei, Theophil & Onomasticon theologicum \\
\hline \multirow[t]{2}{*}{ ALCH } & Avicien de Art Chimiae & $\begin{array}{l}\text { (pseudo) Avicenna; ed. } \\
\text { Celsi, Mino }\end{array}$ & $\begin{array}{l}\text { Possibly De Anima in arte alchemiua } \\
\text { Artis Chemicae Principes, Avicenna a } \\
\text { Geber }\end{array}$ \\
\hline & Prosperi Lib 3, Opuscula & & \\
\hline NATP & Porta de Magia & $\begin{array}{l}\text { Della Porta, } \\
\text { Giambattista }\end{array}$ & Magiae Naturalis \\
\hline ASTRN & Alfragani Astronomia & $\begin{array}{l}\text { al-Farghani, Ahmad ibn } \\
\text { Kathir }\end{array}$ & Possibly Chron. Et Astronomica elem \\
\hline THEO & $\begin{array}{l}\text { Mornayus de veritate } \\
\text { religionis }\end{array}$ & Mornaeus, Phillipus & De Veritate Religionis Christiane \\
\hline THEO & Tileni Syntagma & Tilenus, Daniel & Syntagma disputat Theologiae \\
\hline GEOM & Euclidis element grae & Euclid & Elementum 6 Gr. Lat \\
\hline
\end{tabular}




\begin{tabular}{|c|c|c|c|}
\hline OPTC & Rhodii Optica & Rhodius, Ambrosius & Optica Ambrosii Rhodii \\
\hline HIST & Aeliani varia Historia & Aelian, Claudius & Claudii Aeliani Varia historia \\
\hline THEO & Titelmamus in Epistolas & $\begin{array}{l}\text { Titelmannus } \\
\text { (Titelmanns, Franz) }\end{array}$ & In Epistolas omnes \\
\hline THEO & Soto Institutio Sacerdotu & de Soto, Pedro & Lectiones de institutione sacerdotum \\
\hline THEO & Antonii de Giscandis Postilla & De Gistandis, Anthony & $\begin{array}{l}\text { Either Opus aureum ornatium }(1510) \\
\text { Expositio Evang. Totius anni }(1610)\end{array}$ \\
\hline THEO & Royardi Postilla & & \\
\hline THEO & $\begin{array}{l}\text { Rampigoti Casus } \\
\text { Conscientiae }\end{array}$ & Rampigolis, Anthony & Figurae Bibliorum \\
\hline MEDI & Fuchsii Methodus Medendi & Fuchs, Leonhart & Methodus medendi morbes \\
\hline МАТНI & Gemma Frisius de Astrolabo & Frisius, Gemma & De Astrolabo \\
\hline ALCH & Theatrum Chemicu $\sim 4$ vols & Various & $\begin{array}{l}\text { Theatrum Chemicum, procipuos selec } \\
\text { auctorum tractatus de Chemioe et Lap } \\
\text { Philosophici Antiquitate, veritate }\end{array}$ \\
\hline GEOM & Clavius in Euclidem & $\begin{array}{l}\text { Euclid; Clavius, } \\
\text { Cristoph }\end{array}$ & $\begin{array}{l}\text { Elemnta Lib } 15 \text { cum notis Christoph. } \\
\text { Vol } 2\end{array}$ \\
\hline THEO & $\begin{array}{l}\text { Vivaldus de veritate } \\
\text { Contritionis }\end{array}$ & $\begin{array}{l}\text { Vivaldi, Giovanni } \\
\text { Ludovico }\end{array}$ & De contritionis veritate aureum opus \\
\hline THEO & $\begin{array}{l}\text { Caranzae Summa } \\
\text { Concilioru }\end{array}$ & Carranza, Bartolome & $\begin{array}{l}\text { Summa Conciliorum et Pontificum a } 1 \\
\text { usque Paulum III }\end{array}$ \\
\hline THEO & $\begin{array}{l}\text { Martinez de auxilis divinae } \\
\text { gratiae }\end{array}$ & & \\
\hline THEO & Confessionali Anthonini & $\begin{array}{l}\text { Antinonius Florentinus } \\
\text { (Antoninus of Florence) }\end{array}$ & Confessionale Anthonini \\
\hline
\end{tabular}




\begin{tabular}{|c|c|c|c|}
\hline THEO & $\begin{array}{l}\text { Bertramus de Coropore } \\
\text { Christi }\end{array}$ & Bertramus & De Corpore et sanguine Christi \\
\hline THEO & $\begin{array}{l}\text { Ammoniij Harmonia } \\
\text { Evangel. }\end{array}$ & $\begin{array}{l}\text { Ammonius, } \\
\text { Alexandrius }\end{array}$ & Harmonia Evangelica \\
\hline THEO & $\begin{array}{l}\text { Ancient faith of England; } \\
\text { Saxon Eng }\end{array}$ & & \\
\hline LING & $\begin{array}{l}\text { Dictionariu } \sim \text { Latin - } \\
\text { Germanicu Polonicu } \sim\end{array}$ & & \\
\hline THEO & Expositio Canonis Missae & & \\
\hline THEO & Breviaru ad usu Sarum & & \\
\hline THEO & $\begin{array}{l}\text { De Christo gratis iustificanti } \\
\text { contra Osoriu }\end{array}$ & Foxe, John & Contra Osorium de Christo gratis jus \\
\hline THEO & Conclusiones Cabalisticae & & \\
\hline CHRON & Lydiati Emendaitio Temporu & Lydiate, Thomas & Emendatio Temporum adversus Scalig \\
\hline POLT & Machiavelli Princips & Machiavelli, Nicolo & Princeps \\
\hline THEO & Remiii Daemonolotria & $\begin{array}{l}\text { Remy, Nicholas } \\
\text { (Remigius) }\end{array}$ & Daemonolatreiae libri tres \\
\hline HIST & Bodin de Republique Franc & Bodin, Jean & De la republique, livres 6 \\
\hline LIT & Orlando Furioso - Ital & Ariosto, Ludovico & Orlando Furioso \\
\hline \multirow[t]{3}{*}{ MEDI } & Paracelsi Tom s9 le 2 deus & $\begin{array}{l}\text { Paracelsus, } \\
\text { Theophrastus von }\end{array}$ & Operum tom 1 et 2 \\
\hline & Trelcatii Lo Com & & \\
\hline & $\begin{array}{l}\text { Ethuletherius de Arbor } \\
\text { Scientiae }\end{array}$ & & \\
\hline LINGT & Schinderli gram Heb & Schindlerus, Valentius & Grammatica Hebraica \\
\hline
\end{tabular}




\begin{tabular}{|c|c|c|c|}
\hline POLT & Vigelii Methodus Juris & Vigelius, Nicolas & Methodus Juris \\
\hline POLT & Widdingston Apologia & $\begin{array}{l}\text { Widdrington, Roger } \\
\text { (aka Thomas Preston) }\end{array}$ & $\begin{array}{l}\text { Apologia Cardinalis Bellarmini pro } J_{i} \\
\text { Principum }\end{array}$ \\
\hline THEO & Polani Partitiones & Polani, Amandi & Partitiones Theologicae juxta Natural \\
\hline NATP & Isidori Hispalensis tractatus & Isidore of Seville & $\begin{array}{l}\text { Any of a number of works; inc Opera } \\
\text { and Etymologia (mss) }\end{array}$ \\
\hline \multirow[t]{2}{*}{ HIST } & Historia del Regno di China & & \\
\hline & Smaragdi (?) Dominicalia & & \\
\hline PHIL & $\begin{array}{l}\text { Essaies de Montaigne } \\
\text { Frenche }\end{array}$ & Montaigne, Michel de & Essais \\
\hline MISC & $\begin{array}{l}\text { diverse other Books and } \\
\text { Pamphlets }\end{array}$ & & \\
\hline MEDI & $\begin{array}{l}\text { Fracastorius de Sympathia } \\
\text { Reru }\end{array}$ & Fracastoro, Girolamo & De Sympathia et Antipathia rerum \\
\hline THEO & Officium Diurnu & Roman Catholic Church & Officium Diurnum \\
\hline NATP & Misteria Egyptoriu & Iamblichus & De Mysteriis Aegyptiorum \\
\hline THEO & Piscatoris Aphorismus & Piscator, Johannes & Aphorismi Doctrinae Christiane \\
\hline THEO & Titlemannus in Cantica & $\begin{array}{l}\text { Titelmannus } \\
\text { (Titelmanns, Franz) }\end{array}$ & In Cantica \\
\hline & Flores Bernardi & & \\
\hline
\end{tabular}




\begin{tabular}{|c|c|c|c|}
\hline THEO & Posscuimus de Haereticis & Possevinus, Antonius & De Atheismis Haereticorum \\
\hline HIST & Bedae Historia & Bede the Venerable & Historia Anglorum \\
\hline THEO & Calvinii Catachism Ital & & \\
\hline THEO & Hemignius de Gratia & Hemingius, Nicholas & De Gratia Universali \\
\hline THEO & Index Expurgatorius 1586 & Roman Catholic Church & $\begin{array}{l}\text { Index Librorum Prohibitorum / Index } \\
\text { Expurgatorious }\end{array}$ \\
\hline THEO & Aquinatis Conclusiones & Aquinas, Thomas & Conclusiones \\
\hline THEO & $\begin{array}{l}\text { Epitome distinction } \sim \\
\text { Castaner }\end{array}$ & Castaneus, Lud. & $\begin{array}{l}\text { Distinctionum Philosoph. Et Theologi } \\
\text { destictio }\end{array}$ \\
\hline THEO & Caietarii Summula & $\begin{array}{l}\text { Cajetanus, Thomas de } \\
\text { Vio }\end{array}$ & Summula \\
\hline THEO & Canones Conculu Tridentini & Anonymous & Canones Concilii Tridentini \\
\hline THEO & Dionisius Areopagita & $\begin{array}{l}\text { Dionysius the } \\
\text { Areopagite }\end{array}$ & Multiple works listed \\
\hline THEO & $\begin{array}{l}\text { Jansenii Concordia } \\
\text { Evangelica }\end{array}$ & Jansen, Cornelius & Com. In Concord. Evang. \\
\hline THEO & Canisii Catacismus & Canisius, Peter & Opus Catechisticum \\
\hline THEO & Reuclinus di verbo mirifico & Reuchlin, Johannes & De Verbo Mirifico \\
\hline
\end{tabular}




\begin{tabular}{|c|c|c|c|}
\hline THEO & Justin Martin & Martyr, Justin & Likely Opera Gr Lt cum com Frid Syl \\
\hline THEO & $\begin{array}{l}\text { Psalterium Heb (imperfect) } \\
1616\end{array}$ & Anonymous & Likely Psasmi Ecclesiast et Catn. \\
\hline NATH & Heliodorus & Heliodorus & Historia Aethiopica \\
\hline HIST & Tacitus & Tacitus, Cornelius & Likely Opera \\
\hline HIST & Busbechii Epistolae & $\begin{array}{l}\text { Ghislain de Busbecq, } \\
\text { Augier }\end{array}$ & $\begin{array}{l}\text { Epistolae; or possibly De re Militari c } \\
\text { Turcam }\end{array}$ \\
\hline NATH & Mizaldi Memorabilia & Mizauld, Antoine & $\begin{array}{l}\text { Memorabilium, vtilium, ac iucundoru } \\
\text { centuriae novem }\end{array}$ \\
\hline RELG & $\begin{array}{l}\text { Bee hive of ye Romish } \\
\text { Church }\end{array}$ & Philip of Marnix & The Bee-Hive of the Romish Church \\
\hline GEOG & De Rebus Japonicis & Frois, Luis & Literae Japonenses annis 1571 and 1 \\
\hline RELG & Bonaventura de vita Christi & Psuedo-Bonaventure & Meditationes vitae Christi \\
\hline MISC & $\begin{array}{l}\text { Besides diverse other Bookes } \\
\text { and Pamphlets }\end{array}$ & & \\
\hline
\end{tabular}


Appendix 2: A Reconstruction of Nathaniel Torporley's Library via his Bequest to Sion College

Of the printed materials listed above, the following 31 titles were listed by John Spencer as missing at invent

\begin{tabular}{|l|l|l|l|}
\begin{tabular}{|l} 
Broad \\
Subject
\end{tabular} & $\begin{array}{l}\text { Manuscript Entry in Sion } \\
\text { College Book of Benefactors } / \\
\text { Spencer's Transcriptum }\end{array}$ & Proposed Author & Proposed Title \\
\hline PHIL & $\begin{array}{l}\text { Paraphrasis totius Philosophiae } \\
\text { naturalis }\end{array}$ & $\begin{array}{l}\text { Aristotle; d'Etaples, } \\
\text { Jacques Lefevre }\end{array}$ & $\begin{array}{l}\text { Totius philosophiae naturalis } \\
\text { Paraphrases: adiecto ad Litteram fo } \\
\text { Commentario }\end{array}$ \\
\hline PHIL & Philaltheus in Phisic Aristotelis & $\begin{array}{l}\text { Lucillus Philaltheus } \\
\text { (Maggi, Lucilio) }\end{array}$ & $\begin{array}{l}\text { In IIII. libros Aristotelis de Caelo et } \\
\text { Mundo Commentarii }\end{array}$ \\
\hline PHIL & Picus Mirandola 1506 & $\begin{array}{l}\text { Della Mirandola, } \\
\text { Pico }\end{array}$ & Opera Omnia \\
\hline THEO & Damasceni Theologicae & $\begin{array}{l}\text { Johannes } \\
\text { Damascenus; } \\
\text { D'Etaples, Jacques } \\
\text { Lefevre }\end{array}$ & $\begin{array}{l}\text { Contenta Theologia Damasceni } \\
\text { Diophantus of } \\
\text { Alexandra }\end{array}$ \\
\hline ARTH & Diophanti Arithmetica Lat & $\begin{array}{l}\text { Possibly Buridan, } \\
\text { Jean }\end{array}$ & Possibly Summa de Dialectica \\
\hline & $\begin{array}{l}\text { Pardonis (Buridanis?) } \\
\text { Dialectica }\end{array}$ & &
\end{tabular}




\begin{tabular}{|c|c|c|c|}
\hline & $\begin{array}{l}\text { Liber de principis reru } \\
\text { naturalium }\end{array}$ & & \\
\hline PHIL & Aquinatis Metyphysica & Aquinas, Thomas & Metaphysica et de Anima (MSS) \\
\hline THEO & Concordantiae Biblioru & $\begin{array}{l}\text { Conradus of } \\
\text { Halberstadt }\end{array}$ & Concordantiae Bibliorum \\
\hline MATH & Ceuleriij Aritmet et Geomet & van Ceulen, Ludolph & Fundamenta Arithmetica et Geomet \\
\hline NATP & Metochita in Astit Phys & $\begin{array}{l}\text { Metochites, } \\
\text { Theodore }\end{array}$ & \\
\hline ASTL & Hispani Astrologia & Nabod, Valentin & Hispalensis Epitome Totitus Astrolg \\
\hline MUSC & $\begin{array}{l}\text { Aristoxeni Harmonica } \\
\text { Elementa }\end{array}$ & Aristoxenus & Elementa harmonica \\
\hline THEO & Acinae Sylvis Opera & $\begin{array}{l}\text { Piccolomini, Aeneas } \\
\text { Silvius (Pope Pius } \\
\text { II) }\end{array}$ & Opera \\
\hline THEO & Calvini Institutiones & Calvin, John & Institutiones Theologicae \\
\hline THEO & Sculteti Dommcalia & Scultetus, Abraham & Idea Concionum Dominicalium \\
\hline PHIL & Philo Judaeis Lat 2 vol & Philo of Alexandria & Opera Gr Lat \\
\hline THEO & Rupertus de divinis Officius & Rupert of Deutz & De divinis officiis \\
\hline THEO & Lutherus in Palatas(?) & Luther, Martin & $\begin{array}{l}\text { Possibly Commentary on the Epistle } \\
\text { Galatians }\end{array}$ \\
\hline THEO & Concilium de Eucharistia & & \\
\hline THEO & Royardi Postilla & & \\
\hline THEO & Polani Partitiones & Polani, Amandi & Partitiones Theologicae juxta Natur \\
\hline
\end{tabular}




\begin{tabular}{|c|c|c|c|}
\hline NATP & Isidori Hispalensis tractatus & Isidore of Seville & $\begin{array}{l}\text { Any of a number of works; inc Ope } \\
\text { (print) and Etymologia (mss) }\end{array}$ \\
\hline HIST & Historia del Regno di China & & \\
\hline & Smaragdi (?) Dominicalia & & \\
\hline THEO & Calvinii Catachism Ital & & \\
\hline THEO & Hemignius de Gratia & Hemingius, Nicholas & De Gratia Universali \\
\hline THEO & Epitome distinction $\sim$ Castaner & Castaneus, Lud. & $\begin{array}{l}\text { Distinctionum Philosoph. Et } \\
\text { Theologicarum destictio }\end{array}$ \\
\hline THEO & Justin Martin & Martyr, Justin & $\begin{array}{l}\text { Likely Opera Gr Lt cum com Frid } \\
\text { Sylburgii }\end{array}$ \\
\hline HIST & Tacitus & Tacitus, Cornelius & Likely Opera \\
\hline RELG & Bonaventura de vita Christi & Psuedo-Bonaventure & Meditationes vitae Christi \\
\hline
\end{tabular}


Appendix 3: Titles purchased by the Science Museum, London, from the Hodgson \& Co. auction of Rare Ear Library of Sion College London, 1938-1939

Titles of works are provided as currently presented in the Science Museum, London catalogue, accessible onl

\begin{tabular}{|c|c|c|c|c|c|}
\hline $\begin{array}{c}\text { Broad } \\
\text { Subject }\end{array}$ & Author & Title & Date & Location & Publishe \\
\hline ASTR & $\begin{array}{l}\text { Copernicus, } \\
\text { Nicolaus }\end{array}$ & De revolutionibus orbium coelestium & 1543 & Norimbergae & Johannem Petr \\
\hline GEOM & Archimedes & $\begin{array}{l}\text { [Works. Greek \& Latin] } \\
\text { Archimedous tou Syrakousiou, ta } \\
\text { mechri nyn sozomena, hapanta ... ac } \\
\text { geometra excellentissimi opera }\end{array}$ & 1544 & Basileae & Joannes Herua \\
\hline ASTR & $\begin{array}{l}\text { Copernicus, } \\
\text { Nicolaus }\end{array}$ & $\begin{array}{l}\text { De revolutionibus orbium coelestium } \\
\text { [2. ed] }\end{array}$ & 1566 & Basileae & Henrici Petrini \\
\hline OPTC & Alhazen & Optica Thesaurus & 1572 & Basileae & $\begin{array}{l}\text { Episcopios - N } \\
\text { F Haeredes }\end{array}$ \\
\hline GEOG & $\begin{array}{l}\text { Myritius, } \\
\text { Joannes }\end{array}$ & $\begin{array}{l}\text { Opusculum geographicum rarum, } \\
\text { totius eius negotii rationem }\end{array}$ & 1590 & Inglostadii & Wolfgang Ed \\
\hline GEOM & Euclid & $\begin{array}{l}\text { Euclidis elementorum libri } X V . \\
\text { Graecè \& Latinè. }\end{array}$ & 1598 & Parisiis & Guillaume Caı \\
\hline
\end{tabular}




\begin{tabular}{|c|c|c|c|c|c|}
\hline ASTR & $\begin{array}{l}\text { Bayer, } \\
\text { Johann }\end{array}$ & Uranometria & 1603 & $\begin{array}{l}\text { Augusta } \\
\text { Vindeli }\end{array}$ & S.N. \\
\hline WGMS & $\begin{array}{l}\text { Cappel, } \\
\text { Jacques }\end{array}$ & $\begin{array}{l}\text { De mensuris libris tres : I, De } \\
\text { mensuris linearum ... II, De mensuris } \\
\text { capacitatis ... III, Miscellanea ... }\end{array}$ & 1607 & Francofurti & Wolfgang Rich \\
\hline GEOM & Euclid & Euclidis Elementorum libri $X V$. & 1607 & Pariisis & Guiliemi Caue \\
\hline OPTC & $\begin{array}{l}\text { Kepler, } \\
\text { Johannes }\end{array}$ & $\begin{array}{l}\text { Ioannis Kepleri Sae. Cae. Mtis. } \\
\text { mathematici Dioptrice seu } \\
\text { Demonstratio eorum quae visui \& } \\
\text { visibilibus propter conspicilla non } \\
\text { ita pridem inventa accidunt }\end{array}$ & 1611 & $\begin{array}{l}\text { Augustae } \\
\text { Vindelicorum }\end{array}$ & Davidis Franci \\
\hline TRIG & $\begin{array}{l}\text { Pitiscus, } \\
\text { Bartholomaus }\end{array}$ & $\begin{array}{l}\text { Canon triangulorum } \\
\text { emendatissimus, et ad usum } \\
\text { accomodatissimus }\end{array}$ & 1612 & Francofurti & Nicolai Hofma \\
\hline TRIG & $\begin{array}{l}\text { Pitiscus, } \\
\text { Bartholomaus }\end{array}$ & $\begin{array}{l}\text { Trigonometriae; sive, De dimensione } \\
\text { triangulorum, libri quinque, .... } \\
\text { Editio } 3 ., \text { cui recens accessit } \\
\text { Problematum }\end{array}$ & 1612 & Francofurti & Nicolai Hofma \\
\hline МАТН & $\begin{array}{l}\text { Rheticus, } \\
\text { Georg } \\
\text { Joachim }\end{array}$ & $\begin{array}{l}\text { Thesaurus mathematicus : sive } \\
\text { Canon sinuum ad radium } \\
\text { 1.00000.00000.00000. et ad dena } \\
\text { quaeque scrupula secunda } \\
\text { quadrantis ... }\end{array}$ & 1613 & Francofurti & Nicolaus Hoffr \\
\hline ASTR & $\begin{array}{l}\text { Kepler, } \\
\text { Johannes }\end{array}$ & Tabulae Rudolphinae & 1627 & Ulmae & typis Jonae Sal \\
\hline
\end{tabular}




\begin{tabular}{|c|c|c|c|c|c|}
\hline ASTR & $\begin{array}{l}\text { Scheiner, } \\
\text { Christoph }\end{array}$ & Rosa ursina sive sol & 1630 & Bracciani & Andream Phae \\
\hline МАТН & $\begin{array}{l}\text { Galilei, } \\
\text { Galileo }\end{array}$ & $\begin{array}{l}\text { Discorsi e dimostrazioni } \\
\text { matematiche }\end{array}$ & 1638 & Leida & Elsevirii \\
\hline ASTL & Pisis, H. de. & $\begin{array}{l}\text { Opus geomantice completum, in } \\
\text { libros tres diuisum ... }\end{array}$ & 1638 & Lugduni & Ioan. Ant. Hvg \\
\hline WGMS & $\begin{array}{l}\text { Allacci, } \\
\text { Leone }\end{array}$ & $\begin{array}{l}\text { De mensvra temporvm antiqvorvm, } \\
\text { \& praecipue Graecorvm, exercitatio. }\end{array}$ & 1645 & $\begin{array}{l}\text { Coloniae } \\
\text { Aggripinae }\end{array}$ & Iodicum Kalco \\
\hline PHYS & $\begin{array}{l}\text { Kircher, } \\
\text { Athanasius }\end{array}$ & Ars magna lucis et umbrae. & 1646 & Romae & Hermanni Sch \\
\hline SCIE & $\begin{array}{l}\text { Porta, } \\
\text { Giambattista } \\
\text { della, }\end{array}$ & Natural magick & 1658 & London & $\begin{array}{l}\text { Printed for Tho } \\
\text { Young and Sar } \\
\text { Speed }\end{array}$ \\
\hline SCIE & $\begin{array}{l}\text { Cardano, } \\
\text { Girolamo }\end{array}$ & Opera omnia & 1663 & Lugduni & $\begin{array}{l}\text { Ioannis Antoni } \\
\text { Hvgvetan \& M } \\
\text { Antonii Ravav }\end{array}$ \\
\hline HYDS & $\begin{array}{l}\text { Vossius, } \\
\text { Isaac }\end{array}$ & De motu marium et ventorum liber. & 1663 & Hagae-Comitis & Adriani Vlacq \\
\hline
\end{tabular}




\begin{tabular}{|c|c|c|c|c|c|}
\hline PHYS & $\begin{array}{l}\text { Kircher, } \\
\text { Athanasius }\end{array}$ & $\begin{array}{l}\text { Phonurgia nova : sive } \\
\text { conjugiummechanico-physicum artis } \\
\text { \& naturae paranympha phonosophia } \\
\text { concinnatum. }\end{array}$ & 1673 & Campidonae & Rudolphum Dr \\
\hline ALCH & $\begin{array}{l}\text { Sędziwój, } \\
\text { Michał, }\end{array}$ & $\begin{array}{l}\text { A new light of alchymy : taken out of } \\
\text { the fountain of nature and manual } \\
\text { experience. }\end{array}$ & 1674 & London & $\begin{array}{l}\text { A Clark for Th } \\
\text { Williams }\end{array}$ \\
\hline HORL & $\begin{array}{l}\text { Cumming, } \\
\text { Alexander }\end{array}$ & $\begin{array}{l}\text { The elements of clock and watch- } \\
\text { work }\end{array}$ & 1766 & London & $\begin{array}{l}\text { Printed for the } \\
\text { by J Hughs }\end{array}$ \\
\hline WGMS & $\begin{array}{l}\text { Cappel, } \\
\text { Jacques }\end{array}$ & $\begin{array}{l}\text { De ponderibvs, nvmmis et mensvris } \\
\text { libri } V: \text { cum multis indicibus \& } \\
\text { tabulis ... }\end{array}$ & $\begin{array}{l}1606- \\
1607\end{array}$ & Francofurti & Levini Hulsii \\
\hline МАТН & $\begin{array}{l}\text { Montucla, } \\
\text { Jean Etienne }\end{array}$ & $\begin{array}{l}\text { Histoire des mathématiques. Nouv. } \\
\text { éd. }\end{array}$ & $\begin{array}{l}1799- \\
1802\end{array}$ & Paris & Chez Henri Ag \\
\hline
\end{tabular}


Appendix 4: Titles purchased by the Science Museum, London, from the Sotheby's Honeyman Sales Auction 75 of 115 volumes previously belonging to Robert Brodhead Honeyman and purchased by the Science Muse as part of the current study. The remaining 40 titles were either deemed irrelevant to the mathematical subset deemed unsuitable for the current study owing to their date of publication. Titles have been taken from the ex catalogue data as provided at the beginning of the current project. This catalogue is accessible online via http

\begin{tabular}{|c|c|c|c|c|}
\hline $\begin{array}{l}\text { Broad } \\
\text { subject }\end{array}$ & $\begin{array}{l}\text { SML } \\
\text { Shelfmark }\end{array}$ & Shelving word & $\begin{array}{l}\text { Author entry on } \\
\text { Catalogue }\end{array}$ & Title \\
\hline GEOM & O.B. ORE & ORESME & Oresme, Nicole & Incipit putilis tractatus de latitudinil \\
\hline ASTR & O.B. LEO & LEOPOLD & $\begin{array}{l}\text { Leupoldus, } d u x \\
\text { Austriae. }\end{array}$ & De astrorum Scientia \\
\hline SURV & O.B. KOB & KOBEL & Köbel, Jacob & $\begin{array}{l}\text { Von vrsprung der Teil ug, Masz, v } \\
\text { der Ecker, Wyngart } \sim \text { e, Krautgarten, } \\
\text { was form vnd gestalt die seind, V n } \\
\text { khunst Messen vnd Rechen solle, ist } \\
\text { Regel n, Exempel n, vnnd Figuren }\end{array}$ \\
\hline ASTR & O.B. KOB & KOBEL & Köbel, Jacob & $\begin{array}{l}\text { Astrolabii declaratio ... Cui accessit } \\
\text { iudiciariam }\end{array}$ \\
\hline ASTR & O.B. KOB & KOBEL & Köbel, Jacob & Astrolabii declaratio \\
\hline
\end{tabular}




\begin{tabular}{|c|c|c|c|c|}
\hline ASTR & $\begin{array}{l}\text { Q O.B. } \\
\text { COP }\end{array}$ & COPERNICUS & Copernicus, Nicolaus & De revolutionibus orbium coelestium \\
\hline ARTH & O.B. STI & STIFEL & Styfel, Michael & Arithmetica integra ... \\
\hline NAVG & $\begin{array}{l}\text { Q O.B. } \\
\text { COR }\end{array}$ & CORTES & Cortés, Martin & Breve compendio de la sphera y de lo \\
\hline GEOM & O.B. REC & RECORDE & Record, Robert & $\begin{array}{l}\text { The pathway to knowledg containing } \\
\text { geometrie ... }\end{array}$ \\
\hline ASTR & $\begin{array}{l}\text { Q O.B. } \\
\text { REC }\end{array}$ & RECORDE & Record, Robert & The castle of knowledge \\
\hline ARTH & O.B. REC & RECORDE & Record, Robert & $\begin{array}{l}\text { The whetstone of witte: whiche is th } \\
\text { arithmetike }\end{array}$ \\
\hline SCIE & $\begin{array}{l}\text { Q O.B. } \\
\text { POR }\end{array}$ & PORTA & $\begin{array}{l}\text { Porta, Giambattista } \\
\text { della }\end{array}$ & Magiae natvralis \\
\hline SURV & O.B. BEL & BELLI & Belli, Silvio & Libro del misurar con la vista \\
\hline ASTR & O.B. REN & RENSBERGER & Rensberger, Nicolaus & Aequadorium aller Planeten \\
\hline ASTR & O.B. REN & RENSBERGER & Rensberger, Nicolaus & $\begin{array}{l}\text { Astronomia teutsch : dergleichen vor } \\
\text { aussgangen, darinn verfasst seind vic }\end{array}$ \\
\hline ASTR & O.B. DIG & DIGGES & Dee, John & Parallaticae commentationis praxeos \\
\hline ASTR & O.B. DIG & DIGGES & Digges, Thomas & $\begin{array}{l}\text { Alae seu scalae mathematicae, quibu } \\
\text { coelorum theatra conscendi, \& plane } \\
\text { inauditus methodis explorari... }\end{array}$ \\
\hline
\end{tabular}




\begin{tabular}{|c|c|c|c|c|}
\hline PERS & O.B. RAM & RAMUS & Peckham, John & Perspectivae communis libri tres \\
\hline ARTH & O.B. RAM & RAMUS & Ramus, Petrus & Arithmeticae libri duo : Geometriae \\
\hline GEOM & O.B. RAM & RAMUS & Finck, Thomas & Geometriae rotundi libri XIIII \\
\hline TRIG & O.B. PIT & PITISCUS & $\begin{array}{l}\text { Pitiscus, } \\
\text { Bartholomäus. }\end{array}$ & Trigonometrice, sive De dimensione $t$ \\
\hline MTEO & $\begin{array}{l}\text { Q O.B. } \\
\text { PAD }\end{array}$ & PADUANIUS & Padovani, Fabrizio. & Tractatus duo, alter de ventis, alter a \\
\hline WGMS & F O.B. CLA & CLAVIUS & Clavius, Christoph & Romani calendarii a Gregorio XIII \\
\hline GEOM & $\begin{array}{l}\text { Q O.B. } \\
\text { GAL }\end{array}$ & GALILEI & $\begin{array}{l}\text { Galilei, Galileo, 1564- } \\
1642\end{array}$ & Le operazioni del compasso geometr \\
\hline ASTR & O.B. MUL & MULERIUS & $\begin{array}{l}\text { Mulerius, Nicolaus, } \\
1564-1630 .\end{array}$ & Tabula Frisica luno-solares quadru \\
\hline PHYS & O.B. GAL & GALILEI & $\begin{array}{l}\text { Galilei, Galileo, 1564- } \\
1642\end{array}$ & $\begin{array}{l}\text { Discorso al serenissimo don Cosimo } \\
\text { : intorno alle cose, che stanno in sù } l\end{array}$ \\
\hline LOGS & O.B. NAP & NAPIER & $\begin{array}{l}\text { Napier, John, 1550- } \\
1617 .\end{array}$ & Mirifici logarithmorum canonis desc \\
\hline ASTR & O.B. SAR & SARSIUS & $\begin{array}{l}\text { Grassi, Orazio, } 1583- \\
1654 .\end{array}$ & $\begin{array}{l}\text { Libra astronomica ac philosophica: } \\
\text { opiniones de cometis a Mario Gvidvc } \\
\text { Academia expositce }\end{array}$ \\
\hline ASTR & Q O.B. KEP & KEPLER & Kepler, Johannes & Harmonices mundi \\
\hline
\end{tabular}




\begin{tabular}{|c|c|c|c|c|}
\hline OPTC & O.B. SCH & SCHEINER & Scheiner, Christoph & $\begin{array}{l}\text { Oculus hoc est: fundamentum opticut } \\
\text { oculi anatome, abstrusarum experien } \\
\text { pervestigatione ... }\end{array}$ \\
\hline CSMO & & KEPLER & Kepler, Johannes & $\begin{array}{l}\text { Prodromus dissertationvm cosmogra } \\
\text { Mysterivm cosmographicvm de admi } \\
\text { orbium coelestium... }\end{array}$ \\
\hline MEDI & O.B. HAR & HARVEY & Harvey, William & $\begin{array}{l}\text { Exercitatio anatomica de motu cordi } \\
\text { animalibus }\end{array}$ \\
\hline ASTR & O.B. KEP & KEPLER & Kepler, Johannes & $\begin{array}{l}\text { Ad epistolam ... Jacobi Bartschii ... p } \\
\text { annum } 1629 \text { responsio: de computati } \\
\text { ephemeridum }\end{array}$ \\
\hline ASTR & Q O.B. KEP & KEPLER & Kepler, Johannes & $\begin{array}{l}\text { Tomi primi ephemeridum Ioannis Ke, } \\
\text { anno } 1621 \text { ad } 1628\end{array}$ \\
\hline ARTH & O.B. OUG & OUGHTRED & Oughtred, William & Arithmetica in numeris et speciebus \\
\hline GEOM & O.B. CAV & CAVALIERI & $\begin{array}{l}\text { Cavalieri, } \\
\text { Bonaventura }\end{array}$ & $\begin{array}{l}\text { Lo specchio ustorio trattato delle set } \\
\text { loro mirabili effetti intorno al lume, } \\
\text { moto ancora }\end{array}$ \\
\hline PHYS & O.B. GAL & GALILEI & Galilei, Galileo & $\begin{array}{l}\text { Les mechaniques de Galilee mathem } \\
\text { Duc de Florence }\end{array}$ \\
\hline МАТН & F O.B. STE & STEVIN & Stevin, Simon & Les ouvres mathematiques de Simon \\
\hline
\end{tabular}




\begin{tabular}{|c|c|c|c|c|}
\hline MEDI & O.B. HAR & HARVEY & Aselli, Gaspare & $\begin{array}{l}\text { De lactibus sive lacteis venis, quarto } \\
\text { genere, novo invento Gasparis Aselli } \\
\text { Anatomici Ticinensis, dissertatio }\end{array}$ \\
\hline MEDI & O.B. HAR & HARVEY & Primerose, James & $\begin{array}{l}\text { Antidotum adversus Henrici Regii ... } \\
\text { sive, Vindiciae animadversionum }\end{array}$ \\
\hline SURV & O.B. LEY & LEYBOURN & Leybourn, William & Planometria, or, The whole art of sur \\
\hline МАТН & F O.B. SCH & SCHOTT & Schott, Gaspar & Cursus mathematicus \\
\hline CSMO & O.B. STR & STREETE & Streete, Thomas. & Astronomia Carolina : a new theorie \\
\hline PHYS & Q O.B. GIL & GILBERT & $\begin{array}{l}\text { Grimaldi, Francisco } \\
\text { Maria }\end{array}$ & $\begin{array}{l}\text { Physico-mathesis de lumine, coloribu } \\
\text { adnexis }\end{array}$ \\
\hline МТНI & O.B. LEY & LEYBOURN & Leybourn, William & $\begin{array}{l}\text { The line of proportion or numbers, } c \\
\text { line, made easie ... }\end{array}$ \\
\hline LOGS & O.B. MER & MERCATOR & Mercator, Nicolaus & $\begin{array}{l}\text { Logarithmo-technia: sive, Methodus } \\
\text { nova, accurata, \& facilis }\end{array}$ \\
\hline ASTR & O.B. MOU & MOUTON & Mouton, Gabriele & $\begin{array}{l}\text { Observationes diametrorum solis et } \\
\text { meridianarúmque aliquot altitudinun } \\
\text { fixarum ... huic adjecta est brevis dis } \\
\text { mensurarum geometricarum idea ... }\end{array}$ \\
\hline HYDS & O.B. PER & PERRAULT & Perrault, P. (Pierre) & De l'origine des fontaines \\
\hline
\end{tabular}




\begin{tabular}{|c|c|c|c|c|}
\hline PHYS & O.B. PET & PETTY & Petty, William, Sir & $\begin{array}{l}\text { The discourse made before the Royal } \\
\text { November, } 1674, \text { concerning the use } \\
\text { in sundry important particulars : tog } \\
\text { hypothesis of springing or elastique }\end{array}$ \\
\hline МАТН & O.B. MOX & MOXON & Moxon, Joseph & Mathematicks made easie: or, $A$ mo \\
\hline МТНI & O.B. EVE & EVERARD & Everard, Thomas & $\begin{array}{l}\text { Stereometry made easie, or, The desc } \\
\text { gauging-rod or sliding-rule }\end{array}$ \\
\hline ARTH & O.B. COC & COCKER & Cocker, Edward & Cocker's decimal arithmetick. \\
\hline ARTH & O.B. NEW & NEWTON & Newton, Isaac, Sir & $\begin{array}{l}\text { Arithmetica universalis; sive de comp } \\
\text { arithmetica liber }\end{array}$ \\
\hline МАТН & $\begin{array}{l}\text { Q O.B. } \\
\text { MOI }\end{array}$ & MOIVRE & Moivre, Abraham de & $\begin{array}{l}\text { The doctrine of chances, or, A metho } \\
\text { probability of events in play }\end{array}$ \\
\hline PHYS & O.B. NEW & NEWTON & Newton, Isaac, Sir & De mundi systemate liber Isaaci Ne \\
\hline PHYS & $\begin{array}{l}\text { Q O.B. } \\
\text { MUS }\end{array}$ & $\begin{array}{l}\text { MUSSCHENB } \\
\text { ROEK }\end{array}$ & $\begin{array}{l}\text { Musschenbroek, } \\
\text { Petrus van }\end{array}$ & Physica experimentales, et geometri \\
\hline CALC & O.B. LHO & L'HOPITAL & $\begin{array}{l}\text { L'Hôpital, Guillaume } \\
\text { François Antoine de. }\end{array}$ & The method of fluxions both direct ar \\
\hline PHYS & O.B. NEW & NEWTON & Newton, Isaac, Sir & $\begin{array}{l}\text { A treatise of the system of the world. } \\
\text { wherein are interspersed some alter }\end{array}$ \\
\hline
\end{tabular}




\begin{tabular}{|c|c|c|c|c|}
\hline ASTR & $\begin{array}{l}\text { Q O.B. } \\
\text { LEM }\end{array}$ & LE MONNIER & $\begin{array}{l}\text { Le Monnier, M. } \\
\text { (Pierre-Charles) }\end{array}$ & $\begin{array}{l}\text { Histoire celeste, ou, Recueil de toute } \\
\text { astronomiques faites par ordre du ro. }\end{array}$ \\
\hline PHYS & O.B. ALE & ALEMBERT & $\begin{array}{l}\text { Alembert, Jean Le } \\
\text { Rond d' }\end{array}$ & Traité de dynamique \\
\hline HYDS & O.B. DAL & D'ALEMBERT & $\begin{array}{l}\text { Alembert, Jean Le } \\
\text { Rond d' }\end{array}$ & Traité de l'équilibre et du mouvemen \\
\hline CALC & O.B. SIM & SIMPSON & Simpson, Thomas & The doctrine and application of fluxi \\
\hline PHYS & $\begin{array}{l}\text { Q O.B. } \\
\text { WRI }\end{array}$ & WRIGHT' & Wright, Thomas & $\begin{array}{l}\text { An original theory or new hypothesis } \\
\text { upon the laws of nature, and solving } \\
\text { principles the general phaenomena o } \\
\text { and particularly the Via Lactea: }\end{array}$ \\
\hline ASTR & $\begin{array}{l}\text { Q O.B. } \\
\text { LAC }\end{array}$ & LACAILLE & $\begin{array}{l}\text { La Caille, Nicolas } \\
\text { Louis de }\end{array}$ & $\begin{array}{l}\text { Astronomice fundamenta : novissimis } \\
\text { observationibus }\end{array}$ \\
\hline ASTR & O.B. LEF & $\begin{array}{l}\text { LE FRANCAIS } \\
\text { DE LALANDE }\end{array}$ & $\begin{array}{l}\text { Lalande, Joseph } \\
\text { Jérôme Le Français de }\end{array}$ & Exposition du calcul astronomique \\
\hline MATH & O.B. LHO & L'HOPITAL & $\begin{array}{l}\text { L'Hôpital, Guillaume } \\
\text { François Antoine de }\end{array}$ & $\begin{array}{l}\text { Analyse des infiniment petits : Suivie } \\
\text { commentaire pour l'intelligence des } \\
\text { de cet ouvrage }\end{array}$ \\
\hline PHYS & $\begin{array}{l}\text { Q O.B. } \\
\text { LAG }\end{array}$ & LAGRANGE & $\begin{array}{l}\text { Lagrange, J. L. } \\
\text { (Joseph Louis) }\end{array}$ & Méchanique analitique \\
\hline
\end{tabular}




\begin{tabular}{|c|c|c|c|c|}
\hline SCIE & O.B. MON & MONET & $\begin{array}{l}\text { Lamarck, Jean } \\
\text { Baptiste Pierre } \\
\text { Antoine de Monet de, }\end{array}$ & $\begin{array}{l}\text { Recherches sur les causes des princit } \\
\text { particulièrement sur celles de la com } \\
\text { l'eau dans l'état de vapeurs ... }\end{array}$ \\
\hline ASTR & O.B. LAP & LAPLACE & $\begin{array}{l}\text { Laplace, Pierre } \\
\text { Simon, marquis de, }\end{array}$ & Exposition du systême du monde \\
\hline CALC & $\begin{array}{l}\text { Q O.B. } \\
\text { LAG }\end{array}$ & LAGRANGE & $\begin{array}{l}\text { Lagrange, J. L. } \\
\text { (Joseph Louis) }\end{array}$ & $\begin{array}{l}\text { Théorie des fonctions analytiques, co } \\
\text { calcul différentiel }\end{array}$ \\
\hline МАТН & $\begin{array}{l}\text { Q O.B. } \\
\text { LEG }\end{array}$ & LEGENDRE & $\begin{array}{l}\text { Legendre, A. M. } \\
\text { (Adrien Marie) }\end{array}$ & Essai sur la théorie des nombres \\
\hline МАТН & F O.B. TAR & TARTAGLIA & Tartaglia, Niccolò & General trattato di numeri et misure \\
\hline ASTR & Q O.B. KEP & KEPPLER & Kepler, Johannes & $\begin{array}{l}\text { Ephemerides novae motuum coelestiv } \\
\text { aerae } 1617\end{array}$ \\
\hline МАТН & $\begin{array}{l}\text { F O.B. } \\
\text { WAL }\end{array}$ & WALLIS & Wallis, John & Johannis Wallis ... Opera mathemati \\
\hline ASTR & Q O.B. PIN & PINGRE & $\begin{array}{l}\text { Pingré, Alexandre } \\
\text { Guy. }\end{array}$ & Cométrographie ou traité historique \\
\hline
\end{tabular}

